\title{
A MATTER OF TASTE: \\ THE FATE OF THE ARCHDEACON SMYTHE COLLECTION OF BRITISH WATERCOLOURS \\ IN NEW ZEALAND
}

BY

ANNIKA SIPPEL

A thesis

submitted to the Victoria University of Wellington in fulfilment of the requirements for the degree of Doctor of Philosophy

in Art History

Victoria University of Wellington

(2021) 


\section{Contents}

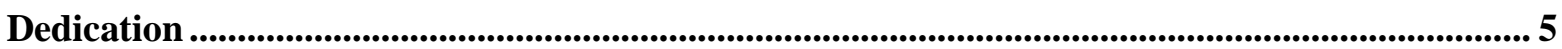

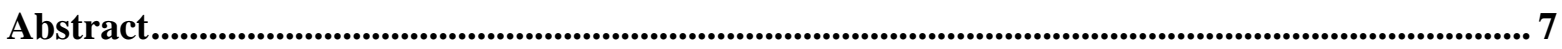

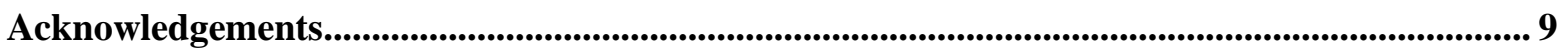

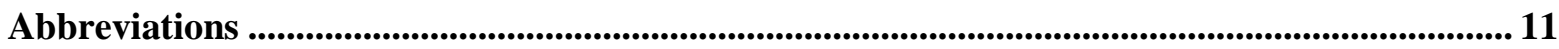

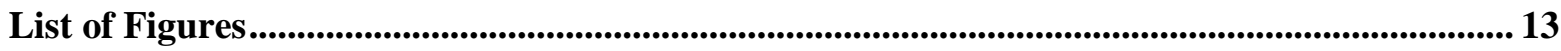

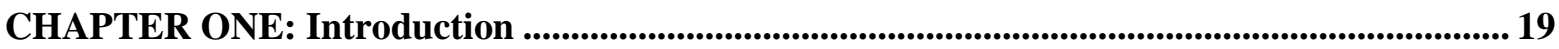

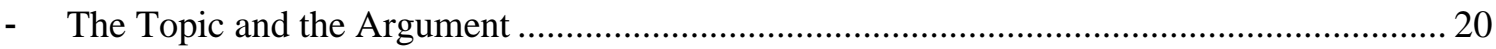

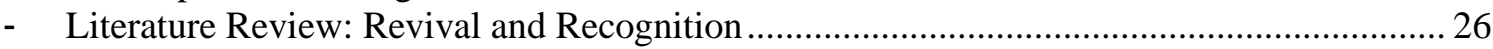

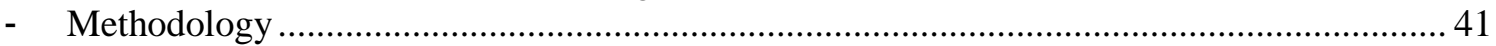

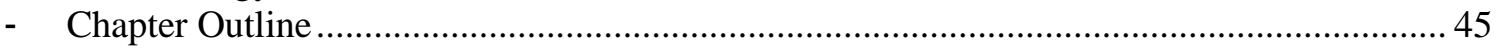

CHAPTER TWO: From Reception to Neglect.............................................................................................. 47

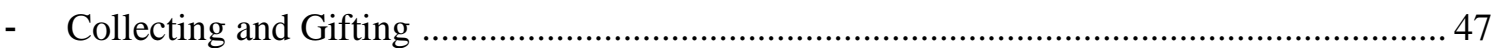

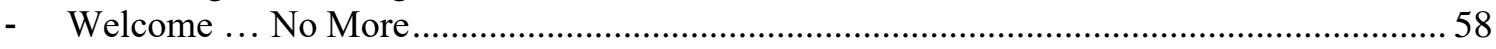

CHAPTER THREE: What Are the Smythe Watercolours?............................................................. 73

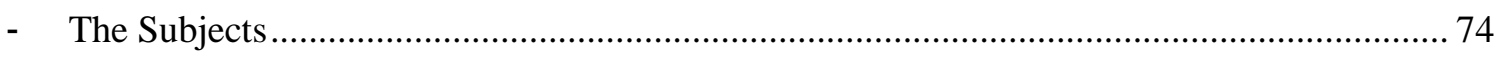

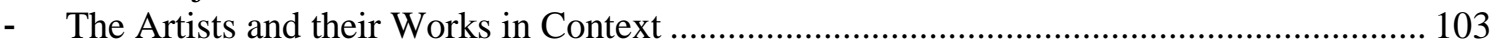

CHAPTER FOUR: The Smythe Watercolours and Taste ......................................................... 117

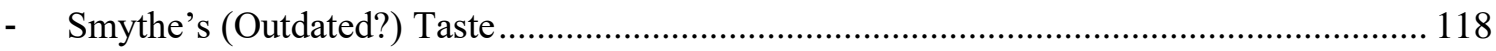

- Shifting Tastes: Collecting Art in New Zealand .................................................................. 138

CHAPTER FIVE: The Smythe Watercolours and Identity.............................................................. 167

- Taste and Identity: Collecting Local and the 'New' New Zealand......................................... 168

- Watercolours: “As National as the Language Itself” ............................................................. 190

CHAPTER SIX: Conclusion ............................................................................................................................... 201

Bibliography …................................................................................................................................................................. 207

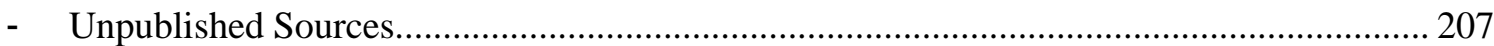

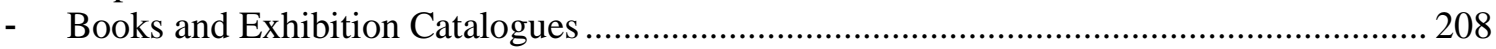

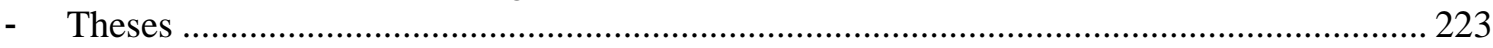

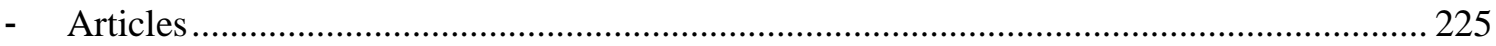

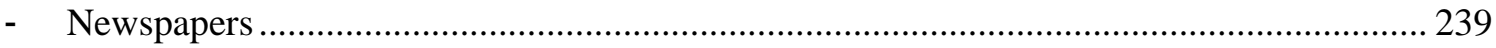

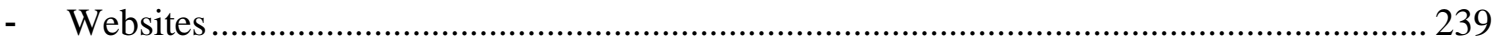

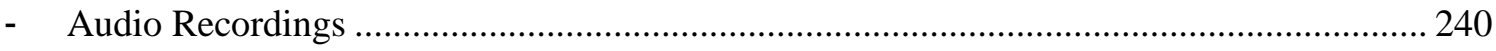

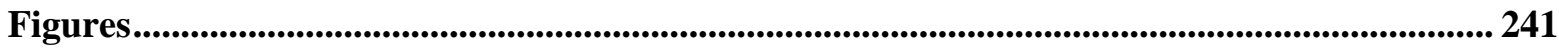

Appendix ................................................................................................................................................................... 287

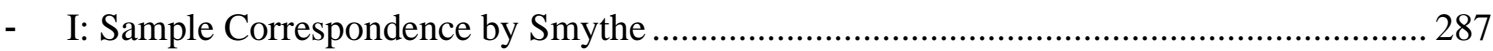

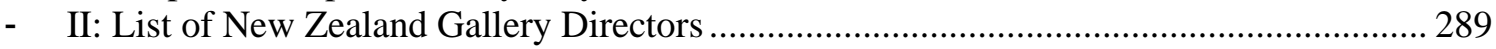




\section{Dedication}

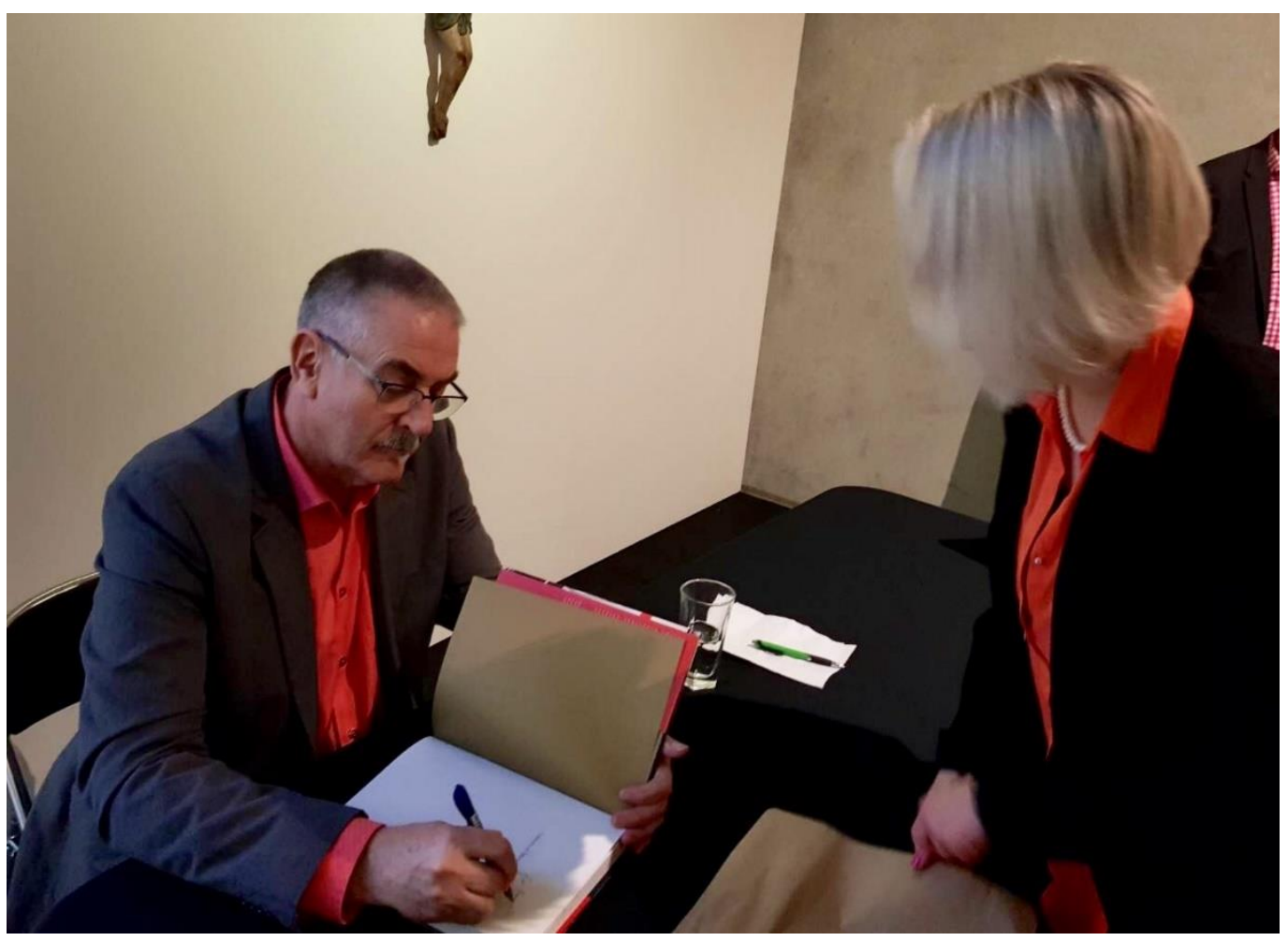

This thesis is dedicated to Roger Blackley (29 July 1953 - 15 May 2019).

Thank you for making sure every supervisor meeting included cake. 


\begin{abstract}
Francis Henry Dumville Smythe, a humble clergyman from England, spent a lifetime amassing his private collection of watercolours. During the $1950 \mathrm{~s}$, he decided to gift them to two art institutions in New Zealand - Dunedin Public Art Gallery and the National Art Gallery in Wellington. They were welcomed with open arms and celebrated as "the finest collection of water colour pictures in the Southern Hemisphere.” However, they soon fell out of favour: rarely exhibited, the collection remains poorly understood and unexplored to this day. Was their initial praise simply a matter of taste?
\end{abstract}

This project looks at the rise and fall of the Smythe collection and aims to reveal the circumstances that led to its current low profile within its respective institutions. The collection itself will be analysed in depth for the first time, and the impact that changing artistic tastes have had on its status will be examined. In New Zealand's case, these shifting tastes are symptomatic of the redefinition of national and cultural identity during the 1950s1980s. How did this redefined national and cultural identity contribute to the continued drop in status of the Smythe collection in New Zealand?

This dissertation considers the geographical contexts of both Britain and New Zealand and seeks to explore new ways of engaging with New Zealand's public art collections, through combining the different research fields of watercolours, taste, and identity. While British watercolours are now mostly considered old fashioned, this thesis will find new ways of making them relevant again. 


\section{Acknowledgements}

First and foremost, I want to thank my supervisors - all five of you! Each and every single one of you has enriched my PhD experience in your own way. David Maskill, thanks for continuing to ask me regularly after I left university if I want to do my $\mathrm{PhD}$ now - frankly, this probably wouldn't have happened if it wasn't for you. Roger Blackley, thanks for always bringing humour and wit into the office and guiding me through the first stages of this project. Geoffrey Batchen, thanks for taking over during a difficult and sad time, and for all the meticulous edits of my drafts. Raymond Spiteri, thanks for taking over during another difficult time - your compassionate leadership really helped a lot of us. Rebecca Rice, thanks for all the insightful and critical feedback which I believe have made me a better writer - I am honoured to have been the first $\mathrm{PhD}$ student you have supervised.

I want to acknowledge the other VUW Art History staff (Peter Brunt, Pippa Wisheart, and Morna Lorden), and my fellow PhD candidates (Anna Rigg, Kirsty Baker and Anna Marie White) for all their hard work. These last 3-4 years have truly been unprecedented and turbulent times, especially for our department. You are all inspirational!

This thesis would have been impossible were it not for the cooperation and support of the Dunedin Public Art Gallery and the Museum of New Zealand Te Papa Tongarewa. I especially want to thank Andrea Hearfield (Collections Manager, Te Papa) and Genevieve Webb (Registrar, DPAG) for allowing me to view hundreds of watercolours in their respective collections. It was a time-consuming job to get them all out of storage for me. I also want to acknowledge Mark Stocker (former Curator, Te Papa) and Tony Mackle (former Collections Manager, Te Papa) for accompanying me on my first visit to view some of the watercolours at Te Papa, and for demonstrating how to look at watercolours. Other staff in Wellington and Dunedin who helped me in my queries include Lauren Gutsell (Assistant Curator, DPAG), Chris Scott (Archivist, DCC), Jennifer Twist (Archivist, Te Papa), Victoria Boyack (Librarian, Te Papa), and Oliver Stead (National Library/Alexander Turnbull Library and former Registrar, DPAG). Also, I want to thank my managers at Te Papa for supporting me in this endeavour and giving me the time off to work on my thesis.

I further want to thank everyone in England who willingly corresponded with me and shared any knowledge they had about Archdeacon Smythe (or other watercolour-related questions I might have had). This includes: Kim Sloan (Curator, British Museum), Catherine Boel (British Museum), Lyn Rees (Central Archive, British Museum), Francesca Hillier (Senior 
Archivist, British Museum), Susannah Walker (Visiting Scholar, British Museum), Fahema Begum (Archivist, V\&A Museum), Lynda McLeod (Associate Director, Librarian, Christie's Archives), Annabel Kishor (Christie's), Simona Dolari (Provenance Researcher, Christie's Archives), Becky Loughead (Library Assistant, Lambeth Palace Library), Stawell Heard (Librarian, Acquisitions and Cataloguing, Royal Museums Greenwich), Amanda Goode (Emmanuel College Archivist), Heather Edwards-Hedley (Assistant Archivist, Haileybury), Richard Barker (Customer Service Advisor Lewes District Council), Charlotte Brunskill (Archivist \& Records \& Data Protection Manager, Paul Mellon Centre), and Timothy Wilcox.

Thank you to my friends for encouraging me to undertake this journey in the first place, and then continuing to support me throughout. Thank you for all the chats, the hot chocolates, the "how's the thesis going?", and for saying you are proud of me. Jamila, sorry if not all your suggestions made it into the thesis, but you have certainly outdone yourself and managed to surprise me yet again. I am so thankful for your thorough and thoughtful feedback and friendship. Don't forget: I love you, bro.

A huge thank you to my family. Es ist ganz schön viel passiert in dieser Zeit, aber wir haben es trotzdem geschafft und einander unterstützt. Wer hätte das gedacht: Der erste Doktor in der Familie! Danke für alles.

Finally, a big thank you to my Herman. We met literally the day before I started my enrolment as a PhD student, and I cannot believe how lucky I was to have met you then. I couldn't have asked for a more supportive and understanding partner to have by my side through this time. 我愛你. 多謝晒. 


\section{Abbreviations}

$\begin{array}{ll}\text { AAG } & \text { Auckland Art Gallery Toi o Tāmaki } \\ \text { AGMANZ } & \text { Art Galleries and Museums Association of New Zealand } \\ \text { CAS } & \text { Contemporary Art Society (London) } \\ \text { DCCA } & \text { Dunedin City Council Archives } \\ \text { DPAG } & \text { Dunedin Public Art Gallery } \\ \text { NAG } & \text { National Art Gallery (Wellington) } \\ \text { NZAFA } & \text { New Zealand Academy of Fine Arts } \\ \text { Te Papa } & \text { Museum of New Zealand Te Papa Tongarewa } \\ \text { TPA } & \text { Te Papa Archives } \\ \text { RA } & \text { Royal Academy (London) } \\ \text { VAA } & \text { Victoria \& Albert Museum Archives } \\ \text { V\&A } & \text { Victoria \& Albert Museum }\end{array}$




\section{List of Figures}

NB. All dimensions are given in millimetres unless otherwise stated. All works are watercolour on paper unless otherwise stated.

\section{Abbreviations}

DPAG Dunedin Public Art Gallery

Te Papa Museum of New Zealand Te Papa Tongarewa

AAG Auckland Art Gallery Toi o Tāmaki

Fig. 1 Kent \& Lacey Studios (established 1894), Portrait of Archdeacon F.H.D. Smythe, M.A., 1938, gelatin silver print on paper, 138 x 99, DPAG, 25-1954.

Fig. 2 Thomas Sandby (1721-1798), Earl of Fortescue's Grounds, Castle Hill, late 1780s90s, 180 x 250, DPAG, 214-195X.

Fig. 3 Paul Sandby (1731-1809), Carnarvon Castle, c. 1771, 180 x 265, DPAG, 735-195X.

Fig. 4 David Roberts (1796-1864), Ras-El-Abiad, Coast of Syria, 1839, 354 x 506, Te Papa, 1957-0009-218.

Fig. 5 Richard Wilson (1714-1782), Cwm Du, Near Tritower, 160 x 205, DPAG, 848-195X.

Fig. 6 Anthony Vandyke Copley Fielding (1787-1855), Fishing Boats in Rough Seas, 222 x 310, DPAG, 1057-195X.

Fig. 7 Joseph Barber (1757-1811), Mountain Torrent, 1829, 153 x 215, Te Papa, 1957-000910 .

Fig. 8 Henry Hine (1811-1895), Landscape, Sussex, 1858, 355 x 544, Te Papa, 1957-0009140 .

Fig. 9 John R. Cozens (1752-1797) [attributed], Hilly Landscape, grey wash drawing, $196 \mathrm{x}$ 280, Te Papa, 1957-0009-322.

Fig. 10 Samuel Atkins (1760-1808), Shipwreck, 350 x 470, DPAG, 945-195X.

Fig. 11 George Chambers (1803-1840), Fishing Boats, 310 x 405, DPAG, 58-195X.

Fig. 12 William Knell (1801-1875), Marine, 125 x 205, Te Papa, 1957-0009-157.

Fig. 13 Richard Parkes Bonington (1802-1828), Harbour at Sunset, 283 x 490, Te Papa, 1957-0009-22.

Fig. 14 James Holland (1799-1870), Sea-Fog Rising, 1836, 165 x 280, DPAG, 183-195X.

Fig. 15 David Cox (snr) (1783-1859), Figures on Beach, North Wales, 270 x 370, DPAG, 386-195X. 
Fig. 16 Diana Beauclerk (1734-1808), Study for a Miniature, 95 x 75, DPAG, 295-195X.

Fig. 17 John Downman (1750-1824), Profile of a Lady with a Black Choker, 1781, $180 \mathrm{x}$ 150, DPAG, 255-195X.

Fig. 18 Adam Buck (1759-1833), Lady Elizabeth Skyes, 120 x 115, DPAG, 256 -195X.

Fig. 19 Henry Edington Hobson (1820-1870), Young Gleaner, 315 x 445, Te Papa, 19570009-143.

Fig. 20 Henry T. Green (1836-1899), Cabbage Field, 1888, 255 x 175, Te Papa, 1957-0009116.

Fig. 21 George Kilburne (1839-1924), The Professor and Pupils, 360 x 515, DPAG, 580$195 X$.

Fig. 22 Charles Cattermole (1832-1900), The Tryst, 320 x 405, DPAG, 337-195X.

Fig. 23 John Masey Wright (1777-1866), Twelfth Night, 204 x 270, Te Papa, 1957-0009267.

Fig. 24 William Blake (1757-1827) [attributed], Son of the Morning, pen and watercolour, 215 x 270, DPAG, 970-195X.

Fig. 25 Henry Fuseli (1741-1825), "There Was a Day When the Sons of God Came to Present Thanks to the Lord...”, 115 x 175, DPAG, 13-1955.

Fig. 26 Myles Birket Foster (1825-1899), Girl with Kitten, 250 x 195, DPAG, 855-195X.

Fig. 27 Thomas Lawrence (1769-1830), Girl Looking at a Bird, 245 x 190, DPAG, 92$195 X$.

Fig. 28 Richard Beavis (1824-1896), Gathering Seaweed, 330 x 460, Te Papa, 1957-000918.

Fig. 29 Richard Beavis, Horses Ploughing, 190 x 290, DPAG, 296-195X.

Fig. 30 Robert Hills (1769-1844), Farmyard, 1812, 492 x 695, Te Papa, 1957-0009-138.

Fig. 31 Henry Alken (1785-1851), The Hunt, 175 x 260, DPAG, 66-195X.

Fig. 32 Hablot Knight Browne (1815-1882), The Hunt, watercolour and pencil graphite, 172 x 250, Te Papa, 1957-0009-36.

Fig. 33 John Leech (1817-1864), Fly Fishing, or "Mr. Hackle arrived at his favourite spot where he knows there is a good trout", 1855, ink and watercolour, 240 x 270, DPAG, 1036$195 X$. 
Fig. 34 John Leech, "Fly Fishing - Mr. Hackle arrives at his favourite spot, where he knows there is a good trout", in Punch 28 (January-June 1855), reproduced online:

https://books.google.co.uk/books?id=_QoDAAAAIAAJ\&dq=editions\%3Ao0ZG0cjtFIAC\& $\mathrm{pg}=\mathrm{PP} 1 \# \mathrm{v}=$ onepage $\& \mathrm{q}=$ fly $\%$ 20fishing $\& \mathrm{f}=$ false.

Fig. 35 Eliza Sharpe (1796-1874), Illustration for Pickwick Papers, 135 x 179, Te Papa, 1957-0009-229.

Fig. 36 Robert Hills, Stag, Te Papa, 1957-0009-139.

Fig. 37 Samuel Howitt (1756-1822), Lion, sepia wash, 114 x 160, Te Papa, 1957-0009-305.

Fig. 38 W.S. Hatton (1873-1938), Lioness and her Cub, c. 1909, 350 x 465, DPAG, 524$195 X$.

Fig. 39 Thomas Sidney Cooper (1803-1902), Sheep, 145 x 260, DPAG, 78-195X.

Fig. 40 Henry Willis (1810-1884), Cows in Winter, 1853, 225 x 330, Te Papa, 1957-0009261.

Fig. 41 David Roberts, Classical Ruins, 240 x 335, DPAG, 706-195X.

Fig. 42 James Baynes (1766-1837), Ruins, 1797, Te Papa, 1957-0009-17.

Fig. 43 Edward Dayes (1763-1804), Entrance to Monastery of St. Augustine, Canterbury, 419 x 548, Te Papa, 1957-0009-87.

Fig. 44 Frederick Goodall (1822-1904), The Mosque, watercolour and gouache, 204 x 305, DPAG, 500-195X.

Fig. 45 Samuel Prout (1783-1852), Venetian Canal, 350 x 260, DPAG, 687-195X.

Fig. 46 John Sell Cotman (1782-1842), The Coliseum, 330 x 480, DPAG, 372-195X.

Fig. 47 C.F. Maltby, Sunderland, 21 April 1826, 211 x 279, Te Papa, 1957-0009-173.

Fig. 48 George Cattermole (1800-1868), An Old English Mansion in the Days of Hawking, 382 x 283, Te Papa, 1957-0009-54.

Fig. 49 Peter De Wint (1784-1849), Barn Exterior, 110 x 185, DPAG, 844-195X.

Fig. 50 James A. Aitken (1846-1897), Street Scene, 229 x 189 (407 x 457), Te Papa, 19570009-3.

Fig. 51 William Henry Hunt (1790-1864), Still Life, 185 x 285, DPAG, 22-1954.

Fig. 52 John Parker (1839-1916), Woman Spinning, 1908, 350 x 258, Te Papa, 1957-0009202.

Fig. 53 George G. Kilburne, The River, 280 x 390, Te Papa, 1957-0009-156. 
Fig. 54 Dante Gabriel Rossetti (1828-1882), Design for a Stained Glass Window, 800 x 545, DPAG, 6-1953.

Fig. 55 Edward Burne-Jones (1833-1898), Design for Stained Glass, ink and watercolour, 375 x 240 (558 x 457), Te Papa, 1957-0009-43.

Fig. 56 Frederick Robinson (1862-1927), Sketch of a Model, 250 x 190, DPAG, 714-195X.

Fig. 57 Unknown, Copy of a Painting of a 17th Century Lady, 330 x 260, DPAG, 888$195 X$.

Fig. 58 Paul Sandby, Views in Wales: 'Fifth Set' / Carnarvon Castle, 1777, etching and aquatint, 205 x 264, The British Museum, 1872,0713.534.

Fig. 59 David Roberts, Ras-El-Abiad, Coast of Syria, lithograph, Te Papa, 1980-0054-1.

Fig. 60 Thomas Rowlandson (1756-1827), Tricks on the Turf, ink and watercolour, $255 \mathrm{x}$ 195, DPAG, 104-195X.

Fig. 61 George Cruikshank (1792-1878), Girl with Apples, 220 x 154, Te Papa, 1957-000983.

Fig. 62 Kate Greenaway (1846-1901), Children Playing, 128 x 180, Te Papa, 1957-0009117.

Fig. 63 Anne Parrott, Frankfort, 360 x 275, DPAG, 672-195X.

Fig. 64 John Ruskin, Italian Mountain Scene, 272 x 372, 1833-1888, Te Papa, 1957-0009225 .

Fig. 65 Hercules Brabazon (1821-1906), Lake Scene, Te Papa, 1957-0009-27.

Fig. 66 Thomas Collier (1840-1891), Kentish Landscape, 1870s-1880s, 210 x 330, DPAG, 153-195X.

Fig. 67 William Beverley (1811-1889), River Scene - Boy Fishing, 165 x 267, Te Papa, 1957-0009-20.

Fig. 68 George Clausen (1852-1944), Landscape, 335 x 505, DPAG, 856-195X.

Fig. 69 William Fisher (1841-1923), Blakeney, 1906, 230 x 285, DPAG, 26-195X.

Fig. 70 William Fisher, Landscape with Stream, 230 x 318, Te Papa, 1957-0009-104.

Fig. 71 John Singer Sargent (1856-1925), Figure with Drapery, 285 x 225, DPAG, 38$195 X$.

Fig. 72 John Sell Cotman, Cottage, 180 x 230, DPAG, 146-195X. 
Fig. 73 John Sell Cotman, Untitled Italian Landscape, 195 x 295, DPAG, 375-195X.

Fig. 74 Joseph Mallord William Turner (1775-1851) [attributed], Crossing the Brook, $270 \mathrm{x}$ 225, DPAG, 118-195X.

Fig. 75 Sybil Andrews (1898-1992), Tillers of the Soil, 1934, colour linocut, 233 x 326, Te Papa, 1953-0003-14.

Fig. 76 John Hoppner (1758-1810), Charlotte, Countess Talbot, c. 1784, oil on canvas, 2380 x 1455, DPAG, 6-1958.

Fig. 77 Jacob Epstein (1880-1959), Torso in Metal from the 'Rock Drill', 1913-1916, bronze, 730 x 640 x 340, AAG, 1961/8, OThe Estate of Sir Jacob Epstein.

Fig. 78 Barbara Hepworth (1903-1975), Cool Moon, 1970-71, lithograph, Te Papa, 19760011-1.

Fig. 79 Melvin Day (1923-2016), Goblet: Uccello Series, 1969, oil on canvas, 1525 x 1525, Te Papa, 1969-0016-1.

Fig. 80 Colin McCahon (1919-1987), Northland Panels, 1958, oil-modified alkyd on canvas, 5638 x 1779, Te Papa, 1978-0009-1/A-H to H-H.

Fig. 81 Frances Hodgkins (1869-1947), Circular Barn, 1939, gouache, 570 x 435, DPAG, 7-1971.

Fig. 82 Selwyn Muru (born 1937), Kohatu, 1965, oil on hardboard, 1203 x 795, Te Papa, 1965-0020-1.

Fig. 83 Alfred Sharpe (1836-1908), Burial Place of Hone Heke, Bay of Islands, 1883, 454 x 750, Te Papa, 1977-0027-1.

Fig. 84 Albin Martin (1813-1888), A New Zealand Landscape, watercolour and gouache, 270 x 372, AAG, M1885/1/170.

Fig. 85 John Buchanan (1819-1898), Milford Sound, 1863, 222 x 509, Hocken Collections, Uare Taoka o Hakena, University of Otago, a9892.

Fig. 86 William Fox (1812-1893), Westoe, c. 1872, 105 x 314, Alexander Turnbull Library, WC-048.

Fig. 87 William Fox, Westoe Rangitikei 1872, 255 x 413, Alexander Turnbull Library, WC050 .

Fig. 88 John Kinder (1819-1903), Mt Hobson and Khyber Pass from Carlton Gore Road, $201 \times 320$, AAG, 1937/15/30. 


\section{Chapter 1: Introduction}

In March 1985, the Art Galleries and Museums Association of New Zealand (AGMANZ) published a special issue of their quarterly which dealt with concerns about collections in New Zealand art museums. The publication covered a range of topics, such as the institutions' collection policies, the limits of collecting, and accessibility. Anne Kirker's contribution, "Aspects of Collection Rationalisation", opened the discussion. She proclaimed that public collections should have "a coherency and demonstrate a pattern of development [... and they] should be readily identifiable."

The problem was that when professional gallery directors and art historians took charge of New Zealand's public art institutions during the second half of the twentieth century, many of their collections revealed an aimless body of often poorly selected works.

Kirker explained the dangers of this situation:

There again, what does one do with those foxed sketches, countless number of them, by a now forgotten painter who once lived in the area. They take up precious space, they all need re-matting (not to mention restoration), they have never been properly catalogued - secretly you would like to burn them all!

Nevertheless, those sketches were donated in good faith and accepted for the collection fifty years ago. Perhaps there really is no aesthetic worth to them and possibly there is little of historical interest either. But let us not be too hasty. The value judgements that curators bring to their positions today can conflict markedly with their predecessors. To dismiss those aspects of the collection that we had no part in forming can be a gross arrogance. ${ }^{2}$

Indeed, Kirker went on to suggest that this rejection of seemingly worthless collection items might lead to overlooking valuable study material, and that art historians should instead attempt to judge them in another way, asking "could they be used as comparative material, or for educative purposes in explaining a certain technique and approach to subject? Are they really all that bad?"3

This thesis is about a collection of watercolours that has fallen victim to the exact scenario described by Kirker. The collection is held in two New Zealand public art

\footnotetext{
${ }^{1}$ Anne Kirker, "Aspects of Collection Rationalisation," AGMANZ Journal 16, no. 1 (March 1985): 2, accessed 4 June 2019 ,

https://christchurchartgallery.org.nz/media/uploads/2017_08/AGMANZ_Journal_Volume_16_Number_1_March_1985_op timized_for_web.pdf.

${ }^{2}$ Ibid.

${ }^{3}$ Ibid.
} 
institutions: Dunedin Public Art Gallery (DPAG) and the Museum of New Zealand Te Papa Tongarewa (Te Papa). ${ }^{4}$ These two sets of watercolours, amounting to 1,436 works of art, were gifted in the 1950s by the British clergyman and art collector Archdeacon Francis Henry Dumville Smythe (1873-1966), even though he never visited New Zealand himself [Fig. 1]. While they were initially eagerly accepted, the watercolours quickly started to be criticised, interest in them faded, and there was indeed a briefly mentioned temptation of burning some of them. ${ }^{5}$

\section{TOPIC AND ARGUMENT OVERVIEW}

This thesis is a study of watercolours. In art institutions today, watercolours together with pencil sketches, pen and ink drawings, prints and other graphic media are collectively known as 'works on paper.' ${ }^{6}$ This classification implies a judgement of inferiority, as 'paper' is associated with 'drawings', and 'drawings' are considered less durable, less esteemed and less valuable than 'paintings.' I have experience with works on paper, having studied a group of Northern Renaissance prints in the collection of Te Papa for my Master's dissertation in $2012 .^{7}$ Rather than being less esteemed, working with works on paper, for me, offers a very personal and sensorial experience.

I first encountered examples of the Smythe watercolours in 2016 when Te Papa opened the exhibition European Splendour: 1500-1800. ${ }^{8}$ This exhibition displayed a wide range of luxury items in a variety of media, including fine furniture, silks, lace, porcelain and painting. The aim was to reveal how the Church, trade, and innovation influenced the production of such items, and how social changes enabled more people of different social standing to be able to own them. Only two Smythe watercolours were displayed: Michel Brandoin's Colosseum, Rome, mid-to-late 18th century (1957-0009-30) and Louis Haghe's Treasury Hall, Ghent, c. 1850-1880 (1957-0009-123). In such a busy exhibition, there was a danger that these works might be swallowed up by the more imposing oil paintings, dresses

\footnotetext{
${ }^{4}$ At the time the gifts were made to Te Papa's forerunner, the National Art Gallery (NAG).

5 This tempting thought was expressed by the president of the DPAG in 1966 and will be discussed in context in the next chapter.

${ }^{6}$ Not all institutions use this specific name for this department. The British Museum, for example, uses 'Prints and Drawings', which seems even more restricting.

${ }^{7}$ Annika Sippel, "Fifteenth and Sixteenth-Century Northern European Prints at the Museum of New Zealand Te Papa

Tongarewa,” MA diss., Victoria University of Wellington, 2012.

8 The exhibition was running from 10 September 2016 to 26 February 2017. I was working as the Front of House Exhibition Supervisor for the art gallery at the time.
} 
and pieces of furniture. Yet they stood their ground, with visitors expressing their delight with the subject matter and amazement over the freshness of the colours, despite the medium's reputation for fragility. ${ }^{9}$

The vulnerable nature of watercolours plays an active role in how they are managed at museums and galleries. Due to their light sensitivity they tend to be stored away for most of their lives. In 1886 the British curator J.C. Robinson had already remarked:

These drawings have been carefully stowed away in portfolios, and sedulously kept from the light. Practically they have suffered no deterioration in our own time. This mode of keeping them is safe and proper, but it has this great inconvenience, in that these treasures are invisible and remain practically unknown to the mass of mankind, and so long as they are kept in that way they must of necessity remain so. ${ }^{10}$

While nowadays they tend to be stored in solander boxes rather than portfolios, the effect is the same: these containers are a double-edged sword that on the one hand preserves the watercolours and on the other keeps them hidden away from view. As a result, many of them never get to be admired or known by the public. This includes most of the Smythe watercolours considered in this dissertation.

Not all the works gifted by Smythe were in fact British or watercolours. He included four Renaissance tempera works (Master of San Miniato's Madonna and Child with Pomegranate, c. 1470; Annunciation to the Shepherds, c. 1475-1480; Adoration of the Magi, c. 1475-1480; and The Pietà, c. 1550) to Dunedin, as well as watercolours by other prominent non-British artists such as the Italian painters Francesco Bartolozzi and Giovanni Cipriani, and the Swiss artist Angelica Kauffman. ${ }^{11}$ Still, British watercolours make up the biggest component of the gift, with 1,436 watercolours (including washes, like sepia or grey washes). While there are also pencil and chalk drawings by some of the major artists of the period, in this thesis I will limit my discussions only to the watercolours from the gift. ${ }^{12}$ However, they are not the sole focus of this thesis. This is also, first and foremost, a study of a collection. Collections as a field of research, rather than their contents, has

\footnotetext{
${ }^{9}$ This was based on the fact that paper could tear easily (more so than canvas or wood), and that the colours would fade quicker than oils.

${ }^{10}$ J.C. Robinson in a letter to The Times, 11 March 1886, cited in Michael Clarke, The Tempting Prospect: A Social History of English Watercolours (London: British Museum Publications, 1981), 150.

${ }^{11} \mathrm{He}$ also included some exhibition catalogues, lecture notes and a book, such as a brochure on Robert Witt's lecture The Art of Collecting held at Te Papa Archives.

12 This decision was based on the practical reason that the sheer size of the collection required selectiveness. In total, he gifted 1,515 items to the DPAG and NAG. Additionally, Smythe himself referred to his collection as a collection of watercolours, and the strong affiliations between the medium and British identity become an essential aspect of my argument.
} 
garnered a lot of attention and input from scholars over recent years, as Rebecca Rice outlines in her thesis "The State Collections of Colonial New Zealand Art: Intertwined Histories of Collecting and Display" (2010). ${ }^{13}$ She explains that this practice directly links art history to other academic fields, such as sociology, and that it can place art collecting into wider historical contexts:

Such an approach is grounded in sociological theory, whereby collections are not considered as neutral compilations of objects, but entities that have evolved out of and been actively constructed in a particular historical moment(s) informed by the aesthetic attitudes, political climate, economic circumstances of the times. Collections are also increasingly recognised as strongly influenced by the personalities involved in their making. ${ }^{14}$

While the Smythe collection was originally made by a single collector, there were indeed other personalities involved in forming its legacy. Its fate was ultimately decided by the gallery directors who chose to accept or reject it.

The Smythe collection is also significant in that it spans several different historical moments and geographical contexts. It was formed during the late nineteenth and early twentieth centuries in England, a period that witnessed two World Wars and the emergence of a modern taste in art. The collection then found its permanent home during the 1950s in two different New Zealand cities, each with a unique cultural background. As a former colony of Britain, New Zealand was also involved in the wars and at the same time saw other major social and cultural changes as it developed a stronger sense of its own independent identity.

I will be arguing that the acquisition of the Smythe watercolours demonstrates the Anglo-centric bias of the mid-twentieth-century New Zealand art establishment, which eventually became displaced and led to the diminished status of this collection. But I will also be arguing that the collection itself enables us to better understand the changing status of watercolours as witnessed by the changing tastes of collectors, both private and institutional, and that these changing tastes are a reflection of wider shifts in cultural identities. Through this, I will find a new place for British watercolours in the history of art in New Zealand.

\footnotetext{
${ }^{13}$ See "Collecting Histories" in Rebecca Rice, "The State Collections of Colonial New Zealand Art: Intertwined Histories of Collecting and Display," PhD diss., Victoria University of Wellington, 2010: 2-36. For examples of histories of collections, see Krzysztof Pomian, Collectors and Curiosities: Paris and Venice, 1500-1800 (Cambridge: Polity Press, 1990); Susan Pearce, On Collecting: An Investigation into Collecting in the European Tradition (London and New York: Routledge, 1995); Philipp Blom, To Have and to Hold: An Intimate History of Collections and Collecting (Woodstock and New York: The Overlook Press, 2003).

${ }^{14}$ Rice, "The State Collections of Colonial New Zealand Art," 11.
} 
Despite watercolour's seemingly old-fashioned image, the medium retains considerable relevance for many scholars - primarily British - who compete to present fresh perspectives on it. In addition, museums and galleries outside New Zealand still actively exhibit watercolours. However, despite the fact that New Zealand's own watercolour tradition drew directly from British watercolours, they have disappeared almost entirely from the discourse of art history in New Zealand, with New Zealand museums and galleries showing minimal interest in exhibiting their holdings.

The acceptance of the Smythe watercolours during the 1950s reveals the strong connection to this embedded - and by this point embattled - British heritage of New Zealand art. Nevertheless, their glory was short-lived, and they were soon forgotten. This moment of New Zealand's art history can reveal aspects of the mobility of taste and expressions of nationalism and needs to be acknowledged alongside the more recent emphasis on an evolving Māori and Pacific context for New Zealand's art production. It is this same mobility of taste to which the Smythe collection fell victim. The collection contains a rich variety of artists and subjects which demonstrate the major developments and aspects of the watercolour medium, as well as showcasing the personal taste of the collector. However, these unique features were insufficient to maintain the collection's status during a time of such innovation and rapidly changing taste. By the time he chose to part with it, Smythe's collection would already be considered outdated and unfashionable by his British contemporaries, and the collection's New Zealand recipients were soon to follow.

It was unfortunate for Smythe and his donation, but there was a growing mismatch between the kind of art that his collection represented and the New Zealand art scene into which it arrived. This discrepancy is an awkward aspect of a bigger history that needs to be considered. Even before Smythe's gift, the National Art Gallery (NAG) in Wellington had a notoriously conservative outlook during this period. The director, Stewart Maclennan was actively seeking out British watercolours for the gallery, strongly believing that New Zealand art owed its origins to artists like John Sell Cotman, Peter De Wint, John Constable and Joseph Mallord William Turner, and not to "charming but minor British artists like Heaphy, Angas, and Brees." 15 In Maclennan's view, it was a national heritage that

\footnotetext{
${ }^{15}$ S.B. Maclennan, "Survey, Trends, and Influences, 1938 to Present," An Encyclopaedia of New Zealand, originally published in Te Ara - The Encyclopedia of New Zealand (1966), accessed 9 April 2020, http://www.TeAra.govt.nz/en/1966/art-in-new-zealand/page-2.
} 
demanded a representative collection of early British watercolours. ${ }^{16}$ This Anglo-centric view was shared by Annette Pearse, curator of the DPAG. Both she and Maclennan were eager to reassure the archdeacon that his gifts were happily accepted and indeed revered by the New Zealand public. However, this does not accurately reflect the broader attitudes current in 1950s New Zealand towards historic English art. In fact, Maclennan and Pearse, and their institutions, represented an old-guard and more conservative position in their policies of art acquisition. In this, they were about to be challenged by supporters of the emerging national and modern canon.

With Smythe collecting watercolours at a time when they seemed to be falling out of fashion in England, maybe he had hoped that they would be appreciated in 'colonial' New Zealand, and that he would in turn receive suitable recognition for gifting them. Indeed, the grand opening exhibition of these works in Dunedin in 1953 described them as "one of the most valuable art collections ever given to an organisation in New Zealand and Australia."17 However, Smythe's presentation came at a time when New Zealand art-collecting institutions were at a crossroads. From the 1950s onwards, New Zealand was actively forging a national identity in direct opposition to everything that these works represented.

The relationships between Britain and New Zealand were, and still are, complex and entangled. Throughout the nineteenth and early twentieth centuries, Britain was considered the 'Motherland', and New Zealanders aspired to emulate not just British art, but more general British culture and traditions in their everyday lives. Whether in politics or education, New Zealand took pride in its status as 'the Britain of the South'. ${ }^{18}$ However, as events such as the horrific battles at Gallipoli during World War One started to cast doubt on Britain's ingrained superiority, this mindset slowly started to change, and New Zealand began to see itself as better than, and different from, Britain. Local heroes and symbols replaced those of the old home, and the focus was placed on New Zealand's unique location in the Pacific and its bicultural foundations. As A.R.D. Fairburn bluntly claimed, "we really are people of a different race, and have no right to be monkeying about with European culture." 19

\footnotetext{
${ }^{16}$ Ironically, it is precisely artists like Charles Heaphy, George French Angas and Samuel Brees, then left for the Alexander Turnbull Library to collect, that became increasingly sought after as significant figures in our national art histories.

17 “Art Collection Opening Tomorrow," Otago Daily Times (18 March 1953), DCCA: Scrapbooks, DPAG 26/3.

${ }^{18}$ Jock Phillips, "Visitors' Opinions about New Zealand - The 'Britain of the South', 1860-1900," Te Ara - The Encyclopedia of New Zealand, accessed 23 June 2020, http://www.TeAra.govt.nz/en/visitors-opinions-about-newzealand/page-2.

${ }^{19}$ A.R.D. Fairburn, cited in Keith Sinclair, A Destiny Apart: New Zealand's Search for National Identity (Wellington: Allen \& Unwin in association with the Port Nicholson Press, 1986), 244.
} 
This was the time, therefore, of a distinctly nationalistic re-orientation of New Zealand's cultural identity away from Britain. It is a process that is still unfolding today, maybe more strongly than ever. Is it a surprise, then, that there is no authority on British watercolours in New Zealand today, and that over recent decades no exhibitions have been held to display them $?^{20}$ Are galleries actually embarrassed by such collections, given they are also reminiscent of now-superseded imperial mind-sets?

Mary Kisler's celebrated book, Angels and Aristocrats: Early European Art in New Zealand Public Collections (2010), briefly mentions Smythe's generous gift, stating that "over a number of years he gave a superb collection of more than 1000 British watercolours to Dunedin Public Art Gallery, and on his death in 1957 he left around 360 British watercolours to the National [Art] Gallery." ${ }^{21}$ There are two mistakes in this statement in relation to his donations to Wellington. Firstly, the watercolours were not bequeathed to the gallery as a single gift, but rather arrived in small parcels over two years. Secondly, they were not donated upon Smythe's death, as he did not die in 1957. He lived on for another decade after the Wellington gifts ended, during which time he sent further works to Dunedin. These inaccurate statements highlight how marginalised the collection has become, even when considered by those scholars holding historical international portfolios.

Despite A.H. Allen (president of the DPAG Society) promising Smythe that "your name and generosity will be perpetuated for generations to come", ${ }^{22}$ it appears that Smythe himself had a more accurate idea of his posterity when he predicted that "no one will have the foggiest idea who Francis Smythe was." ${ }^{23}$ It is time for Smythe to join the roll call of other significant donors, alongside the likes of Bishop Monrad, J.T. Mackelvie, Rex Nan Kivell and John Ilott, and it is time for his 'art-children' (as he termed them) - so lovingly collected over his lifetime - to receive their share of the limelight. ${ }^{24}$

In my thesis, I will mount three main arguments: firstly, that the collection itself is a representative collection of British watercolours that traces the history of the medium from the eighteenth to the late nineteenth century; secondly, that the acquisition and reception of the Smythe collection in the 1950s demonstrates the Anglo-centric bias of the New Zealand art establishment; and, thirdly, that the status of the collection rapidly diminished with the

\footnotetext{
20 Tony Green's project on the Smythe collection in the early 2000s offers an exception to this. Green organised a two-part exhibition at DPAG that looked exclusively at works from the Smythe collection. This will be further discussed in Chapter Two.

${ }^{21}$ Mary Kisler, Angels and Aristocrats: Early European Art in New Zealand Public Collections (Auckland: Godwit, 2010), 36.

22 A.H. Allen to Smythe, 31 October 1955, Dunedin City Council Archives (DCCA): Box 11, DPAG 15/22.

${ }^{23}$ Smythe to DPAG, 30 September 1953, DCCA: Box 11, DPAG 15/22.

${ }^{24}$ Smythe to DPAG, 24 February 1955, DCCA: Box 11, DPAG 15/22.
} 
emergence of a new modern taste in art, as well as the development of a New Zealand cultural and national identity, and the concurrent writing of a national art history. This approach aims to determine the significance of the Smythe collection as a case study that can be placed both within an international discourse that is refocusing attitudes to the British watercolour tradition, and within a national discussion around the reshaping of the history of art in New Zealand. I will also be demonstrating the importance of studying institutional art collecting, which facilitates the understanding of shifting and developing tastes.

As Mary Kisler wrote, "I would argue that our international historic collections are an equally important part of New Zealand's history. Displaced geographically, and all too often relegated for much of the latter twentieth century to storage as either outmoded, irrelevant, or archaic, they too deserve their place in the sun." ${ }^{, 25}$ I agree that such collections can contribute to a deeper history of art and collecting in New Zealand by, among other things, exposing shifting policies of acquisition and tastes. At the symposium New Zealand Art under Erasure, held at City Gallery Wellington on 30 June 2018, chief curator Robert Leonard agreed that a wider and deeper history of New Zealand art institutions and collecting should be considered when looking at New Zealand art and art history. ${ }^{26}$ By focusing on this case study of an international collection amassed during the 1950s, I aim to use this thesis as a starting point for such future study.

Admittedly, Smythe was not a very distinguished collector and the resultant collection certainly has its limitations. However, despite its apparent lack of quality and occasionally misleading attributions, it is representative of a particular period of taste. Additionally, it can be used to examine some of the restrictions collectors of a certain class faced, as well as the impact of shifting contexts. These characteristics all make the Smythe collection a valuable topic for research.

\section{LITERATURE REVIEW: REVIVAL AND RECOGNITION}

In Works of Splendor and Imagination: The Exhibition Watercolor, 1770-1870 (1981), art historian Jane Bayard claims that watercolour painting in Britain was at the forefront of contemporary art during the nineteenth century. She argues that "the rapid advances in

\footnotetext{
${ }^{25}$ Kisler, Angels, 19.

26 This seminar was held at the City Gallery Wellington Te Whare Toi, in partnership with Art History, Victoria University of Wellington. See Robert Leonard, "New Zealand Art Under Erasure" (23 January 2019), accessed 23 April 2019, http://robertleonard.org/2019/01/new-zealand-art-under-erasure/.
} 
technique and the possibility of further innovation made watercolour seem more modern and forward-looking than oil." ${ }^{27}$ Despite this, when I first started mentioning British watercolours as the topic of my research, I was met with rather disparaging responses, like "that's quite old fashioned, isn't it?" and "that's not a very sexy topic." Indeed, while they may have been considered 'sexy' in their heyday, British watercolours were viewed as somewhat boring and dull for most of the twentieth century. They have seemingly become irrelevant and unfashionable. This general attitude has persisted until as recently as 2011, when Tate curator Alison Smith wrote:

It is hardly surprising that, with perhaps the exception of Turner, the study and collecting of historic British watercolour has become a niche activity, alienated from the mainstream, the province of cultivated specialists rather than younger collectors for whom the 'brown' aesthetic of watercolour appears out of place in the cool minimalist space of a modern interior. ${ }^{28}$

Nevertheless, the 2011 exhibition Watercolour at Tate Britain aimed to challenge preconceptions of the status of watercolour. ${ }^{29}$ This was one of the first exhibitions of the current decade to demonstrate a revival of interest in the medium.

While internationally a revival of the watercolour medium is fully underway, in New Zealand only colonial watercolours have been recognised in our art histories. The role of British watercolours in informing these works is largely ignored. Instead, British watercolours have become the scapegoat, or something to react against, and the victim that has lost its former relevance. Indeed, if we can move beyond a strictly national art history, we can broaden the conversation and acknowledge a richer history of art by providing a more global context for understanding art in Aotearoa New Zealand.

\section{Part 1 Revival: Updating the Outdated}

In 2010 Martin Myrone noted, "more recently, watercolour painting has been viewed as largely discredited and irrelevant, too terribly tainted by associations with traditionalism and amateurism." ${ }^{30}$ This statement perfectly describes the old-fashioned image that watercolour

\footnotetext{
${ }^{27}$ Jane Bayard, Works of Splendor and Imagination: The Exhibition Watercolor, 1770-1870 (New Haven: Yale Center for British Art, 1981), 8.

${ }^{28}$ Alison Smith ed., Watercolour (London: Tate Publishing, 2011), 18. The word 'brown' here symbolises the oldfashioned nature of watercolours as a thing of the past. Due to the light sensitivity of the colours, historical watercolours often have a faded, foxed and browned appearance due to their old age and previous display and storing methods. ${ }^{29}$ Tate Britain, Watercolour, 16 February - 21 August 2011, accessed 3 August 2017, http://www.tate.org.uk/whatson/tate-britain/exhibition/watercolour.

${ }^{30}$ Martin Myrone ed., Watercolour in Britain (London: Tate Publishing, 2010), 10.
} 
has held since the mid-twentieth century: usually small-scale, conventional landscapes produced in a medium that many people simply dabbled in. In recent years, however, international scholars have attempted to scrape away those dusty preconceptions in order to reveal the luminous potential inherent in the medium. Alison Smith sums up some of the fresh areas of interest that are explored in recent scholarship:

The development of new approaches to the history of watercolour in Britain in recent years has done much to undermine the authority of the grand narrative projected in the past, by emphasizing institutional history, amateur practice and different schools of watercolour above the notion of a succession of greats, revealing watercolour to be a subject fraught with schisms and uneven in its development. The widespread awareness of issues relating to cultural diversity has also made the British appellation the subject of scrutiny. ${ }^{31}$

Exhibitions have been a key vehicle for bringing watercolours back into the eyes and minds of the general public and the professional scholar alike. The catalogues for such exhibitions make up the major part of recent literature about British watercolours, focusing on previously neglected artists, subjects, time periods and collections.

Jessica Feather's British Watercolours and Drawings: Lord Leverhulme's Collection in the Lady Lever Art Gallery (2010) is an impressive catalogue raisonné of 334 British watercolours and drawings, now housed at the Lady Lever Art Gallery, Port Sunlight. This gallery was founded and built by the industrialist and philanthropist William Hesketh Lever (1851-1925), 1st Viscount Leverhulme, and opened in 1922. Most of the works presented in the catalogue were collected by Lever himself, between 1869 and 1925, and a large part has not been discussed prior to this publication. As Feather explains, "they have until now received little attention as a distinct group, with their history absorbed within more general discussions of the development of Lever's Victorian and eighteenth-century painting collections." 32 The catalogue entries are preceded by an introduction that analyses Lever's taste and collecting practices.

Through this case study, Lever emerges as a collector who was generally oldfashioned in his tastes and who amassed thousands of British watercolours that vary drastically in both type and quality. Feather details the purely decorative origin of his private collection and the lavish sums he spent on works, reflecting his personal financial

\footnotetext{
${ }^{31}$ Smith, Watercolour, 21.

${ }^{32}$ Jessica Feather, British Watercolours and Drawings: Lord Leverhulme's Collection in the Lady Lever Art Gallery (Liverpool: National Museums Liverpool, 2010), xi.
} 
circumstances. His taste - first for contemporary Victorian artists and later for earlier British art - was influenced by outside forces such as the dealer, collector and watercolourist James Orrock (1829-1913). Lever's methods of acquisition are analysed, revealing that he made purchases at auctions and also made use of dealers such as Orrock and, later, F.W. Fox. Feather further discusses Lever's manner of displaying watercolours in his own home, and points to the "dubious authenticity" of some of the works in the collection, claiming that Lever "seems to have been willing to be duped." 33

This is elaborated in the catalogue, where some new attributions are made, while other works are demoted to the status of a copy. For example, Lever acquired Road Through a Park, c. 1810, as a work by Peter De Wint, yet Feather demonstrates that it is in fact an early work by David Cox. The entries, ordered alphabetically by artist, are meticulously researched and presented, successfully bringing together a wealth of information in a coherent manner. It is particularly noticeable that the more obscure works in the collection are treated with the same level of respect and detail as works by the most notable artists such as Turner or Cox.

This is also the goal of my thesis, which, like Feather's catalogue, looks at watercolours amassed by one collector, most of which have never been displayed or analysed before. The New Zealand collections number well over 1000 pieces, so a similar selection process will be necessary. In addition, there are comparable "dubious attributions" to be tested. Despite differences in terms of their purchasing power, Smythe and Lever were contemporaries, collecting British watercolours around the same time. A comparison of their collecting practices will identify trends of the time and determine ways in which Smythe was either adhering to those trends or breaking free from them.

There is a general lack of literature concerning the culture of collecting watercolours, as well as the collectors themselves. ${ }^{34}$ By looking at collectors' practices, we can determine trends in the formation of the canon of watercolour artists and understand the development of many public collections. Despite Smythe's major contribution to New Zealand's public art collections, there is effectively no information available on him. Other collectors, such as Sir George Grey, Bishop Monrad, James Tannock Mackelvie, Sir John Ilott and Sir Rex Nan Kivell, have books or theses devoted to their lives and collections. Peter Entwisle's

\footnotetext{
${ }^{33}$ Feather, British Watercolours and Drawings, xv-xvi.

${ }^{34}$ Among the few examples is Jessica Feather's thesis "The Formation of a Modern Taste in Watercolour: Critics, Curators and Collectors c. 1890-1912,” PhD diss., University of Reading, 2014.
} 
Treasures of the Dunedin Public Art Gallery (1990) and the DPAG's collection survey, Beloved (2009), are currently the only books with more than a passing mention of Smythe. ${ }^{35}$ These two insightful exhibition catalogues trace the development and growth of the DPAG's collection, concentrating on the policies, politics and personalities that have shaped this history of collecting. Smythe was one of those personalities, and the authors present a brief yet lucid story of how, when and why this man gifted his precious collection of British watercolours to Dunedin. What emerges is the image of a kind man who spent a lifetime collecting artworks only to give them away. While the focus is on Smythe's connection with the DPAG's director Annette Pearse, and it is suggested that her charm was a major factor in the archdeacon's decision, we learn little about the man himself. How do his collecting practices reflect or embody the collecting practices current in Britain during the early twentieth century? Did he adhere to an existing canon of artists, or did he make use of agents? What about his personal life? How did his clerical profession support his interests? Was he an amateur watercolourist, too?

At the time of commencing this thesis in 2017, two exhibitions featuring British watercolours were showing simultaneously: Places of the Mind: British Watercolour Landscapes 1850-1950 at the British Museum in London, and Victorian Watercolours from the Art Gallery of New South Wales in Sydney. ${ }^{36}$ These exhibition catalogues are consequently the most recent additions to the body of literature under discussion. ${ }^{37}$ They both focus on later periods of watercolour production, and reveal for the first time many works and artists that have lain dormant in their collections.

Edited by Kim Sloan, with essays by Jessica Feather, Anna Grutzner Robins, Sam Smiles and Frances Carey, Places of the Mind examines landscapes produced in Britain between 1850 and 1950. While it deals with landscape, the characteristic subject of the era of the 'Golden Age' (1790-1850), it also shines a light on the less-studied time period of the late Victorian and Modern ages. In fact, among other things, the claim is made that the 1890s should be seen as a new golden age of watercolour. ${ }^{38}$ The director of the British Museum, Hartwig Fischer, asserts that "this book and the exhibition it accompanies are the

\footnotetext{
${ }^{35}$ Peter Entwisle, Treasures of the Dunedin Public Art Gallery (Dunedin: Dunedin Public Art Gallery, 1990) and Robyn Notman and Lynda Cullen eds., Beloved: Works from the Dunedin Public Art Gallery (Dunedin: Dunedin Public Art Gallery, 2009).

3623 February - 27 August 2017 and 2 June - 3 December 2017 respectively.

${ }^{37}$ Kim Sloan ed., Places of the Mind: British Watercolour Landscapes 1850-1950 (London: Thames \& Hudson, 2017) and Peter Raissis, Victorian Watercolours from the Art Gallery of New South Wales (Sydney: Art Gallery of New South Wales, 2017).

${ }^{38}$ See Jessica Feather “A New 'Golden Age'? The 'Modern' Landscape Watercolour,” in Sloan, Places of the Mind, 6891.
} 
first to explore what came after [that is, after the 'Great Age of British Watercolours'], to look at the ways Victorian and early modern artists interpreted landscape on paper in the

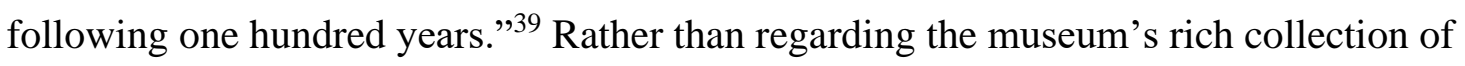
watercolours from 1850-1950 as a sort of 'falling off', the exhibition aimed to demonstrate both the technical brilliance of the works and the imaginative responses of these artists to their times. The authors demonstrate a fresh way of exploring an old topic by focusing on the emotional and spiritual impact that landscape exerted on British watercolourists. One of the highlighted artists is William Russell Flint (1880-1969), a painter whose watercolours despite their captivating virtuosity - "are accorded only a small part, if any, in the canonical history of British landscape. ${ }^{40}$ Flint is also one of the artists included in Smythe's gifts to New Zealand.

The period covered in Places of the Mind incorporates that in which Smythe was compiling his collection of watercolours, making this an invaluable resource for my own research. The artistic developments are analysed against a backdrop of social, political, and personal upheavals, which assist in painting a picture of Smythe's surroundings in England, as well as those of the artists he collected. In the second chapter, "A New 'Golden Age'? The 'Modern' Landscape Watercolour', Jessica Feather explains that during the 1890s and early 1900s many collectors compiled works by earlier artists such as Turner and Cotman alongside contemporary ones like Flint and Paul Nash. ${ }^{41}$ Did Smythe participate in this trend, too?

Peter Raissis' exhibition, Victorian Watercolours, coincided with a major conservation programme of watercolours and their frames at the Art Gallery of New South Wales (AGNSW), meaning that numerous works in the exhibition were displayed and analysed for the first time. Raissis' introductory essay traces the formative years of the AGNSW, with Victorian watercolours representing the first works of art to be purchased for the gallery in 1874. Essentially, they were seen as an educational resource to teach art appreciation and the techniques of watercolour painting. Raissis also emphasises the fact that the early trustees of the gallery aimed to follow middle-class British cultural standards in their art acquisitions, and works from England or Scotland were therefore accorded a special place: ${ }^{42}$

\footnotetext{
${ }^{39}$ Sloan, Places of the Mind, 6.

${ }^{40}$ Ibid., 13.

${ }^{41}$ Ibid., 89.

${ }^{42}$ Raissis, Victorian Watercolours, 14.
} 
Imported British art as opposed to locally produced art was considered most appropriate for Australian colonial galleries generally, so inexorably linked were this country's cultural aspirations to the Empire, and so acute were local pretensions to English civilisation. ${ }^{43}$

While this sentiment certainly mirrored the situation in nineteenth-century New Zealand, British watercolours had lost much of their cachet by the time Smythe made his donations in the mid-twentieth century. As Raissis describes, this demotion was the case also in Australia, where they had become "dusty relics of an artistic era that was now scorned."44 Another recent exhibition was Watercolour in Britain (2010), a touring exhibition organised by Tate Britain as part of the Great British Art Debate. ${ }^{45}$ The aim was to look at watercolour painting with fresh eyes, to reveal the potential technical variety of the medium, and uncover extraordinary works by amateurs and other neglected artists. There are five chapters in the exhibition catalogue, but it is the opening one by the book's editor, Martin Myrone, that best summarises these new ideas. In "Watercolour in Britain: A National Art?", Myrone challenges us to abandon the well-established idea of a 'pure' and correct technique and subject matter for watercolour - that of the renowned masters of the 'Golden Age' - and acknowledge the fact that watercolour is a diverse medium that "may be swift and transparent, but it may also be slow and opaque, dark and aggressive, heavy or intense." 46

The exhibition catalogue for Tate Britain's Watercolour (2011), also part of the Great British Art Debate, was edited by Alison Smith, with the catalogue entries preceded by an introduction by Smith and chapters by Nicola Moorby and David Blayney Brown. The territory covered is very similar to Watercolour in Britain. By going beyond the 'Golden Age' of the earlier nineteenth century and exploring later watercolourists among the Victorian, Modern and Contemporary artists of the twentieth and twenty-first centuries, the authors of both publications document fresh subjects for watercolour that deal, for example, with personal inner vision or war experiences. Furthermore, earlier works are viewed in a new light, such as Turner's 'colour beginnings' that are harbingers of modern abstraction. ${ }^{47}$

\footnotetext{
${ }^{43}$ Raissis, Victorian Watercolours, 11.

${ }^{44}$ Ibid., 18.

45 The Great British Art Debate was a four-year partnership project supported by the Heritage Lottery Fund, which aimed to explore contemporary ideas about nationhood and identity (2008-2012). The four institutions involved were Tate, Tyne \& Wear Archives \& Museums, Norfolk Museums \& Archeology Service, and Museums Sheffield. Find out more on the website: http://www2.tate.org.uk/greatbritishartdebate/about/index.html

${ }^{46}$ Myrone, Watercolour in Britain, 12.

${ }^{47}$ Smith, Watercolour, 185 and 187.
} 
What makes these publications interesting for my own research, however, is their concern with the question of whether British watercolour is indeed a 'national' art. Myrone and Smith briefly explain how watercolour came to be regarded as such during the nineteenth century, but then question the validity of this idea in view of the many international exponents of the medium. These discussions will feed into my investigation of the importance of the 'Britishness' of watercolours in New Zealand, and how this affected the contested history and reception of the watercolour medium in this country. Also, Smythe's initial determination to release his watercolours to British institutions only, as well as his sudden change of heart and willingness to gift his collection to New Zealand instead, is intrinsic to this debate. ${ }^{48}$

Katherine Coombs' British Watercolours 1750-1950 (2012) examines the United Kingdom's national collection of British watercolours, held in the Victoria \& Albert Museum (V\&A), to demonstrate 200 years of the medium's history. ${ }^{49}$ What might at first appear as a rather conventional and broad retelling of this history does in fact focus on some specific areas which are also reflected in the literature surveyed above. For example, Coombs includes a section on the introduction of photography and the impact this had on watercolour painting, while Chapter Four is wholly dedicated to figure subjects in watercolour. With landscape definitively the dominant subject, it was rare for artists to primarily depict figures, which also form a significant portion of Smythe's collection.

The final chapter, "1850-1950: The Tradition of Watercolour in Britain”, similarly looks at watercolours from the later period. Within this chapter there are certainly artists and topics on which Coombs focuses, yet her most innovative contribution concerns the process of reappraisal and rediscovery that occurred during this time. For example, John Sell Cotman was belatedly identified as a leading figure of the watercolour movement only during the early twentieth century. ${ }^{50}$ Also, the increasing value of sketches and unfinished drawings from the nineteenth century onwards is traced against a growing interest in the private aspects of watercolours, culminating in an increasingly blurred distinction between the sketch and the finished artwork. ${ }^{51}$ This scholarship provides a frame through which to view and evaluate the Smythe collection, which was amassed during the time covered by Coombs.

\footnotetext{
${ }^{48}$ Entwisle, Treasures, 26-27.

${ }^{49}$ Katherine Coombs, British Watercolours 1750-1950 (London: V\&A Publishing, 2012).

${ }^{50}$ This is also discussed in depth in Feather's thesis and in Andrew Moore, Norma Watt and Timothy Wilcox eds., John Sell Cotman: Master of Watercolour (Norwich Castle Museum and Art Gallery, 2005).

${ }^{51}$ Coombs, British Watercolours, 124.
} 
As this brief sample of recent international publications has shown, scholars are demonstrating a revived interest in the watercolour medium and are producing innovative research into previously unknown or underappreciated areas of its history and production. These British exhibitions, however, still only present a limited revisionist approach that is inward looking, rather than exploring broader issues related to British watercolours. The Smythe watercolours in New Zealand's collections can be measured against these claims and their worth can thereby be assessed anew within this fresh set of values. While at a glance the Smythe watercolours may seem conventional and dull, consequently having been confined to the hidden depths of the institutions' storage quarters, my research will show that they can be utilised to reveal new narratives, as well as more areas for possible future research.

\section{Part 2 Recognition: New Zealand and British Watercolours}

Mark Stocker's article "Wellington Booty: Modern British Art at the Museum of New Zealand Te Papa Tongarewa" (2010) is a rare example among recent scholarship in calling our attention to the neglect of British art in New Zealand galleries and literature. He attributes this neglect to cultural nationalism, writing that "New Zealand has yet to come to proper terms with its British art-historical inheritance." 52 Despite New Zealand's large holdings of British watercolours, there is no authority on watercolours among scholars in this country, and no apparent desire to interrogate the extent of New Zealand public collections of this medium. Considering that a local watercolour and landscape tradition emerged from the British practice, it is curious that there has been so little professed interest in these works. To highlight this neglect, I will consider a range of recent and iconic New Zealand publications that aim to tell a history of art in New Zealand. The key moments in this literature are the nationalist canon promoted by writers like Gordon H. Brown and Hamish Keith; Francis Pound's post-nationalist accounts; and more recent histories that acknowledge a bicultural art history. These can be supplemented by other histories relating to taste, collecting, and gender. What is the role, if any, of British watercolours in such literature, and why should New Zealand come to terms with its British inheritance?

\footnotetext{
52 Mark Stocker, "Wellington Booty: Modern British Art at the Museum of New Zealand Te Papa Tongarewa," Apollo 171, no. 572 (2010): 41.
} 
The first significant history of painting in New Zealand was written in 1969 by Gordon $\mathrm{H}$. Brown and Hamish Keith. Their book, An Introduction to New Zealand Painting 1839-1967, aimed to acknowledge the contributions of the two more recent generations of New Zealand artists that had emerged during the 1930s-50s. By placing their achievements as the logical succession of previous artists of the nineteenth century, the authors created a link between art and national identity, writing in their Introduction that "this recognition and acceptance of the past is a prerequisite for the present sense of national identification." 53 Their nationalistic agenda was therefore proclaimed early on. They continued to explain that all artists in New Zealand shared two common patterns within their art: a general orientation towards landscape, and a positive response to the distinctive qualities of New Zealand light. ${ }^{54}$ This orthodoxy held that, because of the unique natural light in New Zealand, painters (many of them watercolourists) adapted their previous styles and logically developed the first true 'New Zealand' landscape paintings. In other words, the country itself causes style in painting.

Nearly 50 years later, Keith's publication The Big Picture (2007), based on a six-part TVNZ series, takes a bicultural approach to further verify his nationalistic take on New Zealand art, which he presents as a clash of Pākehā and Māori cultures. ${ }^{55}$ Here Keith reduces the stylistic ambitions of nineteenth-century painters in New Zealand solely to the influence of Turner alone, claiming that they saw him as 'the artist du jour' and made him 'the model' for their style in this new landscape ${ }^{56}$ However, he clearly does not favour Turner as an exemplar, preferring instead topographically 'honest' observations of men like Augustus Earle and John Kinder, ignoring the fact that both of these artists betray the influence of English art in their watercolours. He does state at the beginning of his text, though, that this book "is a personal view." 57

Keith's writing on British art almost sounds like a personal attack: "The habit of purchasing British art and only British art for New Zealand's collections which began at this time established a tradition that went on far too long and, as these things are usually managed, it only ceased at the time when British art got worth buying." ${ }^{58}$ In his

\footnotetext{
${ }^{53}$ Gordon H. Brown and Hamish Keith, An Introduction to New Zealand Painting 1839-1967, new and rev. ed. (Auckland: Collins, 1982), 9.

${ }^{54}$ Ibid.

${ }^{55}$ Hamish Keith, The Big Picture: A History of New Zealand Art from 1642 (Auckland: Random House, 2007). It is also interesting to note that the copy of this book is kept in the Pacifica section in the university library, rather than with other art history books.

${ }^{56}$ Ibid., 77.

${ }^{57}$ Ibid., 7.

${ }^{58}$ Ibid., 96.
} 
consideration of the arrival in the 1890s of Petrus van der Velden, James Nairn, Girolamo Nerli and Claus Edward Friström, Keith writes "all were professional artists, all had some connection with major European movements, all were teachers and not one was English." 59 Later he states that "so long as the British stuffed themselves with our protein it seemed a fair exchange to stuff our galleries with their art." ${ }^{~} 60$ The author clearly has strong negative feelings about New Zealand's collections of British art.

Francis Pound's first significant contribution, and counterpoint to Brown and Keith's arguments, dates from the early 1980s; Frames on the Land: Early Landscape Painting in New Zealand (1983) was the first book setting out to properly acknowledge the powerful influence that British art had on New Zealand artists of the nineteenth century. Pound proposes a new theory which "may startle those who have accepted the comfortable notion of 'new land, new art'." ${ }^{\prime 61}$ Despite acknowledging the research of previous scholars such as Brown and Keith, Pound quickly contests their idea of a 'real' New Zealand. Instead, Pound argues that the very idea of 'landscape' was a European import and that these early landscapes produced in New Zealand demonstrate the characteristics of English genres like the topographic, ideal, sublime, and picturesque.

The book introduces these genres and includes individual examples of New Zealand artists and their works to demonstrate these ideas. While he refers to significant English art theorists such as Edmund Burke and Richard Payne Knight, Pound does not present examples of English art itself to visualise these theories; however, it was both writings and artworks which spread these ideas in New Zealand. Watercolours in particular played a significant role in this propagation, as they were portable and easier to acquire and transport than oils, and watercolour manuals were readily available to local readers. Yet, while Pound does mention watercolours specifically, he generally consigns them solely to the topographical category. My research will ask whether the Smythe watercolours can demonstrate the medium's impact on local art production, and whether their acquisition during the 1950s might indicate that similar beliefs already circulated among art institutions at that time.

In 2009, Pound released the most comprehensive publication of the last decade, originally intended as a sequel to his earlier publication. The Invention of New Zealand: Art and National Identity, 1930-1970 (2009) is described as "a monumental study of

\footnotetext{
${ }^{59}$ Keith, The Big Picture, 97.

${ }^{60}$ Ibid., 139.

${ }^{61}$ Francis Pound, Frames on the Land: Early Landscape Painting in New Zealand (Auckland: William Collins Publishers, 1983), inside dustjacket.
} 
Nationalism in twentieth-century New Zealand art by one of our most brilliant and original art historians." ${ }^{\prime 62}$ Monumental indeed; it consists of ten chapters spreading over more than 400 pages, dealing with such concepts as the invention of 'New Zealand', the sublime forms of solitude and islands, regionalism, primitivism, and the Christianising of landscape. The broad aim was to examine New Zealand nationalist art which, from 1930 to 1970, embarked on the task of discovering the essence of New Zealand, and consequently the creation of a uniquely New Zealand art and culture. ${ }^{63}$ Pound observes that "New Zealand art in the 1930s shows a new self-consciousness of itself as New Zealand art" and that "it is then the participants in a new movement themselves proclaim that something new has begun." ${ }^{\text {"T }}$ The beginning of this 'something new' logically means the end of 'something old'. With a new focus on a local New Zealand identity in art, the 'something old' that had to be rejected was a reliance on non-New Zealand art and ideas.

It is understandable that most of this external influence in New Zealand came from Britain, as the country was part of the British Empire. As Pound writes, "if New Zealand is an isolate [sic] island, it seems it is mainly English detritus that drifts to its shores." $" 65$ Watercolours were the first examples of this, and Pound analyses in depth the way in which the soft lines of Turner and his contemporaries were decisively vetoed and replaced with the harsh lines of the apparently acute New Zealand light. Even locally produced watercolours from the nineteenth century were actively shunned, as the "non-topographic, 'cultivated', Turneresque styles of such nineteenth-century painters as William Mathew Hodgkins and John Gully were reproached for sophistication, softness and sentimentality, and for their mistiness and untruth to New Zealand; and were reviled for 'foreignness' of inspiration."66 Interestingly, Pound stresses that this 'new' New Zealand style, featuring strong clear lines and believed to represent the uniquely local light and atmosphere, and hence the polar opposite to the British tradition, had in fact been directly influenced by the current English style of clarified naturalism, introduced to New Zealand, among others, by the English artist Christopher Perkins. ${ }^{67}$

The 1950s are at the very centre of Pound's discussions, and yet it was precisely at this time that the Smythe watercolours were accepted into two public art collections in New

\footnotetext{
${ }^{62}$ Francis Pound, The Invention of New Zealand: Art and National Identity, 1930-1970 (Auckland: Auckland University Press, 2009), inside dustjacket.

${ }^{63}$ Ibid., xix.

${ }^{64}$ Ibid., 1.

${ }^{65}$ Ibid., 47.

${ }^{66}$ Ibid., 331.

${ }^{67}$ Ibid., 99.
} 
Zealand. The acceptance of this donation appears to be completely out of place with the events described in Pound's analysis. This is because the book looks at the opinions and theories set out by artists, poets and painters, rather than looking at the wider context of 1950s New Zealand art collecting. What was the stance of museums and galleries, and what kind of art were they collecting as a result? What art were private collectors aiming for and why? Was this quest for a New Zealand 'national' art only limited to artists themselves? Pound, of course, focuses on the emergence of a national tradition, and the broader institutional structure was outside his purview. Arguably, a tension between 'popular' and 'academic' views persists, but if we add the history of reception and collection of art to this history of its production, we can reveal a broader understanding of changing tastes in New Zealand

Indeed, several theses have been written on collecting art in New Zealand to recognise the origins of our public collections, but also to understand the tastes and habits of individual collectors and their contexts. These include, for example, theses on the collectors Sir John Ilott, Dr. Walter Auburn and Bishop Monrad. ${ }^{68}$ While such studies are very focused and go into a detailed analysis of the individual's collecting habits, Rebecca Rice's thesis, "The State Collections of Colonial New Zealand Art", provides a wider approach to the subject of collecting in New Zealand. Among published material, Anna Crighton's English, Colonial, Modern and Māori: The Changing Faces of the Robert McDougall Art Gallery, Christchurch, New Zealand, 1932-2002 (2014) provides an excellent overview of the changing collecting tastes of different generations of gallery directors in Christchurch. ${ }^{69}$ These studies demonstrate a different approach to our art history, which focuses on the collectors and collections, rather than monographic approaches to individual artists.

A bicultural approach to art history in New Zealand has emerged more strongly in recent decades, such as Headlands: Thinking Through New Zealand Art (1992), published to accompany an exhibition curated by Robert Leonard and Bernice Murphy. Rather than a general overview of New Zealand art, the essays present on various themes, such as landscape in New Zealand, the role of Māori artists, Christianity in New Zealand art,

\footnotetext{
${ }^{68}$ Penelope Campbell, "Collecting the Pacific 1768-1977: Joseph Banks, Alexander Turnbull, Rex Nan Kivell,” MA diss., Victoria University of Wellington, 2002; Courtney Johnston, "Peter Tomory: The New Zealand Years, 1956-1968," MA diss., Victoria University of Wellington, 2004; Julianne Malpas, “An Incurable Collector: Sir John Ilott (1884-1973) and his Passion for Prints," MA diss., Victoria University of Wellington, 2005; Mathew Norman, "The Print Collection of Bishop Monrad (1811-1887)," MA diss., Victoria University of Wellington, 2006; Emma Reilly, "Walter Auburn and his Collection of Prints," MA diss., Auckland University, 2003; Oliver Stead, "New Lamps for Old: The Activities of Sir Rex de Charembac Nan Kivell as a Collector and Dealer of Fine Art," PhD. diss., University of Otago, 2003.

${ }^{69}$ Anna Crighton, English, Colonial, Modern and Mãori: The Changing Faces of the Robert McDougall Art Gallery, Christchurch, New Zealand, 1932-2002 (Newcastle: Cambridge Scholars Publisher, 2014).
} 
modernism and art criticism. The result is an intelligent compilation of ways in which one can think about art in New Zealand, as the authors set out to "see many new things, as well as seeing old things anew." ${ }^{, 70}$ One prominent example is the emphasis on the interaction of Pākehā and Māori artists, which Bernice Murphy defined as the "special excitement and challenge of the present historical moment."71 Rangihiroa Panoho, in his essay "Māori: At the Centre, on the Margins", describes this interaction as a form of colonisation that started 150 years ago and has now developed to recognise the significance of Māori:

With so much having been taken and so little returned, there is now a need to reassess the Māori role in a partnership that has increasingly marginalised us. In the cultural sphere - the arts - it is now essential for Māori to resume control. Reestablish boundaries for appropriation and move taha Māori (things Māori) back to the centre. A number of Pākehā artists have assisted in this process more recently by directing our attention, in their work, to the importance of Māori culture as central, not peripheral, to our New Zealand identity. ${ }^{72}$

Māori culture is central to a New Zealand identity, and this is a recurring theme in recent scholarship. Yet the author here goes even further when asking us to challenge Western art traditions in New Zealand completely, writing "in New Zealand the real issue is that these Eurocentric attitudes don't belong here and are irrelevant to both our location and culture. Given Aotearoa's geographical isolation from Europe and the presence of such a rich local tribal culture, the question to be asked is: shouldn't the idea of centre/margins be reversed?"73

Indeed, the focus on a Māori and Pacific context for art in New Zealand has become a major thrust of current scholarship. Jonathan Mane-Wheoki's essay “Art's Histories in Aotearoa New Zealand" (2011), for example, foregrounds the importance of such a context by proclaiming that "there can be no coherent, integrated history of art in New Zealand that does not encompass the timeframe of the cultural production of New Zealand's indigenous Māori, or that of the Pacific nations for which the country is a regional hub, or the burgeoning cultural diversity of an emerging Asia-Pacific nation."74

The other prominent revisionist art histories published in New Zealand are concerned with female artists. Anne Kirker's New Zealand Women Artists: A Survey of 150 Years (1993) is the earliest of the feminist publications in New Zealand. Kirker is the first scholar

\footnotetext{
${ }^{70}$ Mary Barr ed., Headlands: Thinking Through New Zealand Art (Sydney: Museum of Contemporary Art, 1992), 12.

${ }^{71}$ Bernice Murphy in ibid.

${ }^{72}$ Rangihiroa Panoho in Barr, Headlands, 124.

${ }^{73}$ Ibid., 133.

${ }^{74}$ Jonathan Mane-Wheoki, “Art's Histories in Aotearoa New Zealand,” Journal of Art Historiography, no. 4 (June 2011): 1 .
} 
to look at women artists from the nineteenth century, who, just like their contemporary but more famous male counterparts, worked primarily in watercolour. Kirker emphasises the strong influence of British or European conventions on their art, when she writes that "these women were thus caught up in the drive to anglicise the antipodean landscape, making it acceptable to English taste. One has the feeling that these women drew and painted less for themselves than for the expectations of a colonisation programme and an audience far removed from New Zealand." ${ }^{75}$ Emily Harris emerges as a prime example of a neglected artist. She is recorded as having written in her diary "why am I not among them", where 'them' refers to the other male colonial artists exhibiting overseas. ${ }^{76}$ In fact, feminist art history and British watercolours are closely interlinked, as many of the amateur watercolourists were indeed women, which led to the gradual shift from a masculine practice to a feminine one. Still, this crucial aspect of the genre is not explored in Kirker's text.

Another pertinent publication is David Eggleton's Towards Aotearoa: A Short History of $20^{\text {th }}$ Century New Zealand Art (2007), which, as the title suggests, focuses on the art of the twentieth century only. ${ }^{77}$ The book follows a chronological timeline, using concise case studies of individual artists and art works to discuss developments and transformations within New Zealand art and nationhood. At the very beginning of his narrative, Eggleton does mention English artists like Turner and Constable as inspiration for picturesque landscape paintings in New Zealand. However, this artist-focused approach, like Pound's Frames, again neglects to mention the collecting of art such as watercolours. This topic is really only approached in publications from individual galleries and museums, such as Beloved: Works from the Dunedin Public Art Gallery and Peter Entwisle's Treasures of the Dunedin Public Art Gallery, and Art at Te Papa (edited by William McAloon, 2009). McAloon describes the NAG's acquisition policy from the mid-twentieth century, which involved the development of a collection of British watercolours. The director, Stewart Maclennan, believed there was a deep art historical rationale and need for it, claiming that "inevitably, our artistic beginnings are recorded almost exclusively in that most English of mediums, watercolours." ${ }^{78}$ However, following this introductory essay, British watercolours play a predictably minimal role within the main body of the publication.

\footnotetext{
${ }^{75}$ Anne Kirker, New Zealand Women Artists: A Survey of 150 Years, rev. ed. (Tortola: Craftsman House, 1993), 20.

${ }^{76}$ Emily Harris cited in ibid., 22.

${ }^{77}$ David Eggleton, Towards Aotearoa: A Short History of $20^{\text {th }}$ Century New Zealand Art (Auckland: Reed Publishing, 2007).

${ }^{78}$ Maclennan, cited in William McAloon ed., Art at Te Papa (Wellington: Te Papa Press, 2009), 9.
} 
A corresponding exclusion is typified in New Zealand literature that deals with international art, as opposed to the previous examples which considered New Zealand art exclusively. British watercolours get severely neglected, despite making up a major component of international art collections. In Art at Te Papa, for example, only five watercolours (by Thomas Rowlandson, John Constable, John Martin, Samuel Palmer, and Simeon Solomon), are featured, and only one of these hails from the Smythe collection (Simeon Solomon's Head, 1895). Similarly, Beloved only discusses seven British watercolours, three of which come from Smythe's gift (by Richard Westall, Henry Bright and Kate Greenaway).

Anne Kirker and Peter Tomory's British Painting 1800-1990 in Australian and New Zealand Public Collections is a summary catalogue that aimed to reveal the collections of British paintings assembled in Australian and New Zealand museums. It was sponsored by the British Council in 1997, in order to strengthen and celebrate the "close ties between Britain and these two countries."79 James R. Potts, director of the British Council in Australia, justified the project by stating "until now there has been no comprehensive compilation of the wide holdings of British paintings in Australian and New Zealand art museum collections and the immense wealth of British paintings held outside Britain has remained unknown except to specialists." ${ }^{\circ 0}$ The authors also point out that the catalogue "could serve as an entry into a number of research topics, such as that of tracing the reception of British art in Australasia." 81 Their 'paintings', however, are exclusively oils. Apart from works on paper, other exclusions include paintings in poor states of conservation or works by artists for whom no biographical information exists. ${ }^{82}$

As this brief selection of literature demonstrates, while there might be a watercolour revival of sorts among international scholars, there has been little recognition of British watercolour holdings within local narratives. New Zealand publications instead actively belittle the British art acquired by art establishments, posing it as the undesired opposite of locally produced New Zealand art. In this scenario, it is usually only oil paintings and modern British art that is deemed worthy of discussion, not nineteenth-century watercolours. There seems to be no defined interest in such watercolours among New Zealand scholars at this

\footnotetext{
${ }^{79}$ Anne Kirker and Peter Tomory, British Painting 1800-1990 in Australian and New Zealand Public Collections (Sydney: The Beagle Press, 1997), 8.

${ }^{80}$ Ibid., 7.

${ }^{81}$ Ibid., 9.

${ }^{82}$ Ibid., 43
} 
stage, in contrast to the research on Māori, Pacific and women's art histories. Nevertheless, my case study of the Smythe gifts will reveal that our holdings of British watercolours are able to open up a more global conversation about the role of British watercolours in collections and contexts beyond the UK and participate in international discussions about the medium. It also allows an insight into collecting practices which have helped to shape New Zealand public art collections, tastes and thinking. In that sense, I will argue that the acquisition of works is just as telling as their subsequent neglect.

\section{METHODOLOGY}

The methodological approach applied in this thesis draws on several models, some of which have already been mentioned in the sampled literature above, others of which will be introduced below. While formal analysis will be included in my discussion of the contents of the collection itself, this dissertation primarily looks at the social circumstances of the formation and reception of the collection. ${ }^{83}$ However, a certain historiography has already been applied in the review of the literature as well, and this method will be expounded later in the thesis too.

To a large degree, this thesis is about connecting the case study of the Smythe watercolours to more general histories of taste and collecting. Through analysing the changing status of these watercolours, I aim to understand the very society which placed the shifting labels of 'good' or 'bad' on the collection and the medium it represents. Therefore, it is a study in sociology as much as in the social history of art. Francis Haskell provides an ideal model for this method in Rediscoveries in Art: Some Aspects of Taste, Fashion and Collecting in England and France (1976). In the introduction, he explains what his tactic entailed:

I have instead tried to look at the phenomenon of changing taste from a varying set of approaches: the availability or otherwise to the collector or connoisseur of recognized masterpieces; the impact of contemporary art; the religious or political loyalties that may condition certain aesthetic standpoints; the effects of public and

\footnotetext{
${ }^{83}$ It is a work of critical theory, by which I mean the assessment and critique of society and culture, which in the case of art history includes a non-artistic analytical agenda through considering the social, historical, and ideological forces and structures that produce works of art.
} 
private collections; the impression made by new techniques of reproduction and language in spreading fresh beliefs about art and artists. ${ }^{84}$

This demonstrates the wide variety of social disciplines that may impact a study in this field, and the range of material to be considered. I would add the difference between socioeconomic groups to this list, as well as the effect of isolation on artistic taste in countries such as New Zealand.

Among the scholars addressing the history of taste, there is one voice that stands out and is undoubtedly the prime methodological model for my thesis. Jessica Feather's catalogue raisonné on Lever has already been discussed as a comparative example of an individual's watercolour collection, as it considers Lever's approaches to collecting and his tastes and relationships with dealers. However, it is Feather's PhD thesis, "The Formation of a Modern Taste in Watercolour: Critics, Curators and Collectors c. 1890-1912” (2014), which best illustrates the inevitable link between the history of watercolour and the history of collecting and shifting tastes. Feather states early on that all of these areas have only recently begun to develop as disciplines within art history, which accounts for the lack of literature. ${ }^{85}$ Therefore, she has based her project on "an analysis of new archival research as well as the collation and new interpretation of primary source material." ${ }^{86}$ I have applied a similar method, wherein I investigate archival material relevant to the Smythe collection, and examine not only local newspaper archives, but also the artworks themselves, to ensure a range of primary source material has been analysed and interpreted.

However, as I pointed out earlier, while my thesis considers the social, historical, and ideological contexts of art, the topic also requires a degree of formal analysis, which creates a fusion of two different methodological approaches. This is also mirrored in Feather's research. She explains that:

I have woven formal analysis of objects together with contextual based analysis of the critical reception of these works, and with the social and biographical context of the collectors themselves. This is an approach which attempts to combine both formalist interpretations of art history and social and cultural interpretations of art history-in a sense arguing that the use of one does not negate, but rather complements, the use of the other. ${ }^{87}$

\footnotetext{
${ }^{84}$ Francis Haskell, Rediscoveries in Art: Some Aspects of Taste, Fashion \& Collecting in England \& France (Ithaca, New York: Cornell University Press, 1976), 7.

${ }^{85}$ Feather, "The Formation of a Modern Taste," 16.

${ }^{86}$ Ibid., 9.

${ }^{87}$ Ibid., 18.
} 
Therefore, she examines the wider contexts for collecting, including the writings of art critics, and the role of curators in public museums. ${ }^{88} \mathrm{I}$ also place the Smythe collection within this broader context, but instead of the early twentieth-century formation of 'modern' taste in Europe, I additionally place it in the context of twentieth-century New Zealand.

The final methodological model is supplied by two scholars who directly engage with New Zealand and art history in writing their history of 'UnAustralian' art. Rex Butler and A.D.S. Donaldson have co-authored several papers which apply a revisionist approach in order to determine what can actually be defined as Australian (or New Zealand) art and, furthermore, to debunk the usefulness of attempting to write a history of either Australian or New Zealand art at all. As part of this examination, they also deal with the history of the circulation of images and the movement of artists. The authors are challenging the conventional ideas about what kind of art should be discussed in 'national' art histories. The conservative mentality the authors are contesting is best exemplified by Hamish Keith's statement in The Big Picture: "There is no escaping the one simple fact that runs through all of this story. The art made here or influenced by this place is the only art that speaks to us directly about our experience." 89 Butler and Donaldson further explain this attitude in "Stay, Go, or Come: A History of Australian Art, 1920-40”, wherein they clarify that typical narratives of Australian art history base their inclusions and exclusions on one undefinable criteria: that "only an art that contributes to the expression of an identifiable national character is understood as Australian art." 90 Therefore, one could say that national art histories, both in New Zealand and Australia, only present artists and artworks that are either produced in their respective countries, or demonstrate the influence of their respective national characters.

To limit the art that is discussed in national art histories in this manner means that other significant cross-overs have potentially fallen 'between the cracks' and become irrelevant as a result. Butler and Donaldson are striving to uncover such 'irrelevant' aspects of our histories. Using the example of various artists' interactions between New Zealand and Australia, they demonstrate a refreshing and convincing revisionist art theory:

And in our UnAustralian history we reverse the perspective of the usual national histories, which are always written from the inside out, and write instead from the

\footnotetext{
${ }^{88}$ Feather, "The Formation of a Modern Taste," 18.

${ }^{89}$ Keith, The Big Picture, 269.

${ }^{90}$ Rex Butler and A.D.S. Donaldson, "Stay, Go, Or Come: A History of Australian Art, 1920-40," Australian and New Zealand Journal of Art 9, no. 1-2 (2008): 119, accessed 23 September 2019, https://www-tandfonlinecom.helicon.vuw.ac.nz/doi/abs/10.1080/14434318.2008.11432798.
} 
outside in. We ask not how other places seem from here but how we might appear from other places. And thus to write a history of New Zealand art from the point of view of Australia is also to write an UnNew Zealand history of art from the point of view of New Zealand. ${ }^{91}$

The authors seek to write "a history of what has been excluded", which is also the goal of my own work. ${ }^{92}$ I aim to use a similar method in order to include a part of our national art collection that has slipped through the cracks because of its seemingly irrelevant status to our national character. The end result will be a re-thinking of art history in New Zealand and a renewed focus on what is viewed as an old-fashioned medium.

\section{CHAPTER OUTLINE}

Chapter Two begins the narrative by examining Smythe's collecting habits, using his letters to explore when and how he amassed his collection, while also considering the reasons for parting with it in the 1950s. This will be followed by a discussion of the circumstances of the gifting itself, and the way in which the collection was initially received by art institutions and the public in New Zealand. This creates a strong contrast to the neglect which the collection has suffered from in the decades since. A brief survey of its exhibition history will further reveal that, while New Zealand watercolours were exhibited prominently during the 1950s-70s, British ones were no longer popular. What caused such a strong shift in status of a single collection and the medium it represents? The chapter will end by proposing two possible explanations: the contents of the collection were of 'bad' quality, or the collection was outdated and did not fit into contemporary aesthetic tastes. The following two chapters will respond to these two theories.

Chapter Three analyses the contents of the collection in more detail through a selection of highlights. These watercolours will be chosen through various criteria and presented in two parts to demonstrate the wealth and value of the collection. The first part of the chapter will consider the subjects represented in the watercolours, revealing the

\footnotetext{
${ }^{91}$ Rex Butler and A.D.S. Donaldson, "Cities within Cities: Australian and New Zealand Art in the $20^{\text {th }}$ Century," Journal of Art Historiography 4 (June 2011): 3-4, accessed 23 September 2019, https://www-proquestcom.helicon.vuw.ac.nz/docview/902572455/D96D4CE72BC24503PQ/17?accountid=14782.

92 Butler and Donaldson, "Stay, Go, Or Come," 120.
} 
surprisingly broad range of genres. This will show that the Smythe collection is rich in landscapes - traditionally acknowledged as the best suited subject for watercolours - yet also exposes other subjects not usually associated with the medium. The second part of the chapter examines the artists represented in the collection in context. This will show that the Smythe collection can be used to tell more than just a short history of the watercolour medium by also engaging with a wider range of social and artistic happenings of the time.

Chapter Four examines the collecting tastes of Smythe and determines whether or not these reflect the British tastes of the early twentieth century. Smythe indeed appears to have been collecting, at least in part, against the trend at a time when the taste for and appreciation of British watercolours was shifting towards favouring a more modern, unfinished aesthetic. The second part will analyse the New Zealand context into which the watercolours arrived, illuminating the initial Anglo-centric bias of local art establishments, and revealing the subsequent repudiation of such a tradition. This was part of a changing taste that focused on a growing awareness of international trends, and more importantly on local New Zealand contemporary art, making the Smythe collection less relevant.

Chapter Five engages with how this change in taste reflects broader shifts in cultural and national identities in New Zealand, and whether these two can indeed be separated at all. While politicians sought a more independent identity for New Zealand, both artists and art historians sought to find international currents in art refracted through a local lens, looking towards the land itself as inspiration. Just as national hymns, flags, holidays, symbols, and museums are important for inventing a new national identity, so too is a national art canon. The local artistic heritage of New Zealand was therefore also reinvented at this time. This saw those watercolourists discussed by Maclennan as "minor British artists" rise to a new status as worthy predecessors for the modern painters of the twentieth century.

Simultaneously, those whose artworks displayed more of the British tradition were rejected. 


\section{Chapter 2: From Reception to Neglect}

As a busy and prominent clergyman with limited financial means, Smythe took almost 50 years building his collection at his home in England, where he also held several small-scale exhibitions. When he finally decided to part with his hundreds of watercolours, their fate was sealed. Though initially reluctant to gift his legacy to any institutions or collectors outside of England, a fateful encounter with a Dunedin curator swayed his decision.

In 1953, the collection travelled far from its origins in England and settled into its new permanent home in New Zealand. While museums and galleries in England had been either reluctant or unable to accept the whole of Smythe's gifts, it seems that Wellington and Dunedin welcomed his generosity with open arms. Nothing was turned away. Yet, just a few decades after this warm welcome, Smythe and his 'art-children' had been virtually forgotten. Criticism of the collection slowly turned to apathy, and while local watercolours continued to be actively exhibited in New Zealand, the Smythe watercolours were increasingly relegated to their storage boxes. This was part of a gradual shift away from holding all things British in high esteem, and instead emphasising a local art tradition.

\section{COLLECTING AND GIFTING}

Francis Henry Dumville Smythe was born in January 1873, son of Francis Cooper Dumville Smythe, solicitor of Staple Inn and Girdlers Hall in London, and Arabella Sophie Smythe. He had one older brother and two younger sisters. In 1899 he married his first wife, Angelina (1878-1944), and together they had two daughters, Vera and Sibyl. In 1960, just six years before his death, he married his second wife, Phyllis (1906-1998), who was three years younger than his youngest daughter. ${ }^{1}$ Smythe was ordained as priest in 1897, two years before receiving his MA from Emmanuel College, Cambridge. He started his clerical career as curate of South Petherton (1897-98), Bunbury (1898-99) and Alfrick (1899-1900), before becoming rector of Horsted Keynes (1900-09). Over the years he held various posts,

\footnotetext{
${ }^{1}$ A. and C. Black, "Smythe, Canon Francis Henry Dumville," Who Was Who, an imprint of Bloomsbury Publishing, 19202016, online edition, Oxford: Oxford University Press, 2014, accessed 17 November 2017, http://www.ukwhoswho.com/view/article/oupww/whowaswho/U54868.
} 
including vicar of Hove (1909-29) and later of Eastbourne (1929-30), then rural dean, prebendary of Chichester (1929-31), proctor, and finally archdeacon of Lewes, retiring in $1946 .^{2}$

These positions saw him actively involved in local affairs and become a supportive voice in various areas of society, as revealed by his appearance in numerous newspaper articles of the time. For example, he was a strong advocate for building new pedestrian pathways in 1939, which he believed would help with two distinct problems that the country was facing at the time: the number of deaths caused on England's roads, and the number of unemployed citizens by providing them with jobs building these new walkways. ${ }^{3}$ In 1937 , he supported a local cinema show to raise funds for building and restoring churches, and he even became involved in politics, dining with the German ambassador in 1939 in an effort to celebrate peace between the two nations. ${ }^{4}$ The community's wellbeing was obviously an endeavour close to his heart. Indeed, while he might not have had the financial ability, he definitely had the passionate intent of a philanthropist, and the gifting of artworks undoubtedly fits into this psyche. Smythe made several gifts of watercolours and drawings to museums and galleries throughout Great Britain, including the British Museum, the Victoria \& Albert Museum (V\&A), and the National Museum in Cardiff. Yet none of these institutions received anything like the quantity he showered on New Zealand.

Smythe's first contact in New Zealand was with the Dunedin Public Art Gallery's (DPAG) curator, and later director, Annette Grace Pearse. ${ }^{5}$ In Treasures of the Dunedin Art Gallery (1990), Peter Entwisle recounts how Pearse went to England in 1951 to make some acquisitions for the gallery, when, at Christie's, she came across a French illumination that caught her fancy. When she was told by Alec Martin that the owner of this particular work had requested that it be sold only to a British institution, she insisted on contacting the

\footnotetext{
${ }^{2}$ Black, "Smythe, Canon Francis Henry Dumville." Most of these places are located around the Sussex region.

3 "Points from Letters," Times [London] (18 February 1939): 8, accessed 3 August 2017, https://link-galecom.helicon.vuw.ac.nz/apps/doc/CS135607378/TTDA?u=vuw\&sid=TTDA\&xid=a897e518.

4 "Sussex Church Builders Support Cinema Show: An Impressive Appeal by Archdeacon Smythe," The Mid-Sussex Times [London] (26 January 1937): 9; "Desire for Peace," Times [London] (12 January 1939): 12, accessed 21 November 2017, https://link-galecom.helicon.vuw.ac.nz/apps/doc/CS203109420/TTDA?u=vuw\&sid=TTDA\&xid=573d84de.

${ }^{5}$ The roles of curator and director were not clearly delineated when Pearse first took up her role at the DPAG. She became the first official director of the gallery in 1951, whereas her predecessor, Robert Neilson, was called curator (as was she, when she first started in 1946). It would be more accurate to use the term curator-director, as the curator was conducting business like a director. For the dates of when the directorships started in the major public galleries, see Athol McCredie, “Going Public: New Zealand Art Museums in the 1970s,” MA diss., Massey University, Wellington, 1999, 66.
} 
owner personally. The owner was Smythe, and Pearse evidently charmed him. This was the beginning of a friendly long-distance relationship that lasted from 1951-1966. ${ }^{6}$

After Pearse returned to New Zealand, the two continued to exchange letters that shed invaluable light on the motivations behind Smythe's generous gifts. Even after Pearse had left the DPAG in 1964, she still reminded the gallery's council to send Smythe his yearly Christmas gift as a thank-you for his generosity. ${ }^{7}$ These gifts included New Zealand lamb and rugs, for example, which Smythe accepted with delight, and which could well have motivated him to continue sending gifts of art in return.

Smythe's other significant contact in New Zealand was Stewart Maclennan of the National Art Gallery (NAG) in Wellington. The first letter offering a gift to Wellington dates from 1956 [Appendix I] ${ }^{8}$ Maclennan made clear that this gift would be accepted with enthusiasm, and this sparked a correspondence between the two men that resulted in a total of 336 works being gifted to the Wellington gallery by the following year.

Smythe's life spanned turbulent and changing times in Britain, including the Victorian and Edwardian eras, and both World Wars. With as good as no published material on Smythe's collection, and very limited archival material surviving, establishing a determinate date for the beginning and conclusion of his collecting activities is difficult. The prime sources therefore are the letters written by Smythe himself during the 1950s, held in the archives of the Dunedin City Council and Te Papa. ${ }^{9}$ These do have to be approached with some caution, though, due to his age at the time of writing them. He repeatedly makes reference to his old age. For example, he called himself "crotchety and old" ${ }^{10}$ urging a quick response from the NAG due to his age - "so if you have room and would like the offer, may I know soon as I am a very old man" 11 - and lamenting to Pearse that "I shall be 89 before this letter arrives, so my years are certainly numbered." 12 Smythe blames his own mishap of forgetting to tick off works from his index before sending them to Wellington on a moment of stupidity. ${ }^{13}$ However, Maclennan claims this happened because "he evidently feels his

\footnotetext{
${ }^{6}$ The last archived letter from Smythe to Pearse is dated 28 October 1965, Dunedin City Council Archives (DCCA): Box 11, DPAG 15/22. However, even after Pearse's retirement in 1964, Smythe must have kept sending parcels to her directly. As late as 1966, the DPAG is thanking Pearse for sending through more Smythe works to the gallery. Isabel Nevill (DPAG Assistant-Secretary) to Pearse, 22 August 1966, DCCA: DPAG 23/10. See also Peter Entwisle, Treasures of the Dunedin Public Art Gallery (Dunedin: Dunedin Public Art Gallery, 1990), 26-28.

${ }^{7}$ See DCCA: Box 11, DPAG 15/22.

${ }^{8}$ Smythe to NAG, 24 June 1956, Te Papa Archives (TPA): MU00008, box 3, item 6.

${ }^{9}$ In the following footnotes, abbreviations for the Dunedin City Council Archives and Te Papa Archives will be DCCA and TPA respectively.

${ }^{10}$ Stewart Maclennan to Smythe, 11 December 1956, TPA: MU00008, box 3, item 6.

${ }^{11}$ Smythe to NAG, 24 June 1956, TPA: MU00008, box 3, item 6.

${ }^{12}$ Smythe to DPAG, 22 December 1959, DCCA: Box 11, DPAG 15/22.

${ }^{13}$ Smythe to NAG, 14 July 1956, TPA: MU00008, box 3, item 6.
} 
years and didn't want to delay." 14 G.G. Gibbs Watson, who was acting as an agent in England for the NAG at the time, further remarked that Smythe was starting to lose his memory. ${ }^{15}$

Despite this, Smythe himself is still the most reliable source on his own actions, even if his account of them might be slightly ambiguous or out of order. In a letter to Pearse in 1955, he wrote that he has "loved these drawings for 50 years. How enthusiastic a collector becomes over his 'art-children'."16 If we assume from this that Smythe had owned the watercolours for the last 50 years, this would place the time of initial purchases around 1905, the beginning of the twentieth century. However, Peter Entwisle claims that the archdeacon had collected British watercolours "since his childhood." 17 Indeed, there is evidence that suggests an earlier beginning date than 1905. In 1956, Maclennan visited the DPAG to look at Smythe's gifts. There, he likely spent some time talking with Pearse, who might have been the source for the following anecdote Maclennan related to Watson the same year:

It appears that the Archdeacon worked with Christie's for some years before entering the Church. While there, he bought a picture (I don't know just what it was) for $£ 5.0 .0$. from a funny little shop in a back street. He sold it at Christie's for $£ 1,000$. He gave the little dealer $£ 100$ and used the rest to start his collection. He isn't wealthy, but has made a life-long hobby of building up his collection. ${ }^{18}$

As Smythe was ordained in 1897, this would mean he was working for Christie's - and thus started his collection - in the 1890s. ${ }^{19}$ This would confirm Smythe's own statement about working at Christie's, as he wrote to Pearse "I note in your letter you hear from Alec Martin. He \& I were young men together at Christies in the year 1896 I think it was, but alas my memory is going." ${ }^{20}$ In fact, Smythe entered the Bishop's College at Blackheath Hill in 1896, so his memory indeed failed him slightly, but was not off by much. It is most likely

\footnotetext{
${ }^{14}$ Maclennan to Watson, 19 July 1956, TPA: MU00009, box 5, item 9.

${ }^{15}$ Watson to Maclennan, 26 July 1956, TPA: MU000044, box 2, item 12.

${ }^{16}$ Smythe to DPAG, 24 February 1955, DCCA: Box 11, DPAG 15/22.

${ }^{17}$ Entwisle, Treasures, 27.

${ }_{18}$ Maclennan to Watson, 19 June 1956, TPA: MU00009, box 5, item 9.

${ }^{19}$ According to the 1965-1966 volume of Crockford's Clerical Directory, an annual directory which provides biographical details about the majority of clerics, Smythe received his BA in 1894 and his MA in 1899 (both from Emmanuel College Cambridge), before entering a Bishops' College in 1896. He was ordained deacon in 1897, and priest in 1898. While Christie's has no records of Smythe working for them, we can assume that this would have occurred before him entering the clergy, and possibly during his studies at Emmanuel College. They in turn were unable to provide me with information on what Smythe would have been studying there, but a BA does not rule out that his studies could have included a form of art history, thus complementing his work at the auction house simultaneously. The Crockford's Clerical Directory entry was provided via Becky Loughead (Library Assistant, Lambeth Palace Library) to Annika Sippel, email correspondence, 18 November 2017.

${ }^{20}$ Smythe to DPAG, 12 January 1964, DCCA: Box 11, DPAG 15/22.
} 
that Smythe was working for Christie's shortly before 1896, but probably only for a short time, as he only referred to one year of employment in his letter. ${ }^{21}$

Nonetheless, this proves that Smythe had a pre-existing interest and knowledge in art, which he would have applied to his own acquisitions from the 1890s onwards. Indeed, he attempts to showcase his experience gained from working at Christie's by suggesting a degree of connoisseurship when making his decisions or talking about his watercolours. For example, he demonstrates his knowledge of artists' signatures as well as recognising their style upon closer inspection. This was the case for an early Paul Sandby watercolour he sent to Dunedin in 1957, with an accompanying letter, stating "today I am sending for the gallery 4 watercolours one by Paul Sandby ... I am not sure about the signature, but I feel sure from inspection that it is his work." 22 He goes on to say that many unsigned drawings were given signatures by a man who worked for a London dealer (no names given). This further shows that he was aware and involved in the happenings of the artworld around him (and apparently was not easily fooled by fake signatures). On the other hand, he also admitted when he lacked the necessary knowledge and was known to ask for advice from higher authorities, such as the British Museum. He explains to Pearse that he consulted this institution about a possible William Blake drawing, describing the rareness and inaccessibility of Blake watercolours due to their high prices:

the only chance I ever had of a Blake was in Bond St where there were three for sale $£ 650 £ 480 £ 520$. I am a poor man \& have never been able to buy guaranteed Blakes. However I will send you some, but with the exception of a lead pencil drawing ... that is the only genuine Blake, for I have no Blakes. The 'some' I mention means Blake School. ... very few people have a Blake \& those who have, are not what I call collectors but people of wealth. I have shown the lead pencil one I picked up years ago \& it is I am told all right (Brit Museum). So I shall send you some which I call School of Blake \& that is all I can do. ${ }^{23}$

As we shall see, the question of funds was a constant issue for Smythe, and one that limited his ability to fully participate in contemporary collecting trends and tastes.

While it is difficult to determine when Smythe started his art collection, it is equally difficult to determine when he stopped collecting. While some collectors provide a record of

\footnotetext{
${ }^{21}$ This short-term employment could also be the reason that Christie's had no prior knowledge of him, but a representative told me they will use this newfound information to start a nominal file on Smythe as a former Christie's employee. Simona Dolari (Provenance Researcher, Christie's Archives) to Annika Sippel, email correspondence, 14 December 2017.

${ }^{22}$ Smythe to DPAG, 14 October 1957 DCCA: Box 11, DPAG 15/22.

${ }^{23}$ Smythe to DPAG, 7 June 1954, DCCA: Box 11, DPAG 15/22. The attribution of the upcoming work by Blake, Son of the Morning [Fig. 24], is thus questionable. The DPAG still lists the watercolour as a genuine Blake; however, it appears as though Smythe himself was not convinced. This work will be discussed on page 91.
} 
when they purchased a particular artwork by writing on the verso, Smythe only did so rarely. For example, on the verso of Peter De Wint's Barn Exterior [Fig. 49] he wrote "bought at Sotheby's 1945 as De Wint sketch.” Thus, we can deduct that he was collecting at least up until his retirement in $1946 .{ }^{24}$ By 1961 he had clearly halted all collecting activities, writing to Pearse that "my collection of drawings has gone at Christies $\& £ 10,000$ was the result of a ... sale where they lumped as many as 30 in a lot - alas. However, I am now too old to collect \& there is no room in this house for a collection." ${ }^{25}$ He was 88 years old at this stage, so the excitement and effort involved in collecting might have been too much for him. From 1953 onwards, he never mentions any new acquisitions in his letters, only commenting on selling and gifting his collection. This must have been his main concern during his later years. Therefore, and in view of his previously-quoted statement that he loved these works for 50 years, it is reasonable to assume that he stopped collecting sometime between 1945 and the early 1950s.

\section{Parting with the Collection}

Before looking at how Smythe's gifts were received, one must consider when and why he was giving his collection away in the first place. In fact, Smythe had been donating and selling works from his various collections (not just watercolours) prior to his gifts to New Zealand during the 1950s. This coincided with his retirement, and the death of his first wife in 1944, both resulting in his move to Elfinsward in Haywards Heath. He wrote, "my wife has recently passed away and as [?] as I am I shall sell this house. As the only member of my family after me is a nephew, [?] Commander in the Navy, and in the days that are coming will never be able \& keep the large number of pictures I have I intend to sell most of them." 26 The reason for his earlier sales, therefore, might have been simply out of necessity and practicality. He no longer had the room required to house his works, and his descendants were not able to look after them. ${ }^{27}$

\footnotetext{
${ }^{24} \mathrm{He}$ was already selling parts of his collection in England during the 1930s, thus he must have been actively buying and selling at the same time.

${ }^{25}$ Smythe to DPAG, 11 May 1961, DCCA: Box 11, DPAG 15/22. Smythe retired in 1946 and moved to Elfinsward in Hayward's Heath shortly afterwards. Elfinsward (now demolished) was an Anglican chapel that was used as a home for retired clergy and also a conference and retreat centre. For more information see http://www.sussexopc.org/index.php? $=400 \& \mathrm{k}=1337 \& \mathrm{t}=$ Church. Smythe's letters were all addressed from this home, meaning he must have had enough room there to hold his massive collection. In 1960, when he married his second wife, Phyllis, he moved to Moorcroft, Bramley. This must be the house referred to in the letter, but whether there was no room for the collection because the house was smaller than his living spaces at Elfinsward, or because his new wife came with her own load of possessions that took up the available space, is not clear.

${ }^{26}$ Smythe to Wace, 5 October 1944, V\&A Archives (VAA): MA/1/S2404.

${ }^{27}$ It is interesting to note, however, that Smythe only referred to his nephew here, when he already had two daughters by this time, and a grandson by his younger daughter. See DCCA: Box 11, DPAG 15/22.
} 
British art historian Sir Robert Witt (1872-1952) offers a deeper look into the possible psychological reasoning behind donating and selling collections:

He [the collector] will go on to try his strength with other collectors in some exhibition. The critics publicly appraise his collection and, in doing so, his taste. $\mathrm{He}$ is encouraged to do still better. Others ask his advice, what to buy, what to discard. Has he anything good enough to be welcomed by his local gallery, even, dare he hope, the National Gallery at Millbank, or the Victoria and Albert Museum? What a privilege to lend, what an honour to present, a permanent memorial of his taste and courage $!^{28}$

Indeed, this summation may reflect Smythe's aspirations. He exhibited watercolours several times throughout his lifetime and having works accepted by prestigious institutions like the V\&A seems like a natural development. Smythe called himself a "lover of the Victoria \& Albert \& of fine art", graciously allowing the museum the first refusal for a sixteenthcentury purse that interested the V\&A in $1927 .{ }^{29}$ After gaining the museum's attention in this manner and upholding regular contact to the staff, he made the bold move of offering a collection of 150 late-eighteenth and nineteenth century drawings, most, he writes, "only pen or pencil, some wash, few coloured, many topographical by men from 1750 on." ${ }^{30}$ The museum's response was positive. The only reason for not accepting the whole gift was apparently due to space limitations.

In fact, the museum even went as far as offering those works which they could not accept to a different institution:

I beg to offer you our very sincere thanks for the magnificent collection of drawings which you have so kindly offered to us as a gift. We have now had the opportunity of examining the contents of your three parcels and have chosen about a hundred drawings for inclusion in the collections here. For reasons of space shortage, it is not possible for us to take a larger number, but as some of the others are of considerable interest it seemed a great pity to send them for salvage immediately. We have taken the liberty of forwarding them to Mr. H.W. Maxwell, Director of the Bristol Art Gallery, as I think he may be only too pleased to have the opportunity of making a selection from them. ${ }^{31}$

There is an element of diplomacy in this response, however, that must be acknowledged. Museums must be careful not to offend potential donors, as will be seen again in some of

\footnotetext{
${ }^{28}$ Sir Robert Witt, in his preface to C.E. Hughes, Catalogue of the Herbert Powell Collection of Water-Colours and Drawings of the Early British School (1931), cited in Kim Sloan, J.M.W. Turner: Watercolours from the R.W. Lloyd Bequest to the British Museum (London: British Museum Press, 1998), 31.

${ }^{29}$ Smythe to Wace, 20 September 1927, VAA: MA/1/S2404.

${ }^{30}$ Smythe to V\&A, 18 November 1948: VAA: MA/1/S2404.

${ }^{31}$ Mr. Laver to Smythe, 29 December 1948, VAA: MA/1/S2404.
} 
Maclennan's responses later. Regardless, through help of the National Art Collections Fund, a further work was accepted by the V\&A in 1949: "We are glad to accept this [a George Heriot watercolour] for the Museum, and it will make a welcome addition to the topographical collection of the Department of Engraving, Illustrations and Design." ${ }^{32}$ Some of the other museums and galleries in Britain that have received watercolours from Smythe include the British Museum, the National Maritime Museum (Greenwich), the Whitworth (Manchester), York Art Gallery, Bristol Museum and Art Gallery, and the National Museum Cardiff.

Nonetheless, not everything that Smythe offered was accepted. Limited space was certainly one major reason for a gallery or museum not to take a gift. ${ }^{33}$ Another reason was the specialised collecting of some institutions. For example, the V\&A rejected another of Smythe's works on the grounds that it was an oil painting:

We are sincerely grateful for your generous offer to give the Museum the replica of the portrait of Lady Parker. Oil paintings have, however, for many years been considered outside the scope of our collections and I do not think that the fact that Lady Parker owned the purse now belonging to the Museum would be a sufficient reason to justify our making an exception in this case. ${ }^{34}$

Further, as discussed in Chapter Four, Smythe's collection of early British watercolours did not fit into the rapidly increasing demand for contemporary art. With the Contemporary Art Society (CAS) growing both in number and influence - the Society had 300 members in 1946, and 1,750 members by 1953 - collecting contemporary British art became the prime focus for many collectors and institutions. ${ }^{35}$ Watercolours like Smythe's would only be accepted if they helped to 'fill gaps' in an already existing collection. As Joseph Darracott put it, while the CAS and private collectors were not morally obliged to 'fill gaps', "a curator [of a public institution] had to keep in mind the ultimate character of the collection, weighing current purchases against possible future benefactions." ${ }^{\text {"36 }}$ This severely limited Smythe's potential gifting activities within Britain.

Additionally, Smythe's collection was sometimes faced with stark discrimination by the artworld elites. While correspondence from the V\&A was always polite and

\footnotetext{
${ }^{32}$ V\&A to Smythe, 4 November 1949, VAA: MA/1/S2404.

${ }^{33}$ If the V\&A could already not take more than 100 watercolours from him in 1948, Smythe must have realised quickly that he would not be able to leave his legacy of over a thousand works to the major institutions in England.

${ }^{34}$ Eric Maclagan (director and secretary) to Smythe, 12 October 1944, VAA: MA/1/S2404.

35 Joseph Darracott, "British Arts and Patrons 1940-1960," in Alan Bowness ed., British Contemporary Art 1910-1990: Eighty Years of Collecting by The Contemporary Art Society (London: the Herbert Press, 1991), 71.

${ }^{36}$ Ibid., 77.
} 
encouraging, not all of his gifts were viewed in such a positive light. Paul Mellon and Tom Girtin, a descendant of the watercolourist Thomas Girtin (1775-1802), both received numerous works from Smythe, only to dismiss them as low quality and often wrongly attributed 'junk. ${ }^{37}$ Girtin wrote to Mellon in 1950:

I have had parcel after parcel of the most aff(?) junk from our mutual friend the Archdeacon, and after crabbing stacks of Girtins, Gainsboroughs, Wilsons, Cromes \& Boningtons, I have just been pulled at stat(?) by a most intriguing drawing which he calls 'in the style of Cozens'. For once he is right. ${ }^{38}$

While this does acknowledge that Smythe did have a keen eye at times, the overall tone of the letter suggests that his tastes and connoisseurly skills were not up to par within British watercolour circles.

The ability to house his legacy locally in Britain, however, appears to have been an important factor for Smythe's selling and donating practice. Though he did end up selling parts of his collections through auction houses, he expressed his preference for leaving them with local galleries "rather than put it with Christies where some American might purchase it." 39 The thought of his collection being shipped off to America was a clear deterrent for Smythe. Similarly, when Pearse wanted to buy the French illumination from Christie's, she was told by the agent, Alec Martin, that the seller had specified to only sell it to a British institution. ${ }^{40}$ Why, then, did he change his mind?

\section{Why New Zealand?}

If he had not made an exception, the Smythe collection would not be in New Zealand today. Smythe started gifting watercolours to New Zealand during the early 1950s, with the first offer being made on 12 June 1953, when he wrote to Pearse [Appendix I]:

I want to offer you 50 to 70 Early English watercolours and pencil drawings for your Art Gallery if you think that they would be acceptable.

The trouble is to get them out to you. On an average they are from 1800-1860 in date. $^{41}$

There were several factors contributing to his change of heart. On the one hand, it has been suggested that Smythe was simply 'charmed' into parting with his collection by Pearse

\footnotetext{
${ }^{37}$ Tom Girtin to Paul Mellon, 14 September 1950, Paul Oppé Archive, Paul Mellon Centre: APO/1/11/2

${ }^{38}$ Girtin to Mellon, 30 July 1950, Paul Oppé Archive, Paul Mellon Centre: APO/1/11/2.

${ }^{39}$ Smythe to Wace, 20 September 1927, VAA: MA/1/S2404.

${ }^{40}$ Entwisle, Treasures, 26-27.

${ }^{41}$ Smythe to Pearse, 12 June 1953, DCCA: Box 11, DPAG 15/22.
} 
herself. ${ }^{42}$ Indeed, her initiative to write to the owner of that illuminated manuscript must have impressed Smythe, and the pair obviously shared a love for art. While their relationship might have started out as a business transaction, it turned into a friendship that lasted over a decade. The two exchanged letters well into the mid-1960s, even after Pearse had retired from the DPAG. Pearse's business strategies and amiable character would most certainly have been a contributing factor for Smythe's decision to donate his collection to Dunedin at this time.

In a similar vein, this could also have facilitated his decision to continue sending gifts to Dunedin specifically for as long as he did. While he did send some watercolours to Wellington, his close relationship with Pearse gave him more motivation to prioritise the DPAG. In 1956 he mentioned sending works to Wellington - most likely after discovering that the National Art Gallery (NAG) was housed there, which would still have constituted an ideal and honoured destination for a private collection - but he also said that he preferred to stick to his "early love." ${ }^{43}$ On 9 April 1957, he wrote that he would not send any more to Wellington. ${ }^{44}$ His "early love", of course, was Dunedin, represented by Pearse herself. Her regular gifts to Smythe, sent as tokens of appreciation, would no doubt have aided in securing the archdeacon's continued devotion. ${ }^{45}$

Unfortunately, Pearse's letters to Smythe no longer exist. Unlike the NAG, DPAG must not have made copies of letters sent out by their staff. Thus, I only have Smythe's words to go by, and he certainly expresses several different reasons for his gifts, other than the persuasive powers of Annette Pearse. One was his religious conviction. He wrote, "I feel I am giving to God as well as to you, for art is the gift of the fruit of God."46 As a clergyman with the family motto tenax in fide (steadfast in the faith), gifting his collection was a religious act of honouring God. Not only that, but Smythe was convinced that God Himself wanted him to give his collection to Dunedin, using Pearse as an agent for his Divine Plan. He wrote, "God must have put it into my heart to share my treasures where they would be best appreciated, and I think He used you as His agent." ${ }^{, 47}$ In another letter he elaborates, "I

\footnotetext{
${ }^{42}$ Mary Kisler, "Displaced Legacies - European Art in New Zealand's Public Collections," The Gordon H. Brown Lecture 2008, accessed 26 July 2017, http://www.victoria.ac.nz/sacr/research/art-history/gordon-h.-brown-lecture-series/MaryKisler-lecture.pdf; also Entwisle, Treasures, 28.

${ }^{43}$ Smythe to Pearse, 14 July 1956, DCCA: Box 11, DPAG 15/22. In his first letter to the NAG in 1956, Smythe explains that he read in a paper that Wellington has an Art Gallery, which is why he decided to send some there. He did not want to "swamp a museum with too much of one thing, as it would spoil the Museum," hence not giving his entire collection to Dunedin only. See Smythe to NAG, 24 June 1956, TPA: MU00008, box 3, item 6.

${ }^{44}$ Smythe to Pearse, 9 April 1957, DCCA: Box 11, DPAG 15/22.

${ }^{45}$ See DCCA: Box 11, DPAG 15/22.

${ }^{46}$ Smythe to Pearse, 31 December 1953, DCCA: Box 11, DPAG 15/22.

${ }^{47}$ Smythe to Pearse, 14 July 1954, DCCA: Box 11, DPAG 15/22.
} 
think God the Holy Spirit inspires and guides us in trying to share and He had His agent in Dunedin, for it was when you told me of the ?8 [sic] English pictures you had, that my inner spirit began to feel a whisper and say how few." ${ }^{48}$ Therefore, Pearse is still seen as a significant factor in Smythe's decision, not because of her own persuasive ability, but rather due to having been chosen by God. Their initial encounter, thus, was not coincidence, but fate.

The act of sharing itself was another strong motivator for Smythe. Consistent with his philanthropist nature as an active member in the community, he actually saw sharing as a joyful activity, claiming "I don't want to be thanked, I want to help people to see the joy of sharing, for we are very apt ... in the nation, where there is plenty, and sometimes a neighbour has only a pittance." 49 This demonstrates that Smythe particularly felt the need to share with someone less fortunate than himself. He wrote to Pearse, "I hope I have filled some gaps. ${ }^{50}$ In his view, there were many gaps to fill, as he saw New Zealand as the poor neighbour whose art galleries hardly had any British watercolours of their own. Thus, sharing his collection with New Zealand, rather than the already well-fed English galleries, would have given him more satisfaction and a proud sense of accomplishment, in keeping with his philanthropic ideals.

In addition to this, although New Zealand was physically too far removed from Britain to actually be categorised as a 'neighbour'; symbolically it was actually much more than this. New Zealand was not just a neighbour, but a family member. Smythe sometimes did not even differentiate between the two countries, calling New Zealanders his people, when he wrote, "I wished on our people overseas to know what the old country was like in their ancestors' time, and to see some of the work of her painters." ${ }^{51}$ Indeed, he wondered how many people in New Zealand actually know these artists, but expressed his delight at being able to help future generations know them better. ${ }^{52} \mathrm{He}$ also attempted to uncover even more directly personal links to New Zealand, for example mentioning alumni from his old college that now live there, including in Dunedin. ${ }^{53}$ This way, although his collection was technically going overseas, it was still in the trusted hands of England's descendants. Such sentiments carry colonial overtones, but seeing that the 1950s was the era of decolonisation,

\footnotetext{
${ }^{48}$ Smythe to Pearse, 17 August 1954, DCCA: Box 11, DPAG 15/22.

${ }^{49}$ Smythe to Watson, 29 July 1956, TPA: MU000044, box 2, item 12.

${ }^{50}$ Smythe to Pearse, 14 October 1953, DCCA: Box 11, DPAG 15/22.

${ }^{51}$ Smythe to Governor General, 16 July 1954, DCCA: Box 11, DPAG 15/22.

${ }^{52}$ Smythe to Pearse, 7 June 1954, DCCA: Box 11, DPAG 15/22.

${ }^{53}$ Smythe to Pearse, 17 June 1954, DCCA: Box 11, DPAG 15/22.
} 
Smythe's gift was in a sense a personal gesture of colonial largesse at a time when England's Empire was fragmenting.

Finally, he revealed that the gift was also a sign of appreciation and gratitude for

New Zealand's services to Britain, which at times he personally witnessed:

The honest truth is I sent the little gift as an unknown, who has a very grateful memory of New Zealand's immediate response of help to the old Mother Country in her hours of peril. I saw this in two world wars and as a chaplain I met New Zealanders and Maoris in the Hospitals.

Now I am a very old man and have lived to hear the gift has been received. I am nearly 81 , but I did hope in my heart to show my appreciation of the kindness always shown to us in Great Britain by New Zealand, and your letter about my small former gift showed me the way.

I am fully repaid because you tell me its ... to be a help in your art gallery. I am overjoyed to hear it. ${ }^{54}$

Although we can see the love that Smythe held for the country and its people, he was unable to make the journey to New Zealand in his lifetime. Smythe's grandson, David PickardCambridge, did, however, make the trip in his place in 1955 (even meeting with Pearse to tour the DPAG). ${ }^{55}$ Yet despite never experiencing the country himself, it is clear from his writings that Smythe did form a strong bond with New Zealand, and he was genuinely happy to have his collection cared for in Dunedin and Wellington. This feeling was mutual, at least at the beginning.

\section{WELCOME ... NO MORE}

Due to the lack of existing outgoing correspondence in the DPAG archives, there is little information about how the collection was initially received. The gifts sent to Smythe by the DPAG as thanks, and the archdeacon's own expression of humble embarrassment at being thanked so much, are strong indicators that Pearse was indeed very satisfied with the collection. In fact, Maclennan informed Smythe that "Mrs. Pearse is delighted with the drawings you sent her." 56 The same certainly applied to Maclennan himself. His letters to Smythe are filled with words of gratitude for and praise of the watercolours. Some examples include: "a most valuable addition"57; "We have been delighted with everything you have

\footnotetext{
${ }^{54}$ Smythe to Pearse, 30 September 1953, DCCA: Box 11, DPAG 15/22.

${ }^{55}$ Smythe to Pearse, 12 May 1955, DCCA: Box 11, DPAG 15/22.

${ }^{56}$ Maclennan to Smythe, 31 October 1956, TPA: MU00008, box 3, item 6.

${ }^{57}$ NAG to Smythe, 19 July 1956, TPA: MU00009, box 5, item 9.
} 
sent us and shall certainly look forward to still another parcel"58; "This means that you have now sent us 267 works to date, and we certainly have an enviable representation of the Early English School"59; "all the works are very welcome indeed." 60

Maclennan goes out of his way to describe and compliment specific works from the collection. Each time a new group of works arrived, he would select some and explain to Smythe why he was grateful to accept them for the Gallery. A letter from 18 December 1956 provides an excellent example of this:

It really is a very lovely set which includes many gems. The Girtin is certainly extremely interesting in every way and the David Cox is one of the most delightful I have seen. The little Samuel Palmer appeals to me tremendously, such lovely use of golden yellows. The Samuel Alken is very typical and we are very lucky to have such a fine example of his work. The two Copley Fieldings are beautifully painted, full of charm. So is the little W. Payne, dated 1791. And you have given us another Muller! and [sic] what a lesson it is in watercolour painting. With Morland, and Gainsborough, we certainly have very distinguished company this time. I am amazed at the variety achieved by such artists as Fripp, Carter and Beverley who use little more than two colours, a coal blue and a warm brown, in the manner of Alexander or J.R. Cozens. Their transparent washes seem to evoke other colours.

This is indeed a delightful selection and it is difficult to express our deep gratitude to you. ${ }^{61}$

Such sentiments of luck, delight and gratitude are frequent occurrences in the personal correspondence of Maclennan. We can imagine that Pearse's letters would have revealed similar feelings and warm welcomes.

However, one significant letter from Dunedin, written by A.H. Allen (the DPAG

Society president) in 1955, does survive, and it is worth quoting it here in full:

During the past two years or more you have continued to donate to this Gallery a most generous and valuable Gift of Early English Water Colour Paintings.

Appreciative acknowledgment has been made in correspondence through our curator, Mrs. A.G. Pearse, and for this reason I have not hitherto communicated with you, but, now your gift must be well-nigh completed, I feel that, on behalf of our Council and Members, I should write and say, 'Thank you' most gratefully.

It is freely acknowledged that in your gift we now possess the finest collection of water colour pictures in the Southern Hemisphere of which we are very proud.

We realise that, in your desire to make acknowledgement of your appreciation of this Dominion, we are most fortunate that you chose our Gallery as the medium to express that desire.

\footnotetext{
${ }^{58}$ Maclennan to Smythe, 21 November 1956, TPA: MU00008, box 3, item 6.

${ }^{59}$ Maclennan to Smythe, 26 November 1956, TPA: MU00008, box 3, item 6.

${ }^{60}$ Ibid.

${ }^{61}$ Maclennan to Smythe, 18 December 1956, TPA: MU00008, box 3, item 6.
} 
We further appreciate that, to part with your lovely collection which represents the hobby and love of a life-time, must mean a great personal sacrifice for you.

Your Pictures now entirely occupy the walls and screens of two of our largest rooms and present a lovely display, known by our public and visitors as 'The Archdeacon Smythe Collection'. Your name and generosity will be perpetuated for generations to come, which we trust will give you pleasure, and express, though very inadequately, our grateful thanks to you. ${ }^{62}$

Allen uses very strong language to express, and at times, exaggerate, the Gallery's reception of the gift. The collection's lack of visibility in subsequent years, despite the Gallery's sincere opinion that it was indeed "the finest collection of water colour pictures in the Southern Hemisphere", demonstrates that this shift was not due to lack of effort, but rather due to a change in taste between 1955 and now. Also, Smythe's name was clearly not perpetuated for as long as was predicted, as within just one decade information on Smythe and his gift was becoming lost. For example, Charlton Edgar, the director of the DPAG from 1965-71, wrote to Maclennan in 1966:

In talking over arrangements this week I was interested to learn from Mr. Miller that Archdeacon Smythe had given the National Gallery a collection of watercolours. I had always been under the impression that he had given works only to the Dunedin Public Art gallery.

... I write to ask if you can give me any information re this matter. In the case of the National Gallery possibly you can tell us how the Archdeacon came to make the gift, how many works are involved and possibly one or two of the more important works? ${ }^{63}$

Considering that Maclennan and Pearse had been working together on a joint catalogue of both galleries' gifts, it is surprising to see that this kind of information did not get passed on. Within just ten years, the new director of the DPAG was not aware that the NAG had also received watercolours from Smythe, or that there had been former conversations between the two galleries about this collection. Furthermore, in view of the fact that the DPAG was still in correspondence with Smythe at this time, it is even more evident that the status of his collection was starting to diminish. Perhaps Pearse's reminder to the gallery to send him his yearly Christmas lamb was indeed not a sign of her commitment and friendship even after retiring, but more so a sign that the gallery was losing interest in Smythe and had to be reminded.

\footnotetext{
${ }^{62}$ A.H. Allen to Smythe, 31 October 1955, DCCA: Box 11, DPAG 15/22.

${ }^{63}$ Charlton Edgar to Maclennan, 8 September 1966, TPA: MU000044, box 2, item 12.
} 
The next part of Edgar's letter, however, is even more shocking. He writes, "actually we have over 800 here but there are very many that are not very good. Some of the collection would be better destroyed though that is strictly off the publication." 64 There is a stark difference between the letter written in 1955 by Allen, and Edgar's opinion in 1966. While the former claimed it was the finest watercolour collection in the Southern Hemisphere, the latter now wished for some of it to be destroyed! Do these opinions simply reflect the different personal tastes of two individuals, or do they reflect a general shift in taste that was occurring at this time? This question will be addressed in the fourth chapter.

Regardless, at the time of their reception, the Smythe watercolours clearly did enjoy an enthusiastic welcome. This is evident not just in letters, but also through council meetings. The Art Gallery Council meeting minutes from 20 October 1954, for example, state that the Dunedin Mayor suggested to invite Smythe to Dunedin as "the guest of the City". ${ }^{65}$ The Smythe watercolours were also put on display almost immediately after arriving in New Zealand, with the first official exhibitions being held in June 1956 in Dunedin, and 1957 in Wellington, where only a small selection of Smythe's watercolours were on show in the Recent Acquisitions exhibition. Both of these exhibitions are mentioned in Maclennan's letters to Smythe, praising the works and highlighting their popularity with the New Zealand public. In 1956 he wrote:

I had the pleasure, very recently, of opening an exhibition at the Dunedin Art Gallery of the complete Collection that you have given to Dunedin. Mrs. Pearse had arranged them beautifully and it was an exciting occasion for me, as it was for the many visitors who attended. The Gallery was kept open in the evenings for a week, to enable as many as possible to see them. ${ }^{66}$

The longer opening hours testify to the success of the exhibition, and the fact that it was decided to keep "about two thirds of them in portfolios" demonstrates a public interest in viewing the watercolours. ${ }^{67}$

It is interesting to note, however, that on the same day Maclennan wrote another letter, this time to Watson. He again mentions his visit to the Dunedin exhibition, yet he describes this event with less enthusiasm than in his letter to Smythe, saying "I went to Dunedin a few weeks ago to open the first complete showing of his gift collection. There is

\footnotetext{
${ }^{64}$ Charlton Edgar to Maclennan, 8 September 1966, TPA: MU000044, box 2, item 12.

${ }^{65}$ Council 20 October 1954, DCCA: Box 1, DPAG 4/5.

${ }^{66}$ Maclennan to Smythe, 3 July 1956, TPA: MU00008, box 3, item 6. Note: the "complete" collection at this time numbered only about 700, as specified by Maclennan in another letter written to Watson, 19 June 1956, TPA: MU00009, box 5 , item 9 .

${ }^{67}$ Maclennan to Watson, 19 June 1956, TPA: MU00009, box 5, item 9.
} 
some good stuff there, though lots of the watercolours are slight and probably from sketch books, but still very worth while." 68 A similar tone can be perceived in Maclennan's reply to Edgar, in which he wrote "there are 342 items, some minor and doubtful works by the important $18^{\text {th }}$ Century English Watercolourists and a number of very good things by the lesser known; a fair proportion is undistinguished." 69 Among his letters of praise addressed to Smythe, these words would seem out of character. Though he does not condemn the watercolours to the same low status as Edgar had done, he never would have used the word 'slight' to describe them to Smythe.

Maclennan demonstrates here his diplomacy in courting Smythe, while acknowledging the uneven quality of the collection to other members of the artworld. While professional institutions like the V\&A or the British Museum usually maintain their reputation through a process of discrimination, the NAG lacked the same status to be as selective as they were, and criticising parts of a collection to the owner was risking not getting anything at all. When faced with a potential gift such as Smythe's, the question of how much one has to accept in order to get the 'good' works is an eternal problem for museums. Particularly during the early stages of the NAG, the desire to build a representative collection of British watercolours virtually from scratch was stronger than the professional criticism expected from such an institution. This is an example of centreperiphery relations, part of a long history of second-rate works being shipped to the former colonies because they were not good enough to be collected by British institutions. ${ }^{70}$ Maclennan could simply not afford to call the watercolours 'junk' as someone with the stature of Paul Mellon could have.

Regardless, a couple of months later, Maclennan wrote to Smythe again about the upcoming Recent Acquisitions exhibition at the NAG. This was to feature a selection of Smythe's gift, together with works acquired overseas by Watson and Mr. E. Heber Thompson, as well as paintings acquired within New Zealand. Maclennan described the project as "a brave showing"71 that would "bring the ducks off the water."72 The exhibition opened together with the gallery's new Print Room on Wednesday, 27 March 1957, and a few days later Maclennan wrote to Smythe that his gifts were indeed the star of the show:

\footnotetext{
${ }^{68}$ Maclennan to Watson, 3 July 1956, TPA: MU00008, box 3, item 6.

${ }^{69}$ Maclennan to Edgar, 14 September 1966, TPA: MU000044, box 2, item 12.

${ }^{70}$ See William McAloon ed., Art at Te Papa (Wellington: Te Papa Press, 2009), 7-8.

${ }^{71}$ Maclennan to Smythe, 14 September 1956, TPA: MU00008, box 3, item 6.

${ }^{72}$ Maclennan to Watson, 19 June 1956, TPA: MU00009, box 5, item 9.
} 
We are holding our exhibition of Recent Acquisitions, and two galleries are devoted to a selection of your gift. They look very well indeed and I can assure you that already they are giving a great deal of pleasure to art lovers in New Zealand. Mr. G. G. Gibbes Watson, Chairman of our Management Committee, who opened the exhibition, referred to your gift as by far the most important ever made to the Gallery from overseas. ${ }^{73}$

The exhibition pamphlet lists all 159 works that were on show, 45 of which came from Smythe's collection (lots 110-155). ${ }^{74}$ They were displayed in Gallery 5 and the gallery's new Print Room. With five works on display, John Sell Cotman was the best-represented artist. Other works, which may have excited the public due to the popularity of the artists, such as J.M.W. Turner, have since been determined to not be by their hands. Maclennan was very optimistic about the public reception of the works and outlined a plan for the future, wherein "we propose to show about 50 framed works at a time, changing them every few months. The rest will be available to visitors in portfolios we have had made. They may be studied, under supervision of course, in our new print room." 75 The educational value of the works was thus strongly emphasised.

Just over a month after this, Maclennan was able to confirm the public's enthusiasm for the watercolours, describing how larger crowds of people were coming to view them. ${ }^{76}$ He detailed more ambitious plans for the collection:

This time I do not write to tell you that another parcel has arrived from you, but to tell you that more and more people are coming to see and enjoy your wonderful gifts to us. ... Later in the year, or early next year, we propose to have a full exhibition of your gift, as we were able to show only a portion in our "Recent Acquisitions" Exhibition. We hope too, in time, to publish a combined catalogue of the early English works you gave to Dunedin and ourselves. Mrs. Pearse and I have approached the Government, who have indicated that they will favourably consider financial assistance for the project. ${ }^{77}$

At the council meeting on 11 August 1954, it was also announced that two anonymous donors had given the gallery $£ 100$ "to be used in the purchase of screens for, and the

\footnotetext{
${ }^{73}$ Maclennan to Smythe, 1 April 1957, TPA: MU00008, box 3, item 6. (see also Maclennan to Smythe, 18 March 1957, TPA: MU00008, box 3, item 6).

${ }^{74}$ National Art Gallery, Exhibition of Recent Acquisitions (Wellington, 1957). The pamphlet states that this selection comes from the collection "of some 350" works presented by Smythe, which is close to the number stated in the NAG director's letter to the director of the DPAG from 14 September 1966 (this letter says that 342 watercolours were gifted, see TPA: MU000044, box 2, item 12). However, the list provided at the TPA in MU000376, box 1, item 9 only lists 327 items, while the current Te Papa website only lists 323 items on Collections Online.

${ }^{75}$ Maclennan to Smythe, 1 April 1957, TPA: MU00008, box 3, item 6.

${ }^{76}$ Keeping in mind, of course, that the public and casual art lovers generally lack the same level of discrimination as shown by artworld insiders.

${ }^{77}$ Maclennan to Smythe, 17 May 1957, TPA: MU00008, box 3, item 6.
} 
framing and mounting of the Archdeacon Smythe gift of Early English Water-Colours.,"78 Similarly, another anonymous donor wished to present "a brass tablet with a suitable inscription for the Archdeacon Smythe Gift." ${ }^{, 79}$ Apparently, not only the gallery then, but also private individuals saw value in these works.

This enthusiasm also spread to other art galleries. In 1957 the Robert McDougall Art Gallery in Christchurch enquired about borrowing works from the Smythe collection for an exhibition, which was approved by the DPAG ${ }^{80}$ However, when Auckland expressed the same request in 1959, it was decided by the council that the Smythe works would no longer be sent away on loans during the donor's lifetime. ${ }^{81}$

Positive sentiments were also echoed by the press, with newspaper articles using flattering language to describe the collection. The Otago Daily Times called it "one of the most valuable art collections ever given to an organisation in New Zealand or Australia"82, and the Evening Star described it as "a benefaction of inestimable value." 83 Apart from the opinions of the writers' themselves, newspaper articles gave further indication of how the works were received by providing quotes from gallery staff members and others. In this manner, the Mayor of Dunedin, Mr. L.M. Wright, was cited as saying "Dunedin must be the envy of many centres in the Dominion and Australia in having such an important and valuable collection. ${ }^{\circ 4}$ Similarly, on the occasion of the opening exhibition in 1953, Mr. H. Mandeno, the president of the DPAG Society, stated that "that gift is just terrific. It almost takes our breath away." 85 Finally, Pearse herself was quoted as saying "if someone had come along and emptied out a sack of golden guineas I could not have been more overwhelmed." ${ }^{86}$ Indeed, she ambitiously claimed that the Smythe watercolours "would make the Dunedin gallery the mecca of every art lover." 87

\section{Out of Sight, Out of Mind: Criticism and Apathy}

Just a couple of years later, the public hype that had been drawing in visitors to see the Smythe watercolours had apparently started to fade. During a council meeting on 4 July

\footnotetext{
${ }^{78}$ Council 11 August 1954, DCCA: Box 1, DPAG 4/5.

${ }^{79}$ Council 23 February 1955, DCCA: Box 1, DPAG 4/5.

${ }^{80}$ Council 3 October 1957, DCCA: Box 1, DPAG 4/5.

${ }^{81}$ Council 3 December 1959, DCCA: Box 1, DPAG 4/6.

82 “Art Collection Opening Tomorrow," Otago Daily Times (18 November 1953), DCCA: DPAG 26/3.

83 "Another Notable Gift from English Donor," Evening Star (9 January 1954), DCCA: DPAG 26/4.

84 "Smythe Collection," Otago Daily Times (3 March 1954), DCCA: DPAG 26/4.

85 "Gift of Water Colours Opened at Art Gallery," Otago Daily Times (20 November 1953), DCCA: DPAG 26/3.

86 "Priceless New Gifts to Art Gallery: Archdeacon Sends Dunedin More Pictures," Otago Daily Times (26 February 1954), DCCA: DPAG 26/4.

87 “'Invaluable' Art Collection Given to Dunedin,” Auckland Star (1953), DCCA: DPAG 26/3.
} 
1955, the DPAG's Chairman “expressed his disappointment with the very poor response of the general public on this occasion [opening of a new Smythe collection exhibition], members concurring with his remarks. ${ }^{~} 88$ Not only did visitation numbers decrease, but the press was also more hesitant to blindly praise the collection's contents. Harry Vye Miller (H.V.M.), writing for the Evening Star, examined the works with a critical eye, claiming, in contrast to previous opinions, that many of the watercolours were not the best. He wrote, "of course, we do not expect to see in this collection the best examples of these men, for those are all safely housed in the British Museum, the Gallery at York, and other historic galleries in Britain; but some are represented by excellent works, and only Cotman's examples are perhaps inadequate to represent his finest qualities." 89 It is interesting to note that the author highlighted Cotman's works particularly as "inadequate", emphasising the continued desire for and prestige of this artist. While the need to show the Smythe collection was recognised early on, and despite Pearse's and Maclennan's initial plans to have regular, and indeed permanent, exhibition spaces set aside for the Smythe watercolours, public display of the collection quickly started to diminish.

Another writer for the Otago Daily Times observed that in Dunedin there was a case of the gallery lacking the necessary means to exhibit the works:

The present resources of the Dunedin Public Art Gallery Society, both financial and physical, are certainly not sufficient to enable the Smyth [sic] collection to be displayed, except at a loss to the walls of the gallery of many other pictures having joint appeal of merit and familiarity to commend them to gallery-goers. ... What, in fact, is required is someone - or some body of citizens - to match the generosity of Archdeacon Smyth [sic] by providing a gallery for the water colours. Until this is done - and until, incidentally, the pictures are catalogued and annotated - the artloving people of Dunedin will not have carried out their obligation to an unknown benefactor. $^{90}$

By 1970 this issue had still not been remedied, as can be learnt from a letter by John Borrie (a former DPAG director) to Charlton Edgar:

Three times now I have had forcefully brought to my notice the fact that we are not showing any of the Smythe collection. Indeed one of our members from Auckland very forcefully said to me. 'With these holdings of the Smythe collection, should we not have as a matter of Art Gallery policy, one display room always set aside for choice pictures of the Smythe collection'. ${ }^{91}$

\footnotetext{
${ }^{88}$ Council 4 July 1955, DCCA: Box 1, DPAG 4/5.

${ }^{89}$ H.V.M., "For Those Who Draw," Evening Star (14 May 1954), DCCA: DPAG 26/4. Harry Vye Miller (1907-1986) was also a Dunedin watercolour artist and teacher.

90 “Art Gallery Has Further Needs," Otago Daily Times (27 February 1954), DCCA: DPAG 26/4.

${ }^{91}$ John Borrie to Charlton Edgar, 11 December 1970, DCCA: DPAG 23/9.
} 
Not only Dunedin locals, but members from other New Zealand centres, such as Auckland, showed an interest in seeing the Smythe watercolours. This desire was, however, not fulfilled. As the collection was shown less and less, its status in New Zealand's institutions and public sphere similarly slowly diminished.

\section{Watercolours' Exhibitions and Popularity in New Zealand}

One should not underestimate the power that exhibitions hold in shaping the public's perception of certain types of art. In the case of British watercolours, the history of exhibitions has always been integral to its development and success. When watercolours first started to be exhibited in Britain during the eighteenth century, they were easily overshadowed by the larger and more colourful oil paintings which they were shown alongside. It was this struggle to prove their own against oil paintings in exhibitions that led to some of the greatest developments in watercolour painting. As Jane Bayard expresses in Works of Splendor and Imagination: The Exhibition Watercolor, 1770-1870, "by the beginning of the century, it had become their [watercolourists'] aim to demonstrate that watercolour could be manipulated to produce works of greater size, force, and strength of colouring than had ever been considered possible." 92

Watercolours were exhibited in England from the 1760s, initially by the Society of Artists of Great Britain (1760-91) and then by the Royal Academy (RA). ${ }^{93}$ It was within this context that a media hierarchy was first introduced which prioritised oil painting as more valuable than watercolours, and which led to watercolours being hung badly in exhibitions. ${ }^{94}$ In response, watercolourists established various Watercolour Societies, which created

\footnotetext{
92 Jane Bayard, Works of Splendor and Imagination: The Exhibition Watercolor, 1770-1870 (New Haven: Yale Center for British Art, 1981), 2.

${ }^{93}$ The Society of Artists of Great Britain (SAGB) was one of three early exhibitions societies, the other two being the Society for the Encouragement of Arts, Manufactures and Commerce, and the Free Society of Artists. Internal unrest among the SAGB administration and exhibition management eventually led to the formation of yet another body: The Royal Academy of Arts. For more information on the SAGB, see Matthew Hargraves, 'Candidates for Fame': The Society of Artists of Great Britain, 1760-1791 (London: Yale University Press, 2005); Algernon Graves, The Society of Artists of Great Britain, 1760-1791, the Free Society of Artists, 1761-1783: A Complete Dictionary of Contributors and their Work from the Foundation of the Societies to 1791 (London: George Bell and Sons, 1907).

${ }^{94}$ For example, watercolours would be placed in the same room as sculpture, however, the dim lighting which favoured the marbles did not benefit the paintings. See Greg Smith, The Emergence of the Professional Watercolourist (Aldershot: Ashgate Publishing Limited, 2002), 27.
} 
avenues to mount exhibitions with the explicit intention of vying with oil paintings. ${ }^{95}$ The first exhibition of this type, by the Old Watercolour Society (OWS) in 1805, was attended by nearly 12,000 people, and during its seven-week run was practically sold out. ${ }^{96}$

In New Zealand, the medium had a similarly problematic exhibition history. Although watercolour was far more widely practiced by local artists than oil during the nineteenth century, exhibitions still seemed to have issues with maximising displays to benefit watercolours. A prominent artist of the time, Alfred Sharpe, remarked in 1883:

In conclusion, I may say that the water colour pictures at the exhibition were just killed, by being shunted on to tables, without any backing above the tops of the frames, under a trying cross light, and surrounded by bright-coloured articles of needlework and of vertu. All artists know how these things kill the effect of delicate water colours, and make them look dead, lustreless, and shabby. ${ }^{97}$

Roger Blackley points out that exhibiting was a crucial aspect for Sharpe, who worked during an "era of organised exhibitions in which large, framed watercolours competed with oil paintings". 98

At the same time though, one might argue that the status of watercolour had always been higher in New Zealand compared to England. Whereas in England watercolours had to fight their way to the top, in New Zealand there were few oils to compete with. In fact, in the 1871 Auckland Society of Artists exhibition, oil paintings were thought to be inferior to the watercolours produced by local artists. ${ }^{99}$ These included such names as J.C. Hoyte, John Kinder and John Gully, who have remained popular until today. Various newspaper articles

\footnotetext{
${ }^{95}$ Several informal sketching clubs and professional societies were set up during this time, which provided spaces for artists to share technical knowledge, stimulate the mind and to promote the status of their medium through exhibitions. The Society of Painters in Water-Colour was the first of these societies, founded in 1804 and holding annual exhibitions from 1805 onwards. Its restricted membership policy eventually resulted in the establishment of two major rival societies: the New Society of Painters in Miniature and Water-Colours in 1807 (which in 1808 changed its name to Associated Artists in Water-Colours, and later again in 1810 to Associated Painters in Water-Colours), and the New Society of Painters in Water-Colours in 1832 (after this the original society changed its name to the Old Water-Colour Society, OWS). See Michael Clarke, "Societies and Clubs," in The Tempting Prospect: A Social History of English Watercolours (London: British Museum Publications, 1981), 74-89; Tim Wilcox and Charles Nugent, The Triumph of Watercolour: The Early Years of the Royal Watercolour Society 1805-55 (United Kingdom: Bloomsbury USA, 2005); John Lewis Roget, A History of the "Old Water-Colour" Society, Now the Royal Society of Painters in Water Colours (London: Longmans, Green, and Co., 1891); J. Hamilton, The Sketching Society (London: Victoria and Albert Museum, 1971).

${ }^{96}$ Simon Fenwick and Greg Smith, The Business of Watercolour: A Guide to the Archives of the Royal Watercolour Society (Aldershot \& Brookfield: Ashgate, 1997), XI. The members of the OWS still hold two exhibitions at Bankside Gallery annually, in Spring and Autumn. See John Krill, English Artists Paper (London: Trefoil Publications, 1987), 120-121, for primary sources on the first exhibition, and see Bayard's thesis, "From Drawing to Painting: The Exhibition Watercolor 1770-1870," PhD diss., Yale University, 1982, for more on the development of watercolour exhibitions.

${ }^{97}$ Alfred Sharpe, "Water Colours at the Exhibition," New Zealand Herald (21 April 1883): 6, cited in Roger Blackley, The Art of Alfred Sharpe (Auckland: Auckland City Art Gallery, 1992), 126.

${ }^{98}$ Blackley, The Art of Alfred Sharpe, 52.

${ }^{99}$ Ibid., 25: "The oil paintings were acknowledged to be inferior to the watercolours, which included works by John Kinder, J.C. Hoyte and John Gully."
} 
of the time are testament to the popularity of the watercolour medium. In 1870, the Star painted watercolours as one of the highlights of an art exhibition:

Ascending to the gallery, the four walls are found to be compactly covered by a fine collection of oil paintings and water-colour drawings. This is unquestionably the strong point of the exhibition, and to those having the slightest taste for art, it will afford ample means of study. ${ }^{100}$

This interest continued into the early twentieth century, when the New Zealand Herald wrote in 1935 that "the loan exhibition of water-colour paintings by the late Miss. M.O. Stoddart, of Christchurch, which is being held in the Art Gallery, is attracting many appreciative visitors. The wide variety of the subjects ... lends a particular interest to the collection." ${ }^{101}$ Such exhibitions devoted entirely to watercolours continued to draw in the crowds well into the 1950s.

These watercolour exhibitions were part of a wider programme of cultural diplomacy in the newly formed Commonwealth. The Empire Art Loan Exhibitions Society put on two large-scale British watercolour exhibitions that travelled around New Zealand, the first in 1949-1950 covered the early period from 1750 to 1850 , while the second, in 1953, showcased works from 1850 to $1914 .{ }^{102}$ New Zealand Listener described the first exhibition as "one of the most important of its kind to visit the country", and W.S. Baverstock (director of the Christchurch gallery) was quoted saying that it was "one of the finest exhibitions yet to come to Christchurch." 103 In view of the huge success of these two watercolour exhibitions, it is understandable that the donation of an even larger collection of British watercolours, such as Smythe's, was desirable for the potential of similar exhibitions in future, seeing that having a local collection would enable exhibitions to be generated from within New Zealand. However, it transpired that these were the last successful large-scale exhibitions of historical British watercolours in New Zealand.

Instead of looking to Britain, galleries started to look towards local artists that had been producing watercolours in New Zealand, as part of a process to identify and construct a

\footnotetext{
100 "The Art Exhibition," Star [Christchurch], Issue 538 (9 February 1870): 2.

101 "Exhibition of Paintings," New Zealand Herald LXXII, no. 22283 (4 December 1935): 15.

102 Auckland Art Gallery Toi o Tamaki, "Empire Art Loan Collections Society Archive," accessed 10 March 2020, https://www.aucklandartgallery.com/explore-art-and-ideas/archives/19628: "The Empire Art Loan Collections Society (later the Empire Art Loan Exhibitions Society) was founded by Sir Percy Sargood, then president of the Dunedin Public Art Gallery Society, in 1932. Exhibitions were brought into galleries in New Zealand, Australia and South Africa from the major public art museums in London. They proved very popular with, for example, over 100,000 visiting the inaugural exhibition, British Art 1863-1933 in Melbourne." It is further interesting to note that the 1950 exhibition was the first postwar exhibition put on by the Society.

${ }^{103}$ New Zealand Listener (5 August 1949) and Star-Sun (2 February 1950), cited in Christchurch Art Gallery Te Puna o Waiwhetu, "Early British Watercolours," accessed 10 March 2020, https://christchurchartgallery.org.nz/exhibitions/earlybritish-watercolour-exhibition.
} 
history of art in New Zealand. Among the exhibitions mounted in Auckland during the 1950s-1960s alone, there were shows on watercolourists like Albin Martin, Hoyte, Richmond, Kinder, John Gully and John Webber, as well as exhibitions like Early Watercolours of New Zealand (1963) and A Colonial View: Paintings of Early New Zealand (1958), which was in fact curated by the New Zealand contemporary artist Colin McCahon. ${ }^{104}$ Francis Pound observes that "all these exhibitions were unprecedented, at once in their very existence on the gallery walls, and in the accompanying presence of proper, if still slender, scholarly catalogues." 105 This shift participated in the nationalist project of actively exploring artistic ancestors for a new generation of New Zealand artists. The exhibiting of New Zealand watercolours is contemporary with the emergence of the first art historical accounts written in New Zealand. These histories, as will be explored in more depth in Chapter Five, celebrated these watercolours as the foundation of all subsequent New Zealand painting.

The other reason for this shift lies in the recognition of the status of early New Zealand watercolours as works of art, rather than mere documentary artefacts; they were no longer simply valued for their ethnographic, historical or topographical observations, but also for their aesthetic qualities as art. Instead of art galleries, these watercolours originally belonged to the realms of museums, libraries and archives, where they had been exhibited in lecture halls or libraries for their historical content. Rebecca Rice traces the history of collecting and exhibiting early New Zealand colonial art in such state institutions, observing that the degree to which they have been re-evaluated as art has "been partial and inconsistent." ${ }^{\prime 06}$ She explores the ways in which colonial art has been exhibited during the early twentieth century (before the opening of the NAG), concluding that "these academy exhibitions, as well as the one-person exhibitions at the [Dominion] Museum, represent the first steps taken by these institutions to select and bring to the public's attention specific artists and their works." 107 For example, in 1923 the New Zealand Academy of Fine Arts (NZAFA) held an exhibition of works by D.K. Richmond and her father J.C. Richmond, a

\footnotetext{
${ }^{104}$ Francis Pound, The Invention of New Zealand: Art and National Identity, 1930-1970 (Auckland: Auckland University Press, 2009), 341. See also Auckland City Art Gallery, Early Watercolours of New Zealand (Auckland, 1963) and Auckland City Art Gallery, A Colonial View: Paintings of Early New Zealand (Auckland: The Pelorous Press, 1958). 105 Pound, Invention, 341.

${ }^{106}$ Rebecca Rice, "The State Collections of Colonial New Zealand Art: Intertwined Histories of Collecting and Display," PhD. diss., Victoria University of Wellington, 2010, 43.

${ }^{107}$ Ibid., 237.
} 
prominent watercolourist in early New Zealand. ${ }^{108}$ Exhibition contexts certainly helped to bring New Zealand watercolours into the spotlight.

The Smythe watercolours have only been exhibited in a dedicated show once since their initial showings during the 1950s. ${ }^{109}$ In 2004, Tony Green, formerly Head of the Department of Art History, University of Auckland, curated a two-part exhibition at DPAG that looked exclusively at works from the Smythe collection. The first part, Characters: High and Low (March-May), focused on figurative works, and the second part, Home and Abroad (May-July), considered landscape subjects. In the brief publication that accompanied these exhibitions, People \& Places: $19^{\text {th }}$ Century British Drawings from the Smythe Collection (2004), Green began by highlighting the direct link between British watercolours and the New Zealand tradition which is celebrated still today:

British drawings and watercolours of the $19^{\text {th }}$ century are an important part of the inheritance of New Zealand artists. The circle of William Mathew Hodgkins was brought up on them. So was his famous daughter Frances and so were the Christchurch artists of the 1910s and 1920s. Even in the 1950s and 1960s these landscapes were still important enough as models to be the subject of critical discrimination by our modernist artists, who rejected the conventions of the atmospheric mood paintings of the school of Turner, favouring instead the barest topographical drawings and coastal profiles, in the name of truth to New Zealand reality. ${ }^{110}$

This also acknowledges that the Smythe watercolours had already become the victim of "critical discrimination" by the 1960s, due to the taste of modernist artists and critics. Instead, the more topographical approach of local artists like Kinder, Hoyte and Heaphy, was preferred, leading hence to the continued popularity of those artists in exhibitions instead of their British models.

While Green's goal was primarily to show off the good things about the Smythe collection, he did not shy away from acknowledging the negative aspects. The last section of People \& Places raises the discussion of the many doubtful attributions in the collection. It appears that Smythe did not always conduct careful and scholarly research into the authenticity and provenance of works he acquired, leaving this task for future owners. Green

\footnotetext{
108 The McDougall in Christchurch also held an exhibition entitled Three Generations: J.C. Richmond, D.K. Richmond, E.K. Atkinson from 9 May - 5 June 1967, demonstrating the continued (or renewed) interest in the artist during the 1960s. See https://christchurchartgallery.org.nz/exhibitions/three-generations-j-c-richmond-d-k-richmond-e-k-at.

${ }^{109}$ Tony Green wrote that 750 works from the Smythe collection were "crammed on to the walls of the former gallery at Logan Park" in 1978, however I could not find any other reference to this exhibition. Tony Green, People \& Places: $19^{\text {th }}$ Century British Drawings from the Smythe Collection (Dunedin: Dunedin Public Art Gallery, 2004), 6. The last mention in the DCCA is from the DPAG council minutes from 1969, which mentions that the Smythe Gallery (Gallery F) needs more attention. Council 6 March 1969, DCCA: Box 2, DPAG Series 4.

${ }^{110}$ Green, People \& Places, 1.
} 
emphasises that this mostly affects the more well-known names in the collection, such as Alexander Cozens, Turner, Cotman, Richard Parkes Bonington and David Cox, most of which have since been declared as copies (or simply wrongly attributed). ${ }^{111}$ In the end, however, Green expresses his desire for future interest in this collection, claiming "there is much to be enjoyed and it is to be hoped that this glimpse of these riches will encourage public interest in this remarkable collection." 112 However, it would seem that Green was not as successful in this goal as he might have liked. It has been seventeen years since his exhibitions, but public interest in the Smythe collection has not been reawakened.

At least in the case of the NAG, the Smythe watercolours were partly responsible for some of the gallery's later acquisitions. During the 1960s and 1970s, Sir John Ilott made numerous gifts of nineteenth-century British prints to the NAG. Some of the artists included in these gifts were Turner, Cotman, John Crome (1768-1821), Bonington, Thomas Girtin (1775-1802) and George Clausen (1852-1944), who are all also represented in Smythe's collection. Part of the reason Ilott made these purchases was the print boom which had increased the prices of prints so much that his usual choice of the Old Masters and British Etching Revivalists were out of his price range. Another reason was to fill a noticeable gap in the gallery's Early English section of its print collection. A final reason was Smythe's gift itself. In a letter to Ilott, Melvin Day (Maclennan's successor as director of the NAG) encourages him to continue with these purchases, seeing that such prints make an excellent complementary collection to the Smythe watercolours, as they "amplify the historical sequence of our Collection so richly adumbrated by the English watercolours." ${ }^{113}$ The Smythe watercolours, therefore, had a direct influence on what the gallery was accepting and hoping to acquire. Another example of this could be the work Ras-el Abiad, Coast of Syria [Fig. 59], a lithograph print made after the watercolour by David Roberts. This print was purchased in 1980, most likely to directly complement the watercolour of the same title from Smythe's gift [Fig. 4].

\footnotetext{
111 Although Green claims "work has begun to turn Smythe's list into a reliable catalogue" and that "many of the drawings have come under expert scrutiny," none of the original attributions have been changed on the DPAG's website. When looking through the collection at Te Papa, on the other hand, I found many handwritten notes about doubtful attributions on the mounts of watercolours, evidence that someone had taken the time to analyse the collection and consider attributions. As a result, many of the original Smythe attributions of the Te Papa works have been changed (for example, all the original Turner works are now listed as 'unknown' in Te Papa's database).

${ }^{112}$ Green, People \& Places, 6.

${ }^{113}$ Day to Ilott, 9 October 1969, TPA: MU00010, box 5, file 51, cited in Julianne Malpas, "An Incurable Collector: Sir John Ilott (1884-1973) and his Passion for Prints,” MA diss., Victoria University of Wellington, 2005, 88.
} 
The Smythe collection of British watercolours is the single largest collection of British watercolours in New Zealand. Green called it "certainly the richest resource of its kind in New Zealand." 114 It was built by Smythe throughout his lifetime in England, and while he attempted to give his collection primarily to British institutions in his old age, most of the works ended up being gifted to New Zealand. It comes as no surprise that the collection was warmly welcomed-with open arms, seeing that there was a strong local tradition of watercolour artists in New Zealand. Still, despite continuous support for watercolour exhibitions, within just a decade the Smythe collection became relegated to the storage rooms and ultimately almost forgotten. Two general reasons for neglecting an art collection in this manner immediately come to mind. One, the artworks in the collection are simply not good enough to merit being displayed or studied; two, the collection is outdated and does not suit the current tastes in art.

Taking a similar approach to Green, but broadening the range of works to be analysed, the next chapter will address the first of these two possibilities by closely examining the contents of the collection, in order to determine whether or not their reception and subsequent treatment was justified.

${ }^{114}$ Green, People \& Places, 1. 


\section{Chapter 3: What are the Smythe Watercolours?}

In her article "A Taste for Art in Colonial Queensland" (2018), Kerry Heckenberg explores her encounter with a neglected collection of early European paintings in the Queensland Art Gallery collections. ${ }^{1}$ The works were part of a bequest by Thomas Lodge Murray-Prior in 1892 and made up the foundation of the gallery. Heckenberg explains that despite their initial welcome, the works soon fell from favour and have not been studied in any great depth. However, her own analyses have revealed the potential of the collection:

After initial enthusiasm (since the pictures did, after all, provide the opportunity to establish a gallery), the paintings have been grudgingly admired, considered better than nothing at all but only second-rate. An examination of the paintings in the light of recent scholarship, however, will nuance this opinion, showing that they offer insights into a very interesting period in the development of European art, its collection and display. Moreover, Murray-Prior seems to have been deeply involved with his art collection. I will argue that it can provide significant insights into the history of art and its appreciation and into the nature of representation. ${ }^{2}$

There is an undeniable similarity between this and Smythe's case. As the previous chapter has exposed, after its enthusiastic reception, the status of the Smythe collection began to decline. However, my research into the contents of the Smythe watercolours will challenge the notion that it is simply a 'bad' collection; rather, given Smythe's financial limitation, it is a collection that demonstrates central tendencies in the history of watercolour, as well as aspects of Smythe's personal taste.

By closely examining the watercolours and artists in the collection, I will reveal that they are a microcosm of the history and development of British watercolours, while at the same time demonstrating the middle-brow taste of Smythe himself. Despite Smythe's obvious interest in some unconventional subject matters, the majority of the works indicates a rather traditional preference for the old masters' scenic landscapes. However, there are also numerous other subjects and lesser-known watercolourists that are worth consideration, as they help to survey the art historical development of the medium, while also challenging the notion that the 'Golden Age' of watercolour ended around the middle of the nineteenth century.

\footnotetext{
${ }^{1}$ Kerry Heckenberg, "A Taste for Art in Colonial Queensland: The Queensland Art Gallery Foundational Bequest of Thomas Lodge Murray-Prior," Queensland Review 25, no. 1 (2018).

${ }^{2}$ Ibid., 120.
} 


\section{THE SUBJECTS}

Traditional histories of British watercolours have focused primarily on the dominance of landscapes produced during the Golden Age (c. 1750-1850). However, Greg Smith emphasises the importance of acknowledging and celebrating a wider range of genres:

History painting and landscape may have played a key role in establishing the watercolour as an innovatory and prestigious commodity, but we must not ignore the part played by specialists in other genres. This is particularly important because of the way in which watercolour histories have tended to concentrate on a few canonical landscape artists, ignoring in the process many of those who were identified in the early nineteenth century archive as key players in the profession's development. Exhibition reviews, in particular, reveal the degree to which the growing status of the profession and its ability to generate a market depended on the development of a wide range of new subject areas, and it was this which created a positive collective image for practitioners, just as much as formal changes associated with individual artists. ${ }^{3}$

The market clearly desired more than just landscapes. The presumption that landscape is the purest way to use watercolour, especially to represent ephemeral aspects of the visible world, is too narrow and does not encompass the whole history of the medium. ${ }^{4}$ The Smythe watercolours prove this contention. They can be sorted into four main subject categories: landscape, figure, animal, and architecture. This range of subject matter allows this single collection to demonstrate major components and characteristics of the British watercolour tradition.

The subjects in the Smythe collection also reveal the collector's taste. While Smythe's financial limitations certainly played a role in what he was collecting, his evident interest in sentimental figure and animal subjects also exposes his middle-brow taste, typical of the late-Victorian and Edwardian eras. This was potentially part of the reason his collection fell out of favour during the twentieth century.

\section{Landscapes}

Landscape is the best-represented genre in the Smythe collection. Early landscapes were typically produced as records of particular places. Careful observation formed the basis of these landscapes, leading to an exact rendering with scientific accuracy - in other words,

\footnotetext{
${ }^{3}$ Greg Smith, The Emergence of the Professional Watercolourist (Aldershot: Ashgate Publishing, 2002), 142.

${ }^{4}$ See Alison Smith ed., Watercolour (London: Tate Publishing, 2011), 9-10.
} 
topography. ${ }^{5}$ It was this association with topography that later became a significant factor in the downgrading of watercolourists, amid the claim that they were more like draughtsmen than artists. ${ }^{6}$ Yet it was out of this topographical branch that landscape truly started to blossom as a subject for art. A topographical landscape could be either a highly detailed terrain with buildings, mountains, or water - effectively, a three-dimensional map - or it could focus on just one architectural structure set within generalised surroundings. ${ }^{7}$ During the eighteenth and early-nineteenth centuries, topography was extremely popular and made up a large part of the watercolourists' output. Lindsay Stainton identifies two of the main factors for topography's popularity: the British love for travel and their concern with private property. ${ }^{8}$

This concern with property was visualised in the sought-after estate portraits that became popular from the seventeenth century onwards. Graham Reynolds calls the British "the most narcissistic of races", since they "wanted views of their houses as well as of themselves and their horses." "John Bonehill and Stephen Daniels further link this 'narcissistic' fascination with painting one's property as a kind of portrait that reflected the aspirations of the nation:

In a nation where the estate was the basis of political power and social prestige, their art recorded landed property and its improvements, in varied and sometimes culturally complex views which included natural wonders and antiquities, and scenes of agriculture, industry and commerce, as well as parks, gardens and mansions. With the growing popularity of touring among all ranks of polite society, estate portraits projected public prospects as well as private views, a picture of the country, the nation, at large. ${ }^{10}$

Indeed, a review of the 1767 exhibition of the Society of Artists at Spring Gardens, which displayed a variety of named places and estate activities, suggested that the domestic

\footnotetext{
${ }^{5}$ Topography is a genre that grew out of the more scientific descriptions and mappings of land features (both natural and manmade). In art, it faithfully and exactly depicts an identifiable location, often including buildings in a rural or urban setting, or a panorama of a town or city. See Robert W. Brown, "Topography," Grove Art Online, 2003, accessed 16 August 2020, https://www-oxfordartonline-

com.helicon.vuw.ac.nz/groveart/view/10.1093/gao/9781884446054.001.0001/oao-9781884446054-e7000085610?rskey=MC5tqd\#oao-9781884446054-e-7000085610-div1-7000085611. For additional reading, see M. Warner, The Image of London: Views by Travellers and Emigrés, 1550-1920 (London: Barbican A.G., 1987); J. Links, Townscape Painting and Drawing (London, 1972); Charles Eldredge, Pacific Parallels: Artists and the Landscape in New Zealand (Washington: New Zealand-United States Arts Foundation, 1991).

${ }^{6}$ Ann Payne, Views of the Past: Topographical Drawings in the British Library (London: The British Library, 1987$), 9$.

${ }^{7}$ Lindsay Stainton, British Landscape Watercolours 1600-1860 (London: British Museum Publications, 1985), 10.

${ }^{8}$ Ibid.

${ }^{9}$ Graham Reynolds, A Concise History of Watercolours (New York and Toronto: Oxford University Press, 1978), 50.

${ }^{10}$ John Bonehill and Stephen Daniels, "'Real Views from Nature in this Country': Paul Sandby, Estate Portraiture and British Landscape Art,” British Art Journal 10, no. 1 (2009): 72.
} 
landscapes on show outshone those of "foreign climes" and "rival haughty Rome; nay, rival Greece." $" 11$

Thomas and Paul Sandby (1721-1798 and 1731-1809), who were represented in that exhibition, became the first watercolourists to make a name for themselves with estate portraiture. ${ }^{12}$ Thomas Sandby's Earl of Fortescue's Grounds, Castle Hill (c. late 1780s-90s, DPAG) [Fig. 2] demonstrates some of the major aspects of this trend. ${ }^{13}$ Castle Hill in Filleigh, Devon, was commissioned in the Palladian style in 1730 by Hugh Fortescue (16961751), with the sham castle on top of the hill behind the mansion being added in 1746 . The architectural element has been reduced to the tiled stone floor and the outline of a massive arched window, acting as a mere frame for the figures and the vast landscape they are admiring. ${ }^{14}$ While Sandby still pays some attention to the texture of the Portland stone walls, details have been suppressed, along with the colour palette, corresponding to his later works, which Luke Herrmann described as "characterized by their loose drawing and their pale colouring." $" 15$ The only vibrant colour in the painting is the red frock coat of the man maybe the Earl himself - who is stretching out his arm and literally presenting the estate grounds to a woman and young boy. We are invited to admire with them, as opposed to admiring them. The view is from within the cupola on top of the main building, hence the high vantage point. This is a rather odd viewpoint, and most other pictures of Castle Hill have been taken from the other direction, looking at the great mansion itself. ${ }^{16}$ In this way, Sandby places our entire focus on the landscape itself: an immaculately kept park, a small river and rolling hills in the distance that are partly covered with lines of trees and a pathway leading to a Triumphal Arch. ${ }^{17}$ The property - indeed nature, or Britain itself - in this view is peaceful and controlled.

\footnotetext{
${ }^{11}$ Cited in Bonehill and Daniels, "Real Views from Nature in this Country," 73.

${ }^{12}$ Examples of their influential series include Views in Scotland (1752), Views of Windsor Great Park (1754-58) or Views in Wales (1775-77). See Bonehill and Daniels, "Real Views from Nature in this Country"; Ann Gunn, "Fidelity and Elegance: The Aquatint Landscapes of Paul Sandby (1731-1809)," The British Library (31 March 2017), accessed 13 February 2018, https://www.bl.uk/picturing-places/articles/the-aquatint-landscapes-of-paul-sandby-1731-1809-fidelity-andelegance; Helen Wyld, "Re-Framing Britain's Past: Paul Sandby and the Picturesque Tour of Scotland," The British Art Journal 12, no. 1 (Summer 2011): 29-36.

${ }^{13}$ Another good example from the Smythe watercolours is John Chesrel Buckler's Home of Sir Peter Leycester Bt., Tabley, Cheshire in Dunedin (19-1958).

${ }^{14}$ The window is indeed giant, much bigger than the original window. This could be a deliberate disproportion to stir associations of the antique in the viewer, comparing the Earl's mansion to the massive temples of ancient Rome.

${ }^{15}$ Luke Herrmann, Paul and Thomas Sandby (London: B.T. Batsford , 1986), 53.

${ }^{16}$ For example, see Castle-Hill, Near South Molton engraved by T. Dixon after a picture by T. Allom, published in Devon \& Cornwall Illustrated (London: H. Fisher, R. Fisher and Jackson, 1832).

17 The layout of the grounds can be clearly seen in the site map of the gardens: http://www.castlehilldevon.co.uk/images/castle-hill-gardens-2017.pdf. This also confirms the location of the artist/viewer in the watercolour, with the sun rising in the East, which - considering the shadows in the picture - means this scene is taking place in the morning.
} 
It was Thomas' brother, Paul Sandby, who successfully combined this fashion for estate portraiture with the British love for travel, which expanded to the British countryside for the first time during the eighteenth century. In fact, the term 'tourist', describing a person travelling for pleasure to places for their objects of interest and scenery, was coined in England at the end of the eighteenth century due to this popular demand for travel and access to 'nature'. As Samuel Pegge wrote in Anecdotes of the English Language (1814), "A Traveller is now-a-days called a Tour-ist."18 Bonehill and Daniels emphasise that Paul Sandby was one of the first artists to look to Britain itself, opening up the landscape at a time when the country was being reshaped and transformed by the conflicting forces of agriculture and war. ${ }^{19}$ Sandby published his watercolours of British estates and crown property, which helped to contribute to this growing interest in the British landscape and encouraged tourism to these national destinations. ${ }^{20}$

The naturalist, antiquarian and travel writer Thomas Pennant promoted Sandby's Views in Wales in his own publication Tour of Wales (1778), encouraging travellers to take a copy of these illustrations with them on their journey, and claiming that "those that wish to anticipate the views in the intended progress may satisfy themselves by the purchase of the late publications of the admirable Mr. PAUL SANDBY, in whose labours fidelity and elegance are united." 21 Sandby's Carnarvon Castle (c. 1771, Dunedin) [Fig. 3], which was also published in print, shows Edward I's castle in Northern Wales, an impressive architectural feat. Construction on the castle began in 1283 and the building was intended as a seat of power "and as a symbol of English dominance over the subdued Welsh.", 22 By 1770, when Sandby travelled to the North of Wales, it had become part of the scenic Welsh landscape, a site to visit and admire in awe. In the watercolour it is viewed from the opposite shore, with ships on the water surrounding it; there is a mountain in the distance on the left, partly hidden by a picturesque tree placed elegantly on the shore. There is also a group of figures in the foreground: a woman and child talk leisurely to a man who is carrying a bundle, while another man leads a laden horse-drawn cart on the left. The figures represent

\footnotetext{
${ }^{18}$ Samuel Pegge, Anecdotes of the English Language: Chiefly Regarding the Local Dialect of London and its Environs, $2^{\text {nd }}$ ed. (London: J. Nichols, Son, and Bentley, 1814), 313.

${ }^{19}$ John Bonehill and Stephen Daniels eds., Paul Sandby: Picturing Britain (London: Royal Academy of Arts, 2009$), 13$. The authors go on to say that, with little pictorial precedent, Sandby had to experiment with a range of compositional setups to accommodate the unexplored landscape, particularly the mountains in Northern Wales.

${ }^{20}$ Ann Gunn, "Fidelity and Elegance."

${ }^{21}$ Thomas Pennant, Tours in Wales, 3 vols. (London: 1778), cited in Gunn, "Fidelity and Elegance."

${ }^{22}$ Daniel Mersey, "Caernarvon Castle - Fit for a Prince," accessed 13 February 2018, http://www.castlewales.com/caernarf.html.
} 
both work and leisure, two aspects of the Northern Welsh landscape which Sandby himself described as "that fertile and Romantick Country." 23

This rise of local tourism did not mean that the British love for overseas travel was abandoned; on the contrary, during this time many British expeditions abroad were undertaken, and some artists even lived in exotic countries for many years at a time. Carl Thompson explains that watercolours of foreign landscapes were similar to British ones in that they represented beautiful, calm scenes - topographical, yet also altered to hide some of the less pleasing realities:

As in the domestic context, the circulation of these prints and paintings helped breed a new global consciousness, making the British familiar with the furthest reaches of their empire. Filtered through the norms of picturesque beauty, the wider world and the very different environments it contained became less alien and threatening. As at home, the beautiful landscapes presented often masked the power relations of the colonial system, erasing any marks of suffering, struggle or discontent. ${ }^{24}$

David Roberts (1796-1864) was one of those traveling artists, residing in Egypt and Palestine in 1838-40, and visiting Spain, Tangier, and Italy. During these tours he produced numerous watercolours which he then turned into published series of lithographs that won him wide popularity and a considerable fortune. ${ }^{25}$ One of these watercolours is Ras-ElAbiad, Coast of Syria (1839, Te Papa) [Fig. 4], which shows an impressive coastline with surging water. There is also a group of travelling figures on the right side, and a small flock of birds on the bottom rock in the centre. Both people and animals are dwarfed by the landscape. There is no indication that Syria would soon become the main stage for the brewing Second Egyptian-Ottoman War (1838-41), in which Britain was about to take part. $^{26}$

Therefore, while still topographical in nature, this work is also idealised. One of the earliest descriptions of this practice of idealisation can be found in Tour of the Lakes (1808) by William Gilpin (1724-1804):

He who works from imagination - that is, he who culls from nature the most beautiful of her productions - a distance here; and there a foreground-combines them artificially; and removing everything offensive, admits only such parts, as are

\footnotetext{
${ }^{23}$ Paul Sandby cited in Gunn, "Fidelity and Elegance."

${ }^{24}$ Carl Thompson, "The Picturesque at Home and Abroad," The British Library, accessed 13 February 2018, https://www.bl.uk/picturing-places/articles/the-picturesque-at-home-and-abroad.

${ }^{25}$ H.L. Mallalieu, The Dictionary of British Watercolour Artists up to 1920: Volume I-The Text, $2^{\text {nd }}$ ed. (Suffolk: Antique Collectors' Club, 1986), 290.

${ }^{26}$ For more on the Second Egyptian-Ottoman War (also called Second Turko-Egyptian War or the Syrian War) see John D. Grainger, The Syrian Wars (Leiden and Boston: Brill, 2010).
} 
congruous; and beautiful; will in all probability, make a much better landscape than he who takes it all as it comes. ${ }^{27}$

By focusing on the artful composition of landscape, and eliminating any distracting or unpleasant features, Gilpin and his followers used their imagination to turn away from topography and naturalism. Instead, their landscape watercolours highlighted notions of beauty, the sublime, poetry, and the power of association. Alongside Gilpin, other writers such as Uvedale Price, Richard Payne Knight, Archibald Alison and Edmund Burke helped to spread these ideas. As Jane Bayard writes in her doctoral thesis, "From Drawing to Painting: The Exhibition Watercolor 1770-1870" (1982), "aesthetic reaction, imagination, and emotion became integral elements in the depiction of landscape, and the art of watercolour was transformed." 28

One such transformation occurred when Edmund Burke (1730-1792) introduced the emotions of the sublime and the beautiful and expounded his theories on how to distinguish between the two. Burke was a political philosopher, born in Dublin. ${ }^{29}$ His Philosophical Enquiry into the Origin of Our Ideas of the Sublime and Beautiful (1757) argues that the sublime can only be reached through intense feelings of pain and terror, standing in direct opposition to his ideas of beauty:

sublime objects are vast in their dimensions, beautiful ones comparatively small; beauty should be smooth, and polished; the great, rugged and negligent; beauty should shun the right line, yet deviate from it insensibly; the great in many cases loves the right line, and when it deviates, it often makes a strong deviation; beauty should not be obscure; the great ought to be dark and gloomy; beauty should be light and delicate; the great ought to be solid, and even massive. They are indeed ideas of a very different nature, one being founded on pain, the other on pleasure. ${ }^{30}$

Burke further links these two concepts directly to the imagination, claiming that our imagination is the driving force behind our feelings of fear (sublime) and hope (beauty). Therefore, by ignoring fact and detail, a landscape could possess emotional significance by employing the expressive visual language of the sublime or the beautiful, and evoke an imaginative response from the viewer. ${ }^{31}$ Some of the ways in which artists achieved this was through a sense of "vast scale, startling contrasts of light and dark, sharp oppositions of

\footnotetext{
${ }^{27}$ Cited in Jane Bayard, Works of Splendor and Imagination: The Exhibition Watercolor, 1770-1870 (New Haven: Yale Center for British Art, 1981), 3.

${ }^{28}$ Jane Bayard, "From Drawing to Painting: The Exhibition Watercolor 1770-1870," PhD diss., Yale University, 1982, 7-8.

${ }^{29}$ For more information on Burke, see David Dwan and Christopher J. Insole eds., The Cambridge Companion to Edmund Burke (Cambridge; New York: Cambridge University Press, 2012).

${ }^{30}$ Edmund Burke, Philosophical Enquiry into the Origin of Our Ideas of the Sublime and Beautiful, $5^{\text {th }}$ ed. (London: J. Dodsley, 1767), 237-238.

${ }^{31}$ Bayard, "From Drawing to Painting," 10.
} 
vertical and horizontal lines, and deep, somber colors." 32 This kind of Burkean atmospheric landscape can be seen in Richard Wilson's (1714-1782) Cwm Du, Near Tritower (DPAG)

[Fig. 5], showing the small Welsh town amidst the hills. This is not a welcoming landscape inviting tourists to admire its beauty, but instead it is dark, gloomy, melancholic, scary, and intimidating. Though it is a real location, the blurred shapes and murky colours make it look like a scene from a dream - or rather, a nightmare.

Sandra Johnson Jordan explains that early representatives of this style used natural features like storms, avalanches or volcanic eruptions to further achieve this goal. ${ }^{33}$ Anthony Vandyke Copley Fielding's (1787-1855) Fishing Boats in Rough Seas (Dunedin) [Fig. 6] pictures a storm to create just such a dramatic scene, the dark sky and wild waves on the right-hand side threatening to swallow up the rest of the scene in a Turneresque manner. Similarly, Joseph Barber (1757-1811) added several different elements to produce a grand view in Mountain Torrent (1829, Wellington) [Fig. 7]. On the left-hand side a group of travellers has settled down with a campfire, seemingly unconcerned by the raging torrent. This has obviously had devastating effects already, as can be seen on the far bank, where several trees have snapped under the force of the water. More water cascades down the mountains, and the perspective used in the centre of the painting, where the mountains are shimmering in a pale blue haze, almost makes it look as though they themselves are turning into the stream of water. The scale and precipitous rendering of the mountains further adds to the high drama of the scene in which nature's powers and beauties are combined.

In addition to the sublime and the beautiful, Gilpin added a third type of visual experience, which he called 'picturesque beauty'. Essentially, this described something that was pleasing to the eye - "that kind of beauty which would look well in a picture." 34 What differentiated it from other types of beauty was the element of roughness. ${ }^{35}$ As Bayard points out, Uvedale Price (1747-1829) further linked this 'roughness' to the historical significance of the picturesque, claiming that "broken tints" and "rugged outlines" suggest the passing of time and therefore appeal to the viewers' historical imagination and

\footnotetext{
32 Bayard, "From Drawing to Painting," 10.

${ }^{33}$ Sandra Johnson Jordan, "The Life and Art of John Webber, R.A.; and his Relationship to the Watercolor and Picturesque Movements in Eighteenth Century England," PhD diss., University of Georgia, 1991, 77.

${ }^{34}$ William Gilpin, Observations on the Western Parts of England Relative Chiefly to Picturesque Beauty, ${ }^{\text {nd }}$ ed. (London: T. Cadell and W. Davies, 1808), 328.

${ }^{35}$ William Gilpin was an artist, clergyman, schoolmaster and writer, most famous for originating the idea of the Picturesque. For more information, see Christine Clearkin, "The Revd William Gilpin (1724-1804): Artist and Man of his Age," British Art Journal 19, no. 1 (2008): 76(8); Stephen Bending, "Vile Things: William Gilpin and the Properties of the Picturesque," Huntington Library Quarterly 80, no. 4 (Winter 2017): 585-607; Zoë Kinsley, "William Gilpin at the Coast: A New Perspective on Picturesque Travel Writing," The Review of English Studies 68, no. 284 (2017): 322-341.
} 
associations. ${ }^{36}$ Thomas Sandby's Earl of Fortescue's Grounds, Castle Hill illustrates some of these features, as the short wall has rough outlines and looks old, worn out and spotty. The arched window framing the scene further spurs the historical imagination by recalling ancient temples in Greece or Rome. This is partly due to its monumental size, which Sandby exaggerated on purpose.

While an element of idealisation still remains, the naturalistic aesthetic dominated landscape painting in Britain during most of the nineteenth century. Watercolour was believed to be particularly well suited to depict naturally occurring phenomena. The translucent quality of watercolour enabled the artist to successfully render subtle changes in atmosphere and light, producing more natural renditions of distance and weather conditions in landscapes than was possible in oil painting. An example of the naturalistic aesthetic is Henry Hine's (1811-1895) Landscape, Sussex (Te Papa) [Fig. 8], in which the artist successfully portrays distance and atmosphere at the same time. The hills and windmills in the distance almost look transparent, giving the viewer the impression that this vast farmland is endless. The sky has a beautiful range of colours that blend imperceptibly into one another, and the clouds are illuminated by natural light.

Another way in which watercolourists used the medium to enhance the naturalism of their paintings was to eliminate outline altogether and instead focus on colour washes. As early as 1791, the German-born watercolourist, drawing master and musician, John Baptist Malchair (1730-1812), observed in his unpublished drawing manual that "natural objects have, strictly speaking, no outline and may be imitated without the help of lines in painting." ${ }^{37}$ William Henry Pyne (1769-1843) stated that Sandby's work, which he otherwise admired, suffered from one fatal flaw, namely "his adherence to a penned outline ... a custom that is entirely at variance with nature." 38 One of the first artists to apply this to watercolour was John R. Cozens (1752-1797). Bayard observes that “Cozens's innovation was modelling with color rather than with line.... This advance in technique from a linear style to a tonal one eventually led, by way of the Monro school, to painting in watercolour as

\footnotetext{
${ }^{36}$ Bayard, Works of Splendor, 4. Like Gilpin, Price's theories revealed that the Picturesque is a visual property of landscape just like Burke's Sublime and Beautiful. However, unlike Gilpin, Price believed that the Picturesque could be artificially designed. For Price's writing on the subject, see Uvedale Price, An Essay on the Picturesque, as Compared with the Sublime and the Beautiful; and, on the Use of Studying Pictures, for the Purpose of Improving Real Landscape (London: J. Robson, 1794). For more information on Price, see Charles Watkins and Ben Cowell, Uvedale Price (1747-1829): Decoding the Picturesque (Woodbridge: Boydell Press, 2012).

${ }^{37}$ Malchair cited in Peter Bicknell and Jane Munro, Gilpin to Ruskin: Drawing Masters and their Manuals, $1800-1860$ (Cambridge: Fitzwilliam Museum, 1987), 25.

${ }^{38}$ William Pyne cited in Smith, Emergence of the Professional, 59.
} 
opposed to mere drawing." 39 Indeed, the wash drawing Hilly Landscape (Te Papa) [Fig. 9], attributed to Cozens, shows no visible pencil lines, just like Hine's work. ${ }^{40}$ In both cases, the hilly landscapes are completely modelled through colour and washes.

\section{Marines}

The biggest subcategory of the landscape genre in the Smythe collection is marine painting, which also carried specifically strong national sentiments for Britain. In 1881, a critic discussing works displayed in The Sea Exhibition by the Fine Art Society observed that "such works must ever have a peculiar charm for Englishmen; they wake a thousand happy memories. They touch the key-note of the old Viking spirit and impulse, which is in the blood of most of us, and is emphatically a part of our birthright." ${ }^{41}$ Additionally, it creates a visual link to the British Empire, which was built on naval superiority. Art Historian Christiana Payne, while acknowledging that Britain's status as an island nation does explain a close bond to the sea, provides new insights into this British fascination:

In addition to the patriotic significance of the sea and coast, there are important implications for the histories of science, religion, charity, and technology. Discoveries made on the coast played a crucial role in debates over evolution; the development of the lifeboat introduced a more modern note to charitable giving, hitherto dominated by paternalism, and the availability of good light at the seaside gave it a vital role in the early development of photography. ${ }^{42}$

As naval historian David Cordingly highlights, one should not forget that the nineteenth century "witnessed the transition from sail to steam and from timber to steel, that saw the abandonment of traditional methods of shipbuilding and experienced a boom in the shipping industry." 43 Additionally, it was a period of mass migration that saw lives being put in danger during travels to new colonies, like New Zealand.

\footnotetext{
${ }^{39}$ Bayard, Works of Splendor, 16. The Monro school is a reference to Thomas Monro (1759-1833), a British physician, art collector, patron and amateur artist. He held regular night gatherings at his private home, thereafter known as Dr. Monro's 'Academy', inviting other artists (including Girtin, Turner, Cotman, and De Wint) to study his collection of watercolours, which involved making copies of Cozens' works. He had been close to Cozens and took care of him after the artist became mentally unwell. For an exhibition review, see Andrew Wilton, "Dr. Thomas Monro and the Monro Academy," The Burlington Magazine 118, no. 878 (1976): 332-333. The Monro 'Academy' inspired other similar private art sessions, such as Girtin's Sketching Club (1799-1800), see David Winter, “Girtin's Sketching Club,” Huntington Library Quarterly 37, no. 2 (1974): 123-149.

${ }^{40}$ The only other work attributed to J.R. Cozens is a chalk drawing at DPAG, Landscape with Bridge (391-195X). Dunedin also holds two pen and wash works by Alexander Cozens (62-195X and 392-195X).

${ }^{41}$ Art Journal (January 1882): 30, cited in Christiana Payne, Where the Sea Meets the Land: Artists on the Coast in

Nineteenth-Century Britain (Bristol: Sansom \& Company, 2007), 14.

${ }^{42}$ Payne, Where the Sea Meets the Land, 14-15.

${ }^{43}$ David Cordingly, Marine Painting in England 1700-1900 (London: Studio Vista, 1974), 135.
} 
In 1859, marine painter J.W. Carmichael described marine painting as the most physically laborious of all the arts, "for the wilder moods of the sea refuse to be painted by any, save by those who, for truth's sake, will, afloat, encounter the storm, and watch night and day the relations between the sky and the sea." 44 Indeed, in addition to skills in draughtsmanship, composition and paint handling, marine artists needed further specialised knowledge of the sea. Cordingly elaborates on this knowledge:

A marine artist must have some understanding of tides and currents. He must be able to show the difference between wind action on shallow estuary waters, and on the deeper waters of the Channel. He must be able to portray waves breaking on a gently shelving beach and waves pounding on outcrops of rock. He must be able to paint reflections on the surface of calm water, or depict the violence of a gale in the Bay of Biscay. ${ }^{45}$

However, this was still not sufficient. To be a successful marine painter, one also needed expert familiarity with ships themselves, including rig and hull construction, flags, naval uniforms, and the way different shaped vessels sit in the water. ${ }^{46}$ This is why artists often kept ship models in their studios. According to Cordingly, John Sell Cotman (1782-1842) "had a collection of ship models among his possessions when he sold up the contents of his Norwich House in 1834." ${ }^{47}$ Cotman also owned a small sailing boat himself, the Jessie, and often sailed along the east coast and Thames Estuary.

One of the earliest marine watercolourists represented in the Smythe collection is Samuel Atkins (1760-1808), whose characteristically delicate precision can be seen in Shipwreck (DPAG) [Fig. 10]. The vessels are painted with such exactness that each line is clearly visible. Atkins had acquired first-hand knowledge, having been at sea during the 1790s, visiting the West Indies and China. But Cordingly criticises Atkins' work for focusing too much on the depiction of ships, claiming "it is the technical accuracy of his shipping which is the chief delight of Atkins' work because his rendering of both calm water and rough sea tends to be conventional in the extreme." 48 As realistic as the ships are, the surface of the sea in Shipwreck seems stylised, the waves too smooth and controlled to really be causing a shipwreck. Compare this to the rough seas in George Chambers' (1803-1840)

\footnotetext{
44 J.W. Carmichael, The Art of Marine Painting in Water-Colours (London: Winsor and Newton, 1859$)$ ), 5.

${ }^{45}$ Cordingly, Marine Painting, 12.

46 Ibid., 11-12.

${ }^{47}$ Ibid., 14. There are two marine watercolours attributed to Cotman among the Smythe works: Boat on Shore (DPAG, 377-195X) and Off the French Coast (Te Papa, 1957-0009-61). The latter is in rather poor condition, with glue damage and rips along the edges, and some noticeable foxing. In contrast to the marine watercolours discussed here, Cotman's examples are more serene with calm waters.

${ }^{48}$ Cordingly, Marine Painting, 94.
} 
Fishing Boats (DPAG) [Fig. 11], or William Knell's (1801-1875) Marine (Te Papa) [Fig. 12], and The Squall (DPAG, 233-195X). Chambers spent most of his childhood and adolescent years on boats, a situation which undoubtedly added authenticity to his artworks. This can be seen in the realistic depiction here of a range of different fishing boats swinging dangerously on the waves. ${ }^{49}$ Knell's works are much more focused on the water, using a palpable scratching out technique to create intense white highlights where the sea foams menacingly around the vessels. This technique required very thick, sturdy paper, while the introduction of white body colour in 1834 also enabled artists to create similar effects on thin, dark paper. ${ }^{50}$

Marine painting specialists usually worked on commission for merchant seamen or naval officers, producing works such as ship portraits or sea battles. By the eighteenth century, however, other artists too turned to the sea and found a market among a clientele who had no professional interest in ships, but rather in the visual beauty of the sea. ${ }^{51}$ In fact, Cordingly argues that the "greatest contribution of this generation of sea painters was not the accuracy of their rendering of ships, however, but their portrayal of atmospheric effects." ${ }^{2}$ One of the most common atmospheric effects to be explored in watercolour was sunrise and sunset, as in Richard Parkes Bonington's (1802-1828) Harbour at Sunset (Te Papa) [Fig. 13]. According to Oliver Warner, Bonington's marine pictures “are less studied than his work in other fields. They are quieter, and obviously painted for his own pleasure." 53 This work, too, exudes an air of stillness and calm, with no visible movement on the water's surface, which instead reflects the colours of the sky. The setting sun's rays are just strong enough to cast a faint ray of light on the sea, while at the same time illuminating the clouds in a shimmer of gold from below. ${ }^{54}$

Other marine examples explored atmospheric effects completely devoid of the sun, such as James Holland's (1799-1870) Sea-Fog Rising (DPAG) [Fig. 14], where most of the painting appears white or grey, with minimal colour in the foreground where the fog has not yet reached. This was one of the most dangerous weather conditions for seafarers to be in, and Holland accurately depicted the limited visibility through very thin layers of wash. Another dark sky can be seen in David Cox’s (1783-1859) Figures on Beach, North Wales

\footnotetext{
${ }^{49}$ In New Zealand there was also in interest in the sea, given that the only way to get there was via treacherous sea voyages. See David Jonhson, New Zealand's Maritime Heritage (Auckland: Collins in association with David Bateman, 1987).

${ }^{50}$ See, for example, Walter Crane's Coastal Scene (Te Papa, 1957-0009-70), also from the Smythe collection.

${ }^{51}$ Cordingly, Marine Painting, 96.

52 Ibid., 113.

${ }^{53}$ Oliver Warner, An Introduction to British Marine Painting (London: B.T. Batsford, 1948), 27.

${ }^{54}$ This work was loaned to the National Gallery of Australia for the exhibition Monet: Impression Sunrise (7 June - 1 September 2019). See https://nga.gov.au/impressionsunrise/ (accessed 20 July 2020).
} 
(DPAG) [Fig. 15], in which the texture of the rough paper adds to the atmospheric effect of the stormy clouds. ${ }^{55}$ Rhyl, a place in Wales that Cox had depicted in several other watercolours of the same style, was considered a resort of sorts. ${ }^{56}$ People from the cities flocked to enjoy the apparently-healthy sea breezes and the exhilarating thrill of the strong winds. ${ }^{57}$ The feeling of cold, wet wind is enhanced by the knowledge that Cox produced this work en plein air, indicated by the wet-on-wet approach of colour application. While there is a small boat on the distant horizon, it is now merely used as a decorative device. Instead, the sea is viewed from a different perspective; that of the beach-goers. They are not venturing on ships to the mercy of the sea, but are instead walking along the shore, watching, listening and feeling its might from a safe distance. The placement of such figures, therefore, can be essential in conveying the atmospheric conditions of a seascape.

\section{Figure Subjects}

Aaron Penley wrote in 1850 that "human Figures are, without doubt, of primary importance, as they often make the real subject of the picture. They require to be so placed that the composition may be assisted, as well as enriched, by their presence." ${ }^{15}$ Still, according to Greg Smith, one of the major omissions from watercolour histories is that of figure subjects, particularly the profitable production of portraitists and miniaturists, and figurative artists specialising in historical and genre subjects. ${ }^{59}$ Part of the reason for this is that the traditional focus on the 'Golden Age' limits research to those subjects which were primarily produced between 1750 and 1850. Katherine Coombs acknowledges that figure subjects only made up 20 percent of the 275 watercolours displayed at the first exhibition of the Society of Painters in Water-Colours (SPW) in $1805 .{ }^{60}$ Jane Bayard agrees that figure painting played a small role in the first 25 years of the SPW exhibitions, claiming that John Francis Rigaud (17421810) was the only member who worked entirely with historical figure subjects at that time. $^{61}$

This is because the Golden Age focused on developing and perfecting the techniques of the watercolour medium, believed to be naturally suited to the characteristics of the

\footnotetext{
${ }^{55}$ Mallalieu, Dictionary, 91. Cox was famous for using rough paper, which eventually came to be known as 'Cox Paper.'

${ }^{56}$ See for example Rhyl Sands, c. 1850, Victoria \& Albert Museum (P.30-1930).

${ }^{57}$ Payne, Where the Sea Meets the Land,102.

${ }^{58}$ Aaron Penley, A System of Water-Colour Painting (London: Winsor and Newton, 1850), 53.

${ }^{59}$ Smith, Emergence of the Professional, 1.

${ }^{60}$ Katherine Coombs, British Watercolours 1750-1950 (London: V\&A Publishing, 2012), 87. Compare this to the $27.5 \%$ or 417 works of figure subjects (most of them are sketched portraits or caricature designs) in the Smythe collection, and the $44.9 \%$ or 681 works of landscapes (not including marines, cityscapes, or architecture). These two categories are the best represented in the collection, further demonstrating Smythe's strong liking for figure subjects.

${ }^{61}$ Bayard, Works of Splendor, 9.
} 
landscape genre, rather than to those of figure painting. As British poet and critic William Cosmo Monkhouse (1840-1901) noted in 1897:

The peculiar qualities of water-colour upon paper - the superior luminousness of ground and transparency of pigment, the absorbent character of paper which favours perfect fusion of tint, the surface which can be altered almost at will by skilful manipulation so that numberless varieties of texture can be obtained - all these are favourable for the rendering of atmospheric effects, so subtle and complicated that oil can only approach them with difficulty, and with a sacrifice of its special qualities. In figure-painting these properties of water-colour are not of the same relative value. Force, solidity, and precision, are of the first importance in figurepainting. ${ }^{62}$

However, those artists who did choose to portray figure compositions demonstrated that watercolour was capable of portraying this force, solidity and precision, while at the same time providing an alternative to this manner of depiction by treating figures with the same subtlety and delicacy as they would landscapes. Once the method of watercolour landscape painting had been effectively applied to figures, the artists of the Victorian era had more liberty in producing figure subjects and narratives.

Watercolour portraits have their roots in a much older art form: miniatures, or limnings. Miniatures - themselves a result of combining illuminated manuscript techniques with the concept of antique portrait medals - first emerged as small portraits in watercolour during the $1520 \mathrm{~s}$, when they were originally painted on vellum. While the generally small scale of miniatures indicates an intimate experience, David Piper further explains that "small enough to be held in the palm of the hand, they could be private; they might be displayed publicly, worn on a long chain, or even, as Elizabeth wore Cecil, on a shoe; but they might also be worn under the dress, over the heart or kept close in a lidded locket." ${ }^{93}$ Miniatures could thus be private and public at the same time, but they were always personal.

Diana Beauclerk's (1734-1808) Study for a Miniature (DPAG) [Fig. 16] shows the great skill required to produce a detailed likeness on such a small scale. With a surface of only $95 \times 75 \mathrm{~mm}$, the artist depicted a young woman in elaborate robes, hair and body embellished with pearls. She is surrounded by a garden, holding yellow flowers in one hand and touching the leaves of a flowering tree on the right side. There is a lot of movement and detail in this small watercolour, executed using very delicate short strokes. A simpler

${ }^{62}$ Cosmo Monkhouse, The Earlier English Water-Colour Painters, $2^{\text {nd }}$ ed. (London: Seeley and Co., 1897), 29.
${ }^{63}$ David Piper, The English Face (London: Thames and Hudson, 1957), 75. 
example is John Downman's (1750-1824) Profile of a Lady with a Black Choker (1781, DPAG) [Fig. 17], where the woman is shown motionless in a portrait pose, with a blank background. H.L. Mallalieu calls Downman "perhaps the most important watercolour portraitist of the late eighteenth century" and continues with an informative description of his portraits:

The most characteristic of his portraits are small ovals, although he occasionally worked on a much larger scale. His works (and his sitters) are pretty and delicate, usually done in light watercolour over black chalk or charcoal. He sometimes even applied the colour for the faces to the back of the paper to give a softer effect. ${ }^{64}$

Likewise, the lady in Dunedin's Downman watercolour has such soft outlines, which seem to melt into the cloudy background around her.

Portraiture was a lucrative business in Britain, and small-scale portrait drawings were as popular as miniatures. David Piper calls such works the "forerunners of the cabinet photograph" which would often stand decoratively upon a piano. ${ }^{65}$ Adam Buck (1759-1833) was one of the most famous portraitists of the early nineteenth century, and Peter Darvall argues that his portraits stand out for two specific qualities, "firstly, for the clarity and careful modelling of the face, usually coloured with the faintest touch of pink" and "secondly, for the distinctive dexterity and liveliness with which he drew the fashionable white day-dresses worn by women in the Regency."66 These dresses are very different from the ones worn by eighteenth-century women. Buck became especially known for painting the Empire silhouette dress, with a low and wide neckline and short puffy sleeves, as seen in Lady Elizabeth Skyes (DPAG) [Fig. 18]. ${ }^{67}$

While all three sitters' faces in these examples have been depicted in great detail, the rest of their bodies show odd proportions. Note in particular the different-sized hands in Beauclerk's work, or Buck's lack of a defined trapezius line - and the remarkably sloped shoulders. Indeed, portraitists working on such a small scale were often criticised, as Ozias Humphry had done about his friend Richard Collins, for being miniature artists whose merit was "wholly confined ... to the circumference of a head" since they had not developed their "inventive faculties" through "academical practice after the human figure." 68 Miniatures and small portraits also became casualties of the introduction of photography in the form of the

\footnotetext{
${ }^{64}$ Mallalieu, Dictionary, 112.

${ }^{65}$ Piper, English Face, 244.

${ }^{66}$ Peter Darvall, A Regency Buck: Adam Buck (1759-1833) (Oxford: Ashmolean Museum, 2015), 67.

${ }^{67}$ Ibid., 73. He painted several hundred Portraits in the Small, mainly between 1820-1830 and mostly measuring about 103 x $93 \mathrm{~mm}$.

${ }^{68}$ Katherine Coombs, The Portrait Miniature in England (London: V\&A Publications, 1998), 99.
} 
daguerreotype in 1839 , and they could be accused of boring monotony. ${ }^{69}$ It is in the more ambitious full-length figure paintings that variety and visual appeal is best expressed.

Serious portraits hardly ever depicted servants or other "less than well-to-do" sitters as anything other than decoration or trappings. ${ }^{70}$ Still, many single-figure paintings in the Smythe collection represent working-class subjects, operating more as genre paintings, such as Henry Edington Hobson's (1820-1881) Young Gleaner (Te Papa) [Fig. 19]. This demonstrates a close link to Realism, an artistic movement that emerged in France during the 1840s in part as a rejection of Romanticism. Instead of the emotional, exotic and dramatic works of the Romantic period, Realism sought to portray everyday people performing ordinary tasks with truth and accuracy. ${ }^{71}$ In Young Gleaner, for example, it is precisely such a servant who takes centre stage. ${ }^{72}$ A young farm worker is shown seated on a rock with a sheaf of wheat and a pottery flagon on her lap. In the background, one can see a field of wheat stooks, probably the place where she has been collecting the leftover wheat from just moments before. The girl has been painted with an air of classic monumentality usually reserved for subjects of a higher class. The face has been painted with short delicate strokes that clearly define her features, similar to the miniatures. The folds of her skirt, on the other hand, have been treated in the same loose manner as the rock she sits on, using diluted colour washes of different shades. Hobson thus took the medium's unique asset, usually reserved for landscapes, and successfully applied it to the human figure.

Figures like these could also become vehicles to represent allegorical, symbolic and emotional meanings. The sentimental burden of these figures was popular during the Victorian era and Smythe's representation of them in his collection reflects his middle-brow taste for 'premodern' times and ideals. ${ }^{73}$ Rural figures especially were seen as "a celebration of the heartlands of England, typically the agricultural and coastal countries of southern England, far from the industrial North ... or the corruption of London and other big urban

\footnotetext{
${ }^{69}$ Jean Bourgoing, English Miniatures (London: Benn, 1928), 21. The simple dress and lack of variety, of course, were also what made them profitable: minimising excessive detail allowed for speed of execution, thus more could be produced in a short time.

${ }^{70}$ Piper, English Face, 154.

${ }^{71}$ For more information on Realism and Romanticism, see Linda Nochlin, Realism and Tradition in Art, 1848-1900: Sources and Documents (New Jersey: Prentice-Hall, 1966); Julian Treuherz, Hard Times: Social Realism in Victorian Art (London: Lund Humphries in association with Manchester City Art Galleries, 1987); Andrew Hemingway and Alan Wallach eds., Transatlantic Romanticism: British and American Art and Literature, 1790-1860 (Boston: University of Massachusetts Press, 2015); William Vaughan, Romanticism and Art (London: Thames and Hudson, 1994).

72 This subject was made famous by the French realist artist Jean-François Millet (1814-1875), whose painting The Gleaners (1857) initially caused a negative stir at the salon, as the positive representation of workers seemed inappropriate for the upper class viewers. However, it quickly became one of the most influential paintings of the nineteenth century, exerting its influence over other artists' subject matter. See Bradley Fratello, "France Embraces Millet: The Intertwined Fates of 'The Gleaners' and 'The Angelus'," The Art Bulletin 85, no. 4 (2003): 685-701, accessed 20 October 2020, www.jstor.org/stable/3177365.

${ }^{73}$ Coombs, British Watercolours, 105.
} 
centres."74 This sentiment is expressed in works like Henry T. Green's (1836-1899)

Cabbage Field (1888, Te Papa) [Fig. 20], where a single woman is standing in the middle of a vast cabbage field. Anna Gruetzner Robins observes that "cabbages, a staple winter food, are a ubiquitous motif in late ninetieth-century painting of rural life."75 The woman here is a farmworker, and the field is the site of her hard labour, reflecting the Victorian belief about the dignity of hard work as the basis for prosperity. ${ }^{76}$

Group portraits in a domestic setting were also popular, including multi-figure paintings of families. The family was of central importance, not only to the private, but also to the public sphere. As Pamela M. Fletcher explains, "the family was the point of contact between the two spheres: both a private refuge of intimacy and relationship, and an economic and social unit, which educated future citizens and served as the central site of consumption."77 George Kilburne's (1839-1924) The Professor and Pupils (DPAG) [Fig. 21] illustrates the education of these future citizens. It shows a group of well-dressed young women being given a lesson by their private tutor in a bourgeois family's interior, decorated with paintings, porcelain, and velvet furniture. Piper explains that this imagery is based on an older tradition of conversation pieces:

[Conversation pieces] had flourished in a bourgeois society, in which dignity was not to be conveyed by the regalia of nobility nor by the sartorial conceits of courtiers, but by the air of solid, decent prosperity with which the sitters occupy their compartments in time and space; the sitters are shown for what they are (though dressed, naturally, in their best) and with what they are, which includes, by a sort of empathy, even their furniture, the capital sunk in their plate, their harpsichords, their pictures and carpets. ${ }^{78}$

The representation of the female subjects in Kilburne's painting contrasts greatly with watercolours of working-class women which highlighted class difference or presented allegoric glorification of principles. Here, the young ladies are not disguised under allegory but are shown, in Piper's words, for what they are: wealthy and educated. Showing off one's prosperity in paintings like these was common, as "some people's fortunes were very great by any standards, and family portraits played a supporting role with their newly built or

\footnotetext{
${ }^{74}$ Coombs, British Watercolours, 105.

${ }^{75}$ Anna Gruetzner Robins, “'South Country' and other Imagined Places," in Kim Sloan ed., Places of the Mind: British Watercolour Landscapes 1850-1950 (London: Thames \& Hudson, 2017), 94.

${ }^{76}$ For the changing illustration of the rural peasantry in painting, see John Barrell, The Dark Side of the Landscape: The Rural Poor in English Painting, 1730-1840 (Cambridge: Cambridge University Press, 1980). Barrell explains that the respectable and hardworking representation does not always align with reality, but more with how the wealthy expected the poor to appear.

${ }^{77}$ Pamela M. Fletcher, "Virtue, Vice, Gossip, and Sex: Narratives of Gender in Victorian and Edwardian Painting," in Dana Arnold and David Peters Corbett eds., A Companion to British Art, 1600 to the Present (New Jersey: Wiley, 2016), 535.

${ }^{78}$ Piper, English Face, 174.
} 
rebuilt mansions and their parks and estates in asserting their dynastic importance and their position in local affairs."79 These ideas recall Thomas Sandby's Earl of Fortescue's Grounds, Castle Hill, discussed earlier.

Along with contemporary subjects, figure watercolours could also represent historical subjects. Cynthia Roman explains that while portraiture was favoured by aristocratic collectors and patrons, on the other hand,

many connoisseurs, critics, and artists advocated history painting as the highest aim of the nation's most ambitious painters and considered the failure of English painters to produce a significant school of history painting to be a failure of national magnitude. ${ }^{80}$

Indeed, some watercolourists made their career by painting historical figure subjects, such as John Masey Wright (1777-1866) and Charles Cattermole (1832-1900). Artists had the option of depicting moments from actual past events, from historical literature or from their own imagination, as Cattermole often did. The Tryst (DPAG) [Fig. 22] is clearly a historical work, recognisable by the costumes of the figures, or perhaps based on theatre. Yet we do not know who these figures are. The title suggests a secret romantic meeting, but the plot thickens with the figure of a young boy lurking in the shadows, observing the couple, who is bathed in light. The forbidden nature of the rendezvous is further emphasised by the chest on the left-hand side, the sole piece of furniture depicted. This has a prominent lock on it hiding something inside, just as the lovers are trying to hide their relationship. Wright, on the other hand, primarily produced Shakespearean subjects. Twelfth Night (Te Papa) [Fig. 23] depicts the two silly characters Sir Toby Belch and Sir Andrew Aguecheek. Good friends, they are seen here dancing together happily after having engaged in their nightly routine of drink and revelry. This time the viewers do not have to invent their own stories for these characters, as their fate is well-known. ${ }^{81}$

A special mention must be made to some figure watercolours in the Smythe collection that seem to defy the limits of the genre discussed so far, as they venture beyond capturing the visible world completely. One of these outsiders was William Blake (17571827), whose figures took inspiration from religion and inner thoughts. As late as 1913, Cecil Eldred Hughes wrote in Early English Water-Colour that “[Blake’s] paintings cannot

\footnotetext{
${ }^{79}$ John Hayes, The Portrait in British Art: Masterpieces Bought with the Help of the National Art Collections Fund (London: National Portrait Gallery, 1991), 17.

${ }^{80}$ Cynthia Roman, "Art and Nation in Eighteenth-Century Britain," in Arnold and Corbett, Companion to British Art, 201.

${ }^{81}$ A more sombre example is "Alas, Poor Yorick!" (Hamlet) (DPAG, n.d., 131-195X), which deals with the grim theme of earthly vanity. The formerly high-spirited jester Yorick has now been reduced to a skull, as death is unavoidable for all.
} 
be regarded as essentially a part of the English school of watercolour." 82 This was because of the confusing and bizarre nature of his watercolours themselves, which broke from any pre-existing traditions. One critic described the catalogue to Blake's exhibition of 1809 as "a farrago of nonsense, unintelligibility, and egregious vanity, the wild effusions of a distempered brain." 83 Indeed, Blake chose to depict imagery beyond what the human eye could see, and through these personal and imaginary subjects he essentially "challenged the conventional association of the medium with naturalism and the sketch, and developed his own recipe for watercolour, harnessing opacity to his mission of visualising the unseen." 84

Son of the Morning (DPAG) [Fig. 24] exemplifies such imagery. The male figure, sitting awkwardly on the rocky ledge as if he is about to stand up or has just fallen down, is looking up into the heavens longingly, perhaps after having been cast out of Heaven. While the figure itself demonstrates some odd, unnatural proportions, it is the colouring which creates the biggest inventiveness in the work. The stylised clouds, forming an arc or gateway over the man, are painted in a range of purple, pink and orange, but in such a way that does not correspond with the beams of light radiating in the centre. Blake's approach to colour was abstract, because he used colour to express emotion rather than to imitate nature. As Monkhouse phrased it, 'this 'mysterious brilliancy', used with great decorative skill, and in perfect spiritual sympathy with the elementary ideas of terror, purity, hope, despair, love, and triumph, which inspired the designs, separate Blake's colour from that of ordinary men, as much as his life and genius were so separated." 85

The group of artists concerned with representing an inner, personal message, such as Blake and Henry Fuseli (1741-1825), are referred to as Visionaries. Alison Smith explains that they "aspired to rise above the challenges presented by medium specificity in claiming the primacy of their own inner vision above allegiance to received ideas of how the medium should be used to represent and express the external world." 86 DPAG boasts an example of Fuseli's watercolours, which, like Blake's, often deal with religious themes. The overall mood of "There Was a Day When the Sons of God Came to Present Thanks to the Lord..." (DPAG) [Fig. 25] is rather sinister, with the predominant colour being black, and the rows of angels on either side displaying drooping heads and weeping gestures. This visualises H.J. Paris' claim that Fuseli's “visions are as evil as Blake's are holy." ${ }^{87}$ Indeed, Fuseli's

\footnotetext{
${ }^{82}$ Cecil Eldred Hughes cited in Bernard Brett, A History of Watercolor (New York: Excalibur Books, 1984), 152.

${ }^{83}$ Brett, A History, 156.

${ }^{84}$ Smith, Watercolour, 12.

${ }^{85}$ Monkhouse, Earlier English Water-Colour Painters, 149.

${ }^{86}$ Smith, Watercolour, 12.

${ }^{87}$ H.J. Paris, English Watercolour Painters (London: Bracken Books, 1987), 36.
} 
watercolours are often violent and eccentric, finding inspiration in Gothic superstition and mythology. ${ }^{88}$ His technical skill is evident, however, in the controlled use of black and grey wash, and the scraping method used to supply form to the angels. The glaring white light in the centre is also achieved convincingly, making the viewer almost recoil from it and cover their eyes just as the central figure, Satan, is doing. The brushstrokes in this figure, which is almost entirely black, are clearly visible, providing movement to an otherwise fullysilhouetted shape.

\section{People and Animals}

A more acceptable category in the figure genre - one that appealed particularly well to Victorian sentiments - was that of people, often female, with animals. While animals commonly featured in portraits of the upper classes to, for example, celebrate a race-winning horse, favourite pets could also help to project the sitter's affectionate character. ${ }^{89}$ In the case of children's portraits, Diana Donald observes that "female portraits characteristically present the subject as a 'child of nature', in a way that is much less common in images of boys." ${ }^{90}$ She argues that women were equated with Nature herself, as "the tender, nurturing role of women as mothers, and their presumed lack of worldly ambition, could identify them with the innocence and purity attributed to Nature herself." 91 There are numerous watercolours of girls with animals in the Smythe collection. However, the most alluring is Myles Birket Foster's (1825-1899) Girl with Kitten (DPAG) [Fig. 26]. ${ }^{92}$ Even though still a child herself, the young girl cradles the cat gently in her arms with a motherly instinct, affectionately leaning her own head against the cat's. The cat in turn appears peaceful, showing no signs of struggle or discomfort, thus emphasising the vision of a harmonic intimacy between human and animal.

This intimate link was further visualised in paintings of women with animal-like physical features, such as the pointy nose of a mouse or the slender neck of a swan. This common trend expanded well beyond the domain of visual art, and writers, such as Edmund Burke, also made similar comparisons. Burke's discussion on the beautiful and the sublime has already been mentioned in relation to landscape. However, he also applied his theories

\footnotetext{
${ }^{88}$ Brett, A History, 158.

${ }^{89}$ Hayes, Portrait in British Art, 17, and Diana Donald, Picturing Animals in Britain 1750-1850 (New Haven and London: Yale University Press, 2007), 19.

${ }^{90}$ Donald, Picturing Animals, 19.

${ }^{91}$ Ibid., 18.

92 This watercolour was later engraved by the artist, a print of which is also in the Smythe collection at Dunedin (Myles Foster, Untitled, engraving, 125 x $100 \mathrm{~mm}, 471-195 \mathrm{X})$.
} 
to human and animal bodies alike, for example comparing the "smooth coats of birds and beasts in animal beauty" to the "smooth skins" of "fine women." 93 He particularly liked to compare women to birds. ${ }^{94}$ Besides their likeness in outer appearance and gentle nature, women were further linked with animals because they apparently shared a similar fate "as the frequent victims of superior male power."95 Thomas Lawrence's (1769-1830) Girl Looking at a Bird (DPAG) [Fig. 27] exemplifies these ideas. ${ }^{96}$ The girl looks forlornly at the little caged bird, perhaps seeing herself in its imprisoned position. Despite her obviously well-off status (as evidenced through her clothing, jewels and intellectual knowledge, represented by the instrument and books), the expensive balustrade of the windowsill mirrors the fenced cage of the bird. In keeping with Burke's comparisons, the smoothness and colour of her skin resembles the feathers of the bird. Her pose echoes the perching stance of the animal, and even the shape of her dress recalls the voluptuous plumage of a bird. Lawrence's work thus fits into an established tradition of identifying women with caged birds, which became a cliché in eighteenth-century art. ${ }^{97}$

Another instance where people are often depicted together with animals is in collaborative partnerships: working together side by side. Farm animals, especially horses, were acknowledged as helpers in the development of civilisation and modernity. Gathering Seaweed (Te Papa) [Fig. 28] and Horses Ploughing (DPAG) [Fig. 29] by Richard Beavis (1824-1896), are two rural scenes displaying such collaboration, where the horses' participation greatly helps the workers in their endeavours. While the subject therefore certainly returns to the themes of Realism discussed earlier, Beavis also had a reputation for the atmospheric treatment of his subjects. Indeed, two thirds of both these watercolours consist entirely of sky and clouds, which identifies the time of day for the viewer and adds atmosphere to the scene. ${ }^{98}$ Therefore, the line between figural and landscape becomes blurred. Another example is Robert Hills' (1769-1844) Farmyard (1812, Te Papa) [Fig. 30].

\footnotetext{
${ }^{93}$ Edmund Burke, Philosophical Enquiry into the Origin of Our Ideas of the Sublime and Beautiful, $5^{\text {th }}$ ed. (London: J. Dodsley, 1767), 213. 
At 695 x 492mm this is one of the largest works in the Smythe collection, most likely created as an exhibition watercolour as a direct challenge to oil paintings. ${ }^{99}$ The scene appears like an idyllic paradise which people and animals co-inhabit peacefully. It may be read as a sequel to Beavis' Horses Ploughing. After working the fields, the horses are now looked after and examined by the men, with a pile of fresh hay - their reward - waiting for them.

One of the most common depictions of people with animals was the hunting scene, such as Henry Alken's (1785-1851) The Hunt (DPAG) [Fig. 31]. Here, the harmonious union of man and animal has been replaced, by the representation of man's conquest of the irrational powers of nature. The people depicted are no longer farmers but the social elite. As Donald explains:

Men of rank are the rightful originators and conductors of the hunt. It is they who direct servants and dogs in pursuit of the prey; but they are only 'followers' of the hunt that ensues: not actively engaged in the business of killing. Their own superiority of mind and spirit supposedly puts them at a remove from its more blatant 'savagery'. 100

In other words, the social hierarchy practiced during a hunt symbolises the natural hierarchy of men and animals. The hunters are thus idealised in pictures, the collecting of which subsequently became an integral part of the hunting culture. ${ }^{101}$

Alken's very active and dynamic watercolour shows a fox hunt, an activity that achieved unprecedented popularity in England during the nineteenth century. It was a sport considered open to the new middle classes and could thus even be considered "a 'national' sport, which united all classes in a shared enthusiasm." ${ }^{102}$ In fact, such illustrations would have been used like instructive manuals for the newly moneyed, demonstrating to them how to distinguish themselves on the hunting field. ${ }^{103}$ It seems as though fox hunting could now be used to overturn the previous social hierarchy of the traditional hunt. However, despite its availability to a wider range of sportsmen, even the fox hunt demonstrated the privileged position of its participants. This was partly because of its increasing artificiality. As Donald notes:

\footnotetext{
${ }^{99}$ For a history of the development of exhibition watercolours, see Bayard, "From Drawing to Painting." See also Richard J. Hearn, "The Production of Paintings in Watercolours in Early 19th Century Britain: The Shift from Oil-Supremacy to Watercolour-Ascendancy," PhD diss., University of Sussex, 1994.

${ }^{100}$ Donald, Picturing Animals, 237.

${ }^{101}$ Ibid., 239.

${ }^{102}$ Ibid., 287, 289.

${ }^{103}$ Ibid., 240.
} 
The breeding of ever-faster thoroughbred horses and dogs symbolised the spirit of modernity, as did the man-made landscape of fenced enclosures which they hunted over. The large-scale management of these counties, which was needed to sustain their more intensive use for hunting, resulted in ever-increasing resort to planted coverts, constructed earths, and purchased or stolen 'bag' foxes. ${ }^{104}$

These man-made landscapes are clearly visible in Alken's work. One of the riders has just jumped over such a constructed and fenced earth wall, with his companions - or competitors - close on his heels. In fact, the speed and competitive nature of the sport often seems to overshadow the actual hunting activity, with riders being more interested in competing against one another in riding and jumping, than in the actual hunt or prey itself. Donald observes that 'the divinely implanted urge to 'exercise a dominion' over animals was, at least in the sphere of fox hunting, replaced by an urge to rival, and to dominate, one's fellow-sportsmen." 105

\section{Caricatures and Satires}

These new middle-class hobbyist hunters presented perfect subjects for another type of figure genre rarely treated by watercolour studies. It is one that Graham Reynolds calls "as national as the watercolour" itself: satires and caricatures. ${ }^{106}$ Like landscapes, comical watercolours help to further emphasise the relationship between pure watercolours and various print media, as they were often produced as preparatory sketches for the finished published product, as well as being finished works on their own. While they initially started out as primarily political, it was the social caricatures of the period that really stood out. ${ }^{107}$ Hablot K. Browne's (1815-1882) The Hunt (Te Papa) [Fig. 32] is a visual comment on the social activity of fox hunting. One of the riders has fallen off his horse and landed clumsily on all fours, consequently resembling the dogs behind him. The comical effect is heightened by his chubby stature and balding head, as well as his dumbstruck facial expression, created by Browne with just a few lines of pencil.

One of the main platforms where such works flourished in print format and enjoyed the greatest popularity was in periodicals, first and foremost Punch. Punch, or The London Charivari, was a British weekly magazine of humour and satire established in $1841 .{ }^{108}$ It

\footnotetext{
${ }^{104}$ Donald, Picturing Animals, 287.

105 Ibid.

${ }^{106}$ Reynolds, A Concise History, 78.

${ }^{107}$ For more information on political caricatures, see Judith Wechsler, "The Issue of Caricature," Art Journal 43, no. 4 (1983): 317, accessed 24 January 2019, www.jstor.org/stable/776727; and Henry Miller, Politics Personified: Portraiture, Caricature and Visual Culture in Britain, c.1830-80 (Manchester: Manchester University Press, 2015).

${ }^{108}$ See Marion Harry Spielmann, The History of "Punch" (London: Cassell, 1895).
} 
featured a great range of comical illustrations, from tiny corner sketches to large full-page wood cuts. In the new Victorian age of moral righteousness, Punch distinguished itself for producing humorous, yet at the same time didactic, images that were funny without giving offence. As Mark Lemon, one of the magazine's founding editors, wrote in the "The Moral of Punch", published in the first volume, "our title, at a first glance, may have misled you into a belief that we have no other intention than the amusement of a thoughtless crowd, and the collection of pence. We have a higher object." ${ }^{109}$ While the text was certainly more important initially, readers soon started to look at the pictures first, especially after the release of a new annual called Punch Almanack in 1842.

This featured well-known comic social illustrations, such as John Leech's (18171864) Fly Fishing in the $28^{\text {th }}$ volume (1855), [Fig. 33] and [Fig. 34]. Leech was the most famous of all Punch cartoonists. He excelled at seeing humour in most scenes of everyday life - yet riding, hunting and fishing seemed to have been some of his favourite hobbies to explore in art. ${ }^{110}$ Like his successor, John Tenniel, Leech sometimes made worked-up watercolour sketches to sell later. ${ }^{111}$ This particular watercolour appears to have been painted before the release of the print, as some details have been altered. The little child, standing on the left bank of the river in the final version, is absent from the original watercolour. ${ }^{112}$ Also, the facial expression of the main character has changed slightly from the original wide-eyed look to the more serious squinting eyes in the print. This, together with his tiptoe pose and the added text, "Mr. Hackle arrives at his favourite spot, where he knows there is a good trout", completes the humour of the scene. The watercolour is more finished than Browne's, but it still retains cartoon-like characteristics, such as the randomly cropped outline of the whole composition.

Even more worked up is Eliza Sharpe's (1796-1874) watercolour depicting characters from Pickwick Papers (Te Papa) [Fig. 35]. This is a fine example of yet another type of comic watercolour: the book illustration. Pickwick Papers (or The Posthumous

\footnotetext{
${ }^{109}$ Mark Lemon, "The Moral of Punch," in Mark Lemon et al., Punch, 4 vols. (London: Punch Publications, 1841), 1, accessed 10 June 2019 ,

https://books.google.co.uk/books?id=eGA2AQAAMAAJ\&printsec=frontcover\#v=onepage\&q\&f=false.

${ }^{110}$ For a well-illustrated biography of Leech, see Frederic George Kitton, John Leech, Artist and Humorist: A Biographical Sketch (London: G. Redway, 1883), accessed 10 June 2019, https://archive.org/details/johnleechartisth00kittiala/page/30/mode/2up. For a selection of his Punch illustrations, see John Leech's Pictures of Life and Character: From the Collection of "Mr. Punch” (London: Bradbury, Agnew, \& Co., 1887), accessed 10 June 2019, https://archive.org/details/picturesoflifech03leecuoft/page/n5/mode/2up.

${ }^{111}$ Spielmann, The History of "Punch," 464.

${ }^{112}$ Sometimes fake watercolour sketches were made after the prints to sell as original drawings. These would resemble the print from Punch quite closely, which is why the differences of this watercolour and the print make me believe it is a genuine preparatory drawing by Leech. Susannah Walker (Visiting Scholar, British Museum) to Annika Sippel, email correspondence, 29 January 2019.
} 
Papers of the Pickwick Club) was a novel by Charles Dickens, issued monthly from April 1836 to November 1837. It included illustrations by Robert Seymour and later also Hablot K. Browne, under the name Phiz. While Sharpe's watercolour might not have been meant to be turned into the final book illustration itself, it still exemplifies the humorous way artists interacted with the literature of the day. The painting is one of the loveliest in the collection, and the amusing facial expression of the Rev. Mr. Stiggins sitting on the back of the carriage is priceless. ${ }^{113}$ In fact, if it were not for his face, with the enlarged nose and eyes, the comic effect of the scene would be non-existent. Sharpe also demonstrates her skill as an artist in this work, not just in the character design, but also in her handling of the medium itself. The subtle use of gouache helps to realistically recreate the look of a dust cloud by the wheel. The colours remain very bright, and she successfully portrayed a range of details, such as the transparent fabric of the woman's veil in the wind, or the shimmering hide of the horse.

\section{Animals}

Watercolours of animals alone are even more rarely mentioned than figure subjects in the scholarship, despite the large number in existence. Just as was the case with fox hunting, the hunting of wild stags was actually something of a rarity in England by the later eighteenth century. Donald explains that "the spread of enclosure and agricultural 'improvement', together with new political ideals, had led to a gradual erosion of the ancient royal forests where deer once roamed freely. Herds of red and fallow deer were, in consequence, imparked by landowners. $" 114$ For artists, this meant they had easy access to animals and were thus able to make sketches from life. Robert Hills, for example, was best known for his intimately observed paintings of animals, paying close attention to textures and colours. In Stag (Te Papa) [Fig. 36], the treatment of the fur and antlers, demonstrating Hills' characteristic stipple-like technique, is markedly different from the treatment of the vegetation around the proud animal. Its posture and lively eyes show it is alert, and the limited ripples on the water around its legs are proof of its still stance. It is perhaps listening for the artist, who seems to have walked in upon an idyllic scene of natural animal beauty.

Besides the wild animals of Europe, British artists were also able to view exotic wild animals from distant lands, without having to travel overseas. Talking about Hills'

\footnotetext{
${ }^{113}$ The other characters are Mr. and Mrs. Tony Weller, because he was a coachman and she a devoted disciple of Stiggins. Rev. Stiggins himself is easily identifiable by his large, red nose (sign of his love for alcohol), the broad brimmed hat, faded green umbrella, his skinny stature, and the chair. Compare with a print by Phiz (Hablot K. Browne) here: https://victorianweb.org/victorian/art/illustration/phiz/pphe/53.html.

${ }^{114}$ Donald, Picturing Animals, 259.
} 
contemporary, Samuel Howitt (1756-1822), Mallalieu writes, "his animal sketches, often done from life at such places as the Menagerie at the Tower of London, are very lifelike indeed." ${ }^{115}$ Such menageries, another famous one being the Exeter Exchange, exhibited a range of wild animals in small cages, presenting them not as natural beings, but rather as "creatures whose unfamiliar physique and compulsive gestures made them look, to the lay visitor, foreign and outlandish."116 They were simply another way to visualise the separation of civilised human society from the untamed wilderness. The menageries would put on feeding 'shows' to demonstrate this. As Donald elaborates further, for the general public it was "difficult not to perceive predatory animals as evil-doers, whose murderous instincts were attributable to bad passions rather than simple need." ${ }^{117}$ However, seeing these animals at a touching distance gave rise to new sentiments, such as an admiration for the animals' aura of power, despite their degraded state. Writing in the New Monthly Magazine in 1824, Terence Templeton observed that the lion, "gazing around him with the air of an imprisoned emperor", still radiated a sensation of majesty to his onlookers. ${ }^{118}$

This statement takes on visual form in Howitt's wash sketch Lion (Te Papa) [Fig. 37] where the animal is shown with the head held high and a rather defiant look on its face. Even though Howitt has removed the bars of the cage and added a rock to create a more natural environment, the lion still appears somewhat confined within the sombre space of the picture. There is no illusion of depth, and we cannot see the entirety of the lion's impressive body. This is very different from the later work by W.S. Hatton (1873-1938), Lioness and her Cub (c. 1909, DPAG) [Fig. 38], where the lions are surrounded by a vast landscape, not looking out at the viewer but into the open sky - still proud, but now also free. Furthermore, the female lion is represented in her role as a nurturing mother, rather than a ferocious beast, creating an even more empathetic view of the wild. ${ }^{119}$

The majority of the animal watercolours in the Smythe collection are not of wild animals, however, but rather of the livestock that Smythe himself would have been accustomed to seeing. This includes Thomas Sidney Cooper's (1803-1902) Sheep (DPAG) [Fig. 39]. Unlike landscapes that might have contained sheep as pastoral embellishment, here they are the sole focus of the composition. Many watercolourists specialised in cattle pictures, and Cooper was known to have used the same formula for many of his works.

\footnotetext{
${ }^{115}$ Mallalieu, Dictionary, 183.

${ }^{116}$ Donald, Picturing Animals, 169.

${ }^{117}$ Ibid., 67.

${ }^{118}$ Cited in ibid., 169.

${ }^{119}$ It is interesting to note that W.S. Hatton is also known for having produced a series of watercolours of New Zealand towns and landscapes in the early 1900s, such as Town and Part of Wellington (Te Papa, 1992-0035-1587).
} 
Mallalieu explains that this led to others easily creating fakes, writing that "his works, which are repetitive, with their groups of cattle or sheep often set in the Canterbury marshes, have been extensively faked, both in his lifetime and later." 120 This work too resembles many of his other watercolours, with a small group of sheep lying in the foreground.

Nevertheless, the single most often represented animal in the collection is the cow; there are 26 watercolours of cows alone, and a further 17 in which cows appear. Cows in Winter (Te Papa) [Fig. 40] by Henry Willis (1810-1884), renowned for his cattle pictures, is an excellent example of the genre, if somewhat unique in depicting a winter rather than a summer scene. The watercolour is in very good condition and illustrates the artist's control of the medium, seen for example in the use of a dry brush to create texture of snow on the roof.

\section{Architecture}

The final genre of watercolours that is prominently represented in the Smythe collection is architecture. Some examples of architectural inclusions, such as private properties or castles, have already been mentioned within the context of landscape. The distinction between the two genres was often blurred, as they both tried to fulfil the requirements of the picturesque, while at the same time having roots in topography. Watercolours of classical antiquity further appealed to antiquarian tastes, while at the same time bringing architecture into the historical genre. David Roberts' Classical Ruins (DPAG) [Fig. 41] showcases these elements. Even though the building is now in pieces, the artist depicted each characteristic with great detail, such as the ridges in the columns and the shapes of the decorative volutes and arches. Even the texture of the ancient white marble has been effectively recreated. While the architectural remains are certainly the main focus of the work, they have started to fuse with the landscape around them, as foliage is growing on the stone surfaces, and dark trees are ornately framing the outline of the ruins on the left side. The overall mood is one of mystery and awe, but also tragedy and nostalgia. This blend is achieved through the foggy atmosphere and the lone figure sitting in the middle of the composition, looking out unto the sea with drooping shoulders. Mirroring the romantic picturesque appeal of the ruin, James Baynes' (1766-1837) Ruins (Te Papa) [Fig. 42] uses similar concepts, such as plants growing on the crumbling masonry and a single figure with a downward glance walking melancholically through the remnants of the past. However, this time the remains we see are

${ }^{120}$ Mallalieu, Dictionary, 87. 
of a Romanesque building that could have once stood in Britain itself, rather than the ancient Roman or Greek ruins that are distant for British viewers, not only in time but also in place.

This aligns with a wider resurgence of interest in English architecture that valued the faithful reproduction of architectural facts. ${ }^{121}$ As Greg Smith elaborates:

The growing appreciation of Gothic architecture as a national treasure and the increasing requirement for accuracy in the representation of monuments meant, therefore, that there was still an opening for a new type of specialist who could realise architectural subjects as attractive commodities while satisfying new scholarly standards. ${ }^{122}$

Edward Dayes (1763-1804) was one of those early artists answering the call for topographically-correct depictions of these national treasures, many of which were mostly in ruins already. This included St. Augustine, seen in Entrance to Monastery of St. Augustine, Canterbury (Te Papa) [Fig. 43]. This is one of Dayes' largest watercolours in the collection, indicating the importance he and the market placed on the subject. Dayes had studied printmaking, and many of his compositions were published as engravings, including a different view of this building. ${ }^{123}$ This knowledge adds to the incredible detail with which he reproduces the characteristic Gothic architecture, including the two prominent bell towers and the pointed arches. These are also picturesquely covered by greenery.

One of the reasons for this revived interest in local history, architecture, and indeed landscape, was Britain's physical isolation from the rest of Europe during the Napoleonic Wars from 1803-1815. Bayard explains that, "not only had the current war with France cut off the supply of contemporary continental paintings, it had also encouraged a sense of nationalism that found an outlet in 'buying British"'; or in other words, in buying British subjects painted by British artists. ${ }^{124}$ However, just as landscape artists sometimes travelled overseas for new and exotic sceneries during the later nineteenth century, so watercolourists ventured abroad for foreign architectural subjects as soon as this isolation was broken. This brought variety to the seemingly endless series of Gothic abbeys and churches. As Greg Smith clarifies, "following the end of the Napoleonic wars, a new generation of tourists, sated with the scenery of Britain, flocked to the continent, and, not surprisingly, a number of

\footnotetext{
${ }^{121}$ Bayard, Works of Splendor, 11.

${ }^{122}$ Smith, Emergence of the Professional, 149.

${ }^{123}$ See St Augustine's Gate, Canterbury, Kent, engraved by J. Rawle after Dayes, published 1802, now held by the Tate, accession number T06396, view on https://www.tate.org.uk/art/artworks/dayes-st-augustines-gate-canterbury-kentengraved-by-j-rawle-t06396.

${ }^{124}$ Bayard, Works of Splendor, 8. A similar sentiment - the importance of New Zealanders painting New Zealand subjects - developed in New Zealand during the twentieth century, which became one of the reasons that the Smythe watercolours have been neglected since. This will be discussed in Chapter Five.
} 
artists sought to cater for the demand for foreign scenes." ${ }^{125}$ Frederick Goodall's (18221904) The Mosque (DPAG) [Fig. 44], most likely produced during his eight-month stay in Cairo, satisfied this curiosity. The focus is on the building's domed roofs, stepped drums, and simple stone block façades, presented in the warm colours of a sunset, with foreign figures and camels occupying the space in front of it. The use of gouache is very effective in this work, especially in creating the shades of the white stone blocks.

Samuel Prout (1783-1852), who also spent time travelling across Europe and especially Italy to find new subjects, became most famous for his overseas architectural watercolours, such as Venetian Canal (Te Papa) [Fig. 45]. It demonstrates his characteristic muted colour palette of a deep ochre resembling crumbling masonry paired with vivid touches of colour on the stylised figures, as well as the common prominent outline of architectural watercolours. ${ }^{126}$ While visible outlines had gradually disappeared from landscapes, they were still very prominent in architectural designs. Prout was particularly known for his use of the reed pen to create granulate textured lines. ${ }^{127}$ The diagonal street view of elaborate façades also allowed him to demonstrate his knowledge of perspective.

One of the most often reproduced buildings - which combined the nostalgic elements of classical ruins with the contemporary passion for overseas travel - was the Coliseum, which also offered an excellent platform for demonstrating an artist's skill in perspective. In The Coliseum (DPAG) [Fig. 46], John Sell Cotman (1782-1842) persuasively uses light and shadow to recreate the perspectival recession of rowed arches around the circular shape of the structure, adding further drama through the atmospheric sky and darkened foreground. Interiors offered another way to illustrate such mathematical knowledge, as in C.F. Maltby's Sunderland (Te Papa) [Fig. 47]. Through a cluster of curves and straight lines, sharp angles and soft bends, dark corners and rays of light, the artist has reconstructed this complex space in a way which highlights the architectural achievements of the building in a realistic manner.

Evidently, interior views as well as exterior ones were a valid setting for architectural pieces. ${ }^{128}$ The features of the inside wall, for example, become prominent in

\footnotetext{
125 Smith, Emergence of the Professional, 151.

126 Mallalieu, Dictionary, 278.

127 Smith, Emergence of the Professional, 153.

128 The genre interior also grew out of Dutch influences on British art. For the development of this genre, see Mary O. Keating, "The Genre Interior in English Painting: From Dutch Origins to Native Solutions," PhD diss., The Pennsylvania State University, 2001. Artists such as Joseph Nash (1809-1878) devoted entire books to the topic. Dunedin has one of the watercolours made in preparation for Nash's four-volume masterpiece, The Mansions of England in the Olden Time (183949, 30-195X). See also Andrew Ballantyne and Andrew Law, Tudoresque: In Pursuit of the Ideal Home (London: Reaktion Books, 2011).
} 
George Cattermole's An Old English Mansion in the Days of Hawking (Te Papa) [Fig. 48].

This painting highlights the sculpted figures on the mantelpiece, which in turn is held up by pilasters and covered by a classical frieze. The roof directly above has been chamfered through moulded beams that extend horizontally above the figures in the room. This watercolour is also of interest for laying bare the artist's working method. Cattermole has clearly drawn the structural features first, with an architect's level of detail and precision, and only added the figures later - perhaps as an afterthought - as the original lines are visible through the body of the dog. It is obviously an unfinished work, yet it is visually appealing and was considered worth collecting. It blurs the lines between the sketch and the finished work, both of which became collector's items.

Indeed, sketch-like watercolours formed a whole new genre for the medium during the nineteenth century, thus challenging ideas of what a watercolour could be. ${ }^{129}$ It is not clear whether, for example, Peter De Wint's (1784-1849) Barn Exterior (DPAG) [Fig. 49] is an unfinished sketch or whether he left it in this raw state intentionally. It is stripped down even more than Cattermole's work, leaving just some broad washes of colour and several lines here and there. It is only by using our imagination that we can make out the architectural shapes of windows and a door on a barn's exterior. This use of the viewers' imagination was one of the reasons for the increased appreciation of sketchier watercolours, which became a positive alternative to the highly finished and detailed works that usually made up annual exhibitions. ${ }^{130}$ Sketches were eagerly sought out by collectors too. Some artists, such as Cox, even made sketches specifically to order for patrons as a result of this trend. ${ }^{131}$ Smythe himself, collecting during the early twentieth century, must have participated in this interest due to the presence of works like these and James A. Aitken's (1846-1897) Street Scene (Te Papa) [Fig. 50] in his collection.

This work is very different from the street scene of Prout, where precision and perspective prevailed. Instead, Aitken has removed those elements and simply arranged disconnected shapes of colour to create the visual illusion of buildings. It is an extraordinarily modern approach. A major aspect of the visual character of the scene is created through the naturally fuzzy edges of the colour blocks, with the white paper shining through the washes here and there, keeping the eye moving. This could not have been achieved by using oil colours.

\footnotetext{
${ }^{129}$ Sloan, Places of the Mind, 78.

${ }^{130}$ Fenwick and Smith, Business of Watercolour, 22-23.

${ }^{131}$ Coombs, British Watercolours, 45-46.
} 
This brief survey of the genres found in the Smythe watercolours has demonstrated that this collection can be used to give a comprehensive overview of the wide range of categories found within the medium, going beyond the overly emphasised dominance of landscapes. While this examination started off with the eighteenth-century topographical watercolours of Paul and Thomas Sandby, who are often presented as the beginning of the progressive 'Golden Age' of watercolour that focused primarily on landscapes, it further explored topics that are sometimes neglected in the scholarship, such as figure and animal subjects. This reveals other ways in which artists used watercolour to engage with their surroundings and society. They made comments on social behaviours and trends, as well as showing off their knowledge of specialty fields and literature. At the same time, the subjects start to reveal more about Smythe's conservative taste. While the collection does contain canonical or popular landscapes, he clearly favoured more sentimental figure and animal subjects too, which better reflect the Victorian era, rather than an emergent modernity, and which likely contributed to the collection falling out of favour in the twentieth century.

\section{THE ARTISTS AND THEIR WORKS IN CONTEXT}

Just as there is a range of genres represented in the Smythe collection, so there is also a range of artists. In Te Papa's collection there are over 227 artists, and most of them are only represented by a single watercolour. ${ }^{132}$ As Stewart Maclennan wrote to Smythe in a letter from 1956, "art lovers in both North and South Islands can now see original works by practically every artist who worked in the period." 133 This is a bold statement that is justified if the only artists considered are the great masters of the Golden Age. Works by many of these famous artists, such as Paul and Thomas Sandby, Edward Dayes, Anthony Vandyke Copley Fielding, Richard Parkes Bonington, David Cox, Robert Hills, Samuel Prout, John Sell Cotman and Peter De Wint have already been mentioned. The only major artists not well represented in the collection are John Constable, of whom Smythe was only able to acquire a couple of drawings, and Alexander and John Robert Cozens. ${ }^{134}$ Still, even

\footnotetext{
13212 of the Te Papa works are categorised as 'Unknown'. At Dunedin, there are over 410 different artists, and 72 'Unknown'.

${ }^{133}$ Maclennan to Smythe, 19 November 1956, TPA: MU00008, box 3, item 6.

${ }^{134}$ John Constable, Flamborough Head (Te Papa, 1957-0009-277) and Leaffrom a Sketch Book (DPAG, 13-1954). There are a couple of wash drawings attributed to John Robert and Alexander Cozens, see 82.
} 
without them, there are enough 'canonical' works in the collection to tell the endorsed story of the history of British watercolour.

However, what makes the Smythe collection more interesting from a contemporary perspective is the depth and breadth of the collection, which is surprising and certainly not always 'canonical'. Indeed, revisionist scholars like Greg Smith have challenged the traditional focus on individual artists. Smith claims that "too many histories of watercolours are organized as a triumphant progress, with the work of key artists signaled as stages in the development of naturalism or even modern art. This tells us ... little about either the period or the specific circumstances in which the watercolour were created." 135 Oliver Warner further claims that "most of the greater figures of the British School have already been fully appraised, it is among those ... who are not widely known, that the more exciting discoveries will be made."136

Broadening the scope of artists to be considered is thus another way of interacting with Smythe's collection in a novel manner today. If we consider artists working outside the canonical group of Golden Age landscape watercolourists, Maclennan's statement might not hold true anymore. The sheer number of practitioners will be too vast to be adequately represented in a collection of this size. However, it will be revealed that even Smythe's collection can, after a closer look, partake in these new discussions and present a representative assemblage of known and lesser-known artists, working both during the period 1780-1850, and beyond.

Additionally, by further abandoning the teleological and canonical narrative, it is possible to demonstrate the richness of the period by considering wider social, political, historical, and economic factors. These all played key roles in affecting some of the artistic choices by the artists, which in turn have defined the watercolour phenomenon in Britain. This revisionist approach adds a thematic structure to an otherwise monotonous list of artists and their achievements, and it reveals the much greater role watercolour played in the art world at large.

\section{'Painting' in Watercolour}

Watercolourists sought to achieve the same level of professional status as oil painters, and struggled to gain visibility for their work in exhibitions, where large-scale, vibrant oil paintings dominated. One solution was to increase the size of the watercolours, another was

\footnotetext{
${ }^{135}$ Smith, Emergence of the Professional, 1.
}

${ }^{136}$ Warner, British Marine Painting, 8. 
to employ brighter colours and fine detail. Greg Smith adds that this development of 'painting' in watercolours "was also promoted by a stylistic feature not covered by the earliest progressivist texts: the use of bodycolour."137

William Henry Hunt (1790-1864) used bodycolour, or gouache, to refine the details of his compositions, add contrasts and give his painted objects solidity, which all made his watercolours look more like oils. Jane Bayard, in her book Works of Splendour (1981), and Marjorie B. Cohn, in Wash and Gouache (1977), both describe his painting style in great depth. They conclude that "it was his glazed impasto technique in particular that brought his pictures to the closest approximation yet seen to oil technique, despite their miniaturist touch." 138 There is no doubt that Hunt was at least in part trying to emulate the miniaturist technique of stippling, as seen in the tiny strokes used to create the fuzzy soft surface of the peaches in Still Life (DPAG) [Fig. 51]. Still, it was his use of gouache, sometimes mixed with watercolours and other times used as a white ground, that gave his works a certain glow and life. While his technique certainly does rival the power of oils, it is intriguing that he chose to apply it to still lives rather than landscapes or history subjects.

John Parker (1839-1916), a landscape and genre painter, was known for his life-like portraits. Woman Spinning (Te Papa, 1908) [Fig. 52] showcases the delicate, short brushstrokes with which he painted the facial features, recalling the work of Hunt and the earlier miniaturists. The garment too has been painted in great detail, carefully choosing when to use specks of bodycolour to highlight specific features. The result is a charming and convincing figure. Even though the watercolour remains unfinished, Parker did sign it as if it were a completed work. At a time when figures became more abstracted in art, when fashion was booming, and watercolour became more expressive than ever before, Parker chose to show us a world of times past. This was not just through the use of old costume, but also through his painterly technique.

The same may be said of George G. Kilburne's (1839-1924) landscape The River (Te Papa) [Fig. 53]. Though Kilburne was primarily a figure painter, producing indoor genre scenes like The Professor and Pupils [Fig. 21], The River, despite the presence of two figures, is overwhelmingly a landscape. The artist went through great pains to depict small details of the scenery, such as individual stems of grass hanging over the edge of the stream,

\footnotetext{
${ }^{137}$ Greg Smith, "Watercolour: Purpose and Practice", in Simon Fenwick and Greg Smith, The Business of Watercolour: A Guide to the Archives of the Royal Watercolour Society (Aldershot \& Brookfield: Ashgate, 1997), 13. See also Hearn, "The Production of Paintings in Watercolours."

${ }^{138}$ Marjorie B. Cohn, Wash and Gouache: A Study of the Development of the Materials of Watercolor (Cambridge, Mass.: Center for Conservation and Technical Studies, Fogg Art Museum, 1977), 51.
} 
and the realistic illustration of the reflections on the water is astounding. Clearly, 'painting' in watercolour as in oil, and effectively disguising the most visual recognisable characteristic of watercolour, - washes - did not stop with Golden Age artists like Hunt. The goal of these artists was to prove that the medium of watercolour was just as versatile as oil. ${ }^{139}$

\section{Business: Commissions, Designs, and other Utilitarian Purposes}

As with other art movements and media, it is easy to fall for the trope of the genius artists who only paint what is in their heart and mind whenever they want to. While watercolourists worked hard to raise their medium from a mere craft to an intellectual art form, they were also working to make a living from their art. Scholarly focus on the professional interests of watercolourists, and the aesthetic and stylistic developments in their works, has often ignored the range of utilitarian purposes watercolours served. ${ }^{140}$ Not only did artists attempt to sell their works at exhibitions, they also worked on commission. In many instances watercolours were produced as designs, the artists working in collaboration with other types of businesses. These designs, just like sketches, eventually became sought-after collectors' items.

Concerned with the role of the creative individual in an increasingly industrial and commercial society, the Pre-Raphaelite Brotherhood looked to the past and were heavily influenced by medieval themes and imagery. ${ }^{141}$ This included medieval craft forms, such as stained-glass windows, which provided an opportunity to further expand the use of watercolours. In 1861, William Morris, a textile designer, poet, novelist, translator, and socialist activist, set up his company Morris, Marshall, Faulkner \& Co., known as 'the Firm'. Sarah Beattie explains that stained glass was one of their biggest successes, and "they took private domestic commissions as well as replacing church windows all over the country." 142 Morris would often turn to his friends - many of whom were members of the Pre-Raphaelites - to create the designs for these stained-glass windows in watercolour. He recognised that "the qualities needed in the design ... are beauty and character of outline;

\footnotetext{
${ }^{139}$ Bayard, "From Drawing to Painting," 53. For a more detailed description of the technical innovations in watercolour as a response to oil painting, see Bayard, "Watercolor Technique and Presentation," in "From Drawing to Painting," 43-80. ${ }^{140}$ Smith, "Watercolour: Purpose and Practice," 7.

${ }^{141}$ For more information on the Pre-Raphaelite Brotherhood, see T.J. Barringer ed., Pre-Raphaelites: Victorian Art and Design (London: Yale University Press, 2012), and Laurie Benson, Medieval Moderns: The Pre-Raphaelite Brotherhood (Melbourne: National Gallery of Victoria, 2015).

${ }^{142}$ Sarah Beattie, "Stained Glass on Paper: Morris \& Co. and the Pre-Raphaelites," Victoria and Albert Museum (13 November 2014), accessed 9 July 2019, https://www.vam.ac.uk/blog/caring-for-our-collections/stained-glass-on-papermorris-co-and-the-pre-raphaelites.
} 
exquisite, clear, precise drawing of incident." ${ }^{143}$ These features are evident in two watercolours in the Smythe collection: Dante Gabriel Rossetti's (1828-1882) Design for a Stained Glass Window (DPAG) [Fig. 54] and Edward Burne-Jones' (1833-1898) Design for Stained Glass (Te Papa) [Fig. 55]. ${ }^{144}$ Both show very delicate and detailed painting, in bright colours and with visible outlines. The use of watercolour also helped to emulate and predict the transparent effect of the final product's coloured-glass component. While they might have been produced as designs, this does not reduce the visual quality of the watercolours themselves. Their impressive size, $800 \times 545 \mathrm{~mm}$ and $558 \times 457 \mathrm{~mm}$, places them among the largest in the entire Smythe collection.

Frederick Robinson (1862-1927) was a Professor of Figure Composition and Decoration at the Glasgow School of Art, as well as an illustrator and a designer, designing costumes, sets and posters for Maurice Maeterlinck's Blue Bird at Haymarket in $1909 .{ }^{145}$ In his watercolours Sketch of a Model (DPAG) [Fig. 56] and Seated Woman (DPAG, 715195X), his main interest was clearly fashion design. One figure is flaunting an elegant fur coat over a vibrantly orange dress, while the other is wearing a plain black skirt complemented by a red blouse with a colourful pattern on it. While the essential features of the costumes are clearly visible, Robinson executed them in a rapid manner. This also means that the individual facial features have been paid less attention to than the overall effect. What further makes these works fascinating is the elusive background, which at first appears rather blank and unimpressive. Still, when one takes the time to focus on the technique at play, one can see elements of Turner's 'colour beginnings'. ${ }^{146}$ There is no apparent perspectival space, and yet the figures are seated firmly, their chairs casting shadows on a seemingly non-existent floor. The pale colour washes surrounding the women create the slightest hints of a backdrop, while at the same time celebrating the visual pleasure derived from pure colour washes.

One of the most disregarded uses for watercolour, or even art in general, is as copies of other artworks. DPAG has two excellent examples: Copy of a Painting of a 17th Century Lady, by an unknown artist [Fig. 57], and Charles Edward Holloway's Copy of a

\footnotetext{
${ }^{143}$ William Morris, 1890, cited in Beattie, "Stained Glass on Paper."

144 The work at Te Papa is also nicely accompanied by a cartoon by Dante Gabriel Rossetti, The Visitation. Design for Stained Glass (1861, 747 x 478mm, 1957-0009-313), and an actual stained-glass window made around 1900 by the artist John Dearle for William Morris \& company (445 x 991 x 29mm, GH020700). See https://collections.tepapa.govt.nz/object/1120436.

${ }^{145}$ Mallalieu, Dictionary, 292.

146 'Colour Beginnings' refers to the atmospheric, and otherwise seemingly subjectless, colour studies of Turner's last years. See Gerald Wilkinson, Turner's Colour Sketches, 1820-34 (United Kingdom: Barrie and Jenkins, 1975); Eric Shanes, Turner's Watercolour Explorations 1810-1842 (United Kingdom: Tate Gallery, 1997); Ian Warrell, Turner's Sketchbooks (London: Tate Publishing, 2014).
} 
Gainsborough Picture (557-195X). While Holloway's watercolour remains sketch-like, quickly executed, and unrefined, Copy of a Painting of a 17th Century Lady is highly finished and detailed, carefully replicating the different textures of fabric, skin and hair. Thus, the former might have been a study of a master's work in order to practice composition, while the latter could have been used as a model for tuition or to preserve an oil painting (or simply to produce a more affordable version of it). ${ }^{147}$

\section{Market: Watercolour and Prints}

As with any business, watercolour was heavily reliant on the market, particularly through a close relationship to printmaking, raising the need to consider issues of reproduction, circulation, popularisation, association with literature, distribution, and affordability. Many artists turned their watercolours into print formats, either as their own published series, as Paul Sandby had done, or as illustrations in magazines, like John Leech's. Timothy Wilcox agrees that "associations with the commerce of publishing and the artisanal craft of engraving" was a usual occurrence for the medium. ${ }^{148}$ In these instances, the watercolours often reveal their intended final form as a print through distinct use of colour and style.

Greg Smith emphasises that "unless the artist acted as his or her own publisher, the choice of subject and their specific treatment were determined by commercial men whose livelihood depended on their understanding of the market." ${ }^{149}$ Furthermore, unless the artists produced the final print themselves, the process involved a whole team of labourers. For that reason, the watercolour had to be executed in a simple manner, avoiding any complex effects. Smith elaborates that "working within the limits of their collaborators' skills encouraged artists to restrict themselves to the 'tinted drawing', especially if aquatint was used in combination with an etched line." ${ }^{150}$ This is the method Sandby used for Views in Wales: 'Fifth Set'/Carnarvon Castle (1777, British Museum) [Fig. 58], the etching and aquatint version of Carnarvon Castle [Fig. 3]. While Sandby was unusual for producing and publishing this print himself, the watercolour still demonstrates the way artists limited their colour palette and details to aid the printmaking process that was to follow.

Lithography became especially popular with topographical imagery from overseas, especially after the success of David Roberts' watercolours which were published as either

\footnotetext{
${ }^{147}$ Smith, "Watercolour: Purpose and Practice", 10. The practice of making copies of Cozens' works, for example, has already been mentioned in regard to the Monro school.

${ }^{148}$ Timothy Wilcox, "Questions of Identity: The Place of Watercolour in British Art," in Colin Harrison, Great British Drawings (Oxford: Ashmolean Museum, 2015), 33.

${ }^{149}$ Smith, "Watercolour: Purpose and Practice," 26.

${ }^{150}$ Ibid., 27.
} 
coloured or uncoloured lithographs. H.L. Mallalieu, in his Dictionary of British Watercolour Artists up to 1920 (1986), explains the characteristics of Roberts' Eastern watercolours: "Much of the Near Eastern work, for which he is best known, was obviously executed with the lithographer in mind, with a limited palette of grey, dusky red, brown and yellow, with careful pencil drawing and white heightening." 151 This description is in line with the execution of Ras-el Abiad, Coast of Syria [Fig. 4] mentioned earlier. Indeed, a lithograph of the same subject can also be found in Te Papa's collection [Fig. 59]. ${ }^{152}$ The muted colours of the watercolour are emphasised in the final print, conveying a feeling of mysticism.

Thomas Rowlandson (1756-1827), who produced and published caricatures similar to Leech and Hablot K. Browne, is well-represented in the Smythe collection. Bernard Brett writes that Rowlandson's delicacy of colour "compare[s] with the work of more serious watercolourists of the age." ${ }^{153}$ Tricks on the Turf (DPAG) [Fig. 60] is an example of his characteristic "juxtaposition of figural pairs, contrasting youth with age, and beauty with ugliness." 154 The figures and the landscape in the background indeed show a certain delicacy of colour, which Judy Egerton observes helps to soften the boisterousness or bawdiness of his characters, and adds an unexpected tenderness to his images. ${ }^{155}$ Rowlandson ignored the changes in technique around him and continued to use pale colours, outlines and underlying monochrome washes, recalling the work of the topographers and anticipating the work of printmakers.

Another caricaturist and prominent book illustrator took this feature to extremes. George Cruikshank's (1792-1878) Girl with Apples (Te Papa) [Fig. 61] is painted in even more subtle colours, infusing the innocent scene with a further nuance of childish purity. The colour has been masterfully applied in washes, so that no individual strokes are visible. While Mallalieu complains that Cruikshank's weakly-drawn women reveal his lack of academic training - and the girl in this work indeed appears rather stylised and doll-like his use of the watercolour medium is extremely effective in this case. ${ }^{156}$ The work also shows the influence of Japanese ukiyo-e woodblock prints, which became popular in Europe during the later nineteenth century. The watercolour's cropped composition, lack of

\footnotetext{
${ }^{151}$ Mallalieu, Dictionary, 290.

152 This lithograph was purchased in 1980 with Ellen Eames Collection funds, possibly because of the Smythe watercolour already in the collection. This shows that the gallery considered the works in its collection when making acquisitions, in this case using the Smythe watercolour to justify the purchase of another work three decades later.

${ }^{153}$ Brett, A History of Watercolor, 166.

${ }^{154}$ Mary Kisler, “Thomas Rowlandson," in William McAloon ed., Art at Te Papa (Wellington: Te Papa Press, 2009), 40.

155 Judy Egerton, British Watercolours (London: The Tate Gallery, 1986), 12.

${ }^{156}$ Mallalieu, Dictionary, 96.
} 
perspective, empty space, flat coloured forms and the oriental porcelain vase in the bottomright corner are all characteristic features of Asian art. ${ }^{157}$

Colour-printed wood engraving became particularly associated with children's books from the 1860s. ${ }^{158}$ Kate Greenaway's (1846-1901) Children Playing (Te Papa) [Fig. 62] shows similar flat blocks of colour and clear outlines, as well as a flatness of space, despite the use of a busy background. ${ }^{159}$ Greenaway was also a book illustrator, and Mallalieu provides a succinct explanation of her success, writing "her drawings created a happy world which had never existed, but which nevertheless has become part of our cultural heritage. Their strength is in perfect drawing and in the muted washes of colour, which re-interpret the methods, as well as the modes, of the late eighteenth century." ${ }^{60}$ These methods are well illustrated in this work. The subject of children in "quaint old-fashioned clothes" displaying their "stylised manners, attitudes and activities" is a perfect reflection of her characteristic depictions of "a visionary dream world of childhood." 161 Part of Greenaway's appeal was that she showed a romanticised view of rural life in an industrial age. The children here symbolise this pure, romanticised life through playing and picking flowers, ignoring the bustle of houses beyond the wall directly behind them. Even though she learnt from and was influenced by other book illustrators, such as Walter Crane, it seems she soon surpassed them in the genre. Writing about Crane, Mallalieu states that "his illustrations for children's books bid fair to equal the appeal of those of K. Greenaway (q.v.), but his touch is a little heavier." 162 Indeed, it was the lightness, simplicity and mild sentiment of works such as Children Playing which dramatically changed this genre of watercolour. ${ }^{163}$

\section{Gender}

Typically, histories of British watercolour ennoble artists who are normally male. Smythe's collection, however, includes a number of female artists, reminding us that watercolour was an acceptable pastime and profession for women. Greenaway is the best represented female artist in the Smythe collection. However, she is not the only one. ${ }^{164}$ Others include Harriet

\footnotetext{
${ }^{157}$ See Janice Katz and Mami Hatayama eds., Painting the Floating World: Ukiyo-e Masterpieces from the Weston Collection (New Haven and London: Art Institute of Chicago, 2018) and Maxwell K. Hearn, How to Read Chinese Paintings (New York: Metropolitan Museum of Art, 2008).

158 Smith, "Watercolour: Purpose and Practice," 28.

159 Jessica Feather claims that this influence of Japanese prints on Greenaway's art was filtered through other artists like Walter Crane, who is also well represented in the collection. See Feather, British Watercolours and Drawings, 106.

${ }^{160}$ Mallalieu, Dictionary, 152.

${ }^{161}$ Feather, British Watercolours and Drawings, 105.

${ }^{162}$ Mallalieu, Dictionary, 93.

${ }^{163}$ Feather, British Watercolours and Drawings, 105.

${ }^{164}$ There are 15 female watercolourists in the collection, which amounts to only $2.3 \%$.
} 
Lister, Harriette Leslie, Eliza Sharpe and Lady Diana Beauclerk. While Greenaway was unusual in that she turned her art into her profession, for most of these other female artists, the aim of watercolour painting was not to produce works to be sold or exhibited. This was largely due to the cultural context which used their gender against them and their art, claiming it to be inherently inferior and just a simple hobby. While men were artists, women were amateur enthusiasts. Kim Sloan explains that "men followed a 'pursuit' - a profession, employment or recreation, this last word bearing the root 'create', which was associated with genius and invention. Women, on the other hand, undertook 'amusements', pleasant diversions from serious business, ways of passing time." 165 Watercolour in particular was considered suited for the female enthusiast, as the medium itself was delicate and nonodorous, thus not too harsh on the equally delicate feminine physique. ${ }^{166} \mathrm{Kim}$ Grant also explains that watercolour painting was an activity sought after by the upper and middle-class women of the nineteenth century, to make productive use of their time:

Arts and Crafts ideology also formed the foundation for the rise in amateur craft production among middle and upper class women in the late nineteenth century. Not only did craft work alleviate the boredom and nervous complaints thought to arise from affluent women's excess of leisure, it was also a productive activity that educated and elevated the entire family's aesthetic sensibility. ${ }^{167}$

It is thus hardly surprising that female watercolourists do not make up a large part of the scholarship on British watercolour. ${ }^{168}$ Firstly, no one wrote them into the histories, secondly, there are simply less of them, and thirdly, the quality of their work was assumed to be lacking, due to the limited means available to execute their art professionally.

As the works by women artists so far have shown, however, their technical skills not only match, but, at times, surpass those of their male contemporaries. For example, Anne Parrott's Frankfort (DPAG) [Fig. 63] challenges the type of watercolour women should be

\footnotetext{
${ }^{165}$ Kim Sloan, 'A Noble Art': Amateur Artists and Drawing Masters c.1600-1800 (London: British Museum Press, 2000), 214. Tradition in the Work of Vanessa Bell, Gwen John and Laura Knight (London: Philip Wilson, 2006); Victorian Women Artists (London: Women's, 1987); “The Mid-Victorian Woman Artist: 1850-1879,” PhD diss., University of London, 1982. See also Joanna Devereux, The Making of Women Artists in Victorian England: The Education and Careers of Six Professionals (Jefferson: McFarland \& Company, 2016); Deborah Cherry, Painting Women: Victorian Women Artists (London: Routledge, 1993). For the New Zealand context, see Caroline Jordan, Picturesque Pursuits: Colonial Women Artists \& the Amateur Tradition (Melbourne: Melbourne University Press, 2005); Catherine Field-Dodgson, "In Full Bloom: Botanical Art and Flower Painting by Women in 1880s New Zealand," MA diss., Victoria University of Wellington, 2003; Anne Kirker, New Zealand Women Artists: A Survey of 150 Years, rev. ed. (Tortola: Craftsman House, 1993).
} 
producing, and with what level of skill. It is not an intimate, private miniature, nor a children's book illustration nor a botanical flower arrangement. It is the work of an artist travelling abroad to study foreign street scenes and architecture, replicating her findings in a convincing and natural manner. At first glance one might even confuse the work for that of Prout or one of his followers, due to the stark outlines and overall beige tonality, combined with the strong emphasis on architecture. ${ }^{169}$

\section{Amateurs}

While watercolour was often advertised as an easy medium for women amateurs to pick up, they were certainly not the only amateurs actively practicing watercolour. An amateur, male or female, was an artist for whom watercolour painting was not their professional business, but a hobby. Drawing in general was thought to teach observation and taste; it was considered a useful accomplishment and innocent pastime, while also a signifier of social distinction. ${ }^{170}$ During the 1750 s this was still restricted primarily to pencil drawing or monochrome washes, but by the nineteenth century watercolour had become the more commonly used medium for amateurs, due to its portability and ease and speed of execution, as opposed to the time-consuming, cumbersome and messy oil painting. ${ }^{171}$ As Timothy Wilcox notes, "watercolour may have given them a crucial identity, individually and collectively", but many of these amateur artists remained active in other types of professions. ${ }^{172}$ In the Smythe collection, for example, amateur representatives include John White Abbott (1763-1851), a surgeon and apothecary, who was a student of Francis Towne, and William Crotch (1775-1847), a composer and organist who started sketching after meeting John Malchair. ${ }^{173}$ Others were so well off that they did not need to work at all, living off family wealth and indulging in painting during their leisure time.

The rise of the amateur was also responsible for the unprecedented number of drawing manuals and masters operating during the nineteenth century. Some of these teachers, however, were attacked by other professional artists, who claimed that their simplification and systematising of their practice - done in order to facilitate the students'

\footnotetext{
${ }^{169}$ For more examples of female watercolourists, see Niamh MacNally, “A Subtle Art," Irish Arts Review 21, no. 3 (2004): 112-115, and Patricia Butler, "A Victorian Watercolourist," Irish Art Review Yearbook 10 (1994): 157-162.

${ }^{170}$ Smith, "Watercolour: Purpose and Practice," 19.

${ }^{171}$ Ibid.

172 Wilcox, "Questions of Identity," 30. Many collectors of watercolour also turned to the practice as a hobby, especially among the clergy. However, I could not uncover any evidence that Smythe himself produced any watercolours.

${ }^{173}$ In New Zealand, the proportion of amateurs was also very high, as most active watercolourists during the nineteenth century were in fact amateurs. See ACAG, Early Watercolours of New Zealand (Auckland, 1963), 2: "few of the painters of the colonial period could be said to be artists by intention: soldiers, surveyors, New Zealand Company draughtsmen, accomplished gentleman, they were all involved in the immediate necessities of colonisation."
} 
imitation of their style - would "undermine the highest professional ideals which center on the imagination and on intellectual endeavor." 174 Regardless, manuals always sold out quickly. ${ }^{175}$ The authors of these instructive manuals often produced amateur watercolours themselves, as can be seen by John Ruskin's Italian Mountain Scene (1833-1888, Te Papa) [Fig. 64], which helped to publicly advocate for amateur practice. ${ }^{176}$

Despite the cheap nature of the medium itself, it was an exclusive and expensive hobby, particularly if a drawing master's or mistress' services were employed. ${ }^{177}$ Many amateurs were part of the social elite of their times, further broadening the gap between the different classes. One of the most famous gentleman amateur artists was Hercules Brabazon Brabazon (1821-1906). After receiving an ample inheritance, he spent his life travelling and painting as he pleased. He only started exhibiting his works in his seventies, after encouragement from his artist friends, like John Singer Sargent (1856-1925). While he was mostly self-taught, this did not diminish his skill in any way. ${ }^{178}$ In fact, Ruskin and the critic D.S. MacColl have been known to praise him as Turner's rival as a colourist. ${ }^{179}$ Lake Scene (Te Papa) [Fig. 65] shows off his skilful handling of watercolour, combining bleeding colours with white gouache and faint charcoal lines to create a sense of fleeting impressions of light. The loose handling and vigorous brushstrokes are reminiscent of James McNeill Whistler, and if it was not for the signature in the bottom right corner, one might easily mistake this piece as a mere plein air sketch. ${ }^{180}$ And yet there is a certain harmony in the colours, and the seemingly random blotches of pigments reflect the natural variety of flora in the landscape.

\footnotetext{
${ }^{174}$ Greg Smith, The Emergence of the Professional Watercolourist (Aldershot: Ashgate Publishing Limited, 2002), 114. See this book for a detailed analysis of the reputation of drawing masters.

${ }^{175}$ Bicknell and Munro, Gilpin to Ruskin, 11. One of the benefits was that they were portable and could thus be used to instruct even in remote places like the British colonies. The English travel writer and poet Emma Roberts wrote from India in 1839 that "there is little in the way of tuition to be had in India and no paintings from which amateurs can take hints for their improvement." Cited in Michael Clarke, The Tempting Prospect: A Social History of English Watercolours (London: British Museum Publications, 1981), 96. With no teachers and no artworks to copy, drawing manuals became essential in spreading the British styles and techniques.

${ }^{176}$ John Ruskin (1819-1900) was a Victorian art critic who wrote The Elements of Drawing (1857). See Andrew Ballantyne, John Ruskin (London: Reaktion Books, 2015).

177 Smith, "Watercolour: Purpose and Practice," 20.

${ }^{178}$ For more information on amateur watercolourists, as opposed to professional ones, see Sloan, 'A Noble Art'; Smith, Emergence of the Professional; Michael Clarke, “Amateurs," in Clarke, The Tempting Prospect, 103-122; Jordan, Picturesque Pursuits.

${ }^{179}$ Hilarie Faberman, "Brabazon, Hercules Brabazon," Grove Art Online, accessed 1 July 2019, https://www.oxfordartonline.com/groveart/view/10.1093/gao/9781884446054.001.0001/oao-9781884446054-e7000010755 .

${ }^{180}$ Sloan, Places of the Mind, 78.
} 
Thomas Collier (1840-1891) tended to paint vast expanses of land under turbulent skies, and his watercolours often looked spontaneous and rapidly executed. ${ }^{181}$ He blurred the lines between amateur and professional, in that painting was his profession, however, as the son of a wealthy tradesman, he had enough financial support without a need to sell his art in order to secure an income. ${ }^{182}$ Scott Wilcox claims that his free and expressive handling of the medium, clearly inspired by the earlier generation of British watercolourists like Cox and De Wint, is what made Collier stand out from his Victorian contemporaries. Kentish Landscape (DPAG, 1870s-1880s) [Fig. 66] is made up of clear washes loosely applied, the colours very bright and fresh. Collier himself described his method in 1883, saying that "I always paint a subject as simply and as direct from nature as possible, using the fewest number of colours I can." ${ }^{" 183}$ This particular work seems to stem from his London period, characterised by a loose, fluid technique. ${ }^{184}$ His friend and art collector, James Orrock, described Collier as "the finest of sky painters, especially of rain and cumulus clouds, while possessing, more mastery of direct modelling and pearl-grey shadows in his skies and landscapes than any member of our brotherhood." 185

\section{Beyond the Golden Age: Impressionist Style}

The loose style of Brabazon and Collier, both working during the Victorian era, shows clear influences of Impressionism. ${ }^{186}$ Just as with the earlier influence of French Realism on English subject matter during the 1840s, the emergence of Impressionism during the 1860s enabled another instance of spreading and sharing new artistic ideas. After Britain's isolation during the Napoleonic Wars had ended in 1815, the country was once again opened to international ideas such as these. The stylistic choices of British watercolourists during the latter nineteenth century are evident of these cultural exchanges. While similar methods could already be observed in earlier Golden Age artists, such as David Cox and William James Müller (1812-1845), ${ }^{187}$ it was during the Victorian and Edwardian eras that artists became even more experimental and modern in their approaches.

\footnotetext{
${ }^{181}$ Scott Wilcox, "Collier, Thomas," Grove Art Online, accessed 1 July 2019, https://www.oxfordartonline.com/groveart/view/10.1093/gao/9781884446054.001.0001/oao-9781884446054-e7000018607.

182 Adrian Bury, The Life and Art of Thomas Collier, R.I. Chevalier of the Legion of Honour 1840-1891 (Leigh-on-Sea: F. Lewis Publishers, 1944), 36.

183 Thomas Collier cited in Wilcox, "Collier, Thomas." See also Bury, The Life and Art of Thomas Collier, 37.

${ }^{184}$ Feather, British Watercolours and Drawings, 44.

${ }^{185}$ Ibid, 46. For examples of Orrock's own painting, see the DPAG watercolours Landscape with Cattle, Amberley (1895, 53-195X), and Untitled (1876, 26-1953).

${ }^{186}$ The influence of Impressionism will be discussed further in the next chapter.

${ }^{187}$ See for example Cox, Landscape with Trees and Cottage, c. 1840s (Te Papa, 1957-0009-65) and Müller, Landscape with River (Te Papa, 1957-0009-187).
} 
William Roxby Beverley (c. 1810-1889), a stylistic follower of Bonington, came from a family of actors and was primarily a scene-painter for the theatre. However, he also produced some watercolours, primarily marine subjects. ${ }^{188}$ His favourite colours to use were brown and blue, which can be seen in his work at Te Papa, River Scene - Boy Fishing [Fig. 67]. The sketchy appearance of the forms recalls the Impressionistic style and at first glance the watercolours look like oil paints that have been thickly applied, like impasto with a palette knife. This is due to the large amount of bodycolour used, as well as the brush directions with which the paint has been applied.

George Clausen (1852-1944) was arguably one of the greatest colourists of the later artists. He was a keen exponent of plein air painting, and his work captures atmosphere rather than detail. ${ }^{189}$ This can be seen in Landscape (DPAG) [Fig. 68], where the overall colour scheme is dominated by soft pastel greens and blues, and the watery paint illustrates Clausen's expertise in the medium. Watercolour is renowned as a medium with a life of its own. Watercolourist Leslie Worth explains some of the difficulties watercolourists are often faced with, including the colour running down the paper, wet areas 'bleeding' into one another, and the colour drying out rapidly or not at all. ${ }^{190}$ Landscape shows that Clausen has indeed mastered these techniques. Despite obvious bleeding, the colours retain their individual hues, and while they mix with each other at times, they never create a dirty or muddy colour.

Mark Fisher's (1841-1923) work was even more reduced to washes of colour and shapes. Fisher is an underrated artist who was strongly influenced by the work of the French painter Camille Corot (1796-1875), as visualised in the beautifully illuminated landscapes Blakeney (1906, DPAG) [Fig. 69] and Landscape with Stream (Te Papa) [Fig. 70]. Corot always displayed a response to the various effects of light, adapting to its changing qualities outdoors. Fisher illustrates the same fast, expressive, fluid, and bright qualities in these works, visualising two different moods created through light. Compared to Collier's, the clouds in the latter have become even more abstract, condensed to seemingly random splodges of grey wash.

Figure painters also experimented with Impressionistic techniques in the medium to portray figurative subjects in novel ways, with intriguing results. While watercolour has earlier been criticised for its unsuitability towards portraits and other figure paintings, these

\footnotetext{
${ }^{188}$ Mallalieu, Dictionary, 39.

${ }^{189}$ Ibid., 78.

${ }^{190}$ Leslie Worth, Working with Watercolour, 1980, cited in Egerton, British Watercolours, 5.
} 
later artists pushed the medium to its limits even further by applying landscape painting techniques to figures. John Singer Sargent is best known for his oil portraits. However, his watercolours primarily turned to landscapes, which are often rapidly executed on damp paper with a mixture of clear colours and gouache. ${ }^{191}$ Figure with Drapery (DPAG) [Fig. 71] is a watercolour completed in the same manner, and yet its main motif is a lone figure. The youth is painted in fluid washes, his blue costume resembling a cloudy sky or a rushing river, and his face is missing any distinctive features. He becomes one with his surroundings, turning into another piece of drapery covering the pieces of architecture or furniture. Sargent's watercolours indeed resemble Impressionist techniques. ${ }^{192}$ While one of his mentors had been Brabazon, Sargent took the loose style of his famous master and developed it further during the later nineteenth century, proving that watercolour was still very much alive and able to adjust.

Many people at the end of the nineteenth century (the time when Smythe was starting his collection) were convinced that the Golden Age of British watercolour had ended around 1850. J.C. Robinson, writing in 1894, claimed that "fifty years from the beginning of the present century may be said to have seen the rise, fullest development, and decline of this fascinating art."193 This brief analysis of the contents of the Smythe collection, however, has helped to challenge this notion. It reveals ways in which artists continued to develop the medium, embracing new subjects, techniques and artistic styles. At the same time, the collection can be used to show other ways in which artists engaged with various social issues and artistic changes around them through the medium. Therefore, the first assumption made at the end of the previous chapter, that the artworks in the collection are simply not good enough to be displayed or studied, does not hold true. The next chapter will situate Smythe's collection in the context of British and New Zealand artistic tastes during the latenineteenth and twentieth centuries to explore the question of 'taste' and its impact on the legacy of Smythe's collection.

\footnotetext{
${ }^{191}$ Although Sargent was American, he is generally included in histories of British watercolours, as he moved to England in 1886 and spent the rest of his life there. It was during his years in England that he slowly abandoned portraiture and focused more on travel studies in watercolour (like the work mentioned here), which led to his ultimate reputation as a formidable watercolourist. See Carter Ratcliff, John Singer Sargent (New York: Abbeville Press Publishers, 1982) and "Some Water Colors by John Singer Sargent in the Museum of Fine Arts, Boston," Art and Progress 3, no. 12 (October 1912): 742-745, accessed 15 January 2020, https://www.jstor.org/stable/20560764.

${ }^{192}$ Sloan, Places of the Mind, 83. Other scholars have suggested he did not fully embrace the Impressionist idiom. See Ratcliff, John Singer Sargent, 97.

${ }^{193}$ J.C. Robinson, "English Art Connoisseurship and Collecting," The Nineteenth Century: A Monthly Review 36, no. 212 (October 1894): 535.
} 


\section{Chapter 4: The Smythe Watercolours and Taste}

Was Smythe following a contemporary trend when he made decisions about which works and artists to include in his collection? This may have been the case when he first started to amass these works. But by the time he donated them to New Zealand during the 1950s, there was a much wider range of watercolours available for consumption in England, which the archdeacon did not actively engage with. By this time, Smythe represented an outdated taste that was no longer popular in England, as changes in style, technique and artistic canon shifted rapidly in the first half of the twentieth century. This context might also have contributed to the decision to gift the collection to an overseas institution.

From the selective highlights of the collection discussed in the previous chapter, which represent a great variety of works and artists, it may be hard at first to discern what was distinctive about Smythe's taste. In order to fully comprehend his taste and intent in collecting these watercolours, one has to consider the wider context in which Smythe was collecting. By considering other collectors, different arbiters of taste and the changing canon of favoured artists during the late-nineteenth and early-twentieth centuries, Smythe's role as a collector becomes clearer. Indeed, perhaps he was deliberately not pursuing a particular taste for a specific subject, artist, or aesthetic quality at all. The result is a collection that was difficult for Smythe to accommodate in 1950s Britain.

However, it transpired that 1950s New Zealand did not provide a better home for his collection. Lagging slightly behind the rest of the world, artists, collectors, and art institutions in New Zealand had only recently started to develop new tastes for modern art that directly clashed with what Alison Smith calls "the 'brown' aesthetic" of British watercolours. ${ }^{1}$ An examination of the type of art was being collected and shown by galleries and private collectors will shed light on why the Smythe collection fell from favour as quickly as it did.

\footnotetext{
${ }^{1}$ Alison Smith ed., Watercolour (London: Tate Publishing, 2011), 18.
} 


\section{SMYTHE'S (OUTDATED?) TASTE}

To analyse Smythe's taste, one must first establish the context of his collecting practices. Given he was actively building his collection between about 1895 and 1950, I will consider the different tastes of contemporary British collectors who developed collections over a similar period, thereby allowing me to determine how much Smythe's collecting engaged with that of his peers. The period when Smythe was beginning to collect, however, is already rather ambiguous for the scholar of collecting histories, as there is a potent lack of literature. Philip McEvansoneya observes that "whilst British Victorian watercolour painting has been written about extensively from an artistic point of view, the patronage and collecting of watercolours in nineteenth-century Britain has been less thoroughly investigated, especially when compared to oil painting." ${ }^{2}$ One of the pioneers in this area is Jessica Feather, whose own thesis, "The Formation of a Modern Taste in Watercolour: Critics, Curators and Collectors c. 1890-1912" (2014), is a milestone in the history of watercolour collecting. When comparing her findings with the contents of the Smythe collection, it becomes clear that Smythe did indeed follow some of the trends that defined a 'modern taste.'

One method of analysing taste is by looking at which artists are being collected, and which parts of their respective oeuvres. As has become evident, Smythe owned examples by hundreds of watercolourists, but some were more popular than others at the time he was collecting. Broadly speaking, collectors in the 1890s and early 1900s were collecting earlier artists like J.M.W. Turner and John Sell Cotman side by side with contemporary practitioners like Singer Sargent and Philip Wilson Steer. Feather begins her thesis by observing that the established canon of artists, still reflected in the sculpture busts of artists commissioned in 1883 for the façade of the former Royal Institute of Painters in Water Colours, was starting to be challenged by the turn of the century. ${ }^{3}$ These busts represented Paul Sandby, John Robert Cozens, Thomas Girtin, Turner, David Cox, Peter De Wint, George Barrett Junior and William Henry Hunt. With the exception of Barrett, all of these artists are represented in the Smythe collection. ${ }^{4}$ Two major changes occurred to this canon

\footnotetext{
${ }^{2}$ Philip McEvansoneya, "'A Thing to Be Seen': Creating the Crampton Collection of British Watercolours in the 1850s," Journal of the History of Collections 21, no. 1 (May 2009): 95, accessed 10 May 2019, https://academic.oucom/jhc/article/21/1/95/762121.

${ }^{3}$ Jessica Feather, "The Formation of a Modern Taste in Watercolour: Critics, Curators and Collectors c. 1890-1912," PhD diss., University of Reading, 2014, 11.

${ }^{4}$ Though there are two watercolours by Barrett's father, George Barrett (1732-1784), in Dunedin, Classical Landscape with Figures (969-195X) and Untitled (7-1953).
} 
of artists as Smythe started his collection: the addition of Cotman and the removal of Hunt. These changes in turn were directly related to a shift in taste regarding stylistic aesthetics, wherein Cotman represented the newly preferred 'sketch', and Hunt the now less favoured, highly finished 'complete' Victorian watercolour. ${ }^{5}$

\section{Cotman, Turner, and the Sketch Aesthetic}

Today, it is standard to consider John Sell Cotman one of the iconic watercolourists of the early nineteenth century, but this was not always the case. In fact, had Smythe been collecting just a few decades earlier, he might not have paid much attention to acquiring Cotman's work at all. Instead, with a total of 24 works (8 at Te Papa and 16 at Dunedin), he is one of the best-represented artists in the collection. In this, Smythe was following a new trend that established Cotman as a significant figure of British watercolours for the first time. As Feather summarises:

from the 1880s onwards he was increasingly promoted as a figure of national importance, both by Norwich collectors such as Reeve but also gradually and significantly by the London art establishment, culminating in his inclusion in major London exhibitions of the 1890s where he is seen as part of the National School. ${ }^{6}$

This only marked the beginning of Cotman's rising fame, which culminated in the middle of the twentieth century, when he was generally considered "the equal of Turner, or even his superior."7

Cotman's watercolours tended to consist of almost abstract broad planes of pure colour, applied in layers to ensure clear, crisp lines. He also eliminated details from his compositions and reduced his subjects to their bare essentials, as can be seen in Cottage (DPAG) [Fig. 72], where the walls look rather incomplete, without detailed brickwork to indicate its material substance. The result appears fresh, genuine, and often unfinished. The art critic Elizabeth Pennell, who saw Cotman's work exhibited in London in 1892, praised these aspects of his "delightful sketches", which she believed showed that he truly "understood" his art. ${ }^{8}$ Other writers agreed that these "sketches" comprised the most notable

\footnotetext{
${ }^{5}$ Feather, "Formation of a Modern Taste," 34-35.

${ }^{6}$ Ibid., 148.

7 Timothy Wilcox, "From Obscurity to Immortality: The Growth of Cotman's Fame," in Andrew Moore, Norma Watt and Timothy Wilcox eds., John Sell Cotman: Master of Watercolour (Norwich Castle Museum and Art Gallery, 2005), 50-51. Wilcox observes, for example, that Martin Hardie devoted more space to Cotman than to Turner in his three-volume book Water-Colour Painting in Britain (1966-1968), and he points out that it is Cotman's Chirk Aqueduct which graces the dust jacket of the second volume, The Romantic Period (1967).

${ }^{8}$ Elizabeth Pennell, “Old Masters at the Royal Academy," The Star, no. 12204 (January 1892): 4, cited in Feather,

"Formation of a Modern Taste," 189.
} 
part of his oeuvre. In 1902, Laurence Binyon (1869-1943), for example, said that they were his "finest work", as opposed to his "finished paintings." ${ }^{9} \mathrm{He}$ explained further that these works had not been in the spotlight until this time, because they were private works "poured out for his own pleasure and without any profit." 10 This gave them an air of spontaneity and a 'sketch-like' aesthetic. It was this sketch aesthetic - influenced by the increasingly popular Impressionist style - that continued to grow in England during the early twentieth century, creating a modern taste for fast, informal, unfinished, and sometimes near-abstract watercolours.

In fact, the lure of the watercolour sketch had already fascinated collectors and art critics as early as 1800 , when they were valued as original ideas by the artist or documents of inventive creativity. As the English artist, writer and cleric William Gilpin (1724-1804) had observed, sketches engaged the imagination of the viewer and gave them "an opening into all those glowing ideas, which inspired the artist; and which the imagination only can translate." 11 In other words, works like Cottage were appreciated for revealing the working processes and thoughts of the artist. This led to a commodification of the sketch as a soughtafter collector's item. Some artists, like Cox, even made sketches to order for patrons to cater to this trend. ${ }^{12}$ While the Society of Painters in Water-Colours had banned unfinished watercolours in 1823, by 1862 they had established a regular winter exhibition devoted solely to sketches and studies. ${ }^{13}$ Many of the works displayed at these exhibitions were not actually sketches as such, but rather carefully worked-out paintings made to look like spontaneous sketches.

Cox's working method exemplifies this strategy [Fig. 15]. He intentionally created a rough look, through broad sketchy washes that left small areas of the paper exposed, seemingly by accident. During Smythe's own time it was the visual aesthetic of this loose manner that collectors like Sir Hickman Bacon (1855-1945) admired and sought in Cox's "sketches", rather than the documentary significance praised by Cox's contemporaries.

\footnotetext{
${ }^{9}$ Laurence Binyon, Masters of English Landscape Painting: J.S. Cotman, David Cox, Peter De Wint (London: The Studio, 1903), v.

${ }^{10}$ Ibid.

${ }^{11}$ William Gilpin, “Three Essays: On Picturesque Beauty; on Picturesque Travel; on Sketching Landscape,” The Monthly Review; or, Literary Journal XI (1793): 20.

${ }^{12}$ Katherine Coombs, British Watercolours 1750-1950 (London: V\&A Publishing, 2012), 45-46.

${ }^{13}$ For more information on the Winter Exhibitions and sketches, see Simon Fenwick and Greg Smith, The Business of Watercolour: A Guide to the Archives of the Royal Watercolour Society (Aldershot \& Brookfield: Ashgate, 1997), 23, 48, 169. The authors explain that the Royal Watercolour Society started their annual 'winter' exhibitions of sketches in 1862. They quote a letter by Sir John Gilbert to J.J., 1862: "I would return to propose for consideration the advisability of getting up a second annual exhibition ourselves, a Winter Exhibition of Sketches - not finished drawings but sketches, first ideas of pictures in chat, pencil or colours, not close framed but mounted and framed in light narrow gilt mouldings - of course for sale."
} 
Smythe seems to have been aware of this fashion and with 18 works, Cox is also one of the best-represented artists in his collection.

Some collectors became almost too obsessed with owning sketches by these artists. Wilcox notes that "Sir Hickman Bacon, destined to become a leading force in the watercolour world in the years preceding the First World War, acquired his first Cotman in 1898, for only 25 guineas. By 1913, he had nearly fifty." 14 English art historian, collector, and critic Paul Oppé (1878-1957) claimed that the disproportionate number of watercolours by Cotman in Bacon's collection indicated the collector was merely following the fashion of the moment, without halting to consider the quality of the works themselves or their personal value to the collector. He suggested that, "had a drastic reduction been effected as was done in the case of the sketches by Cox, which were acquired by Sir Hickman in an even more lavish manner, his real taste would have been better reflected and the artist himself more worthily represented." 15 This shows that, firstly, some collectors' personal taste suffered under the general taste for a specific artist and style, and, secondly, that Cox and Cotman were sometimes collected in an excessive manner as a result.

Even within this context, individuals still expressed personal preferences for specific parts of Cotman's oeuvre. The critics D.S. MacColl and Charles Whibley, for example, had strong opinions on Cotman's use of colour. ${ }^{16}$ Feather observes that MacColl liked the ochres and umbers of Cotman's early work, which he described as "charming and conventional", but that he objected strongly to the "crude" and "bright and abominable colours" in the artist's later phase. ${ }^{17}$ Whibley agreed that the neutral and monochromatic colour palettes of Cotman's earlier works were better, and that the colours in his later works were "not always harmonious." 18 Smythe's watercolours by Cotman are also primarily in muted tones, but he also acquired some bright ones, such as Cottage or Untitled Italian Landscape (DPAG) [Fig. 73]. We cannot know whether he made any distinction between the two styles or whether he was simply eager to get as many Cotmans as he could. Yet the overall look of the Cotman

\footnotetext{
${ }^{14}$ Wilcox, "From Obscurity to Immortality," 70.

${ }^{15}$ Paul Oppé, “The Hickman Bacon Collection of Water-Colours," The Burlington Magazine for Connoisseurs 88, no. 518 (1946): 128, accessed 22 July 2019, http://www.jstor.org.helicon.vuw.ac.nz/stable/869271. Oppé himself was a collector of Cotman - for more information see Anne Lyles and Robin Hamlyn, British Watercolours from the Oppé Collection with a Selection of Drawings and Oil Sketches (London: Tate Gallery, 1997).

${ }^{16}$ Dugald Sutherland MacColl (1859-1948) was a Scottish watercolour painter, art critic, lecturer, and writer. He was art critic for The Spectator (1890-1895) and the Saturday Review (1896-1906), and then keeper of the Tate Gallery (19061911). He also published several art books. In his writings, he was influential in spreading favourable ideas about Impressionism. Charles Whibley (1859-1930) was an English literary journalist and author, with close personal bonds to James Abbott McNeill Whistler. He was a regular contributor to magazines like The Pall Mall Magazine, Macmillan's Magazine, and Blackwood's Magazine, and he published books on a range of topics (from painting and literature to politics).

${ }^{17}$ Feather, "Formation of a Modern Taste," 188.

${ }^{18}$ Ibid., 189.
} 
watercolours, and indeed his entire collection, appears more traditionally subdued in tone, rather than bright, which indicates that he might have been influenced by writers like MacColl and Whibley.

Works by other Golden-Age artists demonstrated a similar sketch-like lack of finish. This led Elizabeth Pennell to appreciate, for example, De Wint's paintings "when he was content not to finish his work" and Turner's "notes and studies he made for his own pleasure", rather than the "less effective but very carefully worked-out vignettes he produced for the express purpose of illustration." 19 The taste for Turner's watercolours in particular was shifting at this time. While Turner had never really surrendered his canonical status, Feather explains that "the centrality of Turner and his art to the watercolour school was an idea that critics would return to in the 1890s, and indeed beyond, albeit admiring a different type of Turner watercolour." ${ }^{20}$ Before Smythe's own time, Turner had been admired as "a Shakespeare of landscape art of infinite and inimitable variety", and his most desirable watercolours were those which exemplified powerful, emotional, Romantic landscapes of the picturesque tradition. ${ }^{21}$

The key figure who established this taste for Turner in the nineteenth century was the critic John Ruskin (1819-1900), who championed Turner as the greatest artist of all times. For example, Ruskin admired Turner's ability to render the truth of landscapes, writing that "Turner's is the closest and most studied approach to truth of which the materials of art admit." 22 While his praises and interpretations of Turner's works, beginning with Modern Painters in 1843, were almost immediately criticised as blind exaggerations, they made sense in a Victorian context. Ruskin's choice of paintings and representation of Turner's life and career reflected his own Evangelical background and Victorian society's aim to find links between art and morality. ${ }^{23}$

\footnotetext{
${ }^{19}$ Elizabeth Pennell, cited in Feather, "Formation of a Modern Taste," 189. Pennell was an American writer, art critic and collector who spent most of her life in London. For more information on Pennell, see Kimberly Morse Jones, Elizabeth Robins Pennell: Nineteenth-Century Pioneer of Modern Art Criticism (Ashgate, 2015).

${ }^{20}$ Feather, "Formation of a Modern Taste," 24

${ }^{21}$ J.C. Robinson, "English Art Connoisseurship and Collecting," The Nineteenth Century: A Monthly Review 36, no. 212 (October 1894): 533.

22 John Ruskin, Modern Painters: Volume I, new ed. (New York: John Wiley \& Sons, 1890), 146, accessed 20 December 2020 ,

https://www.google.co.nz/books/edition/The_Works_of_John_Ruskin_Modern_painters/UZMLAAAAIAAJ?hl=en\&gbpv $=0$.

${ }^{23}$ Ian Warrell, "Exploring the 'Dark Side': Ruskin and the Problem of Turner's Erotica," The British Art Journal 4, no. 1 (2003): 5, accessed 20 December 2020, http://www.jstor.org/stable/41614430. See also Marjorie Munsterberg, "Ruskin's Turner: The Making of a Romantic Hero," The British Art Journal 10, no. 1 (2009): 61-71, accessed 20 December 2020, http://www.jstor.org/stable/41614862.
} 
In reality, Turner had already been notorious for his complicated painting techniques. ${ }^{24}$ William Fawkes explains that he "soaked, blistered, daubed, rubbed, and scratched with his thumb nail, until at length beauty and order broke from chaos." ${ }^{25}$ Of course, he lived to see his inventions become common practice. He was also renowned for using a light, transparent scale of colouring to capture atmospheric effects, and Ruskin praised his exceptional colouring that gave life to his works, writing "wherever Turner gives blue, there he gives atmosphere; it is air, not object." 26 These qualities can be observed in Crossing the Brook (DPAG) [Fig. 74], an inventive, idealised landscape, bathed in atmospheric light created through masterly use of colour. ${ }^{27}$ The use of blue in the shadows is especially effective, and the scratching out on the water's surface helps to produce a glistening effect. The aerial perspective in the central background blurs the smaller details of the landscape, while the foreground abounds with lush foliage.

However, these watercolours did not represent the taste of Smythe's contemporaries. The new taste for the sketch aesthetic was more interested in a part of Turner's oeuvre which he himself had never exhibited, but which modern scholars and critics now believed best illustrated the extremes of his colour principles: advanced sketches generally referred to as 'colour beginnings'. ${ }^{28}$ Graham Reynolds explains that these colour compositions could be both representative and completely formless:

In certain cases it is clear that Turner has taken one of these sheets of paper stained with brilliantly, seemingly haphazard pigment, and adapted it with his creative skill into a sunset scene, a seascape or a topographical scene. Others he left alone, as he may have felt in them that sort of completeness, abstracted from representation, which is now recognized as an expressive form of art. $^{29}$

Indeed, such watercolours might be considered early forerunners of abstraction. As a result, they were sometimes hung upside down by those who could not decipher a hidden form. ${ }^{30}$

\footnotetext{
${ }^{24}$ Jane Bayard, Works of Splendor and Imagination: The Exhibition Watercolor, 1770-1870 (New Haven: Yale Center for British Art, 1981), 10

${ }^{25}$ William Fawkes cited in Marjorie B. Cohn, Wash and Gouache: A Study of the Development of the Materials of Watercolor (Cambridge, Mass.: Center for Conservation and Technical Studies, Fogg Art Museum, 1977), 44.

${ }^{26}$ Ruskin, Modern Painters: Volume I, 158.

${ }^{27}$ The oil version of this painting entered the Tate collection as part of the Turner Bequest in 1856 (reference number N00497). While Te Papa has removed all Turner attributions from Smythe's gifts, at the DPAG they all remain listed under Turner's name, as provided by Smythe. While some of these attributions are questionable, it is not within the scope of this thesis to attempt new attributions. This example is, most likely, a copy made after a print of the oil painting.

${ }^{28}$ Graham Reynolds, A Concise History of Watercolours (New York and Toronto: Oxford University Press, 1978 ), 87.

${ }^{29}$ Ibid. See also Graham Reynolds, Turner (London: Thames and Hudson, 1969, reprinted 1984), 146-150.

${ }^{30}$ See, for example, the review of an 1874 exhibition, which included a brief description of such an occurrence with a Ruskin sketch. "Water-Colour Exhibitions," Saturday Review of Politics, Literature, Science and Art [London] 37, no. 954 (7 February 1874): 179.
} 
Such watercolours, however, are missing from Smythe's collection, which is dominated by more traditional Turner seascapes and countrysides like Crossing the Brook.

Smythe was certainly going against the trend by collecting Turner's earlier landscape works, but he was not alone. Robert Wylie Lloyd (1868-1958), for example, also mainly collected these earlier finished works. Kim Sloan explains the aberrant nature of this approach:

Modern collectors of Turner's works have tended to covet his late views of Venice, loose sketches and colour beginnings, now familiar to them from decades of exhibitions from the Turner Bequest: their taste has been formed by exposure to the work of the Impressionists and modern artists who have taught many to admire the unfinished sketch over meticulous detail or craftsmanship, or by such arbiters of taste in watercolours as Martin Hardie, whose definition of the finest watercolour was one which consisted of pure broad washes. Lloyd, on the other hand, shared the taste of Turner's own Victorian patrons and collectors. ${ }^{31}$

Thus, while Smythe and Lloyd both engaged with a general taste for Turner watercolours, their choice of which Turners to collect was Victorian and outdated. Smythe's collection thus exemplifies a more aesthetically conservative outlook, one that becomes increasingly outmoded during the twentieth century.

\section{Influence of International Art}

In addition to the new sketch aesthetic, the other major shift in taste occurred when Britain increased its engagement with Continental and other overseas art trends. Simon Fenwick and Greg Smith note the influence of Impressionism and Symbolist aesthetic theories from France as providing an alternative to the highly finished Victorian art and further encouraging the popularity of the 'unfinished' sketch. ${ }^{32}$ British watercolours were subsequently often praised specifically for their Impressionist-like qualities. ${ }^{33}$ In the case of William James Müller (1812-1845), Feather observes that a “new awareness of Müller's importance as an artist was clearly emerging in the mid to late 1890 s. ${ }^{34}$ She continues that

\footnotetext{
${ }^{31}$ Kim Sloan, J.M.W. Turner: Watercolours from the R.W. Lloyd Bequest to the British Museum (London: British Museum Press, 1998), 29-30.

${ }^{32}$ Fenwick and Smith, Business of Watercolour, 22-23.

${ }^{33}$ For more information on Impressionism, especially in England, see Anna Gruetzner Robins, A Fragile Modernism: Whistler and His Impressionist Followers (New Haven: Yale University Press, 2007); Kate Flint, Impressionists in England: The Critical Reception (London: Routledge \& Kegan Paul, 1984); Caroline Corbeau-Parsons, Impressionists in London: French Artists in Exile 1870-1904 (London: Tate Publishing, 2017); John House, Impressionism for England: Samuel Courtauld as Patron and Collector (London: Courtauld Institute Galleries, 1994). For writings in support of Impressionism in England, by Frank Rutter and Roger Fry, see Bernard Denvir, The Late Victorians: Art, Design and Society, 1852-1910 (New York: Longman, 1986), 243-248.

${ }^{34}$ Feather, "Formation of a Modern Taste," 221.
} 
this was reinforced by the dealer and artist James Orrock (1829-1913), who "described his admiration for the 'grand impressionist treatment' of Müller's watercolour 'sketches' in the Art Journal in 1895." 35

With private collectors like Gwendoline and Margaret Davies, as well as Samuel Courtauld, who was also encouraging the public museums to collect Impressionist painting, this new style soon helped to form a common aesthetic language for English viewers and artists. ${ }^{36}$ In Smythe's collection, later watercolours like those by George Clausen, Thomas Collier and William Fisher [Fig. 66-Fig. 70] can all be described in these terms. Thus, even if Smythe was not collecting Impressionist works themselves, he was aware of their increasing popularity and was not opposed to collecting watercolours with a similar visual style.

The other non-British art that was integrated into the general taste at this time came from Asia, primarily Japan. While an interest in East Asian art had already emerged among English artists and collectors by the 1860s, Feather explains that "by the 1880s and 1890s, evidence for the wider dissemination of this interest amongst a middle-class, art-educated public was apparent in the large numbers of articles on Japanese art published in periodicals such as The Studio, Magazine of Art and the Art Journal." ${ }^{37}$ At the turn of the century, it was affordable to buy Japanese prints, and for many collectors they formed a complementary counterpart to their watercolour collections. London-based Charles Shannon (1863-1937) and Charles Ricketts (1866-1931), for example, formed one of the most magnificent collections of the time. ${ }^{38}$ Shannon was especially active in acquiring Japanese woodblock prints. Ricketts wrote in a letter in 1914, "Shannon has greatly added to our Japanese print department: our Harunobus are now more numerous and of a higher quality than those belonging to Harmsworth or the British Museum Print Room."39 Indeed, when Shannon died

\footnotetext{
${ }^{35}$ Feather, "Formation of a Modern Taste," 221. On Müller's shifting reputation due to his close ties to collector Joseph Gillot, see also Bernard Denvir, "The Gillot Sale," in Denvir, The Late Victorians, 116-119.

${ }^{36}$ For more information on these collectors, see Andrew Stephenson, "FFeminine' Anatomies of Taste and Cultures of Collecting in Early Twentieth Century Britain: Gwendoline and Margaret Davies as Women art Patrons," Aurora, The Journal of the History of Art 4 (2003); Madeleine Korn, "Exhibitions of Modern French Art and their Influence on Collectors in Britain 1870-1918: The Davies Sisters in Context," Journal of the History of Collections 16, no. 2 (2004): 191-218; and John House, Impressionism for England: Samuel Courtauld as Patron and Collector (London: Courtauld Institute Galleries, 1994).

${ }^{37}$ Feather, "Formation of a Modern Taste," 81.

${ }^{38}$ Charles Haslewood Shannon (26 April 1863 - 18 March 1937) was an artist, best known for his portraits, and Charles de Sousy Ricketts (2 October 1866 - 7 October 1931) was an artist, illustrator, author and printer. The two men met in art school and became lifelong partners. Ricketts also became a known art connoisseur and critic, and he was even offered the position of director of the National Gallery, which he turned down. See Joseph Darracott, The World of Charles Ricketts (New York: Methuen, 1980); and J.G. Delaney, Charles Ricketts: A Biography (New York: Clarendon Press, 1990).

${ }^{39}$ Joseph Darracott ed., All for Art: The Ricketts and Shannon Collection (Cambridge: Cambridge University Press, 1979), 18.
} 
in 1937, over three hundred items from their collection that went to the British Museum were Japanese prints. ${ }^{40}$

For Shannon and others, the attraction lay in the qualities of their designs. As Ricketts wrote in 1900, "I think, at their best, that nothing quite touches a first-rate Jap print, excepting a good Greek Kylix or first-rate Tanagra: even the latter hardly compare; only the masterpieces of the greatest masters go beyond: picked Titian or Rembrandts, or worldfamous frescoes. ${ }^{, 41}$ Impressionist and Post-Impressionist artists themselves were often inspired by Japanese $u k i y o-e$ and started to adapt some of their stylistic characteristics into their own art. Just as British watercolours were admired for their Impressionist qualities, so they started to be compared to Asian prints and paintings as well. Laurence Binyon (18691943), for example, associated Cotman's “tendency to simplify the appearance of things to a system of harmoniously coloured spaces" to Chinese and Japanese artists who "systematically omitted all cast shadows, and preferred to suggest modelling rather than to render it fully." 42 This was another reason for Cotman's popularity at this time. Other works from Smythe's collection, such as George Cruikshank's Girl with Apples [Fig. 61], also demonstrate key characteristics of Japanese art, like clear blocks of colour, strong outlines and cropped views. However, such works make up only a small part of the entire collection.

\section{Rejection of Victorian Art}

A by-product of this new modern taste was the rejection of the highly finished works of the Victorian era, and the removal of artists like Hunt from the established canon. While Smythe was aware of and engaged with the 1890s-1910s British taste for a modern 'sketch-like' aesthetic and collected works by sought-after artists which illustrated these aspects, a large portion of his collection was still very much focused on a more conservative taste from previous decades.

This older Victorian taste, which Smythe gravitated towards, preferred the highly finished, often figurative, watercolours of artists like the Pre-Raphaelites or George Kilburne [Fig. 53]. The domestic, medieval, and innocent nature of these subjects was in line with the later-nineteenth-century aspirations of viewers and collectors of art:

The extraordinary scale of watercolour manufacture during Victoria's reign (the Queen herself was an enthusiastic watercolorist and collector) fed an insatiable

\footnotetext{
${ }^{40}$ Darracott, All for Art, 17.

${ }^{41}$ Ibid., 18 .

${ }^{42}$ Laurence Binyon, "John Sell Cotman," vi., cited in Feather, "Formation of a Modern Taste," 90-91.
} 
appetite for pictures that suited the pocket of middle-class consumers and addressed an audience eager for reassuring images which, in contrast to the art of the foregoing Romantic period, reflected the tamer emotions of a domestic age. ${ }^{43}$

William Henry Hunt, one of the canonical artists immortalised in the busts mentioned by Feather, perfectly illustrated these characteristics. However, by the time Smythe was actively assembling his collection, tastes had already changed. The critic D.S. MacColl, for example, publicly criticised William Holman Hunt for his choice of sentimental subject matter. ${ }^{44}$ Feather observes that in 1892 he wrote "dismissively but with insight as to the changing trajectory of taste: 'In a few short years those complexions, those sheep, those pies, will have gone the dusty way after the Augustus Eggs and other perishables'."45 Indeed, Laurence Binyon wrote in 1933 that "the prestige of Victorian masters has waned." $" 46$

In addition to their sentimental subject matter, Hunt and other Victorian artists were also considered old-fashioned due to their painting technique. The high finish, immaculate detail and evident use of bodycolour created a direct contrast to the new preferred sketch aesthetic. Richard and Samuel Redgrave, authors of A Century of British Painters (1947), were among those critics who emphasised the importance of rejecting bodycolour and focusing on the transparent quality of watercolours. They especially criticised the use of opaque whites, claiming it was "wholly at variance with true water-colour painting, destroying some of its finest qualities, the freshness and purity of colours, as seen by light transmitted through them from the white paper, being wholly lost." ${ }^{\prime 7}$ This is why they praised Turner's technique of scratching and scraping away the surface of the paper to achieve highlights instead. ${ }^{48}$

\footnotetext{
${ }^{43}$ Peter Raissis, Victorian Watercolours from the Art Gallery of New South Wales (Sydney: Art Gallery of New South Wales, 2017), 17.

${ }^{44}$ Other artists suffered a similar wave of criticism, such as Frank Dicksee (1853-1928), whose painting The Funeral of a Viking (1893, Manchester Art Gallery, 1928.13) was described by Arthur Tomson in an article in The Studio (June 1893): "trivial in sentiment and in workmanship; its drama is pure melodrama, worthy of the Adelphi or the Britannia; and as to its accomplishment - well, the sentiment of paint and of colour has been entirely overlooked in the painter's vain struggle with his colossal subject." See Denvir, The Late Victorians, 240.

${ }^{45}$ MacColl, "The Winter Exhibition at Burlington House I. English Masters," 55, cited in Feather, "Formation of a Modern Taste," 60. Augustus Egg (1816-1863) was a genre and history painter, who during the early 1850s started promoting artists like William Holman Hunt and the Pre-Raphaelites. See Hilarie Faberman, "Egg, Augustus," Grove Art Online, 2003, accessed 12 September 2018, https://www-oxfordartonlinecom.helicon.vuw.ac.nz/groveart/view/10.1093/gao/9781884446054.001.0001/oao-9781884446054-e7000025031 ?rskey=otlogt.

${ }^{46}$ Laurence Binyon, English Water-Colours, $2^{\text {nd }}$ ed. (London: Adam \& Charles Black, 1946), 173.

${ }^{47}$ Samuel Redgrave, A Descriptive Catalogue of the Historical Collection of Water-Colour Paintings in the South Kensington Museum (London, 1877), 59-60, cited in Feather, "Formation of a Modern Taste," 25.

${ }^{48}$ Feather, "Formation of a Modern Taste," 25.
} 
However, while MacColl characterised Hunt's elaborate works as "niggling for niggling's sake", the Redgraves actually viewed him as an exception to this rule, ${ }^{49}$ describing Hunt's limited use of opaque white in his many still lives and flower pieces as a "union of opaque and transparent colouring", giving his work force and richness. 50 Similarly, critic Frederick Wedmore (1844-1921), in his review of the 1892 winter exhibition, makes "no contradiction in his admiration of what he perceived as Turner's sketch-like watercolours alongside the very different pictorial qualities in Hunt's works." ${ }^{\text {"1 }}$ The presence of Hunt's Still Life [Fig. 51] in the collection shows that Smythe did not agree with MacColl. When it came to other artists too, he was not completely opposed to the use of bodycolour, as evident from works such as River Scene-Boy Fishing [Fig. 67].

\section{Personal Preference}

Despite all this, Smythe's collecting was not entirely driven by general taste. He still had his own personal agendas for choosing particular artworks. For example, it seems that a John Leech watercolour of a nurse struggling to carry a child as big as herself (Drat the Child, Te Papa, 1957-0009-162), was originally added to the collection for intimately nostalgic reasons. Responding to one of Smythe's letters, which is missing from the archives, Maclennan wrote, "how thrilled you must have been to discover the original of 'More trouble than all my Money', having remembered it since childhood." ${ }^{, 52}$ The missing letter must have explained how Smythe knew the subject of this watercolour in print format, most likely through the published collection of Leech's best Punch drawings in book format, John Leech's Pictures of Life and Character: From the Collection of "Mr. Punch", first published in 1857. ${ }^{53}$ This 'picture book' was intended for that audience which did not see Leech's work in the magazine, such as families. This is the likely setting in which Smythe would have first encountered this picture as a child. Finding it at an auction or dealer's as an adult struck a sentimental chord with the collector, enough to acquire it.

In fact, some writers on collecting, such as Derek Clifford, even strongly advise the use of personal feelings when assembling a collection, concluding "it is the personal quality of judgements of this sort which make every collection so unlike every other if it is

\footnotetext{
${ }^{49}$ MacColl, cited in Feather, "Formation of a Modern Taste," 60.

${ }^{50}$ Redgrave, A Descriptive Catalogue, 44 and 59-60, cited in Feather, "Formation of a Modern Taste," 25.

${ }^{51}$ Frederick Wedmore, "The Winter Exhibition at Burlington House," Standard (7 January 1892), cited in Feather,

"Formation of a Modern Taste," 58.

52 Maclennan to Smythe, 21 November 1956, TPA: MU00008, box 3, item 6.

${ }^{53}$ John Leech's Pictures of Life and Character: From the Collection of "Mr. Punch" (London: Bradbury, Agnew \& Co., 1887), 114.
} 
genuinely made. It is collections made on expert advice which always seem so alike." 54 Thus, the American art dealer and collector Charles Carstairs (1865-1928) acquired numerous works with Venetian subject matter due to his intimate personal connection with the city. In May 1918, for example, he purchased a Singer Sargent watercolour of a Venetian scene, even though, as he wrote to his colleague Charles Henschel, "there was not much profit in it." ${ }^{\circ 5}$ Similarly, Smythe was not deterred by the fact that the religious architectural watercolours in his own collection were not sought-after collection items. Churches make up most of the architectural subjects in his collection. Rather than nostalgia, the reason for Smythe's interest in such watercolours is linked both to his own profession as a member of the clergy and his personal conviction that art and religion are closely interlinked, as he wrote in 1958 that "art is part of religion to me, because real art is inspired by the Holy Spirit of God, at least, so I believe." ${ }^{, 56}$ Maclennan also acknowledged in a letter to Smythe that "a Collection such as yours certainly does reflect the personality of the Collector." $" 57$

\section{Prices and Financial Limits}

In addition to general and personal art tastes, Smythe's collecting was also influenced by prices of works and his financial situation. His collection includes a large number of social satirical watercolours by artists such as Hablot K. Browne, George Cruikshank, John Leech, and Thomas Rowlandson. While the subject matter must have appealed to him personally, the less expensive prices of such works would have been a deciding factor as well. He was following a similar approach to William Lever (1851-1925), whose earliest decorative purchases were also "cheap, illustrative drawings and watercolours, often of a literary and comic nature. ${ }^{" 58}$ Feather explains:

It was not until the second half of the 1890s that Lever began to develop a taste for more significant watercolour and drawing purchases. Up until that point the low cost of these items was the overwhelming factor in determining Lever's acquisitions to decorate his home, although his personal interest in the literature of Dickens and the

\footnotetext{
${ }^{54}$ Derek Clifford, Collecting English Watercolours, 2nd ed. (London: John Baker, 1976), 33.

${ }^{55}$ Charles Carstairs cited in Margaret Iacono, “A Dealer Collects: Reconstructing Charles Stewart Carstairs's Private Art Collection,” Journal of the History of Collections 29, no. 1 (2017): 100-101, accessed 10 May 2019, https://academic.oucom/jhc/article/29/1/93/2503286.

${ }^{56}$ Smythe to DPAG, 1 December 1958, DCCA: Box 11, DPAG 15/22. Religion and God were deciding factors for Smythe's decision to donate his collection to New Zealand. See Chapter Two, 56-57.

${ }^{57}$ Maclennan to Smythe, 11 December 1956, TPA: MU00008, box 3, item 6.

${ }^{58}$ Jessica Feather, British Watercolours and Drawings: Lord Leverhulme's Collection in the Lady Lever Art Gallery (Liverpool: National Museums Liverpool, 2010), xii.
} 
politics of Gladstone, for example, explains some of the choices made within a certain price bracket. ${ }^{59}$

These light-hearted watercolours could be appreciated for their narrative rather than aesthetic qualities and could also be purchased for relatively low prices. ${ }^{60}$

Smythe's personal financial limitations not only dictated which watercolours to purchase, but also which ones were out of reach. In his letters, he repeatedly refers to himself as a poor man and laments the fact that he was often not able to buy a particular watercolour because he did not have the money for it. In 1956 he wrote that he "often missed good specimens for lack of means to buy them", 61 and that he was "a man who has searched $\&$ hunted $\&$ often had to say with Shakespeare 'Alas Farewell thou art too dear for my possessing', only I use the more sad word 'alas'."62 He even claimed that he was "quite poor enough to have refused good drawings at 4-6 guineas", which would help to explain why the earlier-mentioned Blakes selling for $£ 480, £ 520$ and $£ 650$ were unattainable for him. ${ }^{63}$

John Tomlinson explains that this was a common situation for members of the British clergy at this time. He writes, "by the middle of the twentieth century there were no clergy with large incomes, indeed by then they would be just a faint memory. Whereas doctors, lawyers, engineers and accountants were enjoying an increase in real income clergy were growing poorer." 64 This state of affairs became even more dire for clergy wishing to retire, as Smythe had done by the time he was writing his letters to New Zealand. Tomlinson writes, "effectively only those who were in wealthy livings or had private income could retire. Not until 1907 did the Commissioners provide a pension, first at the annual rate of $£ 50$, increased to $£ 75$ in 1915 , and to $£ 200$ in 1926 . The poor pension provision probably prevented many clergy from retiring." ${ }^{65}$ Smythe retired in 1946, and even if the pension had increased more since 1926, it would still not have been enough to keep up his collecting habits and other living standards. This also explains why he moved to Elfinsward after retiring. During his professional career Smythe had always been provided with a house by

\footnotetext{
${ }^{59}$ Feather, British Watercolours and Drawings, xiii.

${ }^{60}$ Other avid collectors of Rowlandson were William Spooner and his wife Mercie 'Mouse' Milling. For more information on their collection, see Michael Broughton, "William Wycliffe Spooner," in Michael Broughton, William Clarke and Joanna Selbourne, The Spooner Collection of British Watercolours at the Courtauld Institute Gallery (London: Courtauld Institute Gallery, 2005), 1-16.

${ }^{61}$ Smythe to DPAG, 2 May 1956, DCCA: Box 11, DPAG 15/22.

${ }^{6}$ Smythe letter to Watson, 12 July 1956, TPA: MU000044, box 2, item 12.

${ }^{63}$ Smythe letter to Watson, 29 July 1956, TPA: MU000044, box 2, item 12.

${ }^{64}$ John William Bruce Tomlinson, "From Parson to Professional: The Changing Ministry of the Anglican Clergy in Staffordshire, 1830-1960," PhD diss., University of Birmingham, 2007, 217.

65 Ibid., 214.
} 
the parish, but once he retired, he did not have enough money to sustain his own household anymore. ${ }^{66}$

Still, the fact that he was able to retire, remarry and move into a new house does suggest that he had some private wealth to fall back on. In fact, during the late nineteenth century it would have almost been impossible to become a clergyman in the first place without such pre-existing private funds. ${ }^{67}$ Smythe needed money to train as a priest, and before that to study at Cambridge for his BA and MA. Therefore, he must have been reasonably well-off to start with. Indeed, his father was a solicitor, then one of the highestpaid professions in Britain. ${ }^{68}$ His family, therefore, had the means and connections to support the younger Smythe's ambitions; and having a member of the clergy in the family certainly helped to boost their social status in turn. Perhaps, then, his later insistence on being 'a poor man' and not having enough funds to purchase the best watercolours was somewhat of an exaggeration on his part.

Nonetheless, when one considers the actual prices of the fashionable watercolours at the time, it is easier to understand his dilemma. Philip McEvansoneya, in his article "Creating the Crampton Collection of British Watercolours in the 1850s" (2009), mentions "the great inflation in watercolour prices, notably for works by Cox and Copley Fielding, which began during the 1860 s and reached its peak in the 1890s." 69 This peak occurred exactly when Smythe started collecting, by which time a Cox could reportedly fetch $£ 3,000$ or more. ${ }^{70}$ In 1924, Smythe’s contemporary Lever is known to have paid $£ 2,583$ for Turner's Lucerne and $£ 609$ for Madox Brown’s Cordelia's Portion. ${ }^{71}$ Such prices were unattainable for Smythe, who said that one of the highest prices he ever paid for an item in his collection was $£ 60$ : "I gave a lot of money for it: 60 (because 2 others wanted it the price was much raised) ... I have very seldom given so high a price for anything in my little collection"72 Furthermore, he had to make multiple payments to pay even just this seemingly small amount. $^{73}$

\footnotetext{
${ }^{66}$ In a letter to A.J.B. Wace (Keeper of the Department of Textiles, V\&A), Smythe also said that he was selling his house after the death of his wife in 1944. See Smythe to Wace, 5 October 1944, V\&A Archives (VAA): MA/1/S2404.

${ }^{67}$ Tomlinson, "From Parson to Professional," 202.

${ }^{68}$ R.V. Jackson, "The Structure of Pay in Nineteenth-Century Britain," The Economic History Review 40, no. 4 (1987): 564, accessed 14 August 2019, www.jstor.org/stable/2596393. The annual earnings of solicitors and barristers rose from an average $£ 448$ at the start of the nineteenth century to a staggering $£ 1,838$ by the middle of the century (as opposed to the clergy, whose annual salary remained between $£ 260$ - $£ 290$ throughout).

${ }^{69}$ McEvansoneya, "A Thing to Be Seen," 107.

${ }^{70}$ Binyon, English Water-Colours, 173.

${ }^{71}$ Feather, Lord Leverhulme's Collection, xix.

${ }^{72}$ Smythe to Wace, 20 September 1927, VAA: MA/1/S2404.

${ }^{73} \mathrm{He}$ wrote on 20 September 1927 that he has already paid $£ 53$ and owed another $£ 7$. Smythe to Wace, 20 September 1927 , VAA: MA/1/S2404.
} 
Turner was by far the most expensive artist to acquire, and by the time Smythe started his collection many of his most typical and desirable works were also already off the market. In his book The Economics of Taste: The Rise and Fall of Picture Prices 1760-1960 (1982), Gerald Reitlinger explains that prices for Turner increased dramatically and were almost impossible to attain during the late nineteenth century. ${ }^{74}$ From 1910 onwards, there was a slow decline in this taste which led to lower prices, and by the 1950 s even Turners had slumped. ${ }^{75}$ This, however, was too late for Smythe. He was no longer buying works, but instead tried to sell off his own collection. Besides, the most significant Turners, especially those illustrating the popular sketch aesthetic, were already in the tight clasps of museums and galleries. Smythe mentioned several times in his letters that "all the finest examples have long ago been snapped up by the museums." "76 Therefore, the fact that Smythe's Turners are of the 'old-fashioned' taste also reflects his financial restrictions and market availability, rather than just personal preference for more finished landscapes or a dislike for near-abstract washes. ${ }^{77}$

\section{The 'Progressive Narrative' and Broad Collecting}

The wide variety of watercolours in Smythe's collection demonstrates that he was not aiming to represent one specific taste at all. He did not focus on solely collecting landscapes or figures, and while earlier nineteenth-century names make up the majority of the artists covered in his collection, they were not his sole focus. While he might have followed trends for some individual artists and styles, he did not limit his own collection to this. Indeed, a visitor to an exhibition of just over 100 of Smythe's watercolours at the South London Art Gallery in 1954, observed that "Canon Smythe has cast his net very widely, and this selection from his haul includes a proportion that is of either topographical or curiosity interest." 78

In fact, twentieth-century collectors may be split into two types: the ones who cast their nets as widely as Smythe had done (exhibiting a middle-brow, vernacular approach), and those who specialised on a smaller selection (high-brow, connoisseurly approach). Like

\footnotetext{
${ }^{74}$ Gerald Reitlinger, The Economics of Taste: The Rise and Fall of Picture Prices 1760-1960, vol. I (New York: Hacker Art Books, 1982), 100-101.

${ }^{75}$ Ibid., 103-104.

${ }^{76}$ Smythe to Allen (DPAG president), 2 May 1956, DCCA: Box 11, DPAG 15/22.

${ }^{77}$ While such works dominate the collection, I have already shown that Smythe did acquire some sketch-like examples too, including some which he had originally attributed to Turner, such as The Fifth Plague (116-195X) and Misty Shore (977195X) in Dunedin.

78 "Exhibition of English Watercolours," Times [London] (9 September 1954): 11, The Times Digital Archive, accessed 20 November 2017, https://link-galecom.helicon.vuw.ac.nz/apps/doc/CS185422633/TTDA?u=vuw\&sid=TTDA\&xid=b6ef249d.
} 
Smythe, John Percy (1817-1889) was concerned with illustrating as many artists as possible. ${ }^{79}$ He built a collection described by a Christie's sale catalogue as more than "fifteen hundred drawings by nearly seven hundred painters of the English Water-Colour School ... forming an almost complete History of Water-Colour art from the commencement of the eighteenth century to the present time." ${ }^{\prime 80}$ Feather references the writings of Henry William Pyne (1769-1843), and Richard and Samuel Redgrave to explain further that "the majority of Percy's collection consisted of one or two examples by a vast number of artists who were mainly minor landscape painters but whose styles did illustrate the narrative told by Pyne and the Redgraves of the 'progression' of water colour from 'tinted' drawing to watercolour painting." 81 This same description could be used for Smythe's watercolour collection.

The narrative of progression mentioned above ties the progress of the watercolour medium to a specific canon of artists, from the topographers to the Romantics, with Girtin and Turner forming the epitome of the medium's triumph. Such a narrative requires numerous participants and representatives to show every step of improvement. Thus, a collector who aimed at demonstrating this story required a large number of watercolours by many artists.

However, such a collector was already in the minority during John Percy's time. Percy's approach had been different from his own contemporaries, such as Henry Vaughan (1809-1899) and James Orrock, as they had focused on acquiring works by a much smaller range of canonical artists. ${ }^{82}$ The same was true for the majority of Smythe's generation, for example Sir Hickman Bacon, who was collecting roughly between 1890 and 1910. His collection was also dominated by Golden-Age artists like Cox, Cotman, Turner, Müller, De Wint, and Girtin. ${ }^{83}$ There is a marked absence of topographical artists like Sandby, Rooker and Dayes, demonstrating that a progressive narrative of watercolour was not his concern. Instead, Bacon aimed to purchase works that illustrated the sketch aesthetic, preferring, for example, the later works of Turner. ${ }^{84}$

Smythe chose not to follow such trends and instead bought whatever he liked and could afford. Through this, even if there was no purposeful approach to showcase the history of the development of watercolour, Smythe cast his net so wide over the medium as to even

\footnotetext{
${ }^{79}$ Feather, "Formation of a Modern Taste," 194.

${ }^{80}$ Ibid., 199.

${ }^{81}$ Ibid., 200.

${ }^{82}$ Ibid., 207.

${ }^{83}$ Ibid., 208 .

${ }^{84}$ Ibid., 218.
} 
include works by artists using large amounts of bodycolour. This was a choice that, even after Smythe's time as a collector had ended, was still considered unusual. Patrick Noon, for example, describes the surprising purchase of a highly-finished Victorian watercolour by Paul Mellon during the 1970s:

The decision to represent the entire range of British achievement in the graphic arts also resulted in the acquisition of some totally unexpected objects. The very first watercolor to be purchased by Paul for the Center for British Art after its incorporation in 1976 was John Frederick Lewis' Frank Encampment in the Desert of Mt. Sinai (Fig. 5). As an expansive morsel of Victorian narrative painting and "licked" technique, it was not at all to Paul's taste, which usually favored painterly bravura, but, like Ruskin before him, he recognized the significance of this tour de force of water color painting. ${ }^{85}$

Thus, some collectors would even disregard their own personal taste in order to attain as wide a collection of watercolours as possible. ${ }^{86}$

\section{Collecting Contemporary and Modern}

Another way in which Smythe's taste was 'exceptional', and indeed outdated, was the almost complete absence of any contemporary artists. During the early twentieth century, there were many watercolourists in Britain exploring new possibilities for the medium, partly in an attempt to challenge the opinion that the Golden Age of British watercolour had ended around 1850. A new engagement with Continental painting styles and current affairs in Europe is reflected in the works of a new generation of artists. Edward Marsh (18721953), a civil servant who worked many years for Winston Churchill, was a collector who illustrated this modern taste for contemporary artists. Initially, Marsh also focused on acquiring Old Master works and then early English watercolours, spending on average

\footnotetext{
${ }^{85}$ Patrick Noon, "Princely Amateur: Paul Mellon and His Collection of British Drawings," Master Drawings 38, no. 3 (Autumn 2000): 343.

${ }^{86}$ In fact, Smythe's own net was cast so wide that it went far beyond British watercolours alone. He was a very broad collector, and an advertisement for a sale at Christie's lists porcelain, glass and needlework among his possessions. See "Flats and Chambers," Times [London] (6 November 1934): 27, The Times Digital Archive, accessed 20 November 2017, https://link-gale-com.helicon.vuw.ac.nz/apps/doc/CS453192550/TTDA?u=vuw\&sid=TTDA\&xid=08e4469c, and also "Sotheby \& Co," Times [London] (23 March 1937): 29, The Times Digital Archive, accessed 20 November 2017, https://link-gale-com.helicon.vuw.ac.nz/apps/doc/CS487141495/TTDA?u=vuw\&sid=TTDA\&xid=6eb5f2e7. It is not within the scope of this thesis to analyse this side of Smythe's collecting practices, but it would make an interesting topic for future research. Other collectors who collected in different areas, such as painting, porcelain and furniture, included Robert Wylie Lloyd, Stephen Courtauld, Herbert Powell, and Agnes and Norman Lupton (Sloan, J.M.W. Turner, 31.) See also Louise Tythacott, "The Power of Taste: The dispersal of the Berkeley Smith Collection of Chinese Ceramics at Cheltenham Art Gallery \& Museum (1921-1960)," Journal of the History of Collections 28, no. 2 (2016): 328, accessed 10 May 2019, https://academic.oucom/jhc/article/28/2/327/2404438; and Frank Herrmann, The English as Collectors: A Documentary Sourcebook, $2^{\text {nd }}$ ed. (New Castle: Oak Knoll Press, 1999).
} 
$£ 200-300$ a year on pictures. ${ }^{87}$ However, David Buckam explains that, after the purchase of Duncan Grant's Parrot Tulips in 1911, "Marsh became a committed collector of such contemporary painters as Stanley Spencer, Walter Sickert, John and Paul Nash, David Bomberg and Mark Gertler." 88 Christopher Hassall, Marsh's biographer, said that Marsh turned his back on the past and by 1914 had "brought together the nucleus of what became one of the most valuable collections of modern work in private hands." ${ }^{89}$ While these artists were mainly known for their works in oils, their names also appear in collections of watercolours. ${ }^{90}$

During the same time as Marsh, public institutions also turned towards contemporary watercolourists for their own collections. The Contemporary Art Society (CAS) was founded in 1910 "to improve the representation in public art galleries of contemporary British artists. ${ }^{91}$ Kim Sloan, curator of British Drawings and Watercolours before 1880 at the British Museum, explains that the CAS set up a fund in 1919 "for the specific purpose of acquiring modern prints and drawings, both British and foreign, which were to remain in the possession of the Society for a period and were then to go to the Prints and Drawings collection of the British Museum." 92 As a result, the museum received over 200 works through the CAS by 1960. These watercolours "reflect the taste of the committee members who not only decided on purchases by the Society but also gifted works from their own collections for distribution." 93 These new purchases and selected gifts, therefore, illustrate a new twentieth-century modern taste that favoured artists like John and Paul Nash (18931977 and 1889-1946), Lucien Pissarro (1863-1944), Edward Wadsworth (1889-1949) and lesser-known names like Robin Wallace. A new canon was born.

Samuel Courtauld (1876-1947), in line with his interests in French Impressionism, spent only modest amounts on contemporary British art. His choices reflected the AngloFrench taste in modernism which preferred representatives of the Bloomsbury Group, or

\footnotetext{
${ }^{87}$ David Buckman, "Marsh, Sir Edward," Grove Art Online, 2003, accessed 1 August 2019, https://www.oxfordartonline.com/groveart/view/10.1093/gao/9781884446054.001.0001/oao-9781884446054-e7000054577.

${ }^{88}$ Ibid.

${ }^{89}$ C.V. Hassall and Mark Pottle, "Marsh, Sir Edward Howard (1872-1953), Civil Servant and Patron of the Arts," Oxford Dictionary of National Biography, accessed 17 September 2019, https://www.oxforddnb.com/view/10.1093/ref:odnb/9780198614128.001.0001/odnb-9780198614128-e-34892.

${ }^{90}$ For more information on Marsh, and a catalogue of his bequest to the Contemporary Art Society (CAS), see The Arts Council of Great Britain, Paintings and Drawings from the Sir Edward Marsh Collection (London: The Favil Press, 1953). See also "Sir Edward Marsh: An Inventory of His Collection at the Harry Ransom Center," accessed 10 June 2019, https://norman.hrc.utexas.edu/fasearch/findingAid.cfm?eadid=00927.

${ }^{91}$ Kim Sloan ed., Places of the Mind: British Watercolour Landscapes 1850-1950 (London: Thames \& Hudson, 2017$), 19$. For more information about the CAS, see Alan Bowness ed., British Contemporary Art 1910-1990: Eighty Years of Collecting by The Contemporary Art Society (London: the Herbert Press, 1991).

${ }^{92}$ Sloan, Places of the Mind, 19.

${ }^{93}$ Ibid.
} 
artists like Walter Sickert (1860-1942), referred to as 'English Impressionists'. ${ }^{94}$ These artists helped to further solidify the link between French Impressionism and the sketch aesthetic in British watercolours. While it was possible for collectors to see Impressionist qualities in works by the earlier artists - those working before the emergence of Impressionism - the contemporary watercolourists of Smythe's and Courtauld's own time were able to fully incorporate and develop these characteristics in Britain itself. This led to a reassessment of watercolours as a type of proto-Impressionism. ${ }^{95}$ Indeed, English art critic Clive Bell defended the work of these 'English Impressionists' by directly linking their work to the Golden Age masters. In 1926 he wrote:

these artists [of the LAA] are still accused by stupid and ignorant people of being Frenchified and exotic ... they did turn [earlier in their careers] to the modern movement and to be sure that movement was essentially French ... But they are adult now. They have found themselves. And themselves ... are as you would have expected profoundly British. These artists have jumped the Slade and Pre-Raphaelite puddles to join hands with their ancestors - Hogarth, Gainsborough, Crome, Cotman and Constable. Wherefore if the English tradition exists anywhere, it exists in the London Association. Here is the nucleus of a modern British school! ${ }^{96}$

Even without notable contemporary works, Smythe's collection of early British watercolours might therefore still have been considered relevant to this modern AngloFrench taste.

Some collectors preferred contemporary artists who were moving further away from Impressionism. Art critic and curator Frank Rutter, for example, praised modern watercolourists like Eric Ravilious, Charles Ginner, Paul and John Nash and Lucien Pissarro for returning to the older, linear, tinted wash tradition of Francis Towne and Cotman, rather than the "blob" and "swash" of Brabazon and Singer Sargent. ${ }^{97}$ Feather clarifies that Rutter belonged to a new generation of critics and artists distancing themselves "from the Impressionist sympathies of a previous generation." 98 While these artists still maintained many of the essential ideas and techniques of the previous Victorian watercolourists and the earlier Golden Age representatives, they simultaneously experimented more with bold

\footnotetext{
${ }^{94}$ Andrew Stephenson, “'An anatomy of Taste': Samuel Courtauld and Debates about Art Patronage and Modernism in Britain in the Inter-War Years," in John House, Impressionism for England: Samuel Courtauld as Patron and Collector (London: Courtauld Institute Galleries, 1994), 42.

95 John Murdoch, "Connoisseurship of Watercolour," in Broughton, Clarke and Selbourne, The Spooner Collection, 48.

${ }^{96}$ Clive Bell, “A Reformation of the English School," Artwork (1926): 5, cited in House, Impressionism for England, 42.

${ }^{97}$ Jessica Feather, “A New 'Golden Age'? The 'Modern' Landscape Watercolour,” in Sloan, Places of the Mind, 69.

${ }^{98}$ Ibid. One should not ignore, however, that earlier on in the twentieth century Rutter encouraged the purchasing of French Impressionist works for the National Collection. See Bernard Denvir, The Late Victorians: Art, Design and Society, 18521910 (New York: Longman, 1986), 243-244.
} 
colours and new types of mark-making. ${ }^{99}$ Anna Greutzner Robins adds that Spencer Gore (1878-1914) "also reduced the natural details, such as the trees and vegetation in the fields, to abstracted geometric forms, but both [Gore and Pissarro] represented identifiable 'seen' landscapes." $" 100$

Pure landscapes also came back into fashion, but this time inspired by Surrealism. In the 1930s, for example, Henry Moore and Paul Nash both "rebelled against staying true to the cosy picturesque image of South Country that filled the popular imagination, and looked for new ways to use the English landscape as a source of inspiration." ${ }^{101}$ The unnatural colouring, strange perspectives, floating objects and curious compositions of Surrealist art, more publicly known in Britain since the 1936 International Surrealist Exhibition in London, offered this. Artists also added another dimension to their watercolours by addressing dream imagery and inner states of mind within their landscapes, resulting in unexpected and bizarre pairings like Paul Nash's Nest of the Wild Stones $(1937,371 \mathrm{x}$ 550mm, watercolour and graphite, Arts Council Collection, London, AC 30). ${ }^{102}$ The jagged flints and smooth pebbles appear gigantic in the surrounding landscape, which in turn seems to softly cradle the objects as if the mountains were indeed a bird's nest.

In Smythe's case, there is only a single landscape that could be described as abstractlike: William Russell Flint's (1880-1969) Untitled Seascape (345 x 270, DPAG, 166195X). ${ }^{103}$ Flint described the act of painting landscape outside as a religious experience, and Untitled Seascape indeed exudes a sense of spiritual calmness. ${ }^{104}$ Apart from this work, the sketchy washes of Brabazon and the abstracted figures of Singer Sargent make up the most 'modern' part of Smythe's collection. By the 1920s, however, their watercolours certainly seemed old-fashioned alongside this new avant-garde. ${ }^{105}$ Thus, without any contrasting contemporary works by Nash, Ravilious or Pissarro, Smythe's collection would have indeed appeared outdated to some.

However, Smythe still believed his watercolours reflected modernity at its finest. In a letter from 1954, he wrote to Pearse that he is "sending some very fine drawings up to very modern times", "so as to bring you up to the moderns." 106 As examples of these "very

\footnotetext{
99 Anna Gruetzner Robins, “'South Country’ and Other Imagined Places,” in Sloan, Places of the Mind, 106.

${ }^{100}$ Sloan, Places of the Mind, 106.

${ }^{101}$ Ibid.

${ }^{102}$ Ibid., 114.

${ }^{103}$ Due to copyright reasons the work cannot be reproduced here, but it can be viewed on: http://collection.dunedin.art.museum/search.do?view=detail\&page $=1 \& \mathrm{id}=34131 \& \mathrm{db}=$ object

${ }^{104}$ The artist likened watercolour painting to a spiritual quest in his 'moral doctrine.' See Sloan, Places of the Mind, 10.

${ }^{105}$ Feather, "A New 'Golden Age'," 69.

${ }^{106}$ Smythe to Pearse, 23 April 1954, DCCA: Box 11, DPAG 15/22.
} 
modern artists', he only named Whistler and Singer Sargent, who were no longer regarded as modern by the 1950s. One could assume from this that Smythe simply did not keep up with the shifting art world of his time. However, we also know that he was still actively collecting up into the 1940s. Interestingly, another part of his letter demonstrates that he was well aware of other popular art movements, but made the personal choice not to collect them. After listing Whistler and Singer Sargent, he added, "but not the Vorticists or that sort of rubbish, because tho some like them I ... can't see any art in them." ${ }^{107}$ Despite Smythe's attempt to bring New Zealand "up to the moderns", his gift was still considered a collection of "Early Watercolours", requiring the DPAG to make additional purchases in the "Contemporary English Section" in order to balance out the old-fashioned Smythe collection. $^{108}$

In conclusion, we can see that while Smythe was following some trends that reflected the interests of collectors during his time, he was largely old-fashioned in most of his choices. At the turn of the century, he actively acquired works by sought-after artists such as Cotman and Turner, and even demonstrated an interest in the sketch aesthetic. However, it seems that he remained stuck in that mind frame throughout the twentieth century, rather than actively engaging with other contemporary trends as they appeared. His choices were not only affected by general taste, but also by his financial circumstances, personal preferences, and market availability. By the time he donated his collection to New Zealand during the 1950s, it is fair to classify it as justly outdated. This should not have rendered it inconsequential, yet it fell out of favour shortly after arriving in New Zealand. The next part of this chapter will therefore consider the ways in which the collection was positioned in light of tastes and collecting habits in New Zealand during the later twentieth century.

\section{SHIFTING TASTES: COLLECTING ART IN NEW ZEALAND}

The examination of Smythe's taste has revealed that shifts in general taste can have a significant impact on the status of artworks. Similarly, developments in New Zealand art and art history after 1950 show how quickly the Smythe watercolours became outdated and

\footnotetext{
${ }^{107}$ Smythe to Pearse, 23 April 1954, DCCA: Box 11, DPAG 15/22.

${ }_{108}$ Maclennan to Watson, 22 May 1956, TPA: MU00009, box 5, item 9. This endeavour was also aided by the donations from the Rex Nan Kivell collection, which will be discussed later in the chapter.
} 
irrelevant. Tate curator Alison Smith claims that this is a natural progression in view of the general rise of modern art, which has subsequently seen the study of British watercolours become a niche activity. ${ }^{109}$ In New Zealand, however, it was not simply a general move towards the modern, but also specifically the local New Zealand modern. By examining firstly other private individuals that were collecting and gifting art to New Zealand institutions during the 1950s, and secondly what these institutions themselves were acquiring, a general picture of taste in art in New Zealand will be established. This will provide a benchmark against which the role and place of Smythe's own collection in New Zealand can be evaluated.

\section{Collecting British}

Before looking at the situation from the 1950s onwards, it is important to briefly consider taste in the period leading up to this time, enabling us to establish the Anglo-centric bias of the art establishment and the subsequent shift in taste in mid-twentieth-century New Zealand. During the early twentieth century, New Zealand's National Art Gallery (NAG) in Wellington was very much a 'child' of the Empire, or the 'Motherland'. As the National gallery, there were certain expectations that had to be considered when making new art purchases. Pamela James writes in her doctoral thesis, "The Lion in the Frame: The Art Practices of the National Art Galleries of New South Wales and New Zealand 1918-1939" (2003), that National galleries "were the Galleries through which official taste would be disseminated to the art viewing public, their purchases providing the models by which art would be gauged." 110 She explains that this 'official taste' was dictated by the London Royal Academy (RA), and that "these satellites of the British Empire vigorously participated in the ethos and work of the London Royal Academy, doing all they could to disseminate its teachings, emulate its aesthetics and indeed purchase its works."111

The highly successful Baillie Exhibition of 1912 offers a good example to demonstrate the reception of this 'official' taste in New Zealand. Organised by John Baillie, an expatriate Wellingtonian who ran the commercial Baillie Gallery in London, this

\footnotetext{
${ }^{109}$ Smith, Watercolour, 18.

${ }^{110}$ Pamela J. James, "The Lion in the Frame: The Art Practices of the National Art Galleries of New South Wales and New Zealand 1918-1939," PhD diss., University of Western Sydney, 2003, 2.

${ }^{111}$ Ibid., 12. The "satellites of the British Empires" she refers to here are the NAG in Wellington, the New Zealand Academy of Fine Arts (NZAFA) and the National Gallery of New South Wales (NGNSW), which first opened under the name The Art Gallery of New South Wales (it was renamed to The National Gallery of New South Wales in 1883, and in 1958 reverted back to The Art Gallery of New South Wales).
} 
exhibition consisted of 400 British 'masterpieces.' 112 The exhibition "immediately roused public interest and achieved a gratifying success." 113 Indeed, it was hailed as "a Royal Academy in miniature" by Wellington's Evening Post. ${ }^{114}$ The fact that each work had been “personally inspected and passed” by Royal Academician George Clausen was emphasised, ${ }^{115}$ and the public was clearly impressed, reviewers noting that "the exhibition exceeded their most sanguine expectations, and every endeavour would be made to retain the best of the pictures for the National Gallery." 116 Eventually more than thirty works were purchased, using funds from public subscriptions that had attained an impressive sum of $£ 5,000 .^{117}$

These sentiments and yearnings for academic art continued over the next decades. In 1932, Col. A.R.D. Carbery, an Irish army doctor and member of the New Zealand Academy of Fine Arts (NZAFA), was quoted in the Otago Daily Times:

Living so remotely from the world's art centres it is necessary - if there is to be any betterment in our standards of taste - that we in New Zealand should be brought more frequently into intimacy with the best contemporary work of British schools. ${ }^{118}$

One of the most sought-after RA artists was William Orpen (1878-1931), who was thought to best represent contemporary British art. Wellington and Dunedin both vied to acquire his self-portrait Après le Bain (1932), but whilst the NZAFA in Wellington was still trying to raise the necessary funds, the work was bought by the DPAG through the Robert Hay Bequest funds. ${ }^{119}$ It is interesting to note, however, that by the time this work caused such excitement in New Zealand, Orpen's reputation in England had already significantly declined. By the 1930s, the Academy and its artists were "increasingly the subject of

\footnotetext{
${ }^{112}$ Rebecca Rice, "The State Collections of Colonial New Zealand Art: Intertwined Histories of Collecting and Display," PhD diss., Victoria University of Wellington, 2010, 95. For a more detailed discussion of this exhibition, see Zofia Milliszewska, “A Taste of Home: The Baillie Exhibition of 1912," Hon diss., Victoria University of Wellington, 2004; and Tony Mackle, "The Enterprising John Baillie, Artist, Art Dealer and Entrepreneur," Tuhinga, 28 (2017): 62-79, accessed 14 July 2020, https://www.tepapa.govt.nz/sites/default/files/tuhinga_28_mackle.pdf.

113 “The National Gallery," New Zealand Times (26 August 1912): 1, accessed 31 August 2020, https://paperspast.natlib.govt.nz/newspapers/NZTIM19120826.2.6.

114 “Art in New Zealand: Four Hundred Paintings," Evening Post (2 March 1912): 9, accessed 31 August 2020, https://paperspast.natlib.govt.nz/newspapers/EP19120302.2.124.

115 “The National Gallery," Evening Post (17 February 1912): 5, accessed 31 August 2020, https://paperspast.natlib.govt.nz/newspapers/EP19120217.2.39.

116 "Exhibition Opened Yesterday," Evening Post (27 April 1912): 9, accessed 31 August 2020, https://paperspast.natlib.govt.nz/newspapers/EP19120427.2.87.

${ }_{117}$ William McAloon ed., Art at Te Papa (Wellington: Te Papa Press, 2009), 4.

118 A.R.D. Carbery, Otago Daily Times (16 April 1932): 22, cited in James, "Lion in the Frame," 118.

${ }^{119}$ See Pamela James' "Lion in the Frame" for more information about Wellington's struggle to complete this purchase, and Dunedin's success. In addition to this, the NGNSW was also trying to buy this portrait, unaware that it had already found its new home in Dunedin. See James, "Lion in the Frame," 152-158. See also Robin Kay and Tony Eden, Portrait of a Century: The History of the N.Z. Academy of Fine Arts 1882-1982 (Wellington: Millwood Press, 1983), 95-96.
} 
criticism for their entrenched conservatism." ${ }^{120}$ From this we can discern that New Zealand's taste in art was clearly lagging behind Britain at this time, and that both Wellington and Dunedin were actively pursuing British art that was already unfashionable before it reached our shores.

This continued veneration of the British model was further demonstrated in 1933, when P.R. Sargood, president and patron of the DPAG, proposed the Empire Art Loans Scheme. This scheme was to see art from the 'Motherland' regularly exhibited in New Zealand. ${ }^{121}$ Similarly, back in Wellington, Edwin Murray Fuller (1892-1933) took on the role of actively putting British art on display in order to "develop" and educate New Zealand public galleries and tastes in an appropriate manner. ${ }^{122}$ His contribution was acknowledged after his death. ${ }^{123}$ E.B. Gunson wrote that "Murray Fuller's death will entail for New Zealand a serious deprivation, in that the collections of contemporary British art which from time to time he brought to this country were not only of outstanding interest to all art lovers, but had become part of our national life." $" 124$

A watercolourist himself, it is not surprising to find that Murray Fuller encouraged this particular medium within his acquisitions. In 1923, for example, the Gallery received ten watercolours by S.J. Lamorna Birch from the Royal Watercolour Society. ${ }^{125}$ In addition to these watercolours and the expected oil paintings, all four Murray Fuller exhibitions also included etchings. Ann Calhoun explains that this might also have reflected Murray Fuller's personal taste and interests. Yet, it could also be linked to a broader "new wave of interest in prints that had taken place with the increase of a monied middle-class during the

\footnotetext{
120 James, "Lion in the Frame," 157.

${ }^{121}$ See ibid., 215-217. The Empire Art Loans exhibitions have already been mentioned in Chapter Two, as the venue which exhibited British watercolours in New Zealand. See page 68.

122 James, "Lion in the Frame," 227. For more information on the Murray Fullers, see Lizzie Bisley, "Distance Makes the Heart Grow Fonder: International Art Exhibitions in Wellington, 1928-1940," Hon diss., Victoria University of Wellington, 2003.

${ }^{123}$ Ann Calhoun, "Two Wellington Entrepreneurs of the Thirties: The Murray Fullers - I Edwin Murray Fuller," Art New Zealand 23 (1982), http://www.art-newzealand.com/Issues21to30/fullers.htm: "E. Murray Fuller died on 25 February 1933, aged 41. In his memory, the Academy purchased a watercolour, Market Place in Zanzibar, 1931, at its Autumn Exhibition. The work had been "hung on the line at the annual exhibition of the Royal Institute of Water Colours in London."”

${ }^{124}$ E.B. Gunson, "Exhibitions of Contemporary Art," Art in New Zealand (1933): 40, cited in James, "Lion in the Frame," 230. After his death, his wife, Mary Murray Fuller, continued in this role. For example, in 1938, on occasion of celebrating the centenary of New Zealand, she was tasked with selecting artworks to be included in the exhibition of British and Continental art. Out of the 562 works she chose, 515 were by British artists, nearly all of them RA members.

${ }^{125}$ Calhoun, "I Edwin Murray Fuller."
} 
'twenties." 126 This 'print revival' can certainly be observed among other private collectors from this time onwards and continued through to the 1950s. ${ }^{127}$

\section{Private Collectors}

Apart from Smythe, there were several other private collectors making large-scale donations to museums and galleries in New Zealand in the mid twentieth century. They, too, often followed a British model and, like the NAG and Smythe, favoured a more conservative taste in art. One of the most prominent was Sir John Ilott (1884-1973), but unlike Smythe, he was a collector of prints rather than watercolours. Ilott started gifting his personal collection of European prints to the NAG in 1952, just a few years before Smythe. Ilott moved to a smaller house in 1953, where he lacked the necessary space to store and display his collection, which was one of the contributing factors of his decision to donate it. ${ }^{128}$ This, too, recalls Smythe's own circumstances.

Ilott started his print collection during the 1920s, before any of the major art institutions in New Zealand had their own print collections. ${ }^{129}$ Due to the lack of literature available in New Zealand at the time, Ilott referred back to Britain for sources and help in his mission. Therefore, Ilott's taste was strongly influenced by the galleries, dealers, and publications in England. Julianne Malpas explains that "Ilott not only bought his prints in Britain, he also formed a collection based on a print canon that was established and promoted in the "Motherland' during the early twentieth century." 130 This canon consisted of a mix of Old Masters, dating all the way back to the Renaissance, and 'modern' Masters of the so-called Etching Revival (c. 1850-1930). These modern masters included Muirhead

\footnotetext{
${ }^{126}$ Calhoun, "I Edwin Murray Fuller."

${ }^{127}$ During the early twentieth century, print collections became popular due to the Etching Revivalists, and the print boom during the 1960s and 1970s which dramatically accelerated the prices of graphic works. Theodore B. Donson explains that "Dealers and collectors were paying tens of thousands of dollars in the early 1970s for proofs of Dürer engravings and Rembrandt etchings that would have cost a few thousand when they were much more common in the 1950s." See Donson, Prints and the Print Market: A Handbook for Buyers, Collectors, and Connoisseurs (New York: Thomas Y. Crowell, 1977), 338. For more information on the etching revival, see David Maskill ed., Traces of the Wake: The Etching Revival in Britain and Beyond (Wellington: Adam Art Gallery Te Pātaka Toi, 2015), and Catherine Scallen, "Rembrandt Print Connoisseurship: Sir Francis Seymour Haden, and the Etching Revival of the Nineteenth Century," Nederlands Kunsthistorisch Jaarboek 69, no. 1 (November 2020): 248-279.

${ }_{128}$ Annika Sippel, "Fifteenth and Sixteenth-Century Northern European Prints at the Museum of New Zealand Te Papa Tongarewa," MA diss., Victoria University of Wellington, 2012, 39. See also Jack Ilott, The Ilott Story (Wellington: Mallinson Rendel, 1993).

${ }^{129}$ Auckland Art Gallery started in the 1930s, and the Monrad collection left to the New Zealand Government in 1869 was only completely accessioned in 1953. This collection of 600 fine prints, particularly sixteenth-century German engravings and seventeenth-century Dutch etchings, are now held at Te Papa. See Mathew Norman, "The Print Collection of Bishop Monrad (1811-1887)," MA diss., Victoria University of Wellington, 2006.

${ }^{130}$ Julianne Malpas, “An Incurable Collector: Sir John Ilott (1884-1973) and his Passion for Prints," MA diss., Victoria University of Wellington, 2005, 5.
} 
Bone, David Young Cameron, Frank Short and William Strang, who were praised for upholding the tradition of the canonical Old Masters. Malpas explains that "these artists were established and promoted by dealers and contemporary print literature as the saviours and rightful heirs to the printmaking tradition of the canonical Old Masters, which was supposedly under threat due to the increasing popularity of abstract art." 131

Just as the RA - and therefore the NAG - preferred the more conservative art of British painters during the 1920s and 1930s, so print dealers and agents in England did not promote the modern movements. Harold Wright, for example, who was the most influential person on Ilott's collecting practices, was “openly opposed to modern abstract art and did not believe that artists like Picasso faced a long future in the business." 132 This suited Ilott's own personal tastes, as he clearly disliked anything too modern, writing "as you know, I am not entirely enthusiastic about the moderns." ${ }^{133}$ His son, Jack, further affirmed this when he said "no - he didn't collect many moderns ... he was a tolerant man - and accepted Picasso as a great - but not as his particular cup of tea." 134 Thus, Smythe was not alone in his obvious aversion to (some) modern art, which had resulted in his rather outdated watercolour collection. ${ }^{135}$

Ilott's print collection shared a similar fate, as the taste of the 1920s and 1930s with which he had started his collection soon became unfashionable in view of modern art's rising popularity. Malpas observes that:

Ironically, the representational qualities of such etching, and the consistency of their subject matter made them appear monotonous and uninteresting to many collectors after the 1930s as the popularity of abstract art and the Modernist movement increased, together with other media like lithography and colour prints. ${ }^{136}$

Yet, Ilott still pursued the same canon from his earlier collecting during the 1950s too. Another collector interested in a similar range of artists as Ilott was Walter Auburn (19061979) in Auckland, even though he started his print collection as late as 1957, when Ilott's

\footnotetext{
${ }^{131}$ Malpas, "An Incurable Collector," 5.

132 David Maskill, "Imperial Lines: Harold Wright (1885-1961): Printmaking and Collecting at the End of Empire: The Margaret Manion Lecture 2007," Melbourne Art Journal 11-12 (2009): 98, cited in Sippel, "Northern European Prints," 42. ${ }^{133}$ Ilott to Maclennan, 1 July 1963, TPA: MU00009, box 13. file 51 b, cited in Malpas, "An Incurable Collector," 48. 134 Jack Ilott to Ann Calhoun, 28 February 1987, TPA: MU000044, Box 2, File 6, cited in Malpas, "An Incurable Collector," 48.

${ }^{135}$ Mary Murray Fuller is another example of a collector who did not particularly like modern art. Ann Calhoun writes: "In her opinion, said Mrs. Murray Fuller, those who had broken away from the conventions of art and had instituted ultramodern movements, were making no progress ... There was now in progress a swing back to old traditions, but art had benefited by the upheaval." See Calhoun, "II Mary Murray Fuller."

${ }^{136}$ Malpas, “An Incurable Collector,” 10.
} 
taste had already become passé. ${ }^{137}$ Clearly, old-fashioned art tastes were not all too uncommon in New Zealand at this time, and it is important to remember that the director who accepted Smythe's gift, Maclennan, was the same who welcomed and encouraged Ilott's old-fashioned print collection. The popularity of this conservative taste was reinforced by the public's positive reaction to Ilott's collection when it was exhibited in 1953, along with the gift collections of two other collectors, Bishop Monrad and Rex Nan Kivell. ${ }^{138}$ The exhibition was held at the NAG for one month, but was then extended for another four months due to the high public interest, as Maclennan wrote that "substantial interest was reflected in Gallery attendances, which reached record figures."139

Rex Nan Kivell's gift collection, however, demonstrates that by the 1950s more individuals and art institutions were aspiring to a new taste for modernism. Rex Nan Kivell (1898-1977), the New Zealand-born director of the Redfern Gallery in London, had always aspired to lead the life of a gentleman. According to Oliver Stead, starting his own private collection was "an important marker of status in realising that aspiration." 140 While he initially focused on travel art either made in or showing images of the Pacific - he was very proud of his first acquisitions of Augustus Earle, William Strutt and Conrad Martens - by the time Smythe's watercolours arrived in New Zealand, Nan Kivell's focus had starkly shifted. ${ }^{141}$ One significant reason for this shift was his role as director of a prominent dealer gallery in London, which required him to stay on top of prevailing trends in contemporary art.

Nan Kivell was personally still rather conservative in his tastes and not a fan of abstract and non-figurative art. ${ }^{142}$ But he saw himself in the role as a promoter of contemporary art, which he expressed in a letter to The Times in relation to a ban on importing works of art which was being considered by the New Zealand Government at the time, writing "I know the absolute necessity in acquainting the public with every new change in idiom, and that pictures must be seen to appreciate the rapidly changing theories

\footnotetext{
${ }^{137}$ For more information on Auburn, see ibid., 12-13; and Emma Reilly, "Walter Auburn and his Collection of Prints," MA diss., Auckland University, 2003.

${ }^{138}$ Bishop Monrad, originally from Denmark, donated his private collection of European prints to Te Papa's predecessor, the Colonial Museum, in 1869. This was "the earliest European print collection to be donated to a public institution outside Europe." "European Master Prints: The Founding Gift of Bishop Monrad," Te Papa exhibition (22 September 2011 - 4 March 2012), cited in Sippel, "Northern European Prints," 1. For more information on Monrad, see Norman, "The Print Collection of Bishop Monrad (1811-1887)."

${ }^{139}$ Maclennan to the editor of the Evening Post, 31 May 1956, TPA: MU000008, box 4, item 1.

140 Oliver Stead, "New Lamps for Old: The Activities of Sir Rex de Charembac Nan Kivell as a Collector and Dealer of Fine Art," PhD diss., University of Otago, 2003, 34.

${ }^{141}$ Ibid., 42. For more information on his private Pacific collection, see Penelope Campbell, "Collecting the Pacific 17681977: Joseph Banks, Alexander Turnbull, Rex Nan Kivell," MA diss., Victoria University of Wellington, 2002.

${ }^{142}$ Some of the artists he preferred, like Ben Nicholson, Barbara Hepworth and Naum Gabo, still maintained links to the British landscape tradition in their work with abstraction. See Stead, "New Lamps for Old," 193.
} 
and emotions of cultural development." 143 Therefore, he viewed the Redfern Gallery as an educational tool, more like a public gallery than a commercial dealer, and himself as a public benefactor (which is also reflected in his many loans and gifts to public collections). ${ }^{144}$ While sometimes his less adventurous preferences clashed with the more risky tastes of his associates, - for example, Erica Brausen and her close ties to Francis Bacon - at times he also demonstrated rewarding foresight. ${ }^{145}$ In 1952 the Redfern exhibited 50 preparatory sketches in watercolour and gouache by Graham Sutherland (1903-1980). These works were in fact originally mere preparatory sketches for Sutherland's Origins of the Land (1951), which was commissioned on the occasion of the Festival of Britain. ${ }^{146}$ The Redfern's exhibition, however, was favourably received and indeed set a new trend, turning Sutherland's studies into a regular source of income for the artist, and popular collectibles for dealers and galleries. ${ }^{147}$

After the death of Paul Nash in 1946, Nan Kivell presented the V\&A with a group of graphic works by the artist as a tribute to his life and work. Stead explains that this marked the beginning of his gifting of prints to public collections over the next decade. ${ }^{148}$ His first gift to New Zealand was made in 1952. A group of 181 prints, almost all of them wood engravings, was originally intended for J.C. Beaglehole, who convinced the donor to present these works to the NAG instead. Maclennan accepted the prints happily, especially since they represented the style of British printmaking that succeeded the Etching Revivalists who had dominated Ilott's collection, and thus created a welcome transition and demonstrated recent developments in printmaking practice. This shows that Maclennan was also able to put his otherwise conservative taste aside at times, in order to build the gallery's historical collection. ${ }^{149}$

The warm welcome he received from the NAG encouraged him to make a second donation the following year, which he divided into four separate groups to be given to each of the main public art galleries in New Zealand. ${ }^{150}$ Stead explains:

\footnotetext{
${ }^{143}$ R.N.K. to the Editor, The Times, 22 August 1958, National Library of Australia: MS4000, cited in Stead, "New Lamps for Old," 198.

144 Stead, "New Lamps for Old," 191.

${ }^{145}$ Erica Brausen (1908-1992) was a German art dealer and gallerist who established the Hanover Gallery in London in 1948. She was also an avid promoter of Francis Bacon. See Stead, "New Lamps for Old," 185-190; and Barry Joule, "Obituary: Erica Brausen," The Independent (30 December 1992), accessed 31 August 2020,

https://www.independent.co.uk/news/people/obituary-erica-brausen-1565959.html.

146 The Festival of Britain was a national celebration marking the centenary of the Great Exhibition in 1851.

${ }^{147}$ Stead, "New Lamps for Old," 202.

${ }^{148}$ Ibid., 184.

${ }^{149}$ Malpas, "An Incurable Collector," 47. Maclennan's own printmaking activities could also have influenced his decision. ${ }^{150}$ Auckland City Art Gallery, the National Art Gallery, the Robert McDougall Art Gallery in Christchurch, and Dunedin Public Art Gallery.
} 
Taken as a whole this was quite an extraordinary gift to Nan Kivell's homeland, covering the full range of graphic output by British printmakers from the early 1920s to 1952. Several important movements were represented, including the wood engraving revival of the 1920 s, the colour linocut movement, the fine book movement, and the more recent lithography movement. ${ }^{151}$

Thus, while most of these prints were still figurative and often dealt with similar subjects as the Smythe watercolours, the style was completely different. For example, Tillers of the Soil by Sybil Andrews (1934, Te Papa) [Fig. 75], shares the subject matter of Richard Beavis' Horses Ploughing [Fig. 27]. Yet, Beavis' idyllic landscape and vast, cloudy sky, have been replaced by Andrews' brightly-coloured, geometric forms. The horses, now clearly in the foreground, have been stylised into unnatural-abstracted shapes, just like the farmer behind them.

However, this new style was reportedly too different for some. William Sykes Baverstock (1893-1975), director of the Robert McDougall Art Gallery, Christchurch, refused the gift offered to the gallery by Nan Kivell, apparently on the grounds that the works were 'too modern'. ${ }^{152}$ Indeed, the artistic model upheld by most public galleries until this point was very narrow and limited many new aesthetic developments. The biggest impact of this could be observed in the galleries' responses to modernism and local New Zealand art. ${ }^{153}$

\section{0s: The Conservative Tastes of Wellington and Dunedin}

An analysis of the tastes of the individual gallery directors and their public galleries of the 1950s reveals that, apart from Auckland, they were opposed to accepting modern art and

\footnotetext{
${ }^{151}$ Stead, "New Lamps for Old," 206.

152 Ibid., 207. They were accepted 40 years later. Anna Crighton also recounts that in 1958 an exhibition of 70 works by British abstract painters, arranged by Nan Kivell, was accepted by the McDougall, even though Baverstock was personally uncomfortable with it: "He insisted that it would be controversial, that the paintings were too large and that they would take up considerable space in the gallery." See Anna Crighton, English, Colonial, Modern and Māori: The Changing Faces of the Robert McDougall Art Gallery, Christchurch, New Zealand, 1932-2002 (Newcastle: Cambridge Scholars Publisher, 2014), 94. In 2005 Christchurch Art Gallery held an exhibition to highlight the Nan Kivell print collection: Graphica Britannica: Highlights from the Rex Nan Kivell Gift (13 May 2005 - 8 October 2006). See the website https://christchurchartgallery.org.nz/exhibitions/graphica-britannica for more details.

${ }_{153}$ While the big public art galleries were rather slow in promoting contemporary, modern art - especially by domestic artists - smaller dealer galleries were set up for the first time in the 1950s which showed drastically different works than the major art galleries. In Wellington especially, the Helen Hitchings Gallery set new standards for exhibiting modern New Zealand art, followed closely by Peter Webb's gallery in Auckland, and several others. A new taste in art was therefore more poignant among smaller galleries than the official public institutions of the main centres. See Crighton, English, Colonial, Modern and Māori, 68-71. For more information on the Helen Hitchings Gallery, see Janet Paul, "The Helen Hitchings Gallery in Wellington,” Landfall 3, no. 4 (1949): 357-359, accessed 11 April 2020, http://www.landfallarchive.org/omeka/items/show/22174.
} 
still adhered to a conservative, Anglo-centric taste when Smythe's collection arrived. ${ }^{154}$ As Athol McCredie writes in his thesis "Going Public: New Zealand Art Museums in the 1970s" (1999), public galleries "had become bastions of tradition and symbols of enduring values for whom change was not going to come easily." 155 The personalities that directly influenced the acquisition practices of each institution were driving factors in this change. While private collectors like Ilott and Smythe (and to a lesser degree Nan Kivell) were seemingly slow in accepting new approaches to artmaking, the same may be said about the directors who accepted their gifts. ${ }^{156}$

Annette Pearse was Smythe's first contact in New Zealand. She was born in Scotland in 1893 and, after studying art in Glasgow and later London, emigrated to New Zealand with her husband in $1924 .{ }^{157}$ She was not optimistic when applying for the role of curator at the DPAG upon the resignation of Robert Neilson, but was pleasantly surprised when she got the job. ${ }^{158}$ Her appointment itself is already telling of the dominating taste in Dunedin at the time. The applicants for the role had been narrowed down to Pearse and Colin McCahon, a practicing artist who demonstrated a more progressive interest in modernism and local art. At a special meeting on 6 February 1946, the DPAG council voted unanimously in Pearse's favour; preference was given to the British-trained over the local contemporary.

Pearse held the role from 1946 to 1964, becoming the gallery's first official director in 1958. By this time, the DPAG already had a well-established preference for British art, reinforced when it joined the British National Art Collections Fund (now called The Art Fund) in 1933. ${ }^{159}$ This helped the gallery with overseas purchases, and after paying the one guinea joining fee, the DPAG commissioned the fund to buy Victorian art, an arrangement

\footnotetext{
${ }^{154}$ See Athol McCredie, "Going Public: New Zealand Art Museums in the 1970s," MA diss., Massey University, Wellington, 1999, reprinted 2006, for information on provincial galleries, art societies, and other smaller private galleries, as I will only be dealing with three of the metropolitan public art galleries.

${ }^{155}$ McCredie, "Going Public," 59.

${ }^{156}$ For a list of the directors discussed in this thesis, and their years in office at their respective galleries, see Appendix II. ${ }^{157}$ Robyn Notman and Lynda Cullen eds., Beloved: Works from the Dunedin Public Art Gallery (Dunedin: Dunedin Public Art Gallery, 2009), 14.

${ }^{158}$ Robert Neilson was the first curator not only in Dunedin, but in the whole of New Zealand. This was the first time that a role was created to provide professional care and advice for a collection. See Entwisle, Treasures, 18. While Maclennan became the first official director in 1948, it was the directors Westbrook, and then Tomory, in Auckland, who were the first appointees that had actual professional and appropriate work experience in the field. They will be discussed later in the chapter.

${ }^{159}$ Smythe also made frequent use of the National Art Collections Fund whilst selling works from his collection. The Art Fund website writes under an entry like Hercules Brabazon Brabazon's Sketchbook, presented by Smythe in 1949: "One of 79 drawings presented by Archdeacon F H D Smythe through 5 separate gifts through the Art Fund between 1947 and 1950." However, most of these works are apparently "unlocated according to 2004 audit." See https://www.artfund.org/supporting-museums/art-weve-helped-buy/artwork/2749/sketchbook-1949-hercules-brabazonbrabazon (accessed 7 April 2020). One of the watercolours donated by Smythe to the British Museum through the Art Fund was J.H. Fidlor's landscape watercolour, 1808 (301 x 424 mm, 1950,0127.1). See https://research.britishmuseum.org/research/collection_online/collection_object_details.aspx?objectId=746449\&partId=1\& searchText=Smythe+Art+Fund\&page $=1$ (accessed 7 April 2020).
} 
that continued until 1982. ${ }^{160}$ The 1919 Smeaton Bequest of ten thousand pounds similarly reinforced the gallery's British character. Peter Smeaton's only request was that during the first twenty years the acquisitions purchased from the interest must be British. ${ }^{161}$

While Pearse was later criticised for her conservative tastes, she was merely continuing a tradition already in train at the gallery. For example, in 1925-6 the New Zealand and South Seas Exhibition was held in Dunedin, and the gallery paid $£ 420$ for Solomon J. Solomon's Eros (c. 1921, DPAG, 16-1926). ${ }^{162}$ Peter Entwisle observes that by 1926 the neoclassical style of this painting was already considered severely old fashioned elsewhere, emphasising the state of New Zealand's - or Dunedin's - taste. ${ }^{163}$

Pearse's plan, according to Robyn Notman, was to "build up and extend its [the DPAG's] existing strengths." 164 These strengths were evidently in the Old Masters of Europe, specifically Britain. This explains why she did not actively pursue New Zealand modernist art, despite admitting she has $\underline{d}$ nothing against modern and contemporary art in general. In fact, she put on several progressive touring loan exhibitions in her time, including on abstract German graphic art in 1955, and British sculpture in 1957, but all were of European art. ${ }^{165}$ By the end of the 1950s, it was often claimed that Dunedin's "foreign collections were without equal in New Zealand." 166 Entwisle elaborates that "the steady build up made possible by the Smeaton bequest and greatly assisted by Archdeacon Smythe had seen a systematic advance towards the founder's vision of a collection that was national if only by virtue of its importance."167

Apart from the Smythe watercolours, Pearse's other major achievements were in British portraiture. One of her most significant acquisitions was Thomas Gainsborough and John Hoppner's Charlotte, Countess Talbot (c. 1784, DPAG) [Fig. 76]. Gainsborough was one of the most successful portrait painters of his day, and this work epitomises British elegance and aristocracy. ${ }^{168}$ It also represents the conservative taste that the DPAG was aiming for under Pearse's leadership.

\footnotetext{
${ }^{160}$ Notman and Cullen, Beloved, 13.

${ }^{161}$ Entwisle, Treasures, 17.

${ }^{162}$ For more information and a reproduction of this painting, see Notman and Cullen, Beloved, 157.

${ }^{163}$ Entwisle, Treasures, 20.

${ }^{164}$ Notman and Cullen, Beloved, 14.

165 Ibid.

166 Entwisle, Treasures, 31.

${ }^{167}$ Ibid. The founder was William Mathew Hodgkins, who aimed to build a collection that illustrated European and colonial New Zealand art history.

${ }^{168}$ For more information about this painting, see Notman and Cullen, Beloved, 80. Pearse had also acquired another portrait by the other most famous British portraitist, Sir Joshua Reynolds, just a year after becoming curator. This work, Maria, Countess Waldegrave (1764-65), was bought through the NACF using the Smeaton Fund, just like the portrait by Gainsborough and Hoppner was. See Notman and Cullen, Beloved, 78.
} 
In fact, Pearse had purchased this painting on the advice of Alec Martin, Christie's agent and managing director, who was also involved in the Smythe transaction. ${ }^{169}$ A former colleague of Smythe's, Martin became a friend and accomplice in Pearse's acquisitions, and a major influence on her taste. ${ }^{170}$ In his obituary, Martin was described as a "Victorian uncle", because of his "winged collar and cherubic smile."171 However, the reasoning for this might also be extended beyond his looks, as he famously "retains an affection for standards and ideals which are now no longer fashionable." 172 This traditionalist taste was reflected by many of his social relationships: among his friends were collectors and artists, like Sir Robert Witt, Wilson Steer, Walter Sickert and Singer Sargent. ${ }^{173}$

The DPAG already owned oil paintings by Turner and Copley-Fielding, so it comes as no surprise that Pearse was actively pursuing watercolours by these and other British artists well before her contact with Smythe. ${ }^{174}$ In 1949 and 1950 she purchased watercolours by Gainsborough, Rowlandson, George Dance and Paul Sandby. This is similar to the situation in Wellington, where Maclennan's letters reveal that the NAG was already actively collecting British watercolours before Smythe's gifts. As he wrote to the archdeacon in 1956, "we are anxious to build up in every way we can a fully representative collection of the water colour arts of Britain of the period covered by your collection." 175 This was affirmed by G.G. Gibbes Watson, the NAG's chairman and agent in England, who noted that the value in such collecting lay in the fact that it created a basis for all subsequent British art that may get collected. He wrote to Smythe, "I may say that our policy has been for many years to build up, as far as practicable, the collection of early English water colours as we think that that school is the foundation of all that is best in subsequent British painting."176

\footnotetext{
${ }^{169}$ See Chapter Two for more information on Alec Martin and Smythe.

${ }^{170}$ When Pearse retired in 1964, Martin presented a terracotta bust, Bust of a Lady, by Lucas de Montigny, 1782 (7-1964), to the gallery through the NACF, in honour of her services. Entwisle, Treasures, 33.

${ }^{171}$ D.S., "Obituary: Sir Alec Martin," Apollo 93, no. 112 (1 June 1971): 537.

172 "Profile: Sir Alec Martin,” Apollo 77, no. 16 (1 June 1963): 517.

${ }^{173}$ For more information on Alec Martin, see "A London Diary: Sir Alec Martin Leaves Christie's: Cricket, and the Bridegroom-To-Be: The Grand Gesture in Bond Street," The Field [London] 212, no. 5527 (11 December 1958): 1140; James White, "Sir Alec Martin: An Appreciation," The Irish Times (18 May 1971): 8; D.S., "Obituary: Sir Alec Martin," Apollo 93, no. 112 (1 June 1971): 537; "Profile: Sir Alec Martin," Apollo 77, no. 16 (1 June 1963): 517.

174 Turner, Dustanborough Castle, Northumberland, c. 1799 (oil on canvas, 4-1931); Copley Fielding, Balloch Ferry (oil on canvas, 1-1938).

${ }^{175}$ Maclennan to Smythe, 13 July 1956, TPA: MU000044, box 2, item 12.

${ }^{176}$ Watson to Smythe, 10 July 1956, TPA: MU00008, box 3, item 6.
} 
Stewart Maclennan also had a personal interest in watercolour, working as an artist himself before taking on the directorship at the NAG in 1948. ${ }^{177}$ Like Pearse, he studied art at the Royal College of Art in London in 1935, where his tutors included such artists as John and Paul Nash, Edward Bawden and Eric Ravilious. Their styles were to influence his later work. John Toft explains that Maclennan won several prestigious awards in watercolour painting. ${ }^{178}$ While he also worked in other graphic media - like woodcuts and linocuts watercolour was his declared favourite.

While this personal link, combined with the availability and affordability of British watercolours, made them a choice object of collection, Maclennan had another reason for acquiring them. He genuinely believed that New Zealand art history had its beginnings in this particular medium. He made this conviction clear when he wrote:

It would seem to be logical that New Zealand, so similar in area and climate to Britain whose people settled here, should lean strongly towards British tradition in art, and substantially this is what has happened. Inevitably, our artistic beginnings are recorded almost exclusively in that most English of mediums, watercolours.

We have to decide, however, whether we are to accept as our starting point the works of charming but minor British artists like Heaphy, Angas, and Brees, just because they happened to come to New Zealand, or to forge the links back to Cotman, De Wint, Constable, and Turner. Believing this to be the proper course, the National Art Gallery has acquired through the Sir Harold Beauchamp Fund, a small but choice collection of eighteenth century English watercolours. ${ }^{179}$

It is ironic that Maclennan would shrug off the early New Zealand watercolourists as a side note, as they would soon become more popular than his preferred British watercolourists. In this he was following a trend from the earlier twentieth century, in which watercolours of artists like John Gully, Charles Heaphy and William Fox were considered as part of the historical collection, rather than art. ${ }^{180}$

It was largely due to this attitude that William McAloon concludes that "collecting during the post-war period remained steadfastly British." 181 This also reflected the taste of the NZAFA, of which Maclennan was an active member. McAloon explains that when the

\footnotetext{
${ }^{177} \mathrm{He}$ was very active in the arts community already before becoming director. He became an artist member of the New Zealand Academy of Fine Arts in 1941 and was on the Academy Council from 1943 to 1949, the last ten years as vicepresident. He also served as president of the Wellington Art Club from 1953 to 1955. John Toft, "Stewart Bell Maclennan A.R.C.A: National Art Gallery Director and Prominent $20^{\text {th }}$ Century New Zealand Watercolourist," Watercolour New Zealand, accessed 8 April 2020, https://www.watercolournewzealand.nz/tutorials/article_Maclennan.htm.

178 Toft, "Stewart Bell Maclennan."

${ }^{179}$ Maclennan, "Survey, Trends, and Influences, 1938 to Present," An Encyclopaedia of New Zealand, originally published in Te Ara - The Encyclopedia of New Zealand (1966), http://www.TeAra.govt.nz/en/1966/art-in-new-zealand/page-2.

${ }^{180}$ For an in-depth discussion on the changing role of colonial art in New Zealand's art history, and in New Zealand collections, see Rebecca Rice's PhD thesis "The State Collections of Colonial New Zealand Art."

${ }^{181}$ McAloon, Art at Te Papa, 9.
} 
NAG opened in 1936, most of the artworks - more than three hundred New Zealand and British works - had come from the Academy's own collection. He continues, "it was under the Academy's increasingly conservative direction that the collection of New Zealand art would continue to develop for the next thirty years." ${ }^{182}$ Like Pearse, Maclennan received some harsh criticism for continuing this artistic model. In 1954, Charles Brasch wrote that the recent British purchases “would [not] have been bought at this stage of the Gallery's development by a director who knew his job." ${ }^{183}$ Some critics of the NAG had hoped that with the appointment of a professional director, there might be change in the air.

Maclennan did implement some changes, but not in the way the critics had hoped. While before Maclennan's directorship acquisitions were selected from exhibitions that brought European art to New Zealand, such as the Baillie or Murray Fuller exhibitions, now the gallery employed the aid of London-based advisors. This role was first filled by Mary Murray Fuller herself, and in 1951 the position was taken over by Ernest Heber Thompson (1891-1971). ${ }^{184}$ Heber Thompson was an expatriate New Zealander who had studied at the Royal College of Art, was a member of the Royal Society of Painter-Etchers and Engravers and an exhibitor at the RA - "exactly the sort of credentials to give the committee of management confidence", ${ }^{185}$ and exactly the sort of person to advocate a more academic taste. Heber Thompson and Maclennan, together with Watson, enjoyed a friendly relationship and shared strong business bonds and ambitions for the National collection. ${ }^{186}$

Like Pearse, they were not particularly interested in acquiring modern art. Yet, in view of the rising popularity of modernist art movements, Maclennan could not avoid the topic much longer. However, he did advise Heber Thompson not to present the committee with anything "too adventurous." 187 This appears to have suited his own personal tastes too, as he wrote in a letter to Heber Thompson in 1961, "what a strange phase we are passing through with action painting, abstract expressionism, nihilism and what have you ... I just can't convince myself that art is permanently heading that-a-way ... our enforced

\footnotetext{
${ }^{182}$ McAloon, Art at Te Papa, 6.

${ }^{183}$ Charles Brasch cited in ibid., 11.

${ }^{184}$ For more information on Ernest Heber Thompson, his knowledge of British art and his aversion to abstraction, see Chelsea Nichols, "How to Collect Great Art the "Wrong' Way," Off the Wall (6 August 2016), accessed 25 August 2020, file:///C:/Users/schoe/AppData/Local/Temp/MA_DOC001751_TePapa_How-to-collect-great_full.pdf, and listen to one of his letters to Maclennan here: "Letter from a Modern Art Collector - Ernest Heber Thompson," recording created for the Ngā Toi |Arts Te Papa audio guide, Spring 2014, accessed 25 August 2020, https://collections.tepapa.govt.nz/topic/7991. 185 McAloon, Art at Te Papa, 9.

${ }^{186}$ Watson, originally from a legal background, turned to art and collecting in the 1930s, becoming president of the NZAFA 1938-1949. In 1938 he was also appointed to the Board of Trustees of the National Art Gallery and Dominion Museum. For more information, see "Watson, Gordon Graham Gibbes, C.M.G.," An Encyclopaedia of New Zealand, originally published in Te Ara - The Encyclopedia of New Zealand (1966), accessed 25 August 2020, http://www.TeAra.govt.nz/en/1966/watson-gordon-graham-gibbes-cmg.

${ }^{187}$ Maclennan to Heber Thompson, 17 July 1953, TPA: MU000009, box 8, item 7, cited in McAloon, Art at Te Papa, 9.
} 
moderation in buying may yet be a blessing." 188 Indeed, he was convinced that too much modernism - particularly abstraction and expressionism - did not suit the New Zealand lifestyle, claiming "our way of life is too even, too temperate, and too secure economically, socially, and in politics and climate to foster a deeply emotional or violently expressive art." 189

Maclennan was not completely opposed to modern art, however. He offered examples of what was acceptable and what was not, clearly indicating his preference for some artists over others:

Abstract simplification as practised by John Weeks represents the generally accepted limit of modernity in New Zealand. There are a few more extreme practitioners. Colin McCahon has reduced subject matter to Rothko terms of geometric simplicity but much work in contemporary European idiom is frankly derivative and mannerist. ${ }^{190}$

In 1953 he wrote a review of an exhibition of Contemporary British lithographs, where he acknowledged the engaging qualities of some modern art:

They are extremely interesting. The general effect is one of gaiety. The very first visitor to the Exhibition at the National Gallery burst into laughter - so spontaneously that I joined in. 'What good fun', was his comment. Some later visitors were puzzled by some of the prints and some were annoyed. Some liked them very much. There's certainly nothing tame about the Collection and very few visitors remain indifferent. ${ }^{191}$

This openminded approach also explains why he happily accepted Nan Kivell's gift of modern prints, a gift which, as noted, was rejected by the Robert McDougall Art Gallery in Christchurch.

\section{Auckland's Taste for the Modern}

The fact that these galleries were not run by trained professionals, and lacked a clear gallery policy, supported the lack of engagement with modern art during the 1950s. Charles Brasch argued in 1949:

\footnotetext{
${ }^{188}$ Maclennan to Heber Thompson, 20 July 1961, TPA: MU000009, box 8, item 7, cited in McAloon, Art at Te Papa, 9. ${ }^{189}$ Maclennan, "Survey, Trends, and Influences, 1938 to Present."

${ }^{190}$ Ibid. Note that this is the second New Zealand gallery to consider McCahon too extreme, as the DPAG chose Pearse over him for the role of curator in 1946. Although these two occasions occurred under different pretexts (one with McCahon as an artist, the other with McCahon as a potential gallery director), it is telling of McCahon's status among the more conservative leadership of art institutions in New Zealand.

${ }^{191}$ Stewart Maclennan, “Art Review: Contemporary British Lithographs,” Design Review 5, no. 1 (1953): 13.
} 
The galleries are run by their trustees (eighteen of them in Dunedin), committees of local 'amateurs' whose knowledge of painting is usually confined to what they have seen in New Zealand or on a hurried tour of England, assisted by a curator or keeper who in some cases may be no better equipped than themselves. They have to frame policy, if they can; they have to pass every painting that is bought. The state of the New Zealand galleries makes it clear that no real policies have ever been framed - or if framed have not been followed, and that paintings are seldom bought except for their negative qualities: their chief merit must be not to offend any one on the council. That lets in almost anything that looks familiar, and keeps out almost anything that looks unfamiliar, irrespective of artistic merit. Hence the rejection of Frances Hodgkins's paintings: they were damned because they were 'different'. ${ }^{192}$

According to Brasch, the only way to have good collections in New Zealand was to have professional directors, men "trained for their work, by experience in properly run galleries (which means overseas ones)." ${ }^{193}$ Peter Tomory (1922-2008), who in fact was one of those trained men, noted in his recollections of the 1950s that "to establish a truly professional institution, it was essential to stop the use of the gallery by amateur societies, brewers, and other closet aesthetes promoting chocolate-box art. The most effective treatment was not only going on the offensive but being offensive as well." ${ }^{194}$ This is exactly what the Auckland Art Gallery (AAG) did. It hired two professional directors, first Eric Westbrook (1915-2005) and then Tomory, who took a provocative stance by promoting a different art to the other art centres.

At the start of the 1950s, the AAG was similar to the other galleries regarding modern art. It had only one small collection of lively contemporary paintings of oils and watercolours, given to the gallery by Lucy Wertheim. ${ }^{195}$ According to Janet Paul, this collection was "uneven, experimental, but gay", and it was "the only real stimulus to young

\footnotetext{
${ }^{192}$ Charles Brasch, “Art Gallery Policy,” Landfall 3, no. 2 (1949): 181, accessed 14 April 2020, http://www.landfallarchive.org/omeka/items/show/22172. This editorial was written in response to the Christchurch Gallery's rejection of Frances Hodgkins' The Pleasure Garden (1932); see also Warren Feeney, “'The Great Art War': Alan Brassington and Frances Hodgkins's The Pleasure Garden," Journal of New Zealand Art History, no. 28 (2007): $97-$ 113. For a more detailed discussion of the Pleasure Garden incident, including some rare behind-the-scenes insights into the reasoning behind the rejection, see Crighton, English, Colonial, Modern and Māori, 45-50. For some contemporary opinions of the incident, see Michael Vance, "One Painting Started a Cultural War: The Way We Were June 17, 1949," The Press [Christchurch] (19 June 2010), accessed 11 April 2020, https://global-factiva-com.helicon.vuw.ac.nz/ga/default.aspx. See also T.H. Scott, "The Frances Hodgkins Controversy," Landfall 3, no. 4 (1949): 360-374, accessed 11 April 2020, http://www.landfallarchive.org/omeka/items/show/22174.

${ }^{193}$ Brasch, "Art Gallery Policy," 182.

${ }^{194}$ Peter Tomory, "The Bridgehead Revisited," Landfall 185: The Fifties Issue (Auckland: Oxford University Press, 1993), 16.

${ }^{195}$ Lucy Carrington Wertheim (1883-1971) was another donor of modern English art. Like Nan Kivell, she was a gallery owner, art dealer and collector in London and gifted 183 paintings to the Auckland Gallery in 1948 and 1950, including works by Frances Hodgkins, Alfred Wallis and Christopher Wood. For more information see "Mrs. Lucy Wertheim Encouraging Young Artists," The Times [London] (15 December 1971). See also Ariane Bankes, "From One Woodpecker to Another," Country Life (14 March 2018): 126-127, which looks at the work of Suzanne Cooper, one of the artists recently rediscovered from among her gifts.
} 
Auckland painters who hurried occasionally through the dim grey-walled gallery." 196 This all changed with the arrival of Eric Westbrook, who became director in 1952. Westbrook's ambition was to bring a 'modern spirit' to the AAG, not just to the contents of its collection. During his time, the building underwent dramatic internal alterations, artificial lighting was installed, and programming of concerts, plays, poetry readings and evening art classes was introduced. ${ }^{197}$

Westbrook was born in London and in his youth trained as a painter, under the tutelage of artists like Walter Sickert and Mark Gertler. However, he was always drawn to the interpretive side of the arts profession, referring to himself as a true 'gallery man'. ${ }^{198}$ After the war, he worked in several museum and lecturing roles, until he became director of the Wakefield City Art Gallery in Yorkshire in 1946, making him Britain's youngest gallery director at the time. ${ }^{199}$ It was here that he first revealed his taste for modern art and caused a controversy with his retrospective exhibition on Henry Moore. ${ }^{200}$

He took this experience, and his 'modern spirit', to the AAG in 1952, where he was director until 1955. ${ }^{201}$ Upon arrival, he was saddened to find it a "very run-down gallery."202 Apart from the changes he made to the building itself, he experimented with exhibitions, putting the AAG at the forefront of progressive art displays in New Zealand. Westbrook's intentions as a director were expressed in the catalogue for the first exhibition held by him in the gallery, which Janet Paul summarises as: ${ }^{203}$

1. To acquire examples of the best and most original artists working in this country today.

2. To create a fully representative selection of the work of Frances Hodgkins which will be of interest beyond the shores of New Zealand.

\footnotetext{
196 Janet Paul, "Round the Galleries: Auckland," Landfall 8, no. 4 (1954): 298, accessed 12 April 2020, http://www.landfallarchive.org/omeka/items/show/22193.

${ }^{197}$ Alexa Johnston, “A National Treasure: A History of the Gallery's Collections," in Auckland Art Gallery Toi o Tāmaki, Auckland Art Gallery Toi o Tämaki: The Guide (London: Scala, 2001), 8. This also supports his statement that he was concerned with the unity of the arts, as he told Hazel de Berg in an interview in 1962. Eric Westbrook (interviewee) and Hazel de Berg (interviewer), "Eric Westbrook Interviewed by Hazel de Berg in the Hazel de Berg Collection," 1962, sound recording, accessed 15 April 2020, https://nla.gov.au/nla.obj-214256961/listen.

${ }^{198}$ Westbrook (interviewee) and de Berg (interviewer). Westbrook also believed that employing artists in gallery positions, such as administrative roles as directors, was a mistake. At the start of the interview, he wanted to make clear that he himself is not a failed artist, critic or art historian, but that he is a gallery man through and through.

199 Peter Perry, “Obituary: Dr. Eric Westbrook, CB 1915-2005,” Art Bulletin of Victoria 46 (2006), accessed 15 April 2020, https://www.ngv.vic.gov.au/essay/obituary-dr-eric-westbrook-cb-1915-2005/.

200 The British Arts Council then decided to host a touring exhibition of Moore's work, and Westbrook was employed as the exhibitions officer, travelling throughout Europe for several years. He described this time as a "tremendous mine of experience," and "one of the most valuable experiences that any gallery man could have." See Westbrook (interviewee) and de Berg (interviewer).

${ }^{201}$ After his time in New Zealand, he became the director of the National Gallery of Victoria. For more information on what he accomplished there, see Peter Perry's obituary, and the interview with de Berg.

${ }^{202}$ Westbrook (interviewee) and de Berg (interviewer)

203 This was an exhibition of acquisitions from 1952-53.
} 
3. To build a representative collection of prints and drawings of the nineteenth and twentieth centuries from all parts of the world.

4. To gather works of British artists since 1900 in the fields of painting and sculpture.

5. To provide a standard collection of representative works of all periods, not necessarily by artists with great names, but those who show most clearly the character of their age.

6. The discovery and encouragement of New Zealand craft workers by commissioning pottery and weaving from local workers. ${ }^{204}$

Other exhibitions manifested these intentions further. For example, together with Colin McCahon (1919-1987), he organised an exhibition of New Zealand abstraction, Object and Image (1954). Although not the first exhibition to show abstract works, Hamish Keith points out that "it was the first to demonstrate a consistent attitude towards abstraction, and if this attitude was only a passing one for some of the painters involved it did indicate a changing climate." ${ }^{205}$ Also, the acquisitions among modern sculpture were one of Westbrook's most significant achievements during his tenure and became a highlight of the Auckland midcentury collections.

Another way in which Westbrook differentiated his gallery from the others was in employing McCahon, the artist who had been snubbed by other galleries, as curator (19531964). This was an acknowledgment of his role in modern New Zealand art, as well as modern art itself. McCahon continued working at the gallery under Westbrook's successor, Peter Tomory, who was director from 1956-1964. Like Westbrook, Tomory had garnered professional experience in the field before coming to New Zealand. Starting his gallery career as an assistant curator at York City Art Gallery in 1950, he soon moved into more senior roles and by 1954 he was also working on touring exhibitions with the Arts Council in London. ${ }^{206}$ During these occupations, Tomory already displayed signs of progressive collecting. As Keeper at Leicester during the 1940s, he bought several German Expressionist works and held two expressionist exhibitions. While such acquisitions were unusual for the 1940s and 1950s, Courtney Johnston explains that the Leicester collection of German art is now “internationally renowned and seen to reflect the institution's progressive collecting policies." 207 Additionally, these purchases also reflected Tomory's own personal

\footnotetext{
${ }^{204}$ Paul, "Round the Galleries," 299-300.

${ }^{205}$ Hamish Keith, cited in Gordon H. Brown, New Zealand Painting 1940-1960: Conformity and Dissension (Wellington: Queen Elizabeth II Arts Council of New Zealand, 1981), 54.

${ }^{206}$ For a brief overview of his life and career, see his obituary by David Alexander, "Peter Tomory: Distinguished Art Historian," Independent (29 May 2008), accessed 15 April 2020, https://www.independent.co.uk/news/obituaries/petertomory-distinguished-art-historian-835821.html. For a more detailed account of his time in New Zealand, see Courtney Johnston, "Peter Tomory: The New Zealand Years, 1956-1968," MA diss., Victoria University of Wellington, 2004. ${ }^{207}$ Johnston, "Peter Tomory," 54.
} 
taste. ${ }^{208}$ He had travelled to Germany before the war, which is where his interest in German expressionism originated. ${ }^{209}$

Tomory shared Westbrook's interest in modern sculpture and continued to make purchases in this area after arriving in New Zealand. One of Tomory's major coups was the acquisition of Jacob Epstein's The Rock Drill (1913-1916) [Fig. 77] in 1961, which was one of the first artworks to signal sculpture's break from naturalistic representation. ${ }^{210}$ Indeed, this figure looks more machine than humanoid, recalling the geometric shapes of the Tillers of the Soil [Fig. 75]. Epstein himself described the figure as a 'monster', writing "here is the armed, sinister figure of today and tomorrow. No humanity, only the terrible Frankenstein's monster we have made ourselves into." ${ }^{211}$ Epstein had connections with the Vorticists, a group of artists concerned with the darker side of the machine age. This was also the group of artists singled out by Smythe in his letter as an example of modern art which he cannot bring himself to like. Tomory described the bronze as "one of the most significant works of the modern era." ${ }^{212} \mathrm{He}$ was proud of the purchase, noting that other galleries had also shown interest in the work, and that the director of a museum of modern art in Vienna was "most annoyed that we got in first for that one." 213

Tomory had demonstrated his taste for modern sculpture much earlier than this acquisition though, seeing that he helped to arrange the exhibition Henry Moore in 1956. This was the first major exhibition of modern art seen in New Zealand. Just as it had done in England under Westbrook, the exhibition "immediately provoked controversy." 214 Alexa Johnston writes that Tomory achieved local notoriety through this, living up to his earlier stated need for being offensive. ${ }^{215}$ Incidentally, he also achieved huge audience numbers for the gallery through this exhibition.

\footnotetext{
${ }^{208}$ Whilst teaching at La Trobe University in Melbourne during his later years, Tomory also started his own print collection, which reveals his interest in earlier European works. The collection was later bought by Auckland, where an exhibition was held in 2005 to celebrate it. See "A Connoisseur's Eye: Prints from the Tomory Collection," accessed 15 April 2020, https://www.aucklandartgallery.com/whats-on/event/a-connoisseurs-eye-prints-from-the-tomory-collection. 209 Johnston, "Peter Tomory," 53-54: "While Tomory did not buy any German expressionist paintings for Auckland, he added a number of 20th-century German prints to the collection. These include works by George Grosz, Käthe Kollwitz, Lyonel Feininger, Lovis Corinth and Erich Heckel."

210 Ibid., 68.

211 Jacob Epstein, Let There Be Sculpture: An Autobiography (London: Joseph, 1940), 60.

212 "Major Purchases Lift City Gallery Standard," Star (16 March 1961): 4, cited in Johnston, "Peter Tomory," 67. ${ }^{213}$ Ibid.

214 "Moore Sculptures on Display," Auckland Weekly News (26 September 1956): 29, cited in Mark Stocker, "Sculpture and Installation Art - Early Modern Sculpture," Te Ara - The Encyclopedia of New Zealand, accessed 15 April 2020, http://www.TeAra.govt.nz/en/zoomify/41967/henry-moore-exhibition-auckland-1956. Mark Stocker also claims that this exhibition "raised national awareness not only of sculpture but of modern art. ... Many sceptics were converted in the process" and it encouraged domestic sculptors to explore ways of working in a modern way.

${ }^{215}$ Alexa Johnston, “A National Treasure: A History of the Gallery's Collections," in Auckland Art Gallery Toi o Tāmaki, Auckland Art Gallery Toi o Tāmaki: The Guide (London: Scala, 2001), 9.
} 
Tony Green argues that Westbrook and Tomory both helped to transform the AAG "from a Victorian mausoleum into a modern art museum." ${ }^{216}$ It was the first major modern art gallery in New Zealand. Initially, many of their touring exhibitions proved too modern for the other galleries, like the McDougall, which turned down the Henry Moore exhibition in $1956 .{ }^{217}$ Dunedin saw a similar situation, where the Visual Arts Association was actively combatting the DPAG's resistance to showing Auckland's touring contemporary art exhibitions and instead had to resort to organising alternative venues. ${ }^{218}$ Both the DPAG and the NAG notoriously turned down the 1958 British Abstract Painting touring exhibition, Maclennan claiming it was "not worthy" of the gallery. ${ }^{219}$ Tomory concluded that the galleries' attitudes to contemporary art were timid, writing 'timidity has been the keynote in this respect of all the galleries except that in Auckland, which is the only one where painting of the last twenty years has been collected seriously." ${ }^{220}$ However, from the late 1960s onwards, with the arrival of a new generation of gallery directors, Dunedin and Wellington (and Christchurch) finally began to catch up with Auckland's taste.

\section{0s: The Modern Aesthetic Spreads}

In Wellington, Maclennan was succeeded by another artist-director who was also actively engaging with modern international art trends. Melvin Day (1923-2016) was director of the NAG from 1968-1978. Whilst working as a teacher in Rotorua, he was first introduced to the works of Pablo Picasso and Georges Braque through his connection with the orthopaedic surgeon and amateur painter Wilfred Stanley Wallis (1891-1957). ${ }^{221}$ A visit to Europe in 1949 reaffirmed and cemented his love for Cubism, which was to influence his own art in future. ${ }^{222}$ He was also the first New Zealander to study art history at the Courtauld Institute in London, where he became acquainted with the art of fifteenth-century Florence. ${ }^{223}$ While

\footnotetext{
${ }^{216}$ Tony Green, "Modernism and Modernization," in Mary Barr ed., Headlands: Thinking Through New Zealand Art (Sydney: Museum of Contemporary Art, 1992), 152.

${ }^{217}$ McCredie, "Going Public," 62.

${ }^{218}$ Ibid., 53.

${ }^{219}$ Ibid., 69.

${ }^{220}$ Peter Tomory, “Art," 176-207, in A.L. McLeod ed., The Pattern of New Zealand Culture (Melbourne: Oxford University Press, 1968), 203.

${ }^{221}$ David Millar, "Day, Melvin (Norman Pat)," Grove Art Online, 1 December 2004, accessed 16 April 2020, https://wwwoxfordartonline-com.helicon.vuw.ac.nz/groveart/view/10.1093/gao/9781884446054.001.0001/oao-9781884446054-e7000097767.

${ }^{222}$ For more information on Day's art, see Ray Thorburn, "Full Circle: Paintings by Melvin Day,” Art New Zealand 32 (Spring 1984), accessed 16 April 2020, http://www.art-newzealand.com/Issues31to40/day.htm.

${ }^{223}$ For more information on how Italian Renaissance art influenced his own painting, see Mark Hutchings, "The Italian Inheritance: Contemporary Responses to Early Renaissance Imagery by Four New Zealand Painters,” MA diss., University of Auckland, 1988.
} 
his own art often fused these two traditions, Te Papa claims that it also impacted his development of the modern art collection. ${ }^{224}$

Among his modernist purchases was an abstract lithograph by Barbara Hepworth (1903-1975): Cool Moon (1970-71) [Fig. 78]. ${ }^{225}$ The moon's unnatural shape makes it almost unrecognisable, and the lines and circles recall aspects of geometry. These features also elicit Day's own work, Goblet: Uccello Series (1969) [Fig. 79]. The colour palette, the centralised rectangular shape and geometric references can all be found in Day's painting, demonstrating that his artistic tastes are mirrored in both his practice and collecting. ${ }^{226}$

However, arguably the NAG's most significant addition to the collection under Day was Colin McCahon's masterpiece Northland Panels (Te Papa, 1958) [Fig. 80], purchased in May 1978. Upon hearing the news of the purchase, critic Neil Rowe wrote, "they are the most substantial single acquisition the National Gallery has ever made."227 These works mark a turning point in the career and style of McCahon, and they perfectly illustrate the influence of non-British international art. The Northland Panels were painted after a fourmonth stay in the US, where McCahon was exposed to everything from Old Masters to recent American art. ${ }^{228}$ The enormous scale and looser brushwork of the paintings show the impact of the mural-sized works of the Abstract Expressionists, while at the same time demonstrating a reaction to the vast American landscapes and cities he saw. ${ }^{229}$ McAloon also observes that McCahon saw an exhibition of the Japanese painter Tomioka Tessai in San Francisco, and the influence of such Eastern sources can be seen in the "scroll-like format of the panels and their vertical arrangement of space."230

Nevertheless, it seems that Rowe did not necessarily praise the decision of buying this work due to its demonstration of a new international, modern taste. In fact, he continued by claiming that the Northland Panels "will prove to be the cornerstone in the development

\footnotetext{
224 “Goblet: Uccello Series,” Te Papa Collections Online, accessed 16 April 2020, https://collections.tepapa.govt.nz/object/39674.

${ }^{225}$ The same year that the NAG purchased Cool Moon, the AAG received a similar Hepworth print, Winter Solstice, 1971 (1976/57/26), from the Institute of Contemporary Prints. It was not until the 1990's, however, that the AAG made its first own Hepworth purchases, when it bought five works from her Opposing Forms series. Dunedin's only Hepworth work is an ink on paper drawing, Water Movement (78-1973), which was bequeathed by Charles Brasch in 1973.

${ }^{226}$ Meanwhile, Maclennan had already made another impressive Hepworth purchase in 1964, when the gallery acquired the controversial bronze sculpture Oval Form (Trezion), 1964 (Te Papa, 1964-0014-1).

${ }^{227}$ Neil Rowe, "McCahon Panels Go to Gallery for \$25,000," Evening Post (11 May 1958): 4, cited in McAloon, Art at Te Papa, 13.

${ }^{228}$ William McAloon, "Northland Panels," in Mark Stocker ed., New Zealand Art at Te Papa (Wellington: Te Papa Press, 2018), 164.

229 "McCahon's Northland Panels," text originally published in Tai Awatea, Te Papa's onfloor multimedia database (1998), accessed 21 April 2020, https://collections.tepapa.govt.nz/topic/946. McCahon famously recalled: "I had seen deserts and tumbleweed in fences and the Salt Lake Flats, and the Faulkner country with magnolias in bloom, cities - taller by far than kauri trees." See McAloon, "Northland Panels," 164.

${ }^{230}$ McAloon, "Northland Panels," 164. For a succinct, but more in-depth discussion of McCahon's life and works, see "Colin McCahon," in Brown and Keith, An Introduction to New Zealand Painting 1839-1967, 183-198.
} 
of a truly representative national collection of contemporary New Zealand art." ${ }^{231}$ The acceptance of this work, therefore, acknowledges specifically New Zealand modern art in public collections. This shift towards collecting local, though happening at the same time, was more significant than the shift towards modern art in New Zealand. Indeed, prior to the 1960s New Zealand art had been just as neglected by the nation's main art galleries as modern art.

\section{0s: Collecting New Zealand Art}

In Dunedin, the gallery's focus had been firmly fixed on the art of Europe, despite actually being the centre for a developing New Zealand modernism (some artists working there included R.N. Field, Doris Lusk, Colin McCahon and Toss Woollaston). ${ }^{232}$ As early as 1939, Dunedin had already made the headlines for neglecting its local artists, when McCahon's Harbour Cone from Peggy's Hill (1939) was rejected by the Otago Art Society. This resulted in several other young vanguard artists to protest by withdrawing their works from the exhibition as well. ${ }^{233}$ In 1963, just a couple of years before Pearse's retirement, the DPAG Council commissioned Dr. Esmond de Beer to write a report on and make recommendations for the collection. De Beer's main criticism was that "the representation of current New Zealand art is notably poor."234

In Wellington, the need for a collection of national artists was also recognised early on. After the opening ceremony of the NAG in 1936, artist and critic Roland Hipkins noted, "it is obvious that while much money has been, and is being, spent on art from overseas ... yet the acquisition of the best New Zealand art is imperative, and must be projected if we are

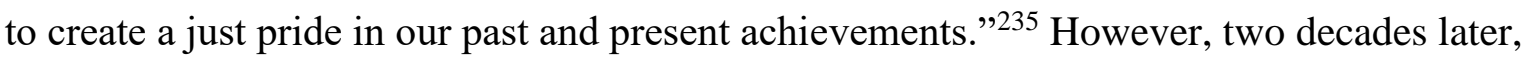
Maclennan had still not achieved such a representative collection. McAloon describes the severe negligence in this area:

In 1955, for example, the Robert McDougall Art Gallery in Christchurch purchased Rita Angus's regionalist icon Cass, 1936, and a year later acquired MT Woollaston's boldly expressionistic Sunset, Grey River, 1955, and Louise Henderson's cubist still

\footnotetext{
${ }^{231}$ Rowe, "McCahon Panels Go to Gallery for $\$ 25,000, " 4$.

${ }^{232}$ McCredie, "Going Public," 73.

${ }^{233}$ Caroline Jordan and Rebecca Rice, “'Cultural Propaganda' and the Politics of Taste: The Carnegie Corporation's Cancelled Art of New Zealand Exhibition, 1941," Australian and New Zealand Journal of Art 14, no. 2 (2014): 133, accessed 22 November 2019, https://doi.org/10.1080/14434318.2014.973634.

${ }^{234}$ Esmond de Beer, 1963, cited in Notman and Cullen, Beloved, 16.

${ }^{235}$ Roland Hipkins, "The National Art Gallery Exhibitions," Art in New Zealand 9, no. 33 (1936): 17, cited in McAloon, Art at Te Papa, 1.
} 
life Grapes and Lilies, 1955. It would be more than a decade before the National Art Gallery acquired a work by any of these painters. ${ }^{236}$

In Wellington's case, the dominant power of the NZAFA was partly to blame for this. During Day's tenure, the Academy's role on the board of trustees was finally reduced to a single seat in 1972, and for the first time it had no representation on the NAG council, giving Day and the gallery more freedom in their acquisitions. ${ }^{237}$

When the German-British art historian Nikolaus Pevsner visited New Zealand in 1958, he claimed upon departure that he had learnt little about New Zealand art and artists during his six-week stay, "because none of your galleries, with the exception of Auckland, has a collection of New Zealand painting ... Even in Auckland the collection is small - in other main centres it is practically non-existent." ${ }^{238}$ However, had he visited only one or two decades later, he would have found a completely different gallery landscape. In fact, the new generation of gallery directors' - Edgar and Lloyd in Dunedin, Day and Bieringa in Wellington, and Tomory and Docking in Auckland [Appendix II] - most significant contributions were in buying New Zealand art, rather than simply modern art. This shift in taste towards acquiring works by contemporary New Zealand artists is directly linked to a changing attitude towards a national identity, which will be discussed further in the next chapter.

J.D. Charlton Edgar (1903-1976) had already expressed his sympathy for New Zealand artists well before becoming director of the DPAG in 1965. Edgar and his wife, Mona Marguerite Barnetson, emigrated to Dunedin from Scotland in 1931, where he became a painting instructor at the Dunedin School of Art at King Edward Technical College. Among his students were Toss Woollaston, Doris Lusk, Patrick Hayman and McCahon, all of whom became significant figures in the contemporary art scene. Edgar was also a member of the council of the DPAG during the 1930s, where, as Entwisle observes, "tension existed between detractors and champions of the local avant-garde."239 During his time as head of the art department at Auckland Training College from 1943-63, he also

\footnotetext{
${ }^{236}$ McAloon, Art at Te Papa, 11.

${ }^{237}$ Ibid., 13.

${ }^{238}$ Auckland Star (25 August 1958): 5, cited in Notman and Cullen, Beloved, 25. For a conversation between Pevsner and members of the Wellington District Branch, covering town planning, current fashions in architecture in England, difference between functionalism and utilitarianism, and the development of a national style of architecture, see Journal of the NZ Institute of Architects: Including Proceedings and Architectural Notes 25, no. 7 (August 1958): 185-196, accessible via the National Library of New Zealand, https://natlib-primo.hosted.exlibrisgroucom/primoexplore/fulldisplay?vid=NLNZ\&docid=INNZ7121817320002837\&context=L\&search_scope=INNZ. ${ }^{239}$ Peter Entwisle, "Edgar, James Douglas Charlton," Dictionary of New Zealand Biography, first published in Te AraThe Encyclopedia of New Zealand (1998), accessed 14 May 2020, https://teara.govt.nz/en/biographies/4e3/edgar-jamesdouglas-charlton.
} 
taught modernists like Stanley Palmer, Para Matchitt and Ralph Hotere. In 1961 he donated a collection of twentieth century New Zealand works to the Hocken Library, which helped to transform it into a more representative, modern institution. ${ }^{240}$

Edgar was appointed director of the DPAG upon Pearse's retirement in 1965, and immediately made changes to the gallery's acquisitions and public programmes. ${ }^{241} \mathrm{He}$ stated that a changing scene "is the life-blood of culture institutions especially if they are pointed intelligently to topical and constant productions in the Arts." 242 Therefore, he acknowledged the need for the development of temporary and travelling exhibitions, as well as the acquisition of works by contemporary local artists. As part of this philosophy, he initiated a programme of solo exhibitions by living New Zealand artists, such as his former colleagues at the Dunedin School of Art, R.N. Field and W.H. Allen, whom he heralded as the instigators of modernism in New Zealand. ${ }^{243}$ Other artists represented in the collection during his directorship include Toss Woollaston, Ralph Hotere, Frances Hodgkins, and the first McCahon which was accepted in 1971. ${ }^{244}$

The acquisition of works by Hodgkins are particularly noteworthy, as she was herself from Dunedin, but also because they accumulated quite rapidly during Edgar's time, as “one was bought in 1966, another in 1967, six arrived in 1970 and ten in 1971."245 Since then, the collection has grown even more and is now considered, along with Auckland's, to be the most important group of her works in a public institution. ${ }^{246}$ Circular Barn (DPAG, 1939)

[Fig. 81] is one of the works purchased in Edgar's final year at the DPAG. This small gouache work shows off her expressive brushwork and creative colouring, taking a traditional subject such as a barn - not unlike those seen in some of the Smythe watercolours

\footnotetext{
${ }^{240}$ Entwisle, "Edgar, James Douglas Charlton."

${ }^{241}$ Notman and Cullen, Beloved, 17. For example, he introduced art classes for children on Saturday mornings and a more regularly changing exhibition schedule.

${ }^{242}$ Wendy Carnegie and Brenda Gamble, "Who You Should Know - I," Art Galleries and Museums Association of New Zealand 2, no. 10 (August 1971): 4, accessed 18 May 2020,

https://christchurchartgallery.org.nz/media/uploads/2017_10/AGMANZ_News_Volume_2_Number_10_August_1971.pdf. ${ }^{243}$ Entwisle, "Edgar, James Douglas Charlton."

${ }^{244}$ Notman and Cullen, Beloved, 17. This McCahon work, Helensville 3, 1971 (17-1971) was bequeathed by Mrs. Gerald Lindo Ferguson. For more detailed examples of Edgar's acquisitions, see Entwisle, Treasures, 34. For example, he also collected some New Zealand prints by artists like E. Mervyn Taylor, Eileen Mayo and Rona Dyer. Besides contemporary New Zealand artists, the other area in which Edgar made significant advances was in collecting Australian painters, like Sidney Nolan, Arthur Boyd and William Dobell.

${ }^{245}$ Entwisle, Treasures, 36.

${ }^{246}$ Ibid. Frances Hodgins was particularly important for Dunedin as she was born and raised there. Her father, William Mathew Hodgkins, was also at the centre of Dunedin's artistic activities, having co-founded the Otago Society of Artists (later the Otago Art Society) in 1875 and also being involved in initiating the early developments of the DPAG. For more information on Hodgkins, see E.H. McCormick, Portrait of Frances Hodgkins (Auckland: Auckland University Press, 1981); Pamela Gerrish Nunn, "Frances Hodgkins: A Question of Identity," Woman's Art Journal 15, no. 2 (Autumn 1994 Winter 1995): 9-13, accessed 18 May 2020, https://www.jstor.org/stable/1358598; and E.H. McCormick, Works of Frances Hodgkins in New Zealand (Auckland: Auckland City Art Gallery, 1954) for a catalogue of her works in New Zealand before 1954.
} 
discussed earlier in Chapter Three - and distorting the space and objects. ${ }^{247}$ Robyn Notman concludes that "Charlton Edgar made good progress with collecting the New Zealand moderns but his Directorship was relatively brief", as he retired in 1971 after just six years in the role. ${ }^{248}$ Peter Entwisle agrees that because of Edgar's directorship, "the period of the Dunedin gallery's neglect of the local and contemporary was ended."249

His successor, L.C. Lloyd (director 1971-1980), came directly from his role as conservator at the AAG. He, too, made his mark quickly. In 1972 he proposed that the gallery should house the New Zealand Photographic Society's collection, which initiated the collecting of photography in Dunedin. This has since become a prominent collection strength of the gallery. ${ }^{250}$ His most radical suggestion, however, was to cease buying European paintings altogether on the grounds that they were too expensive. ${ }^{251}$ While this was not accepted by the Council, they did acknowledge the need to continue building the New Zealand collection. Milan Mrkusich, Philip Trusttum and Brent Wong were all acquired, but also older New Zealand artists such as William Mathew Hodgkins, and historic works of relevance to the collection, for example G.P. Nerli’s Portrait of a Girl (oil on canvas, 1890, 2-1972). ${ }^{252}$

In response to the widely held opinion that the NAG in Wellington was not "living up to its name as a national gallery" in this regard, the government eventually provided special grants to enable the purchasing of contemporary New Zealand art. ${ }^{253}$ In 1966, works by Robert Ellis, Ralph Hotere, John Drawbridge, Melvin Day and Toss Woollaston entered the gallery's collection, and the first Rita Angus painting was acquired in 1967. When

\footnotetext{
${ }^{247}$ In his obituary for Hodgkins, the artist Eardley Knollys described her practice in great detail: "She was never an abstract artist, she never denied herself the pleasure of representing the charm she saw around her; but she abandoned conventional realism. Her pictures are always of recognisable objects, though selected, sometimes distorted, and freely altered in scale." See Eardley Knollys, "Frances Hodgkins," The Burlington Magazine for Connoisseurs 89, no. 532 (July 1947): 197-198, accessed 18 May 2020, https://www.jstor.org/stable/869636.

${ }^{248}$ Notman and Cullen, Beloved, 17.

${ }^{249}$ Entwisle, Treasures, 37.

${ }^{250}$ Ibid. For more information on the growing popularity of photography in New Zealand public collections, see John B. Turner, "Some Notes and Queries on the Collecting of Photographs by Libraries, Museums and Art Galleries in N.Z.," Art Galleries and Museums Association of New Zealand 14, no. 2 (June 1983): 2-7,

https://christchurchartgallery.org.nz/media/uploads/2017_08/AGMANZ_News_Volume_14_Number_2_June_1983_optimi zed_for_web.pdf. Luit Bieringa (director of the NAG 1979-1989) was also a prominent champion of New Zealand photography. Among other things, he made a movie about Ans Westra. See Alastair Bull, "Coaxing Westra Out from Behind the Lens," New Zealand Herald (9 August 2006),

https://www.nzherald.co.nz/lifestyle/news/article.cfm?c_id=6\&objectid=10395319 and Luit Bieringa, Ans Westra Private Journeys/Public Signposts (Wellington, N.Z.: BWX: TVNZ, 2006).

${ }^{251}$ Entwisle, Treasures, 37.

${ }^{252}$ Although Nerli was born in Siena, Italy, he is still considered a significant part of art history in New Zealand due to his influence on generations of New Zealand artists. He lived in Dunedin from 1893-96, where he was on the council of the Otago Art Society, and one of three artists who opened the Otago Art Academy. Among his numerous students was Frances Hodgkins. For more information on Nerli, see Michael Dunn, Nerli: An Italian Painter in the South Pacific (Auckland: Auckland University Press, 2005); Peter Entwisle, Nerli: An Exhibition of Paintings \& Drawings (Dunedin: Dunedin Public Art Gallery, 1988).

253 “Aloof Art Gallery,” Dominion (18 March 1966): 2, cited in McAloon, Art at Te Papa, 12.
} 
Melvin Day took over from Maclennan in 1968, he continued to buy local, with artists such as Mrkusich, McCahon, Pat Hanly, Bill Sutton, Drawbridge and Jan Nigro being listed among acquisitions in $1970 .{ }^{254}$ Day also organised the exhibition Contemporary New Zealand Painting (1972) to showcase such works. ${ }^{255}$

However, it was Day's successor, Luit Bieringa (director 1979-1989), who truly manifested the taste for New Zealand artists in the capital. Even outside of his role as gallery director, Bieringa was a prominent advocate and promoter of contemporary New Zealand art. He was acting as president of (and contributor to) the Art Galleries and Museums Association of New Zealand (AGMANZ), taking an active part in the local art scene. He wrote several articles for the AGMANZ journal, including obituaries for McCahon and Ronald Norris O'Reilly, a former director of the Govett-Brewster Art Gallery. ${ }^{256}$

As director of the NAG, Bieringa wrote an article on the progress of developing a collection policy at the NAG in 1985, which he believed was of the highest priority. He wrote that "the legacy of passive acquisition in the past presents a major obstacle which of necessity must be hurdled but should not delay an immediate and fresh approach to present and future collecting modes." 257 One of the approaches highlighted was that "as a supposedly national institution its obligations should be more New Zealand-centric and sympathetic to a nation-wide perspective, not however at the expense of international collecting. $" 258$ Thus, while international purchases were still conducted, Bieringa clearly focused his efforts more on local art. ${ }^{259}$ Mrkusich, Don Driver, Gordon Walters, Don Peebles, Trusttum, Gretchen Albrecht, Para Matchitt and Ralph Hotere were all acquired. Also in 1985, the gallery spent an unprecedented \$130,000 on McCahon's Practical

\footnotetext{
${ }^{254}$ McCredie, "Going Public," 69.

${ }^{255}$ Artists included in the exhibition were Day himself, McCahon, Rita Angus, Philip Trusttum, John Drawbridge, Ian Scott, Pat Hanly, Milan Mrkusich, Ralph Hotere, Don Peebles, Bill Sutton, Don Binney and Gordon Walters. See National Art Gallery, Contemporary New Zealand Painting (Wellington, 1972), for more information. McAloon, Art at Te Papa, 13. ${ }^{256}$ See Luit Bieringa, “Obituary: Colin McCahon 1919-1987,” AGMANZ Journal 18, no. 2 (1987): 28, accessed 4 June 2020 ,

https://christchurchartgallery.org.nz/media/uploads/2017_08/AGMANZ_Journal_Volume_18_Number_2_Winter_1987_op timized_for_web.pdf; and Bieringa, “Obituary: Ronald Norris O'Reilly (9-10-1914/10-7-82),” AGMANZ News 13, no. 3 (September 1982): 15-16, accessed 4 June 2020,

https://christchurchartgallery.org.nz/media/uploads/2017_10/AGMANZ_News_Volume_13_Number_3_September_1982. pdf. Bieringa emphasised and admired that O'Reilly himself had a widely recognised "life-long involvement and interest in contemporary New Zealand and indigenous art." Bieringa, "Obituary: Ronald Norris O'Reilly," 15. For more information on O'Reilly as a promoter of contemporary New Zealand art, see Crighton, English, Colonial, Modern and Māori, 65-68. ${ }^{257}$ Luit Bieringa, "Collecting and Collection Policies at the National Art Gallery," AGMANZ Journal 16, no. 1 (March 1985): 20, accessed 4 June 2020,

https://christchurchartgallery.org.nz/media/uploads/2017_08/AGMANZ_Journal_Volume_16_Number_1_March_1985_op timized for_web.pdf.

${ }^{258}$ Ibid., 21.

${ }^{259}$ Some of the international acquisitions were prints and further British works, however, there was also a notable shift to international works "closer to home," i.e., Australian. Contemporary Australian works were finally collected more actively, including works by artists like Jenny Watson, Rosalie Gascoigne, Tim Johnson, Peter Tyndall and Imants Tillers. See McAloon, Art at Te Papa, 14.
} 
Religion: The Resurrection of Lazarus Showing Mount Martha (1969-70, 1985-0022-1), which William McAloon points out was the highest price ever paid for a work by a living New Zealand artist at this stage. ${ }^{260}$ The exhibition Content/Context: A Survey of Recent New Zealand Art (1986), Bieringa writes in the introduction of the accompanying catalogue, came about "in response to a need expressed by many involved in the arts for a more substantial coverage of contemporary New Zealand art."261

Auckland witnessed a similar development. Athol McCredie observes that "though Westbrook acquired large numbers of British works he also believed that the gallery had to focus more strongly on New Zealand artists and he began by building up an important collection of Frances Hodgkins' work."262 These were exhibited for the first time in 1954, in the exhibition Frances Hodgkins and Her Circle. Charles Brasch wrote in Landfall, "it is probably safe to say that the exhibition, Frances Hodgkins and her Circle, held at the Auckland City Art Gallery in June, was the most important exhibition of painting ever to have been held in New Zealand." 263 He continues that the exhibition really should have been shown at other galleries too, but due to inadequate co-operation between the galleries, and lack of funding, this was never achieved ${ }^{264} \mathrm{He}$ concludes:

It is ironical that Auckland alone, the one New Zealand city with which Frances Hodgkins had no connection (it is doubtful if she ever visited it), has tried to do her honour: belatedly, after her death, at the instance of an art gallery director from England. Dunedin to which she belonged and whose special pride she should be, has neglected her steadily and neglects her still. ${ }^{265}$

Mary Kisler recalls that Colin McCahon and Peter Tomory "had a great regard for one another, even if sometimes Colin felt that Peter's natural attraction for international

\footnotetext{
${ }^{260}$ McAloon, Art at Te Papa, 14.

${ }^{261}$ National Art Gallery (NZ), Content/Context: A Survey of Recent New Zealand Art 1986 (Wellington: National Art Gallery, 1986), 9.

${ }^{262}$ McCredie, "Going Public," 67.

${ }^{263}$ Charles Brasch, "Frances Hodgkins in Auckland," Landfall 8, no. 3 (1954): 209, accessed 11 April 2020, http://www.landfallarchive.org/omeka/items/show/22194. Brasch does acknowledge that Westbrook would not have been able to set up this exhibition without the previous work done by McCormick, who had already searched out and catalogued Hodgkins' entire oeuvre in New Zealand. The exhibition catalogue for this show, which includes a foreword by Westbrook and an essay by McCormick, can be found on the website of the Auckland Art Gallery, https://www.aucklandartgallery.com/page/frances-hodgkins-and-her-circle.

${ }^{264}$ Brasch, "Frances Hodgkins in Auckland," 212.

265 Ibid.
} 
historic art meant that that part of the collection received more of his attention." ${ }^{266}$ Anna Crighton, however, writes that "his emphasis was always equally, if not more, on the promotion of contemporary New Zealand art."267 Tomory’s former student and colleague from Melbourne, Elizabeth Cross, concludes that he in fact found the perfect balance of both during his time in New Zealand:

He is respected to this day for his tenacious insistence on professional standards, on the importance of supporting local artists by showing their work whilst simultaneously building a significant collection of international art, both historical and Modernist, which he believed would serve the interests of the community, the discipline of art history and provide rich stimulus for contemporary artists. ${ }^{268}$

This idea of unifying New Zealand and international art, finding a link and narrative for both, was expressed in Tomory's collecting and exhibiting practices. ${ }^{269}$ While local artists were certainly on the agenda, especially in regards to exhibitions, it was only with Tomory's successor, Gil Docking (1919-2015), that contemporary New Zealand artists were truly being collected actively in Auckland. ${ }^{270}$

Docking (director 1965-1972) not only collected and exhibited local contemporary art, but he also wrote a book on New Zealand art's history, Two Hundred Years of New Zealand Painting (1971). The last part of the book is the most progressive, as it is dedicated to nine young emerging painters who, as Docking writes, "while still under thirty years of age in 1969, appear to be establishing some new directions in New Zealand painting, or are

\footnotetext{
${ }^{266}$ Mary Kisler, “A Man of His Time - Peter Tomory 1922-2008,” 26 March 2008, accessed 15 April 2020, https://www.aucklandartgallery.com/article/a-man-of-his-time-peter-tomory-1922-2008. While Tomory had always shown a keen interest in modern, contemporary art, he certainly had a natural inclination towards the historical. He published numerous texts in this area, such as European Paintings Before 1800 in Australian and New Zealand Public Collections: Summary Catalogue (Sydney: Beagle Press, 1989). His most significant art historical find - which made him a recognised scholar internationally - was also in historical European art. In 1963 he discovered thirty-seven Fuseli drawings in a private collection in Dunedin, which was subsequently bought by the AAG, and which led to Tomory's publication on Fuseli in 1972, the first monograph on the artist. See Tomory, The Life and Art of Henry Fuseli (London: Thames and Hudson, 1972); see also Nicolas Powell, "The Auckland Collection of Fuseli Drawings," The Burlington Magazine 110, no. 781 (1968): 227-224, accessed 8 June 2020, www.jstor.org/stable/875601. For a comprehensive list of Tomory's published writings, see Courtney Johnston, "Peter Tomory's Published Writings," 177-185, in Johnston's thesis "Peter Tomory: The New Zealand Years, 1956-1968," MA diss., Victoria University of Wellington, 2004.

${ }^{267}$ Crighton, English, Colonial, Modern and Māori, 108. The author proceeds to emphasise that Tomory used to travel around the country, gathering pictures for the AAG's annual Contemporary New Zealand Painting shows. Promoting emerging local artists was an important aspect of Tomory's directorship.

${ }^{268}$ Elizabeth Cross, "Peter Alexander Tomory, 1922 - 2008," Art Monthly Australia 209 (May 2008): 29, accessed 8 Jun 2020, https://search-informit-org.helicon.vuw.ac.nz/doi/10.3316/informit.186181630425955. See also Mary Kisler, "The Peter Tomory Archive," Reading Room 3 (2009): 154-163, accessed 5 June 2020, https://issuu.com/aucklandartgallery/docs/readingroom_03_2009?e=7464930/4676568.

${ }^{269}$ See Peter Tomory, "Unifying Art-in New Zealand," Connoisseur (May 1959): 9-11, and Johnston, "Peter Tomory: The New Zealand Years." Tomory's taste in New Zealand art was certainly influenced by McCahon, and they often worked together on planning exhibitions and selecting local artists for display.

${ }^{270}$ Courtney Johnston explains that Tomory initially put off buying New Zealand works, as he first wanted to familiarise himself with the local painting scene. However, even when he finally started to actively exhibit local artists, a large number of the works shown were actually on loan from artists. See Johnston, "Peter Tomory: The New Zealand Years," 46.
} 
restating in a personal way some of the conclusions arrived at by older artists." ${ }^{271}$ Alexa Johnston claims that Docking's book “established the national pre-eminence of the New Zealand art collection." ${ }^{272}$ Indeed, among his new acquisitions were Gordon Walters, Donald Binney, Michael Smither, Michael Illingworth, Rita Angus, Don Peebles, and Ralph Hotere. $^{273}$

In conclusion, taste in New Zealand shifted greatly between 1950 and 1980. While art institutions were initially guided by the RA, and conservative British painting was the preferred choice, during the 1950s - when Smythe's watercolours arrived - this started to change. Initially only Auckland, but after 1960 Wellington and Dunedin also started looking towards modern art instead. By the 1970s, it was in fact New Zealand art that had established itself as the main collecting focus of all major galleries. While some individual gallery directors were more old-fashioned in their tastes than others, generally the Smythe watercolours did not fulfil the New Zealand galleries' requirements. This was especially true when the taste for British art had been eclipsed by a growing nationalism that favoured New Zealand artists. In the Introductory essay for the exhibition After Cubism, Before Pop (2013), which looked at Te Papa's collection of twentieth-century International art, Mark Stocker wrote that "from the art on show, it's virtually impossible to distinguish what is 'Kiwi' and what is not. In the melting pot of international modernism, national identity is probably the last thing that matters anyway." 274 The next chapter will show that national identity certainly did matter when it came to art galleries' acquisitions and exhibitions, whilst an imperial identity, based on New Zealand's status as part of the British Empire, did not.

\footnotetext{
${ }^{271}$ Gil Docking, Two Hundred Years of New Zealand Painting, rev. ed. (Auckland: David Bateman, 1990), 196.

272 Alexa Johnston, “A National Treasure," in Auckland Art Gallery Toi o Tāmaki, Auckland Art Gallery Toi o Tāmaki: The Guide, 9.

${ }^{273}$ See also the catalogue to a sculpture exhibition put on show under Docking, Recent New Zealand Sculpture: Auckland City Art Gallery Festival Exhibition, 1966 (Auckland: The Gallery, 1966).

${ }^{274}$ Mark Stocker, “After Cubism, Before Pop," Off the Wall 1 (March 2013), accessed 16 April 2020, https://collections.tepapa.govt.nz/document/4164.
} 


\section{Chapter 5: The Smythe Watercolours and Identity}

In the decades following the gift of Smythe's collection to the NAG and DPAG, the focus on collecting shifted to the modern and the local - to an art made in this place and which professed to respond uniquely to this place. As a result, the Smythe watercolours were pushed even further from society's gaze and desire. A new call to collect local meant British watercolours were no longer relevant. One must not forget, however, that it was not merely a taste for art that was changing in New Zealand during the twentieth century. Indeed, the second half of the twentieth century bore witness to profound changes that would reshape New Zealand's cultural - even national - identity. During the mid-twentieth century, New Zealand's national character underwent a massive shift; for the first time, New Zealanders began to identify themselves in opposition to British identity. One consequence was that the British influence on local artists during the colonial era was downplayed in favour of an emergent national tradition. The turn towards collecting local artists was only one symptom of this. The Smythe collection, therefore, might have been neglected not only for its unsuitability for a certain trend in art, but also for its inappropriateness to the construction of a new national identity. ${ }^{1}$ This chapter will explore these hypotheses and through this, aim to better understand the fate of British watercolours in New Zealand history and culture.

To examine how this shift in cultural and national identity affected the place of British watercolours in New Zealand's collections and art history, one must first determine how these shifts were reflected in New Zealand's museums and galleries. This will be followed by considering what type of identity the watercolours themselves actually represented, in order to understand how inappropriate they were for this new ideological framework. Additionally, this will reveal how a forgotten collection of seemingly unimportant works can be used to engage New Zealand art history with broader sociohistorical themes and disciplines, such as nationalism and patriotism in politics and geography.

\footnotetext{
${ }^{1}$ While I am primarily focusing on national identity, i.e. a New Zealand identity, this is just one of many identities that New Zealanders could - and still can - choose from. For a more in-depth discussion of other identities, such as the identity as a woman, as a worker, as iwi, etc., see David Novitz and William E. Willmott eds., Culture and Identity in New Zealand (Wellington: GP Books, 1989).
} 


\section{TASTE AND IDENTITY: COLLECTING LOCAL AND THE 'NEW’ NEW ZEALAND}

The last chapter has revealed that the 1950s and early 1960s were a period of transition for art galleries, particularly in Auckland where the initial neglect of New Zealand art was starting to be addressed by the gallery directors. While it was still difficult to find local New Zealand art works in the metropolitan galleries in Dunedin and Wellington (and Christchurch) during that time, the next generation of directors quickly changed this. The emerging taste for modernism and abstraction was accompanied by a powerful preference for local contemporary artists. By the middle of the 1980s, Peter Entwisle could observe that "almost every institution is collecting contemporary New Zealand art."2

Indeed, the nationality of these artists was a major contributor to the collecting of their works, as they signalled the emergence of a truly local modernism. By collecting contemporary New Zealand artists, the museums and galleries were celebrating the appearance of professional native-born painters who were looking inwards to their country of birth for inspiration, rather than overseas. ${ }^{3}$ This was important, as it was believed that only native-born artists would have the unique viewpoint to depict New Zealand subjects authentically. As M.H. Holcroft noted, "only now, in the work of painters who have been born in the land, are we finding a true representation in colour, cleansed of the softer tones which came from English eyes when the earlier artists set up their easels beneath the cabbage trees"; 4 a position that Francis Pound has summarised as "painting ... should be painted of New Zealand, by New Zealanders, for New Zealanders". 5 The fact that successful

\footnotetext{
${ }^{2}$ Peter Entwisle, "Thoughts Towards a Nationally Co-ordinate Collecting Policy," AGMANZ Journal 16, no. 1 (March 1985): 4-5, accessed 4 June 2020,

https://christchurchartgallery.org.nz/media/uploads/2017_08/AGMANZ_Journal_Volume_16_Number_1_March_1985_op timized_for_web.pdf.

${ }^{3}$ In a way, literature was leading the way in this regard. For more information on literature and how writers supported ideas about national identity prior to the 1960s, see "The Singers of Loneliness," 239-254, in Keith Sinclair, A Destiny Apart: New Zealand's Search for National Identity (Wellington: Allen \& Unwin in association with the Port Nicholson Press, 1986).

${ }^{4}$ M.H. Holcroft, Encircling Seas (Christchurch: Caxton Press, 1946), 195, cited in Francis Pound, The Invention of New Zealand: Art \& National Identity, 1930-1970 (Auckland: Auckland University Press, 2009), 79.

${ }^{5}$ Pound, Invention, 61. The same was said about the writing of a New Zealand history. Thomas Cholmondley had already claimed in 1854 that any history of New Zealand should be written "by a New Zealander, and not by an Englishman; by a born citizen of the new nation, and not by a colonist." Thomas Cholmondley, Ultima Thule; Or, Thoughts Suggested by a Residence in New Zealand (London, 1854), 344, cited in Sinclair, A Destiny Apart, 57.
} 
painters were born in New Zealand, and not in England, was a source of pride for the nation, and pride is one of the seeds of nationalism. ${ }^{6}$

The painters themselves often expressed similar sentiments about their own nationality. In 1961, Toss Woollaston (1910-1998) wrote, "to us, who happen to be born in this country, and to no one else, can fall the task of making New Zealand art." ${ }^{, 7} \mathrm{He}$ further explained that he was bound to the land of his birth, and happy to develop his artistic career locally:

I was born here and my people are here, and I feel that I have an interest and love for this country, its characteristic landscape, and its people: and my inclination has been to stay here [instead of going off to Europe] where I find an absorbing interest, which I feel is indissolubly bound to the soil of New Zealand. ${ }^{8}$

Another painter, Robin White (born 1946), also commented that she was happy with her homeland and that it has its own heritage to draw from, claiming "I really do feel this is my country. I've got no particular interest in any other artistic heritage and I don't feel I owe anything to what's happened in Britain, America, France or Italy." 9

As galleries began to collect in line with this rhetoric, the close link between shifting artistic tastes and a newfound importance on local identity was accentuated. Essentially, the identity of artists helped to boost the cultural identity of New Zealand. Rebecca Rice confirms that "at some stage in a nation's development therefore, the collection and display of one's national art becomes a crucial component of history and identity making." 10 To simply say that art had to reflect a New Zealand identity, however, is too vague. As numerous scholars have pointed out in the past, cultural and national identities are forever changing and can never be clearly defined. ${ }^{11}$ Therefore, in order to see the change in New

\footnotetext{
${ }^{6}$ Sinclair, A Destiny Apart, 27. Already in 1934, the role of artists in achieving national pride was predicted, as one Art in New Zealand editorial observed that "New Zealand will one day have cause to be as proud of her painters and poets as she is of her All Blacks or frozen lamb." See "Ourselves," Art in New Zealand 7, no. 2 (December 1934): 59, cited in Pound, Invention, 79. The All Blacks and New Zealand lamb had already become symbols of New Zealand national culture and identity by this stage.

${ }^{7}$ Toss Woollaston cited in Gil Docking, Two Hundred Years of New Zealand Painting, rev. ed. (Auckland: David Bateman, 1990), 158.

8 Toss Woollaston cited in John Caselberg, "Havens for Art: Nelson, Dunedin and the Growth of Local Art," Art New Zealand 15 (1980), accessed 17 June 2020, https://www.art-newzealand.com/Issues11to20/havens.htm.

${ }^{9}$ Robin White, “Art and Conservation Are Synonymous," Art New Zealand 7 (1977), accessed 17 June 2020, http://www.art-newzealand.com/Issues1 to40/environrw.htm.

${ }^{10}$ Rebecca Rice, "The State Collections of Colonial New Zealand Art: Intertwined Histories of Collecting and Display," PhD diss., Victoria University of Wellington, 2010, 22.

${ }^{11}$ For example, see David McCrone and Frank Bechhofer, Understanding National Identity (Cambridge: Cambridge University Press, 2015); Kynan Gentry, History, Heritage, and Colonialism: Historical Consciousness, Britishness, and Cultural Identity in New Zealand, 1870-1940 (Manchester: Manchester University Press, 2015); Jock Phillips, "Our History, Our Selves: The Historian and National Identity," The New Zealand Journal of History 30, no. 2 (October 1996): 107-123, accessed 28 April 2020,

https://ndhadeliver.natlib.govt.nz/delivery/DeliveryManagerServlet?dps_pid=IE39848558.
} 
Zealand's perception of a national identity, one must first consider what type of identity was manifest prior to the 1950s, followed by an assessment of the new identity sought out after the 1950s. This will reveal a shift from a previously British-focused identity to a 'new' New Zealand one which acknowledges the country's unique position as a Pacific nation, seeking more independence from Britain and looking inward, rather than back 'Home'.

\section{British Identity in New Zealand}

Peter Entwisle claims that, "until about the First World War to be New Zealand was automatically to be British." 12 Indeed, Britain was considered 'Home', as suggested by the title of Alan Mulgan's popular book Home: A Colonial's Adventure (1927). ${ }^{13}$ This was one of numerous published literary pilgrimages about a colonist's encounter with the 'Motherland', the popularity of which suggests that the idea of Britain as the homeland was "not the narrow obsession of a few." ${ }^{14}$ In Mulgan's case, Home became his most popular book. In it he describes the "wonderful time" he had during his one-year long trip to England - a trip which was financially supported by his own employers. ${ }^{15}$ He begins his journey in New Zealand - his birthplace - describing how he grew up to love England and, like many New Zealanders, developed a dream of visiting 'Home' himself:

England and English things were always before my eyes ... I had some affection for the country of my parents, but infinitely more for England. It was a huge, mysterious, awful, sacred, and yet always lovable place, this England, a land of immemorial things, of shining heroes, of imperfectly understood but fascinating ritual, of marvelous romance, of world-embracing authority and prestige. ${ }^{16}$

E.H. McCormick agreed that "education, reading, prevailing sentiment, economic interest all turned the New Zealand writer's thoughts and ambitions towards England; and, given the opportunity, it was to England she or he migrated." ${ }^{17}$ Pamela James also affirms that for

\footnotetext{
${ }^{12}$ Peter Entwisle, Treasures of the Dunedin Public Art Gallery (Dunedin: Dunedin Public Art Gallery, 1990), 12.

${ }_{13}$ Alan Mulgan, Home: A Colonial's Adventure (London: Longmans, 1930). Alan Edward Mulgan (1881-1962) was a New Zealand journalist, literary editor, and prolific writer. Lawrence Jones claims that he helped to define the spirit of an age, and other examples of his writing, such as The New Zealand Citizen (1914) and Maori and Pākehā: A History of New Zealand (written with A.W. Shrimpton, 1922), "are representative of the type of idealistic and imperialistic historical writing then in vogue." For more information, see Lawrence Jones, "Mulgan, Alan Edward," Dictionary of New Zealand Biography, first published in Te Ara - The Encyclopedia of New Zealand (1998), accessed 10 June 2020, https://teara.govt.nz/en/biographies/4m67/mulgan-alan-edward.

${ }^{14}$ Felicity Barnes, New Zealand's London: A Colony and its Metropolis (Auckland: Auckland University Press, 2012 ), 16.

${ }^{15}$ Ibid., and Mulgan, Home, 226.

${ }^{16}$ Mulgan, Home, 6-7.

${ }^{17}$ E.H. McCormick, New Zealand Literature (Oxford: O.U., 1959), 85,
} 
young countries like New Zealand, which were part of the Empire, but geographically far removed, "to claim Britishness was to claim its power, prestige, longevity and wealth."18 As part of this, Britain's long history was also claimed, serving as a prehistory of white settlement in New Zealand. Historian Fiona Hamilton explains that the first European settlers perceived of themselves as arriving in a land without history: "Europeans arriving in New Zealand believed that their landfall marked the beginning of historical time, measurable in the progress of 'civilization' and contrasting with a 'timeless' Māori past."19 However, as the first European settlement was only established at Kerikeri in 1822 (followed by British annexation of the country in 1840), New Zealand was a young country according to this measurement. Too young, in fact, with too shallow historical roots to boast of a historical consciousness of its own. ${ }^{20}$ James Michael Gore elaborates:

Broadly therefore, both Australia and New Zealand were regarded as young countries among the nations of the world, and as such had no history worthy of preservation or display. Compared with the British national past for example, which was organised primarily around the exploits of monarchs, great statesmen and military heroes, there was little history of similar substance in either Australia or New Zealand. There was no 'suitable' history upon which to construct a distinct national identity, and consequently museums succeeded in perpetuating traditionally narrow images that relied on the nation being 'British'. ${ }^{21}$

A British heritage and identity, therefore, filled this gap. Māori history was not yet considered part of the country's age and identity. In fact, British history was the only history being taught in schools, which had the dual outcome of detaching Māori from their roots and raising young Pākehā as Britons rather than New Zealanders. ${ }^{22}$ Claudia Bell, senior lecturer at the University of Auckland, recalls having to learn a list of British kings and queens at

\footnotetext{
${ }_{18}$ Pamela J. James, "The Lion in the Frame: The Art Practices of the National Art Galleries of New South Wales and New Zealand 1918-1939," PhD diss., University of Western Sydney, 2003, 3.

${ }^{19}$ Fiona Hamilton, "Pioneering History: Negotiating Pākehā Collecting Memory in the Late Nineteenth and Early Twentieth Centuries," New Zealand Journal of History 36, no. 1 (2002): 75, accessed 29 April 2020, https://ndhadeliver.natlib.govt.nz/delivery/DeliveryManagerServlet?dps_pid=FL39848425.

${ }^{20}$ Gentry, History, Heritage, and Colonialism, 15.

${ }^{21}$ James Michael Gore, "Representations of History and Nation in Museums in Australia and Aotearoa New Zealand - the National Museum of Australia and the Museum of New Zealand Te Papa Tongarewa," PhD diss., University of Melbourne, 2002,89 .

${ }^{22}$ The history taught in schools essentially taught children that New Zealand was an outpost of Britain. See Ivan Snook,

"The Education System," 160-171, in Novitz and Willmott, Culture and Identity.
} 
school during the 1950s, commenting “"history” seemed to mean kings and queens, as monarchy was the assumed "natural' historic state." 23

School subjects in general, like the teachers and their teaching methods, were based on the British system, regardless of whether they were useful in New Zealand or not. While some simply saw it as a mindless habit brought over from Britain, Ivan Snook claims that "it was a symbol for the fact that, so far from 'Home', New Zealanders (at least the wealthy ones) shared the English culture." ${ }^{24}$ Cultural gaps were also significant, as New Zealand was considered to be too young to have had the opportunity to develop its own unique traditions. Stewart Maclennan still wrote in one of his letters to Smythe in 1956, "many of our Christmas cards depict snow scenes, though it is almost midsummer here. We like to retain English customs and even indulge in substantial Christmas dinners with plum puddings, although salads would really be more seasonable!"25

Despite the physical distance to Britain, and despite living in reversed seasons, these traditions were upheld as if they had always existed in New Zealand. English settlers had sought to "carve out a new England in a new land." ${ }^{26}$ Indeed, New Zealand came to be known as 'the Britain of the South'. ${ }^{27}$ Ormund Burton, writing in 1935, confirmed the popular opinion that New Zealanders belonged to the British race. ${ }^{28}$ This sentiment was reiterated by Smythe himself, who viewed New Zealanders as Englishmen simply living abroad, referring to them as "our people overseas." 29

Such feelings were expressed not simply in the cultural sector, but across different areas of New Zealand society. Pamela James writes that in New Zealand, "aesthetic taste

\footnotetext{
${ }^{23}$ Claudia Bell, Inventing New Zealand: Everyday Myths of Pākehā Identity (Auckland: Penguin, 1996), 7. Bell elaborates further how this one-sided education taught students a limited history and cultural tradition: "Our 'history' was British imperial history. We were kept ignorant about the impact of Pākehā settlement on Maori. ... The body of knowledge transmitted to us at school linked us to our British heritage. In fact, there was no sense of any other. We did not look at anything published by the first New Zealand writers. We did not even know that such literature existed. It seemed that literature, like art and music, could only come from Europe. Indeed, all art appeared defined by Europe." Bell, Inventing New Zealand, 21-22.

${ }^{24}$ Ivan Snook, "The Education System," 160-171, in Novitz and Willmott, Culture and Identity, 162.

${ }^{25}$ Maclennan to Smythe, 21 November 1956, TPA: MU00008, box 3, item 6. For more information on Christmas cards in New Zealand, and how their production and designs engaged with notions of nationalism and British traditions, see Peter Gilderdale, "Summer Scenes and Flowers: The Beginnings of the New Zealand Christmas Card, 1880-1882," Backstory, no. 3 (2017): 5-25, accessed 26 January 2021, https://doi.org/10.24135/backstory.vi3.26 .

${ }^{26}$ Sinclair, A Destiny Apart, 6. See also Edith Searle Grossman, "The Growth of a Colonial Sentiment," Empire Review IX, no. 52 (May 1905): 350-353.

${ }^{27}$ Jock Phillips, "Visitors' Opinions about New Zealand - The 'Britain of the South', 1860-1900," Te Ara - The Encyclopedia of New Zealand, accessed 23 June 2020, http://www.TeAra.govt.nz/en/visitors-opinions-about-newzealand/page-2.

${ }^{28}$ Ormund Burton, The Silent Division: New Zealanders at the Front 1914-1919 (Sydney: Angus \& Robertson, 1935), 321, cited in Novitz and Willmott, Culture and Identity, 93: "We who belonged to the British race had grown up at a time when Kitchener and Roberts were public idols. The occupation of Egypt, the conquest of the Sudan, the smashing of the Boxer Rising and the Boer War were the great events of our childhood. The righteousness of those conquests had scarcely been discussed. Britain of course was always right."

${ }^{29}$ Smythe to Governor General, 16 July 1954, DCCA: Box 11, DPAG 15/22.
} 
and political conviction were at one in this regard." ${ }^{30}$ In fact, a political report to the New Zealand Cabinet on the occasion of Imperial Federationist L.S. Amery's visit to New Zealand in 1927, claimed that the British Imperial sentiment at that time was stronger than any national New Zealand one: "If Imperial sentiment is strong in Australia, in New Zealand it is a passion, almost a religion. Alone of the dominions, New Zealand is much more interested in her Imperial, than in her national status." ${ }^{11}$

A similar sentiment could be observed during the touring Centennial Exhibition of New Zealand Art in 1940, which was supposed to showcase the chronological development of the arts in New Zealand from its pre-colonial days to the present. This was a celebration of the nation's achievements in art, aimed at presenting the New Zealand public with their own cultural heritage. However, the exhibition did not prove as popular in some locations as was hoped for, which A.H. McLintock blamed on the prominent focus on the 'New Zealandness' of the show's promotion. He wrote that "everyone moans about the war but I'm afraid the term 'N.Z. Art' damns it. If we called it Hottentot, Chinese, or even German, we'd get a better run." 32 Indeed, the painting which drew in most of the crowds in Auckland was Frank Salisbury's Coronation of King George VI (1938). Rebecca Rice observes the irony in this, seeing that while the government was "attempting to nourish a locally inscribed national culture, it seemed the masses would only emerge for reminders of the imperial centre." 33

A noticeable shift occurred, however, when New Zealanders changed their perception of themselves from the 'most' British to the 'best' British; better than Britain itself, that is. This sentiment was already identified in the 1870s, when Anthony Trollope characterised the New Zealander as ‘among John Bulls ... the most John Bullish':

But in New Zealand the assurance is altogether of a different nature. The New Zealander among John Bulls is the most John-Bullish. He admits the supremacy of England to every place in the world, only he is more English than any Englishman at

\footnotetext{
${ }^{30}$ James, "The Lion in the Frame," 210.

31 "Notes on Mr. Amery's Tour in Australia and New Zealand, December 1927," circulated to the New Zealand Cabinet, 8 February 1928, cited in Gordon H. Brown, New Zealand Painting, 1920-1940: Adaptation and Nationalism (Wellington: Queen Elizabeth II Arts Council of New Zealand, 1975), 6.

${ }^{32}$ McLintock to Mulligan, 27 March 1940, ANZ: IA1, series 1, record 62/106, part 5, cited in Rebecca Rice, "Transforming the 'Unimaginative and Literal' into an Art for the Nation: Writing and Exhibiting New Zealand's Art History in the Twentieth Century," Journal of Art Historiography 7 (December 2012): 16. See also James Cowan's comments on a 19067 exhibition in Christchurch, observing that the British works stole the spotlight from any New Zealand works: "There was a great deal of honest artistic work throughout the rooms, and some exceedingly beautiful work, but inevitably the lustre of the New Zealand artists was dimmed by the glory of form and colour that filled the adjoining British gallery." James Cowan, Official Record of the New Zealand International Exhibition of Arts and Industries, Held at Christchurch, 1906-7: A Descriptive and Historical Account (Wellington: Government Printer, 1910), 268, cited in Rice, "The State Collections of Colonial New Zealand Art," 214.

${ }^{33}$ Rebecca Rice, "Transforming the 'Unimaginative and Literal' into an Art for the Nation," 17-18.
} 
home. He tells you that he has the same climate, - only somewhat improved; that he grows the same produce, - only with somewhat heavier crops; that he has the same beautiful scenery at his doors; - only somewhat grander in its nature and more diversified in its details; that he follows the same pursuits and after the same fashion, - but with less of misery, less of want, and a more general participation in the gifts which God has given to the country. ${ }^{34}$

James Belich argues for a 'recolonisation' that occurred in New Zealand roughly between the 1880s and the 1920s. He explained the term as "a renewal and reshaping of links between colony and metropolis after an earlier period of colonisation." ${ }^{35}$ The result was that New Zealand was often seen as a 'Brighter Britain.' ${ }^{36}$

During the fighting at Gallipoli, New Zealanders had already expressed their criticism of the British troops, unimpressed by their retreat from positions that New Zealanders had won, culminating in the disastrous actions at Chunuk Bair. ${ }^{37}$ Additionally, New Zealanders did not approve of the intrusion of the class system of Great Britain into its military, which clashed with their own pride in having a citizens' army. ${ }^{38}$ The weak and incompetent reputation of the British during WWI went hand in hand with the high praise for the New Zealand troops. Comments such as "the plains of Troy never echoed to the feet of such heroes", helped to boost national pride, ${ }^{39}$ and Smythe himself had observed the admirable New Zealand fighting spirit in his letters. ${ }^{40}$ O.E. Burton was convinced that it took a dramatic event like this to make New Zealanders aware of their identity, and he wrote that it was then that "New Zealand very definitely became a nation." 41 The idea that New Zealand was indeed superior to Britain continued well into the 1940s.

By the 1950s there was a sense of a dual identity and national self-image of New Zealand being British and better than the British. James Michael Gore observes in his PhD dissertation "Representations of History and Nation in Museums in Australia and Aotearoa

\footnotetext{
${ }^{34}$ Anthony Trollope, Australia and New Zealand (Melbourne: George Robertson, 1873), 632, cited in Jock Phillips, "The New Zealanders - Better Britons," Te Ara - The Encyclopedia of New Zealand, accessed 11 June 2020, http://www.TeAra.govt.nz/en/document/1915/anthony-trollopes-australia-and-new-zealand-1873.

35 James Belich, Paradise Reforged: A History of the New Zealanders from the 1880s to the Year 2000 (Auckland: Allan Lane; Penguin, 2001), 30. Stuart Ward observed that "Belich's argument was in many respects an answer to Sinclair's $A$ Destiny Apart, which was an attempt to locate the origins of New Zealand nationalism in the late-nineteenth century." Stuart Ward, "The 'New Nationalism' in Australia, Canada and New Zealand: Civic Culture in the Wake of the British World," 231-263, in Kate Darian-Smith, Patricia Grimshaw, and Stuart Macintyre eds., Britishness Abroad: Transnational Movements and Imperial Cultures, Carlton: Melbourne University Press, 2007, 260.

${ }^{36}$ E.H. McCormick, Letters and Art in New Zealand (Wellington: Department of Internal Affairs, 1940), 131. Also seen in the title of William Delisle Hay, Brighter Britain! Or, Settler and Maori in Northern New Zealand (London: Richard Bentley and Son, 1882).

${ }^{37}$ Sinclair, A Destiny Apart, 159-160. The author notes a few examples in his endnotes for this, including from Australian soldiers who expressed similar complaints.

${ }^{38}$ Ibid., 160.

${ }^{39}$ Ibid., 171.

${ }^{40}$ Smythe to Pearse, 30 September 1953, DCCA: Box 11, DPAG 15/22.

${ }^{41}$ O.E. Burton, “A Rich Old Man,” 138, cited in Sinclair, A Destiny Apart, 171.
} 
New Zealand" (2002), that while New Zealanders were generally proud "of their British heritage of free speech, impartial justice and of a powerful homeland in terms of commerce, industry and imperial possessions", they believed they were better in many other respects, such as class, manners, sport, and war. ${ }^{42}$ David Ausubel confirms that this dual identity still existed in 1960, that "the New Zealander feels that he resembles his British forebears in being reserved, unsentimental, respectful of authority, mindful of discipline, and given to understatement; but he vigorously disavows British snobbishness, self-conceit, arrogance, haughty condescension and patronising airs."43

This shift from aiming to imitate the parent country to improving on it, can be interpreted as a redemptive impulse of the newer country. ${ }^{44}$ Seeking redemption by proclaiming New Zealand is better than its former coloniser was the first step towards distancing New Zealand identity from a British one. However, James Belich notes that this in itself was not enough to achieve a new New Zealand identity, as "both Better and Greater Britain motifs implied a reproduction of Britain. ... The Greater British expectation was of ultimate independence, though not of the elimination of British links." 45 These British links had to be destroyed before any sense of an independent identity could be attained. As Stuart Ward observes, "so long as they relied on Britishness for their ethnic categories of inclusion and exclusion, settler-colonial identities provided no basis for the development of a selfsufficient national myth." "46 Smythe's watercolours arrived in New Zealand exactly at the time when this was starting to happen. The 1950s and the following decades witnessed a distinct split from Britain and the subsequent assertion of a new identity.

\section{Non-British Identity: Towards an Independent New Zealand}

Susan Wild explains in her thesis "Creating New Zealand: Pākehā Constructions of National Identity in New Zealand Literary Anthologies" (2015), that other former British colonies, like the United States, Canada, South Africa and Australia, have all "been marked by an identifiable breach from their colonizing parent, or clearly expressed assertion of separate

\footnotetext{
${ }^{42}$ Gore, "Representations of History and Nation," 37.

${ }^{43}$ David Ausubel, The Fern and the Tiki: An American View of New Zealand (Sydney, 1960), 8-9, cited in ibid.

${ }^{44}$ Darian-Smith, Grimshaw and Macintyre, Britishness Abroad, 6.

45 James Belich, Making Peoples: A History of the New Zealanders from Polynesian (Auckland: Penguin Random House New Zealand, 2007). For more by Belich, see Belich, Replenishing the Earth: The Settler Revolution and the Rise of the Anglo-World, 1783-1939 (Oxford: Oxford University Press, 2009).

${ }^{46}$ Ward, "The 'New Nationalism' in Australia, Canada and New Zealand," in Darian-Smith, Grimshaw and Macintyre, Britishness Abroad, 235. Ward elaborates: "It is this dependence on an ethnic Britishness that placed settler-colonial 'nationalisms' on a less sure footing than other, more conventional nineteenth-century national ideologies. They cannot be regarded as analogous to the phenomenon of 'dual nationalities' today, which depend on the arbitrary personal histories of the individuals who can claim them."
} 
identity." ${ }^{47}$ New Zealand, on the other hand, has no such critical moment or "origin event" in its young history. Wild clarifies:

New Zealand can draw upon no comparable single historical event - one involving the community in an act of collective national re-imagining and beginning - as an emblematic assertion of its independence from Britain. Rather than an abrupt political and emotional rift, the account of New Zealand's path towards separate nationhood has been one of gradual constitutional change. ${ }^{48}$

Still, scholars have attempted to find such a definitive moment in time and have consequently supplied a variety of options. These include 1856 and the advent of elected government; 1907 and the achievement of Dominion status; 1915, when New Zealanders fought united on the slopes of Gallipoli; ${ }^{49}$ or 1947, when the Statute of Westminster was passed and New Zealand became fully independent (dropping the 'Dominion' title). ${ }^{50}$

Regardless, the move away from Britain eventually resulted in a complete rejection of a British identity in New Zealand. Already in 1905, New Zealand novelist Edith Searle Grossman had written that "a strong patriotic feeling has grown up for the land of our birth. ... The sentiment for England has receded into the background." ${ }^{51}$ Lyndsay Head, historian and University of Canterbury lecturer, agrees that "we were New Zealanders first, and British second - or not at all." 52 Indeed, just as calling oneself Canadian is a renunciation of being American, so identifying oneself as a New Zealander was becoming more likely a proclamation of not being British. ${ }^{53}$ Art Historian Jonathan Mane-Wheoki also concedes that "Pākehā are the people who define themselves by what they are not. Who want to forget their origins, their history, their cultural inheritance ... to deny their origins so that we can

\footnotetext{
${ }^{47}$ Susan Wild, "Creating New Zealand: Pākehā Constructions of National Identity in New Zealand Literary Anthologies," PhD diss., Victoria University of Wellington, 2015, 18.

${ }^{48}$ Wild, "Creating New Zealand," 18-19.

${ }^{49}$ For more information on this theory, see Christopher Pugsley, Gallipoli: The New Zealand Story (Auckland: Hodder and Stoughton, 1984); Pugsley, The Anzac Experience: New Zealand, Australia and Empire in the First World War (Auckland: Reed, 2004); and Jeff Hopkins-Weise, Blood Brothers: The Anzac Genesis (Adelaide: Wakefield Press, 2009). Susan Wild also highlights that others, like Lloyd Jones, have emphasised New Zealand's international sporting achievements as major components of the construction of a new self-identity. See Wild, "Creating New Zealand," 20, and Sinclair, "Peace Hath its Victories: Sport," in A Destiny Apart, 143-155 + 258.

${ }^{50}$ See Belich, Paradise Reforged. New Zealand signed the Treaty of Versailles in 1919 as a sovereign nation, and the Balfour Declaration of 1926 established the equal status of Britain and self-governing New Zealand, which became law through the Statute of Westminster in 1931 (only adopted in 1947). See also Sinclair, A Destiny Apart, 103; and "The Legacy of War," Ministry for Culture and Heritage, accessed 8 March 2018, https://nzhistory.govt.nz/war/first-world-waroverview/impact-on-international-relations.

${ }^{51}$ Edith Searle Grossman, "The Growth of a Colonial Sentiment," Empire Review IX, no. 52 (May 1905): 350-353, cited in Sinclair, A Destiny Apart, 6.

${ }^{52}$ Lyndsay Head, "Culture on the Fault Line," in Michael King ed., Pākehāa: The Quest for Identity in New Zealand (Auckland: Penguin, 1991), 24-25.

${ }^{53}$ David Pearson, The Politics of Ethnicity in Settler Societies: States of Unease (Basingstoke \& New York: Palgrave, 2001), 16.
} 
all start off afresh." ${ }^{54}$ Until the middle of the twentieth century, the concept of imperial citizenship still persisted and there was simply no need to define separate citizenships for former colonies like New Zealand, Australia or Canada. In New Zealand, however, this concept collapsed with the introduction of the British Nationality and New Zealand Citizenship Act in $1948 .{ }^{55}$ The New Zealand nationality was now official. ${ }^{56}$

This rejection of being British coincided with Britain itself undergoing a change in identity, one that would exacerbate the difference between Britain and New Zealand. After being the first country to sign an association agreement with the European Economic Community (EEC) in 1954, the United Kingdom first applied to join the European Communities (EC) in 1961. ${ }^{57}$ Though the first two attempts had failed, Britain officially joined the EC in 1973. Joining Europe was the final blow to the receding British Empire upon which the global sense of Britishness had rested. Political historian John Pocock wrote on the impact this move had on New Zealand's cultural fate:

when you told us that you were now Europeans, which we, as New Zealanders, were not; so that after all those generations in which you had allowed the notion of empire to shape your identity (or so you now tell us, by way of justifying what you do now, since you no longer have the Empire), we were to learn that you cared as little for our past as for our future. What you did, of course, was irrevocably and unilaterally to disrupt a concept of Britishness which we had supposed we shared with you ... In effect, you threw your identity, as well as ours, into a condition of contingency, in which you have to decide whether it is possible to be both British and European (given that you do not particularly believe in either), while we have to decide in what sense if any we continue to be British or have a British history. ${ }^{58}$

\footnotetext{
${ }^{54}$ Jonathan Mane-Wheoki cited in Wild, "Creating New Zealand," 30.

${ }^{55}$ Carl Bridge and Kent Fedorowich, eds., The British World: Diaspora, Culture and Identity (London: Taylor \& Francis Group, 2003), 8. The authors explain that "the Irish Free State was the first Dominion to assert and define its own citizenship when it passed the Irish Nationality and Citizenship Act" in 1935. This was initially not considered significant by the Commonwealth, however when Canada followed in 1946, the attitude changed. Australia, New Zealand and South Africa were thus only the latest additions to this revolution. For more information, see Randall Hansen, Citizenship and Immigration in Post-war Britain: The Institutional Origins of a Multicultural Nation (Oxford, 2000); Nicholas Mansergh, Survey of British Commonwealth Affairs: Problems of Wartime Co-operation and Post-War Change 1939-1952 (Oxford, 1958); and lan R.G. Spencer, British Immigration Policy since 1939: The Making of Multicultural Britain (London, 1997). For a copy of the British Nationality and New Zealand Citizenship Act, see http://www.nzlii.org/nz/legis/hist_act/bnanzca19481948n15493.pdf.

56 This shift was further cemented when the Dominions started changing their flags (such as the removal of the Union Jack in Canada), abandoned imperial honours, and announced Britain legally as a 'foreign' country. Bridge and Fedorowich, The British World, 9. See this page for more examples, and also a discussion of the usage of the term 'Britain.'

${ }^{57}$ The European Communities (EC) is the collective term for the three communities that were set up after WWII: European Economic Community (EEC), European Coal and Steel Community (ECSC) and European Atomic Energy Community (EAEC). The ECSC and EEC would later be integrated into the European Union.

${ }^{58}$ J. Pocock, "Conclusion: Contingency, Identity, Sovereignty," in Alexander Grant and Keith Stringer eds., Uniting the Kingdom? The Making of British History (London; New York: Routledge, 1995), 297. See also J. Pocock, "British History: A Plea for a New Subject," The New Zealand Journal of History 8, no. 1 (April 1974): 3-21, accessed 1 May 2020, https://ndhadeliver.natlib.govt.nz/delivery/DeliveryManagerServlet?dps_pid=IE39862032.
} 
While there is clear resentment towards Britain for disrupting the global concept of

Britishness and thus robbing New Zealand of an important part of its identity, there is also a feeling of relief. It was the final push needed for New Zealand to look inwards and to its surrounding neighbours, rather than to Britain and distant Europe. One of the first changes to be celebrated, for example, was the introduction of New Zealand history as a subject in universities during the $1960 \mathrm{~s}$ and 1970s. ${ }^{59}$

Political leaders also began to voice their opinions on New Zealand's status as an independent nation. Prime Minister Norman Kirk proclaimed in his speech on the inaugural New Zealand Day in 1974: ${ }^{60}$

For 134 years we have been making a nation and we are perhaps to ask ourselves. "are we yet a completed nation? Have we yet achieved a true New Zealand civilization?" Not yet ... Now as a nation we are independent and on our own. As Britain joins her destiny with Europe's, we must draw more upon the spiritual and cultural strength of the people who make our nation. ${ }^{61}$

Some of the initiatives commenced by Kirk's government to display New Zealand's new independence included withdrawing troops from Vietnam, cancelling the 1973 Springbok rugby tour, sending a frigate to Mururoa to protest French nuclear testing, and sponsoring communes (Ohu) ${ }^{62}$ Furthermore, through his enthusiastic pursuit of an independent foreign policy, Kirk can be said to have steered New Zealand more towards Asia and the Pacific. ${ }^{63}$ This newfound attention on New Zealand's place in the Pacific became especially important as the country severed ties from Britain and Europe, choosing to focus on its status as an island nation instead. As Lyndsay Head observes, "we were beginning to use the term 'Pacific nation' with shy pride, and to bend the land to serve a self-image that centred

\footnotetext{
${ }^{59}$ F.E.S. Kaplan ed., Museums and the Making of "Ourselves": The Role of Objects in National Identity (London \& New York, 1994), 103, cited in Gore, "Representations of History and Nation," 97. See also Jock Phillips, "Our History, Our Selves: The Historian and National Identity," The New Zealand Journal of History 30, no. 2 (October 1996): 107-123, accessed 28 April 2020, https://ndhadeliver.natlib.govt.nz/delivery/DeliveryManagerServlet?dps_pid=IE39848558. ${ }^{60}$ Under Kirk, Waitangi Day was renamed New Zealand Day, and it was officially made a public national holiday. "The change was simply an acceptance that New Zealand was ready to move towards a broader concept of nationhood. For some years overseas diplomatic posts had marked the day, and it seemed timely, in view of the country's role on the international stage, that the national day be known as New Zealand Day." It was changed back to Waitangi Day in 1975. See "Waitangi Day 1970s," Ministry for Culture and Heritage, accessed 2 July 2020, https://nzhistory.govt.nz/politics/treaty/waitangiday/waitangi-day-1970s.

${ }^{61}$ Norman Kirk, inaugural "New Zealand Day," February 1974, in Darian-Smith, Grimshaw and Macintyre, Britishness Abroad, 242.

${ }^{62}$ McCredie, "Going Public," 81.

${ }^{63}$ Ken Ross, "Norman Kirk's 'OE': Ken Ross Reflects on the Prime Minister's Visits to South-East Asia, London and Washington," New Zealand International Review 40, no. 5 (2015): 18-21, accessed 2 July 2020, https://nziia.org.nz/Portals/285/documents/lists/256/NZIRSepOct2015Vol40No5.pdf. For more information on Kirk, see David Grant, The Mighty Totara: The Life and Times of Norman Kirk (Auckland, 2014); J. Dunmore, Norman Kirk (Palmerston North, 1972); M. Hayward, Diary of the Kirk Years (Wellington, 1981).
} 
on the ways we were different from Europe." ${ }^{64}$ Attempts to claim a 'Pan-Pacific identity' were not simply based on geographical facts alone, but also on the changing population of New Zealand. While New Zealand had traditionally been one of the most ethnically homogenous settler societies, ${ }^{65}$ from the 1950s onwards there was an influx of other ethnic groups, such as Pacific Islanders, to the point that "some Pacific Islands, such as the Cook Islands and Niue, are now represented by greater numbers in New Zealand than in their countries of origin." ${ }^{\prime 66}$ While they were still considered a minority group and often faced discrimination, if not mistreatment, Kirk's and other subsequent formations of more diversified economic links with the rest of the world from the 1970s onwards led to a wider acceptance of New Zealand's apparent cultural diversity. ${ }^{67}$

The most significant rise of population numbers in New Zealand was that of Māori. Between the 1950s and 1980s, the Māori population had doubled, showing an increase from $6 \%$ in 1951 to $12 \%$ (of Māori descent) in $1986 .{ }^{68}$ Indeed, one of the biggest shifts in identity beginning in the 1970s was the wider inclusion and appreciation of Māori culture, and recognising New Zealand as a truly bicultural country. Contemporary Māori artist Ngapine Allen suggests that the aspirations for a unique bicultural New Zealand identity went back even further, describing how in the International Exhibition at Christchurch in 1906 "indigenous people were paraded as exhibits before the Anglo-Saxon populace - evidence of a little Pacific empire. The 1906 exhibition marked the beginning of the New Zealand search for a local and international identity." ${ }^{\prime 69}$ However, the use of Māori cultural references acted more like a narrative device in this case, like "a racial prologue that was set aside in order to allow the 'real' story to begin with the arrival of white settler culture", as Jordan

\footnotetext{
${ }^{64}$ Lyndsay Head, "Culture on the Fault Line," in King, Pākehā, 24-25.

${ }^{65}$ Gore, "Representations of History and Nation," 48. The author elaborates that this was aided through strict policies regarding immigration, such as the Immigration Restriction Amendment Act of 1920, which stated that "persons not born in Britain could only apply for residence if they made postal applications in advance." This made it very difficult for those who had little English skills. For the history of immigration in New Zealand and its effects on national identity, see S.W. Greif ed., Immigration and National Identity in New Zealand: One People, Two Peoples, Many Peoples? (Palmerston North, 1995). For the changing ethnic composition of New Zealand, see A. Zodgekar, "Population," in Paul Spoonley, David Pearson and Ian Shirley eds., New Zealand Society: A Sociological Introduction (Palmerston North, 1990), 293-309. ${ }^{66}$ Gore, "Representations of History and Nation," 51. It is important to note, however, that Pacific Islanders were encouraged to come to New Zealand as blue-collar workers, employed in factories and other unskilled labour positions. ${ }^{67}$ This culminated in the 1987 Immigration Act, which stated that migrants were to be selected based on personal merit rather than ethnic origin. "As a result, the number of Asian immigrants has risen dramatically. In the 1991 to 1994 period, for example, Asians accounted for 54.2 per cent of the 69,090 approvals granted by the Immigration Service for permanent migration into New Zealand." Gore, "Representations of History and Nation," 50.

${ }^{68}$ Spoonley, Pearson and Shirley, New Zealand Society, 298.

${ }^{69}$ Ngapine Allen, "Maori Vision and the Imperialist Gaze," in Tim Barringer and Tom Flynn eds., Colonialism and the Object: Empire, Material Culture, and the Museum (London; New York: Routledge, 1998), 150.
} 
and Rice frame it. ${ }^{70}$ There was still no affirmation of a 'living tradition', ${ }^{71}$ instead, Māori culture was used more as a tourist attraction. ${ }^{72}$

This view persisted well into the 1950s and 1960s, when increased Māori urbanisation resulted in the first widespread contact between Māori and Pākehā since the 1860s. ${ }^{73}$ The 1970s and 1980s, however, witnessed many changes in attitude and law. This was headed by Māori asserting their distinct political and cultural rights through various strategies - including marches, occupations, and public demonstrations - that raised public and official awareness of Māori concerns. Michael Gore explains the subsequent initiatives that were introduced to address Māori claims and to provide a framework that would embed biculturalism within Aotearoa New Zealand:

This biculturalism was effectively launched by the passing of the Treaty of Waitangi Act 1975, repositioning the Treaty as New Zealand's founding document. This was sustained by the Waitangi Tribunal, set up in 1975 to adjudicate the claims of Māori against the Crown under the terms of the Treaty, and by the Department of Māori Affairs adopting a policy of Tu Tangata in 1977, which emphasised community development rather than assimilation. The Māori Language Act 1987 then adopted Māori as an official language of New Zealand, while between 1984 and 1988 the Labour Government expanded the resources of the Waitangi Tribunal by giving it the power to investigate claims dating back to $1840 .{ }^{74}$

Athol McCredie confirms that New Zealanders who returned home during the 1980s after a prolonged absence "were 'stunned by the contrast' between the Pākehā-dominated society they had left in which Māori were largely invisible, regarded as curiosities, or treated as the butt of jokes, and the new profile Māori now had in New Zealand society." 75

An important contributor to this was the Te Mãori exhibition (1984), and how museums consequently collected and displayed Māori art and history. ${ }^{76}$ Te Māori had wide implications throughout New Zealand and the international art scene. Ken Gorbey explains why it was significant:

\footnotetext{
${ }^{70}$ Jordan and Rice, “'Cultural Propaganda' and the Politics of Taste,” 128.

${ }^{71}$ Ibid.

${ }^{72}$ On the other hand, one argument put forward has been that the tourist interest in tikanga Maori from outside of New Zealand was in fact "the single most important factor behind the emergence of a wider desire within New Zealand to preserve it." See Gentry, History, Heritage, and Colonialism, 15. See also Burton Benedict, "International Exhibitions and National Identity," Anthropology Today 7, no. 3 (1991): 5-9, accessed 30 August 2020, https://www.jstor.org/stable/3032792.

${ }^{73}$ Michael King, The Penguin History of New Zealand (Auckland: Penguin, 2003), 470.

${ }^{74}$ Gore, "Representations of History and Nation," 58.

${ }^{75}$ McCredie, "Going Public," 84.

76 This exhibition toured the United States from 1984-86, and then New Zealand in 1987. For more information, see Stacey Hanham, "The Te Mãori Exhibition: An Examination of its Organisation and Impacts as Seen by Those Who Developed the Exhibition," MA diss., Victoria University of Wellington, 2000.
} 
The Te Mãori exhibition has opened in New York to critical acclaim and great interest in the early morning ceremony at the Met. New Zealand is on the map. We feel the pride that comes of great national achievements. It is a milestone. It might also be, 1 would suggest, a watershed, for the most important thing about the exhibition has not been that a New Zealand exhibition has made it in one of the great art capitals of the world, but rather that the Māori people have controlled the destiny of their significant cultural property, their taonga, and have placed upon that peculiarly European institution, the exhibition, their own particular feel and mana. ${ }^{77}$

Unlike the 1906 International Exhibition at Christchurch, this time Māori were directly involved in planning the displays. While it was certainly considered a source of national pride, it also revolutionised the way Māori art was portrayed in museums, and what role it played in a New Zealand identity. The AGMANZ journal dedicated an entire volume to the theme. In the opening statement, Peter Tapsell, Minister for the Arts, proclaimed that "if we are to properly display our history, then we must first recognise that till now the predominant art form of Aotearoa has been that of the Māori, so it is only right that that race should be prominently represented in cultural displays." $" 78$

The growing influence of Māori culture was not only seen in cultural displays, but also in modern art as well, such as in the paintings by Selwyn Muru (born 1937). Muru, of Ngāti Kuri and Te Aupōuri descent, was strongly influenced by international modernist styles when he first emerged as an artist during the 1960s. Muru was also "the first contemporary Māori artist to have a work acquired by the National Art Gallery." 79 Despite his European style, his art demonstrates an intimate relationship with New Zealand's culture, especially its newfound bicultural identity. Through the incorporation of te reo Māori in the title of the painting Kohatu (1965, Te Papa) [Fig. 82], the artist not only refers to his own personal Māori roots, but also to the country's indigenous past. While te reo Māori only became officially recognised as a national language of New Zealand in 1987, the 1970s saw the emergence of several groups committed to strengthening the Māori culture and language, in an effort to preserve the Māori identity. ${ }^{80}$

\footnotetext{
${ }^{77}$ Ken Gorbey, "New Zealand Museums - Is there Life after Te Māori?,” AGMANZ Journal 15, no. 4 (1984): 2, accessed 3 July 2020 ,

https://christchurchartgallery.org.nz/media/uploads/2017_08/AGMANZ_Journal_Volume_15_Number_4_December_1984 _optimized_for_web.pdf.

${ }_{78}$ Peter Tapsell, "Statement from the Minister for the Arts," AGMANZ Journal 15, no. 4 (1984): 2, accessed 3 July 2020 , https://christchurchartgallery.org.nz/media/uploads/2017_08/AGMANZ_Journal_Volume_15_Number_4_December_1984 _optimized_for_web.pdf. Te Māori directly inspired numerous other Maori art exhibitions, including in contemporary art, as outlined by Stacey Hanham, "The Te Mäori Exhibition," 49-50.

${ }^{79}$ Megan Tamati-Quennell, “Kohatu,” William McAloon ed., Art at Te Papa (Wellington: Te Papa Press, 2009), 259.

${ }^{80}$ For example, Māori language week was introduced in 1975, and in 1978 New Zealand's first officially bilingual school opened at Rūātoki in the Urewera. For more information, see "Te Wiki o Te Reo Māori - Māori Language Week: Page 2 History of the Māori language," accessed 30 June 2020, https://nzhistory.govt.nz/culture/maori-language-week/history-ofthe-maori-language.
} 
It is not merely the language used that engages with contemporary cultural shifts, but the meaning of the word as well. 'Kohatu' means stone and the thickly layered paintwork indeed does evoke a rocky cave interior. ${ }^{81}$ Together this creates a direct reference to rock art, which is emphasised even further by the incorporation of abstracted figures and images found in the rock art of the South Island's Waitaha people. Megan Tamati-Quennell points out that this was the oldest art form in New Zealand, and Muru therefore evokes timelessness and New Zealand indigenous history. ${ }^{82}$

\section{New Zealand Art and New Zealand Identity}

Art itself played a vital role in nurturing a local identity. A beginning moment of the 'new' New Zealand self-consciousness in art was the first issue of the journal Art in New Zealand (1928-1947). ${ }^{83}$ This not only enabled artists to become familiar with the art of their contemporaries in other centres, and read reviews of exhibitions, it also allowed them to become part of a native art tradition by seeing the connections to their nineteenth-century antecedents. New Zealand painting was born as past and present were reunited and commonalities between the colonial and the modern became evidence of an 'innate' New Zealand character represented through art. ${ }^{84}$

It was in this magazine that the idea of a 'new' New Zealand art was first acknowledged by critics and scholars. In 1934, the editorialist wrote that "a proportion of artists, the younger generation for the greater part ... are breaking away from the colonial art tradition and launching out for themselves." ${ }^{.85}$ Critics and writers of the 1950s and 1960s, like Charles Brasch, E.H. McCormick and Peter Tomory, recognised that the 1930s were the starting point of this new nationalist art. Brasch wrote in 1958 that "the first foreshadowings of what we may now venture to call the New Zealand imagination ... began to appear some thirty years ago." ${ }^{86}$ The questions remained: when did a national 'indigenous' art actually begin and how can an 'innate' New Zealand character be represented in art?

One way to achieve this was by rejecting any relevance of other nation's (especially British) artistic influences. Already in 1932, poet A.R.D. Fairburn observed that New

\footnotetext{
${ }^{81}$ Tamati-Quennell, “Kohatu,” 259.

${ }^{82}$ Ibid.

${ }^{83}$ Pound, Invention, 2.

${ }^{84}$ Ibid., 3.

85 "Ourselves," Art in New Zealand 6, no. 4 (June 1934): 175, cited in Ibid., 6.

${ }^{86}$ Charles Brasch, A Private Collection of New Zealand Paintings (Auckland: Auckland City Art Gallery, 1958), 5, cited in Pound, Invention, 6.
} 
Zealanders should turn to New Zealand itself for inspiration. He wrote to his fellow poet R.A.K. Mason from England:

I'd like to go back to NZ and be a New Zealander. Not a wistful student of French Impressionism and Post-Impressionism ... But just a New Zealander. I would like to live in the backblocks of NZ, and try to realise in my mind the real culture of that country. Somewhere where I might escape the vast halitosis of the Press, and the whole dreadful weight of modern art and literature. Because we really are people of a different race, and have no right to be monkeying about with European culture. ${ }^{87}$

Many artists turned away from the 'prettiness' of essentially Victorian art traditions - those represented in the Smythe watercolours - and instead painted the reality of the New Zealand landscape ${ }^{88}$ Francis Pound elaborates that "the realism the Nationalists prefer is seen as the product of being forced by the Depression to face things as they really are - minus the maternal English screen, minus the fogs of sentiment, minus all aestheticism, all 'illusion' in the full brutality of their economic and material fact." ${ }^{\circ 9}$ By removing British models and illusions, landscape was the obvious choice for a pure New Zealand art.

A significant aspect of the realism of the New Zealand landscape was the natural light, which, when accurately represented in art, would result in clear, harsh outlines. This phenomenon was defined in direct opposition to the soft English tradition by Fairburn in 1934:

There is no golden mist in our air, no Merlin in our woods, no soft warm colours to breed a school of painters from the stock of Turner, Crome, Cotman, and Wilson Steer. Hard, clear light reveals the bones, the sheer form, of hills, trees, stones and scrub. We must draw rather than paint, even if we are using a brush, or we shall not be perfectly truthful. ${ }^{90}$

All the artists he gives as examples are also represented in the Smythe collection, reemphasising its irrelevance to the developments in New Zealand, or rather, what New Zealand artists were expected to react against.

The argument that a natural clarity of light caused a particular style in painting, is exemplified by Hamish Keith's claim that:

\footnotetext{
${ }^{87}$ A.R.D. Fairburn, cited in Sinclair, A Destiny Apart, 244.

${ }^{88}$ Some of the writers from the 1930s who complained about artists painting simply "pretty calendar effects" include Frederick Page, John Cam Duncan, and James Shelley, who wrote "so many of the pictures are just 'pretty bits' of scenery fashioned on familiar English patterns." See James Shelley, "Russell Clark," Art in New Zealand 11, no. 2 (December 1938): 57.

${ }^{89}$ Pound, Invention, 12.

${ }^{90}$ Fairburn cited in Brown and Keith, An Introduction to New Zealand Painting, 9.
} 
The colonial painters began from the conventional forms of English painting, but just as the forms of social life they had brought with them were inevitably adapted, so too were the imported concepts of painting ... due to the problems presented by the unique forms of the New Zealand landscape and the harsh clarity of its light. The degree to which this adaptation was accomplished or attempted is the measure of the quality of colonial painting. ${ }^{91}$

Essentially, the native landscape and light would naturally manifest itself in any art created here, resulting in an innately New Zealand art. However, one must not forget that the hardedged clarity of style in New Zealand painting was actually part of a wider stylistic shift towards a clarified naturalism also evident in other places like Britain, Europe and America. ${ }^{92}$

This style of the 1930s came to be known as Regional Realism. In its acknowledgement and celebration of the natural light in New Zealand, and by taking landscape as its prime subject, it helped to boost new national ideals of a New Zealand identity in creative expression. ${ }^{93}$ Cubism and abstraction were described as 'ultra-modern' and considered too foreign to contribute anything meaningful to this New Zealand cultural identity. It was not until the 1950s that a true New Zealand 'ultra-modernism' began, ${ }^{94}$ when McCahon, for example, applied what he had learned of Cubism to the local landscape, therefore reinventing the standard Nationalist subject for a modern New Zealand. ${ }^{95}$

McCahon's Northland Panels [Fig. 80] have already been noted for their engagement with international modernisms. This can be seen in the massive scale and loose brushwork, and at times the almost complete abstraction of the landscape represented. However, the subject of the work - the landscape itself - is conceived in terms of New Zealand. After returning to his home in Titirangi from his trip to the U.S. in 1958, where he had been exposed to the vast landscapes of the American countryside, McCahon felt enclosed by the thick, native bush. As a response, he painted the sweeping spaces he remembered from Northland, reminiscing "we went home to the bush of Titirangi. It was cold and dripping and shut in.... I fled north in memory and painted the Northland Panels. I was just bursting for the wide open spaces."96

\footnotetext{
${ }^{91}$ Hamish Keith, New Zealand Art: Painting 1827-1890, 3, cited in Pound, Invention, 336.

92 Pound, Invention, 97.

${ }^{93}$ For an example of a painting demonstrating this Regional Realist style, see Rata Lovell-Smith, Hawkins, 1933 (Christchurch Art Gallery, 81/33). A similar argument was brought forward in England to justify the 'innate' English nature of watercolour, as will be discussed later in the chapter.

${ }^{94}$ Pound, Invention, 225.

${ }^{95}$ Ibid., 228.

${ }^{96}$ Colin McCahon cited in "McCahon's Northland Panels," Tai Awatea, Te Papa's onfloor multimedia database (1998), accessed 21 April 2020, https://collections.tepapa.govt.nz/topic/946.
} 
McCahon decided to present an honest representation of the "uniquely New Zealand" landscape. It is true in the sense that he portrays not just the beauty of the land (here the lush colours of the green hills and the indicated presence of the native tui), but also its roughness (here the harsh lines and the black and grey colours of the stormy weather conditions). One method he applied to achieve this was removing any remnants of the European tradition that had dominated New Zealand landscape painting in the past. Thus, McCahon's subjects were directly engaging with current themes of nationalism (as opposed to regionalism); trying to find national icons that were unique to New Zealand. ${ }^{97}$ Instead of idealised, glamorous tourist scenes like Milford Sound, he purposely decided to present simple snapshots of the land. In Landscape Theme and Variations (Series B) (1963, Te Papa, 2011-0028-1/1-8 to 8-8) he is not even presenting a particular identifiable landscape, as he had done in the Northland Panels. "Nor is this the tourist's landscape", he wrote. "I am dealing with the essential monotony of this land ... a 'landscape with too few lovers'."98 By this he expressed his concern with the neglect of the local countryside, which he believed deserved more attention and recognition from its inhabitants.

Rather than the specifically nationalist style of the 1920s and 1930s, Brown and Keith describe McCahon's and his contemporaries' works as a type of "less obvious regionalism", which incorporated the new international art now being collected by New Zealand galleries. The authors conclude that "this was undoubtedly a healthy sign, for it marked a degree of maturity in which the strains of regionalism and internationalism could mix to create something new." 99

\section{New Art Canon}

The desire for a 'New Zealand art' was not solely a twentieth-century phenomenon, but had already begun in the previous century. One vocal advocate was Alfred Sharpe, who came to New Zealand in 1859 and was settled in Auckland by 1866. Like other early colonial artists, Sharpe had received his art training in Britain (Birkenhead School of Arts) and brought with him to New Zealand the writings of drawing masters like Aaron Penley and Thomas

\footnotetext{
${ }^{97}$ In his role as curator at the AAG, McCahon was also actively involved in the recovery of nineteenth-century artists, for example through a vibrant exhibition programme, including A Colonial View (1958) mentioned on page 69.

98 "Landscape Theme and Variations (Series B)," text originally created for Michael Parekowhai, Colin McCahon, Jim Allen exhibition at Te Papa, August - September 2012, accessed 11 May 2020, https://collections.tepapa.govt.nz/object/43333. For more information on McCahon and his art, see Gordon H. Brown, Towards a Promised Land: On the Life and Art of Colin McCahon (Auckland: Auckland University Press, 2010).

${ }^{99}$ Brown and Keith, An Introduction to New Zealand painting, 147
} 
Rowbotham. ${ }^{100}$ In his own writings, however, Sharpe advocated shedding the British 'skin' and approaching watercolour in New Zealand from a new local standpoint, since "to represent accurately the scenery of a totally new country we must divest ourselves of oldworld and antiquated notions of art and begin de novo at Nature's shrine."101

Sharpe stressed the importance of painting the New Zealand landscape, claiming that was the one subject in which New Zealanders could in fact surpass British artists. Writing in the New Zealand Herald in 1881, he said, "we can never compete with European or Continental artists in stereotypic scenery, or figure-painting, but we can at any rate faithfully reproduce our own aboriginal scenery, ere its peculiarities are lost for evermore." ${ }^{102} \mathrm{He}$ promoted a realist approach, true to nature, which celebrated the New Zealand landscape rather than trying to idealise, colonise or 'Britainise' it. This can best be seen in his own watercolours, which picture New Zealand scenery with almost photographic accuracy, advocating that it should not be altered, but left as it is found in nature. ${ }^{103}$ In Burial Place of Hone Heke, Bay of Islands (1883, Te Papa) [Fig. 83], acquired by the NAG in the late 1970s, Sharpe presents us with the true nature of the unkempt New Zealand landscape. If it were not for the figure in the centre, one could easily believe this forest was untouched by human hand. There is a profusion of native plants, including ferns, puriri and karaka, and all of them are recorded with astonishing precision. The colours perfectly create the illusion of the sun's rays which can barely make it through the thick foliage of the trees, with most of the scene beyond their reach. ${ }^{104}$

A strong local art tradition was required to support this new cultural identity and watercolours like Sharpe's were essential for the creation of a new canon of artists to represent this artistic heritage. As Francis Pound phrased it, "in order to invent a new national self, what had to be done was to invent a new version of the past - a revolutionary version appropriate for the forming of the national self to come." 105 Artists like McCahon represented not just a 'national' art, but one of a canon of artists that had inherited and

\footnotetext{
${ }^{100}$ Roger Blackley, "Sharpe, Alfred," Dictionary of New Zealand Biography, first published in Te Ara - The Encyclopedia of New Zealand, 1993, accessed 8 March 2018, https://teara.govt.nz/en/biographies/2s18/sharpe-alfred.

${ }_{101}$ Alfred Sharpe, "Art Training," Auckland Evening Star (12 May 1884), cited in Roger Blackley, The Art of Alfred Sharpe (Auckland: Auckland City Art Gallery, 1992), 10.

102 Alfred Sharpe, "An Art Gallery for Auckland," New Zealand Herald (9 December 1881), cited in Blackley, The Art of Alfred Sharpe, 125.

103 Alfred Sharpe, "Hints for Landscape Students in Water Colour," 1880-82, cited in Blackley, The Art of Alfred Sharpe, 141.

${ }^{104}$ However, Roger Blackley points out that there are also foxgloves in the foreground. Sharpe used these alien species to comment on the irrevocable damage of colonisation on the native landscape. The painting is further loaded with meaning by referencing Ngāpuhi chief Hōne Heke, who became a leading opponent of British rule in New Zealand. See Blackley, The Art of Alfred Sharpe, 68.

${ }^{105}$ Pound, Invention, 329.
} 
transformed the artistic heritage set out by earlier local artists like Sharpe. Watercolours, the earliest European artworks created in New Zealand, played an essential role in this history, manifest in renewed interest in nineteenth-century watercolours and exhibitions held during the twentieth century. ${ }^{106}$

In Britain the amateur often faced backlash for their lack of training; in New Zealand this was precisely the quality celebrated by the first art historians, such as in the national narrative by Brown and Keith. The authors believed that the amateur topographers presented the purest representation of New Zealand, because they were untainted by any British professional painting traditions and instead directly responded to the landscape. ${ }^{107}$ Even though most scholars agree that the New Zealand watercolour tradition grew out of the British tradition represented by Smythe's collection, art historians of the twentieth century pursuing a 'purer' representation of New Zealand instead sought out artist who appeared to look only to New Zealand itself; the Englishness of early watercolours had to be repressed. Ironically, this selective approach is very similar to Clive Bell's defence of the 'English Impressionists', wherein he created a link between their work and that of the Golden Age watercolourists, ignoring anyone who did not fit into that national narrative. ${ }^{108}$

In his catalogue text for the 1940 Centennial Exhibition, McLintock explained the commonly held view that among nineteenth-century artists, those whose work was infused with the British style laid the foundations of a local art tradition:

In general, however, these men were surveyors, not imaginative artists; they saw New Zealand as a future home for Englishmen, not as an artists' paradise and their attitude was topographical rather than interpretative. Thus it was not until the days of Richmond, Gully and Barraud that New Zealand possessed men who were eager to devote their talents to the furtherance of national art. These men arrived in New Zealand early in the fifties with little or no training but imbued with a sound knowledge of the works of Turner, Constable and other English landscape painters. ${ }^{109}$

While Peter Tomory later agreed that artists like John Gully were the first 'professional' artists, he did not agree necessarily that they were the imaginative forerunners of modern

\footnotetext{
106 See pages 66-69.

${ }^{107}$ Gordon H. Brown and Hamish Keith, An Introduction to New Zealand Painting 1839-1967, new and rev. ed. (Auckland: Collins, 1982), 13.

${ }^{108}$ Refer back to page 136. Indeed, one should not forget that English art histories, like that written by Bell, were key influences on New Zealand art histories, just as British painting manuals influenced those written by Sharpe in New Zealand.

${ }^{109}$ McLintock, National Centennial Exhibition, 11. This knowledge and influence of British artists like Turner will be examined further in the last part of this chapter, to explain why this part of the early New Zealand works did not fit into the new canon.
} 
artists. He wrote that their landscapes were still purely physical and lacked any expression of feeling:

The general absence of this quality is the reason one cannot relate this period to those that followed. Even if we consider transitional artists like J.C. Hoyte and John Gully, who enjoyed both public demand and esteem, any element of feeling in their work is largely superficial. ${ }^{110}$

As a theorist, Tomory, of course, was interested in identifying and articulating a modernist framework for evaluating artists' works. The art historians' own contexts and goals, therefore, meant that they did not necessarily agree about specific artists' qualities. The new ideals of clear-cut lines, simplified forms, and un-romanticised landscapes, however, were generally agreed upon and the established canon had to be reinvented to reflect this. As a result, amateurs and surveyors like William Fox, Charles Heaphy, John Buchanan and John Kinder were admired for their aesthetic difference to British watercolours. At the same time, formerly admired artists, like John Gully (1819-1888) - considered the 'Turner of New Zealand' - were critiqued for producing 'English' landscapes. ${ }^{111}$

A good example of the English pastoral picturesque style in New Zealand is Albin Martin (1813-1888), who had close bonds to other British artists like John Linnell (his teacher and close friend), Samuel Palmer and George Richmond. Together, Palmer and Martin travelled through Italy, sketching and painting along the way. This time undeniably had an impact on Martin's style, which he applied to the New Zealand landscape - a landscape which he thought was finer than anything he had ever seen, and comparable to the drawings of Albrecht Dürer. ${ }^{112}$ In fact, the paintings he produced show more of his artistic training in Europe than of the true nature of New Zealand. As John Stacpoole and Una Platts observe in their biography of Martin, "he was so faithful to his English and Italian masters that these paintings might almost have been done in Italy." ${ }^{113}$ Despite its title, A New Zealand Landscape (Auckland Art Gallery Toi o Tāmaki) [Fig. 84], indeed does not look like a New Zealand landscape at all. It is a poetic pastoral scene, with dancing shadows on the ground, elegantly placed tall trees with no sense of New Zealand native identity, and a

\footnotetext{
${ }^{110}$ Peter Tomory, The Pattern of New Zealand Culture, 1968, cited in Johnston, "Peter Tomory: The New Zealand Years," 115.

${ }^{111}$ Mona Gordon, “The Early Artists of New Zealand IV. John Gully - the Turner of New Zealand," The New Zealand Railways Magazine 15, no. 3 (1 June 1940): 35-39. This comparative reference, originally intended as praise, did not align with the nationalist goals of the 1950s - it is precisely his Turneresque qualities which saw Gully eliminated from the canon of great New Zealand artists at this time.

112 John Stacpoole and Una Platts, "Martin, Albin," Dictionary of New Zealand Biography, first published in Te Ara - The Encyclopedia of New Zealand (19993), accessed 22 February 2018, https://teara.govt.nz/en/biographies/2m34/martin-albin. ${ }^{113}$ Ibid. See also Roger Blackley, Albin Martin (Auckland: Auckland City Art Gallery, 1988).
} 
group of figures strolling through the scene towards an idyllic farmstead in the centre. ${ }^{114}$ Watercolours like these could not be looked back to as the founding fathers for a locally responsive art.

Instead, the documentary art produced by someone like John Buchanan (1819-1898), who did not have any formal art training, seemed to fulfil these requirements. Before coming to New Zealand in 1851, Buchanan worked as an apprentice pattern designer in Glasgow, so he had some experience as a draughtsman. ${ }^{115}$ This, together with his passion for botany, led to his employment by James Hector during his 1863 expeditions of the West Coast. One of the watercolours produced during this time was Milford Sound (1863, Hocken Collections, Uare Taoka o Hakena, University of Otago) [Fig. 85], which Tomory argued displayed a "revolt against the topographical iconography."116 Linda Tyler observes, however, that Buchanan never considered himself to be an artist, and this particular watercolour was originally stored as part of the Geological Survey material at the Otago Museum until Buchanan was rediscovered and two of his works were reproduced in Landfall by Charles Brasch. ${ }^{117}$ After officially joining the canon of New Zealand art history in this way, other writers like McLintock agreed that Buchanan's works were often "exquisite in colour and arrangement and strikingly modern in their treatment of form", which can be seen in the simplified shapes and clear-cut lines in Milford Sound. ${ }^{118}$ E.H. McCormick also praised the artist, observing that "Buchanan was free from the nineteenthcentury Romantic conventions which so hampered his contemporaries, both the artists and the poets ... enabled him to escape the tyranny of an imported tradition and to achieve a degree of emancipation found only rarely even among later writers and artists."119

Leonard Bell wrote in 1984 that some of the praise heaped upon the topographic watercolourists of the nineteenth century might have been too exaggerated:

There has been a tendency among some writers on New Zealand art to exaggerate the aesthetic quality of paintings by other amateurs of the early Colonial period -

\footnotetext{
${ }^{114}$ The tree looks very similar to the one in Samuel Palmer's [attributed] Italian Lake (1957-0009-200), also in the Smythe collection at Te Papa.

115 Nancy M. Adams, "Buchanan, John,” Dictionary of New Zealand Biography, Te Ara - The Encyclopedia of New Zealand, accessed 2 July 2020, https://teara.govt.nz/en/biographies/1b42/buchanan-john. See also Linda Tyler, Art in the Service of Science: Dunedin's John Buchanan, 1819-1898 (Auckland: Gus Fisher Gallery, 2012), and Linda Tyler (interviewee) and Jesse Mulligan (interviewer), "Masterpieces with Linda Tyler," Afternoons with Jesse Mulligan (30 June 2016), sound recording, accessed 15 November 2020,

https://www.rnz.co.nz/national/programmes/afternoons/audio/201806521/masterpieces-with-linda-tyler.

116 Tomory, cited in Johnston, "Peter Tomory: The New Zealand Years," 114.

${ }^{117}$ Tyler, Art in the Service of Science, 4; and Linda Tyler, "Drawn from Nature: Art and Science in the Work of John Buchanan," PhD diss., University of Auckland, 2018, 25-26.

${ }^{118}$ McLintock, National Centennial Exhibition, 11. It is therefore not surprising to find that it also became the cover of Gil Docking's 1971 book Two Hundred Years of New Zealand Painting.

${ }^{119}$ McCormick, Letters and Art, 102-103.
} 
William Fox, Charles Heaphy, John Buchanan, for example. It seems as if Histories and Art Histories of new lands need artists of high merit - a means of validating European presence, perhaps. If they do not exist they can be invented. ${ }^{120}$

In this case, it might not have been to validate a European presence, but rather to validate an 'innate' New Zealand style that will emerge in art no matter whether the artist was born here or lived here long enough to be infused by it. The dates and names of these artists might change depending on who wrote the art history, but the antithesis always remained the same: as Pound summarised, "that of the topographic, and true to New Zealand, the 'natural' and 'immediate', as opposed to the 'cultivated', unnatural and untrue to New Zealand." 121 What was highlighted was that the amateur artists raised into the new canon of New Zealand art by modern art historians were working within their artistic conventions, untainted by the tradition of professional English watercolourists, whose influence would only be read as negative by writers seeking landscapes true to this place. Of course, these were the artists represented in the Smythe collection, accounting, in part for the side-lining of this collection in the 1960s and 1970s.

The next part of this chapter, therefore, will examine the identity represented by the Smythe watercolours, as well as the ways in which this identity manifested itself in the influence of the British watercolour tradition on early artists' works in New Zealand. This will demonstrate that this imperial identity did not align with attempts to establish a distinctive identity for New Zealand in the mid-twentieth century.

\section{WATERCOLOURS: “AS NATIONAL AS THE LANGUAGE ITSELF"122}

The Smythe watercolours represented a typically 'British' identity through patriotic imagery: marinescapes gave visual form to the pride felt in being a successful island nation; architectural watercolours presented national treasures from the past; and landscapes showed the unique British countryside that tourists and locals alike aspired to visit. ${ }^{123}$ Thomas Rowbotham, in his 1855 treatise The Art of Sketching from Nature, wrote that Britain indeed offers the best 'picturesque beauty':

\footnotetext{
${ }^{120}$ Leonard Bell, “Colonial Fortunes: The New Zealand Paintings of Commander R.A. Oliver,” Art New Zealand 30 (Autumn 1984), accessed 23 June 2020, https://www.art-newzealand.com/Issues21to30/oliver.htm.

${ }^{121}$ Pound, Invention, 337.

122 Adrian Bury, "Water-Colour: The English Medium," Apollo 19 (1934): 85.

${ }^{123}$ Refer back to Chapter Three.
} 
London and its environs abound with subjects of picturesque beauty. Hampstead, Highgate; the banks and wharves of the Thames down even to the Nore; every suburban locality; all the green lanes, and the commons with which they communicate, abound with materials which may be wrought into pictures of the highest degree of interest. These are the localities which have contributed to form many of the best of our landscape-painters; and so it is elsewhere; there is no spot in the country so entirely divested of picturesque character, as not to supply to the cultivated taste subject-matter for an interesting picture. ${ }^{124}$

However, it was not only the British countryside that was considered extremely beautiful and desirable to visit and depict in art, but the climate was also thought to be unique compared with other European countries. The poet Charles Kingsley described some of the positive British characteristics as a direct result of the country's weather conditions, writing in Ode to the North-East Wind (1854), "'Tis the hard gray weather Breeds hard English men." ${ }^{25}$ Watercolour was considered the perfect medium for capturing Britain's distinct weather effects. ${ }^{126}$ There was a strong emphasis on 'Britishness' and no art medium was better suited to personify this nationalistic pride than watercolour, which became "so thoroughly synonymous with Great Britain that many critics and historians eventually believed that it was invented there." 127 This, of course, was not true.

However, the developments in style, technique and materials adopted by British watercolour artists during the eighteenth and nineteenth centuries can be seen as an original contribution to the older European tradition, so a sense of nationalistic pride is understandable. ${ }^{128}$ These innovations had such a decisive impact that watercolour was quickly referred to as a truly British art, according to Rowbotham "a school altogether unapproached by that of any other nation in the world." 129 These ideas, first expressed by writers like W.H. Pyne (1769-1824), persisted well into the twentieth century. Indeed, J. Littlejohns emphasised in the opening to British Water-Colour Painting and Painters of Today (1931) the innate link between the English weather, character, and watercolour:

\footnotetext{
124 Thomas Rowbotham, The Art of Sketching from Nature, $18^{\text {th }}$ ed. (London: Winsor and Newton, 1855), 49-50. ${ }^{125}$ Charles Kingsley, The Works of Charles Kingsley (Philadelphia: J.D. Morris, 1899), 310-312. See also Stephen Bone, British Weather (Italy: Collins, 1946). This was a common theme in discussions about national character, even in New Zealand. Rutherford Waddell wrote in 1899 that "as it is held the calm confidence of the English people is due in no small degree to the uniformity of their climatic conditions, it is concluded that the capriciousness of the New Zealand climate will 'make character more eager, inventive and resourceful'." See Waddell, "The Influence of Climate on Character," first published in The Review of Reviews, 15 August 1899, report from the New Zealand Times on this article cited in Sinclair, A Destiny Apart, 82. It is also mentioned in "The Australasian Review of Reviews," The Review of Reviews (October 1899): 401, accessed 24 June 2020, https://search-proquest-

com.helicon.vuw.ac.nz/docview/3906097?accountid=14782\&rfr_id=info\%3Axri\%2Fsid\%3Aprimo.

${ }^{126}$ Sloan, Places of the Mind, 86.

${ }^{127}$ Sandra Johnson Jordan, "The Life and Art of John Webber, R.A.; and his Relationship to the Watercolor and Picturesque Movements in Eighteenth Century England," PhD diss., University of Georgia, Michigan: UMI, $1991,65$. ${ }^{128}$ Bayard, Works of Splendor, 8.

${ }^{129}$ Thomas Rowbotham and T.L. Rowbotham, The Art of Landscape Painting in Water Colours (London: Winsor and Newton, 1850), v.
} 
Water-colour is an English Art - our one undoubted contribution to the progress of painting. It arose here, grew and flourished in its native soil, and ... remains distinctively our own. Our climate is peculiarly conducive to its employment, and our temperament ... well expressed by its specific qualities. ${ }^{130}$

Therefore, it was not simply the subjects of watercolours that represented a British identity, but watercolour itself - the very medium - became directly associated with Britain during the nineteenth century. In 1855, England exhibited 114 watercolours at the Exposition Universelle in Paris, making this the first time that painting took a feature role in Britain's display at an international exhibition. ${ }^{131}$ The comments by French critics and commentators demonstrate that the watercolourists' goals of rivalling oil painting had been achieved, but also that the medium was considered truly British. For example, French novelist and journalist Edmond About wrote:

I can pass without transition from oil to watercolour paintings; these two genres are less distinct in England than with us. More than one painting presents the paleness and the faded grace of watercolour; more than one watercolour has the vigour of an oil painting. Watercolour is, for the English, a national art. ${ }^{132}$

Adrian Bury, in 1934, described watercolour as "the essence of an achievement wholly and exquisitely English. ... It is as national as the language itself, as much part of England as her contours and climate." 133 This attitude has, to a degree, remained largely unchanged until today, particularly in regard to watercolours and landscapes. Catherine Jolivette, in her doctoral thesis "The 'Britishness' of British Art: Landscape, Art and Identity, 1951-1956" (2003), admits:

even today British critics, curators and historians of British art still insist on essentializing national identity, frequently to locate it in landscape art. They assert that there is something "British" about the gentlemanly strolls of Richard Long, the organic curves of Henry Moore's topographical reclining figures, Constable's skies or Turner's use of light. ${ }^{134}$

\footnotetext{
${ }^{130}$ Littlejohns cited in Katherine Coombs, British Watercolours 1750-1950 (London: V\&A Publishing, 2012), 127.

${ }^{131}$ Paul Greenhalgh explains that prior to this, at the Great Exhibition of 1851, there was very little painting on display, as the focus was more on industrial and imperial propaganda. See Paul Greenhalgh, Fair World: A History of World's Fairs and Expositions, from London to Shanghai, 1851-2010 (Berkshire: Papadakis, 2011), 246.

132 About cited in Graham Reynolds, A Concise History of Watercolours (New York and Toronto: Oxford University Press, 1978), 47-48.

133 Bury, "The English Medium," 85.

${ }^{134}$ Catherine Jolivette, “The 'Britishness' of British Art: Landscape, Art and Identity, 1951-1956,” PhD diss., Pennsylvania state University, 2003, 4.
} 
In fact, this also recalls the sentiments of New Zealand writers and painters regarding their local light and landscapes.

Nonetheless, today scholars are also challenging these claims. Martin Myrone, for example, asserts that the history of British watercolour and culture has fallen victim to a certain type of essentialist thinking, meaning they are accorded an underlying 'essence' which remains unchanging over time:

The individual freedom and expressive genius of the painters of the 'golden age', the freedom and transparency evident in their watercolours, and the superior freedoms supposedly sustained by Britain's particular political culture, have been cast as mutually supportive. Particularly in the wake of violent revolutions in Europe at the end of the eighteenth century, and a growing movement for political reform in the early nineteenth century, the transparency and directness of watercolour seemed to speak of health and honesty, values cherished as belonging peculiarly to a politically conservative, common-sensical nation like Britain. ${ }^{135}$

Alison Smith further raises the issue of cultural diversity which has "made the British appellation the subject of scrutiny." 136 Can a watercolour still be considered truly British if it was produced in and depicts Egypt, India or Syria? What if the artist has non-British parents or has lived most of his life overseas? Similarly, returning to our own local context, is a watercolour produced by a British immigrant in New Zealand during the early nineteenth century a New Zealand or a British work of art?

Despite alternative ways of thinking about British watercolours that are being made nowadays, in the 1950s when the Smythe's gifts arrived in New Zealand, these watercolours still very strongly represented a British identity. This Britishness of British watercolours did not fit into the next three decades that, as has been shown, witnessed a redefinition of New Zealand's identity. Still, as we have seen, other types of contemporary British art, such as paintings by Barbara Hepworth or sculptures by Jacob Epstein, continued to be collected well into the 1970s. Therefore, simply being British was not enough to condemn the Smythe watercolours to their neglected state. This is because a country's identity is not fixed but changes in response to shifting social, economic, and political circumstances; and the Smythe watercolours represented an outdated identity that had already changed in Britain itself.

\footnotetext{
${ }^{135}$ Martin Myrone ed., Watercolour in Britain (London: Tate Publishing, 2010), 10.

${ }^{136}$ Alison Smith ed., Watercolour (London: Tate Publishing, 2011), 21.
} 


\section{New British Identity}

Just like New Zealand, Britain was also undergoing a transformation of identity during the mid-late twentieth century, and while the Smythe watercolours still reflected an older British imperial identity, Barbara Hepworth and other modern British artists reflected new ideas about a British identity that was already preparing for the move to join Europe in the 1970s. Jolivette explains:

The shrinking of the British Empire during the years that followed the Second World War resulted not only in a revision of global cartography, but a reassessment of the domestic terrain. The need to redefine of British national identity within its more restricted, insular parameters coincided with a reconsideration of which subjects were appropriate for the landscape artist. ${ }^{137}$

Therefore, the focus on the empire was reduced, and Britain became more inward looking. For example - and similarly to New Zealand - foreign influences were deemed as negative, and artists were encouraged to look towards their domestic terrain. Paul Greenhalgh further links this rejection of the foreign to Britain's long history of warring with other nations, first with France until 1851, and afterwards due to maintaining their vast overseas colonies; thus "Britons were defined by conflict against an external 'Other'.,"138

In 1952, John Blake called for a new national school of art that rejected modern movements from the continent or America, writing:

Gainsborough, Constable, the Pre-Raphaelites, the New English group, Spencer and Nash, Ivon Hitchens, all in a sense rebelled against forms which had become stale through overuse. All found new vitality in an intense study of life around them. This is surely the greatest need in painting today. We must forget Picasso and Braque and Mondrian and Matisse, forget the topsy-turvy intellectual jargon of the 'New Renaissance,' forget the habit of accepting the domination of foreign ideas, and produce an art without an ism, a national art that springs from our own soil... eventually, out of the steady growth of a new tradition, will come a new Turner, a new Constable, who will once again establish the supremacy of English art over that of her European neighbours. ${ }^{139}$

In this manner, an amateur artist like Winston Churchill could receive higher praise than a professional artist like William Gear, whose abstracted landscapes were, some believed, tainted by "a menacing 'foreign' Bolshevism." 140 Still, artists working in a more

\footnotetext{
${ }^{137}$ Jolivette, "The 'Britishness' of British Art," 125.

${ }^{138}$ Greenhalgh, Fair World, 165.

${ }^{139}$ John E. Blake, "Chiefly Concerning Landscape," Ark, Journal of the Royal College of Art, no. 5 (1952): 26-39, cited in Jolviette, "The 'Britishness' of British Art," 160.

140 Jolviette, "The 'Britishness' of British Art," 140.
} 
contemporary style, such as Graham Sutherland, were the preferred choice to represent Britain on the international stage, like the Venice Biennale in 1952. In such a case, careful efforts were made to directly relate Sutherland's art to those of the acceptable British precedents. The Institute of Contemporary Arts, for example, called him "probably our most inspired landscape painter since Turner and Constable." ${ }^{141}$ J.P. Hodin regarded him as "a living link with those spiritual values which found their visual expression in the works of Turner, in the English watercolourists, and especially in Samuel Palmer and William Blake."142

In reality, Jolviette observes that the spiky thorn trees and gnarled roots that typified Sutherland's artworks had little affinity to the Romanticism of Turner and Constable. Instead, Sutherland's aestheticism shared more visual qualities with the post-war 'Geometry of Fear' sculptors discussed by Herbert Read. ${ }^{143}$ The figurative works of artists like Robert Adams, Lynn Chadwick, Reg Butler and William Turnbull directly engaged with Britain's new environment and mental state after the war, resulting in twisted and tortured figures that mirrored the anxieties and fears of the period.

Indeed, the pictorial landscape watercolours of the nineteenth century could no longer accurately represent the Britain of the twentieth century, and any attempt to link contemporary artists to such a tradition was futile and unwarranted. Jolviette explains further that the favourite subject of the watercolourists, landscape, was becoming irrelevant during the latter 1950s as well:

landscape had been devalued to the extent that landscape artists no longer represented the nation on the international stage. By 1956, at the Venice Biennale the Romantic landscapes and sculptures of pre-war modernism had been replaced by figuration in the form of the edgy, urban visions of the Kitchen Sink School and the angular, anxious personages of Lynn Chadwick. ${ }^{144}$

\footnotetext{
141 "The Art of Graham Sutherland: An Important Retrospective”, Institute of Contemporary Arts, 11 April - 5 May 1951, cited in Jolviette, "The 'Britishness' of British Art," 132.

142 J.P. Hodin, The Dilemma of Being Modern: Essays on Art and Literature, (London: Routledge \& Kegan Paul, 1956), 120, cited Jolviette, "The 'Britishness' of British Art."

${ }^{143}$ Herbert Read, New Aspects of British Sculpture, XXVI Venice Biennale, British Pavilion (London: Westminster Press, 1952), exhibition catalogue. Herbert Read was one of the founders and directors of the Institute of Contemporary Arts in London. He coined the term 'Geometry of Fear' in this exhibition catalogue to describe the angst-ridden look of the work of a group of eight British sculptors who had exhibited together at the Venice Biennale 1951. The spindly forms and tortured surfaces of their sculptures encapsulated the anguish and bewilderment of the post-war generation. Ian Chilvers and John Glaves-Smith, "Geometry of Fear," in A Dictionary of Modern and Contemporary Art (Oxford: Oxford University Press), https://www-oxfordreference-

com.helicon.vuw.ac.nz/view/10.1093/acref/9780191792229.001.0001/acref-9780191792229-e-977. For more information on Read's 'Geometry of Fear', see David Hulks, "Francis Bacon and the Geometry of Fear," Sculpture Journal 19, no. 1 (2010): 79+, accessed 25 March 2020, https://link-gale-

com.helicon.vuw.ac.nz/apps/doc/A243453592/AONE?u=vuw\&sid=AONE\&xid=c9dc0a75; David Goodway, "Herbert Read," in Anarchist Seeds Beneath the Snow: Left-Libertarian Thought and British Writers from William Morris to Colin Ward (Liverpool: Liverpool University Press, 2006), 175-201.

${ }^{144}$ Jolviette, "The 'Britishness' of British Art," 252.
} 
Clearly, art was evolving alongside the British identity at this time, and because the Smythe watercolours stemmed from a different period in Britain's history, they also reflected an older manifestation of British identity to that represented by contemporary artworks. In New Zealand, the Smythe watercolours were not simply viewed as the predecessors to modern British painting, but rather, they represented a specifically imperial identity which New Zealand was in the process of distancing itself from.

\section{Watercolours and Imperial British Identity}

In spite of this complicated relationship to national art histories, watercolours themselves have remained a popular medium in New Zealand and continued to be exhibited until the present day. New Zealand had no European old master paintings to learn from, so it was a natural progression to look to one's surroundings for inspiration, which explains why landscape watercolours immediately took centre stage. ${ }^{145}$ The only artistic traditions to draw upon were those brought over by settlers and explorers. Watercolour, being a highly mobile medium, became a practical choice to bring to a new land. The increased number of printed manuals further added to the strong influence British watercolours had on New Zealand productions. ${ }^{146}$ As Peter Entwisle writes in Treasures, "this field of painting is interesting for New Zealanders as our own watercolour tradition grows directly from it."147

As the shift to a New Zealand canon of artists has shown, the impact of British watercolours on the New Zealand tradition is acknowledged, and the result is (partly) celebrated, but at the same time these British roots are rejected. Therefore, even though the watercolours from the Smythe collection had never been in New Zealand before, the traces of their 'untruthful' Romanticism can be seen when examining the subjects and styles of early New Zealand watercolours in direct relation to them. In this way, British watercolours themselves become the pretty, sentimental, and idealised colonisers of the land. The way some of these early artists painted New Zealand was with the express purpose of recording

\footnotetext{
145 This is treated in depth in Rebecca Rice, "Producing 'New Zealand Art' 1865-1890," 118-158, in Rice, "The State Collections."

${ }^{146}$ Painting manuals and their international dispersion greatly supported the development of landscape painting and amateur practice. During the nineteenth century the number of drawing manuals, drawings masters and students (especially female) increased significantly. The most comprehensive study of this is Peter Bicknell and Jane Munro's book, Gilpin to Ruskin: Drawing Masters and their Manuals, 1800-1860 (1987), which looks at the writings of some major individuals (Cox, Prout and Harding for example) and then discusses manuals that deal with specific subjects like perspective, waterfalls, trees, and colour theory. The first manual devoted entirely to landscape painting in watercolour (James Robert's Introductory Lessons) was released in the early nineteenth century, followed by 150 books published in the next thirty years alone.

${ }^{147}$ Entwisle, Treasures, 27.
} 
the "future home for Englishmen", using the prominent language of British watercolours. These works, unlike those praised by twentieth-century writers like McLintock, McCormick and Tomory, did not contribute to their development of a New Zealand art heritage, but rather helped to embed the British imperial traditions in the colony.

Estate portraits in New Zealand, for example, display similar themes and visual language to those of Thomas Sandby's Earl of Fortescue's Grounds, Castle Hill [Fig. 2]. It is only natural for British artists working in a foreign land to employ such familiar devices: one's culture cannot be easily removed from one's activities. Culture is part of our education, relationships and ultimately, the lives we live. William Fox's (1812-1893) watercolour of Westoe (1872-75, Alexander Turnbull Library) [Fig. 86], his estate in Rangitikei, is a prime example of this. As in Sandby's work, the two elegantly dressed figures on horseback lead our eye towards the homestead, presenting the large area of the pastoral run, and beyond it Ruapehu and its impressive mountain chain. The groomed farmland contrasts strongly with the unkempt plants of the native bush in the right-hand foreground, like a piece of refined culture born from wild nature. The viewpoint enables us to see the entirety of Fox's property, including the main house, constructed 1872-74, in the middle.

Another of Fox's watercolours, Westoe Rangitikei 1872 (Alexander Turnbull Library) [Fig. 87], focuses more on the building itself and its beautiful flower garden. In fact, if it were not for the New Zealand native cabbage trees, one could easily mistake this scene for a British home. Cheryll Sotheran expresses this view in her article "The Later Paintings of William Fox" (1978):

In the Westoe paintings, Fox painted his house as an English country seat, transplanted to the New Zealand landscape, which by association assumes qualities of serenity, productivity, the charm of traditional pursuits. The garden scenes (reproduced below), with their curiously heightened palette (contributed to in one case by the fact that the painting was done on 'plain brown paper') represent stylised figures going through the motions of aristocratic behavior - watering gardens which have been laboriously created by 'social inferiors,' dallying at evening in a carefully orchestrated garden. The figures are surrounded, almost oppressed, by the New Zealand bush - which is however identifiable as such only by carefully-described specimens of native plants. The scene remains in fact wilfully European. ${ }^{148}$

\footnotetext{
${ }^{148}$ Cheryll Sotheran, "The Later Paintings of William Fox," Art New Zealand 11 (1978), accessed 27 July 2017, http://www.art-newzealand.com/Issues11to20/fox.htm.
} 
Fox is showing us a colonial ideal through his estate portraits, covering up the rough corners of New Zealand during the late nineteenth century. Just as Sandby's watercolours display a peaceful image of rural Britain and David Robert's Ras-El-Abiad, Coast of Syria [Fig. 4] hides any traces of the looming Second Egyptian-Ottoman War, so these pictures "could be said to constitute a deliberate attempt to replace political and racial disorder with an ideal of civilisation existing in the rural areas of New Zealand."149

It is hardly possible to separate art produced during times of colonisation from other colonial activities, as the "early colonial artist tried to do much the same with his subject as the settler intended to do with his land: to impose on it a European pattern, a transplanted culture. $" 150$ One of the best examples to demonstrate this is John Kinder (1819-1903), an Anglican clergyman, teacher, and artist. He learnt from Aaron Penley, a noted British watercolourist and teacher who wrote several manuals on the subject, and this training clearly influenced his style from an early stage. McCormick said that Kinder "retained in New Zealand the vision of a domesticated English countryside which he transferred, with often charming results, to his renderings of the New Zealand landscape." ${ }^{151}$ Michael Dunn goes further to claim that this domesticated New Zealand landscape truly reflects ideas of colonialism:

In his photographs and paintings Kinder imposed a sense of order on his views, as if regulating them to current conventions of composition where clarity and intelligibility were paramount. This tidiness, combined with the serene calmness of the depicted weather conditions, can give a Utopian or idealised dimension to his colonial scenes. ... His art expresses a positive view of the colonising process. ${ }^{152}$

In Kinder's watercolour Mt Hobson and Khyber Pass from Carlton Gore Road (Auckland Art Gallery Toi o Tāmaki) [Fig. 88], we are presented with a tidy representation of New Zealand as an ideal 'Little Britain': vast meadows for newly imported cattle to graze upon; trees lined up in orderly fashion; farmhouses and fences demarcating private properties. This is exactly the type of perfect, cultivated land that the settlers wished to own and show off to

\footnotetext{
${ }^{149}$ Sotheran, "The Later Paintings of William Fox." Compare this work with the 1965 painting Colonial Garden Bird by Don Binney (Te Papa, 1971-0031-1). The colonial style villa is now overshadowed by a native bird, the tui, which takes up even more space than the building in the painting. The inclusion of native birds was also relevant to the search for national icons, as the kiwi (and previously the moa) had become a well-established symbol of New Zealand by the 1970s. In contrast, the animals depicted in the Smythe watercolours - exotic lions that represent British Imperial expansion, stags and cows that reflect the British countryside and aristocratic hobbies - held little relevance in this New Zealand narrative.

${ }^{150}$ Auckland City Art Gallery, Five New Zealand Watercolourists (Auckland: The Pelorus Press, 1958), 4.

${ }^{151}$ McCormick, Letters and Art, 101.

${ }^{152}$ Michael Dunn, "Kinder, John," Dictionary of New Zealand Biography, first published in Te Ara - The Encyclopedia of New Zealand (1993), accessed 6 March 2018, https://teara.govt.nz/en/biographies/2k7/kinder-john.
} 
everyone back in the 'old England'. This landscape has been colonised by the artist's idealising hand.

In his influential book Frames on the Land: Early Landscape Painting in New Zealand (1983), Francis Pound states that the first exhibition of the Auckland Society of Artists, held on 1 March 1871, signified the 'Englishness' of the New Zealand artistic endeavour, as most of the paintings shown were English or copies of English works done by New Zealand artists. ${ }^{153}$ While some of them succeeded in creating unique works that entered the New Zealand art canon, others were merely mirroring the British art tradition. The production of such watercolours in New Zealand owes more to British watercolour conventions than to the natural landscapes encountered in the colony. Indeed, Pound's main argument is that "artistic conventions carried to nature determine the way nature is seen[;] that nature is invisible outside the conventional genres of seeing." 154 These conventions were carried to New Zealand in what Pound calls the settlers' "cultural baggage", which, when unpacked, 'Claudianised', annexed, and Britainised New Zealand. ${ }^{155}$ British settlers colonised the land, and British watercolours colonised the art which intended to represent this land.

Pound's criticism echoes that of Tomory, who in 1960 wrote that these types of New Zealand watercolours had "no real significance within the tradition of national identity."156 Without the intent to identify what was distinctive and unique to New Zealand, these works - and their British counterparts - could not contribute to the narrative sought by curators and writers during the twentieth century. The Smythe watercolours exemplify a taste associated with the idea of New Zealand as an extension of Britain; they expose New Zealand's colonial past. Smythe's very act of gifting them to New Zealand because it is a former colony of Britain reveals colonial and imperial overtones. For the emerging generation of artists and critics, this was exactly the past they would reject and re-invent. This is why, above all else, the Smythe watercolours could not be accepted and exhibited freely without incurring thoughts of the British empire as the colonial power which had turned this country into a remote copy of Britain herself. These associations directly clashed with the visions of a 'new' New Zealand that was no longer just a daughter of Britain, but her very own person.

\footnotetext{
${ }^{153}$ Pound, Frames on the Land, 70.

${ }^{154}$ Ibid., 11.

${ }^{155}$ Ibid., 20, 42.

${ }^{156}$ Peter Tomory, "Review of Bernard Smith's European Vision and the South Pacific, 1728-1850 [1960]," Journal of the Polynesian Society 69 (1960): 416-17, cited in Johnston, "Peter Tomory: The New Zealand Years," 113.
} 
Overall, it has become clear that shifting tastes and identities can exert a major influence on an artwork's status, or in this case, on an entire collection. The twentieth-century taste for modern and contemporary New Zealand artists was directly linked to a changing national identity, which sought new cultural icons and national narratives to establish a stronger sense of independence. These goals conflicted with the identities embodied in the Smythe watercolours, which served as reminders of British colonisation and Empire, and the artistic predecessors that it had created (but which could no longer be situated in a New Zealand national art history). Nonetheless, one should not forget that such identities are never fixed. Jock Philips reminds us that "the country never arrives at a fixed sense of national identity; each generation makes its own discovery, and forges its own identity, for itself." ${ }^{\text {"157 A }}$ different generation may yet result in a different outcome for the Smythe collection.

${ }^{157}$ Phillips, “Our History, Our Selves,” 116. 


\section{Chapter 6: Conclusion}

After about 50 years of collecting, Archdeacon Smythe had amassed an impressive private collection of 1,436 watercolours, ranging in dates from the later eighteenth to the early twentieth century, and with hundreds of different artists represented. In 1953 he started gifting this watercolour collection bit by bit to two New Zealand art institutions, where they remain to this day: the Dunedin Public Art Gallery, and the National Art Gallery in Wellington (Te Papa's forerunner). Today, there remain two key mysteries surrounding this collection: why did Smythe donate it to New Zealand, despite never having visited here or having any prior links to the country, and why did the collection fall out of favour so quickly after arriving here?

The first mystery has been solved rather swiftly, as Smythe wrote many letters to the directors of the respective art galleries, in which he explained some of his reasoning. One major justification, for example, was religion. Smythe was a very religious man and was convinced that God had chosen New Zealand for him, even calling the curator of the DPAG, Annette Pearse, one of God's agents. Another contributing factor was Smythe's perception of New Zealand as a close relative of Britain, and in his philanthropic nature he wanted to share some of Britain's treasures with her rightful next of kin. In the end, however, Smythe explains that these gifts are actually a sign of gratitude to New Zealand for always coming to Britain's aid in times of need. He elaborates that he witnessed this noble New Zealand spirit first-hand during two world wars, and that he met many New Zealand soldiers at the hospitals during his time as chaplain.

The collection was warmly received in Dunedin and Wellington, and hailed by the president of the DPAG as "the finest collection of water colour pictures in the Southern Hemisphere of which we are very proud." ${ }^{158}$ He continued that this veneration extended to the collector himself, promising Smythe in 1955 that his name and generosity "will be perpetuated for generations to come." ${ }^{159}$ Seeing that my research represents the first attempt to create a biography and description of Smythe's collecting habits, the president's promise was clearly not fulfilled. Other collectors who have made major donations to New Zealand art institutions have already received such scholarly treatment. In Smythe's case, however, it

${ }^{158}$ A.H. Allen to Smythe, 31 October 1955, DCCA: Box 11, DPAG 15/22.
${ }^{159}$ Ibid. 
was not merely his name as a donor, but also the collection he gifted which quickly lost its status. In fact, the next president of the DPAG wrote to the NAG in 1966: "Some of the collection would be better destroyed."160

Through aiming to discover what led to this drastic change in attitude towards the Smythe watercolours, my research has engaged with various fields and cultural contexts. The third chapter employed formal analysis to carefully examine the watercolours themselves, in order to determine whether poor quality and content of the collection justified the negative judgement it eventually received. Despite examples of lower aesthetic value, it was discovered that the collection also has a great deal of educational worth and contributes to the narrative of the medium's development in Britain. It boasts some excellent examples by well-known and lesser-known artists, and its wide range of subject matter challenges what is traditionally included in written watercolour histories.

The second hypothesis was that the collection was outdated and did not suit the dominant tastes of the time. By looking at the tastes and trends of art collectors in England during the time of Smythe's collecting, I have discovered that his personal tastes were indeed rather old fashioned. While he does demonstrate some engagement with current trends, such as the popularity of the sketch aesthetic and the subsequent rediscovery of the artist John Sell Cotman (who is one of the best-represented in the collection), he mostly does not reflect the new modern tastes of the twentieth century. Instead, a lot of the watercolours he collected still showed the older, highly worked-out Victorian style. Smythe also did not actively collect contemporary artists and movements as they appeared during his 50 years of collecting, focusing primarily on nineteenth-century art. At the same time, though, it has been revealed that his wide, and seemingly aimless, collecting practices were in themselves one of the acceptable collecting habits available during the twentieth century; a middle-brow rather than connoisseurial approach exemplified by other collectors too. It was also noted that market availability and Smythe's financial circumstances further restricted his collecting practices, meaning he was not always able to acquire what he desired.

The outdated state of the collection was even further revealed during the decades following its arrival in Dunedin and Wellington, as New Zealand art institutions reflected the shifting tastes of the period. The directors of major art galleries were slowly moving away from the model of British museums and galleries, and instead broadened their collecting activities to other international art, with a new focus on modern and abstract art.

\footnotetext{
${ }^{160}$ Charlton Edgar to Maclennan, 8 September 1966, TPA: MU000044, box 2, item 12.
} 
The Dunedin and Wellington gallery directors who had accepted Smythe's watercolours during the 1950s were considered to be notoriously conservative even during their own times, on occasion speaking out directly against international modernism, abstraction and expressionism. Their successors, however, were more daring and progressive in their acquisitions. In Wellington, Maclennan was succeeded by Melvin Day, an artist himself, who had developed a love for Cubism during his earlier years as a teacher. Among his modern purchases was Colin McCahon's masterpiece Northland Panels, which has been described as "the most substantial single acquisition the National Gallery has ever made.""161 It perfectly illustrates the influence of international art applied to a purely New Zealand landscape.

This also signals the other major shift in taste and collecting habits of public galleries at the time: not only did they pursue modern art, but New Zealand modern art. While it was difficult to find New Zealand painting in public galleries at the start of the 1950s, by the 1970s basically every institution was actively collecting local art. By collecting contemporary New Zealand artists, museums and galleries were celebrating their new role in promoting New Zealand arts and culture. The national identity of artists helped to boost the cultural identity of New Zealand. The special focus on local New Zealand artists was therefore also directly related to a shifting focus on the country's distinct character.

Prior to the 1950s, New Zealand's links to England, the 'Motherland', were so strong that New Zealand was often referred to as 'the Britain of the South'. Not only was British art collected and exhibited in the galleries, but British history was being taught in schools, British songs were sung on special occasions, and British Christmas traditions were observed during the arguably inappropriate summer season. While it is therefore not surprising to find the Smythe collection so easily accepted in this Anglo-centric environment, it was precisely around the time when the watercolours arrived that things were starting to change, and the next three decades witnessed a complete shift in New Zealand national and cultural identity. This shift was characterised by a distinct move away from the British model as New Zealand gained stronger independence and chose to focus on its physical location and status as an island nation, particularly acknowledging its significance as a bicultural nation.

Not only were artists like McCahon important in spreading this newfound identity by eliminating British styles from their works and focusing on showing unidealised reflections

${ }^{161}$ Neil Rowe, "McCahon Panels Go to Gallery for \$25,000," Evening Post (11 May 1958): 4, cited in William McAloon ed., Art at Te Papa (Wellington: Te Papa Press, 2009), 13. 
of their country, but museums and galleries also supported this agenda by promoting a national art history through their collections. Scholars attempted to link the new canon of modern painters to previous generations of New Zealand artists, in order to show the natural development of the native tradition. Older topographical New Zealand watercolours, previously considered documentary artefacts more than artworks, were celebrated as worthy predecessors for the new modern art. The Smythe watercolours, on the other hand, became a reminder that many of the earliest artworks created in New Zealand were directly influenced by British imperial attitudes and art styles, rather than by the country itself. While a truthful depiction of the land in art was in line with other national ideals and symbols of independence, the idealised Romanticism and Britishness of the Smythe watercolours could no longer empathise with the 'new' New Zealand identity of the later twentieth century.

Pamela James has boldly claimed that historians are uncomfortable with exploring and declaring the importance of Britishness within Australian and New Zealand social histories:

A tendency in both Australian and New Zealand art historical writing to dismiss past patronage, and the exhibitions and models of these institutions, as simple 'conservative' or 'traditional' has been typical in judging art practices which have subsequently become peripheral. Also, as these British art practices are seen to reflect an historical and political alliance no longer considered advantageous by most Australians and New Zealanders, any acknowledgment of the importance of the British model in art history has become problematic. ${ }^{162}$

James' research, and my own studies, have shown that a disregard of this part of our histories can result in significant gaps in our nation's art histories. This thesis has discovered significant links between artistic taste and collecting habits in New Zealand and the dramatic impact they can have on an entire collection of over a thousand British artworks. At the same time, these shifting tastes and reputations of collections can be directly related to major social and political changes in New Zealand, adding another layer of meaning to the field of collection histories.

To return to Anne Kirker's article “Aspects of Collection Rationalisation”, which opened this thesis, "even if those very early bequests to your gallery comprised 'indifferent' material chosen by a less discriminating eye we should remember that lesser quality objects, 162 Pamela J. James, “The Lion in the Frame: The Art Practices of the National Art Galleries of New South Wales and New
Zealand 1918-1939," PhD diss., University of Western Sydney, 2003, 307. 
even forgeries or copies, can have merit as study material."163 This dissertation has ventured to show that the Smythe watercolours have this merit; it is a collection that can be used as material to study a certain technique of watercolour painting, the style of a particular artist, the collecting habits of twentieth-century collectors and institutions, and the Anglo-Saxon bias and its subsequent rejection by New Zealand artistic tastes and identities.

While the Smythe watercolours' fate is certainly a matter of taste, my research has shown that examining why a collection is not popular can be just as insightful as examining why it is, and that by looking at something that has fallen out of mind we can discover new ways of engaging with our national art collections, histories and everchanging identities.

${ }^{163}$ Anne Kirker, “Aspects of Collection Rationalisation,” AGMANZ Journal 16, no. 1 (March 1985): 3, accessed 4 June 2019 ,

https://christchurchartgallery.org.nz/media/uploads/2017_08/AGMANZ_Journal_Volume_16_Number_1_March_1985_op timized_for_web.pdf. 


\section{Bibliography}

\section{Unpublished Sources}

\section{City Council Archives, Dunedin}

Box 1, DPAG Series 4, Council and A.G.M. Minutes.

- $\quad$ DPAG 4/5, Council 23 May 1952-20 March 1958

- $\quad$ DPAG 4/6, Council Minutes 1 May 1958-6 Oct. 1960

Box 2, DPAG Series 4, Council and A.G.M. Minutes.

- $\quad$ DPAG 4/8, Council Minutes 4/3/65 - 5/6/69

Box 10, DPAG Series 15, Inwards Letters, Yearly and Subject Files.

- $\quad$ DPAG $15 / 11$ - 1940-50

- DPAG 15/12 - Correspondence re bequests, estates, investments, debentures, purchases, 1919-52 (in alphabetical order plus General)

- $\quad$ DPAG $15 / 15$ - 1951

- $\quad$ DPAG $15 / 16-1952$

- $\quad$ DPAG $15 / 17-1953$

Box 11, DPAG 15/22 - Ven Archdeacon F.H.D. Smythe letters to Mrs. A.C. Pearse, 195365 and lists of Smythe Collection.

Box 12, DPAG Series 15, Inwards Letters, Yearly and Subject Files.

- $\quad$ DPAG $15 / 24$ - Jan 1959 - Feb 1960

- $\quad$ DPAG $15 / 27$ - 1962-66

- $\quad$ DPAG $15 / 28-1967$

- $\quad$ DPAG $15 / 25$ - Nov 1959 - Dec 1960

- $\quad$ DPAG 15/26 - Jan - Dec 1961

DPAG 23/10 - Miscellaneous Material Including: some correspondence to do with Smythe Collection.

DPAG 23/9 - Letters from Mr. John Borrie to Mr. Charlton Edgar concerning ... Smythe Collection (showing of).

Scrapbooks, DPAG 26/3 and DPAG 26/4.

\section{Te Papa Archives, Wellington}

MU00008, box 3, item 6 - No. 92 National Art Gallery, Archdeacon Smythe Collection, Correspondence 1956 and 1957.

MU00009, box 5, item 9 - National Art Gallery, Correspondence relating to Mr. G.G. Watson overseas - purchases 1956 (Includes Lady Ramsay, Archdeacon Smythe, etc., and miscellaneous.) 
MU000044, box 2, item 12 - Archdeacon Smythe Collection of English Watercolours and Drawings.

MU000376, box 1, item 9.

British Museum, Department of Prints and Drawings, Department Archives, London "List of works presented by Archdeacon Francis Henry Dumville Smythe to the Department of Prints and Drawings", report generated from the British Museum Index and Database (also available on the BM website at Collections Online).

Prints and Drawings Department Letter Books, Letters Received, vol. for 1939-1944.

Reports to the Trustees by the Keeper of Prints and Drawings for the years 1939, 1948-1950.

Victoria and Albert Museum Archives, London

MA/1/S2404 - Nominal File: Archdeacon Smythe, F.H.D.; Victoria and Albert Museum. Registry.

Paul Oppé Archive, Paul Mellon Centre, London

APO/1/11/2 Correspondence with Thomas Girtin.

\section{Books and Exhibition Catalogues}

Alison, Archibald. Essay on the Nature and Principles of Taste. $6^{\text {th }}$ edition, Edinburgh: Heirs of D. Willison, 1825.

Alston, J. William. Hints to Young Practitioners in the Study of Landscape Painting, $3^{\text {rd }}$ edition, London: Longman, Hurst, Rees, \& Orme, 1805.

Arnold, Dana, and David Peters Corbett, eds. A Companion to British Art: 1600 to the Present, New Jersey: John Wiley \& Sons, 2016.

Auckland Art Gallery Toi o Tāmaki. Auckland Art Gallery Toi o Tāmaki: The Guide. London: Scala, 2001.

Auckland City Art Gallery. A Colonial View: Paintings of Early New Zealand. Auckland: The Pelorous Press, 1958.

A Summary Catalogue of the Collection of the Auckland City Art Gallery. Auckland: The Pelorous Press, 1964. Around the World with William Fox. Auckland: The Pelorous

Press, 1972. 
Press, 1962.

. British Taste in the Nineteenth Century. Auckland: The Pelorous

Auckland: Brett, 1925.

. Catalogue of the Art Gallery Including the Mackelvie Collection.

. Early Identities: An Exhibition of Portraits Held at the Auckland

City Art Gallery. Auckland: The Pelorous Press, 1955.

Early Watercolours of New Zealand. Auckland, 1963.

Press, 1958.

. Five New Zealand Watercolourists. Auckland: The Pelorous

. James Crowe Richmond. Auckland: The Pelorous Press, 1957.

. John Gully 1819-1888. Auckland: The Pelorous Press, 1960.

Thirty-seven New Zealand Paintings from the Collection of

Charles Brasch and Rodney Kennedy. Auckland: Auckland City Art Gallery, 1958.

Ballantyne, Andrew. John Ruskin. London: Reaktion Books, 2015.

Ballantyne, Andrew and Andrew Law. Tudoresque: In Pursuit of the Ideal Home. London: Reaktion Books, 2011.

Barr, Mary, ed. Headlands: Thinking Through New Zealand Art. Sydney: Museum of Contemporary Art, 1992.

Barrell, John. The Dark Side of the Landscape: The Rural Poor in English Painting, 17301840. Cambridge: Cambridge University Press, 1980.

Barringer, T.J. ed. Pre-Raphaelites: Victorian Art and Design. London: Yale University Press, 2012.

Barringer, Tim and Tom Flynn, eds. Colonialism and the Object: Empire, Material Culture, and the Museum. London; New York: Routledge, 1998.

Barnes, Felicity. New Zealand's London: A Colony and its Metropolis. Auckland: Auckland University Press, 2012.

Bayard, Jane. Works of Splendor and Imagination: The Exhibition Watercolor, 1770-1870. New Haven: Yale Center for British Art, 1981.

Belich, James. Making Peoples: A History of the New Zealanders from Polynesian. Reprint, Auckland: Penguin Random House New Zealand, 2007. First published 1996.

. Paradise Reforged: A History of the New Zealanders from the 1880s to the Year 2000. Auckland: Allan Lane; Penguin, 2001. 
Replenishing the Earth: The Settler Revolution and the Rise of the AngloWorld, 1783-1939. Oxford: Oxford University Press, 2009.

Bell, Claudia. Inventing New Zealand: Everyday Myths of Pākehā Identity. Auckland: Penguin, 1996.

Benson, Laurie. Medieval Moderns: The Pre-Raphaelite Brotherhood. Melbourne: National Gallery of Victoria, 2015.

Bicknell, Peter, and Jane Munro. Gilpin to Ruskin: Drawing Masters and their Manuals, 1800-1860. Cambridge: Fitzwilliam Museum, 1987.

Binyon, Laurence. English Water-Colours. $2^{\text {nd }}$ edition, London: Adam \& Charles Black, 1946.

Masters of English Landscape Painting: J.S. Cotman, David Cox, Peter

De Wint. London: The Studio, 1903.

Blackley, Roger. The Art of Alfred Sharpe. Auckland: Auckland City Art Gallery, 1992.

Art Gallery, 1990.

Two Centuries of New Zealand Landscape Art. Auckland: Auckland City

Blom, Philipp. To Have and to Hold: An Intimate History of Collections and Collecting.

Woodstock and New York: The Overlook Press, 2003.

Bone, Stephen. British Weather. Italy: Collins, 1946.

Bonehill, John, and Stephen Daniels, eds. Paul Sandby: Picturing Britain. London: Royal Academy of Arts, 2009.

Bourgoing, Jean. English Miniatures. London: Benn, 1928.

Bowness, Alan, ed. British Contemporary Art 1910-1990: Eighty Years of Collecting by The Contemporary Art Society. London: The Herbert Press, 1991.

Brett, Bernard. A History of Watercolor. New York: Excalibur Books, 1984.

Bridge, Carl, and Kent Fedorowich, eds. The British World: Diaspora, Culture and Identity. London: Taylor \& Francis Group, 2003.

Broughton, Michael, William Clarke and Joanna Selbourne. The Spooner Collection of British Watercolours at the Courtauld Institute Gallery. London: Courtauld Institute Gallery, 2005.

Brown, Gordon H. New Zealand Painting, 1900-1920: Traditions and Departures. Wellington: Queen Elizabeth II Arts Council of New Zealand, 1972.

New Zealand Painting, 1920-1940: Adaptation and Nationalism.

Wellington: Queen Elizabeth II Arts Council of New Zealand, 1975. 
. New Zealand Painting 1940-1960: Conformity and Dissension.

Wellington: Queen Elizabeth II Arts Council of New Zealand, 1981.

Towards a Promised Land: On the Life and Art of Colin McCahon.

Auckland: Auckland University Press, 2010.

Brown, Gordon H. and Hamish Keith. An Introduction to New Zealand Painting 1839-1967.

New and revised edition, Auckland: Collins, 1982. First published 1969.

Burke, Edmund. Philosophical Enquiry into the Origin of Our Ideas of the Sublime and Beautiful. $5^{\text {th }}$ edition. London: J. Dodsley, 1767.

Bury, Adrian. The Life and Art of Thomas Collier, R.I. Chevalier of the Legion of Honour 1840-1891. Leigh-on-Sea: F. Lewis Publishers, 1944.

Catalogue of the Mackelvie Collection for Auckland. Auckland, 1885.

Carmichael, J.W. The Art of Marine Painting in Water-Colours. London: Winsor and Newton, 1859.

Caygill, Marjorie and John Cherry, eds. A.W. Franks: Nineteenth-Century Collecting and the British Museum. London: British Museum Press, 1997.

Cherry, Deborah. Painting Women: Victorian Women Artists. London: Routledge, 1993.

Clarke, Michael. The Tempting Prospect: A Social History of English Watercolours. London: British Museum Publications, 1981.

Clarke, Michael and Nicholas Penny, eds. The Arrogant Connoisseur: Richard Payne Knight 1751-1824. Manchester: Manchester University Press, 1982.

Clifford, Derek. Collecting English Watercolours. $2^{\text {nd }}$ edition, London: John Baker, 1976.

Cohn, Marjorie B. Wash and Gouache: A Study of the Development of the Materials of Watercolor. Cambridge, Mass.: Center for Conservation and Technical Studies, Fogg Art Museum, 1977.

Coombs, Katherine. British Watercolours 1750-1950. London: V\&A Publishing, 2012. The Portrait Miniature in England. London: V\&A Publications, 1998.

Corbeau-Parsons, Caroline. Impressionists in London: French Artists in Exile 1870-1904. London: Tate Publishing, 2017.

Cordingly, David. Marine Painting in England 1700-1900. London: Studio Vista, 1974.

Crighton, Anna. English, Colonial, Modern and Māori: The Changing Faces of the Robert McDougall Art Gallery, Christchurch, New Zealand, 1932-2002. Newcastle: Cambridge Scholars Publisher, 2014. 
Cross, Francis W., and John R. Hall. Rambles Round Old Canterbury. $3^{\text {rd }}$ edition, Canterbury: Cross \& Jackman, 1884.

Cruise, Colin. Love Revealed: Simeon Solomon and the Pre-Raphaelites. London and New York: Merrell, 2005.

Darian-Smith, Kate, Patricia Grimshaw, and Stuart Macintyre, eds. Britishness Abroad: Transnational Movements and Imperial Cultures. Carlton: Melbourne University Press, 2007.

Darracott, Joseph, ed. All for Art: The Ricketts and Shannon Collection. Cambridge: Cambridge University Press, 1979. The World of Charles Ricketts. New York: Methuen, 1980.

Delaney, J.G. Charles Ricketts: A Biography. New York: Clarendon Press, 1990.

Denvir, Bernard. The Late Victorians: Art, Design and Society, 1852-1910. New York: Longman, 1986.

Devereux, Joanna. The Making of Women Artists in Victorian England: The Education and Careers of Six Professionals. Jefferson: McFarland \& Company, 2016.

Docking, Gil. Two Hundred Years of New Zealand Painting. Revised edition, Auckland: David Bateman, 1990.

Donald, Diana. Picturing Animals in Britain 1750-1850. New Haven and London: Yale University Press, 2007.

Don't Forget to Feed the Cat: The Travel Letters and Sketches of Stewart Bell Maclennan. Compiled by Mary Bell Thornton. Wellington: The Cuba Press, 2019.

Donson, Theodore B. Prints and the Print Market: A Handbook for Buyers, Collectors, and Connoisseurs. New York: Thomas Y. Crowell, 1977.

Dunn, Michael. Nerli: An Italian Painter in the South Pacific. Auckland: Auckland University Press, 2005.

Dwan, David and Christopher J. Insole eds. The Cambridge Companion to Edmund Burke. Cambridge: Cambridge University Press, 2012.

Egerton, Judy. British Watercolours. London: The Tate Gallery, 1986.

Eggleton, David. Towards Aotearoa: A Short History of $20^{\text {th }}$ Century New Zealand Art. Auckland: Reed Publishing, 2007.

Eldredge, Charles. Pacific Parallels: Artists and the Landscape in New Zealand. Washington: New Zealand-United States Arts Foundation, 1991. 
Empire Art Loan Exhibitions Society. Exhibition of British Water-Colours 1850-1914. Australia and New Zealand, 1952-53.

Wellington, 1949. Exhibition of Early British Water-Colours.

Entwisle, Peter. Nerli: An Exhibition of Paintings \& Drawings. Dunedin: Dunedin Public Art Gallery, 1988.

Gallery, 1990. . Treasures of the Dunedin Public Art Gallery. Dunedin: Dunedin Public Art

Epstein, Jacob. Let There Be Sculpture: An Autobiography. London: Joseph, 1940.

Feather, Jessica. British Watercolours and Drawings: Lord Leverhulme's Collection in the Lady Lever Art Gallery. Liverpool: National Museums Liverpool, 2010.

Fenwick, Simon and Greg Smith. The Business of Watercolour: A Guide to the Archives of the Royal Watercolour Society. Aldershot \& Brookfield: Ashgate, 1997.

Flint, Kate. Impressionists in England: The Critical Reception. London: Routledge \& Kegan Paul, 1984.

Gamble, Brenda and Peter Shaw. Auckland City Art Gallery: A Centennial History. Auckland: Auckland City Art Gallery, 1988.

Gentry, Kynan. History, Heritage, and Colonialism: Historical Consciousness, Britishness, and Cultural Identity in New Zealand, 1870-1940. Manchester: Manchester University Press, 2015.

Gerrish Nunn, Pamela. From Victorian to Modern: Innovation and Tradition in the Work of Vanessa Bell, Gwen John and Laura Knight. London: Philip Wilson, 2006.

. Victorian Women Artists. London: Women's, 1987.

Gilmour, Robin. The Victorian Period: The Intellectual and Cultural Context of English Literature 1830-1890. London; New York: Longman, 1993.

Gilpin, William. Observations on the Western Parts of England Relative Chiefly to Picturesque Beauty. $2^{\text {nd }}$ edition, London: T. Cadell and W. Davies, 1808.

. Three Essays: On Picturesque Beauty: On Picturesque Travel: And on Sketching Landscape: To Which Is Added a Poem on Landscape Painting. London: R. Blamire, 1794.

Going Once: 250 Years of Culture, Taste and Collecting at Christie's. London: Phaidon, 2016.

Goodway, David. Anarchist Seeds Beneath the Snow: Left-Libertarian Thought and British Writers from William Morris to Colin Ward. Liverpool: Liverpool University Press, 2006. 
Grainger, John D. The Syrian Wars. Leiden and Boston: Brill, 2010.

Grant, Alexander, and Keith Stringer, eds. Uniting the Kingdom? The Making of British History. London; New York: Routledge, 1995.

Grant, David. The Mighty Totara: The Life and Times of Norman Kirk. Auckland, 2014.

Graves, Algernon. The Society of Artists of Great Britain, 1760-1791, the Free Society of Artists, 1761-1783: A Complete Dictionary of Contributors and their Work from the Foundation of the Societies to 1791. London: George Bell and Sons, 1907.

Green, Tony. People \& Places: $19^{\text {th }}$ Century British Drawings from the Smythe Collection. Dunedin: Dunedin Public Art Gallery, 2004.

Greenacre, Francis. The Bristol School of Artists: Francis Danby and Painting in Bristol 1810-1840. Bristol: City Art Gallery Bristol, 1973.

Greenhalgh, Paul. Fair World: A History of World's Fairs and Expositions, from London to Shanghai, 1851-2010. Berkshire: Papadakis, 2011.

Greif, S.W. ed. Immigration and National Identity in New Zealand: One People, Two Peoples, Many Peoples?. Palmerston North, 1995.

Gruetzner Robins, Anna. A Fragile Modernism: Whistler and His Impressionist Followers. New Haven: Yale University Press, 2007.

Griffiths, Antony. Landmarks in Print Collecting: Connoisseurs and Donors at the British Museum Since 1753. London: British Museum Press, 1996.

Hackett Fischer, David. Fairness and Freedom: A History of Two Open Societies, New Zealand and the United States. Oxford: Oxford University Press, 2012.

Hamilton, J. The Sketching Society. London: Victoria and Albert Museum, 1971.

Hansen, Randall. Citizenship and Immigration in Post-war Britain: The Institutional Origins of a Multicultural Nation. Oxford, 2000.

Hargraves, Matthew. 'Candidates for Fame': The Society of Artists of Great Britain, 17601791. London: Yale University Press, 2005.

Harris, Alexandra. Romantic Moderns: English Writers, Artists and the Imagination from Virginia Woolf to John Piper. New York: Thames \& Hudson, 2010.

Haskell, Francis. Rediscoveries in Art: Some Aspects of Taste, Fashion \& Collecting in England \& France. Ithaca, New York: Cornell University Press, 1976.

Hassell, Christopher. Edward Marsh, Patron of the Arts: A Biography. London: Longmans, 1959. 
Harrison, Colin. Great British Drawings. Oxford: Ashmolean Museum, 2015.

Hay, William Delisle. Brighter Britain! Or, Settler and Māori in Northern New Zealand. 2 vols. London: Richard Bentley and Son, 1882.

Hayes, John. The Portrait in British Art: Masterpieces Bought with the Help of the National Art Collections Fund. London: National Portrait Gallery, 1991.

Hayward Gallery. The Impressionists in London. London: The Arts Council of Great Britain, 1973.

Hearn, Maxwell K. How to Read Chinese Paintings. New York: Metropolitan Museum of Art, 2008.

Hemingway, Andrew and Alan Wallach eds. Transatlantic Romanticism: British and American Art and Literature, 1790-1860. Boston: University of Massachusetts Press, 2015.

Herrmann, Frank. The English as Collectors: A Documentary Sourcebook. $2^{\text {nd }}$ edition, New Castle: Oak Knoll Press, 1999.

Herrmann, Luke. Paul and Thomas Sandby. London: B.T. Batsford, 1986.

Holme, Geoffrey, ed. Masters of Water-Colour Painting. London: The Studio, 1922.

House, John. Impressionism for England: Samuel Courtauld as Patron and Collector. London: Courtauld Institute Galleries, 1994.

Hughes, C.E. Early English Water-Colour. $3^{\text {rd }}$ edition, London: Ernest Benn, 1950.

Ilott, Jack. The Ilott Story. Wellington: Mallinson Rendel, 1993.

John Leech's Pictures of Life and Character: From the Collection of "Mr. Punch." London: Bradbury, Agnew \& Co., 1887.

Jonhson, David. New Zealand's Maritime Heritage. Auckland: Collins in association with David Bateman, 1987.

Johnson, Miranda. The Land Is Our History: Indigeneity, Law, and the Settler State. New York: Oxford University Press, 2016.

Jordan, Caroline. Picturesque Pursuits: Colonial Women Artists \& the Amateur Tradition. Melbourne: Melbourne University Press, 2005.

Kaplan, Flora E.S., ed. Museums and the Making of "Ourselves": The Role of Objects in National Identity. London \& New York: Leicester University Press, 1994.

Katz, Janice and Mami Hatayama eds. Painting the Floating World: Ukiyo-e Masterpieces from the Weston Collection. New Haven and London: Art Institute of Chicago, 2018.

Kauffmann, C.M. John Varley 1778-1842. London: B.T. Batsford, 1984. 
Kay, Robin and Tony Eden. Portrait of a Century: The History of the N.Z. Academy of Fine Arts 1882-1982. Wellington: Millwood Press, 1983.

Keith, Hamish. The Big Picture: A History of New Zealand Art from 1642. Auckland: Random House, 2007.

King, Michael, ed. Pākehā: The Quest for Identity in New Zealand. Auckland: Penguin, 1991. . The Penguin History of New Zealand. Auckland: Penguin, 2003.

Kingsley, Charles. The Works of Charles Kingsley. Philadelphia: J.D. Morris, 1899.

Kirker, Anne. New Zealand Women Artists: A Survey of 150 Years. Revised edition, Tortola: Craftsman House, 1993.

Kirker, Anne and Peter Tomory. British Painting 1800-1990 in Australian and New Zealand Public Collections. Sydney: The Beagle Press, 1997.

Kisler, Mary. Angels and Aristocrats: Early European Art in New Zealand Public Collections. Auckland: Godwit, 2010.

Kitton, Frederic George. John Leech, Artist and Humorist: A Biographical Sketch. London: G. Redway, 1883. Accessed 10 June 2019. https://archive.org/details/johnleechartisth00kittiala/page/30/mode/2up.

Kolenberg, Hendrik, and Anne Ryan and Patricia James, eds. $19^{\text {th }}$ Century Australian Watercolours, Drawings and Pastels: From the Gallery's Collection. New South Wales: Art Gallery of New South Wales, 2005.

Krill, John. English Artists Paper. London: Trefoil Publications, 1987.

Lambourne, Lionel and Jean Hamilton. British Watercolours in the Victoria and Albert Museum: An Illustrated Summary Catalogue of the National Collection. London: Sotheby Parke Bernet, 1980.

Lemon, Mark and Henry Mayhew, Tom Taylor, Shirley Brooks, Francis Cowley Burnand, and Owen Seaman, eds. Punch. 4 vols. London: Punch Publications, 1841. Also available online, https://books.google.co.uk/books?id=eGA2AQAAMAAJ\&printsec=frontcover\#v=onepage $\& \mathrm{q} \& \mathrm{f}=$ false.

Lewis Roget, John. A History of the "Old Water-Colour" Society, Now the Royal Society of Painters in Water Colours. London: Longmans, Green, and Co., 1891.

Links, J. Townscape Painting and Drawing. London, 1972.

Lockett, Richard. Samuel Prout (1783-1852). London: B.T. Batsford, 1985. 
Lyles, Anne, and Robin Hamlyn. British Watercolours from the Oppé Collection with a Selection of Drawings and Oil Sketches. London: Tate Gallery, 1997.

Mallalieu, H.L. The Dictionary of British Watercolour Artists up to 1920: Volume I-The Text. $2^{\text {nd }}$ edition, Suffolk: Antique Collectors' Club, 1986.

. The Dictionary of British Watercolour Artists up to 1920: Volume II - The Plates. $2^{\text {nd }}$ edition, Suffolk: Antique Collectors' Club, 1986. . Understanding Watercolours. Suffolk: Antique Collectors' Club, 1985.

Mansergh, Nicholas. Survey of British Commonwealth Affairs: Problems of Wartime Cooperation and Post-War Change 1939-1952. Oxford, 1958.

Maskill, David, ed. Traces of the Wake: The Etching Revival in Britain and Beyond. Wellington: Adam Art Gallery Te Pātaka Toi, 2015.

McAloon, William, ed. Art at Te Papa. Wellington: Te Papa Press, 2009.

McCormick, E.H. Letters and Art in New Zealand. Wellington: Department of Internal Affairs, 1940. . New Zealand Literature. Oxford: O.U.P., 1959.

1981. Portrait of Frances Hodgkins. Auckland: Auckland University Press, Art Gallery, 1954. Works of Frances Hodgkins in New Zealand. Auckland: Auckland City

McCrone, David and Frank Bechhofer. Understanding National Identity. Cambridge: Cambridge University Press, 2015.

McLeod, A.L., ed. The Pattern of New Zealand Culture. Melbourne: Oxford University Press, 1968.

McLintock, A.H., ed. National Centennial Exhibition of New Zealand Art Catalogue. Wellington: Department of Internal Affairs, 1940. Accessed 21 April 2019. http://nzetc.victoria.ac.nz/tm/scholarly/tei-GovArt.html.

Miller, Henry. Politics Personified: Portraiture, Caricature and Visual Culture in Britain, c.1830-80. Manchester: Manchester University Press, 2015.

Mogford, Henry. Hand-book for the Preservation of Pictures. $6^{\text {th }}$ edition, London: Winsor and Newton, 1861.

Monkhouse, Cosmo. The Earlier English Water-Colour Painters. $2^{\text {nd }}$ edition, London: Seeley and Co., 1897. 
Moore, Andrew, Norma Watt and Timothy Wilcox eds. John Sell Cotman: Master of Watercolour. Norwich: Norwich Castle Museum and Art Gallery, 2005. Exhibition catalogue.

Muir, Ramsay. The Character of the British Empire. London: Constable and Co., 1917.

Mulgan, Alan. Home: A Colonial's Adventure. London: Longmans, 1930.

Myrone, Martin, ed. Watercolour in Britain. London: Tate Publishing, 2010.

National Art Gallery (NZ). A Guide Book to the National Art Gallery of New Zealand. Wellington: National Art Gallery, 1969.

Gallery, 1984. . Aspects of New Zealand Art 1890-1940. Wellington: National Art Gallery, 1936. Catalogue of Pictures and Works of Art. Wellington: National Art Gallery, 1972. Contemporary New Zealand Painting. Wellington: National Art Content/Context: A Survey of Recent New Zealand Art 1986. Wellington: National Art Gallery, 1986. Early New Zealand Watercolours and Drawings from the Chevalier, J. C. Richmond and Swainson Collections at the National Art Gallery Wellington, New Zealand. Wellington: R.E. Owen, 196-?. Exhibition of Drawings and Watercolours from the SPOONER and WITT Collections. Wellington: Madison Printing Co., 1976. Exhibition of Recent Acquisitions. Wellington: National Art Gallery, 1957. . Souvenir Catalogue of Pictures and Works of Art for Opening Exhibition August, 1936. Wellington: National Art Gallery, 1936. The First Fifty Years: British Art of the $20^{\text {th }}$ Century: From the Collection of the National Art Gallery. Wellington: National Art Gallery, 1981.

New Zealand Exhibition, 1865: Reports and Awards of the Jurors and Appendix. Dunedin: Mills, Dick \& Co., 1866.

Nochlin, Linda. Realism and Tradition in Art, 1848-1900: Sources and Documents. New Jersey: Prentice-Hall, 1966.

Notman, Robyn and Lynda Cullen, eds. Beloved: Works from the Dunedin Public Art Gallery. Dunedin: Dunedin Public Art Gallery, 2009. 
Novitz, David, and William E. Willmott, eds. Culture and Identity in New Zealand. Wellington: GP Books, 1989.

Official Catalogue of the New Zealand Exhibition. Dunedin: Mills, Dick \& Co., 1865.

Palmer, Arnold, ed. Recording Britain. 4 vols. Oxford: Oxford University Press in association with the Pilgrim Trust, 1946-1948.

Paris, H.J. English Watercolour Painters. London: Bracken Books, 1987.

Payne, Ann. Views of the Past: Topographical Drawings in the British Library. London: The British Library, 1987.

Payne, Christiana. Where the Sea Meets the Land: Artists on the Coast in NineteenthCentury Britain. Bristol: Sansom \& Company, 2007.

Pearce, Susan. On Collecting: An Investigation into Collecting in the European Tradition. London and New York: Routledge, 1995.

Pearson, David. The Politics of Ethnicity in Settler Societies: States of Unease. Basingstoke \& New York: Palgrave, 2001.

Pegge, Samuel. Anecdotes of the English Language: Chiefly Regarding the Local Dialect of London and its Environs. $2^{\text {nd }}$ edition, London: J. Nichols, Son, and Bentley, 1814.

Penley, Aaron. A System of Water-Colour Painting. London: Winsor and Newton, 1850. . The English School of Painting in Water-Colours. New and revised edition, London: A. Tarrant, 1874.

Peters Corbett, David, Ysanne Holt and Fiona Russell, eds. The Geographies of Englishness: Landscape and the National Past 1880-1940. New Haven \& London: Yale University Press, 2002.

Pevsner, Nikolaus. The Englishness of English Art. London: The Architectural Press, 1956.

Pomian, Krzysztof. Collectors and Curiosities: Paris and Venice, 1500-1800. Cambridge: Polity Press, 1990.

Pound, Francis. Frames on the Land: Early Landscape Painting in New Zealand. Auckland: William Collins Publishers, 1983.

1993. , ed. Landfall 185: The Fifties Issue. Auckland: Oxford University Press, The Invention of New Zealand: Art \& National Identity, 1930-1970. Auckland: Auckland University Press, 2009. 
Price, Uvedale. An Essay on the Picturesque, as Compared with the Sublime and the Beautiful; and, on the Use of Studying Pictures, for the Purpose of Improving Real Landscape. London: J. Robson, 1794.

Raissis, Peter. Victorian Watercolours from the Art Gallery of New South Wales. Sydney: Art Gallery of New South Wales, 2017.

Ratcliff, Carter. John Singer Sargent. New York: Abbeville Press, 1982.

Read, Herbert. New Aspects of British Sculpture, XXVI Venice Biennale, British Pavilion. London: Westminster Press, 1952. Exhibition catalogue. . The Meaning of Art. London: Faber \& Faber, 1931.

Redgrave, Richard and Samuel. A Century of British Painters. London: Phaidon, 1947.

Reitlinger, Gerald. The Economics of Taste: The Rise and Fall of Picture Prices 1760-1960. 3 vols. New York: Hacker Art Books, 1982.

Reynolds, Graham. A Concise History of Watercolours. New York and Toronto: Oxford University Press, 1978.

Books, 1988. . English Watercolours: An Introduction. New York: New Amsterdam . Turner. London: Thames and Hudson, 1969.

Robert McDougall Art Gallery. A Guide to the Collections of the Robert McDougall Art Gallery, Christchurch, New Zealand. Christchurch: Christchurch City Council Parks, Recreational and Cultural Committee, 1973.

Roget, John Lewis. A History of the 'Old Water-Colour' Society. London: Longmans, Green, and Co., 1891.

Rowbotham, Thomas, and T.L. Rowbotham. The Art of Landscape Painting in Water Colours. London: Winsor and Newton, 1850.

Newton, 1855. The Art of Sketching from Nature. $18^{\text {th }}$ edition, London: Winsor and

Ruskin, John. Modern Painters: Volume I. New edition, New York: John Wiley \& Sons, 1890. Allen, 1883 . Modern Painters: Volume II. Revised edition, Sunnyside, Orpington: George . Modern Painters: Volume III. New York: John Wiley \& Sons, 1879. . Modern Painters: Volume IV. New York: John Wiley \& Sons, 1884. 
Saines, Chris, ed. Auckland Art Gallery Toi o Tāmaki: A Place for Art. Auckland: Auckland Art Gallery Toi o Tāmaki, 2013.

Selborne, Joanna, ed. Life, Legend, Landscape: Victorian Drawings and Watercolours. London: The Courtauld Gallery, 2011.

Shanes, Eric. Turner's Watercolour Explorations 1810-1842. United Kingdom: Tate Gallery, 1997.

Shaw-Miller, Simon, and Sam Smiles, eds. Samuel Palmer Revisited. New York: Routledge, 2016.

Sinclair, Keith. A Destiny Apart: New Zealand's Search for National Identity. Wellington: Allen \& Unwin in association with the Port Nicholson Press, 1986.

. The Native Born: The Origins of New Zealand Nationalism. Palmerston North: Massey University, 1986.

Sir Geoffrey Agnew, 1908-1986, Dealer and Connoisseur: An Exhibition of Old Master and English Pictures and Watercolours Lent by his Friends, June 1 - July 22, 1988. London: Thos. Agnew \& Sons, 1988.

Sloan, Kim. 'A Noble Art': Amateur Artists and Drawing Masters c.1600-1800. London: British Museum Press, 2000.

Alexander and John Robert Cozens: The Poetry of Landscape. New Haven and London: Yale University Press, 1986. , ed. Places of the Mind: British Watercolour Landscapes 1850-1950. London: Thames \& Hudson, 2017. . J.M.W. Turner: Watercolours from the R.W. Lloyd Bequest to the British Museum. London: British Museum Press, 1998.

Smith, Alison, ed. Watercolour. London: Tate Publishing, 2011.

Smith, Greg. The Emergence of the Professional Watercolourist. Aldershot: Ashgate Publishing Limited, 2002.

Spencer, Ian R.G. British Immigration Policy since 1939: The Making of Multicultural Britain. London, 1997.

Spielmann, Marion Harry. The History of “Punch.” London: Cassell, 1895.

Spoonley, Paul, David Pearson and Ian Shirley eds. New Zealand Society: A Sociological Introduction. Palmerston North, 1990. 
Stachurski, Christina. Reading Pākehā?: Fiction and Identity in Aotearoa New Zealand. Amsterdam: Rodopi, 2009.

Stainton, Lindsay. British Landscape Watercolours 1600-1860. London: British Museum Press, 1985.

Stechow, Wolfgang. Dutch Landscape Painting of the Seventeenth Century. 3rd ed., Oxford: Phaidon, 1981.

Stocker, Mark, ed. New Zealand Art at Te Papa. Wellington: Te Papa Press, 2018.

Sutton, Denys. Christie's Since the War, 1945-1958: An Essay on Taste, Patronage and Collecting. London: Christie, Manson \& Woods, 1959.

Sutton, Peter C. and Albert Blankert. Masters of 17th-Century Dutch Landscape Painting. Boston: Museum of Fine Arts, 1987.

Tate Gallery. Paint and Painting. London: Tate Gallery, 1982.

The Arts Council of Great Britain. Paintings and Drawings from the Sir Edward Marsh Collection. London: The Favil Press, 1953.

Tomory, Peter. European Paintings before 1800 in Australian and New Zealand Public Collections: Summary Catalogue. Sydney: Beagle Press, 1989.

Treuherz, Julian. Hard Times: Social Realism in Victorian Art. London: Lund Humphries in association with Manchester City Art Galleries, 1987.

Tyler, Linda. Art in the Service of Science: Dunedin's John Buchanan, 1819-1898.

Auckland: Gus Fisher Gallery, 2012.

Vaughan, William. Romanticism and Art. London: Thames and Hudson, 1994.

Venn, John and J.A. Alumni Cantabrigienses from the Earliest Times to 1900. Cambridge: Cambridge University Press, 1922-54.

Vennell, C.W. The Mackelvie Trust. Auckland: Wilson \& Horton, 1971.

Wainwright, Clive. The Romantic Interior: The British Collector at Home 1750-1850. New Haven and London: Yale University Press, 1989.

Warner, M. The Image of London: Views by Travellers and Emigrés, 1550-1920. London: Barbican A.G., 1987.

Warner, Oliver. An Introduction to British Marine Painting. London: B.T. Batsford, 1948.

Warrell, Ian. Turner's Sketchbooks. London: Tate Publishing, 2014.

Watkins, Charles and Ben Cowel. Uvedale Price (1747-1829): Decoding the Picturesque. Woodbridge: Boydell Press, 2012. 
Wilcox, Scott. British Watercolors: Drawings of the $18^{\text {th }}$ and $19^{\text {th }}$ Centuries from the Yale Centre for British Art. New York: Hudson Hills Press, 1985.

Wilcox, Scott and Christopher Newall. Victorian Landscape Watercolors. New York: Hudson Hills Press, 1992.

Wilcox, Timothy and Charles Nugent. The Triumph of Watercolour: The Early Years of the Royal Watercolour Society 1805-55. United Kingdom: Bloomsbury USA, 2005.

Wilkinson, Gerald. Turner's Colour Sketches, 1820-34. United Kingdom: Barrie and Jenkins, 1975.

\section{Theses}

Bayard, Jane. "From Drawing to Painting: The Exhibition Watercolor 1770-1870." PhD diss., Yale University, 1982.

Bisley, Lizzie. "Distance Makes the Heart Grow Fonder: International Art Exhibitions in Wellington, 1928-1940." Hon diss., Victoria University of Wellington, 2003.

Brown, Maria. "The History and Function of the Auckland City Art Gallery in Constructing a Canon of Modernist New Zealand Art.” MA diss., University of Auckland, 1999.

Campbell, Penelope. "Collecting the Pacific 1768-1977: Joseph Banks, Alexander Turnbull, Rex Nan Kivell.” MA diss., Victoria University of Wellington, 2002.

Feather, Jessica. "The Formation of a Modern Taste in Watercolour: Critics, Curators and Collectors c. 1890-1912.” PhD diss., University of Reading, 2014.

Field-Dodgson, Catherine. "In Full Bloom: Botanical Art and Flower Painting by Women in 1880s New Zealand.” MA diss., Victoria University of Wellington, 2003.

Gore, James Michael. "Representations of History and Nation in Museums in Australia and Aotearoa New Zealand - the National Museum of Australia and the Museum of New Zealand Te Papa Tongarewa." PhD diss., University of Melbourne, 2002.

Hanham, Stacey. "The Te Mãori Exhibition: An Examination of its Organisation and Impacts as Seen by Those Who Developed the Exhibition." MA diss., Victoria University of Wellington, 2000.

Hearn, Richard P.J. "The Production of Paintings in Watercolours in Early $19^{\text {th }}$ Century Britain: The Shift from Oil-Supremacy to Watercolour-Ascendancy." PhD diss., University of Sussex, 1994.

Hutchings, Mark. "The Italian Inheritance: Contemporary Responses to Early Renaissance Imagery by Four New Zealand Painters.” MA diss., University of Auckland, 1988. 
James, Pamela J. "The Lion in the Frame: The Art Practices of the National Art Galleries of New South Wales and New Zealand 1918-1939." PhD diss., University of Western Sydney, 2003.

Johnston, Courtney. "Peter Tomory: The New Zealand Years, 1956-1968." MA diss., Victoria University of Wellington, 2004.

Jolivette, Catherine. "The 'Britishness' of British Art: Landscape, Art and Identity, 19511956.” PhD diss., Pennsylvania State University, 2003.

Jordan, Sandra Johnson. "The Life and Art of John Webber, R.A.; and his Relationship to the Watercolor and Picturesque Movements in Eighteenth Century England." PhD diss., University of Georgia, 1991.

Keating, Mary O. "The Genre Interior in English Painting: From Dutch Origins to Native Solutions." PhD diss., The Pennsylvania State University, 2001.

Malpas, Julianne. “An Incurable Collector: Sir John Ilott (1884-1973) and his Passion for Prints.” MA diss., Victoria University of Wellington, 2005.

McCredie, Athol. "Going Public: New Zealand Art Museums in the 1970s." MA diss., Massey University, Wellington, 1999 (reprinted 2006).

Milliszewska, Zofia. “A Taste of Home: The Baillie Exhibition of 1912.” Hon diss., Victoria University of Wellington, 2004.

Norman, Mathew. "The Print Collection of Bishop Monrad (1811-1887).” MA diss., Victoria University of Wellington, 2006.

Nunn, Pamela Gerrish. “The Mid-Victorian Woman Artist: 1850-1879.” PhD diss., University of London, 1982.

Reed, Stewart. "Policy, Taste or Chance? - Acquisition of British and Foreign Oil Paintings by the Art Gallery of New South Wales From 1874 to 1935." MartAdm diss., University of New South Wales, 2013.

Reilly, Emma. "Walter Auburn and his Collection of Prints." MA diss., Auckland University, 2003.

Rice, Rebecca. "The State Collections of Colonial New Zealand Art: Intertwined Histories of Collecting and Display." PhD diss., Victoria University of Wellington, 2010.

Rosenfeld, Jason M. "New Languages of Nature in Victorian England: The Pre-Raphaelite Landscape, Natural History and Modern Architecture in the 1850s." PhD diss., New York University, 1999.

Sippel, Annika. "Fifteenth and Sixteenth-Century Northern European Prints at the Museum of New Zealand Te Papa Tongarewa.” MA diss., Victoria University of Wellington, 2012. 
Smith, Alan. "The State and National Identity: The Role of Cultural Institutions in Fostering a Distinctive New Zealand National Identity." MA diss., Victoria University of Wellington, 1992.

Stead, Oliver. "New Lamps for Old: The Activities of Sir Rex de Charembac Nan Kivell as a Collector and Dealer of Fine Art." PhD diss., University of Otago, 2003.

Tomlinson, John William Bruce. "From Parson to Professional: The Changing Ministry of the Anglican Clergy in Staffordshire, 1830-1960." PhD diss., University of Birmingham, 2007.

Tyler, Linda. "Drawn from Nature: Art and Science in the Work of John Buchanan." PhD diss., University of Auckland, 2018.

Wild, Susan. "Creating New Zealand: Pākehā Constructions of National Identity in New Zealand Literary Anthologies.” PhD diss., Victoria University of Wellington, 2015.

\section{Articles}

\section{Scholarly}

Beattie, Sarah. "Stained Glass on Paper: Morris \& Co. and the Pre-Raphaelites." Victoria and Albert Museum. Accessed 9 July 2019. https://www.vam.ac.uk/blog/caring-for-ourcollections/stained-glass-on-paper-morris-co-and-the-pre-raphaelites.

Beavington Atkinson, J. "Etching: Its Relation to the Artist, the Amateur, and the Collector." The Art Journal 6, (1880): 348-350. Accessed 2 November 2017. www.jstor.org/stable/20569606.

Bell, Leonard. "Colonial Fortunes: The New Zealand Paintings of Commander R.A. Oliver." Art New Zealand 30 (Autumn 1984). Accessed 23 June 2020. https://www.artnewzealand.com/Issues21 to30/oliver.htm.

Bending, Stephen. "Vile Things: William Gilpin and the Properties of the Picturesque." Huntington Library Quarterly 80, no. 4 (Winter 2017): 585-607.

Benedict, Burton. "International Exhibitions and National Identity." Anthropology Today 7, no. 3 (1991): 5-9. Accessed 30 August 2020. https://www.jstor.org/stable/3032792.

Bieringa, Luit. "Collecting and Collection Policies at the National Art Gallery." AGMANZ Journal 16, no. 1 (March 1985): 20-21. Accessed 4 June 2020. https://christchurchartgallery.org.nz/media/uploads/2017_08/AGMANZ_Journal_Volume_1 6_Number_1_March_1985_optimized_for_web.pdf. 
https://christchurchartgallery.org.nz/media/uploads/2017_08/AGMANZ_Journal_Volume_2 0_Number_4_1989_optimized_for_web.pdf.

Accessed 4 June.

“President's Report.” AGMANZ News 15, no. 1 (March 1984): 21-23.

2020https://christchurchartgallery.org.nz/media/uploads/2017_08/AGMANZ_News_Volum e_15_Number_1_March_1984_optimized_for_web.pdf.

. "President's Report to the 1983 Conference of the Art Galleries and

Museums Association of New Zealand.” AGMANZ News 14, no. 2 (June 1983): 16-18.

Accessed 4 June 2020.

https://christchurchartgallery.org.nz/media/uploads/2017_08/AGMANZ_News_Volume_14 _Number_2_June_1983_optimized_for_web.pdf.

. “Obituary: Colin McCahon 1919-1987.” AGMANZ Journal 18, no. 2

(1987): 28. Accessed 4 June 2020.

https://christchurchartgallery.org.nz/media/uploads/2017_08/AGMANZ_Journal_Volume_1

8_Number_2_Winter_1987_optimized_for_web.pdf.

“Obituary: Ronald Norris O’Reilly (9-10-1914/10-7-82).” AGMANZ News

13, no. 3 (September 1982): 15-16. Accessed 4 June 2020.

https://christchurchartgallery.org.nz/media/uploads/2017_10/AGMANZ_News_Volume_13 _Number_3_September_1982.pdf.

."The Politics of Consumption and Display." AGMANZ Journal 15, no. 4

(December 1984): 27-28. Accessed 4 June 2020.

https://christchurchartgallery.org.nz/media/uploads/2017_08/AGMANZ_Journal_Volume_1

5_Number_4_December_1984_optimized_for_web.pdf.

Binyon, Laurence. "The British Water-Colour." Saturday Review (19 December 1908): 7534. Accessed 20 July 2019. https://search-proquest-

com.helicon.vuw.ac.nz/docview/9192716/675465B9BDD94A93PQ/1?accountid=14782.

Black, A. and C. "Smythe, Canon Francis Henry Dumville." Who Was Who, an imprint of Bloomsbury Publishing (1920-2016). (Oxford: Oxford University Press, 2014). Accessed 17 November 2017. http://www.ukwhoswho.com/view/article/oupww/whowaswho/U54868.

Bledisloe, Viscount. "National Art Gallery and Dominion Museum: The Proper Function of an Art Gallery and Museum." Speech held on 14 April 1934. Accessed 30 June 2020. https://gg.govt.nz/publications/national-art-gallery-and-dominion-museum.

Bonehill, John and Stephen Daniels. "'Real Views from Nature in this Country': Paul Sandby, Estate Portraiture and British Landscape Art." British Art Journal 10, no. 1 (2009): 72-77. Accessed 27 June 2017. http://www.jstor.org/stable/41614863.

Brasch, Charles. “Art Gallery Policy.” Landfall 3, no. 2 (1949): 176-182. Accessed 14 April 2020. http://www.landfallarchive.org/omeka/items/show/22172.

. "Frances Hodgkins in Auckland." Landfall 8, no. 3 (1954): 209-212.

Accessed 11 April 2020. http://www.landfallarchive.org/omeka/items/show/22194. 
Brown, Robert W. "Topography." Grove Art Online (2003). Accessed 16 August 2020. https://www-oxfordartonlinecom.helicon.vuw.ac.nz/groveart/view/10.1093/gao/9781884446054.001.0001/oao9781884446054-e-7000085610?rskey=MC5tqd\#oao-9781884446054-e-7000085610-div17000085611.

Buckman, David. "Marsh, Sir Edward." Grove Art Online (2003). Accessed 1 August 2019. https://www.oxfordartonline.com/groveart/view/10.1093/gao/9781884446054.001.0001/oao -9781884446054-e-7000054577.

Bury, Adrian. "Water-Colour: The English Medium.” Apollo 19 (1934): 85-89. Accessed 11 February 2020. https://search.proquest.com/docview/1542751306?accountid=14782.

Butler, Patricia. "A Victorian Watercolourist." Irish Art Review Yearbook 10 (1994): 157 162. Accessed 2 November 2017. www.jstor.org/stable/20492783.

Butler, Rex and A.D.S. Donaldson. "Cities within Cities: Australian and New Zealand Art in the $20^{\text {th }}$ Century." Journal of Art Historiography 4 (June 2011): 1-15. Accessed 23

September 2019. https://www-proquest-

com.helicon.vuw.ac.nz/docview/902572455/D96D4CE72BC24503PQ/17?accountid=14782.

. "Stay, Go, Or Come: A History of Australian Art, 1920-

40." Australian and New Zealand Journal of Art 9, no. 1-2 (2008): 118-143. Accessed 23

September 2019. https://www-tandfonline-

com.helicon.vuw.ac.nz/doi/abs/10.1080/14434318.2008.11432798.

Calhoun, Ann. "Two Wellington Entrepreneurs of the 'Thirties: The Murray Fullers - I Edwin Murray Fuller." Art New Zealand 23 (1982). Accessed 26 July 2017. http://www.artnewzealand.com/Issues21 to30/fullers.htm.

. "Two Wellington Entrepreneurs of the "Thirties: The Murray Fullers - II Mary Murray Fuller.” Art New Zealand 24 (1982). Accessed 26 July 2017. https://www.artnewzealand.com/Issues21 to30/fullers24.htm.

Carnegie, Wendy and Brenda Gamble. "Who You Should Know - I." Art Galleries and Museums Association of New Zealand 2, no. 10 (August 1971): 3-4. Accessed 18 May 2020. https://christchurchartgallery.org.nz/media/uploads/2017_10/AGMANZ_News_Volume_2_ Number_10_August_1971.pdf.

Caselberg, John. "Havens for Art: Nelson, Dunedin and the Growth of Local Art." Art New Zealand 15 (1980). Accessed 17 June 2020. https://www.art-

newzealand.com/Issues11to20/havens.htm.

Christchurch Art Gallery Te Puna o Waiwhetu. "Early British Watercolours." Accessed 10 March 2020. https://christchurchartgallery.org.nz/exhibitions/early-british-watercolourexhibition.

Clearkin, Christine. "The Revd William Gilpin (1724-1804): Artist and Man of his Age." British Art Journal 19, no. 1 (2008): 76(8). 
Codell, Julie F. "Righting the Victorian Artists: The Redgraves' A Century of Painters of the English School and the Serialization of Art History." Oxford Art Journal 23, no. 2 (2000): 95-119. Accessed 19 July 2019. https://doi-org.helicon.vuw.ac.nz/10.1093/oxartj/23.2.95.

Cole, Douglas. 'The Problem of 'Nationalism' and 'Imperialism' in British Settlement Colonies.” Journal of British Studies 10, no. 2 (May 1971): 160-182. Accessed 29 April 2020. https://www-jstororg.helicon.vuw.ac.nz/stable/175353?seq=1\#metadata_info_tab_contents.

Cross, Elizabeth. "Peter Alexander Tomory, 1922-2008." Art Monthly Australia 209 (May 2008): 29-30. Accessed 8 June 2020. https://search-informitorg.helicon.vuw.ac.nz/doi/10.3316/informit.186181630425955.

D.S. “Obituary: Sir Alec Martin.” Apollo 93, no. 112 (1 June 1971): 537. Accessed 8 April 2020. https://search-proquestcom.helicon.vuw.ac.nz/docview/1366980637?rfr_id=info\%3Axri\%2Fsid\%3Aprimo.

Entwisle, Peter. "Edgar, James Douglas Charlton." Dictionary of New Zealand Biography. First published in Te Ara - The Encyclopedia of New Zealand (1998). Accessed 14 May 2020. https://teara.govt.nz/en/biographies/4e3/edgar-james-douglas-charlton.

. "Pearse, Annette Grace." Dictionary of New Zealand Biography 5 (2000). First published in Te Ara - The Encyclopedia of New Zealand. Accessed 11 October 2017. https://teara.govt.nz/en/biographies/5p20/pearse-annette-grace.

Faberman, Hilarie. "Brabazon, Hercules Brabazon." Grove Art Online. Accessed 1 July 2019.

https://www.oxfordartonline.com/groveart/view/10.1093/gao/9781884446054.001.0001/oao -9781884446054-e-7000010755.

2018. https://www-oxfordartonlinecom.helicon.vuw.ac.nz/groveart/view/10.1093/gao/9781884446054.001.0001/oao9781884446054-e-7000025031?rskey=otlogt.

Feeney, Warren. "The Great Art War': Alan Brassington and Frances Hodgkins's The Pleasure Garden.” Journal of New Zealand Art History, no. 28 (2007): 97-113.

Fraser, Ross. "The Gallery’s First Eighty Years.” Quarterly, no. 49 (1971): 2-22. Auckland: Auckland City Art Gallery.

. "The Reverend John Kinder: Painter and Photographer." Art New Zealand 2 (1976). Accessed 26 July 2017. http://www.art-newzealand.com/Issues1 to40/kinder.htm.

Fratello, Bradley. "France Embraces Millet: The Intertwined Fates of 'The Gleaners' and 'The Angelus'." The Art Bulletin 85, no. 4 (2003): 685-701. Accessed 20 October 2020. www.jstor.org/stable/3177365. 
Gerrish Nunn, Pamela. "Frances Hodgkins: A Question of Identity." Woman's Art Journal 15, no. 2 (Autumn 1994 - Winter 1995): 9-13. Accessed 18 May 2020.

https://www.jstor.org/stable/1358598.

Gibbons, Peter. "Cultural Colonization and National Identity." New Zealand Journal of History 36, no. 1 (April 2002): 5-17.

Gilderdale, Peter. "Summer Scenes and Flowers: The Beginnings of the New Zealand Christmas Card, 1880-1882.” Backstory, no. 3 (2017): 5-25. Accessed 26 January 2021. https://doi.org/10.24135/backstory.vi3.26 .

Gilpin, William. "Three Essays: On Picturesque Beauty; on Picturesque Travel; on Sketching Landscape.” The Monthly Review; or, Literary Journal XI (1793): 17-22.

Gorbey, Ken. "New Zealand Museums - Is there Life after Te Māori?" AGMANZ Journal 15, no. 4 (1984): 2. Accessed 3 July 2020.

https://christchurchartgallery.org.nz/media/uploads/2017_08/AGMANZ_Journal_Volume_1 5_Number_4_December_1984_optimized_for_web.pdf.

Gordon, Mona. "The Early Artists of New Zealand IV. John Gully - the Turner of New Zealand." The New Zealand Railways Magazine 15, no. 3 (1 June 1940): 35-39.

Grant, Kim. "'Paint and Be Happy': The Modern Artist and the Amateur Painter - A Question of Distinction." The Journal of American Culture 34, no. 3 (September 2011): 289-303. Accessed 5 July 2019. https://onlinelibrary.wiley.com/doi/epdf/10.1111/j.1542734X.2011.00781.x.

Grossman, Edith Searle. "The Growth of a Colonial Sentiment." Empire Review IX, no. 52 (May 1905): 350-353.

Gunn, Ann. "Fidelity and Elegance: The Aquatint Landscapes of Paul Sandby (1731-1809)." The British Library (31 March 2017). Accessed 13 February 2018.

https://www.bl.uk/picturing-places/articles/the-aquatint-landscapes-of-paul-sandby-17311809-fidelity-and-elegance.

Hamerton, P.G. “The Poor Collector.” Longman's Magazine 6, no. 35 (September 1885): 481-495.

Hamilton, Fiona. "Pioneering History: Negotiating Pākehā Collecting Memory in the Late Nineteenth and Early Twentieth Centuries." New Zealand Journal of History 36, no. 1 (2002): 66-81. Accessed 29 April 2020.

https://ndhadeliver.natlib.govt.nz/delivery/DeliveryManagerServlet?dps_pid=FL39848425.

Hassall, C.V. and Mark Pottle "Marsh, Sir Edward Howard (1872-1953), Civil Servant and Patron of the Arts." Oxford Dictionary of National Biography (23 September 2004). Accessed 17 September 2019. https://www.oxforddnb.com/view/10.1093/ref:odnb/9780198614128.001.0001/odnb9780198614128-e-34892. 
Heckenberg, Kerry. "A Taste for Art in Colonial Queensland: The Queensland Art Gallery Foundational Bequest of Thomas Lodge Murray-Prior." Queensland Review 25, no. 1 (2018): 119-136.

Hipwell, Arthur C. "Modern Trends in New Zealand Painting." Meanjin 6, no. 3 (Spring 1947): 177-180. Accessed 21 July 2017.

http://search.informit.com.au/documentSummary;dn=629148942337278;res=IELLCC.

Hulks, David. "Francis Bacon and the Geometry of Fear." Sculpture Journal 19, no. 1 (2010): 79+. Accessed 25 March 2020. https://link-gale-

com.helicon.vuw.ac.nz/apps/doc/A243453592/AONE?u=vuw\&sid=AONE\&xid=c9dc0a75.

Iacono, Margaret. "A Dealer Collects: Reconstructing Charles Stewart Carstairs's Private Art Collection." Journal of the History of Collections 29, no. 1 (2017): 93-108. Accessed 10 May 2019. https://academic.oup.com/jhc/article/29/1/93/2503286.

Jackson, R.V. "The Structure of Pay in Nineteenth-Century Britain." The Economic History Review 40, no. 4 (1987): 561-570. Accessed 14 August 2019. www.jstor.org/stable/2596393.

Jacques, Shulla. "A Glance at the History of Display and Mounting of British Watercolours." The Paper Conservator 24, no. 1 (2000): 35-43. Accessed 13 June 2017. https://doi.org/10.1080/03094227.2000.9638426.

Johnston, Courtney. "Feeling and Illustration: Reading Peter Tomory's Art History." Journal of New Zealand Art History 27 (2006): 27-37.

Jordan, Caroline, and Rebecca Rice. "'Cultural Propaganda' and the Politics of Taste: The Carnegie Corporation's Cancelled Art of New Zealand Exhibition, 1941." Australian and New Zealand Journal of Art 14, no. 2 (2014): 118-140. Accessed 22 November 2019. https://doi.org/10.1080/14434318.2014.973634.

Keane, Basil. "Ngā Rōpū Tautohetohe - Māori Protest Movements." Te Ara - The Encyclopedia of New Zealand (20 June 2012). Accessed 21 March 2021.

http://www.TeAra.govt.nz/en/nga-ropu-tautohetohe-maori-protest-movements.

Kinsley, Zoë. "William Gilpin at the Coast: A New Perspective on Picturesque Travel Writing." The Review of English Studies 68, no. 284 (2017): 322-341.

Kirker, Anne. "Aspects of Collection Rationalisation.” AGMANZ Journal 16, no. 1 (March 1985): 2-3. Accessed 4 June 2019.

https://christchurchartgallery.org.nz/media/uploads/2017_08/AGMANZ_Journal_Volume_1 6_Number_1_March_1985_optimized_for_web.pdf.

. “Peter Tomory’s New Zealand Years.” Art New Zealand 40 (Spring 1986).

. "T.A. McCormack: A New Talent to Emerge in the Nineteen-Thirties." Art New Zealand 27 (1983). Accessed 21 July 2017. http://www.artnewzealand.com/Issues21 to30/mccormack.htm. 
Kisler, Mary. “A Man of His Time - Peter Tomory 1922-2008." Auckland Art Galleyr (26 March 2008). Accessed 15 April 2020. https://www.aucklandartgallery.com/article/a-manof-his-time-peter-tomory-1922-2008.

. "Displaced Legacies - European Art in New Zealand's Public Collections."

The Gordon H. Brown Lecture 2008. Accessed 26 July 2017.

http://www.victoria.ac.nz/sacr/research/art-history/gordon-h.-brown-lecture-series/MaryKisler-lecture.pdf.

June 2020.

. “The Peter Tomory Archive.” Reading Room 3 (2009): 154-163. Accessed 5

https://issuu.com/aucklandartgallery/docs/readingroom_03_2009?e=7464930/4676568.

Knollys, Eardley. "Frances Hodgkins." The Burlington Magazine for Connoisseurs 89, no. 532 (July 1947): 197-198. Accessed 18 May 2020. https://www.jstor.org/stable/869636.

Korn, Madeleine. "Exhibitions of Modern French Art and their Influence on Collectors in Britain 1870-1918: The Davies Sisters in Context." Journal of the History of Collections 16, no. 2 (2004): 191-218.

Leonard, Robert. "New Zealand Art Under Erasure." (23 January 2019). Accessed 23 April 2019. http://robertleonard.org/2019/01/new-zealand-art-under-erasure/.

Lewis, Meredith E. “English Water Colour.” Watercolor (Spring 2006): 30-43. Accessed 28 June 2017.

go.galegroup.com/ps/i.do?p=PPFA\&sw=w\&u=vuw \&v=2.1\&id=GALE\%7CA143720315\&i $\mathrm{t}=\mathrm{r} \&$ asid=76920afd13052353aecefdd2405503b8.

Mackle, Tony. "Stewart Bell Maclennan: The Man for the Job." The Journal of New Zealand Art History 26 (2005): 55-67.

."The Enterprising John Baillie, Artist, Art Dealer and Entrepreneur."

Tuhinga, 28 (2017): 62-79. Accessed 14 July 2020.

https://www.tepapa.govt.nz/sites/default/files/tuhinga_28_mackle.pdf.

Maclennan, Stewart. “Art Review: Contemporary British Lithographs.” Design Review 5, no. 1 (1953): 13-14. Accessed 8 April 2020. http://nzetc.victoria.ac.nz/tm/scholarly/teiArc05_01DesR-t1-body-d5.html.

"Survey, Trends, and Influences, 1938 to Present." An Encyclopaedia of New Zealand. Originally published in Te Ara - The Encyclopedia of New Zealand (1966). Accessed 9 April 2020. http://www.TeAra.govt.nz/en/1966/art-in-new-zealand/page-2.

MacNally, Niamh. “A Subtle Art.” Irish Arts Review 21, no. 3 (2004): 112-115. Accessed 2 November 2017. www.jstor.org/stable/25503087.

Marsh, Ngaio. "The Development of the Arts in New Zealand." Journal of the Royal Society of Arts 99, no. 4840 (1951): 246-259. Accessed 27 June 2017.

http://www.jstor.org/stable/41365110. 
Maskill, David. "Imperial Lines: Harold Wright (1885-1961): Printmaking and Collecting at the End of Empire: The Margaret Manion Lecture 2007." Melbourne Art Journal 11-12 (2009): 98.

McCahon, Colin. "Beginnings." Landfall 20, no. 4 (1966): 360-364. Accessed 11 May 2020. http://www.landfallarchive.org/omeka/items/show/22242.

"Necessary Protection." Art New Zealand 7 (August-October 1977): 45.

Accessed 11 May 2020. http://www.art-newzealand.com/Issues1 to40/environcm.htm.

McEvansoneya, Philip. “"A Thing to Be Seen': Creating the Crampton Collection of British Watercolours in the 1850s." Journal of the History of Collections 21, no. 1 (May 2009): 95110. Accessed 10 May 2019. https://academic.oup.com/jhc/article/21/1/95/762121.

McLintock, A.H., ed. "Beginnings: 1642-1939." An Encyclopaedia of New Zealand. Originally published in Te Ara - The Encyclopedia of New Zealand (1966). Accessed 11 October 2017. http://www.TeAra.govt.nz/en/1966/art-in-new-zealand.

. "Survey, Trends, and Influences, 1938 to Present." An Encyclopaedia of New Zealand. Originally published in Te Ara - The Encyclopedia of New Zealand (1966). Accessed 11 October 2017. http://www.TeAra.govt.nz/en/1966/art-in-new-zealand/page-2.

"Maclennan, Stewart Bell." An Encyclopedia of New Zealand.

Originally published in Te Ara - The Encyclopedia of New Zealand (1966). Accessed 8 April 2020. http://www.TeAra.govt.nz/en/1966/Maclennan-stewart-bell.

Meaney, Neville. "Britishness and Australian Identity: The Problem of Nationalism in Australian History and Historiography." Australian Historical Studies 32, no. 116 (2001): 76-90. Accessed 29 April 2020. https://doi.org/10.1080/10314610108596148.

Millar, David P. "Day, Melvin (Norman Pat)." Grove Art Online (1 December 2004). Accessed 16 April 2020. https://www-oxfordartonlinecom.helicon.vuw.ac.nz/groveart/view/10.1093/gao/9781884446054.001.0001/oao9781884446054-e-7000097767.

Moore Heleniak, Kathryn. "Victorian Collections and British Nationalism: Vernon, Sheepshanks and the National Gallery of British Art." Journal of the History of Collections 12, no. 1 (2000): 91-107. Accessed 10 May 2019. https://academic.oup.com/jhc/article/12/1/91/765730.

Munsterberg, Marjorie. “Ruskin's Turner: The Making of a Romantic Hero.” The British Art Journal 10, no. 1 (2009): 61-71. Accessed 20 December 2020. http://www.jstor.org/stable/41614862.

Myrone, Felicity. "British Topography: 'Our Real National Art Form'?” The British Library. Accessed 13 February 2018. https://www.bl.uk/picturing-places/articles/britishtopography-our-real-national-art-form.

Nichols, Chelsea. "How to Collect Great Art the 'Wrong' Way." Off the Wall 6 (August 2016). Accessed 25 August 2020. 
file://C:/Users/schoe/AppData/Local/Temp/MA_DOC001751_TePapa_How-to-collectgreat_full.pdf.

Noon, Patrick. "Princely Amateur: Paul Mellon and His Collection of British Drawings." Master Drawings 38, no. 3 (Autumn 2000): 338-345. Accessed 3 September 2018.

www.jstor.org/stable/1554441.

Oppé, Paul. "The Hickman Bacon Collection of Water-Colours." The Burlington Magazine for Connoisseurs 88, no. 518 (1946): 127-28. Accessed 22 July 2019.

http://www.jstor.org.helicon.vuw.ac.nz/stable/869271.

Paul, Janet. "Round the Galleries: Auckland." Landfall 8, no. 4 (1954): 297-301. Accessed 12 April 2020. http://www.landfallarchive.org/omeka/items/show/22193.

“The Helen Hitchings Gallery in Wellington.” Landfall 3, no. 4 (1949): 357-

359. Accessed 11 April 2020. http://www.landfallarchive.org/omeka/items/show/22174.

Perry, Peter. "Obituary: Dr. Eric Westbrook, CB 1915-2005.” Art Bulletin of Victoria 46 (2006). Accessed 15 April 2020. https://www.ngv.vic.gov.au/essay/obituary-dr-ericwestbrook-cb-1915-2005/.

Petch, Alison. "Two Nineteenth-Century Collectors-Curators Compared and Contrasted: General Augustus Henry Lane Fox Pitt-Rivers (1827-1900) and Augustus Wollaston Franks (1826-1897)." Museum History Journal 7, no. 2 (2014): 188-204. Accessed 24 October 2017. http://dx.doi.org/10.1179/1936981614Z.00000000031.

Phillips, Jock. "Our History, Our Selves: The Historian and National Identity." The New Zealand Journal of History 30, no. 2 (October 1996): 107-123. Accessed 28 April 2020. https://ndhadeliver.natlib.govt.nz/delivery/DeliveryManagerServlet?dps_pid=IE39848558.

."The New Zealanders." Te Ara - The Encyclopedia of New Zealand.

Accessed 11 June 2020. http://www.TeAra.govt.nz/en/the-new-zealanders.

. "Visitors' Opinions about New Zealand - The 'Britain of the South', 1860-

1900." Te Ara - The Encyclopedia of New Zealand. Accessed 23 June 2020.

http://www.TeAra.govt.nz/en/visitors-opinions-about-new-zealand/page-2.

Pocock, J. "British History: A Plea for a New Subject." The New Zealand Journal of History 8, no. 1 (April 1974): 3-21. Accessed 1 May 2020.

https://ndhadeliver.natlib.govt.nz/delivery/DeliveryManagerServlet?dps_pid=IE39862032.

“Profile: Sir Alec Martin.” Apollo 77, no. 16 (1 June 1963): 517. Accessed 8 April 2020. https://search-proquest-

com.helicon.vuw.ac.nz/docview/1366963770/fulltextPDF/F706149304E04975PQ/1 ?accoun tid=14782.

Riccardi-Cubitt, Monique. "Mario Praz (1896-1982): Anglophile and Aesthete." The British Art Journal 1, no. 1 (Autumn 1999): 63-69. Accessed 10 May 2019.

www.jstor.org/stable/41615353. 
Rice, Rebecca. "Transforming the 'Unimaginative and Literal' into an Art for the Nation: Writing and Exhibiting New Zealand's Art History in the Twentieth Century." Journal of Art Historiography 7 (December 2012): 1-28.

Robinson, J.C. "English Art Connoisseurship and Collecting." The Nineteenth Century: A Monthly Review 36, no. 212 (October 1894): 523-537.

Ross, Ken. "Norman Kirk's 'OE': Ken Ross Reflects on the Prime Minister's Visits to South-East Asia, London and Washington." New Zealand International Review 40, no. 5 (2015): 18-21. Accessed 2 July 2020.

https://nziia.org.nz/Portals/285/documents/lists/256/NZIRSepOct2015Vol40No5.pdf.

Scallen, Catherine. "Rembrandt Print Connoisseurship: Sir Francis Seymour Haden, and the Etching Revival of the Nineteenth Century." Nederlands Kunsthistorisch Jaarboek 69, no. 1 (November 2020): 248-279.

Scott, T.H. "The Frances Hodgkins Controversy.” Landfall 3, no. 4 (1949): 360-374. Accessed 11 April 2020. http://www.landfallarchive.org/omeka/items/show/22174.

Sketchley, R.E.D. “English Art Collectors.” The Art Journal (July 1911): 232-236.

Skinner, Damian. "Settler-Colonial Art History: A Proposition in Two Parts." Journal of Canadian Art History 35, no. 1 (2014): 130-145, 157-175. Accessed 22 April 2020. https://www.jstor.org/stable/24591977.

Skocpol, Theda. "Social History and Historical Sociology: Contrasts and Complementarities." Social Science History 11, no. 1 (1987): 17-30. Accessed 31 January 2020. www.jstor.org/stable/1171044.

"Some Water Colors by John Singer Sargent in the Museum of Fine Arts, Boston." Art and Progress 3, no. 12 (October 1912): 742-745. Accessed 15 January 2020. https://www.jstor.org/stable/20560764.

Sotheran, Cheryll. "The Later Paintings of William Fox." Art New Zealand 11 (1978). Accessed 27 July 2017. http://www.art-newzealand.com/Issues11 to20/fox.htm.

Stephenson, Andrew. "'Feminine' Anatomies of Taste and Cultures of Collecting in Early Twentieth Century Britain: Gwendoline and Margaret Davies as Women Art Patrons." Aurora, The Journal of the History of Art 4 (2003): 174-185. Accessed 19 July 2019. http://link.galegroup.com.helicon.vuw.ac.nz/apps/doc/A166945214/AONE?u=vuw\&sid=A ONE\&xid=a0d38a7b.

Stocker, Mark. "After Cubism, Before Pop." Off the Wall 1 (March 2013). Accessed 16 April 2020. https://collections.tepapa.govt.nz/document/4164. . "Sculpture and Installation Art - Early Modern Sculpture." Te Ara - The Encyclopedia of New Zealand. Accessed 15 April 2020. http://www.TeAra.govt.nz/en/sculpture-and-installation-art/page-3. 
"Wellington Booty: Modern British Art at the Museum of New Zealand Te Papa Tongarewa." Apollo 171, no. 572 (2010): 40-47. Accessed 23 February 2018.

https://go-gale-

com.helicon.vuw.ac.nz/ps/i.do?id=GALE\%7CA219374247\&v=2.1\&u=vuw\&it=r\&p=AON $\mathrm{E} \& \mathrm{sw}=\mathrm{w}$.

Tapsell, Peter. "Statement from the Minister for the Arts." AGMANZ Journal 15, no. 4 (1984): 2. Accessed 3 July 2020.

https://christchurchartgallery.org.nz/media/uploads/2017_08/AGMANZ_Journal_Volume_1 5_Number_4_December_1984_optimized_for_web.pdf.

“The Mackelvie Trust.” Quarterly, no. 60 (1975): 2-15, Auckland: Auckland City Art Gallery.

Thompson, Carl. "The Picturesque at Home and Abroad." The British Library. Accessed 13 February 2018. https://www.bl.uk/picturing-places/articles/the-picturesque-at-home-andabroad.

Thorburn, Ray. "Full Circle: Paintings by Melvin Day." Art New Zealand 32 (Spring 1984). Accessed 16 April 2020. http://www.art-newzealand.com/Issues31 to40/day.htm.

Toft, John. "Stewart Bell Maclennan A.R.C.A: National Art Gallery Director and Prominent $20^{\text {th }}$ Century New Zealand Watercolourist." Watercolour New Zealand. Accessed 8 April 2020. https://www.watercolournewzealand.nz/tutorials/article_Maclennan.htm.

Tomory, Peter. "Looking at Art in New Zealand." Landfall 12, no. 2 (1958): 153-169. Accessed 11 April 2020. https://www.landfallarchive.org/omeka/items/show/22208.

. "The Bridgehead Revisited." Landfall 185: The Fifties Issue (1993): 15-16.

Auckland: Oxford University Press. . "Unifying Art-in New Zealand.” Connoisseur (May 1959): 9-11.

Turner, John B. "Some Notes and Queries on the Collecting of Photographs by Libraries, Museums and Art Galleries in N.Z." Art Galleries and Museums Association of New Zealand 14, no. 2 (June 1983): 2-7. Accessed 16 September 2020.

https://christchurchartgallery.org.nz/media/uploads/2017_08/AGMANZ_News_Volume_14 _Number_2_June_1983_optimized_for_web.pdf.

Tythacott, Louise. "The Power of Taste: The Dispersal of the Berkeley Smith Collection of Chinese Ceramics at Cheltenham Art Gallery \& Museum (1921-1960)." Journal of the History of Collections 28, no. 2 (2016): 327-343. Accessed 10 May 2019. https://academic.oup.com/jhc/article/28/2/327/2404438.

Vaughan, William. "The Englishness of British Art." Oxford Art Journal 13, no. 2 (1990): 11-23. Accessed 11 February 2020. www.jstor.org/stable/1360334.

Venemans, Dick. "An Early Book on Dutch Art in the English Language: The Beauties of the Dutch School; Selected from Interesting Pictures of Admired Landscape Painters: An 
Anglo-Dutch Collaboration." Dutch Crossing 34, no. 3 (2010): 271-277. Accessed 20 August 2020. https://doi.org/10.1179/030965610X12820418688697.

Warrell, Ian. "Exploring the 'Dark Side': Ruskin and the Problem of Turner's Erotica." The British Art Journal 4, no. 1 (2003): 5-14. Accessed 20 December 2020.

http://www.jstor.org/stable/41614430.

Wechsler, Judith. “The Issue of Caricature.” Art Journal 43, no. 4 (1983): 317. Accessed 24 January 2019. www.jstor.org/stable/776727.

Wheoki, Jonathan Mane. “Art's Histories in Aotearoa New Zealand.” Journal of Art Historiography, no. 4 (June 2011).

White, Robin. “Art and Conservation are Synonymous.” Art New Zealand 7 (1977). Accessed 17 June 2020. http://www.art-newzealand.com/Issues1 to40/environrw.htm.

Wilcox, Scott. "Collier, Thomas.” Grove Art Online. Accessed 1 July 2019. https://www.oxfordartonline.com/groveart/view/10.1093/gao/9781884446054.001.0001/oao -9781884446054-e-7000018607.

Wilton, Andrew. "Dr. Thomas Monro and the Monro Academy." The Burlington Magazine 118, no. 878 (1976): 332-333.

Winter, David. “Girtin's Sketching Club.” Huntington Library Quarterly 37, no. 2 (1974): 123-149.

Wyld, Helen. "Re-Framing Britain's Past: Paul Sandby and the Picturesque Tour of Scotland." The British Art Journal 12, no. 1 (Summer 2011): 29-36. Accessed 17 November 2017. http://www.jstor.org/stable/41615213.

Young, Eric. “A Watercolour by Anthony Devis.” Quarterly, no.64 (1977): 8-10. Auckland: Auckland City Art Gallery.

\section{Newspaper}

"A Hand of Friendship for the Deaf and Dumb: Mid-Sussex Friends Give a Party in Brighton.” The Mid-Sussex Times (23 January 1934): 11.

“A London Diary: Sir Alec Martin Leaves Christie's: Cricket, and the Bridegroom-to-be: The Grand Gesture in Bond Street." The Field [London] 212, no. 5527 (11 December 1958): 1140. Accessed 8 April 2020. https://search-proquestcom.helicon.vuw.ac.nz/docview/1715175971/B144E3C663D0495CPQ/4?accountid=14782.

Alexander, David. "Peter Tomory: Distinguished Art Historian." Independent [London] (29 May 2008). Accessed 15 April 2020. https://www.independent.co.uk/news/obituaries/petertomory-distinguished-art-historian-835821.html.

"Art in New Zealand: Four Hundred Paintings." Evening Post (2 March 1912): 9. Accessed 31 August 2020. https://paperspast.natlib.govt.nz/newspapers/EP19120302.2.124. 
"Brownie Service at Haywards Heath: An Address by Archdeacon Smythe." The MidSussex Times (20 March 1934): 9.

“Desire for Peace.” Times [London] (12 January 1939): 12. Accessed 21 November 2017. https://link-gale-

com.helicon.vuw.ac.nz/apps/doc/CS203109420/TTDA?u=vuw\&sid=TTDA\&xid=573d84de

Entwisle, Peter. "Kauffmann Work Included in Gifts to Gallery." Otago Daily Times (13 March 2017): 7.

"Exhibition of English Watercolours." Times [London] (9 September 1954): 11. The Times Digital Archive. Accessed 20 November 2017. https://link-galecom.helicon.vuw.ac.nz/apps/doc/CS185422633/TTDA?u=vuw\&sid=TTDA\&xid=b6ef249d.

“Exhibition of Paintings.” New Zealand Herald LXXII, no. 22283 (4 December 1935): 15.

"Exhibition Opened Yesterday." Evening Post (27 April 1912): 9. Accessed 31 August 2020. https://paperspast.natlib.govt.nz/newspapers/EP19120427.2.87.

"Flats and Chambers." Times [London] (6 November 1934): 27. The Times Digital Archive. Accessed 20 November 2017. https://link-galecom.helicon.vuw.ac.nz/apps/doc/CS453192550/TTDA?u=vuw\&sid=TTDA\&xid=08e4469c.

"General Exhibition of Watercolour Drawings." The Reader [London] 5, no. 113 (25 February 1865): 232-233.

“Gully's New Zealand.” Otago Witness 1341 (11 August 1877). Accessed 21 February 2018. http://paperspast.natlib.govt.nz/newspapers/OW18770811.2.16.

Joule, Barry. "Obituary: Erica Brausen.” The Independent [London] (30 December 1992). Accessed 31 August 2020. https://www.independent.co.uk/news/people/obituary-ericabrausen-1565959.html.

“On Mr. Williams's Exhibition of Water-Colour Drawings.” Edinburgh Magazine and Literary Miscellany 10 (February 1822): 239-243.

"Painting Skies, the Dutch Method." New York Times (22 July 1877): 4. Accessed 20 August 2020. https://search-proquestcom.helicon.vuw.ac.nz/docview/93657543?accountid=14782.

"Points from Letters." Times [London] (18 February 1939): 8. Accessed 3 August 2017. https://link-galecom.helicon.vuw.ac.nz/apps/doc/CS135607378/TTDA?u=vuw\&sid=TTDA\&xid=a897e518.

"Shortage of Priests." The Herald [London] (28 May 1943): 3.

"Sotheby \& Co." Times [London] (23 March 1937): 29. The Times Digital Archive. Accessed 20 November 2017. https://link-galecom.helicon.vuw.ac.nz/apps/doc/CS487141495/TTDA?u=vuw\&sid=TTDA\&xid=6eb5f2e7. 
"Sussex Church Builders Support Cinema Show: An Impressive Appeal by Archdeacon Smythe." The Mid-Sussex Times (26 January 1937): 9.

“Sussex Church Notes.” The Mid-Sussex Times (19 June 1934): 7.

“The Art Exhibition.” Star [Christchurch] 538 (9 February 1870): 2.

“The National Gallery." Evening Post (17 February 1912): 5. Accessed 31 August 2020. https://paperspast.natlib.govt.nz/newspapers/EP19120217.2.39.

"The National Gallery." New Zealand Times (26 August 1912): 1. Accessed 31 August 2020. https://paperspast.natlib.govt.nz/newspapers/NZTIM19120826.2.6.

"The Water-Colour Exhibitions." Saturday Review of Politics, Literature, Science and Art [London] 49. No. 1262 (3 January 1880): 18-19.

"The Water-Colour Winter Exhibition of Sketches and Studies." Saturday Review of Politics, Literature, Science and Art [London] 21, no. 540 (3 March 1866): 264-265.

Vance, Michael. "One Painting Started a Cultural War: The Way We Were June 17, 1949." The Press (19 June 2010): C10. Accessed 11 April 2020. https://global-factivacom.helicon.vuw.ac.nz/ga/default.aspx.

“Water-Colour Exhibitions.” Examiner [London] 174 (28 April 1811): 268-269.

"Water-Colour Exhibitions." Saturday Review of Politics, Literature, Science and Art [London] 9, no. 236 (5 May 1860): 568-569.

"Water-Colour Exhibitions." Saturday Review of Politics, Literature, Science and Art [London] 37, no. 954 (7 February 1874): 178-179.

“Water-Colour Exhibitions.” The Athenaeum [London] 4147 (20 April 1907): 481-482.

White, James. "Sir Alec Martin: An Appreciation.” The Irish Times (18 May 1971): 8. Accessed 8 April 2020. https://search-proquestcom.helicon.vuw.ac.nz/docview/525748427/B144E3C663D0495CPQ/3?accountid=14782.

"Willingness to Die for Beliefs: Archdeacon and Communist Example - Worthing 'Recall' Thanksgiving." The Herald [London] (4 December 1937). Accessed 3 October 2017. 


\section{Newspapers}

England

Examiner

The Field

The Herald

The Independent

The Mid-Sussex Times

The Reader

The Saturday Review

The Times

New Zealand

Auckland Star

Evening Star

Evening Post

Otago Daily Times

Otago Witness

New Zealand Herald

New Zealand Listener

New Zealand Times

Press

Star-Sunday

\section{Websites}

Art Fund (National Art Collections Fund): https://www.artfund.org/.

Auckland Art Gallery Toi o Tāmaki: https://www.aucklandartgallery.com/.

Caernarfon Castle: http://www.castlewales.com/caernarf.html.

Castle Hill, Devon: http://www.castlehilldevon.co.uk/history.

Christchurch Art Gallery - Library and Archives: AGMANZ and Te Ara: https://christchurchartgallery.org.nz/about/library/agmanz.

Dunedin Public Art Gallery - Collection:

http://collection.dunedin.art.museum/simpleSearch.page.do.

Find New Zealand Artists: https://findnzartists.org.nz/.

Genes Reunited: http://www.genesreunited.co.uk/home/index.

Landfall Archive: https://www.landfallarchive.org.

Museum of New Zealand Te Papa Tongarewa - Collections Online:

https://collections.tepapa.govt.nz/. 
Oxford English Dictionary: http://www.oed.com/.

Papers Past: https://paperspast.natlib.govt.nz/.

Tate: https://www.tate.org.uk/.

Te Ara Encyclopaedia of New Zealand: https://teara.govt.nz/en.

The British Museum: https://www.britishmuseum.org/.

The British Newspaper Archive: https://www.britishnewspaperarchive.co.uk/.

The Times Digital Archive: https://www.gale.com/intl/c/the-times-digital-archive.

Victoria and Albert Museum: https://www.vam.ac.uk/.

Watercolour New Zealand: http://www.watercolournewzealand.nz/about/index.htm.

\section{Audio Recordings}

"Letter from a Modern Art Collector - Ernest Heber Thompson." Sound recording created for the Ngā Toi |Arts Te Papa audio guide (Spring 2014). Accessed 25 August 2020. https://collections.tepapa.govt.nz/topic/7991.

Tyler, Linda (interviewee) and Jesse Mulligan (interviewer). "Masterpieces with Linda Tyler." Afternoons with Jesse Mulligan (30 June 2016). Sound recording. Accessed 15 November 2020.

https://www.rnz.co.nz/national/programmes/afternoons/audio/201806521/masterpieceswith-linda-tyler.

Westbrook, Eric (interviewee) and Hazel de Berg (interviewer). "Eric Westbrook Interviewed by Hazel de Berg in the Hazel de Berg Collection" (1962). Sound recording. Accessed 15 April 2020. https://nla.gov.au/nla.obj-214256961/listen. 


\section{Figures}

NB. All dimensions are given in millimetres unless otherwise stated. All works are watercolour on paper unless otherwise stated.

\section{Abbreviations}

DPAG Dunedin Public Art Gallery

Te Papa Museum of New Zealand Te Papa Tongarewa

AAG Auckland Art Gallery Toi o Tāmaki

\section{CHAPTER ONE}

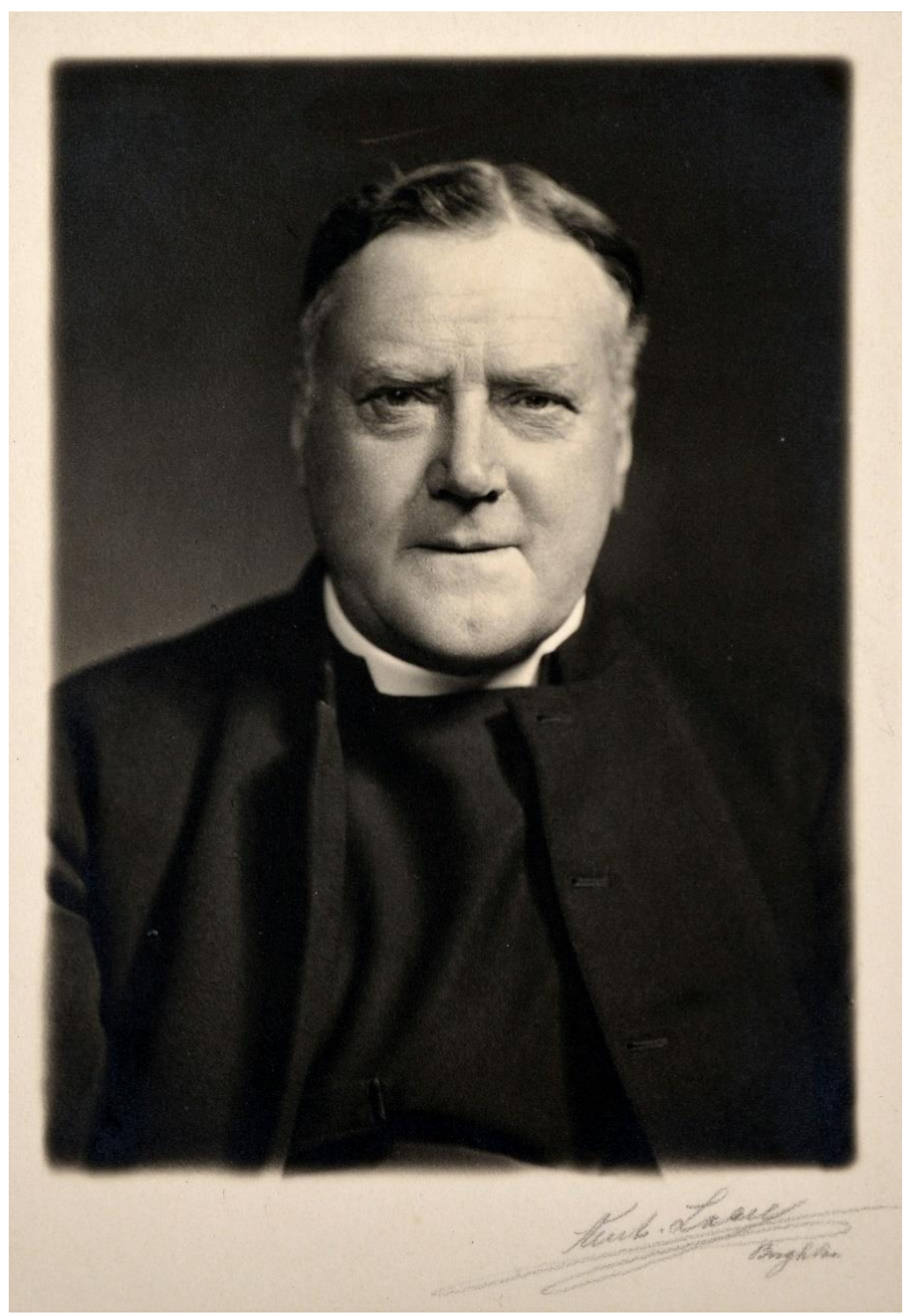

Fig. 1 Kent \& Lacey Studios (established 1894), Portrait of Archdeacon F.H.D. Smythe, M.A., 1938, gelatin silver print on paper, 138 x 99 mm, DPAG, 25-1954. 


\section{CHAPTER THREE}

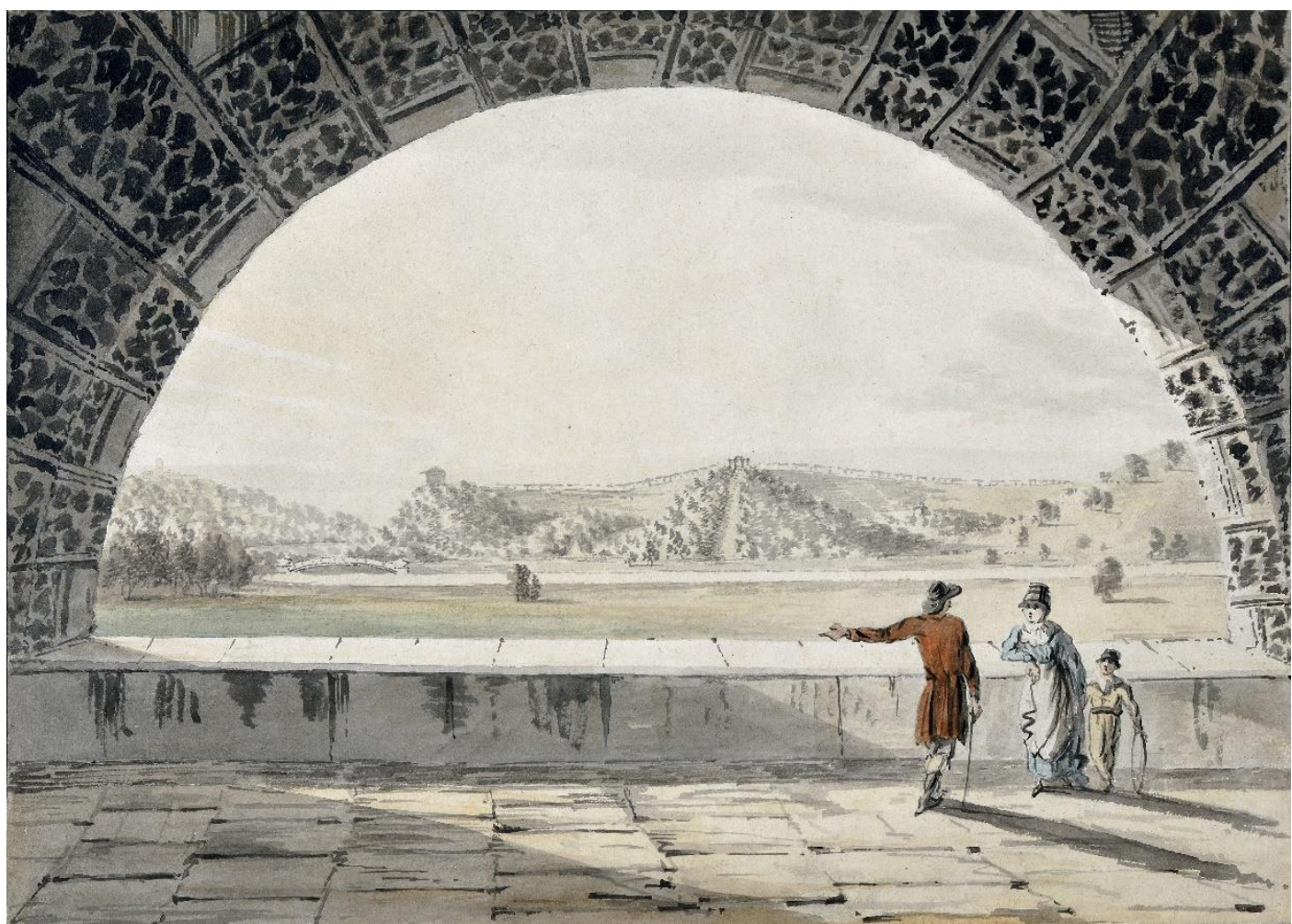

Fig. 2 Thomas Sandby (1721-1798), Earl of Fortescue's Grounds, Castle Hill, late 1780s90s, 180 x 250, DPAG, 214-195X.

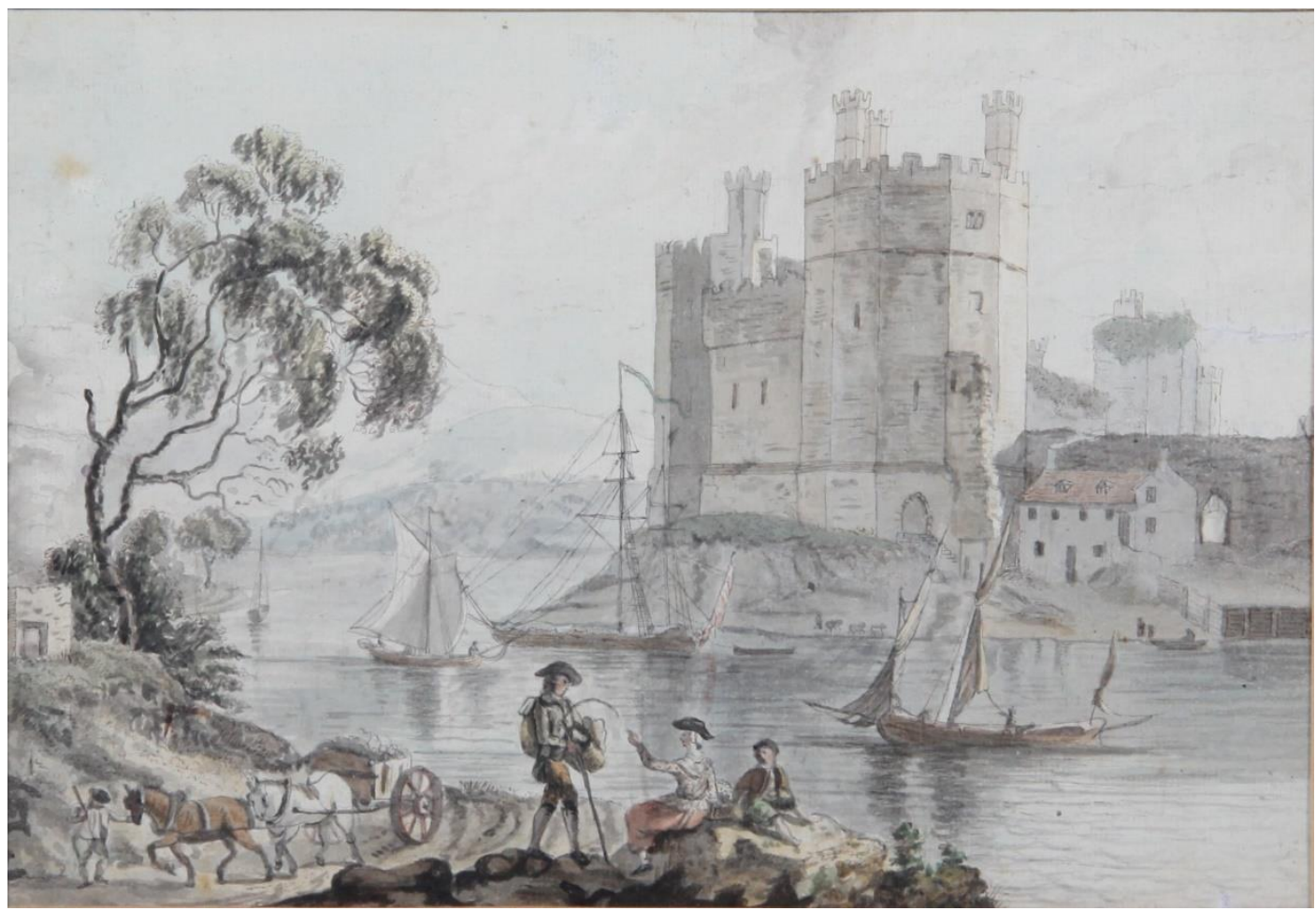

Fig. 3 Paul Sandby (1731-1809), Carnarvon Castle, c. 1771, 180 x 265, DPAG, 735-195X. 


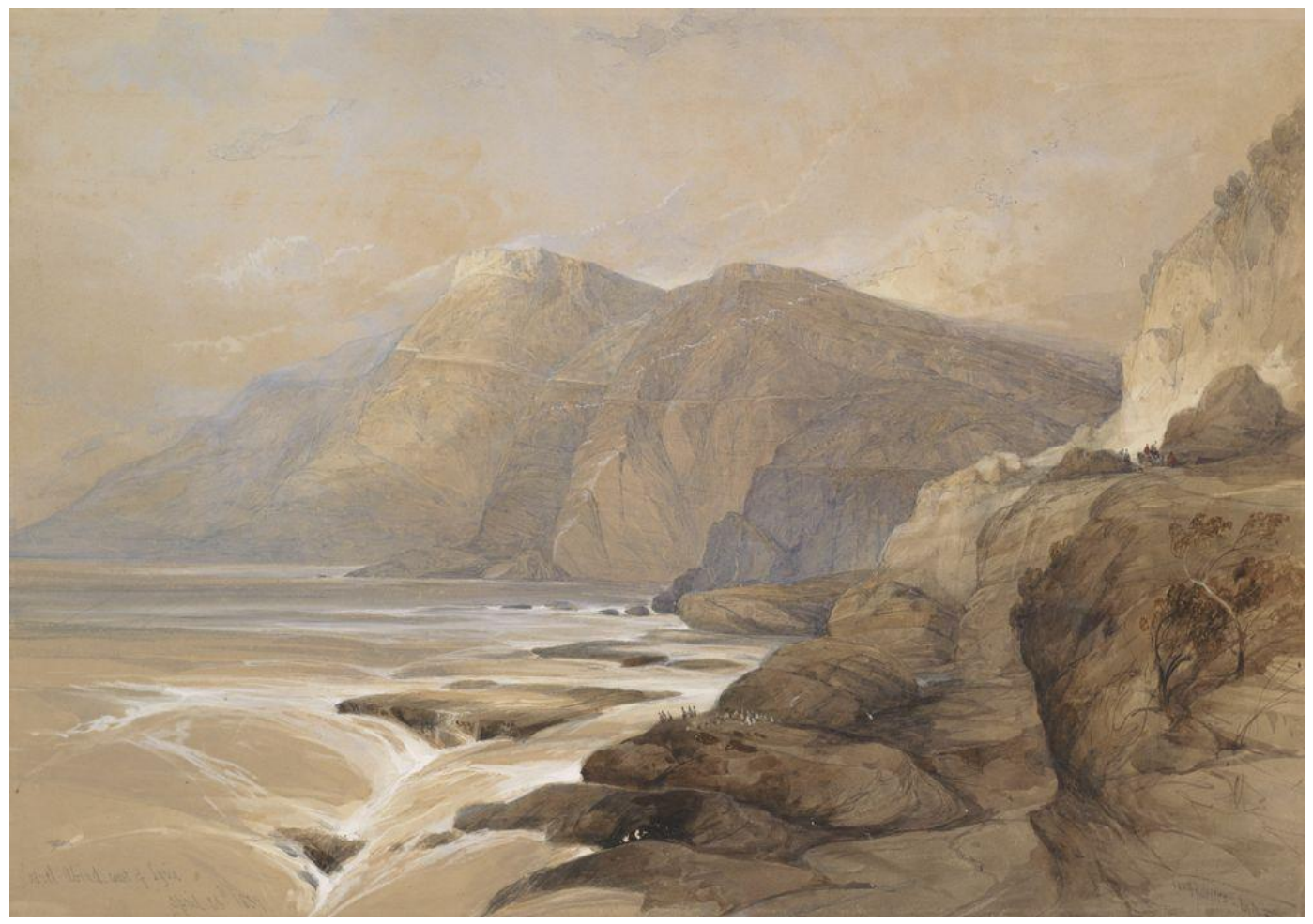

Fig. 4 David Roberts (1796-1864), Ras-El-Abiad, Coast of Syria, 1839, 354 x 506, Te Papa, 1957-0009-218.

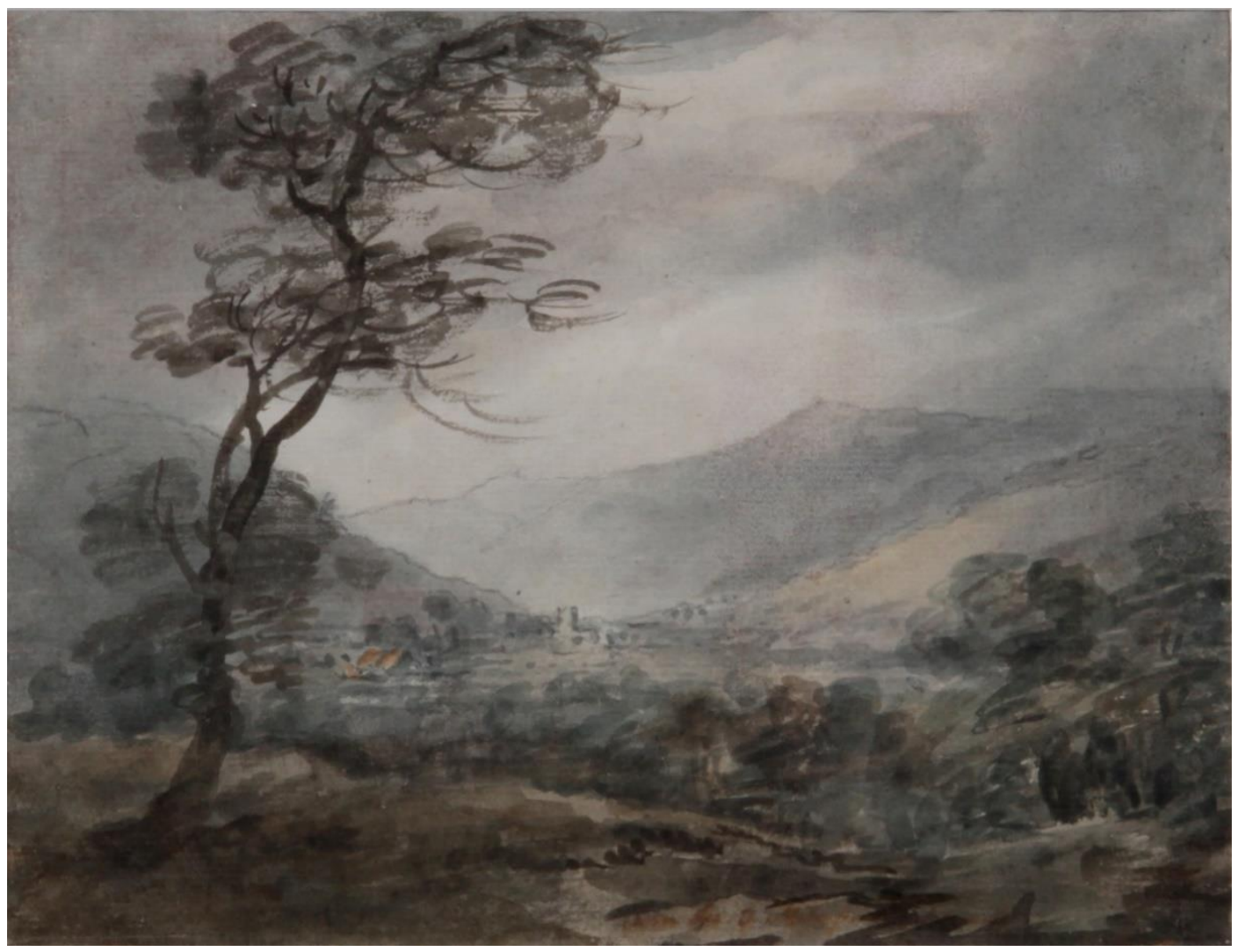

Fig. 5 Richard Wilson (1714-1782), Cwm Du, Near Tritower, 160 x 205, DPAG, 848-195X. 


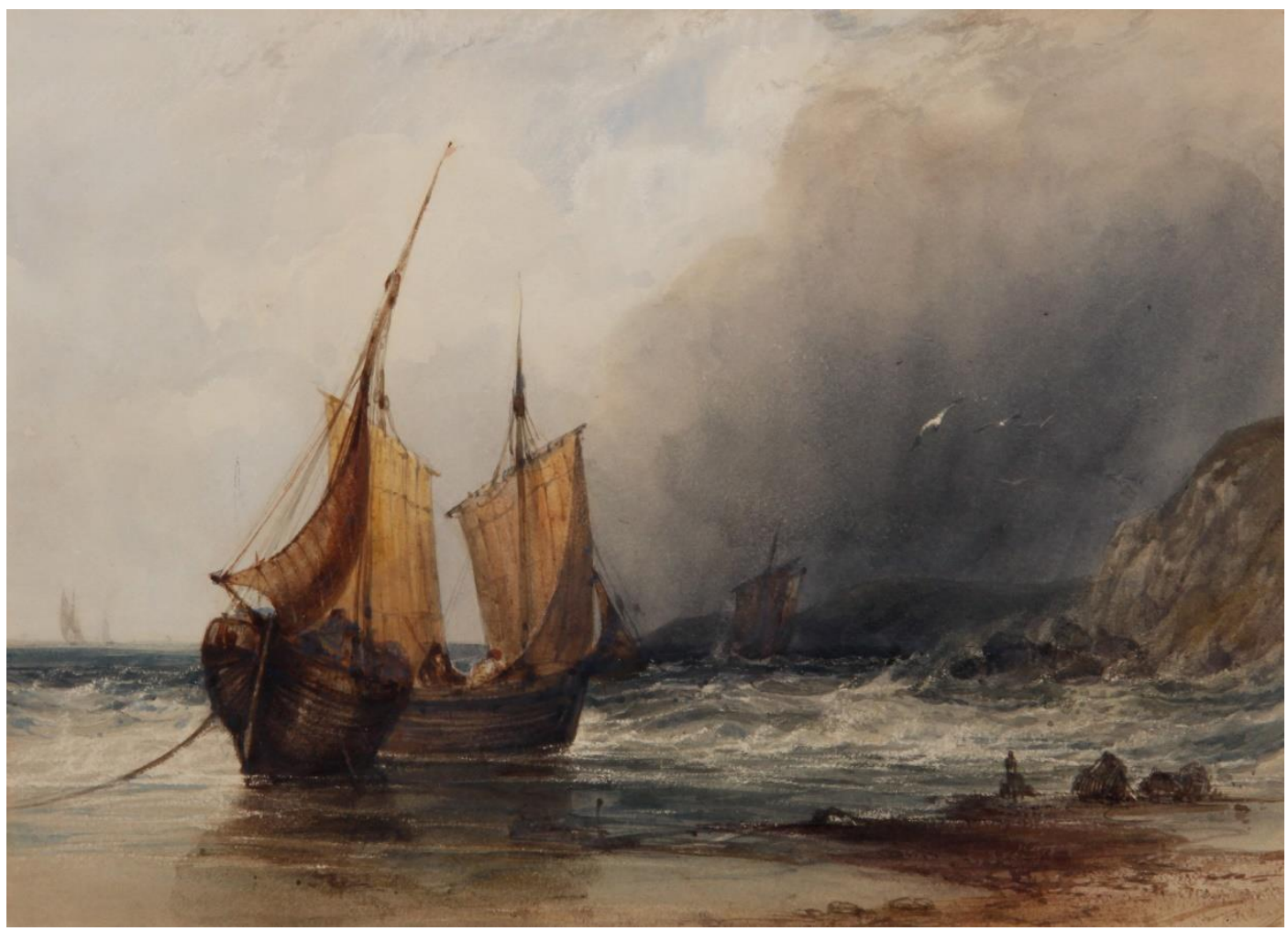

Fig. 6 Anthony Vandyke Copley Fielding (1787-1855), Fishing Boats in Rough Seas, 222 x 310, DPAG, 1057-195X.

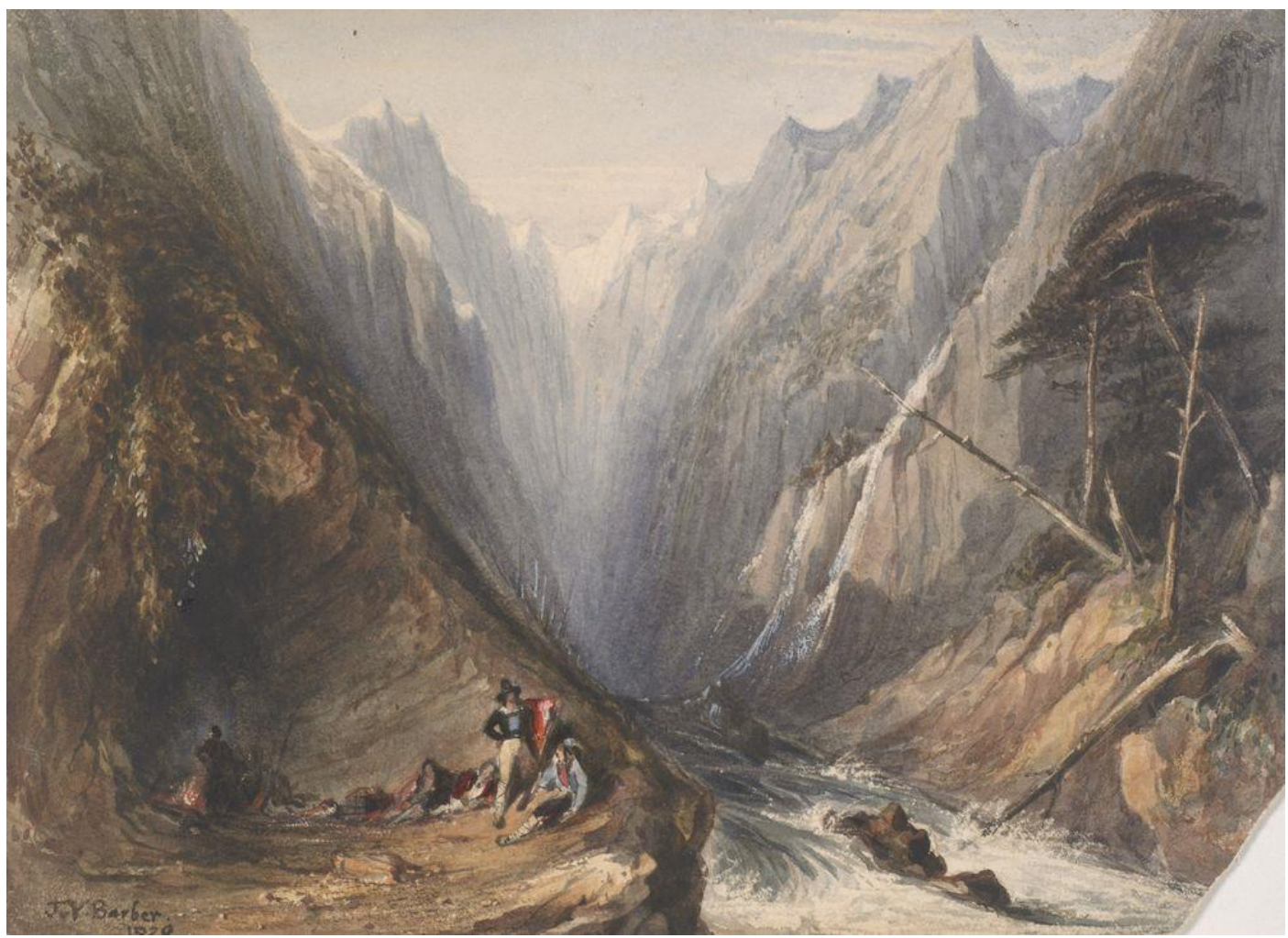

Fig. 7 Joseph Barber (1757-1811), Mountain Torrent, 1829, 153 x 215, Te Papa, 1957-000910. 


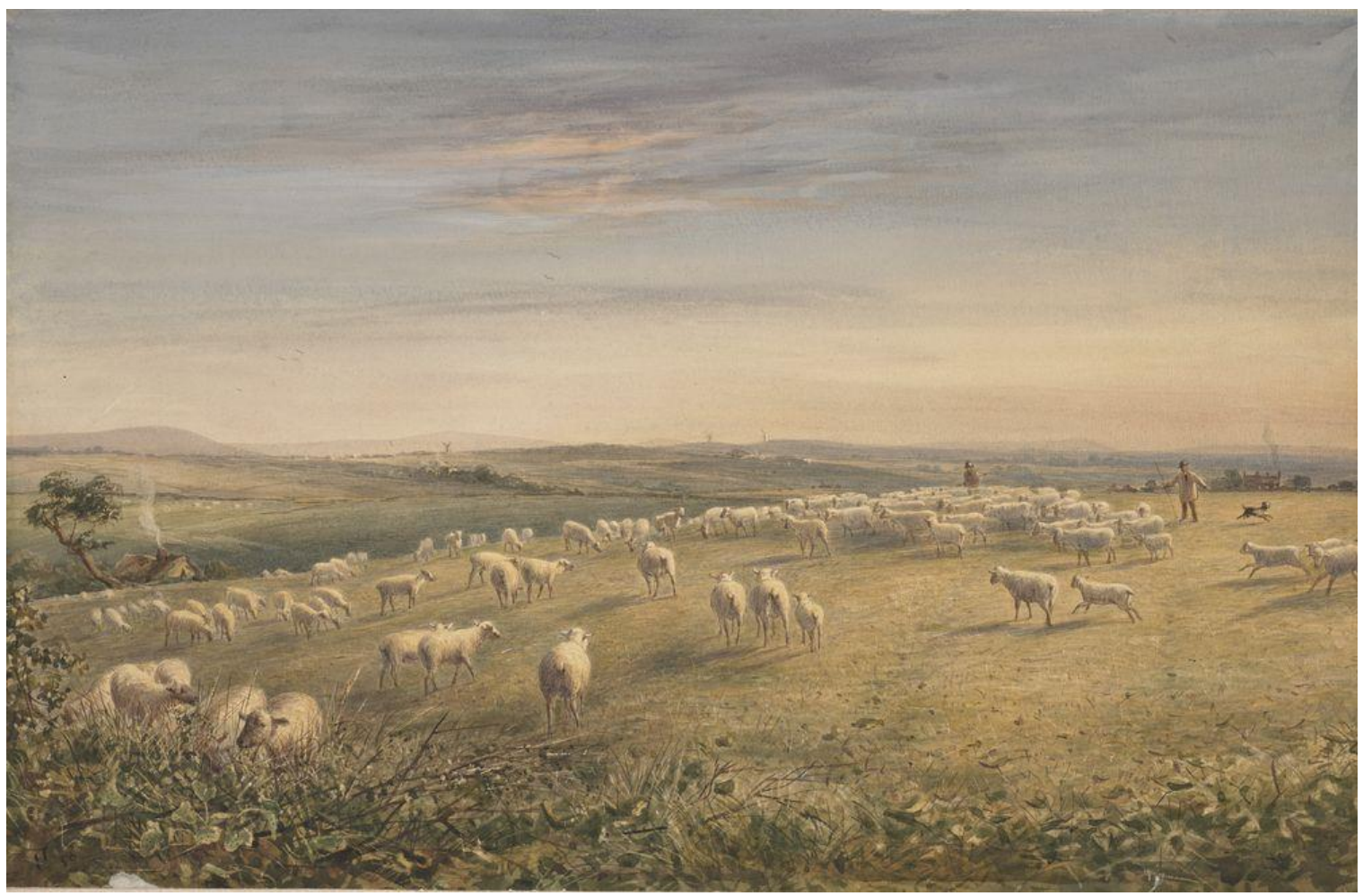

Fig. 8 Henry Hine (1811-1895), Landscape, Sussex, 1858, 355 x 544, Te Papa, 1957-0009140 .

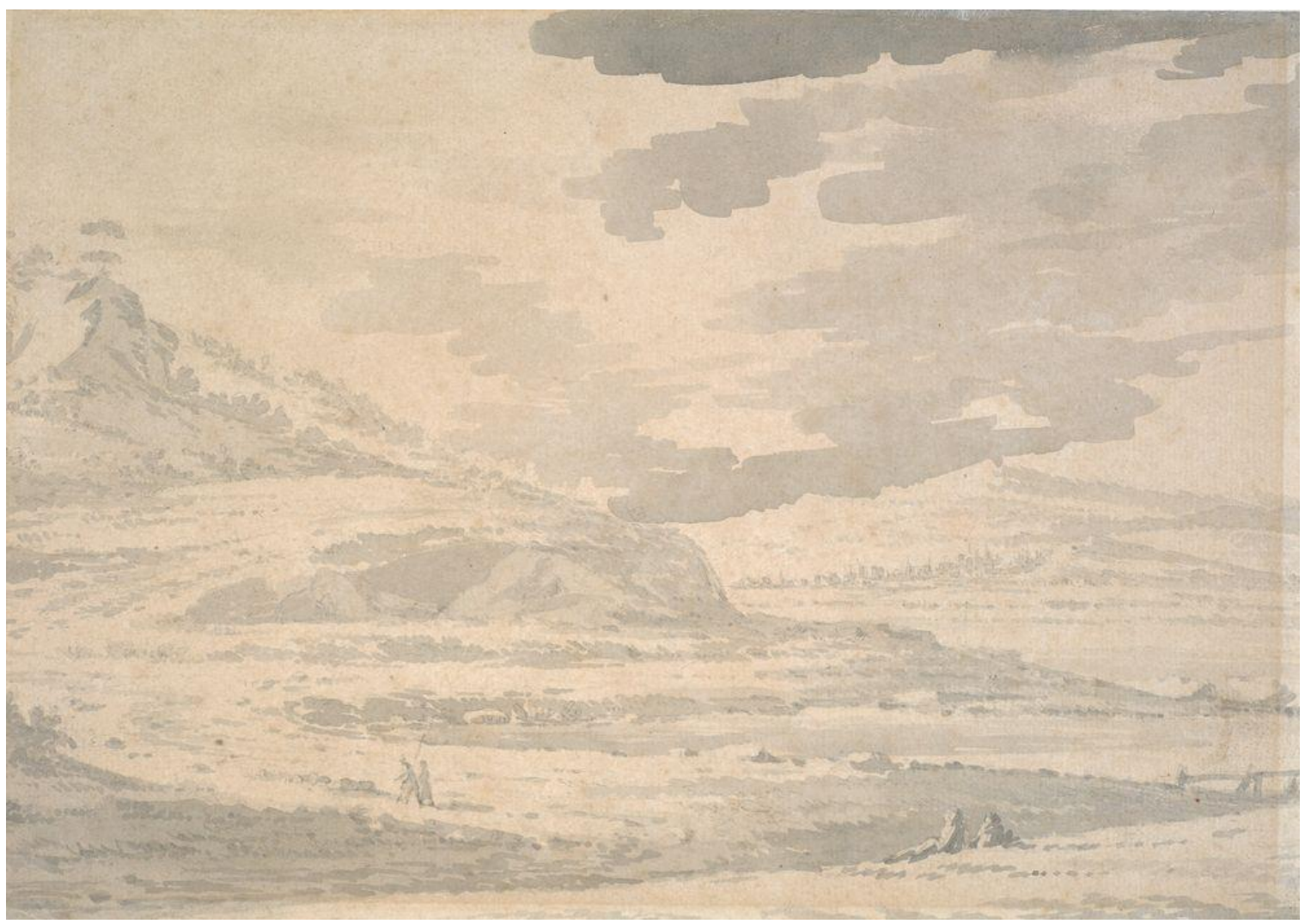

Fig. 9 John R. Cozens (1752-1797) [attributed], Hilly Landscape, grey wash drawing, $196 \mathrm{x}$ 280, Te Papa, 1957-0009-322. 


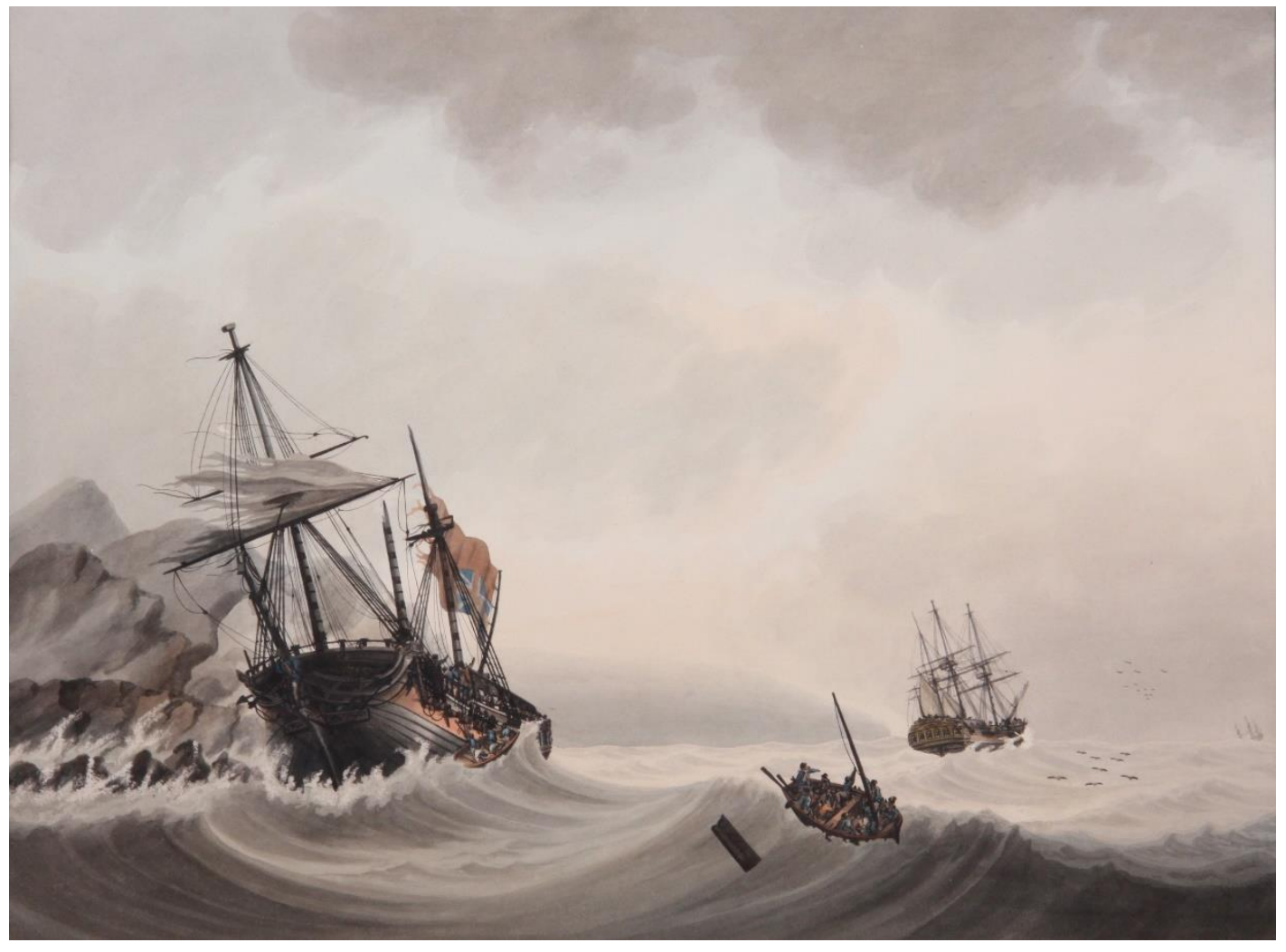

Fig. 10 Samuel Atkins (1760-1808), Shipwreck, 350 x 470, DPAG, 945-195X.

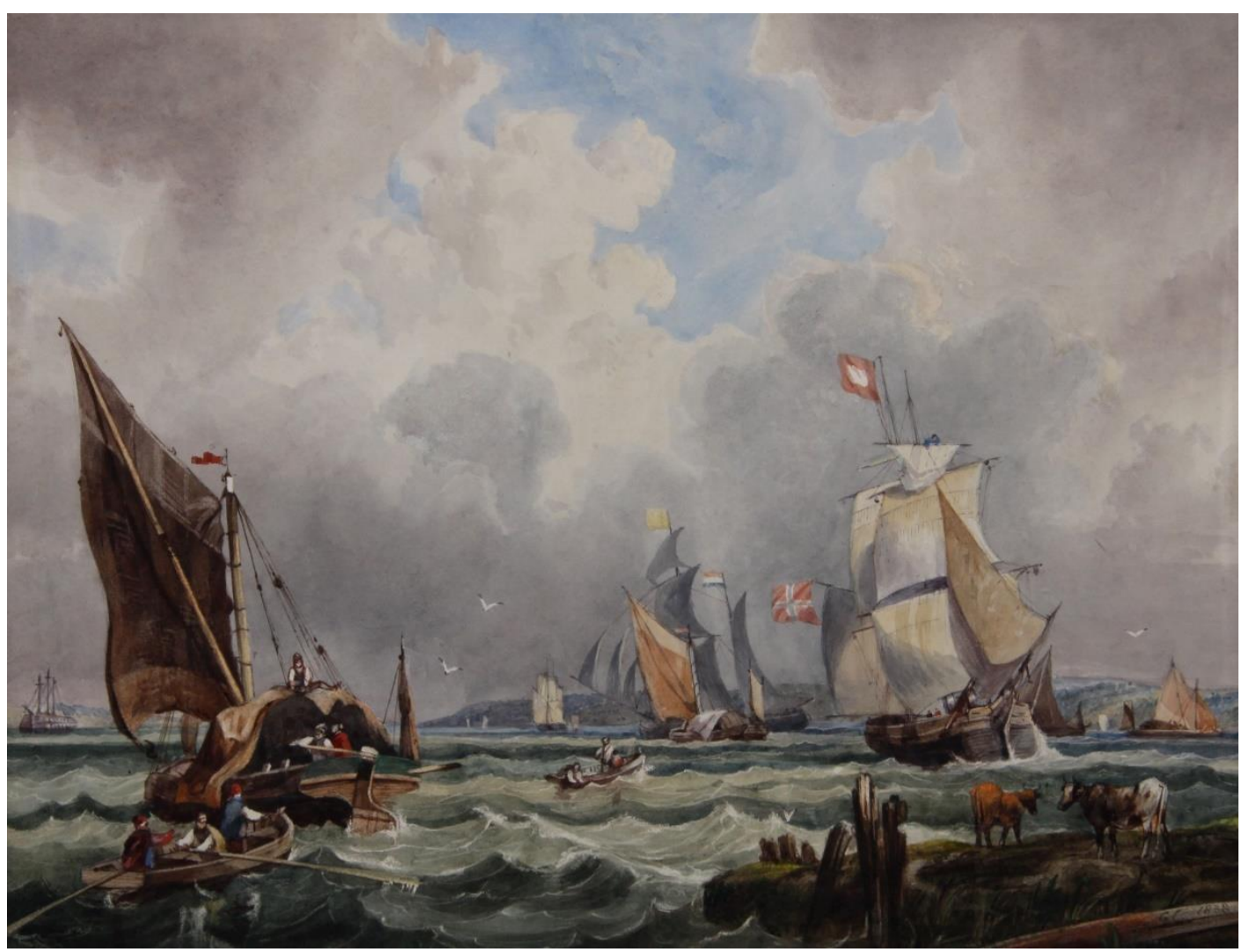

Fig. 11 George Chambers (1803-1840), Fishing Boats, 310 x 405, DPAG, 58-195X. 


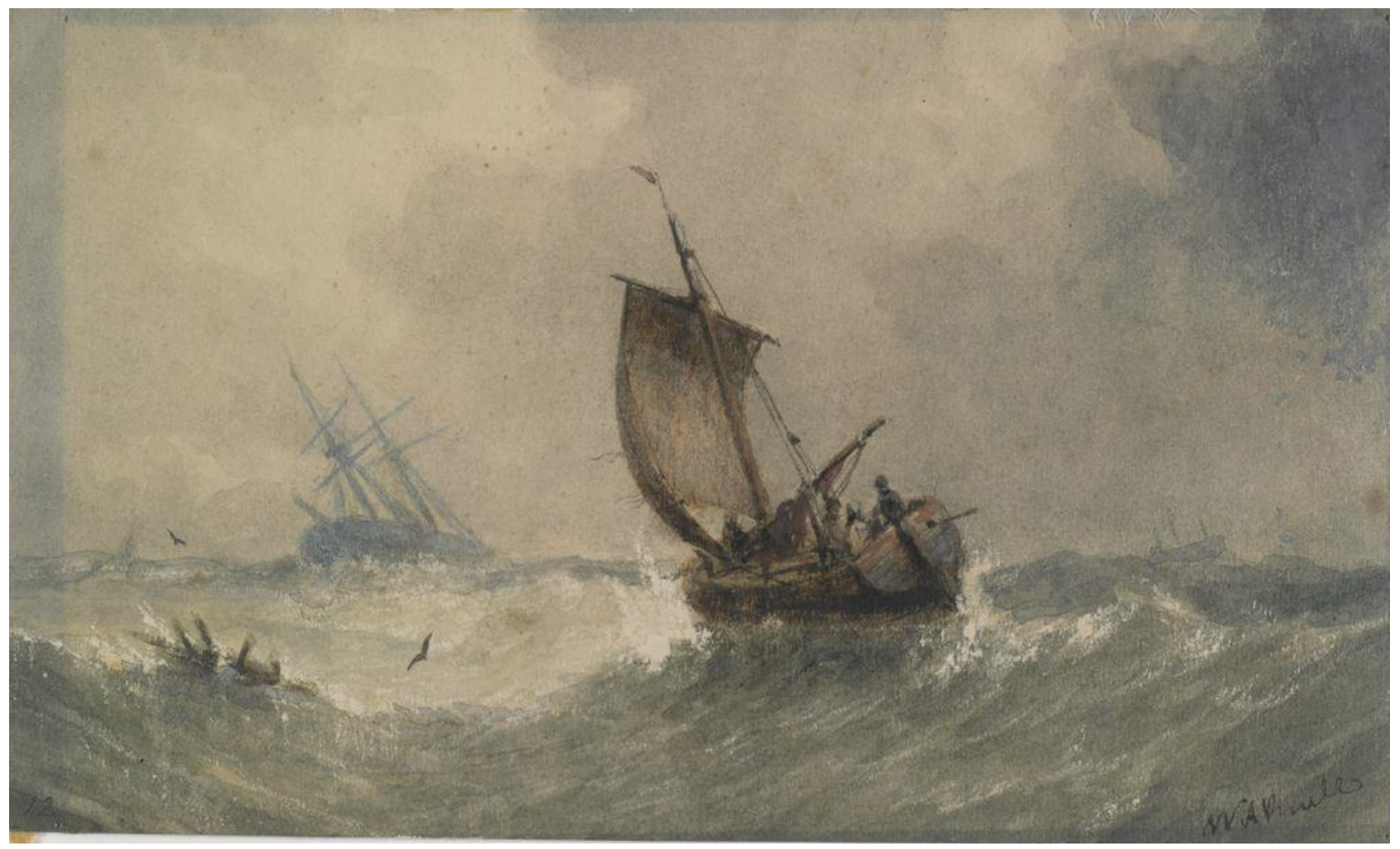

Fig. 12 William Knell (1801-1875), Marine, 125 x 205, Te Papa, 1957-0009-157.

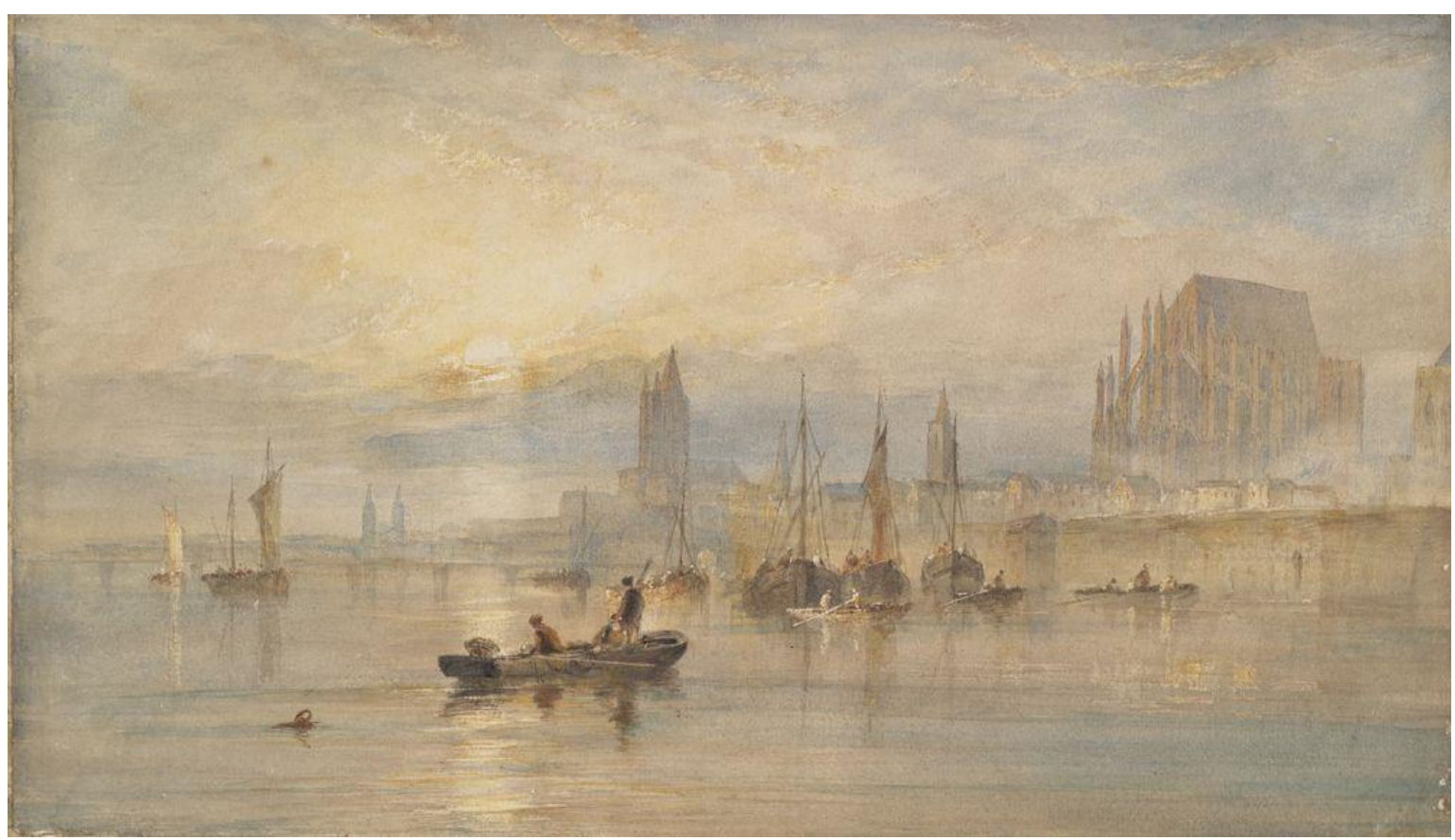

Fig. 13 Richard Parkes Bonington (1802-1828), Harbour at Sunset, 283 x 490, Te Papa, 1957-0009-22. 


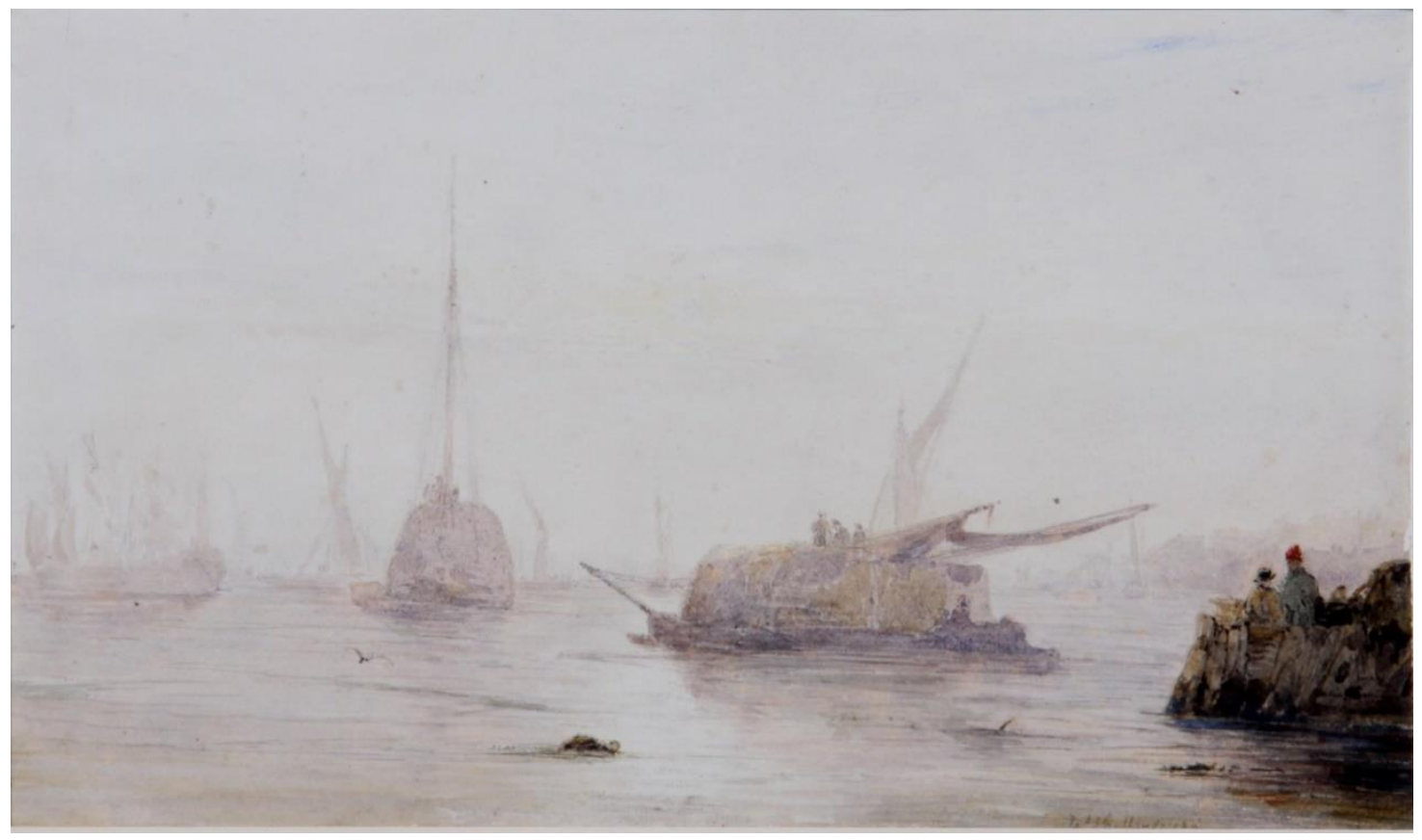

Fig. 14 James Holland (1799-1870), Sea-Fog Rising, 1836, 165 x 280, DPAG, 183-195X.

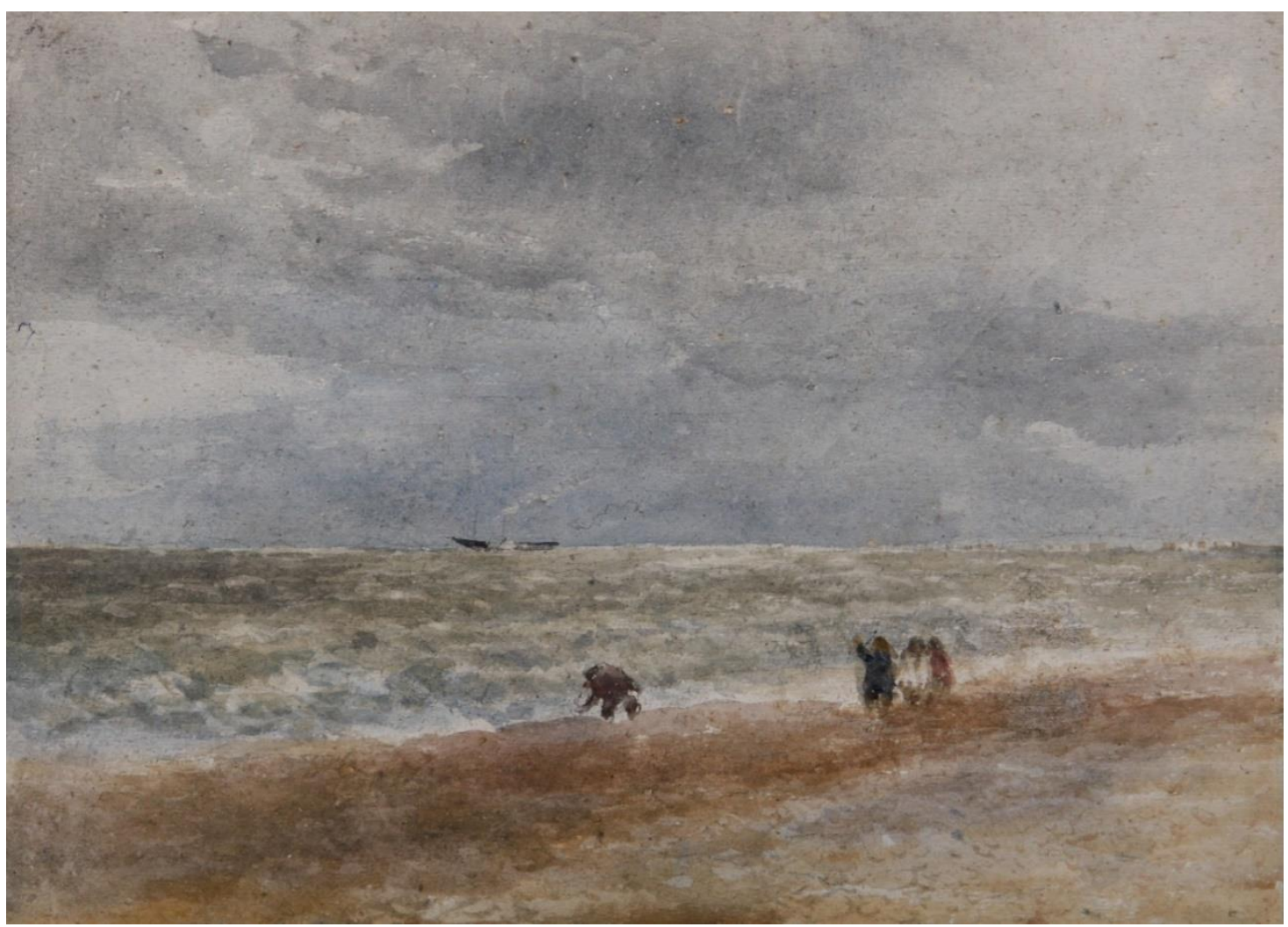

Fig. 15 David Cox (snr) (1783-1859), Figures on Beach, North Wales, 270 x 370, DPAG, 386-195X. 


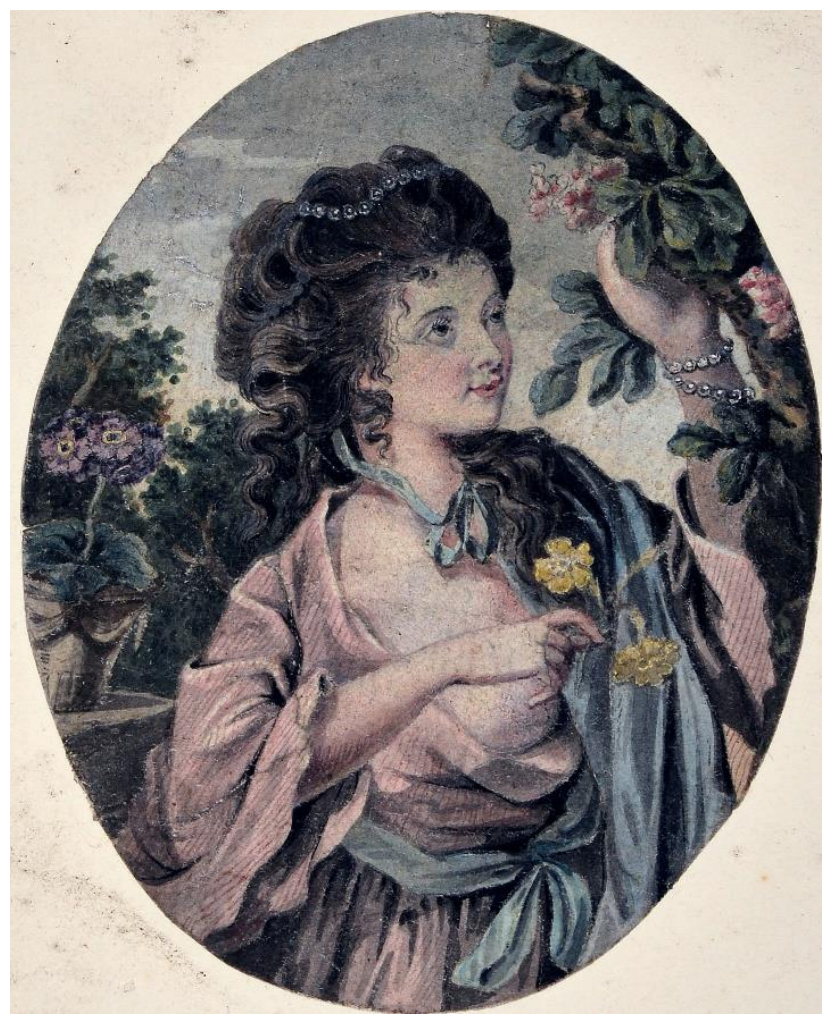

Fig. 16 Diana Beauclerk (1734-1808), Study for a Miniature, 95 x 75, DPAG, 295-195X.

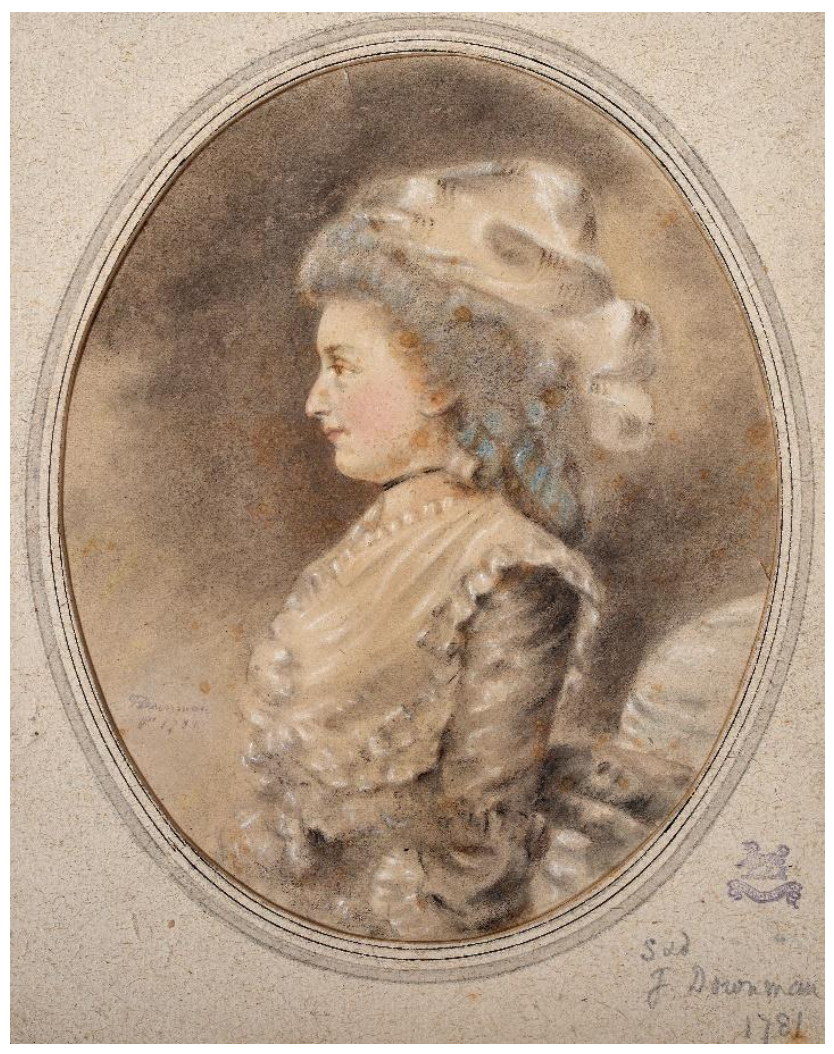

Fig. 17 John Downman (1750-1824), Profile of a Lady with a Black Choker, 1781, $180 \mathrm{x}$ 150, DPAG, 255-195X. 


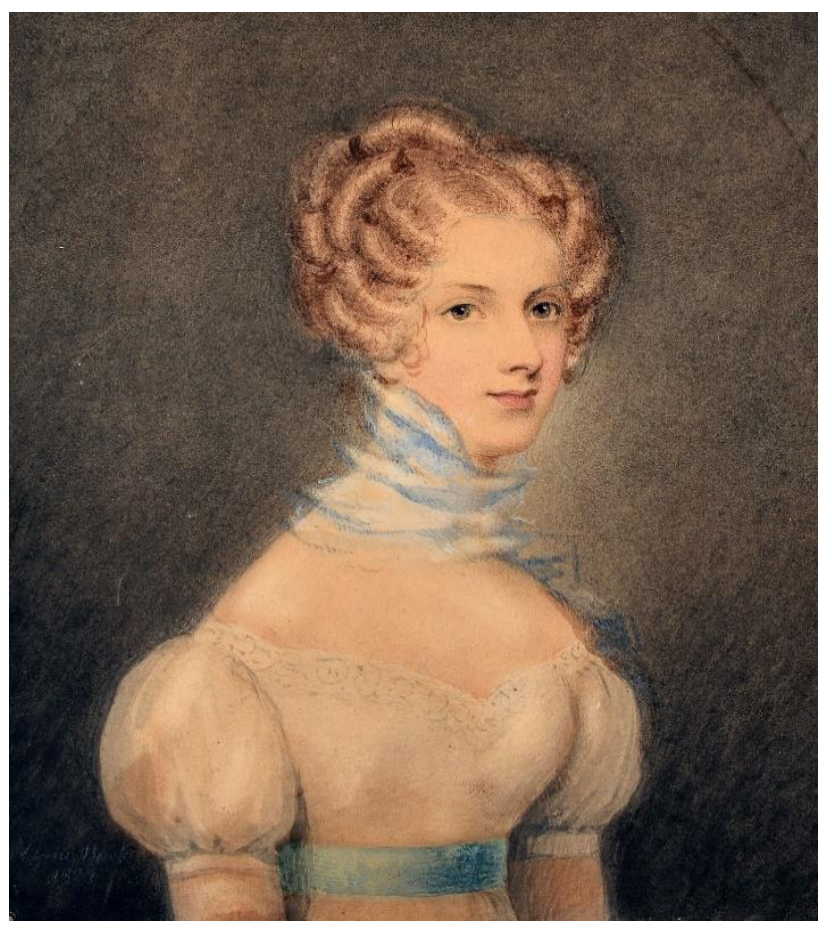

Fig. 18 Adam Buck (1759-1833), Lady Elizabeth Skyes, 120 x 115, DPAG, 256 -195X.

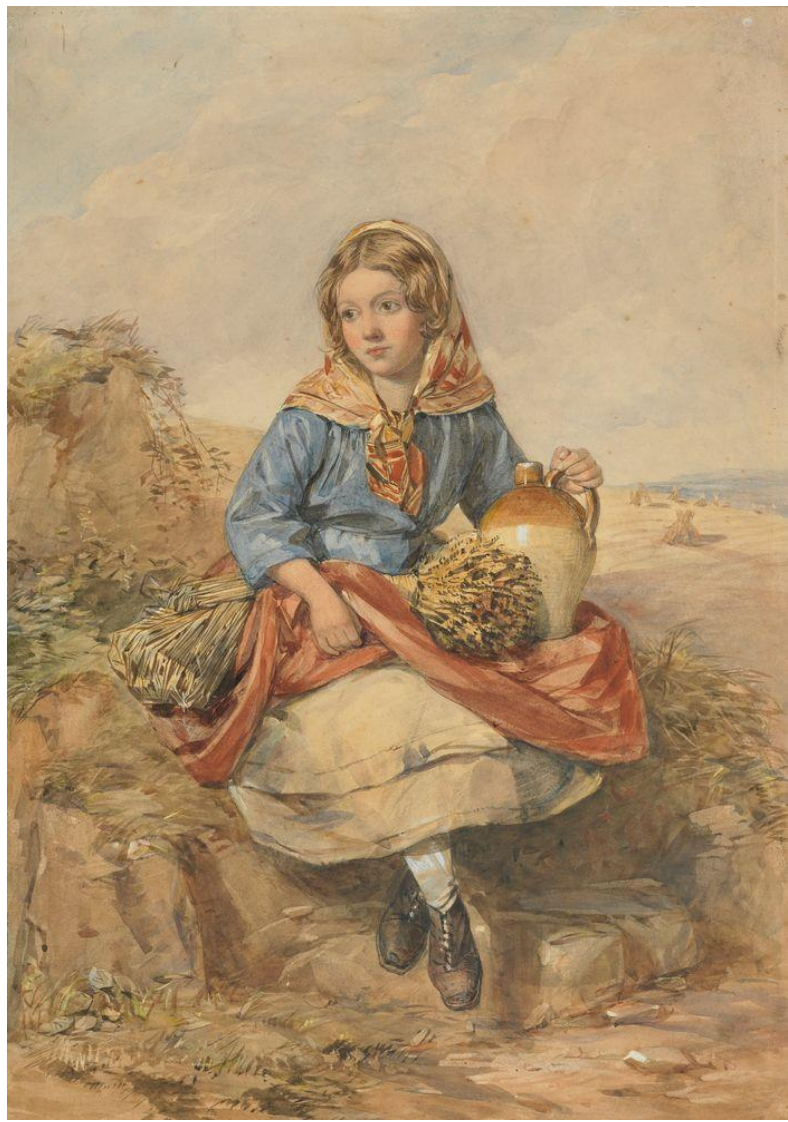

Fig. 19 Henry Edington Hobson (1820-1870), Young Gleaner, 315 x 445, Te Papa, 19570009-143. 


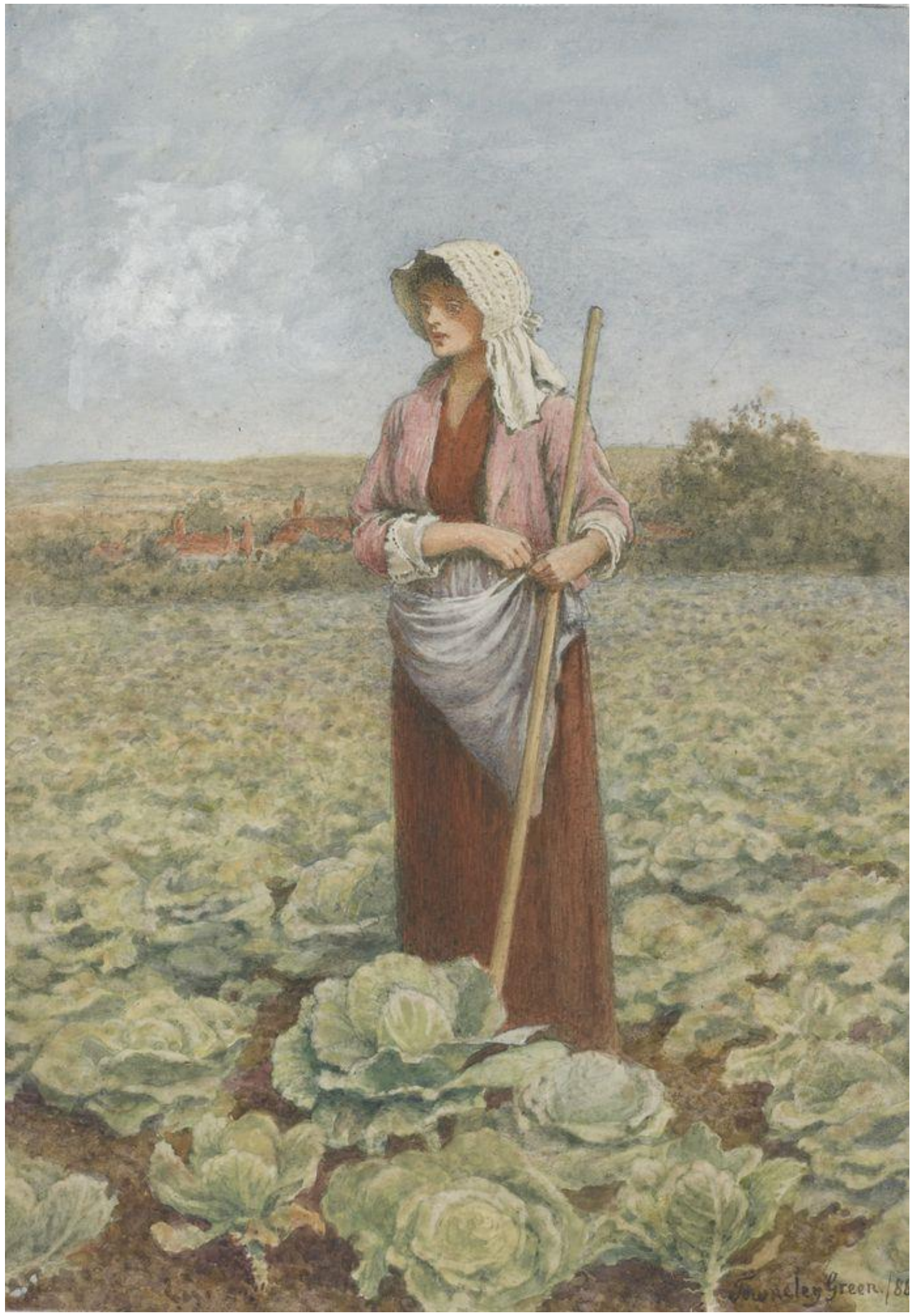

Fig. 20 Henry T. Green (1836-1899), Cabbage Field, 1888, 255 x 175, Te Papa, 1957-0009116. 


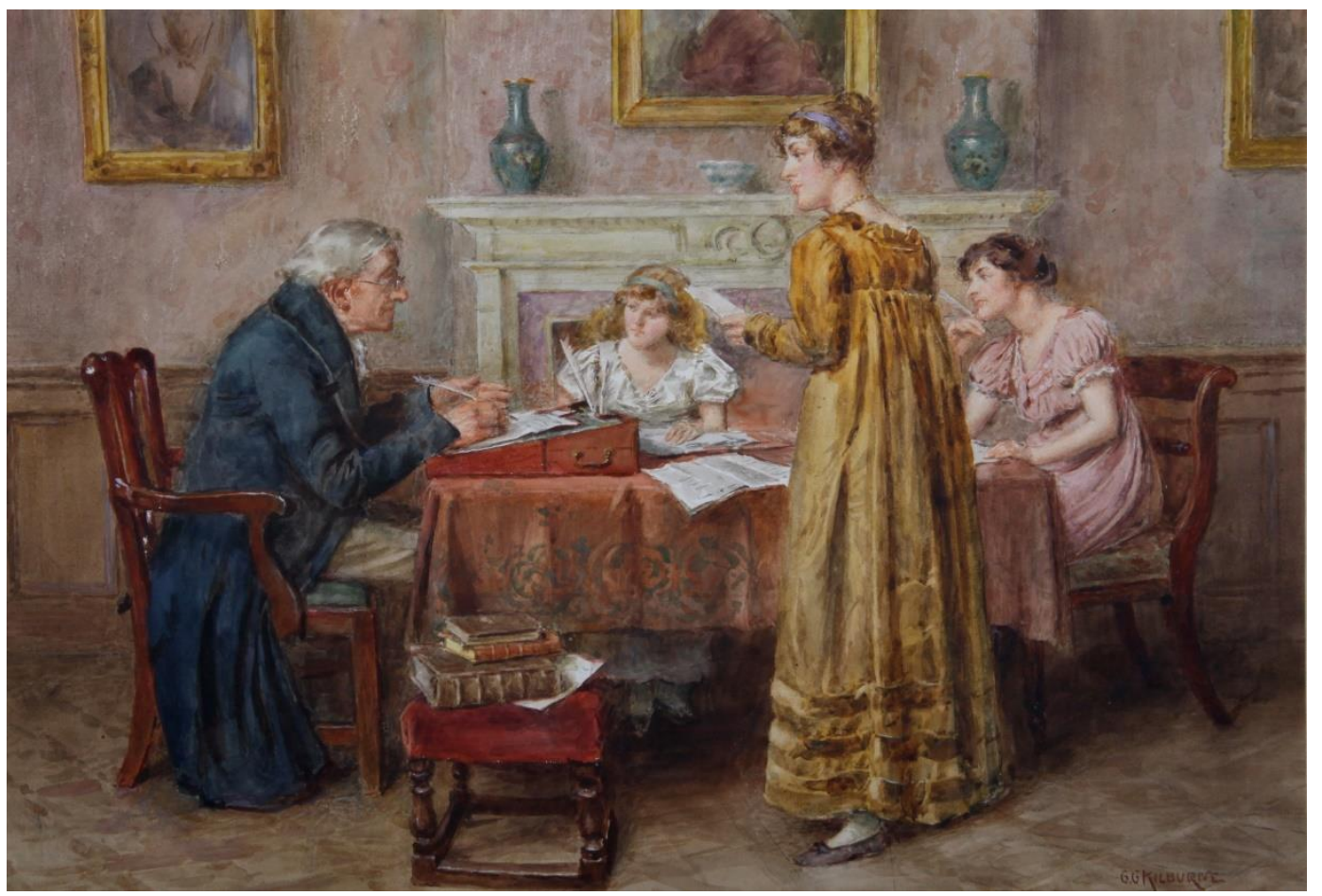

Fig. 21 George Kilburne (1839-1924), The Professor and Pupils, 360 x 515, DPAG, 580$195 X$.

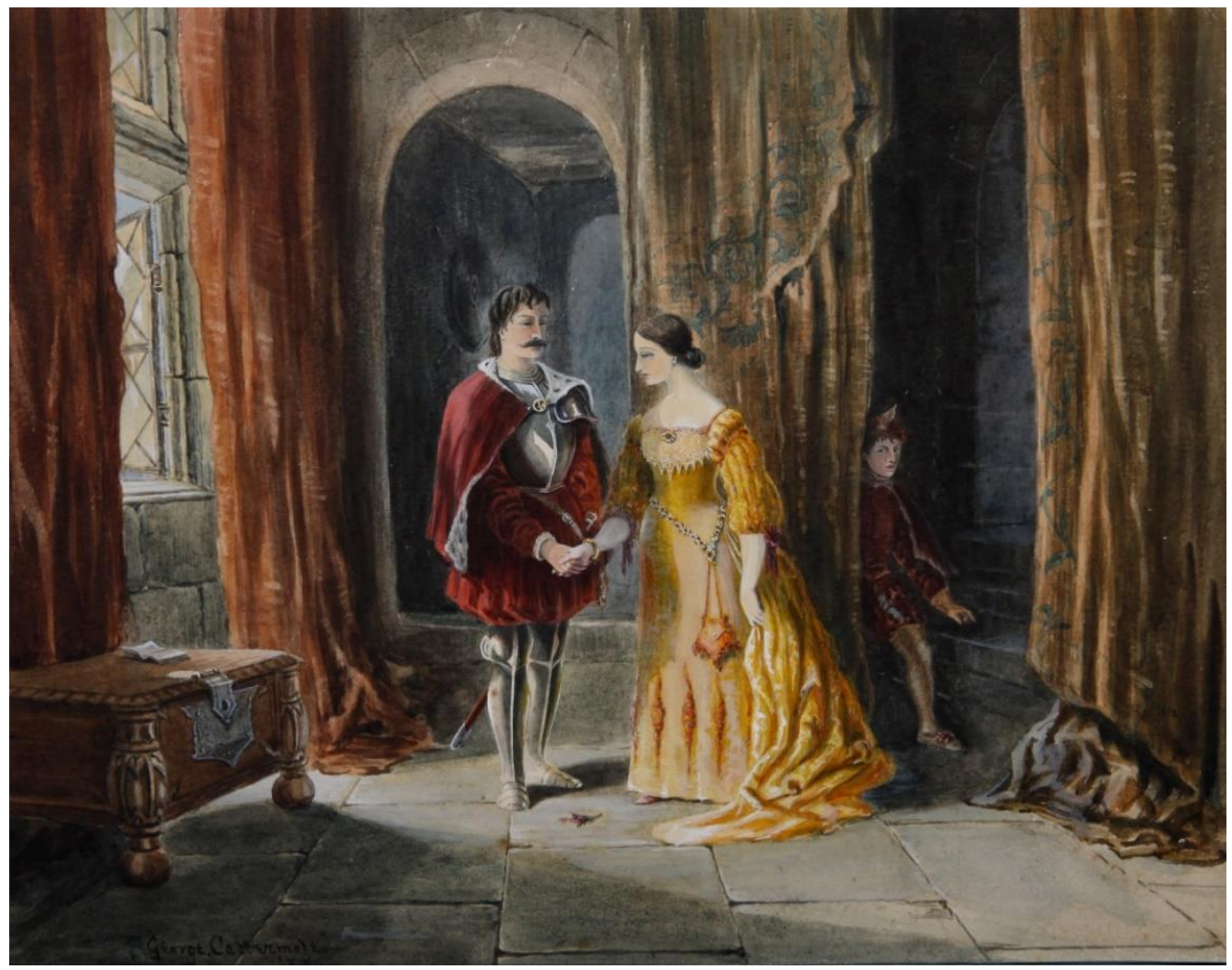

Fig. 22 Charles Cattermole (1832-1900), The Tryst, 320 x 405, DPAG, 337-195X. 


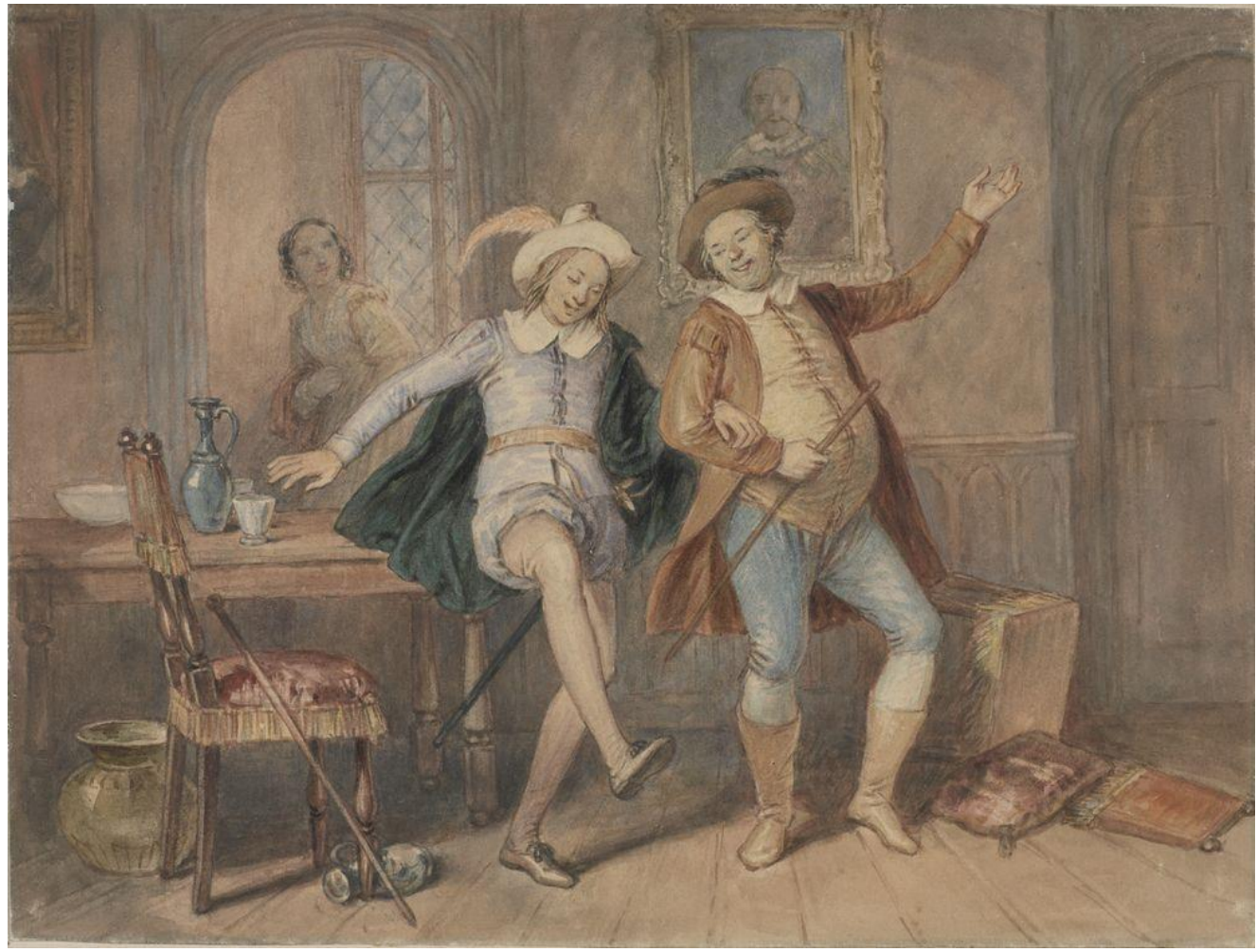

Fig. 23 John Masey Wright (1777-1866), Twelfth Night, 204 x 270, Te Papa, 1957-0009267.

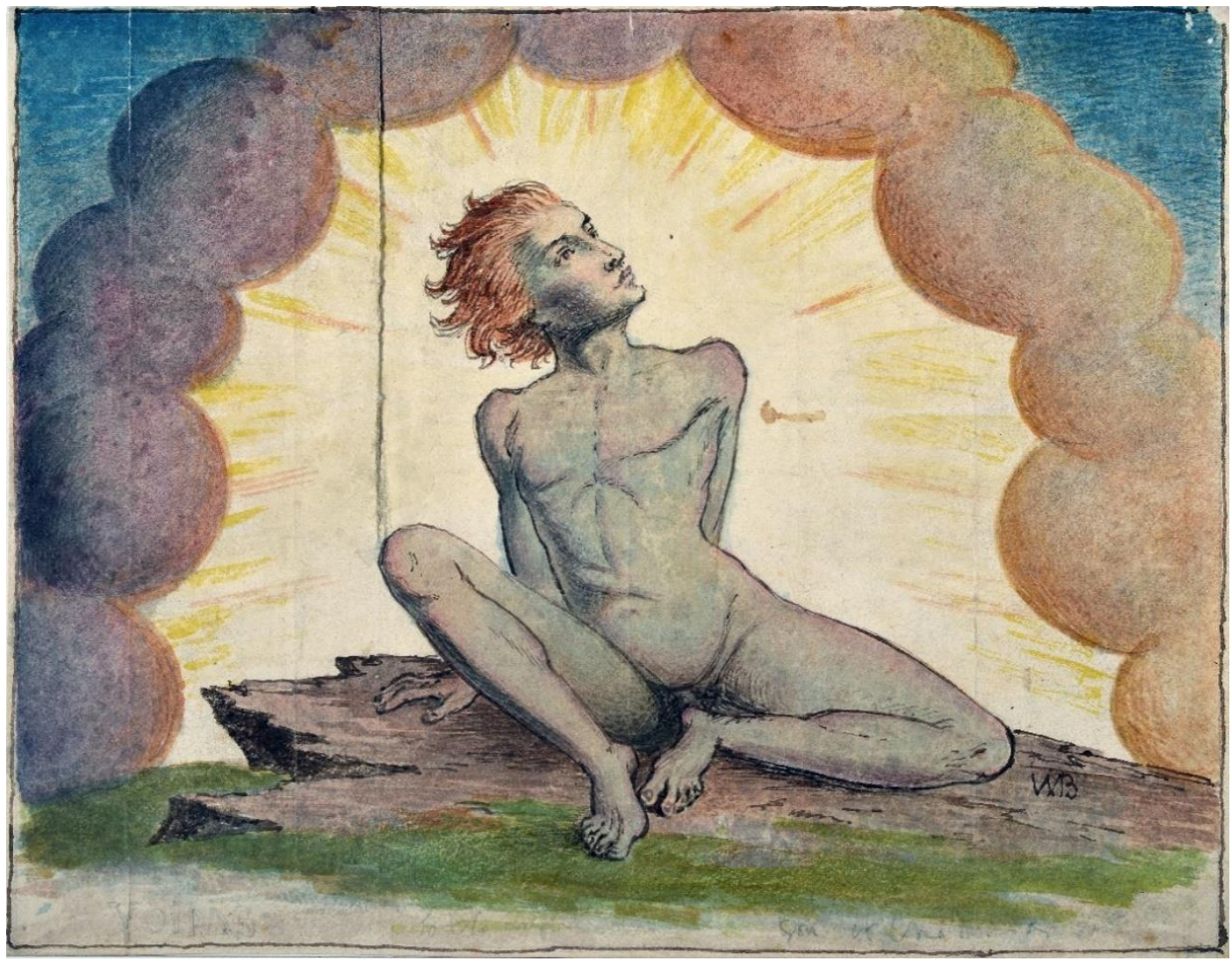

Fig. 24 William Blake (1757-1827) [attributed], Son of the Morning, pen and watercolour, $215 \times 270$, DPAG, 970-195X. 


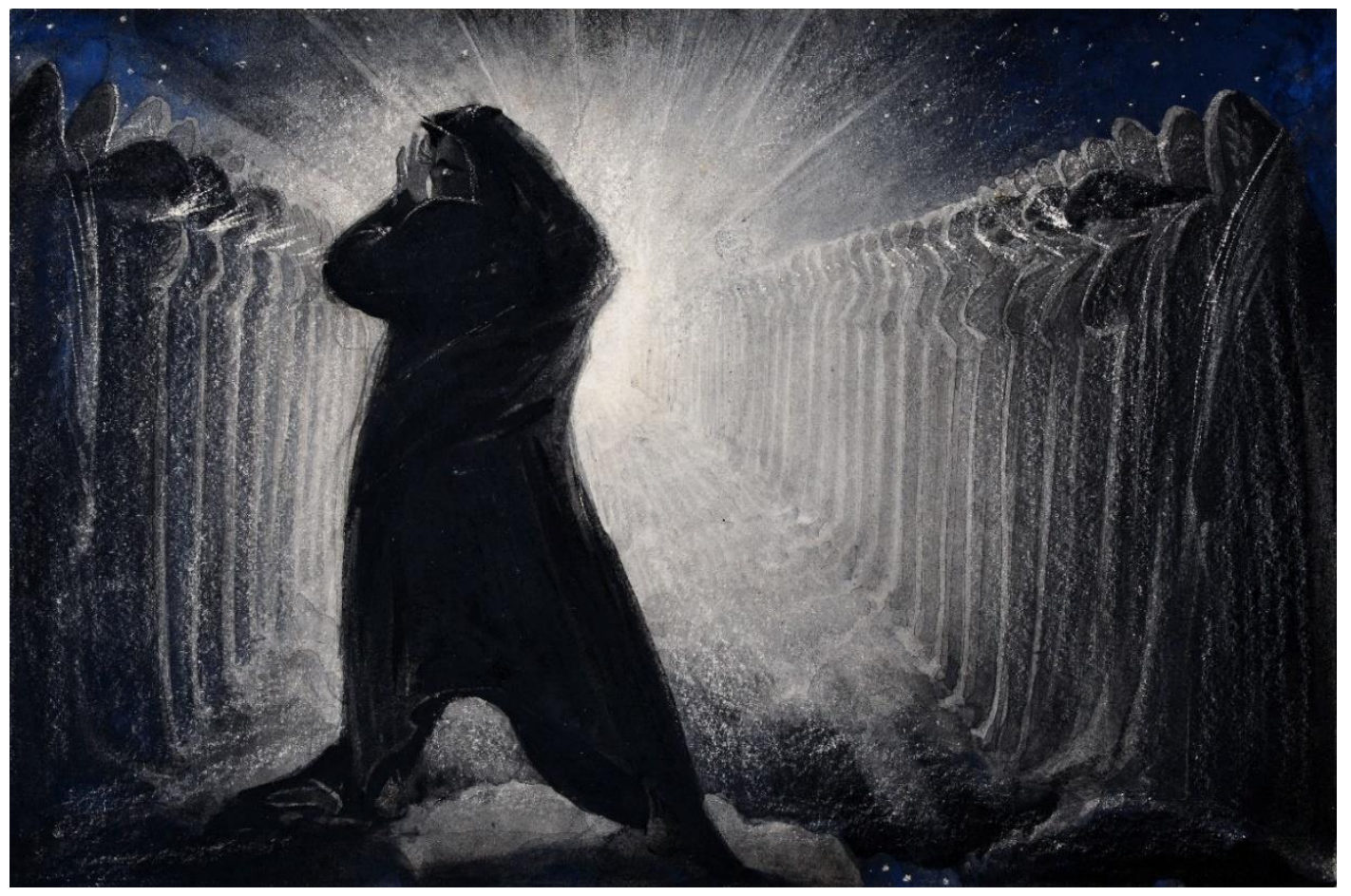

Fig. 25 Henry Fuseli (1741-1825), "There Was a Day When the Sons of God Came to Present Thanks to the Lord...”, 115 x 175, DPAG, 13-1955.

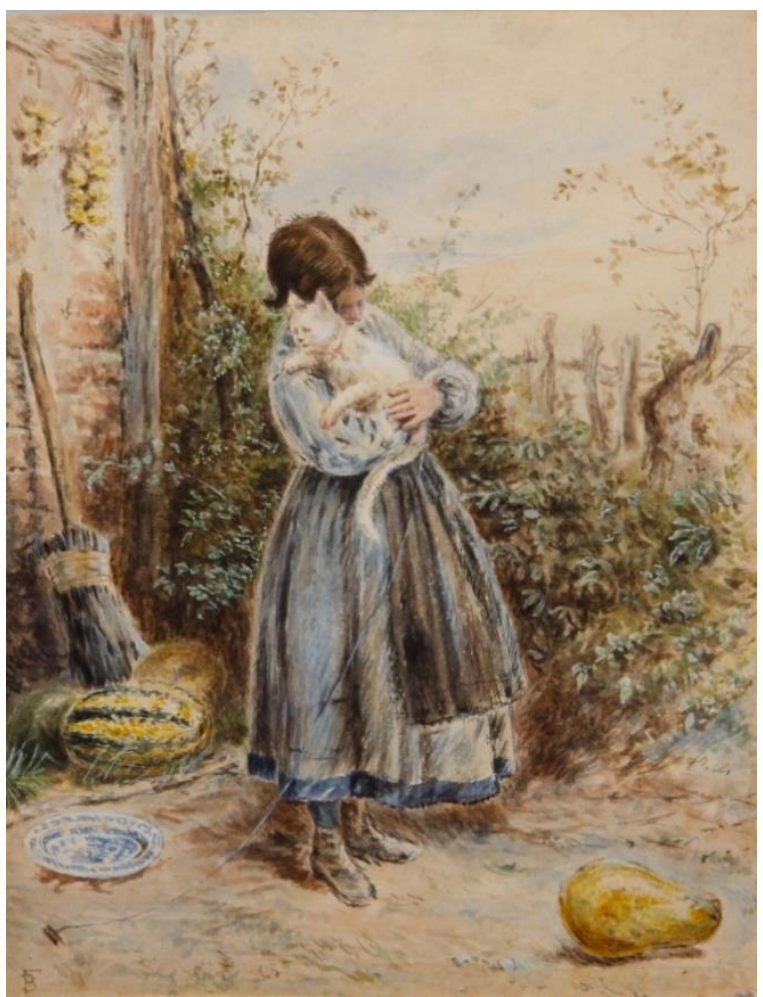

Fig. 26 Myles Birket Foster (1825-1899), Girl with Kitten, 250 x 195, DPAG, 855-195X. 


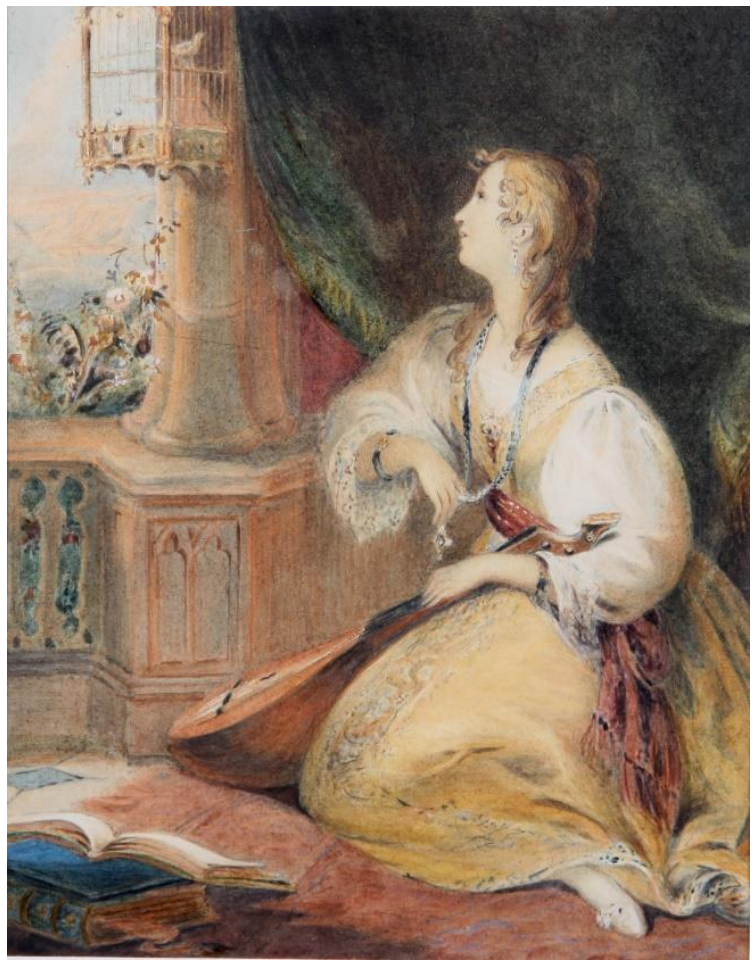

Fig. 27 Thomas Lawrence (1769-1830), Girl Looking at a Bird, 245 x 190, DPAG, $92-$ $195 X$.

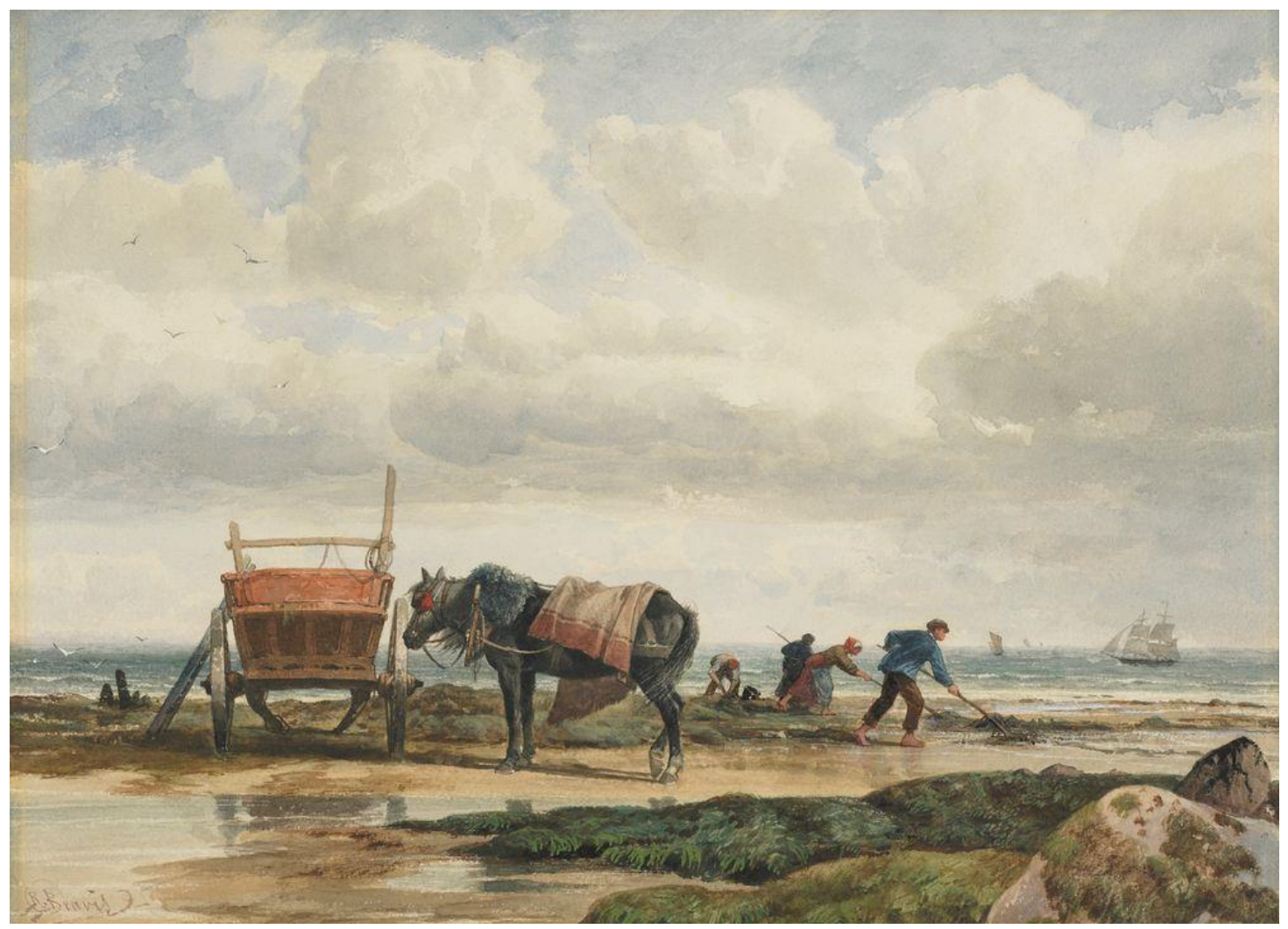

Fig. 28 Richard Beavis (1824-1896), Gathering Seaweed, 330 x 460, Te Papa, 1957-000918. 


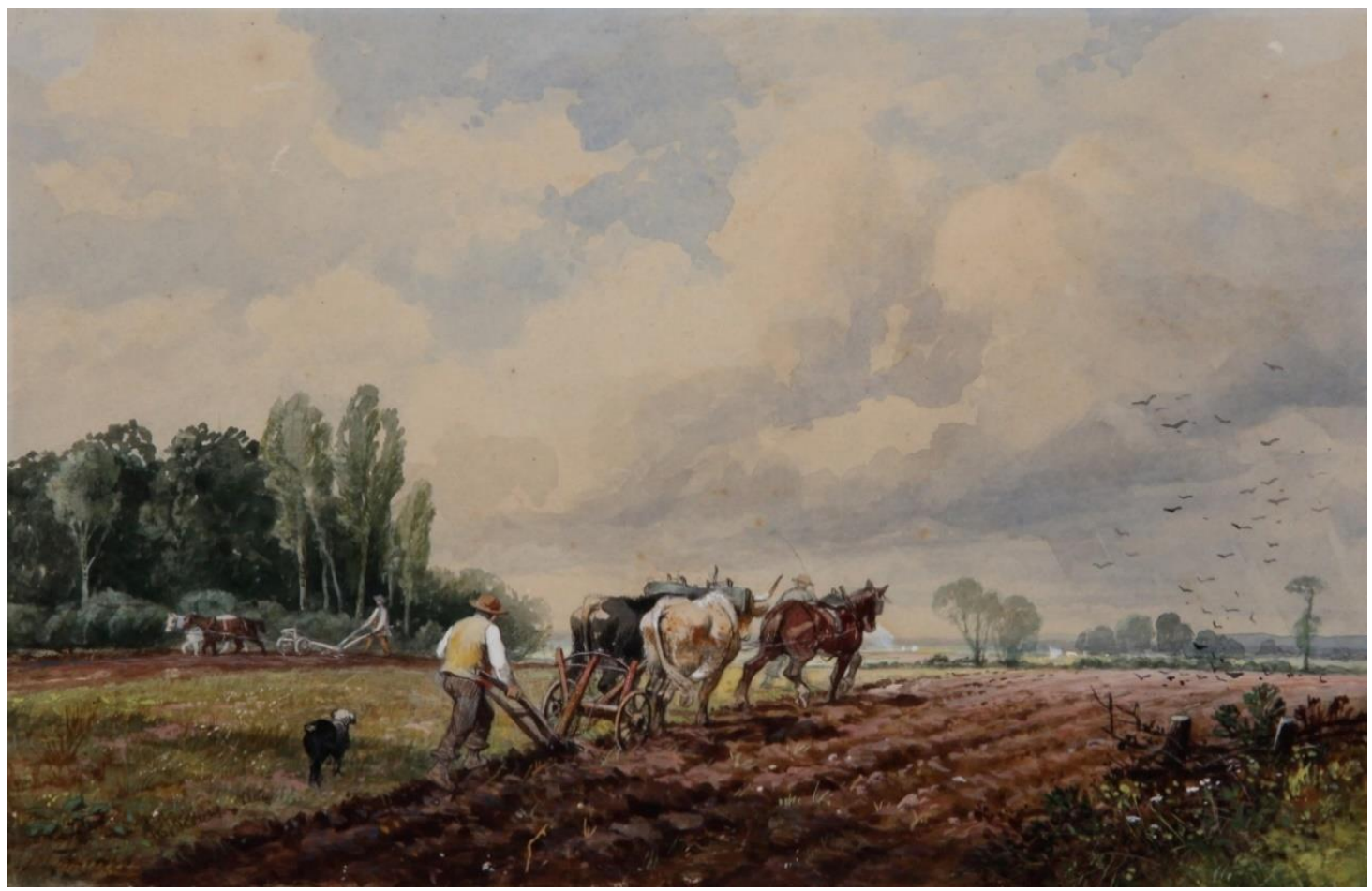

Fig. 29 Richard Beavis, Horses Ploughing, 190 x 290, DPAG, 296-195X.

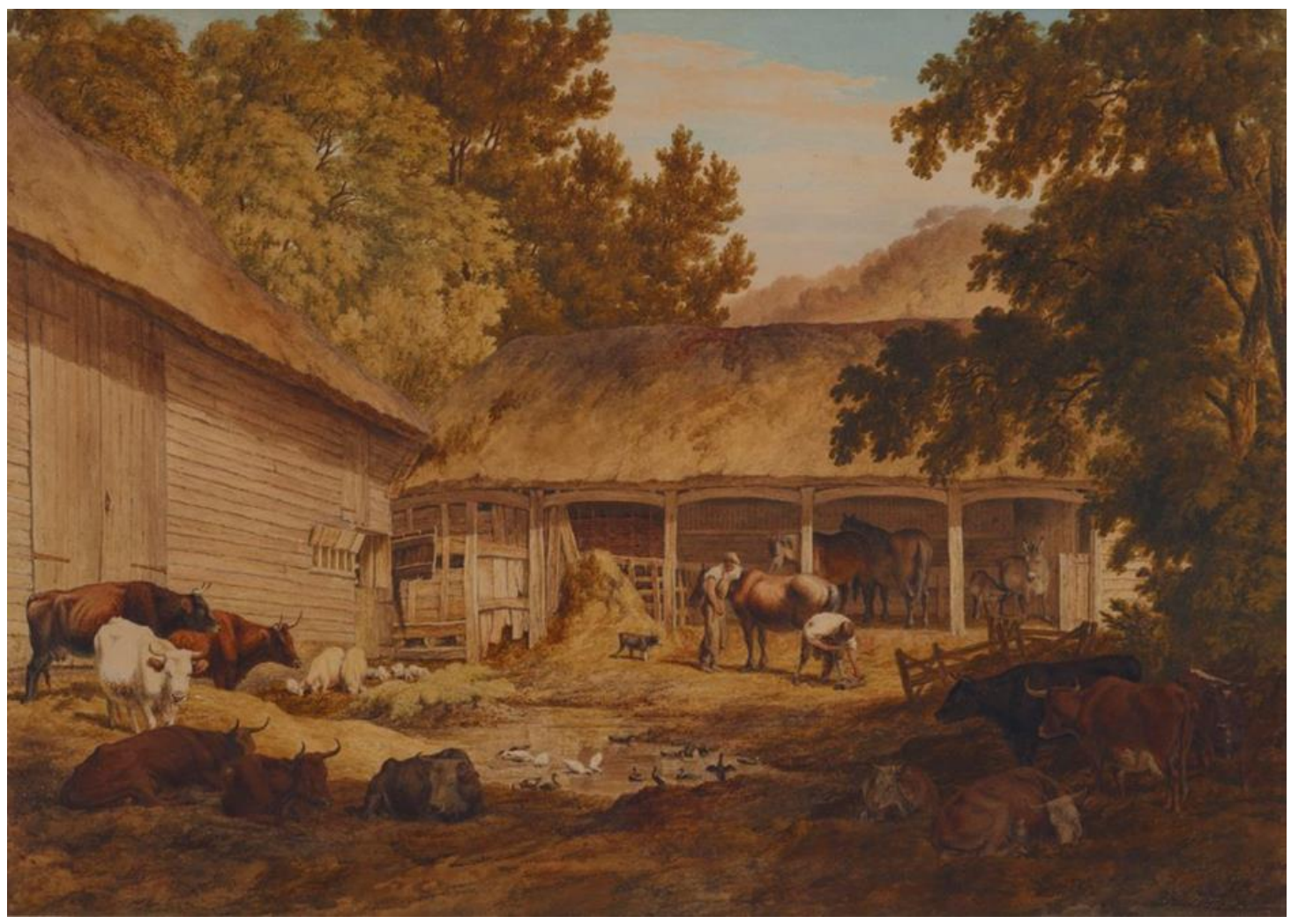

Fig. 30 Robert Hills (1769-1844), Farmyard, 1812, 492 x 695, Te Papa, 1957-0009-138. 


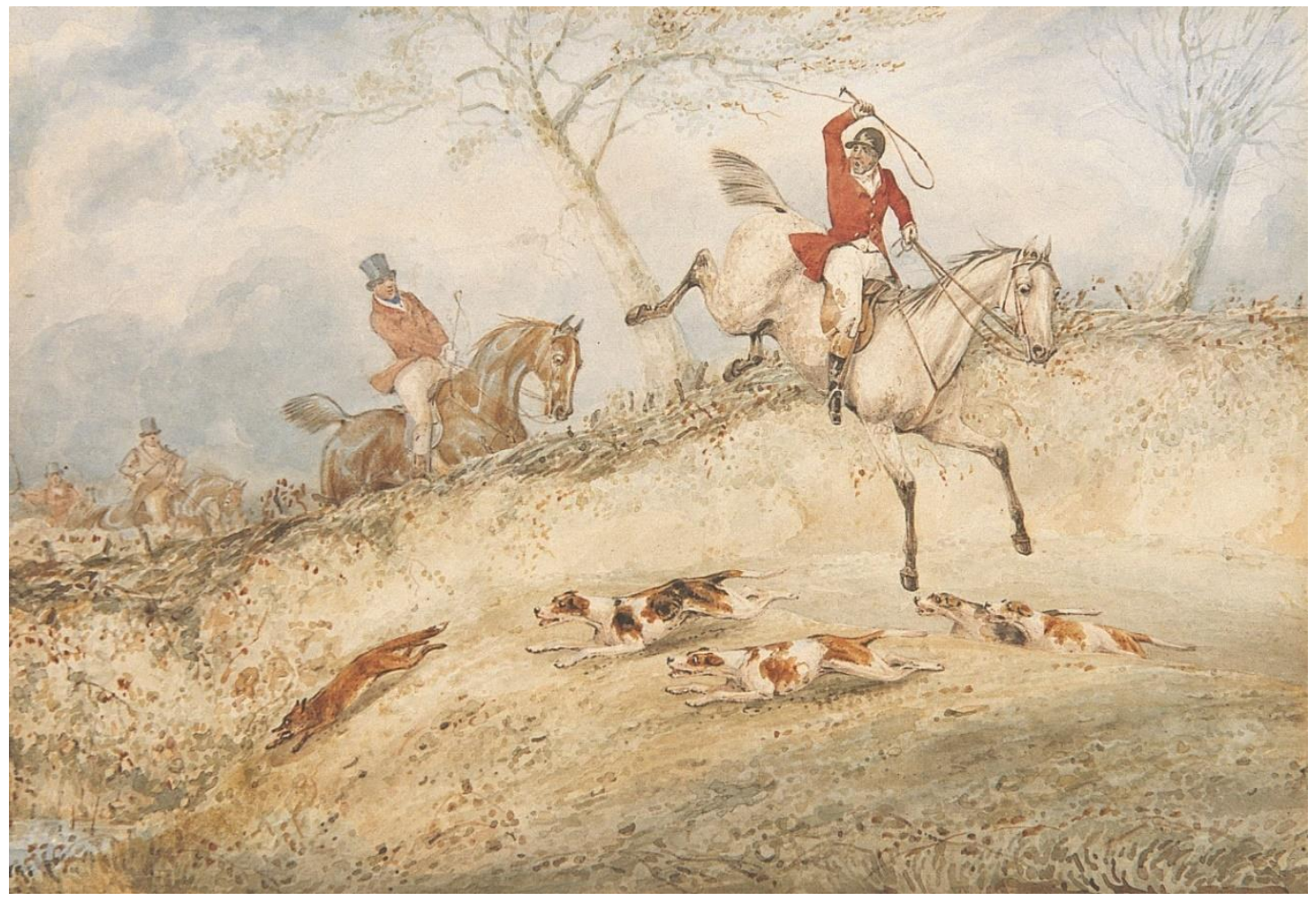

Fig. 31 Henry Alken (1785-1851), The Hunt, 175 x 260, DPAG, 66-195X.

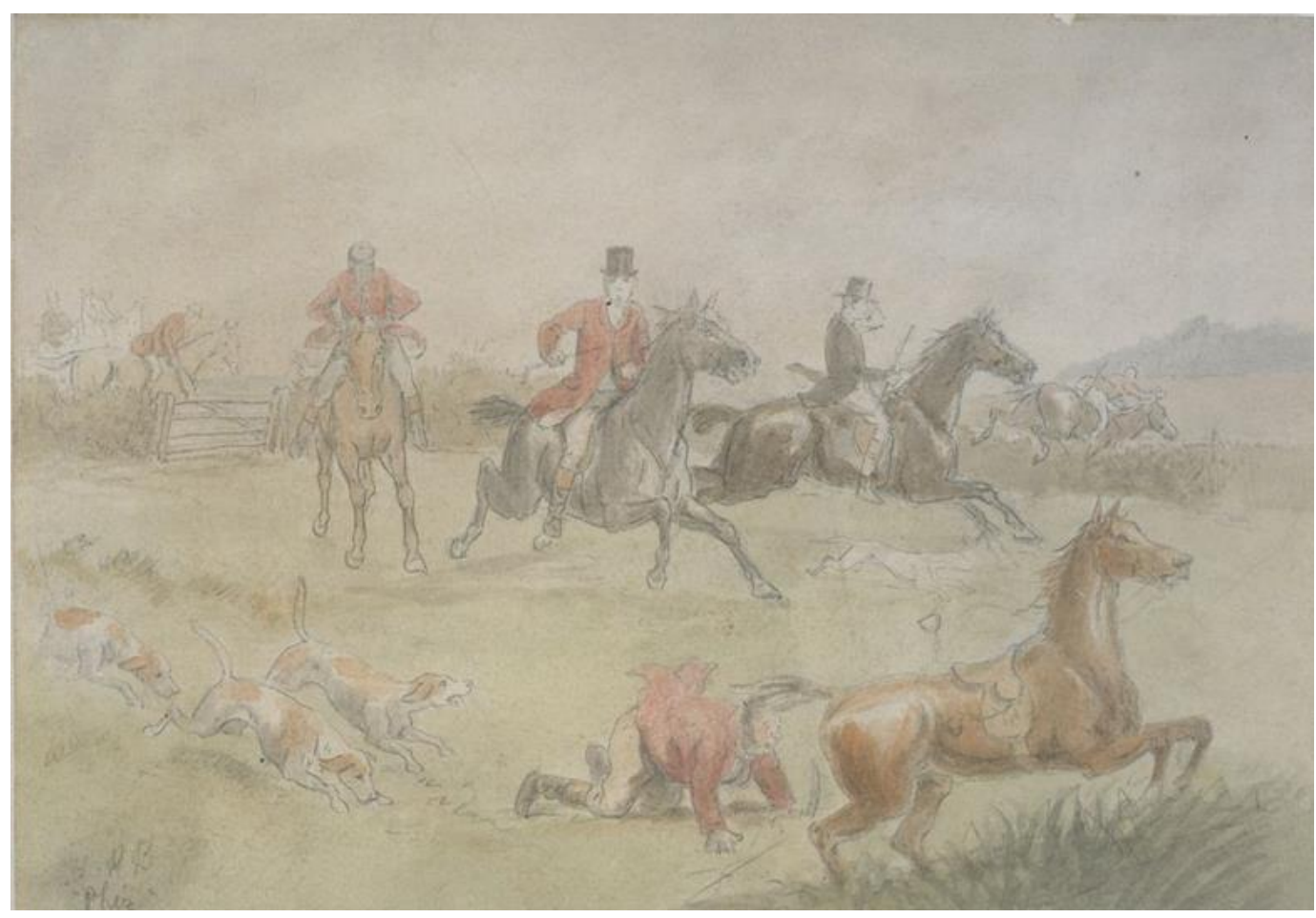

Fig. 32 Hablot Knight Browne (1815-1882), The Hunt, watercolour and pencil graphite, 172 x 250, Te Papa, 1957-0009-36. 


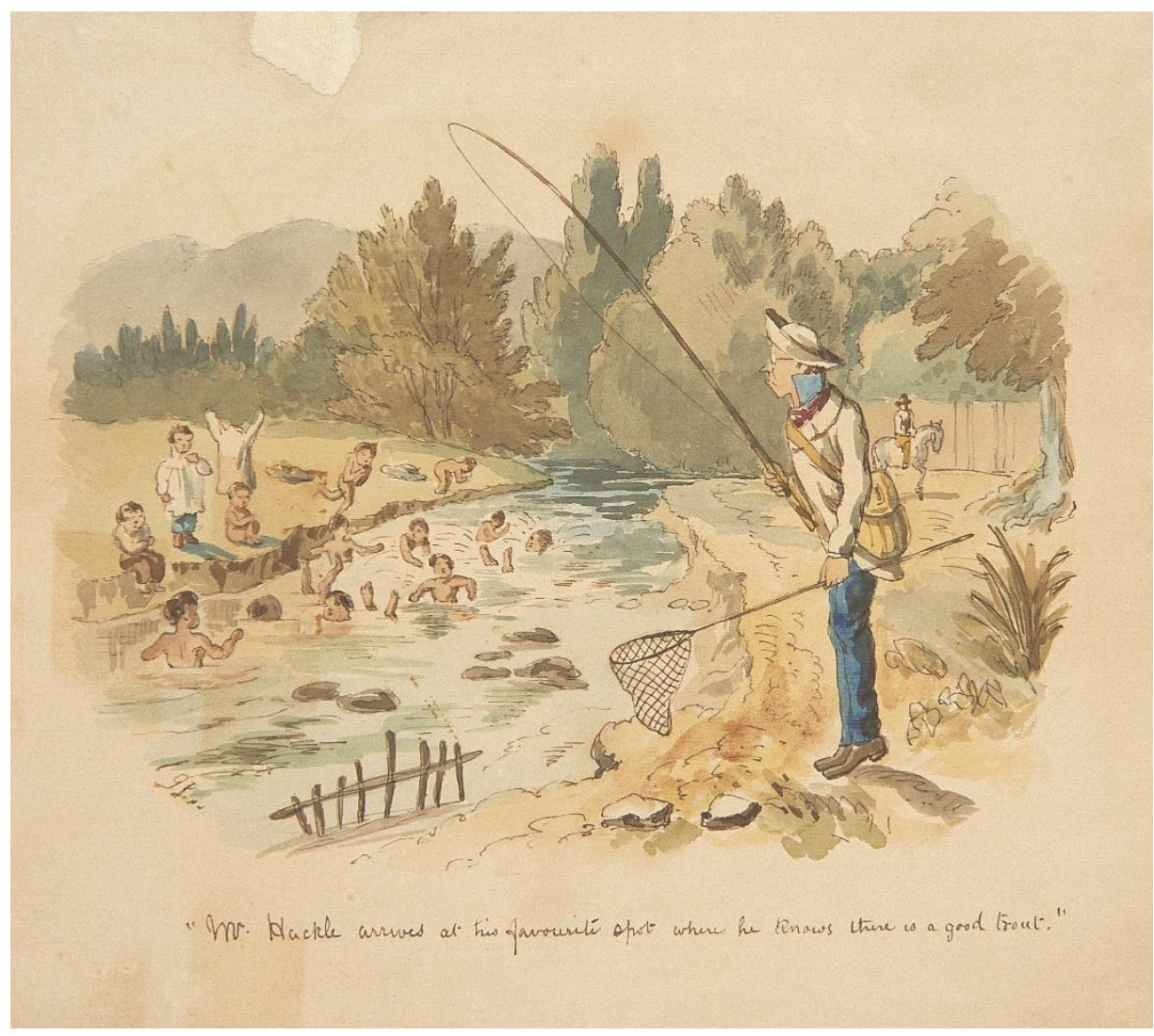

Fig. 33 John Leech (1817-1864), Fly Fishing, or "Mr Hackle arrived at his favourite spot where he knows there is a good trout", 1855, ink and watercolour, 240 x 270, DPAG, 1036$195 X$.

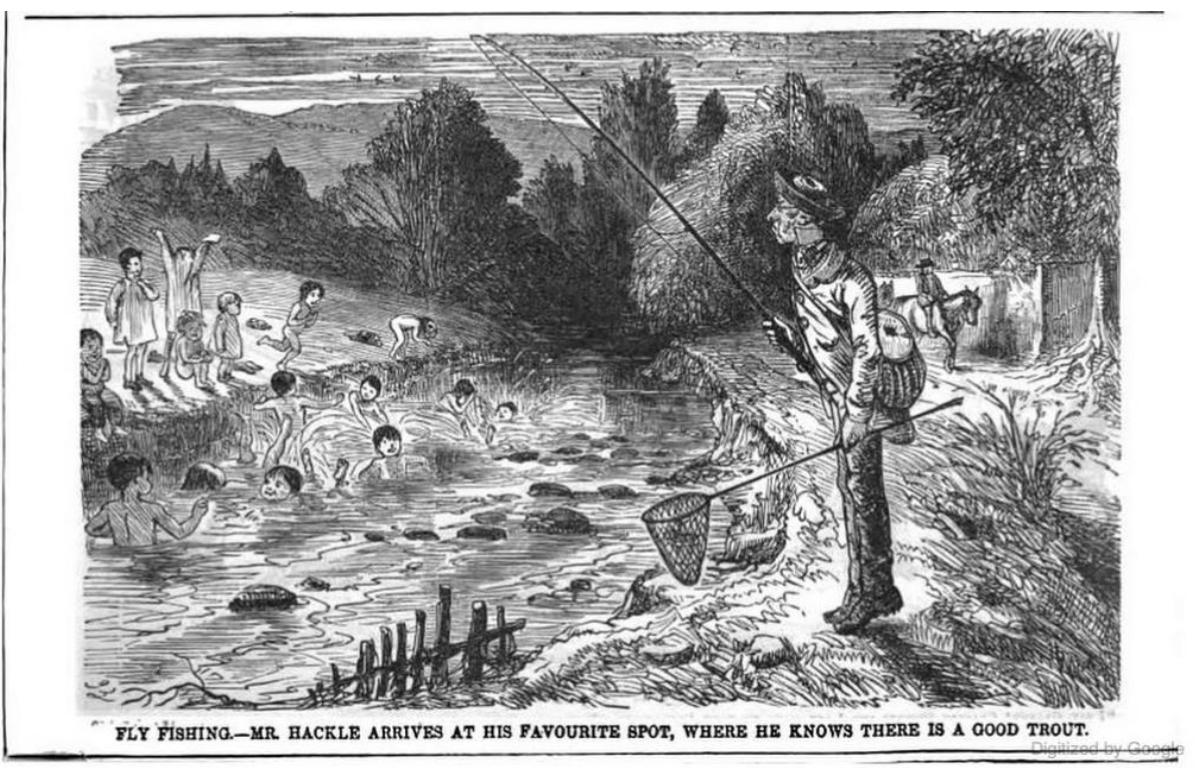

Fig. 34 John Leech, "Fly Fishing - Mr Hackle arrives at his favourite spot, where he knows there is a good trout", in Punch 28 (January-June 1855), reproduced online: https://books.google.co.uk/books?id=_QoDAAAAIAAJ\&dq=editions\%3Ao0ZG0cjtFIAC\& $\mathrm{pg}=\mathrm{PP} 1 \# \mathrm{v}=$ onepage $\& \mathrm{q}=$ fly $\% 20$ fishing $\& \mathrm{f}=$ false. 


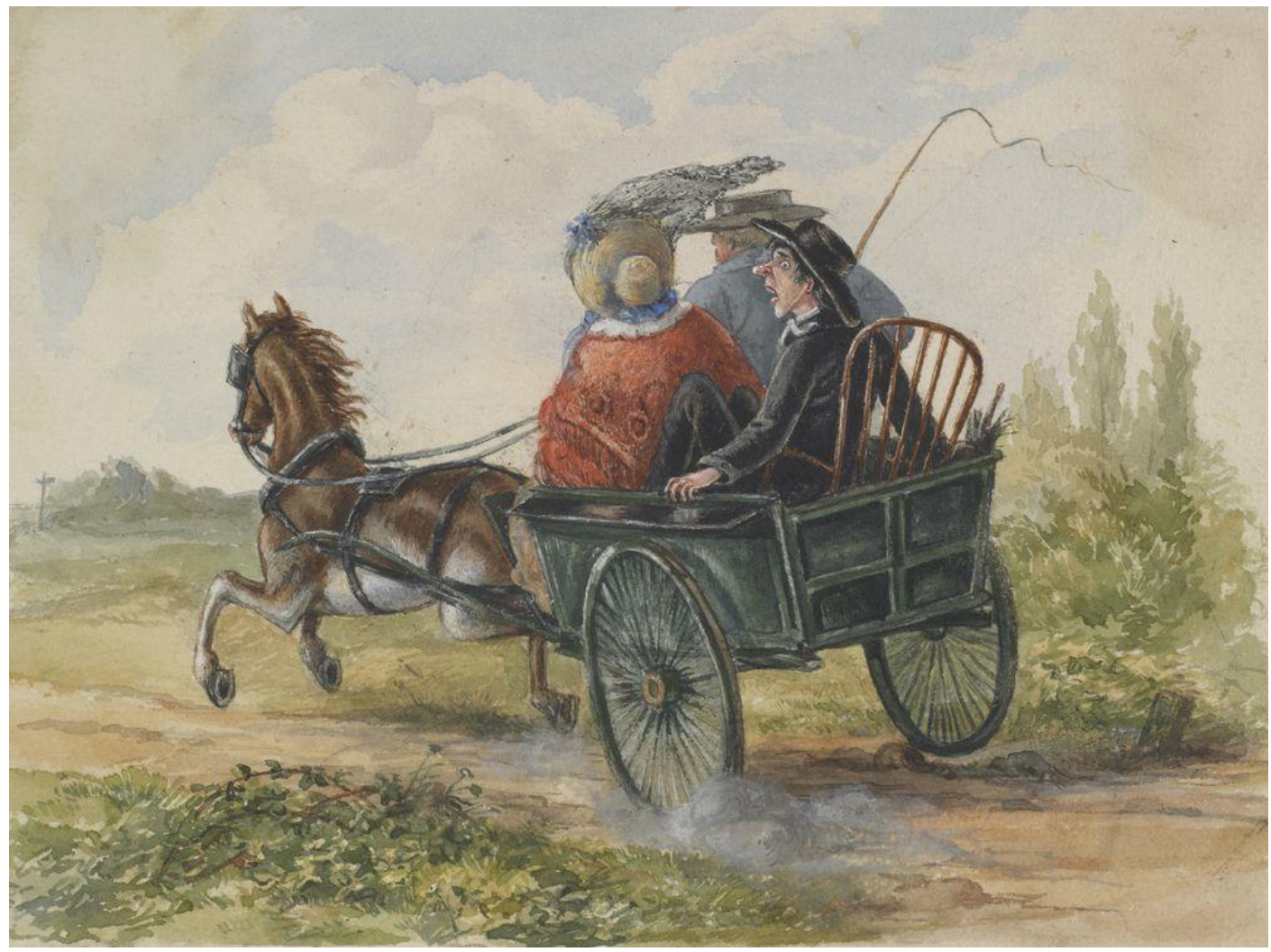

Fig. 35 Eliza Sharpe (1796-1874), Illustration for Pickwick Papers, 135 x 179, Te Papa, 1957-0009-229.

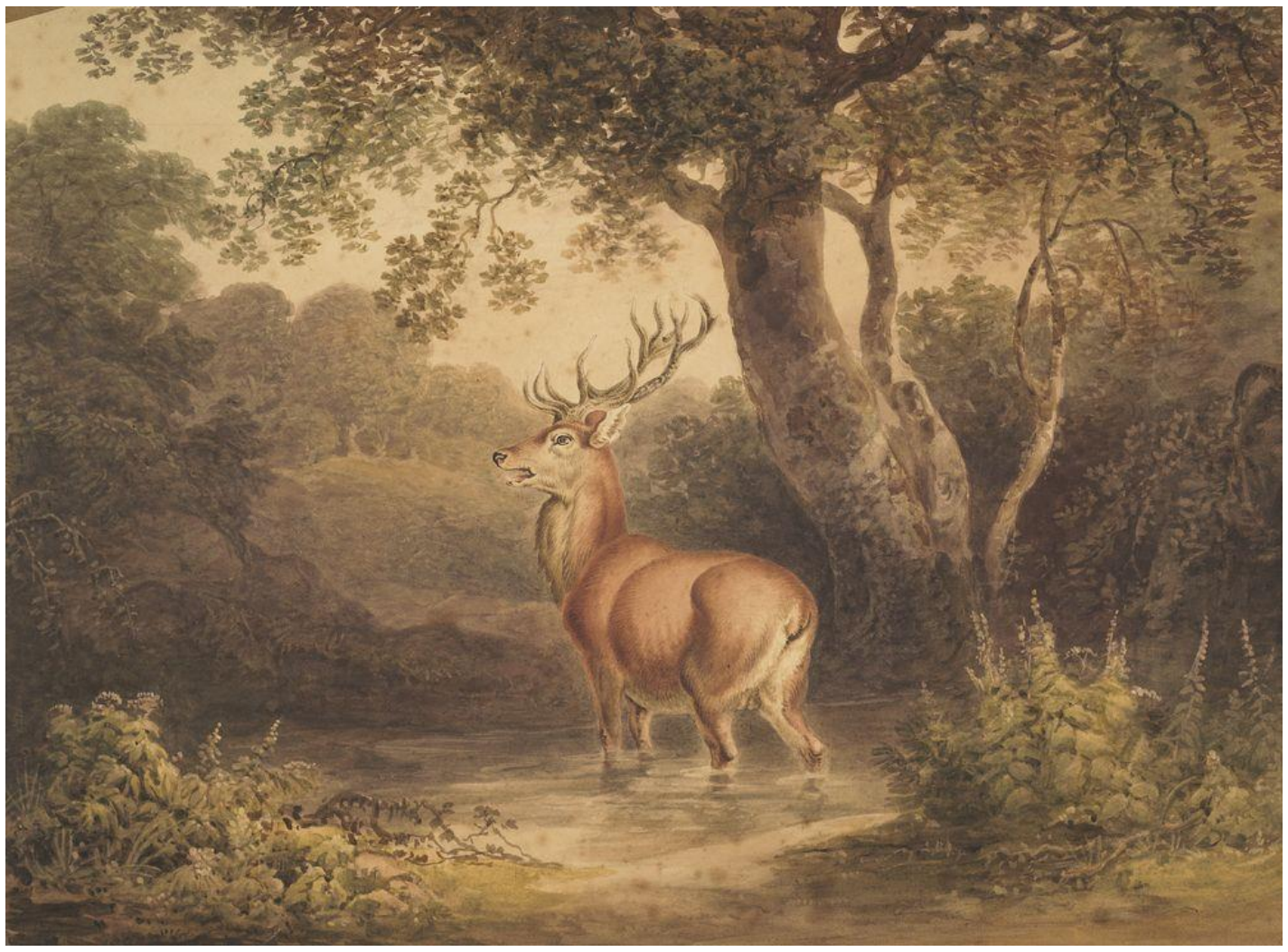

Fig. 36 Robert Hills, Stag, Te Papa, 1957-0009-139. 


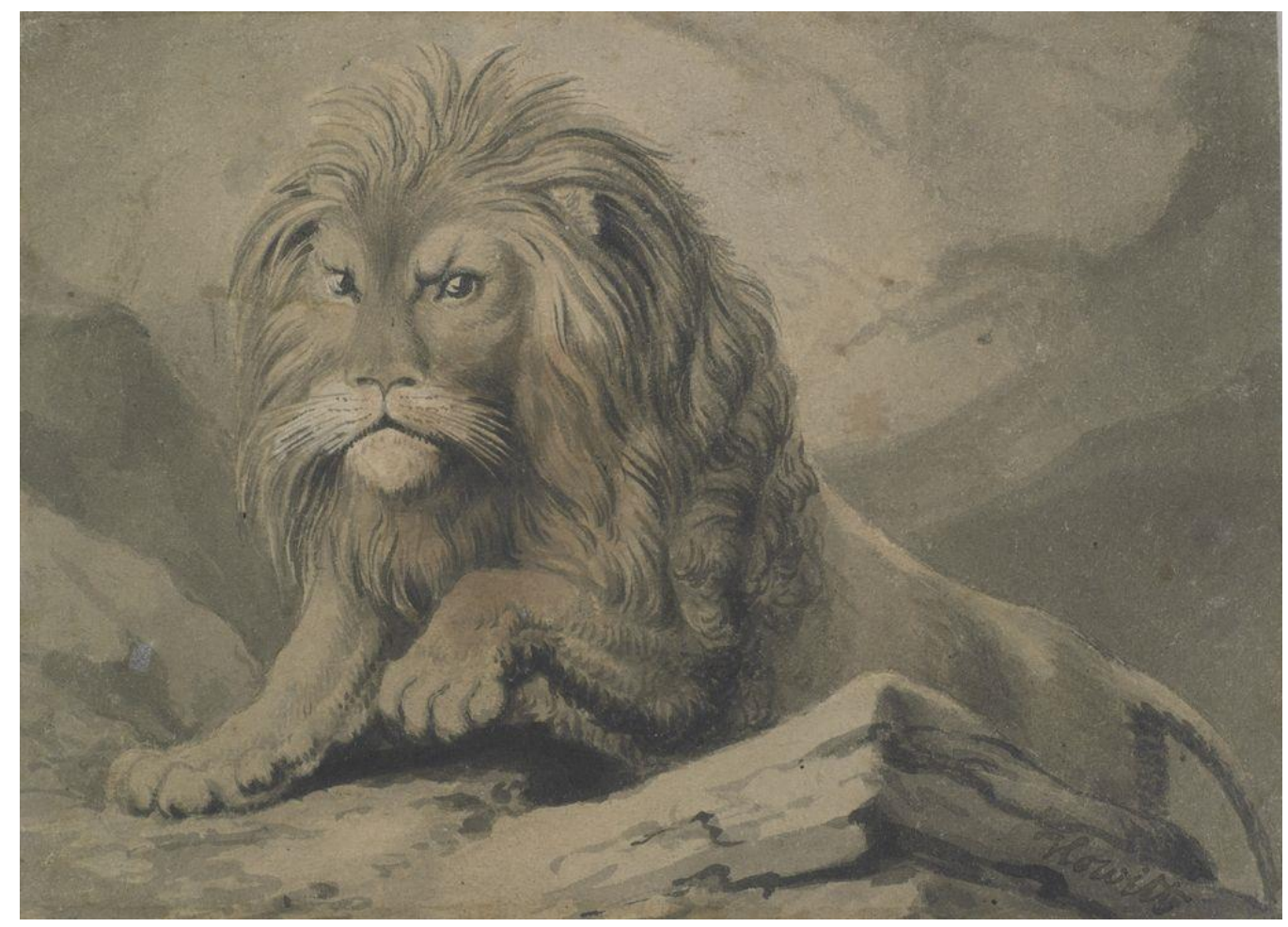

Fig. 37 Samuel Howitt (1756-1822), Lion, sepia wash, 114 x 160, Te Papa, 1957-0009-305.

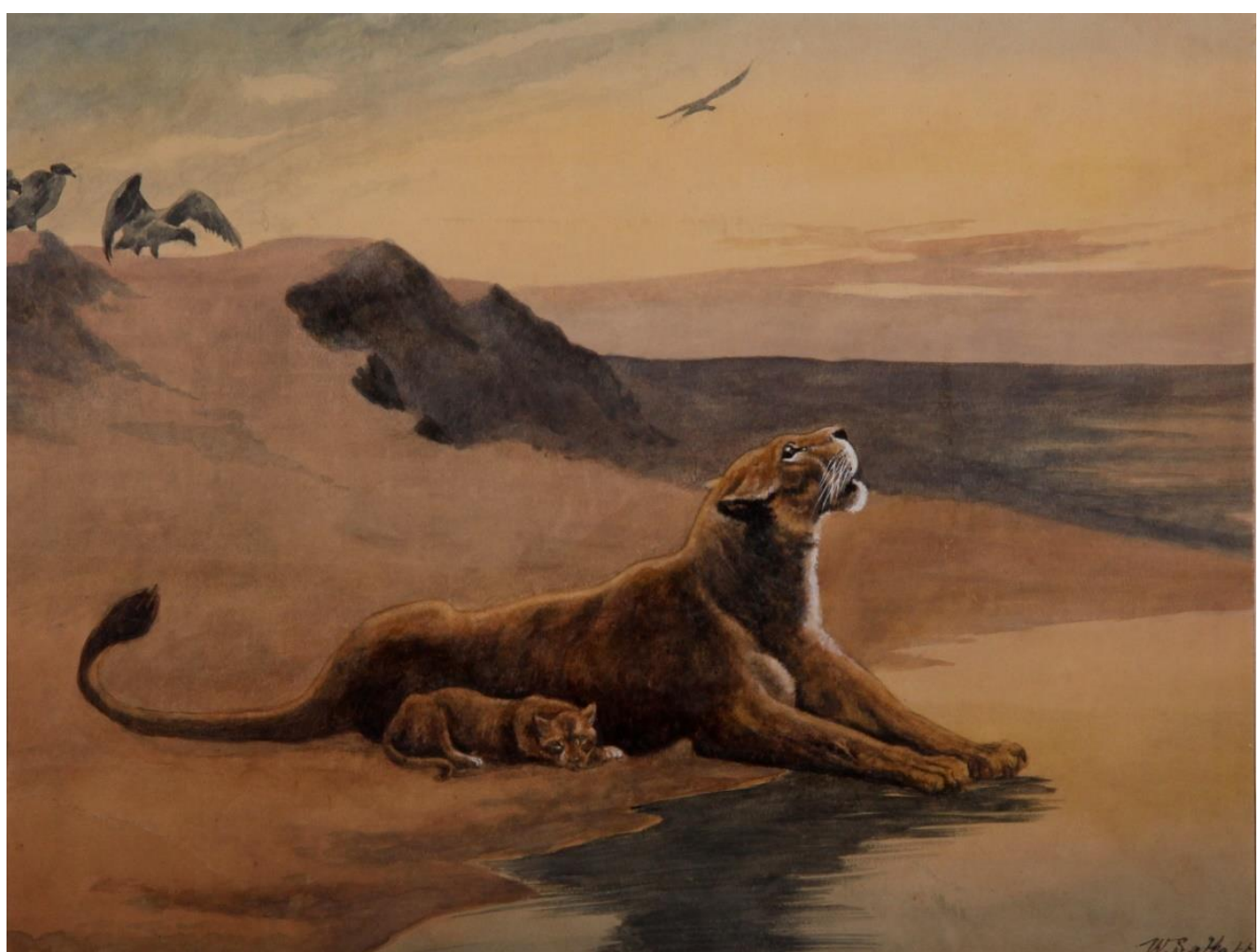

Fig. 38 W.S. Hatton (1873-1938), Lioness and her Cub, c. 1909, 350 x 465, DPAG, 524$195 X$. 


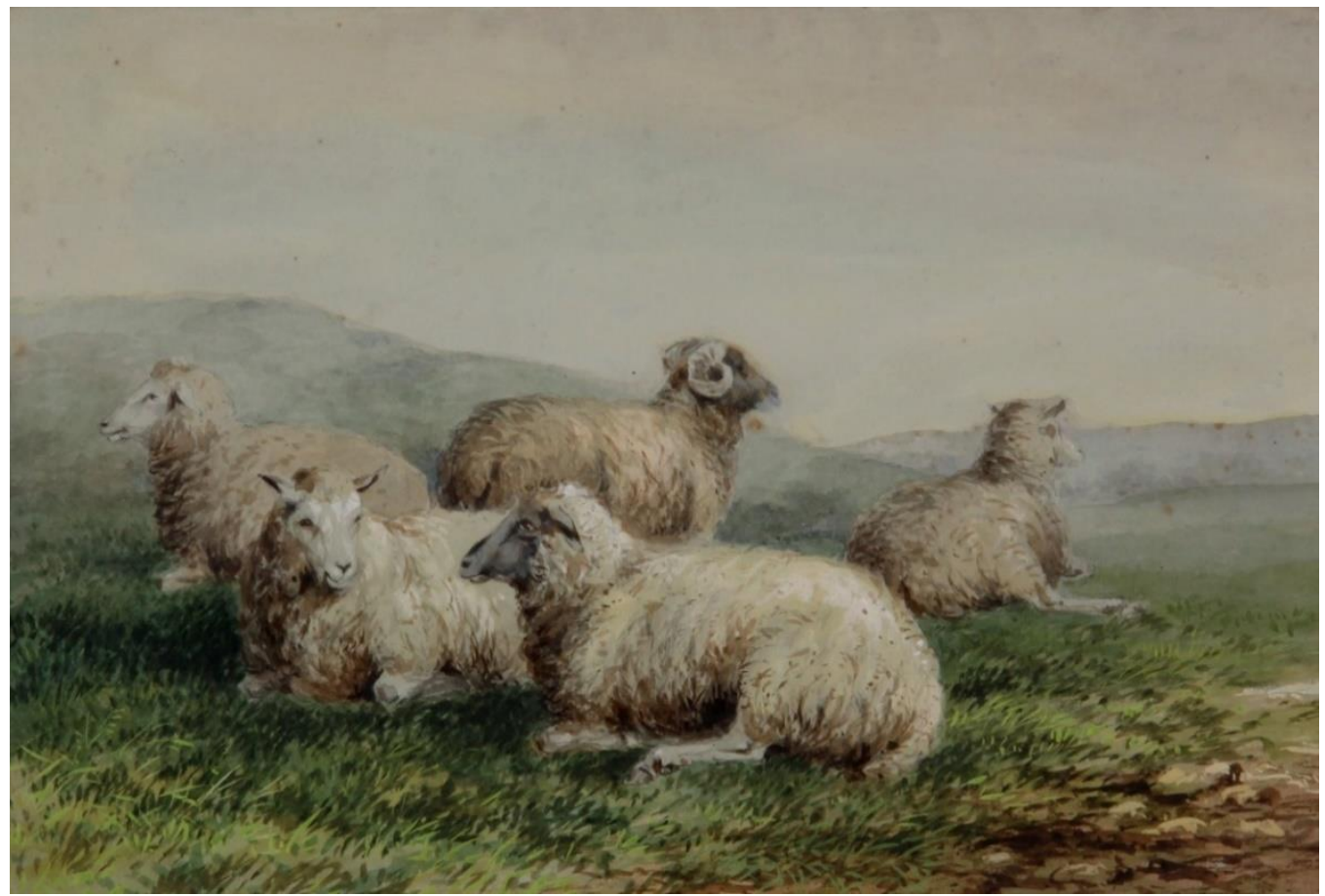

Fig. 39 Thomas Sidney Cooper (1803-1902), Sheep, 145 x 260, DPAG, 78-195X.

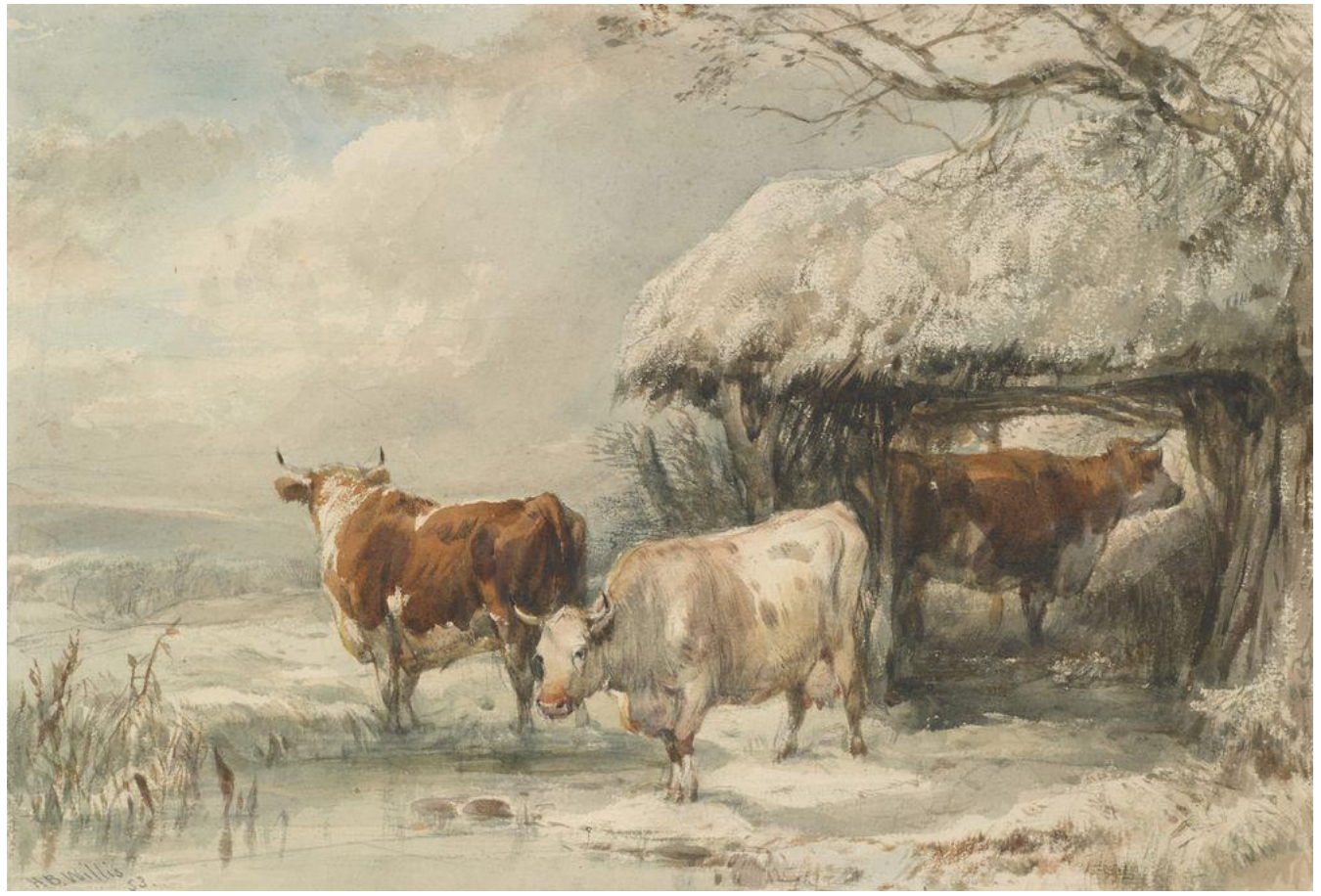

Fig. 40 Henry Willis (1810-1884), Cows in Winter, 1853, 225 x 330, Te Papa, 1957-0009261. 


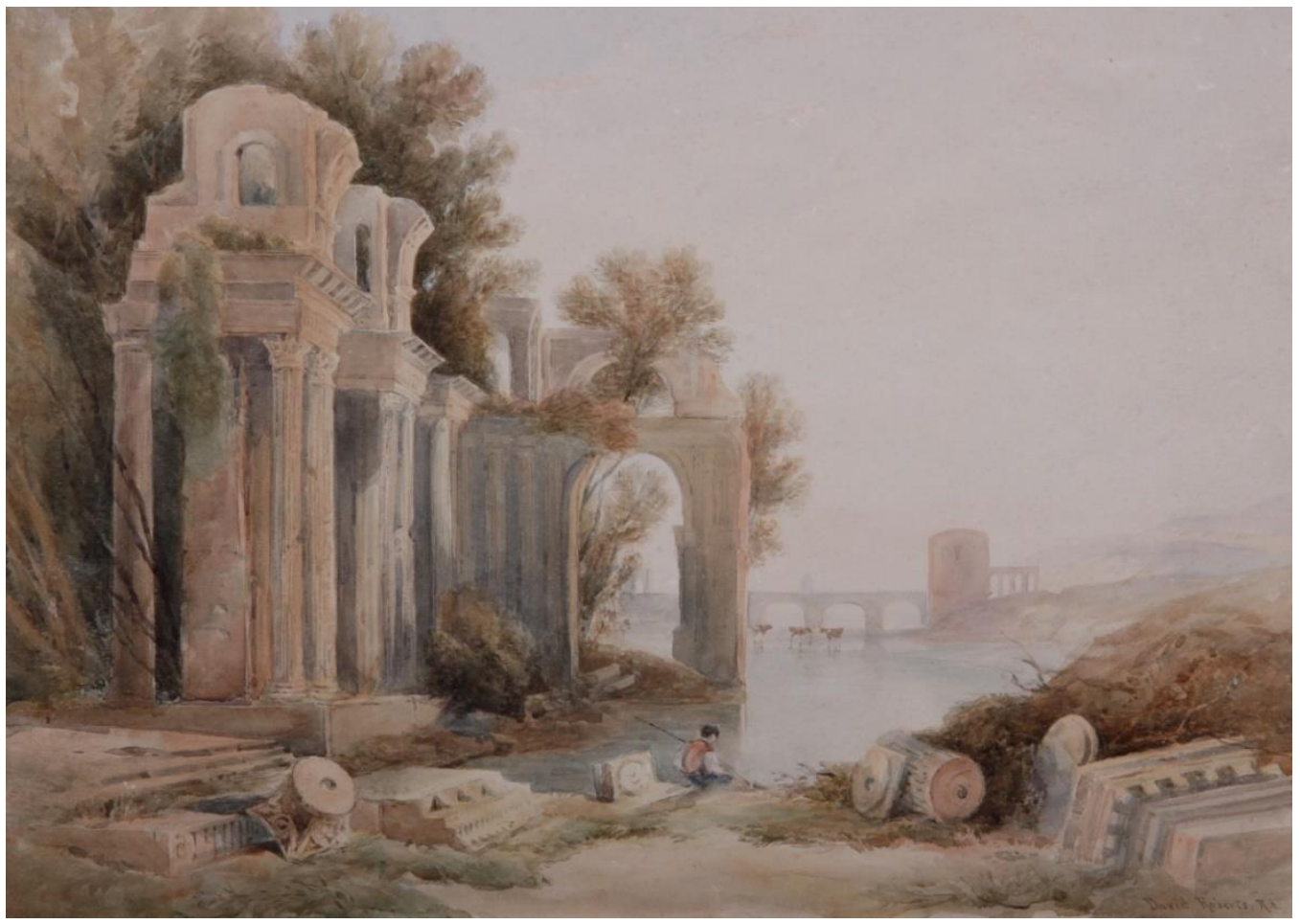

Fig. 41 David Roberts, Classical Ruins, 240 x 335, DPAG, 706-195X.

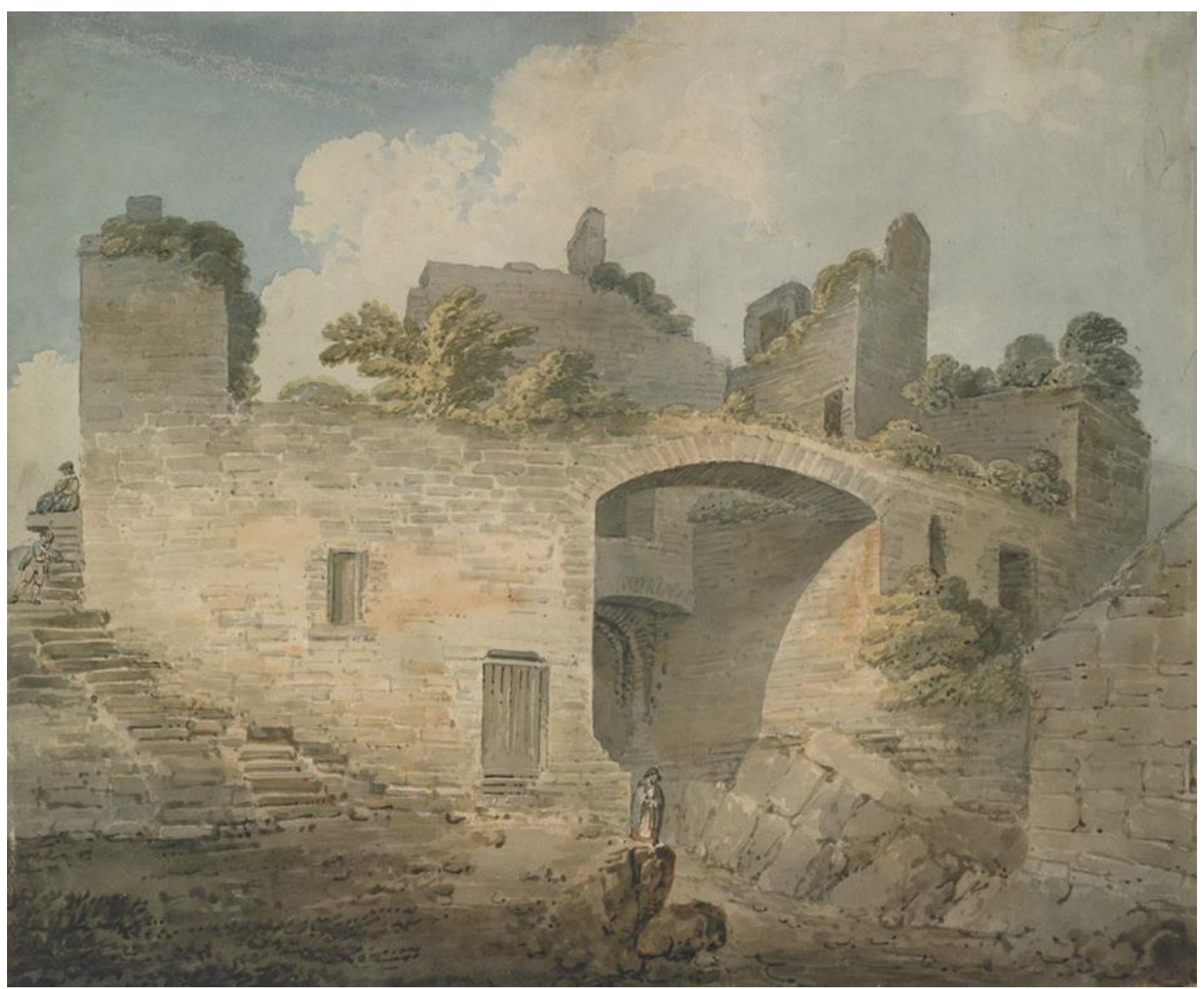

Fig. 42 James Baynes (1766-1837), Ruins, 1797, Te Papa, 1957-0009-17. 


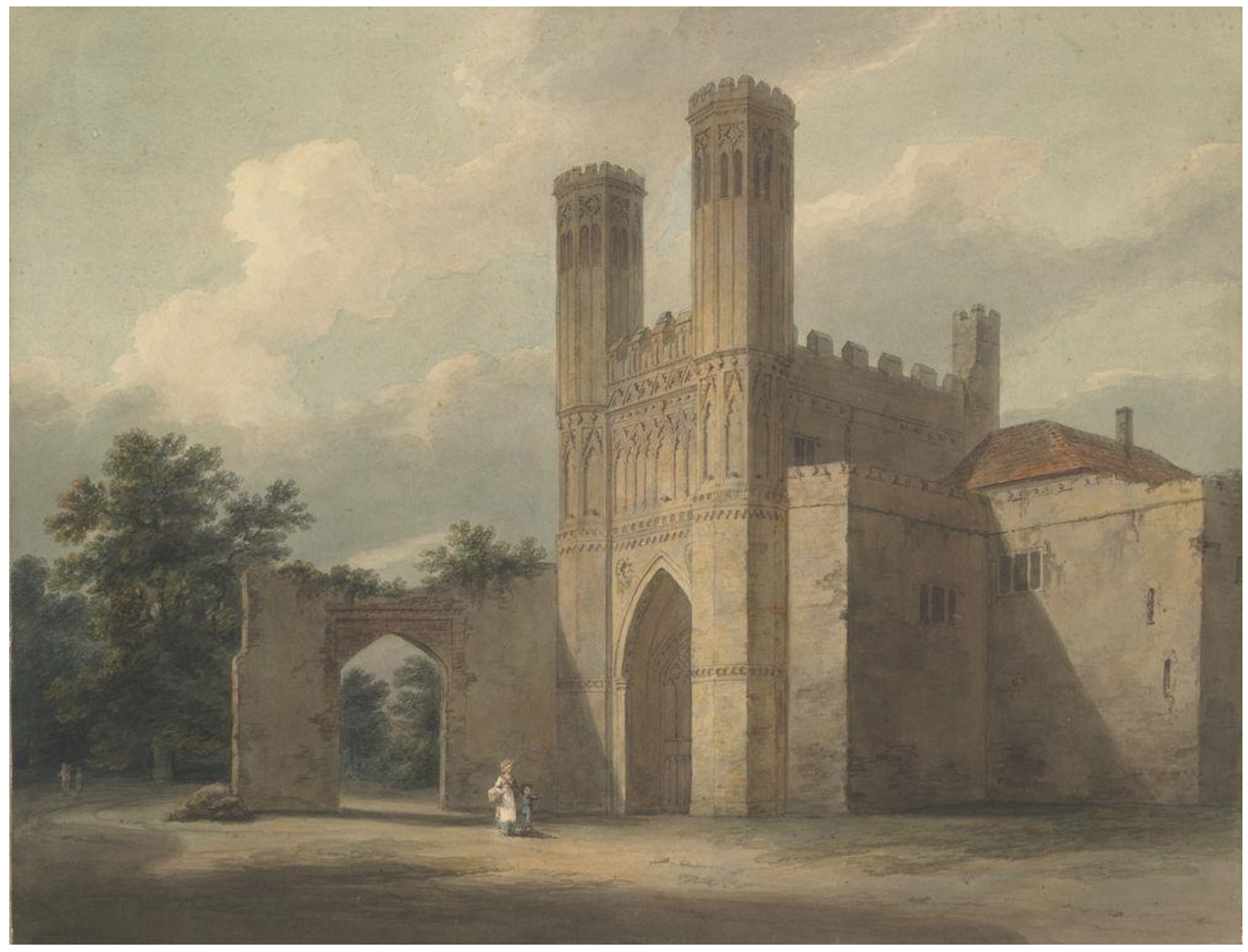

Fig. 43 Edward Dayes (1763-1804), Entrance to Monastery of St. Augustine, Canterbury, 419 x 548, Te Papa, 1957-0009-87.

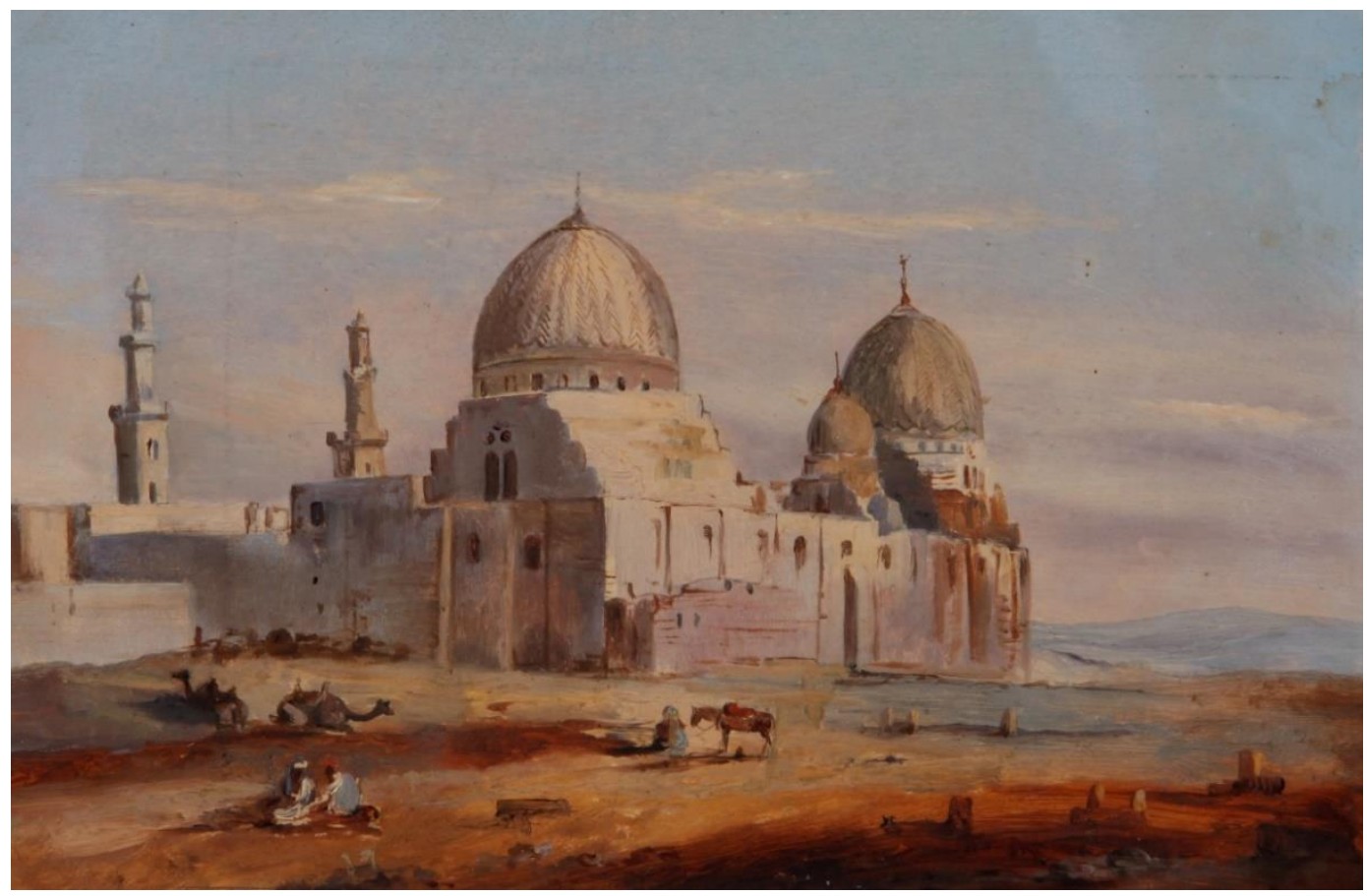

Fig. 44 Frederick Goodall (1822-1904), The Mosque, watercolour and gouache, 204 x 305, DPAG, 500-195X. 


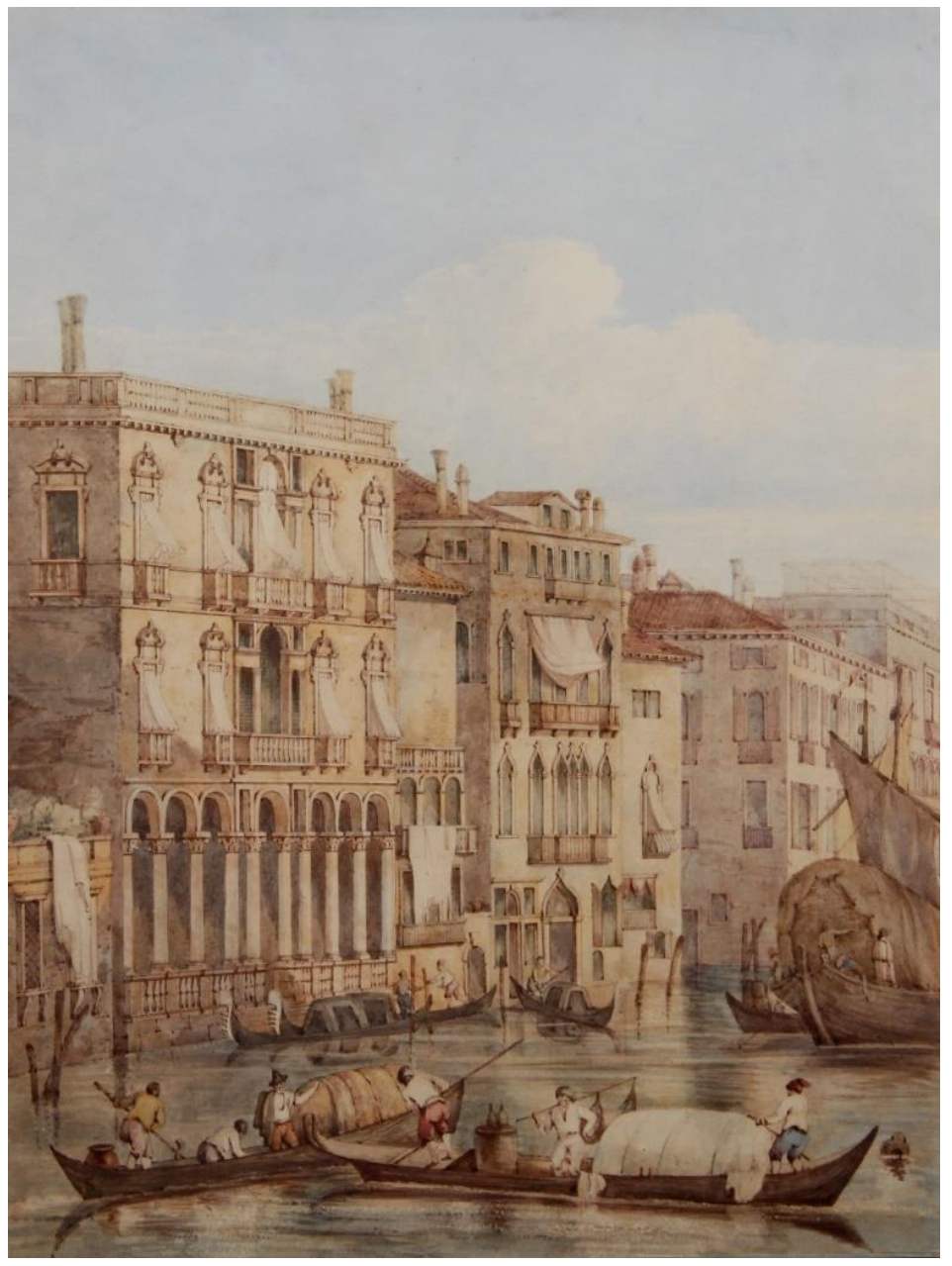

Fig. 45 Samuel Prout (1783-1852), Venetian Canal, 350 x 260, DPAG, 687-195X.

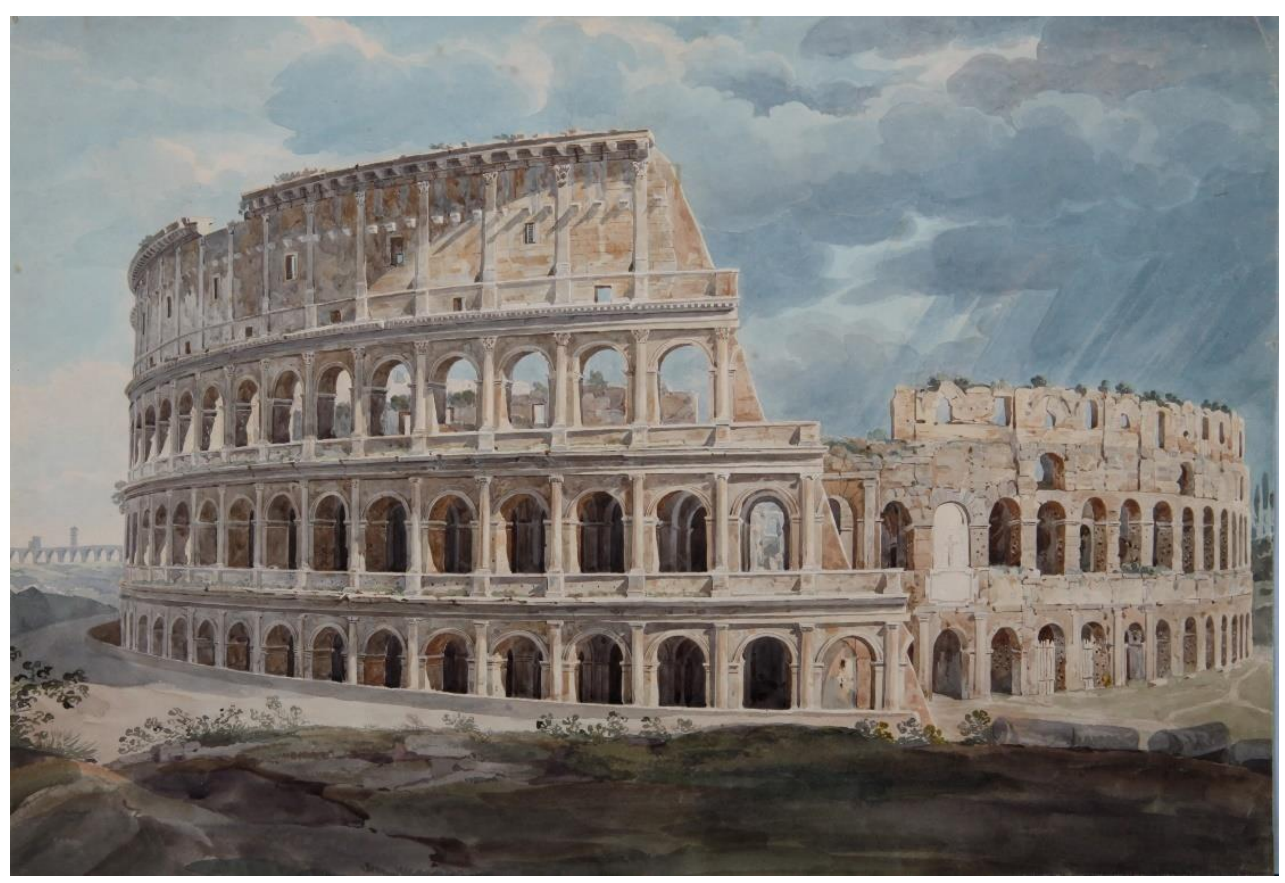

Fig. 46 John Sell Cotman (1782-1842), The Coliseum, 330 x 480, DPAG, 372-195X. 


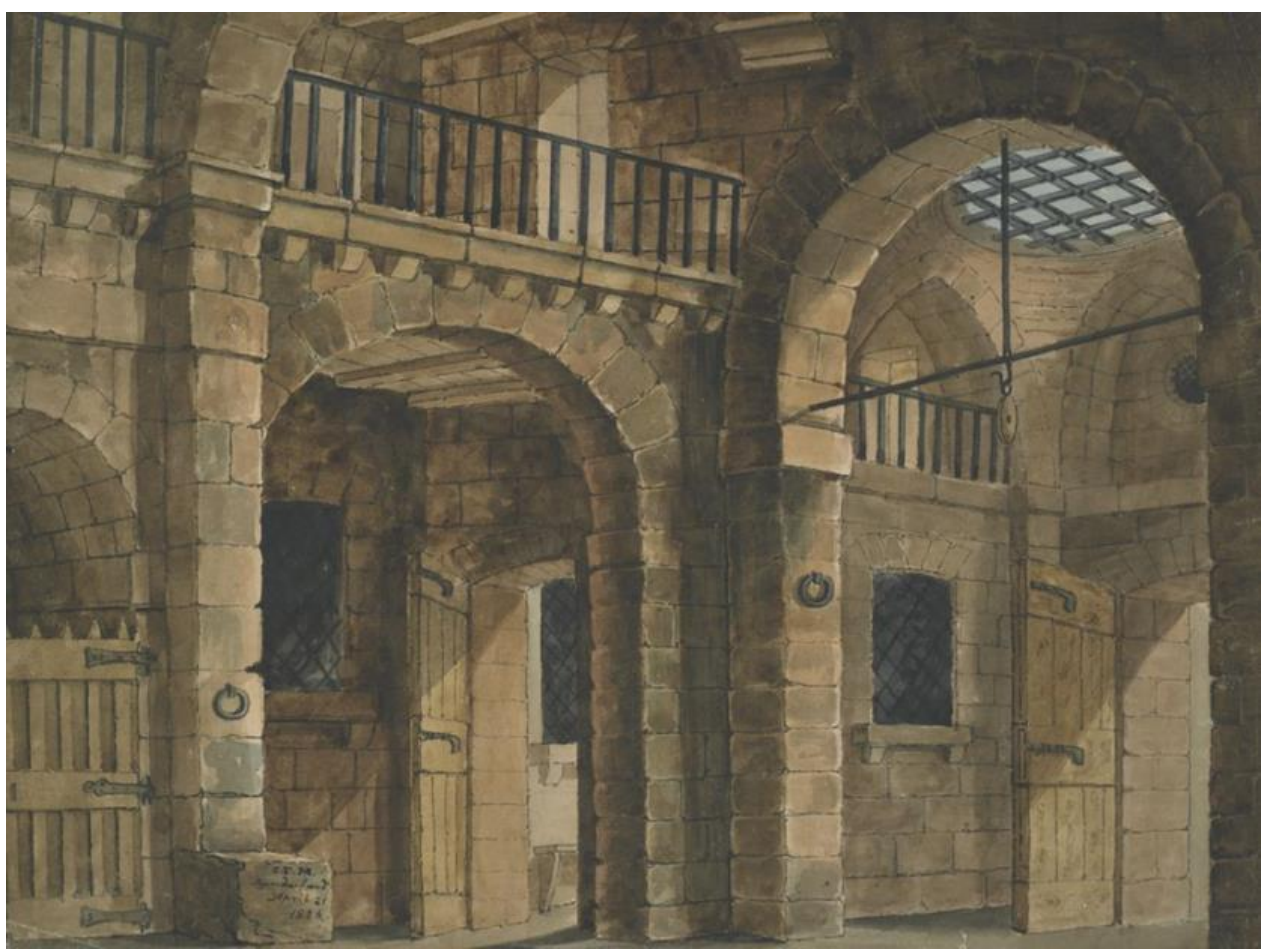

Fig. 47 C.F. Maltby, Sunderland, 21 April 1826, 211 x 279, Te Papa, 1957-0009-173.

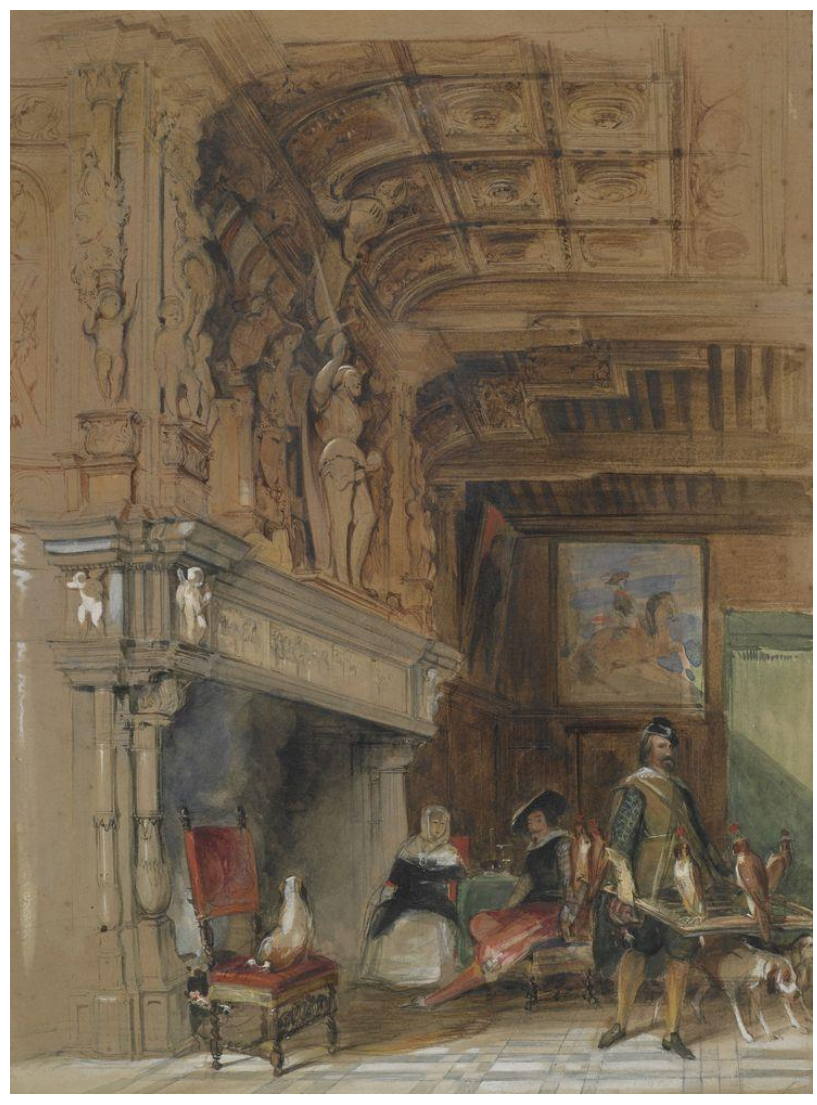

Fig. 48 George Cattermole (1800-1868), An Old English Mansion in the Days of Hawking, 382 x 283, Te Papa, 1957-0009-54. 


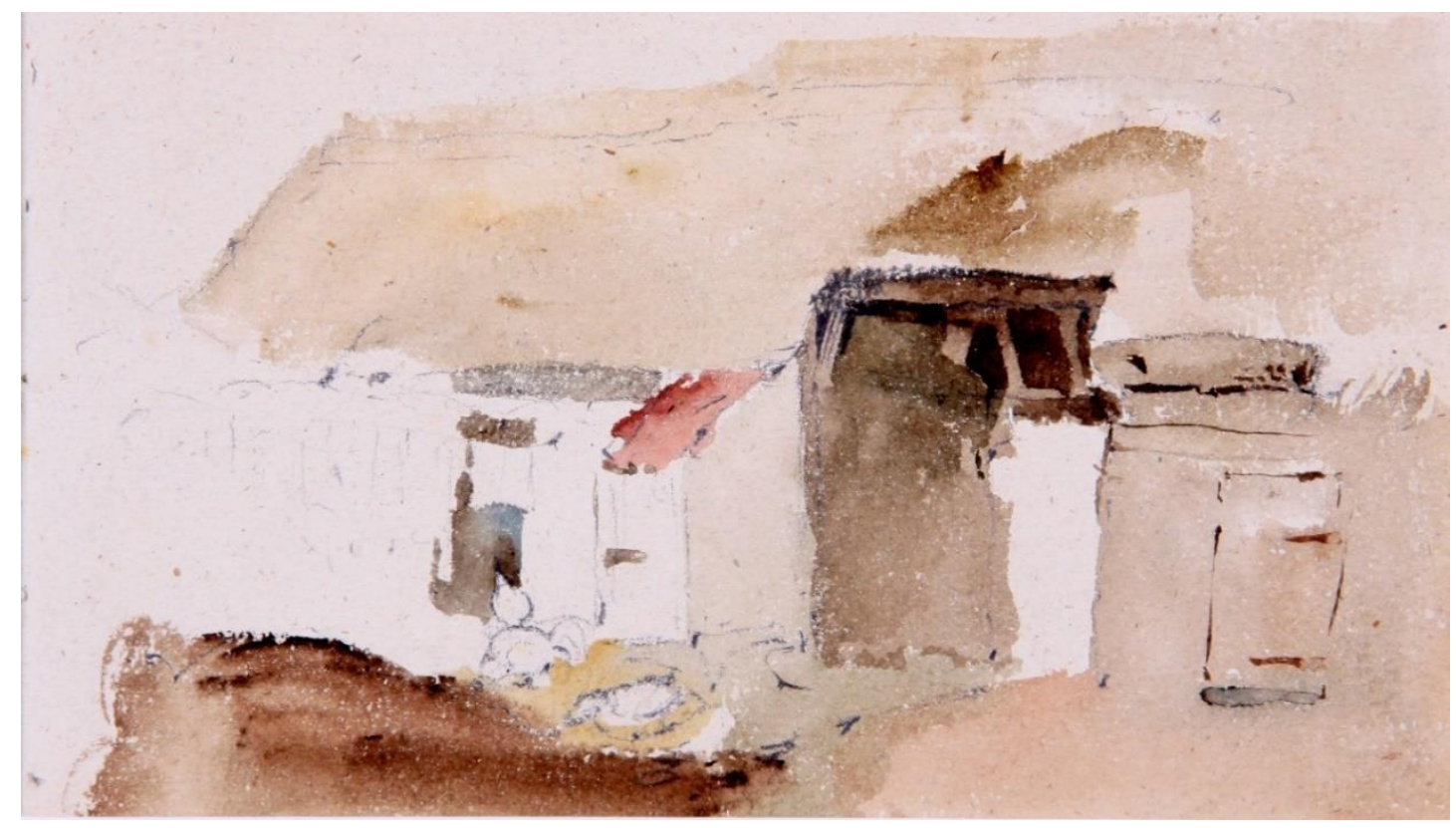

Fig. 49 Peter De Wint (1784-1849), Barn Exterior, 110 x 185, DPAG, 844-195X.

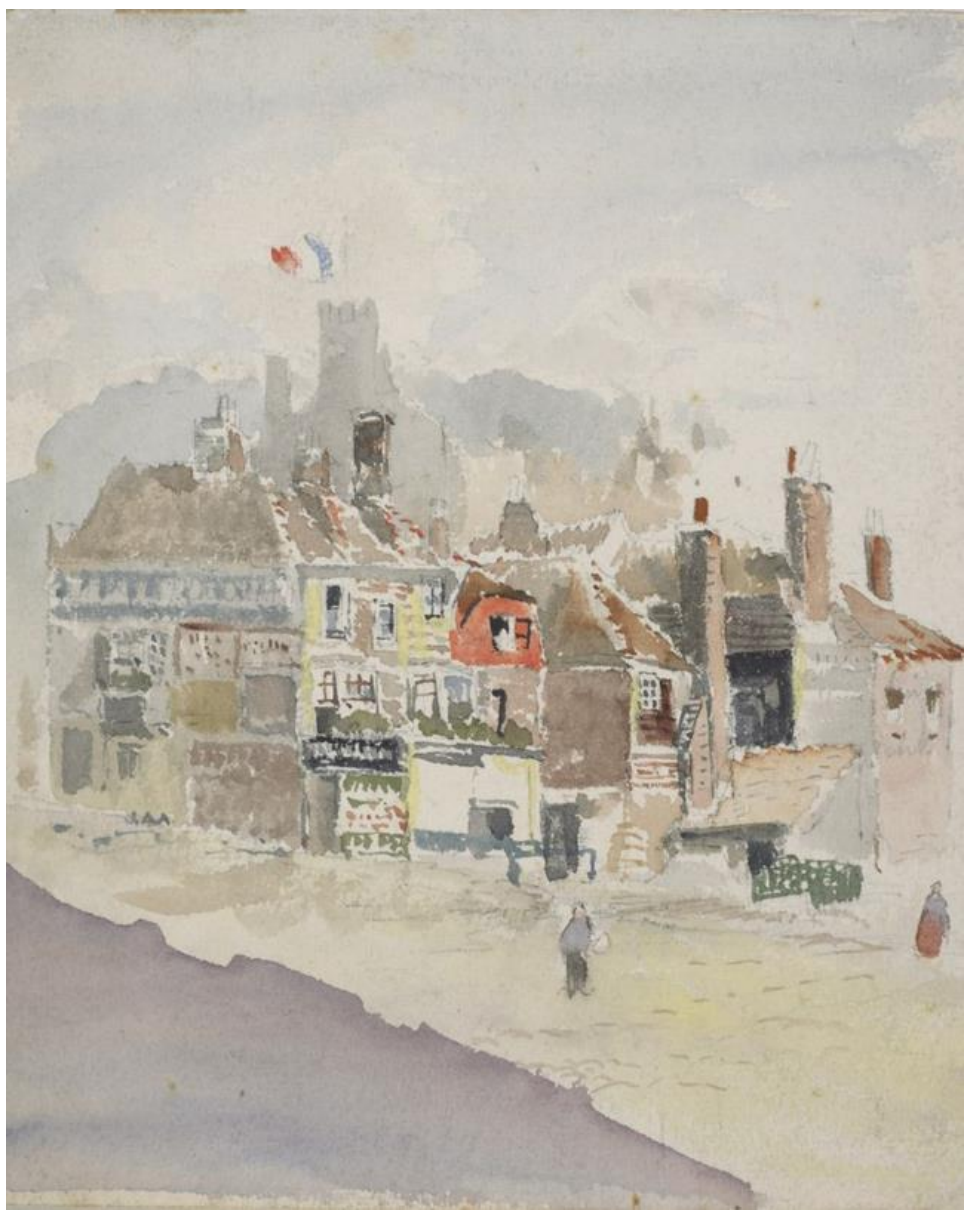

Fig. 50 James A. Aitken (1846-1897), Street Scene, 229 x 189 (407 x 457), Te Papa, $1957-$ 0009-3. 


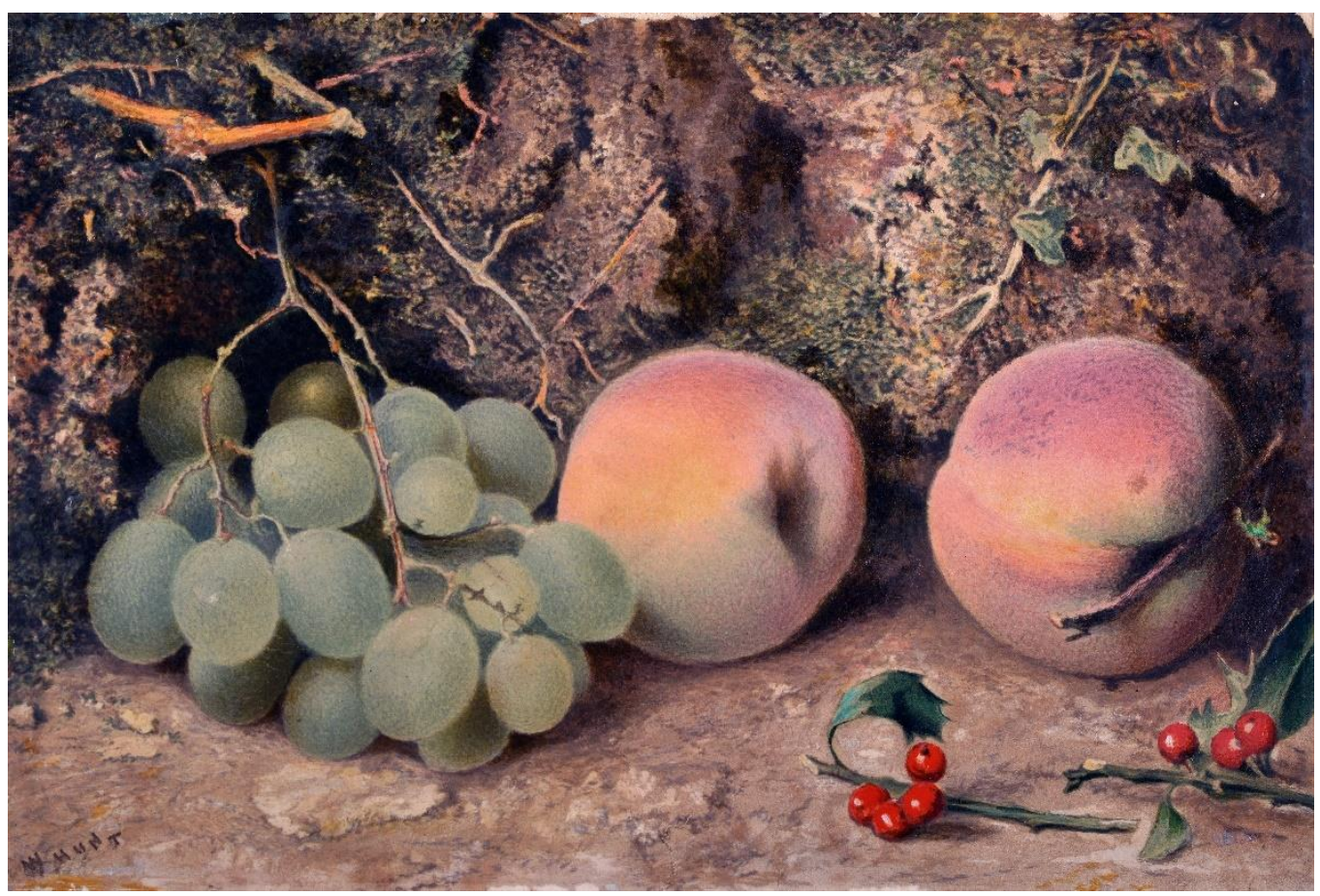

Fig. 51 William Henry Hunt (1790-1864), Still Life, 185 x 285, DPAG, 22-1954.

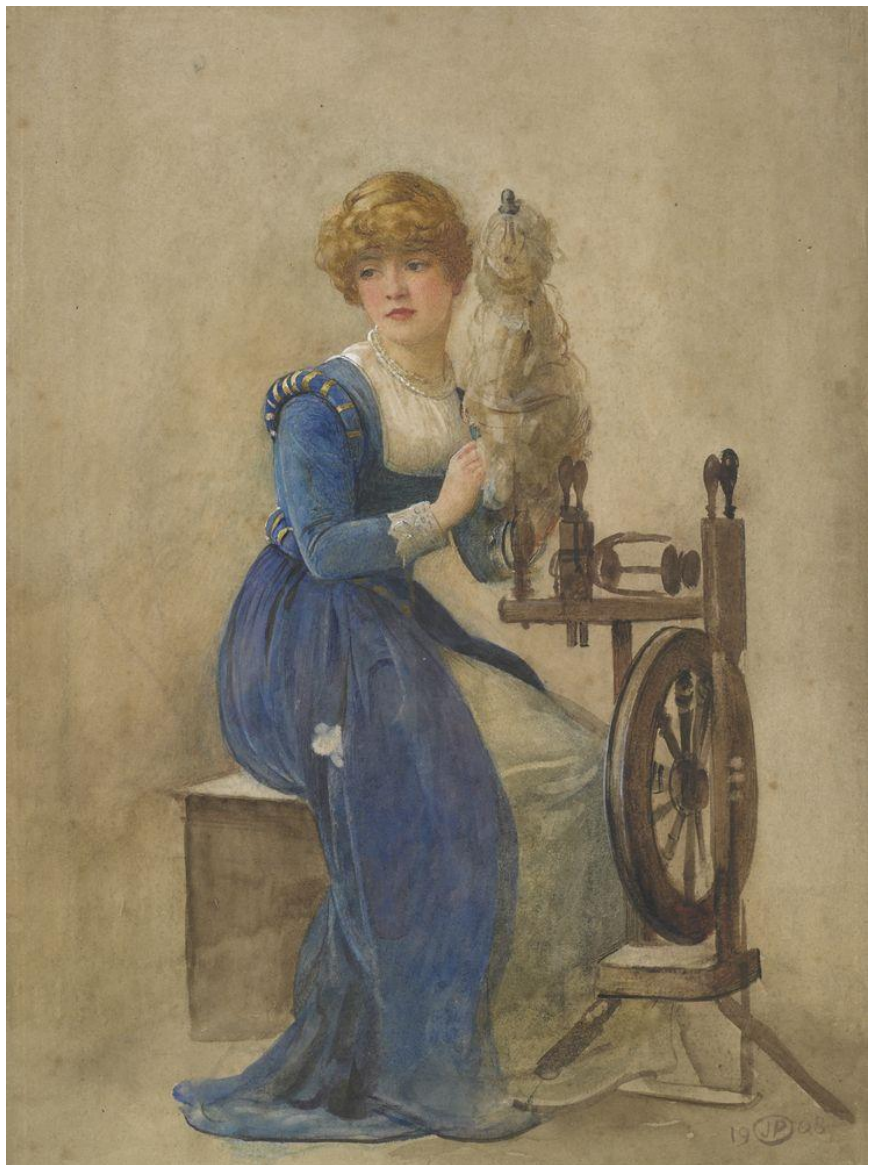

Fig. 52 John Parker (1839-1916), Woman Spinning, 1908, 350 x 258, Te Papa, 1957-0009202. 


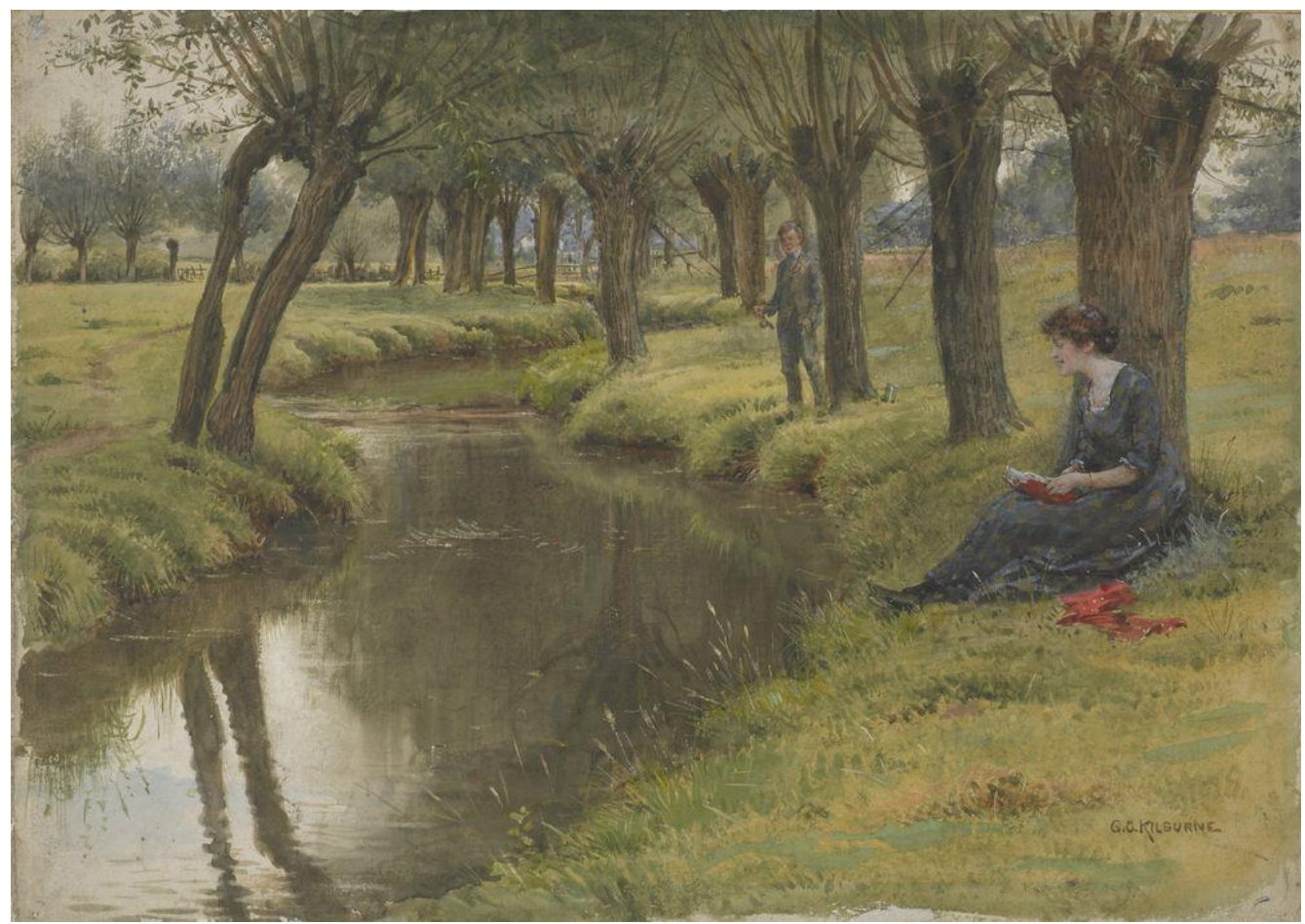

Fig. 53 George G. Kilburne, The River, 280 x 390, Te Papa, 1957-0009-156.

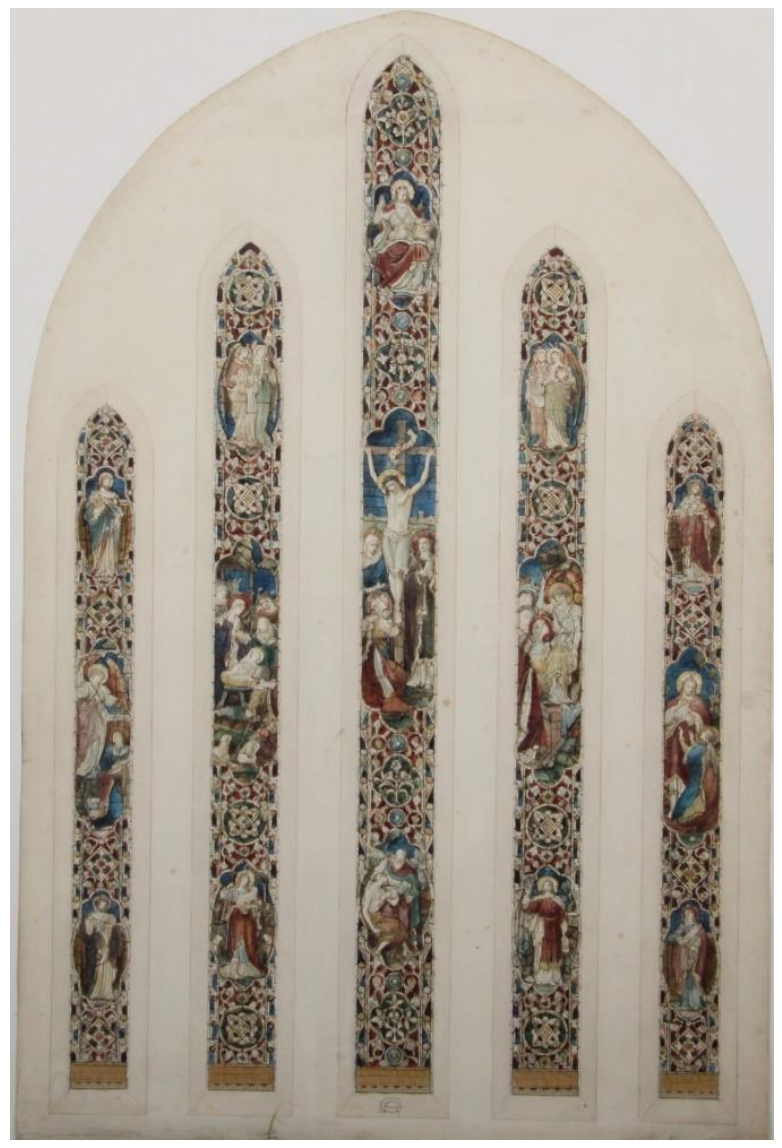

Fig. 54 Dante Gabriel Rossetti (1828-1882), Design for a Stained Glass Window, 800 x 545, DPAG, 6-1953. 


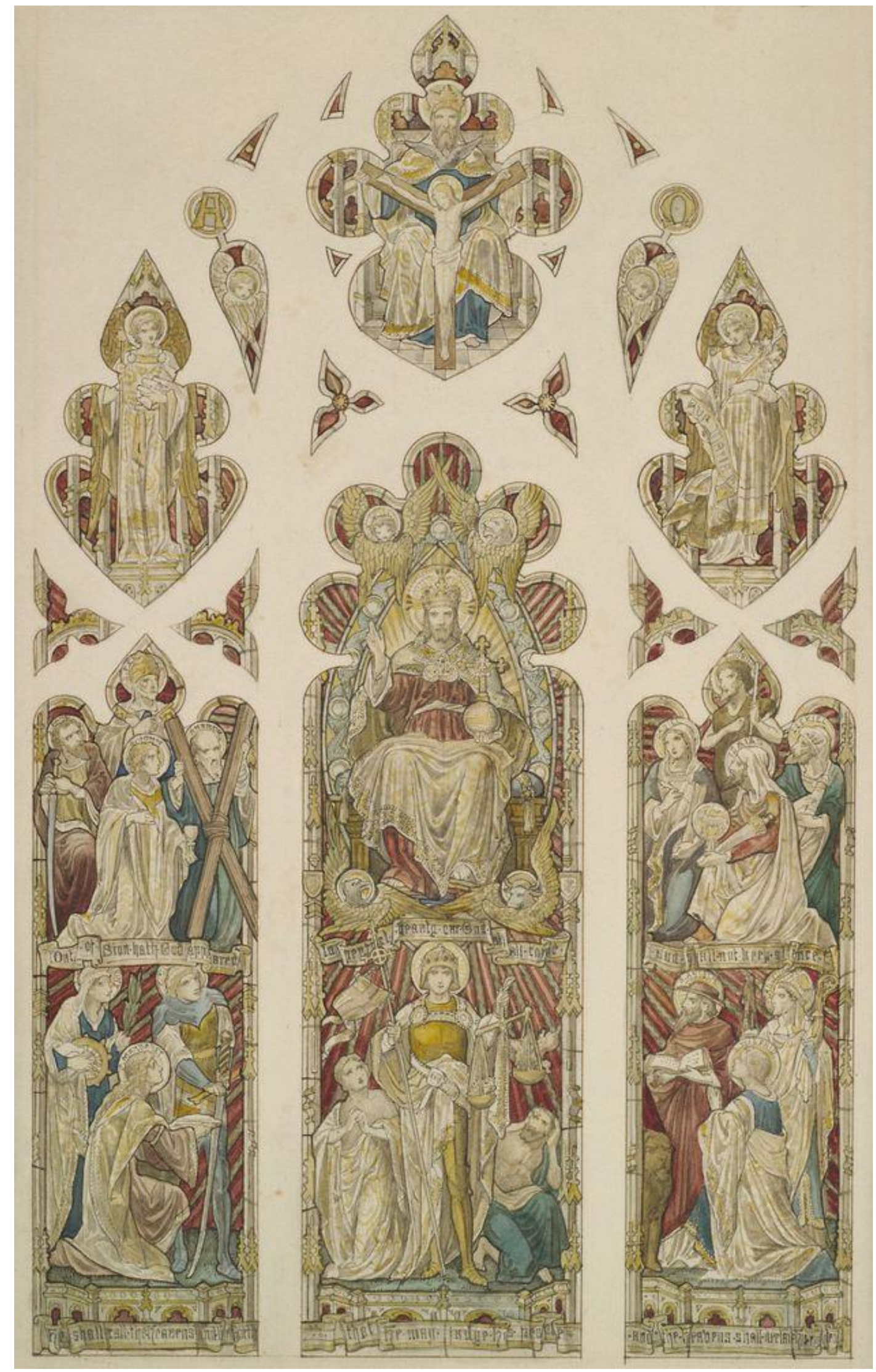

Fig. 55 Edward Burne-Jones (1833-1898), Design for Stained Glass, ink and watercolour, 375 x 240 (558 x 457), Te Papa, 1957-0009-43. 


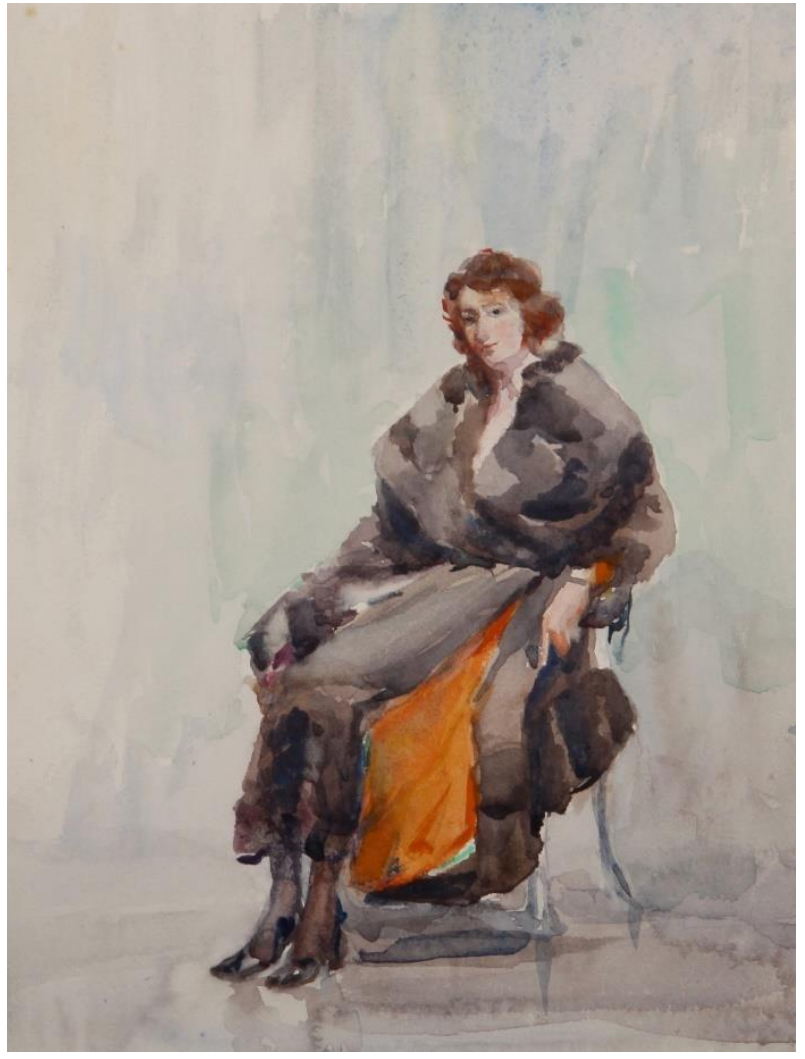

Fig. 56 Frederick Robinson (1862-1927), Sketch of a Model, 250 x 190, DPAG, 714-195X.

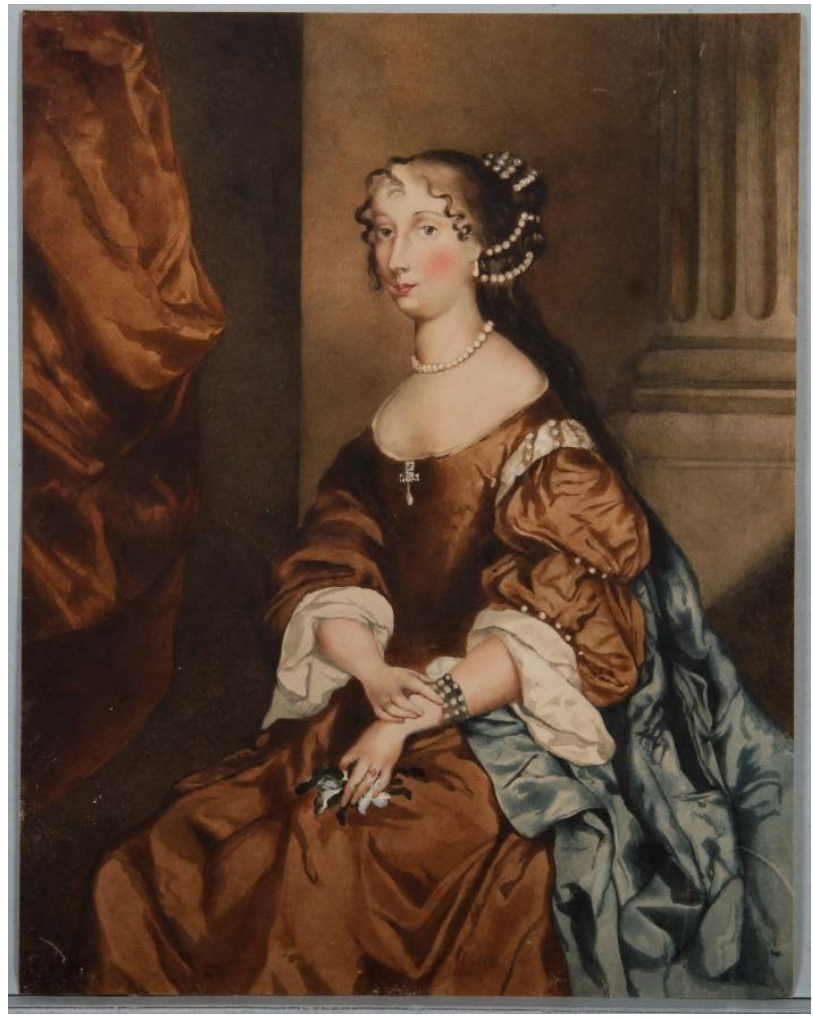

Fig. 57 Unknown, Copy of a Painting of a 17th Century Lady, 330 x 260, DPAG, 888$195 X$. 


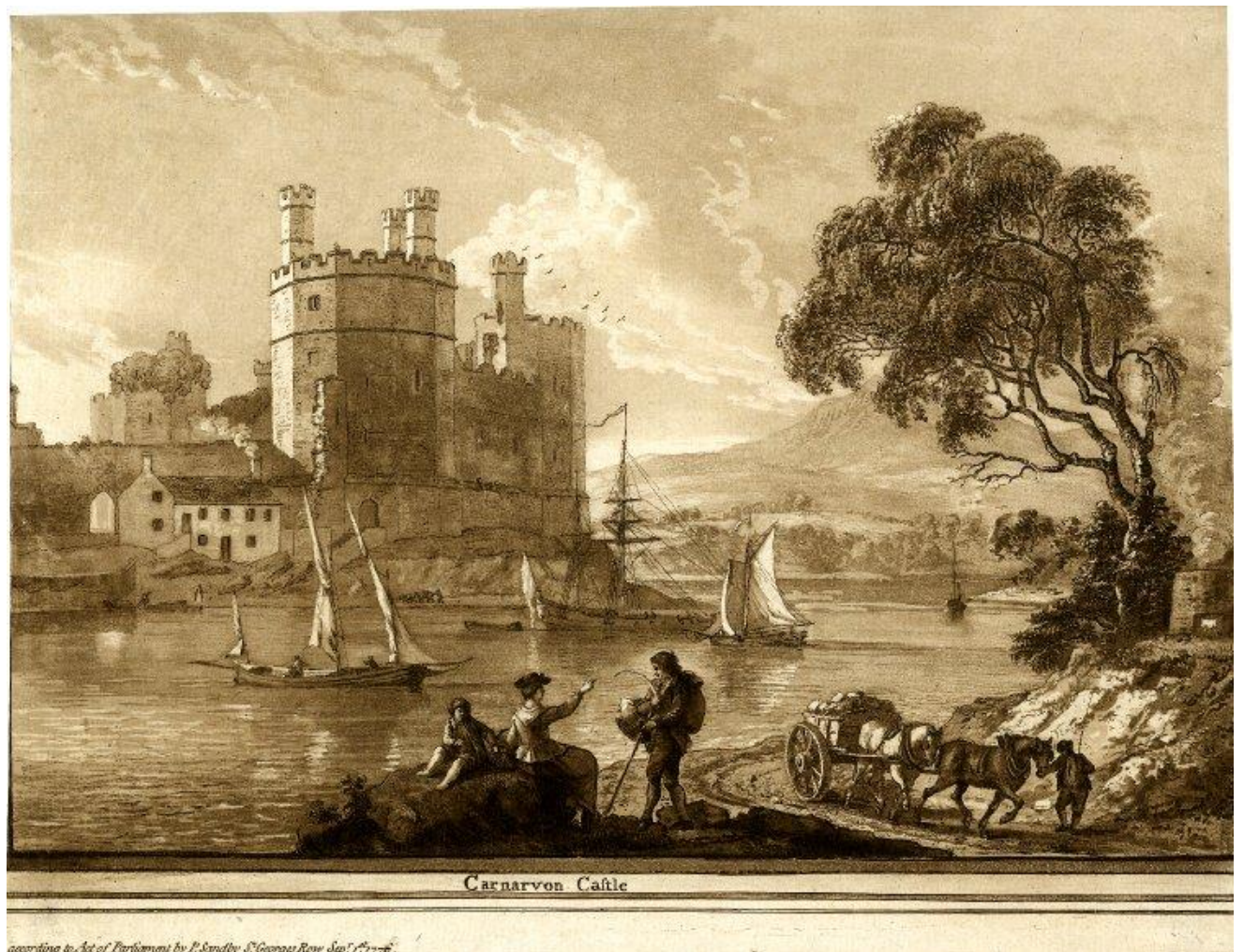

Fig. 58 Paul Sandby, Views in Wales: 'Fifth Set' / Carnarvon Castle, 1777, etching and aquatint, 205 x 264, The British Museum, 1872,0713.534.

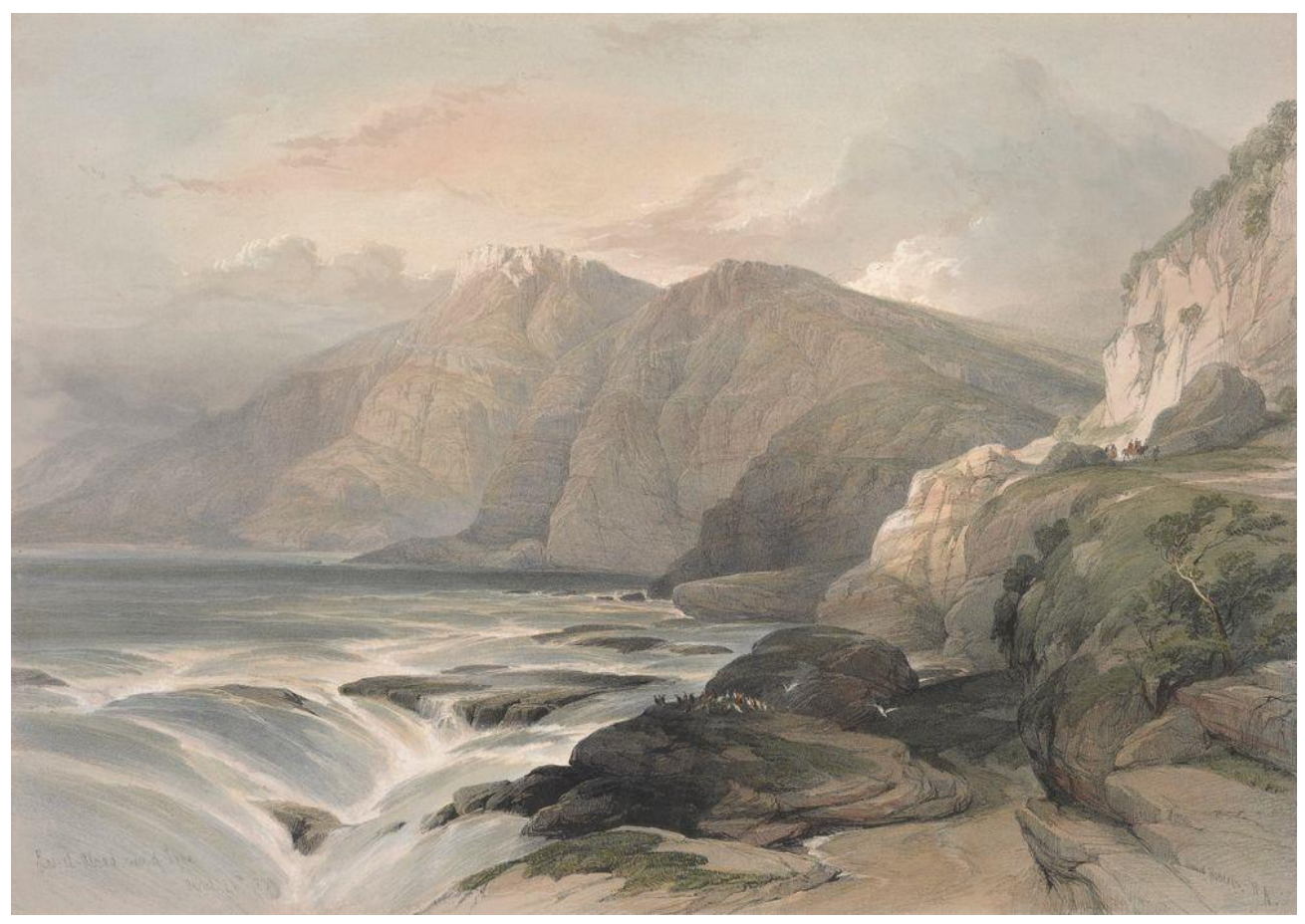

Fig. 59 David Roberts, Ras-El-Abiad, Coast of Syria, lithograph, Te Papa, 1980-0054-1. 


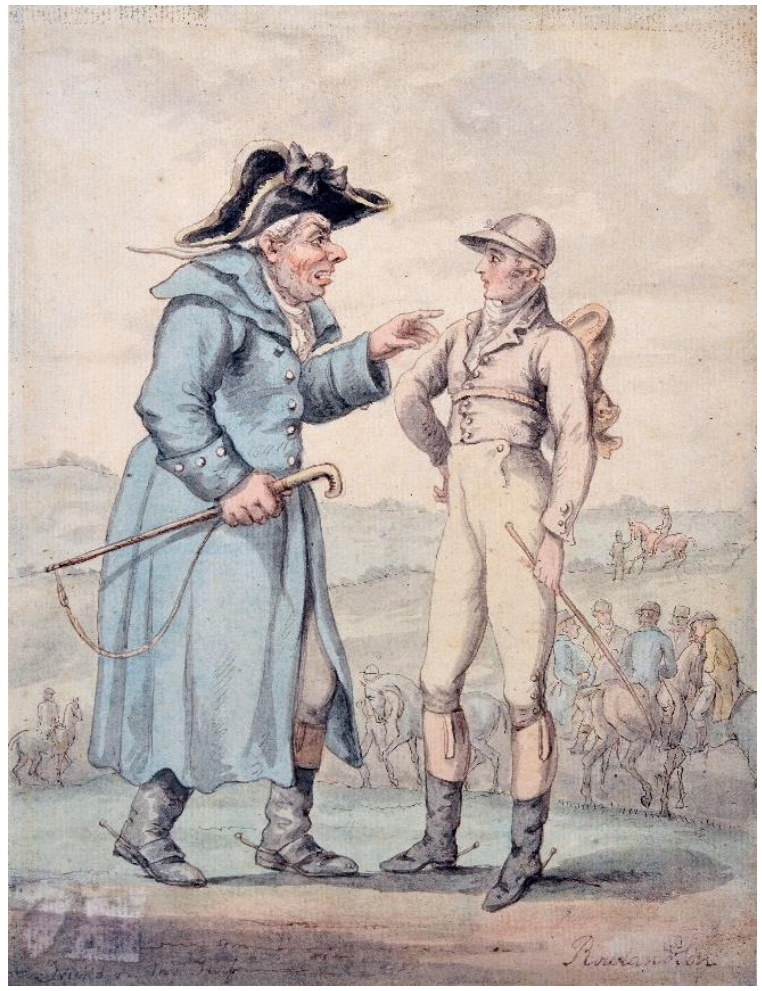

Fig. 60 Thomas Rowlandson (1756-1827), Tricks on the Turf, ink and watercolour, $255 \mathrm{x}$ 195, DPAG, 104-195X.

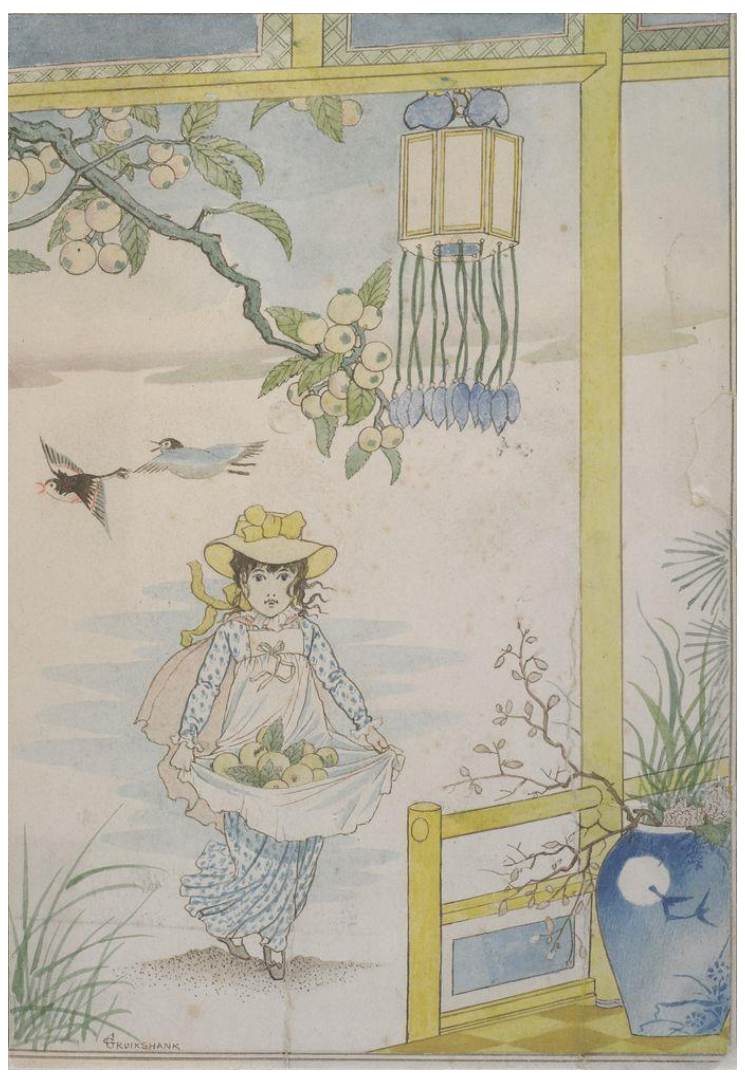

Fig. 61 George Cruikshank (1792-1878), Girl with Apples, 220 x 154, Te Papa, 1957-000983. 


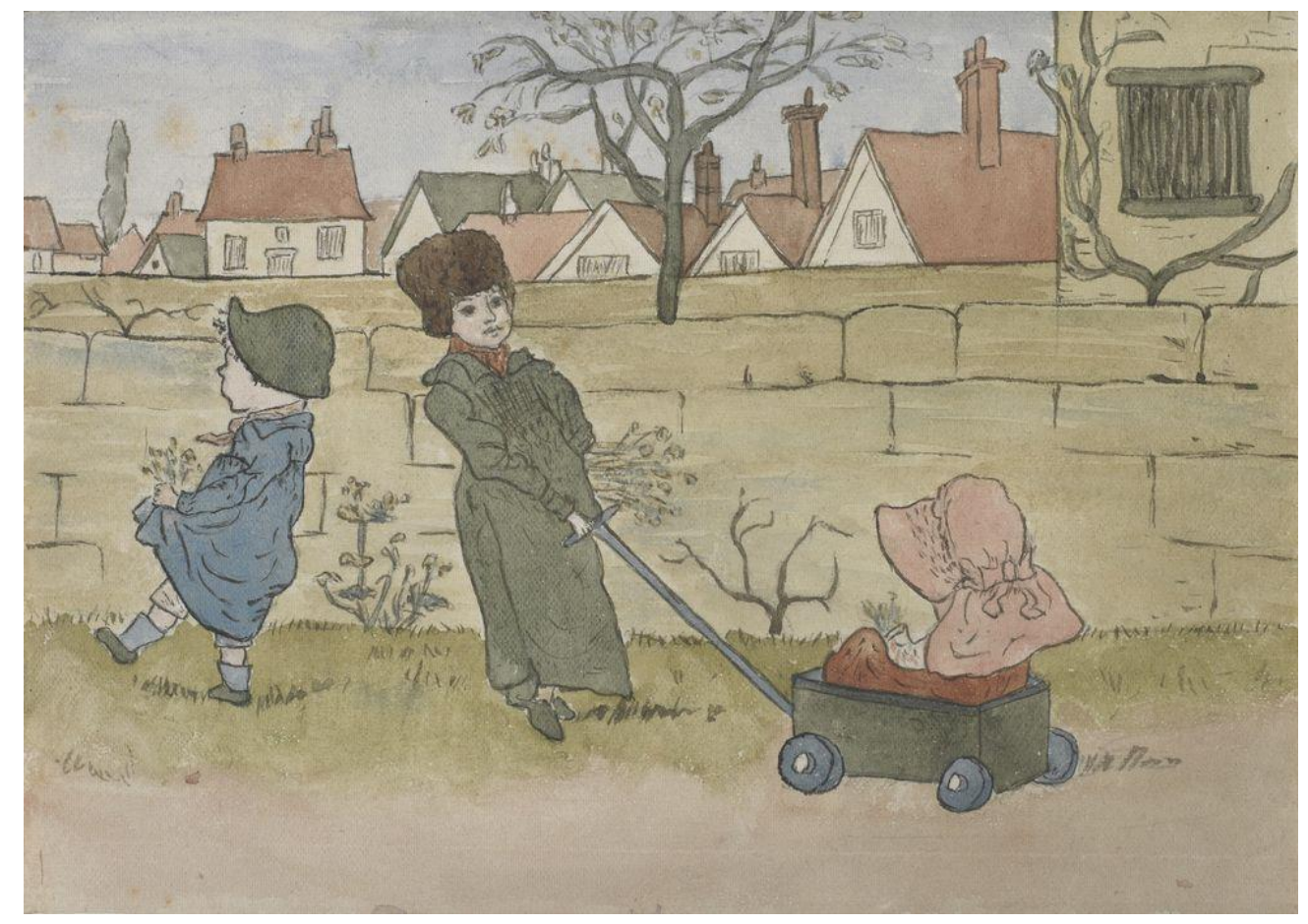

Fig. 62 Kate Greenaway (1846-1901), Children Playing, 128 x 180, Te Papa, 1957-0009117.

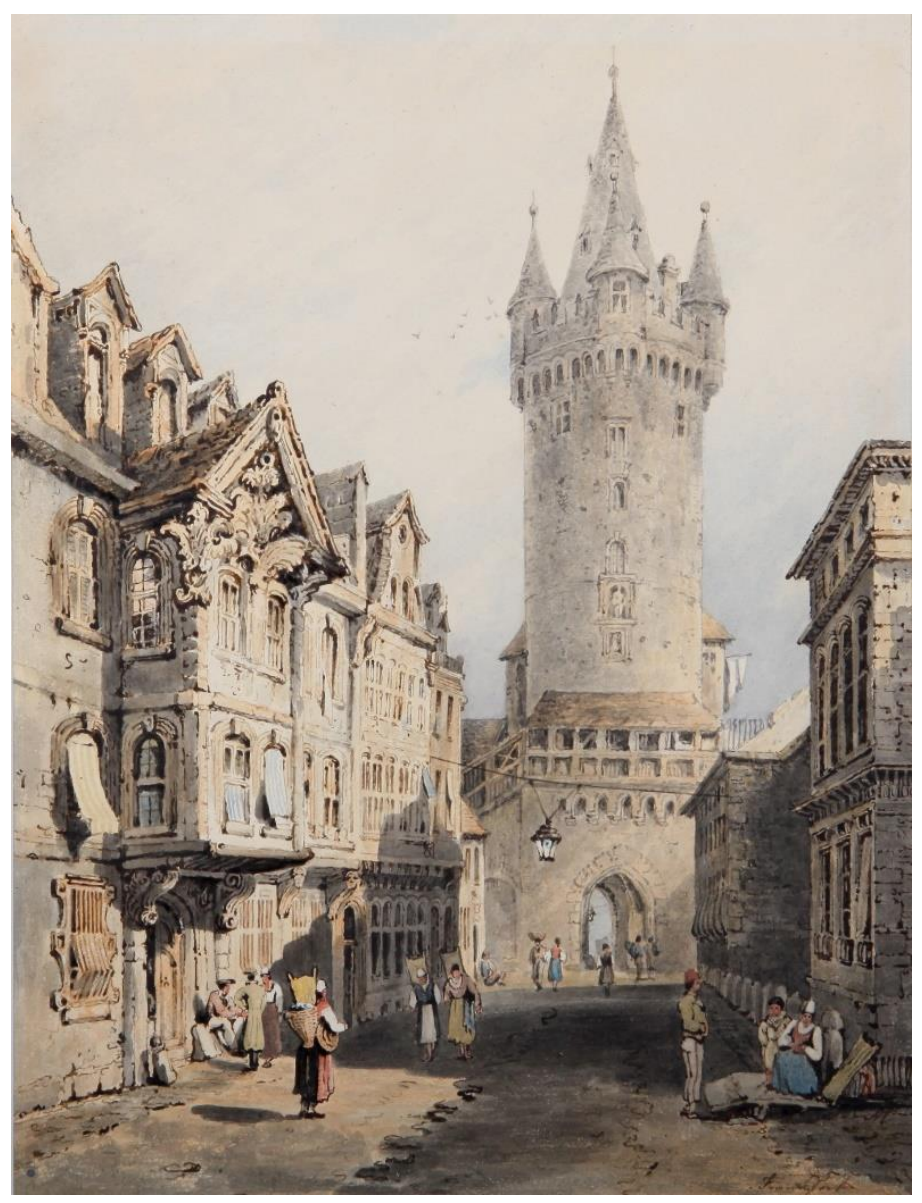

Fig. 63 Anne Parrott, Frankfort, 360 x 275, DPAG, 672-195X. 


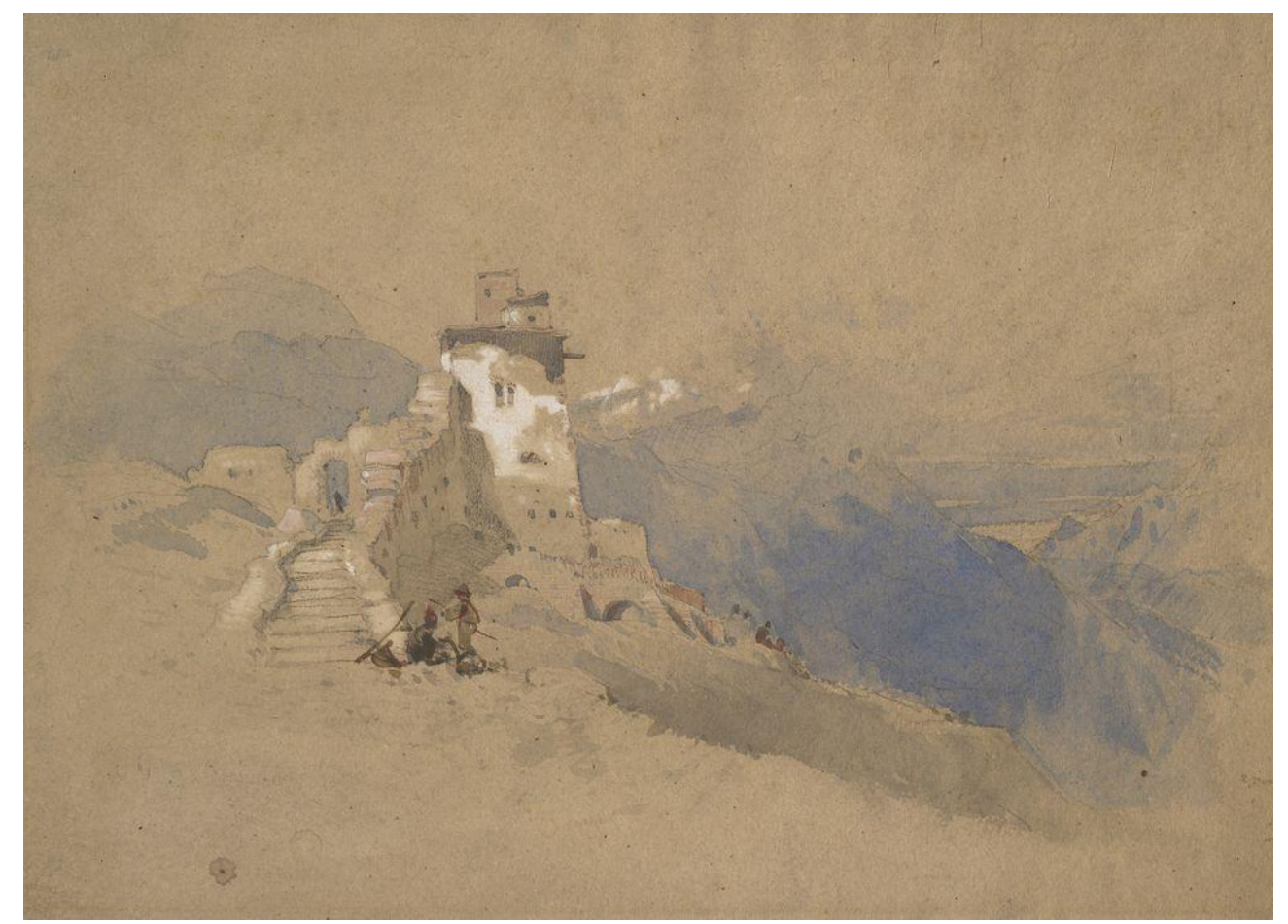

Fig. 64 John Ruskin, Italian Mountain Scene, 272 x 372, 1833-1888, Te Papa, 1957-0009225 .

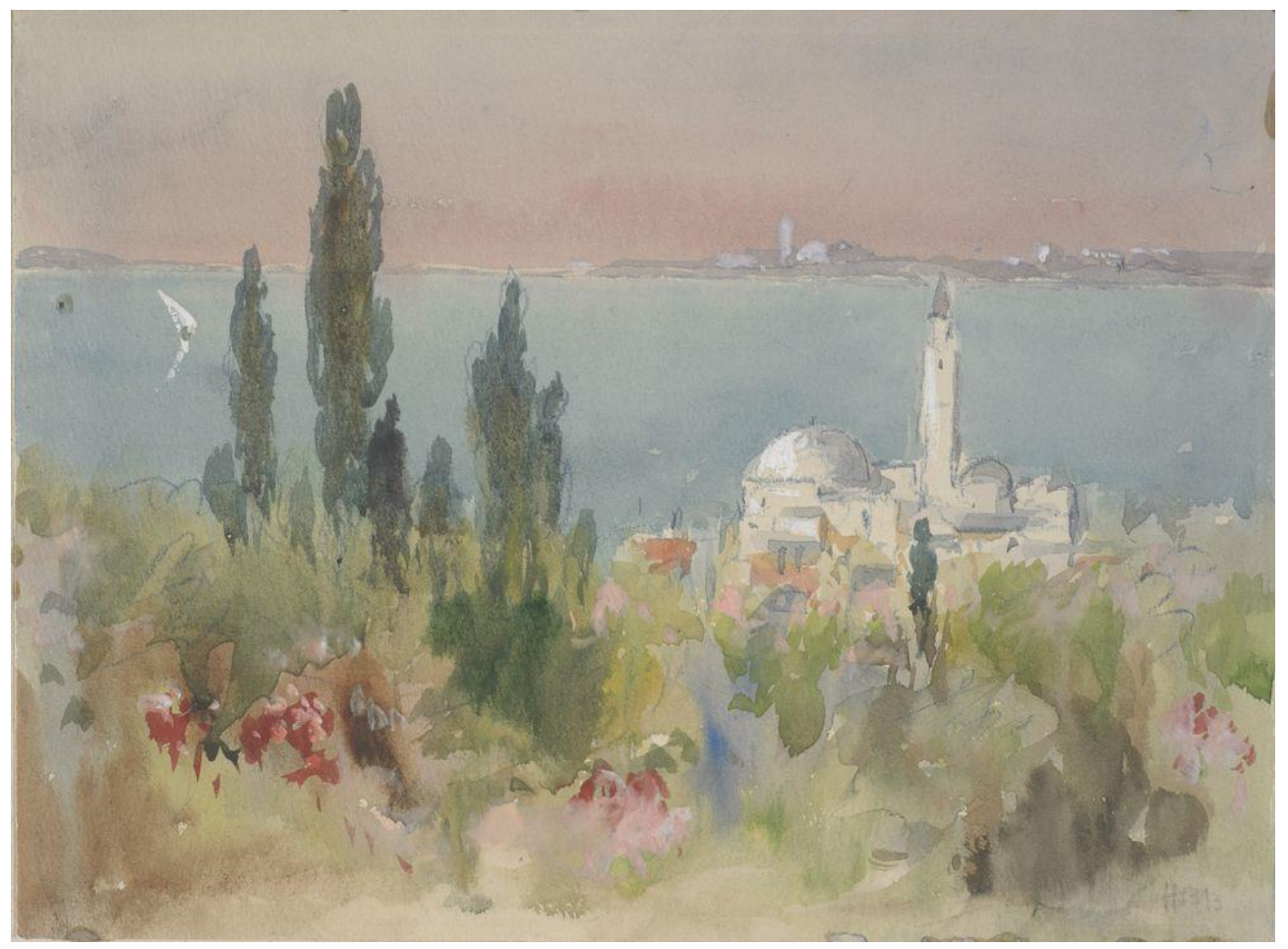

Fig. 65 Hercules Brabazon (1821-1906), Lake Scene, Te Papa, 1957-0009-27. 


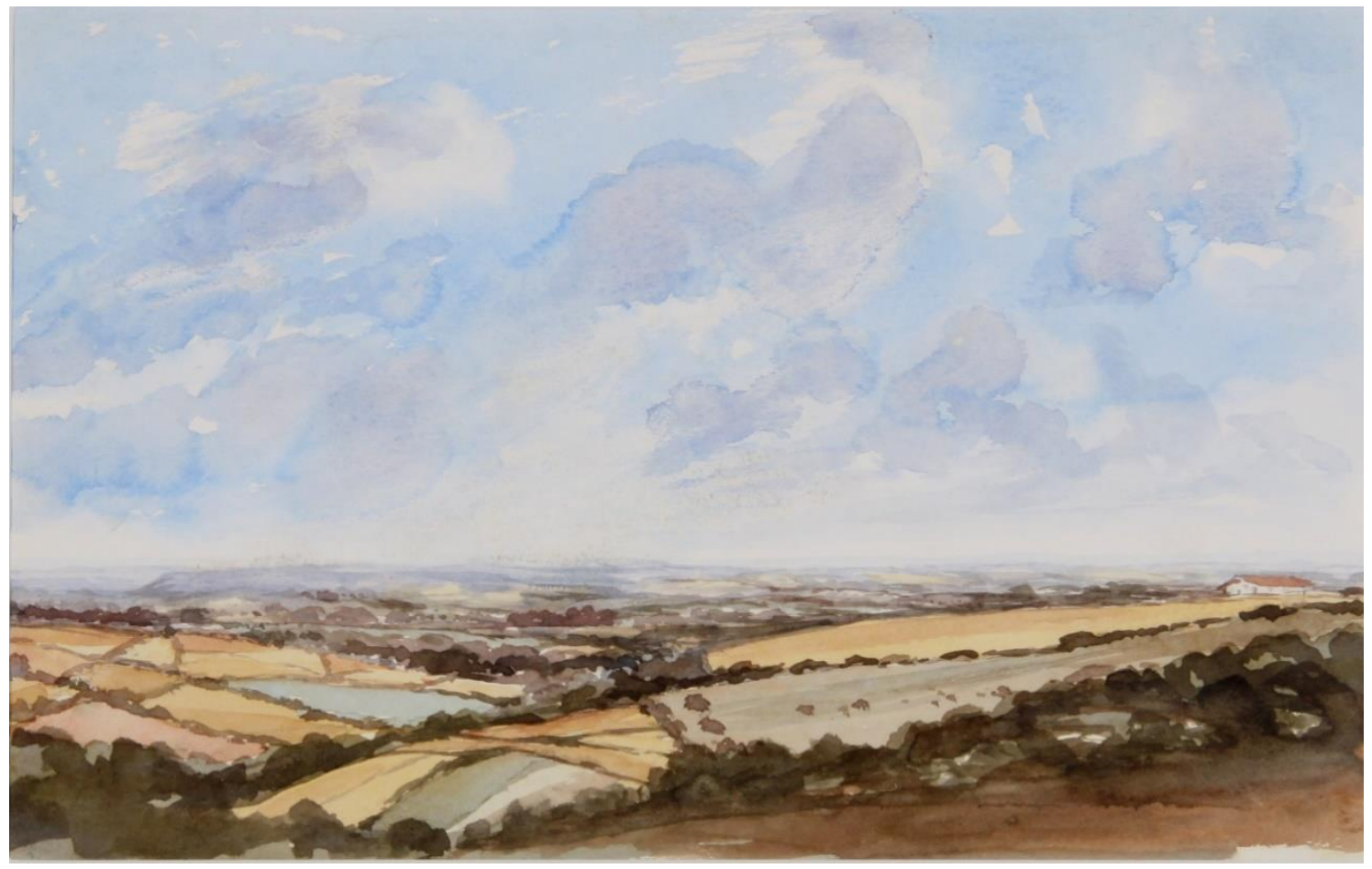

Fig. 66 Thomas Collier (1840-1891), Kentish Landscape, 1870s-1880s, 210 x 330, DPAG, 153-195X.

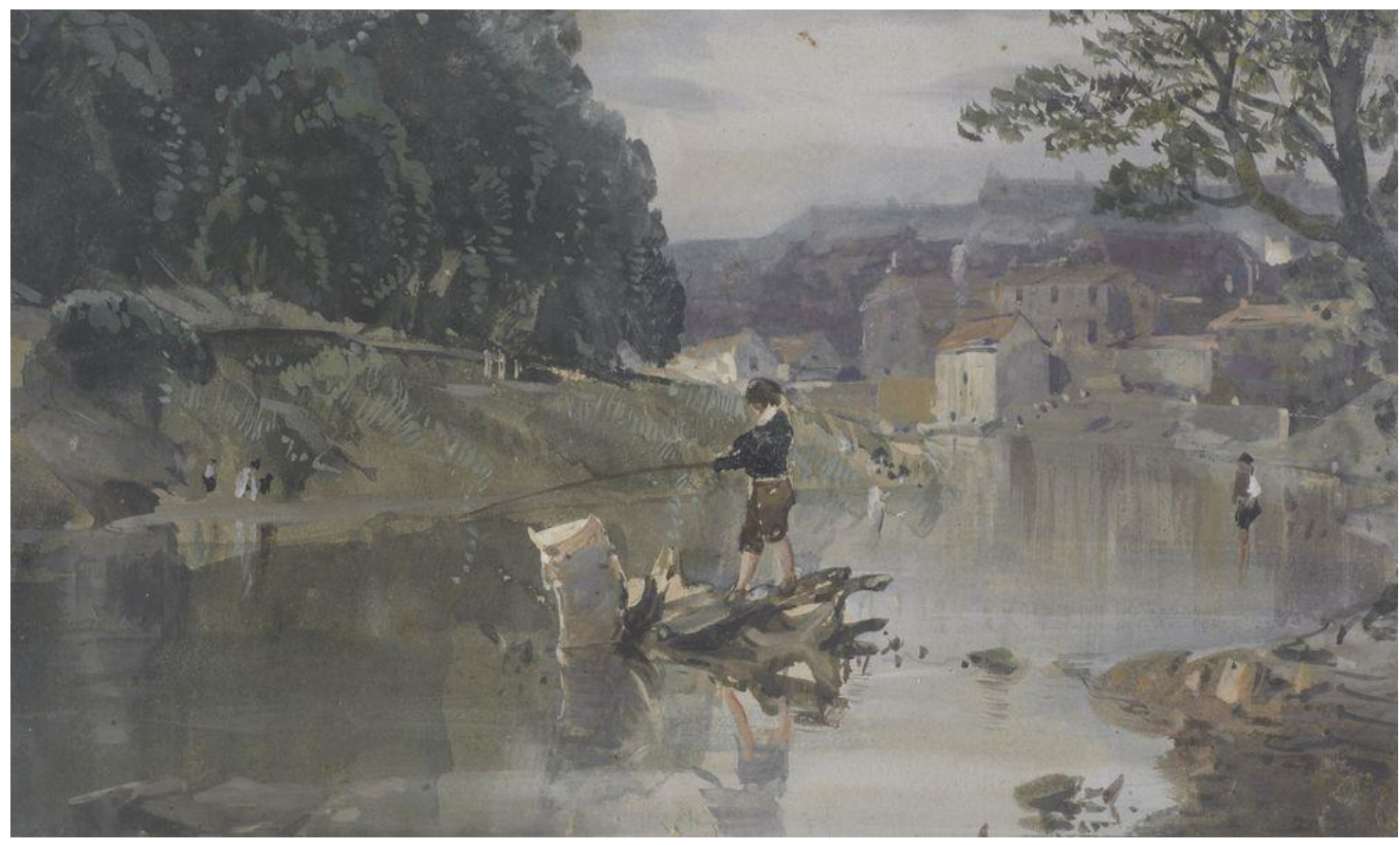

Fig. 67 William Beverley (1811-1889), River Scene - Boy Fishing, 165 x 267, Te Papa, 1957-0009-20. 


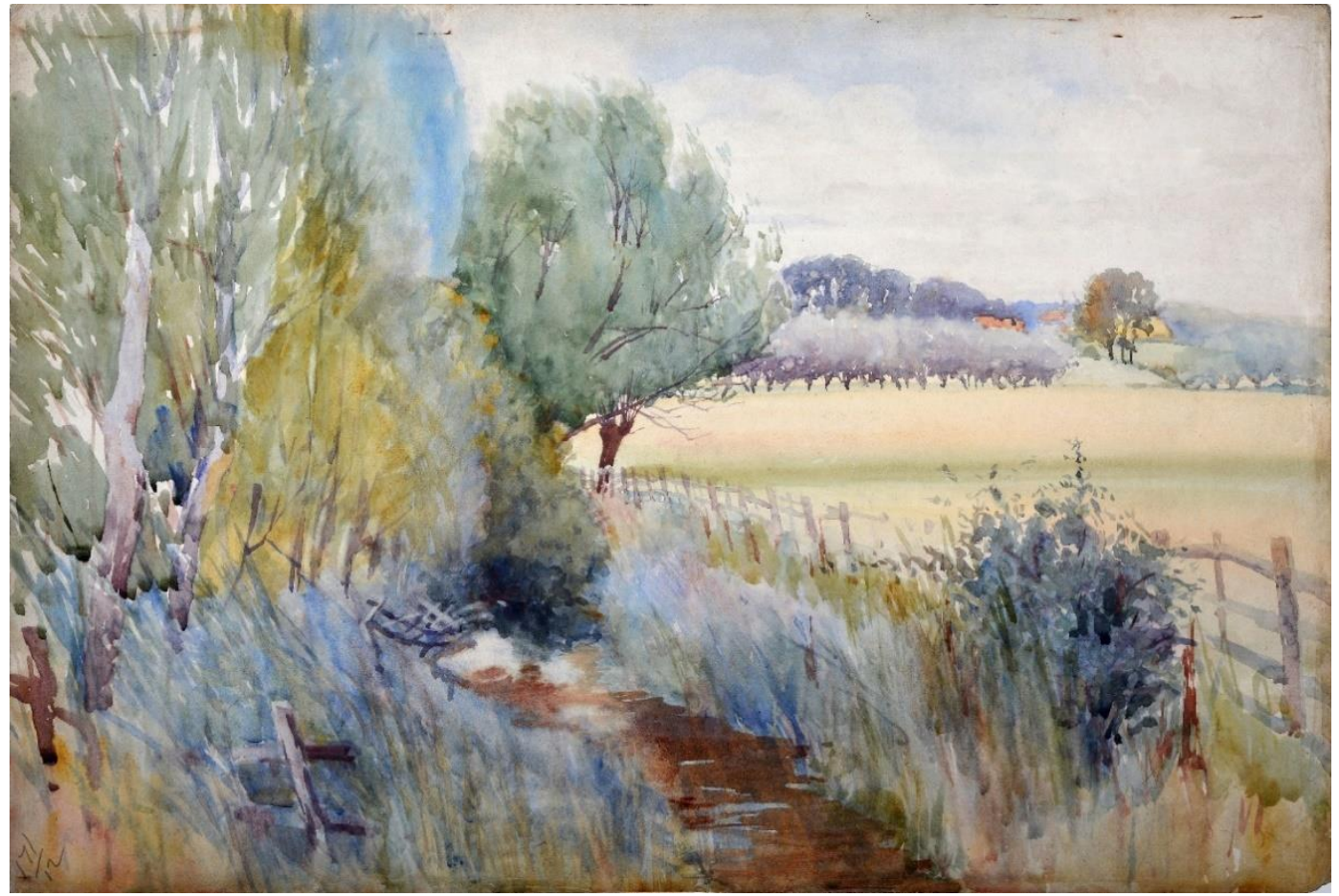

Fig. 68 George Clausen (1852-1944), Landscape, 335 x 505, DPAG, 856-195X.

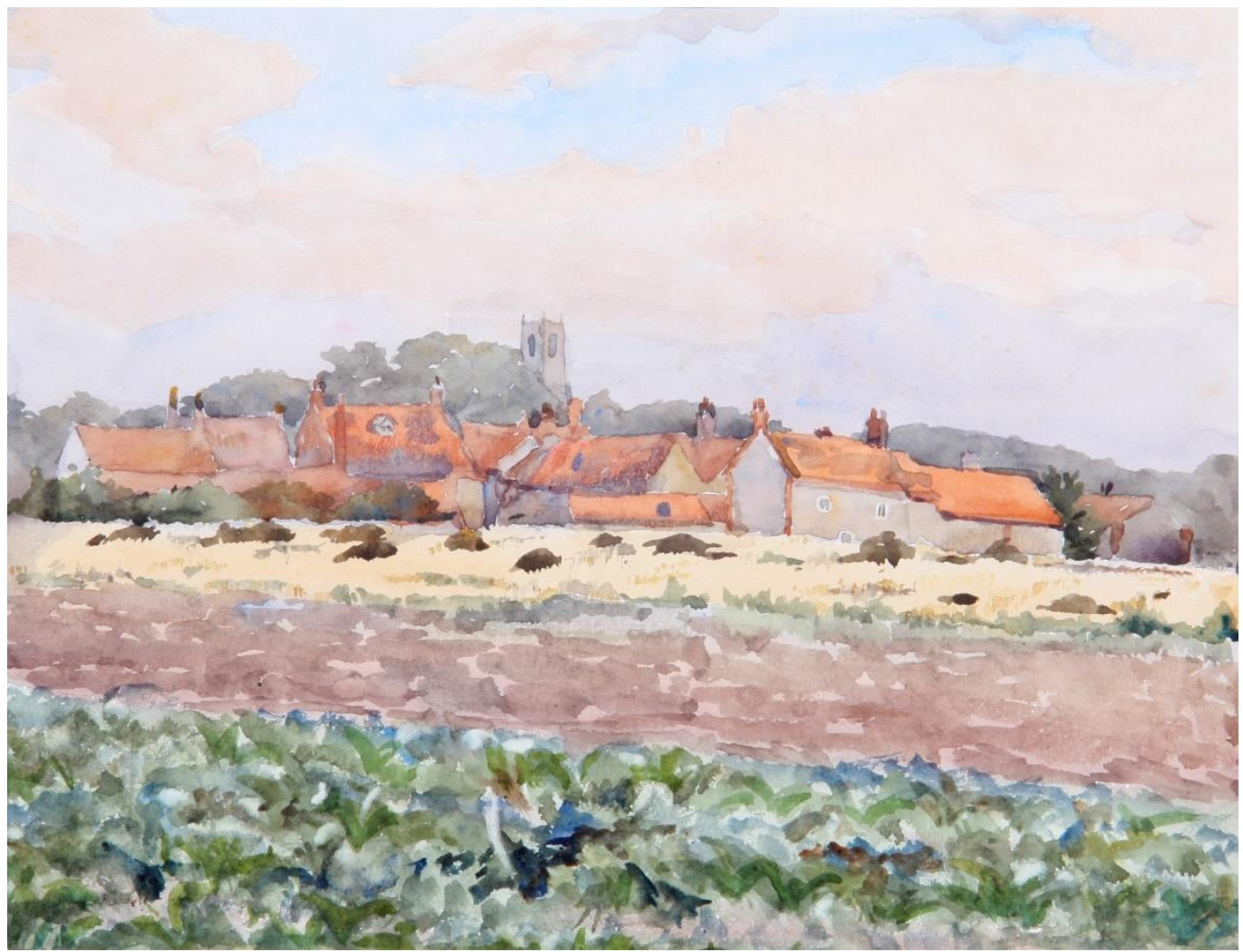

Fig. 69 William Fisher (1841-1923), Blakeney, 1906, 230 x 285, DPAG, 26-195X. 


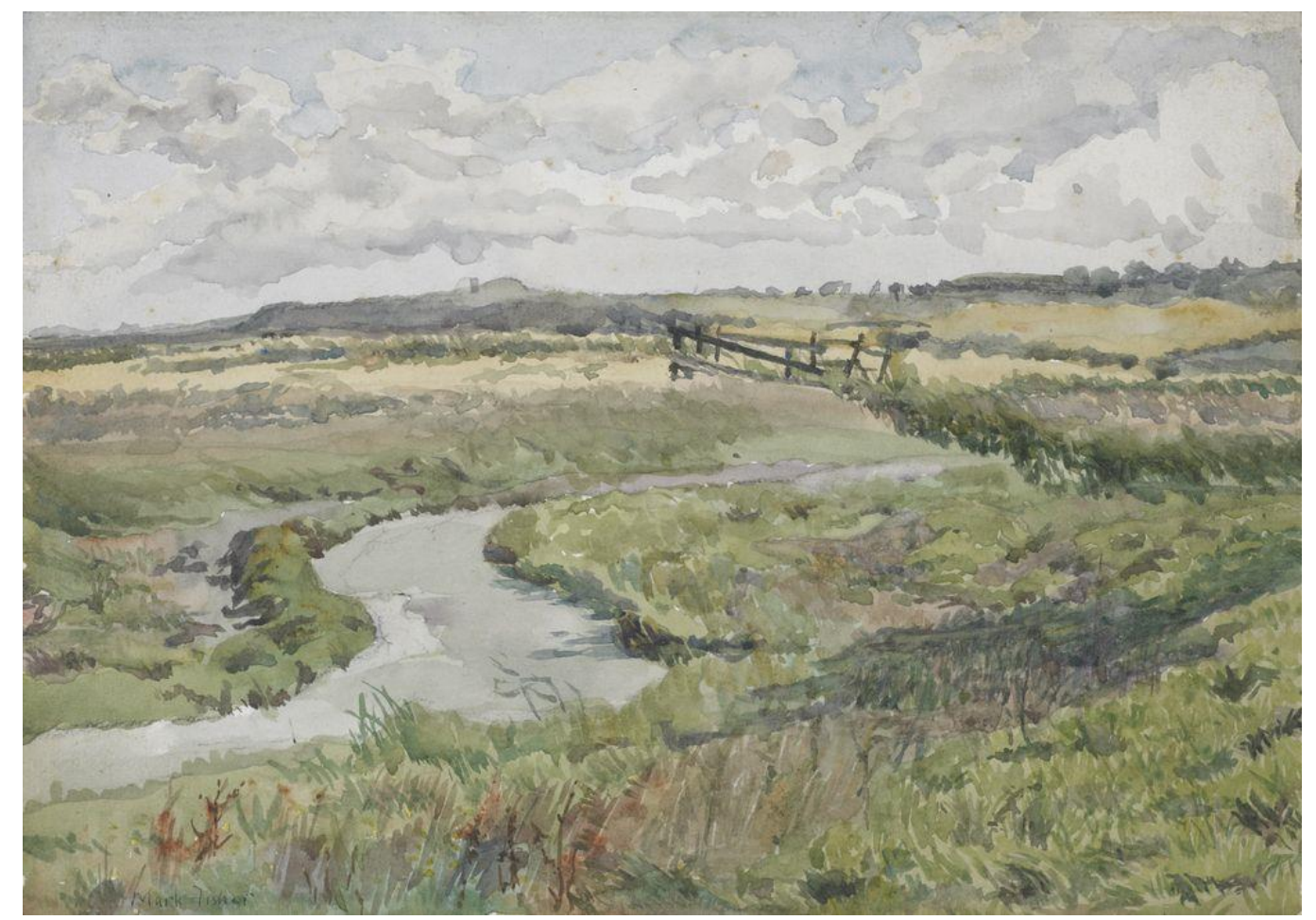

Fig. 70 William Fisher, Landscape with Stream, 230 x 318, Te Papa, 1957-0009-104.

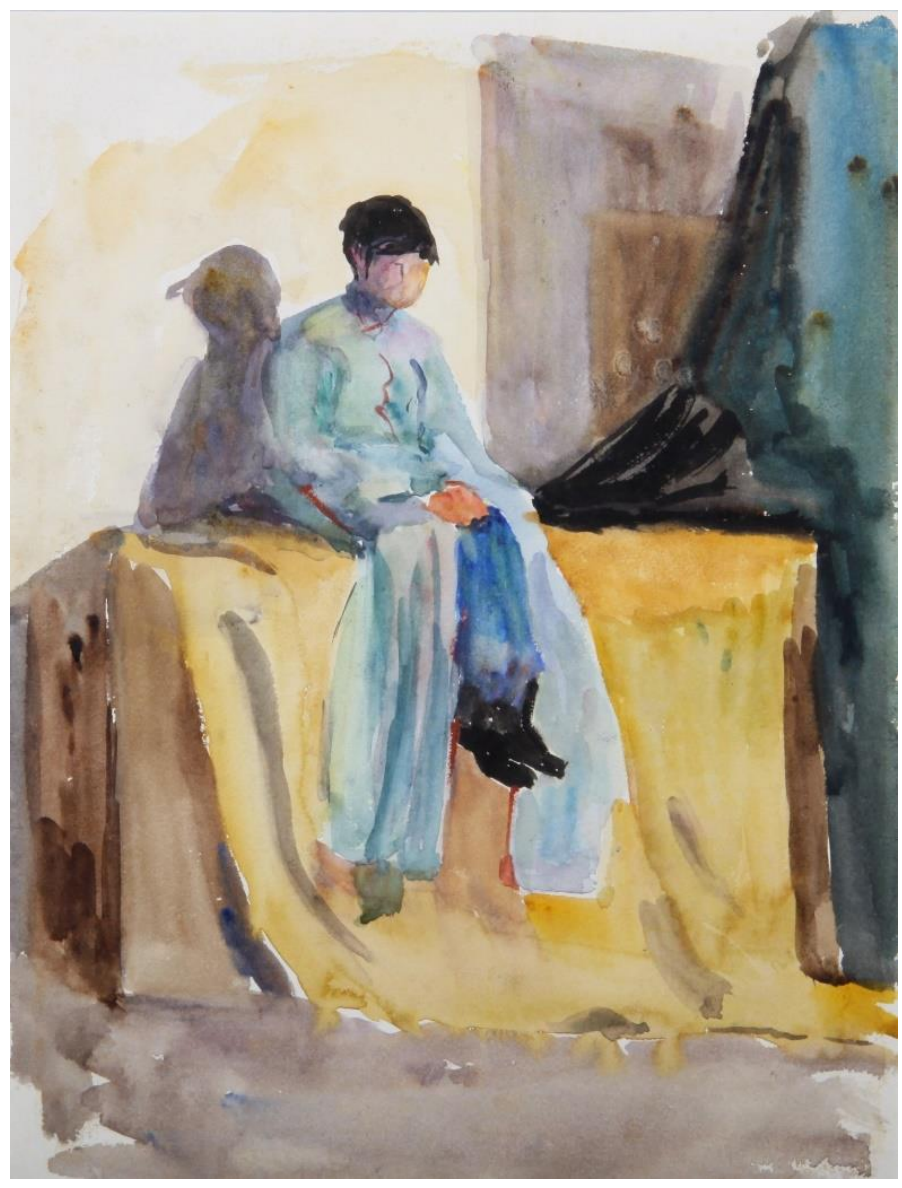

Fig. 71 John Singer Sargent (1856-1925), Figure with Drapery, 285 x 225, DPAG, 38195X. 


\section{CHAPTER FOUR}

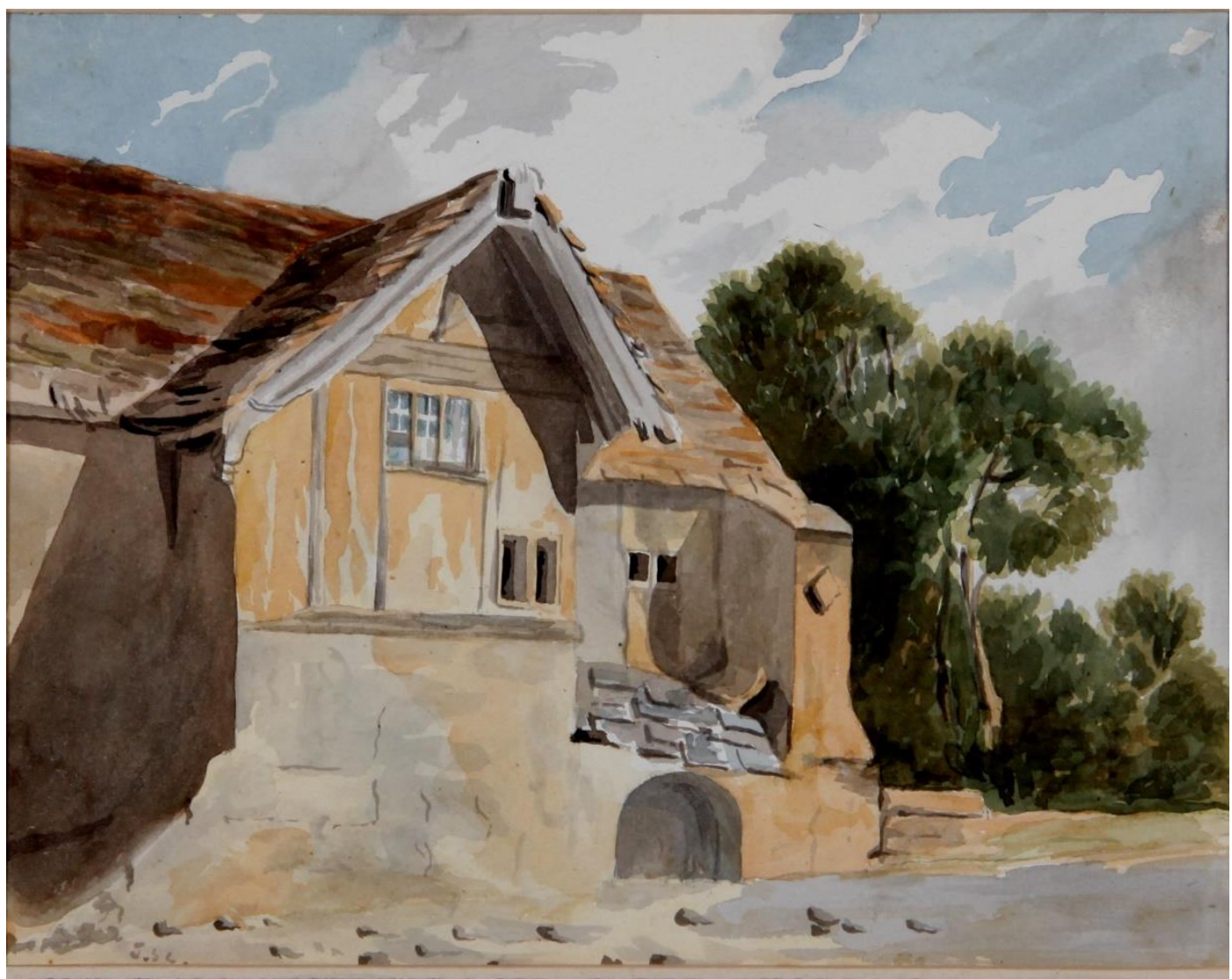

Fig. 72 John Sell Cotman, Cottage, 180 x 230, DPAG, 146-195X.

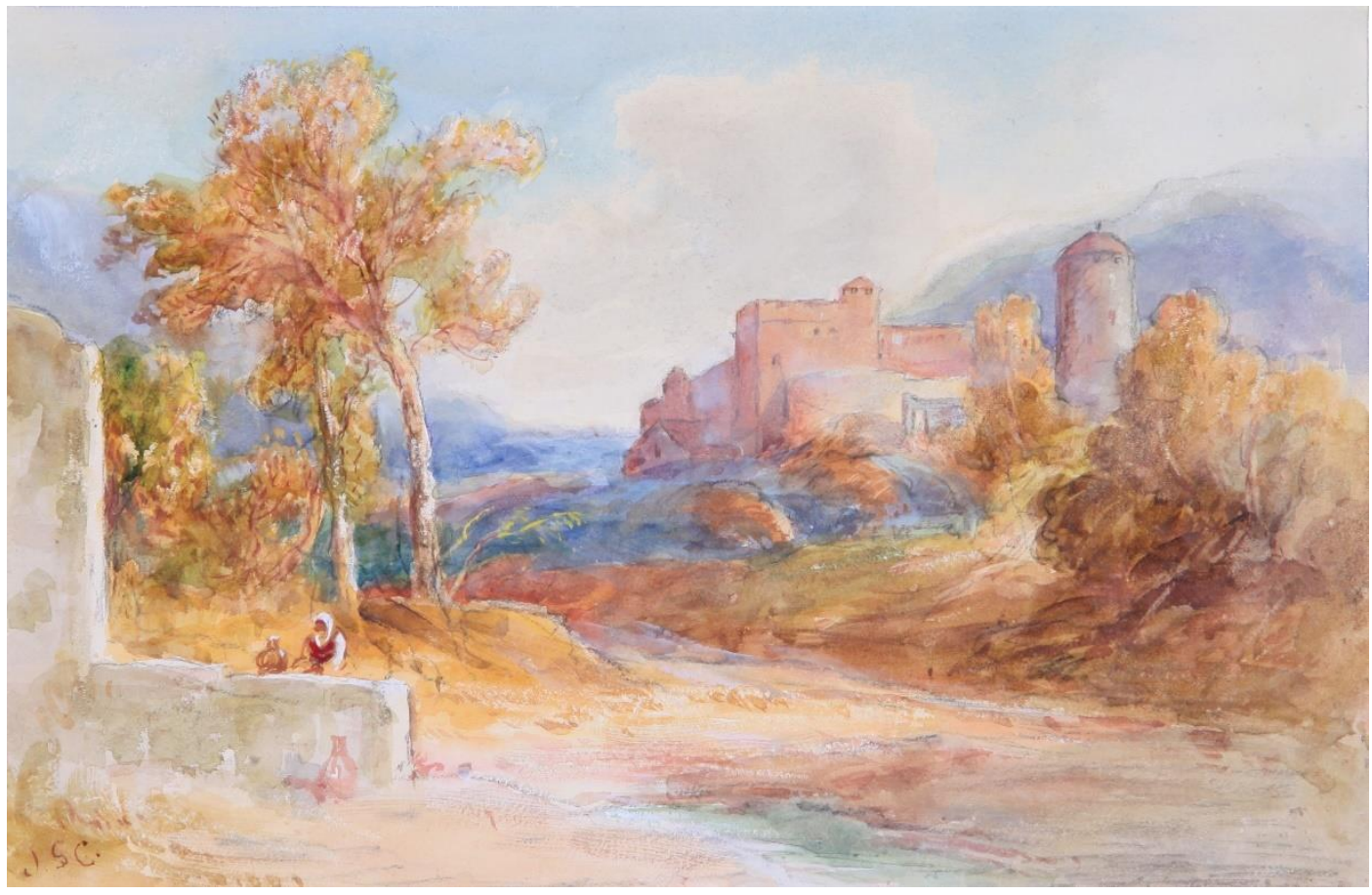

Fig. 73 John Sell Cotman, Untitled Italian Landscape, 195 x 295, DPAG, 375-195X. 


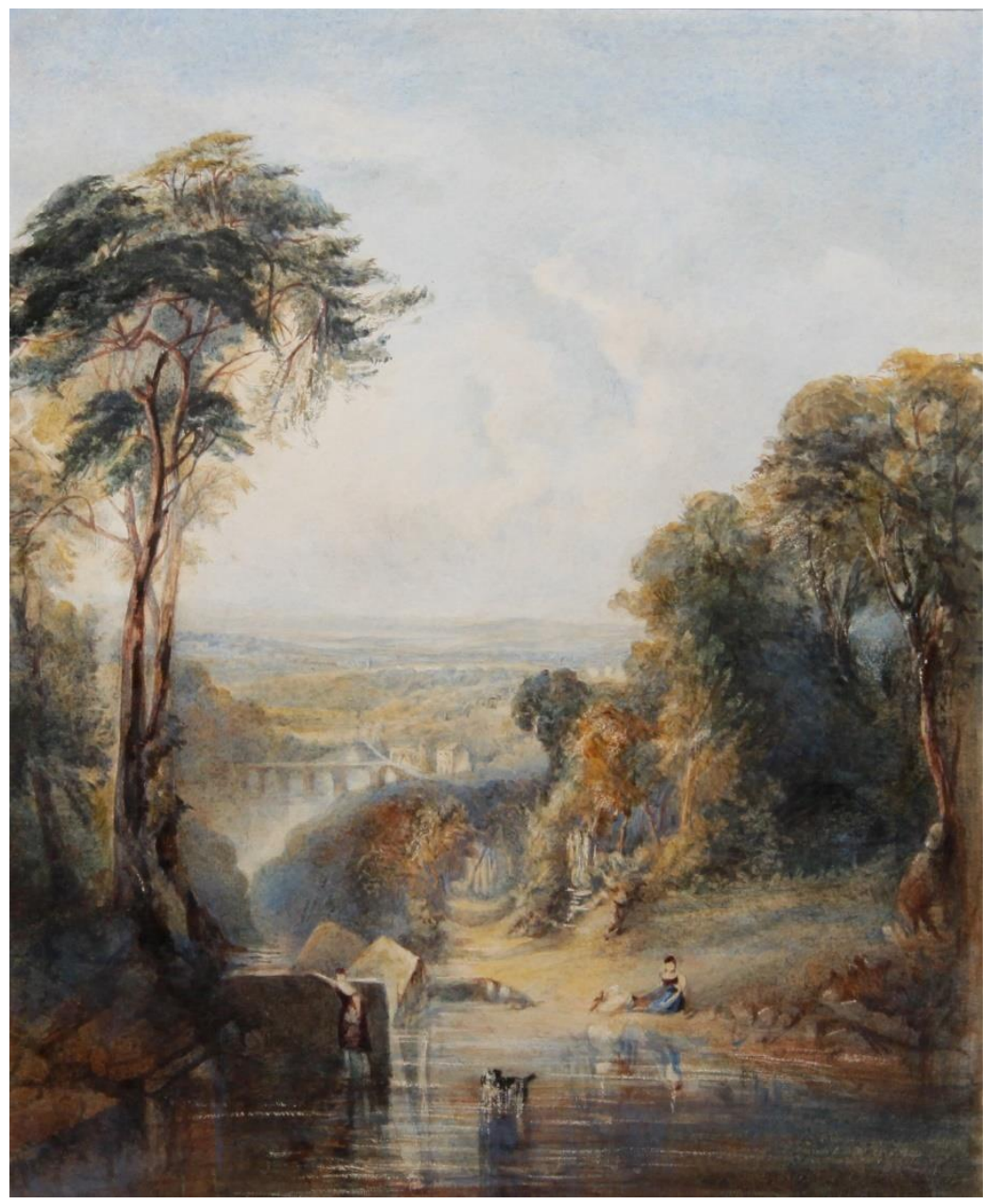

Fig. 74 Joseph Mallord William Turner (1775-1851) [attributed], Crossing the Brook, $270 \mathrm{x}$ 225, DPAG, 118-195X.

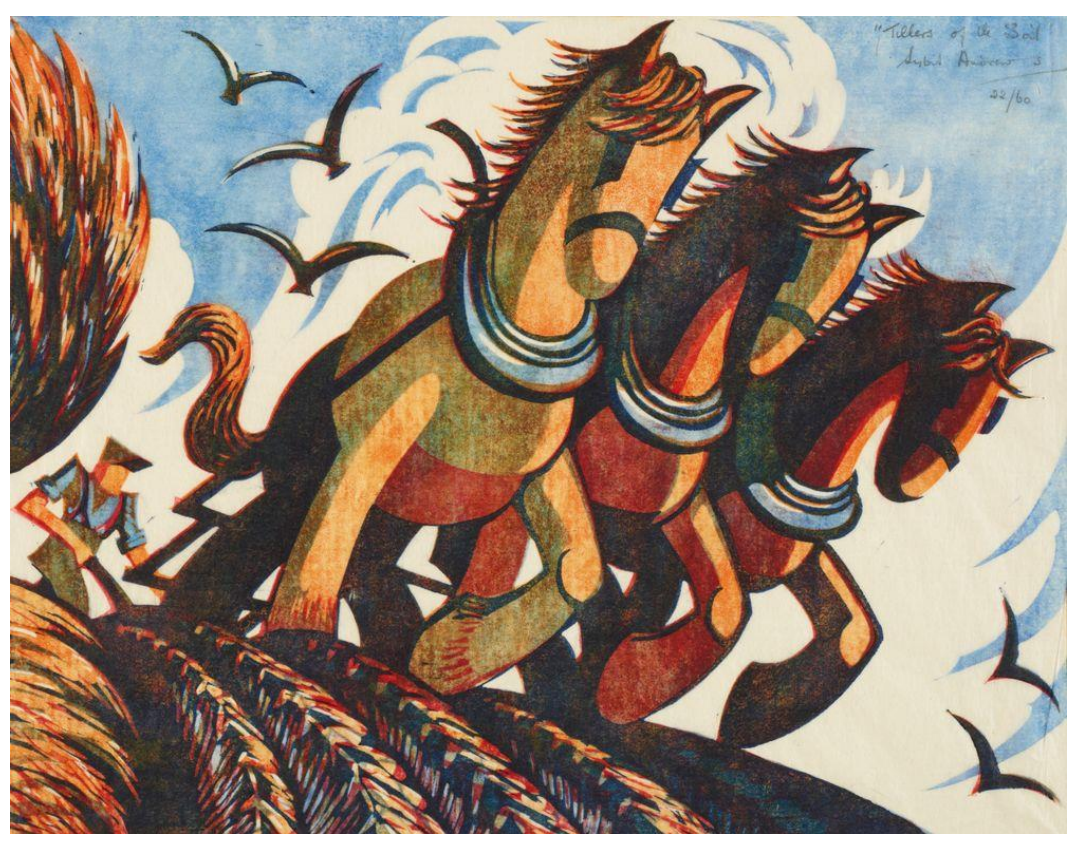

Fig. 75 Sybil Andrews (1898-1992), Tillers of the Soil, 1934, colour linocut, 233 x 326, Te Papa, 1953-0003-14. 


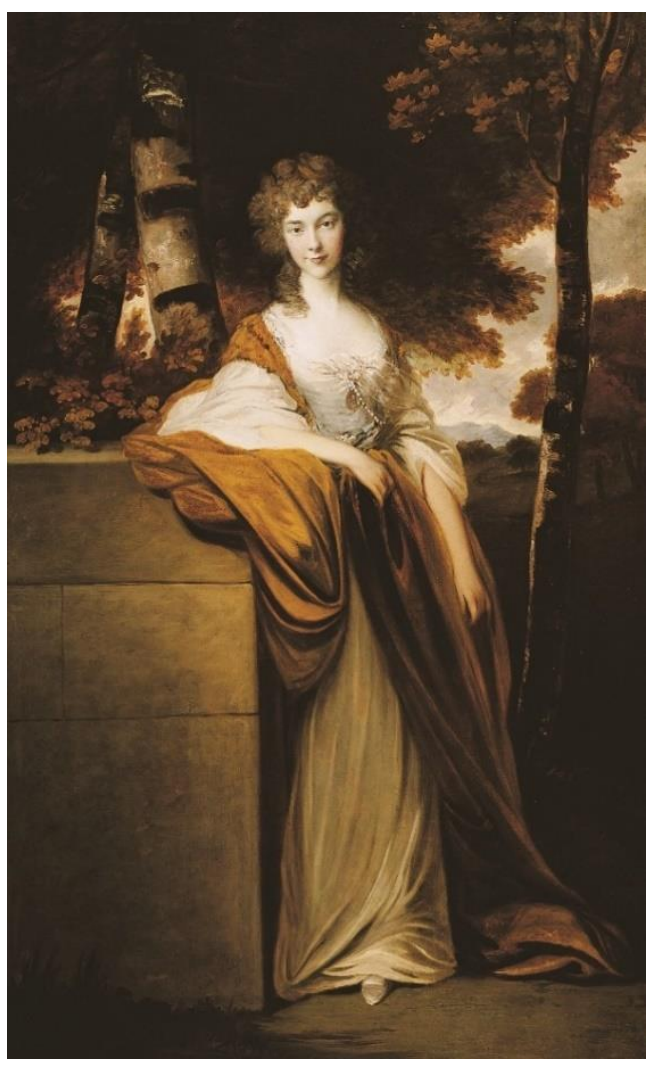

Fig. 76 John Hoppner (1758-1810), Charlotte, Countess Talbot, c. 1784, oil on canvas, 2380 x 1455, DPAG, 6-1958.

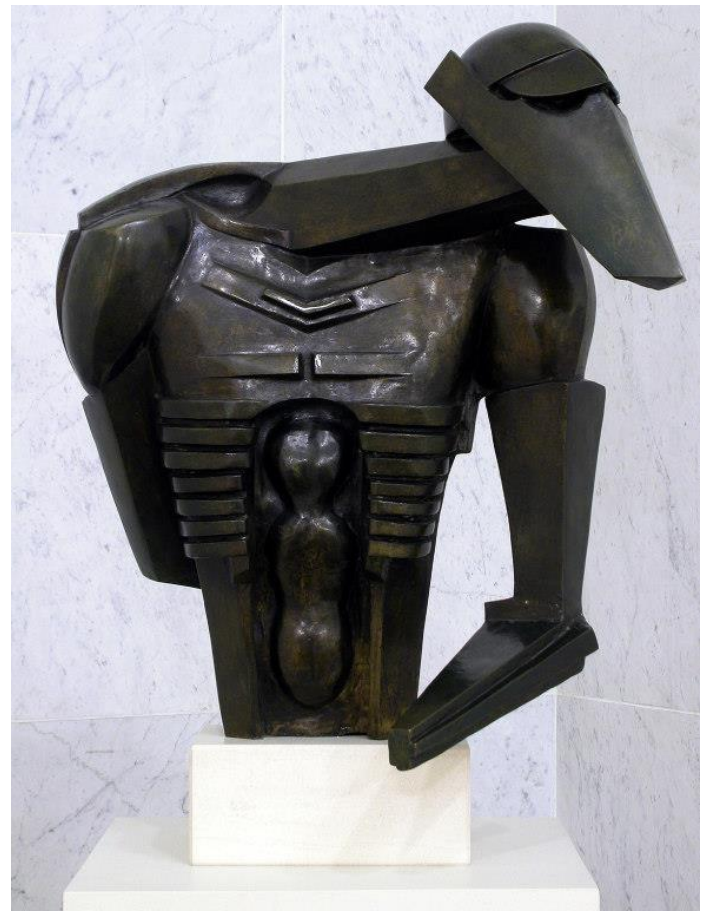

Fig. 77 Jacob Epstein (1880-1959), Torso in Metal from the 'Rock Drill', 1913-1916, bronze, 730 x 640 x 340, AAG, 1961/8, (T) Estate of Sir Jacob Epstein. 


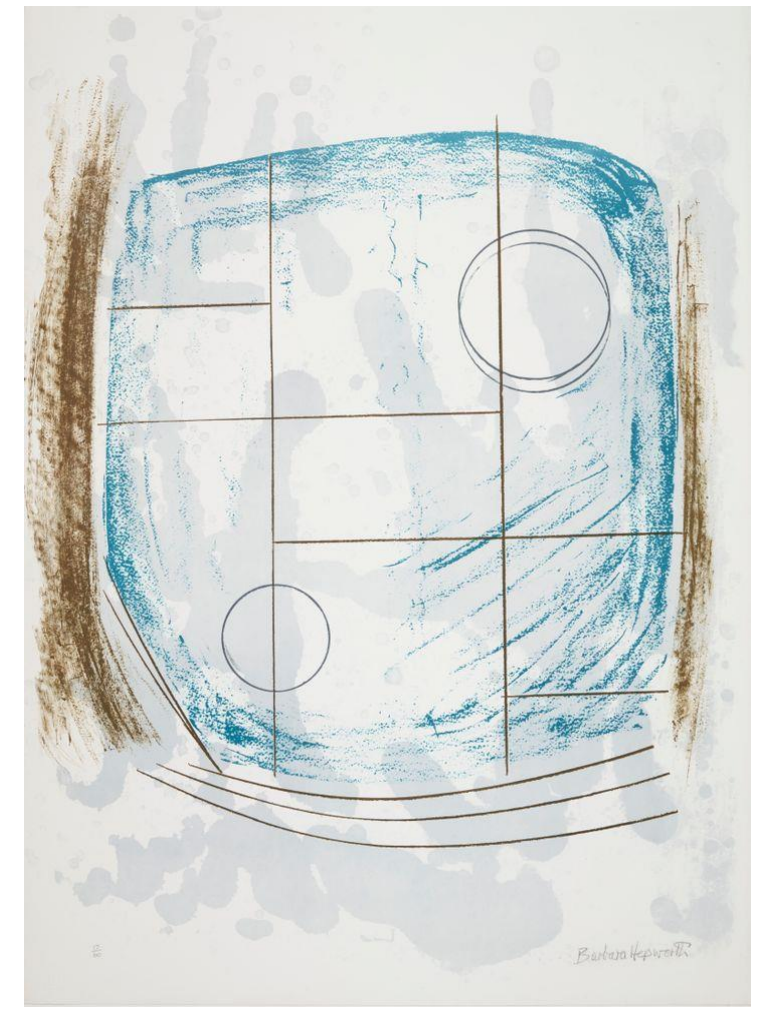

Fig. 78 Barbara Hepworth (1903-1975), Cool Moon, 1970-71, lithograph, Te Papa, 19760011-1.

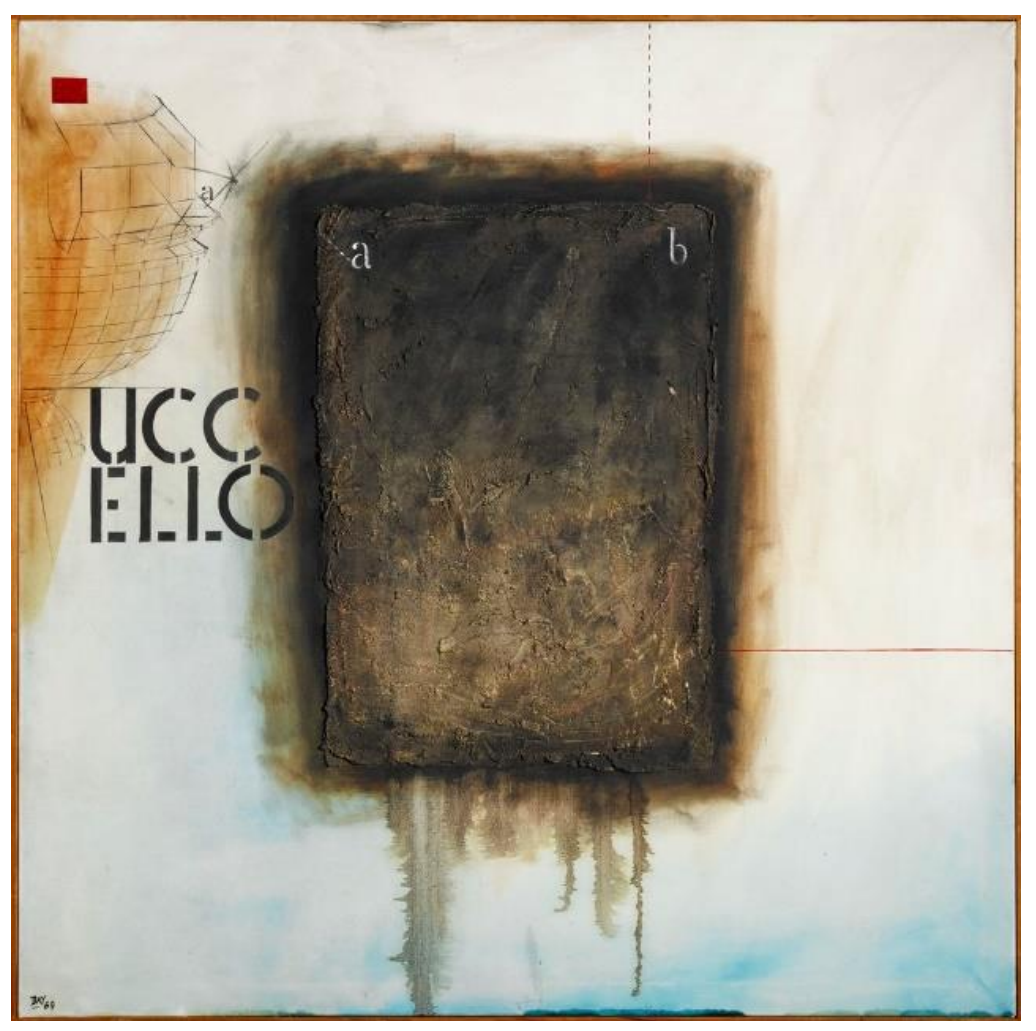

Fig. 79 Melvin Day (1923-2016), Goblet: Uccello Series, 1969, oil on canvas, 1525 x 1525, Te Papa, 1969-0016-1. 

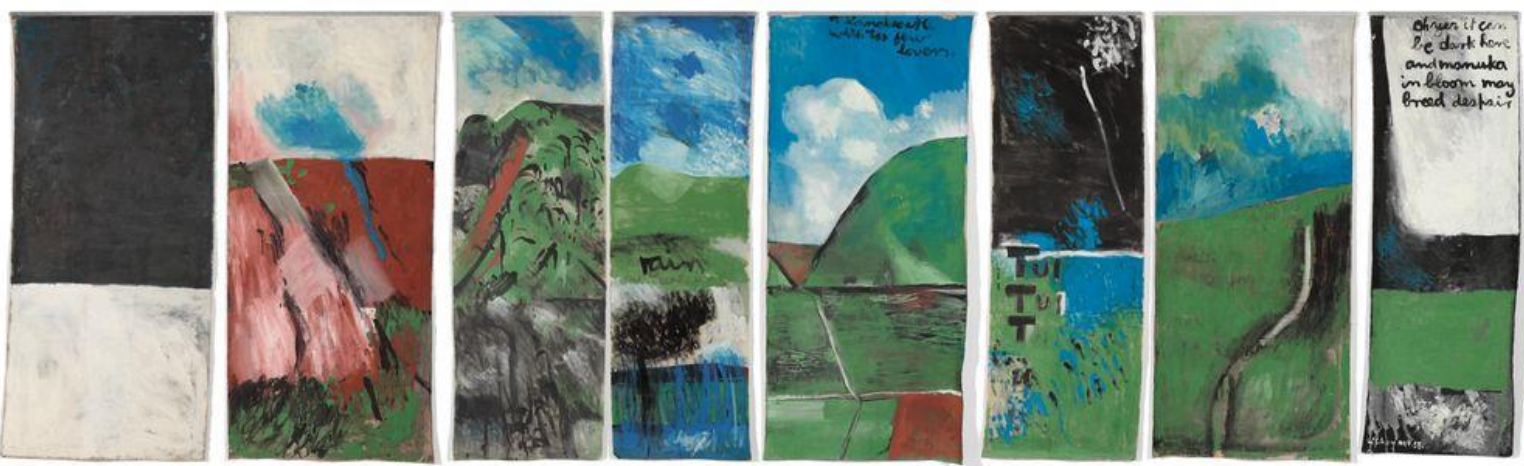

Fig. 80 Colin McCahon (1919-1987), Northland Panels, 1958, oil-modified alkyd on canvas, 5638 x 1779, Te Papa, 1978-0009-1/A-H to H-H.

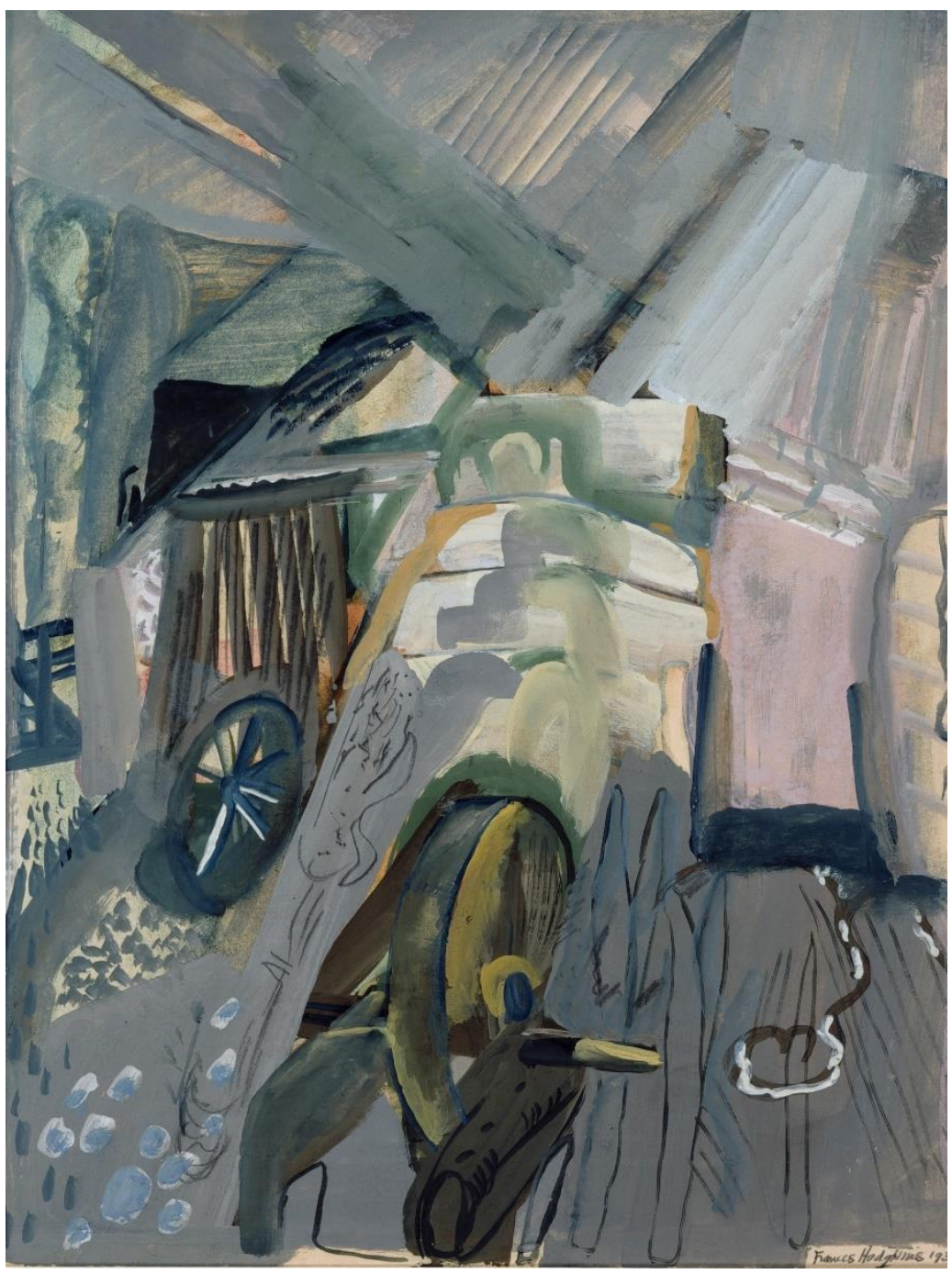

Fig. 81 Frances Hodgkins (1869-1947), Circular Barn, 1939, gouache, 570 x 435, DPAG, 7-1971. 


\section{CHAPTER FIVE}

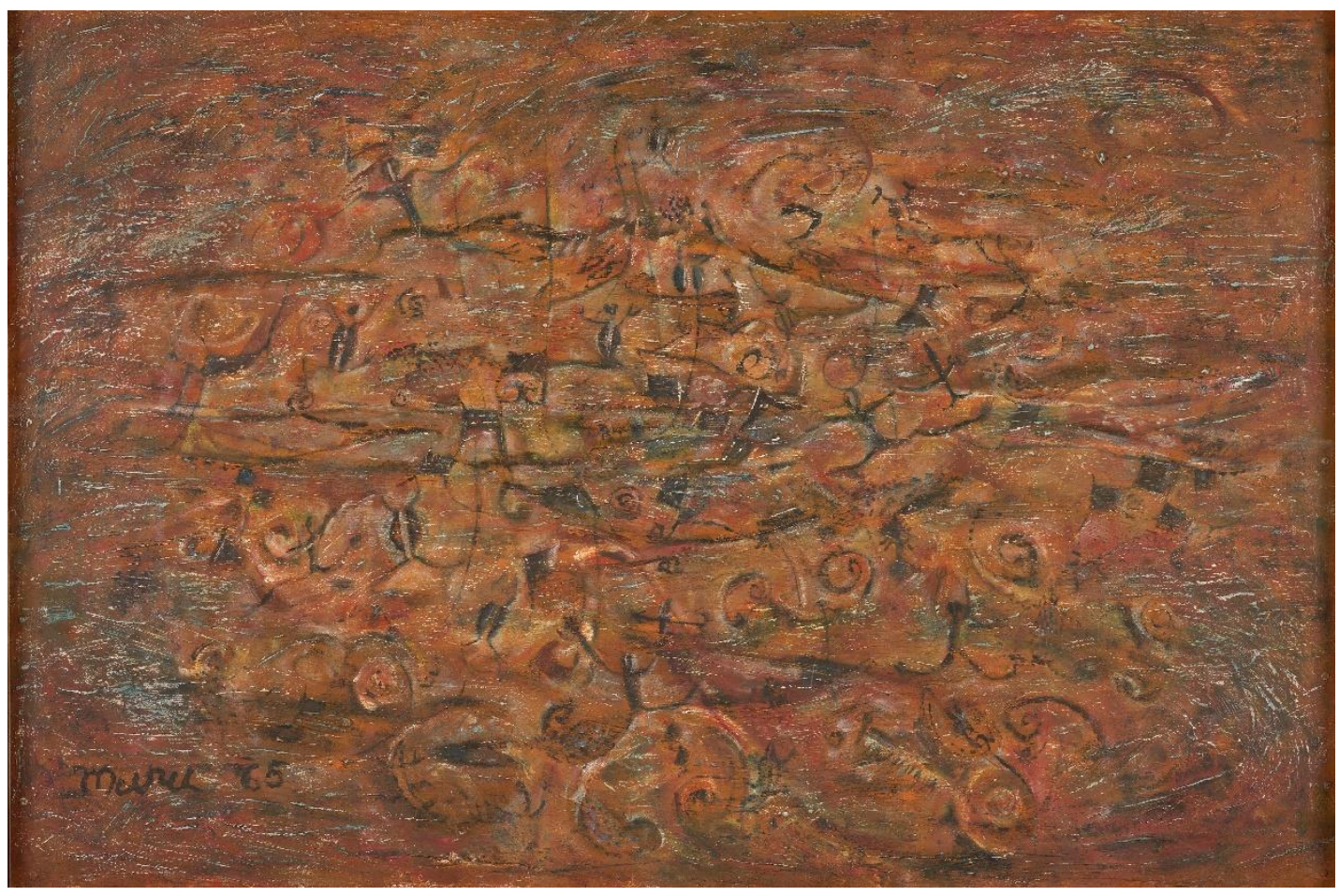

Fig. 82 Selwyn Muru (born 1937), Kohatu, 1965, oil on hardboard, 1203 x 795, Te Papa, 1965-0020-1.

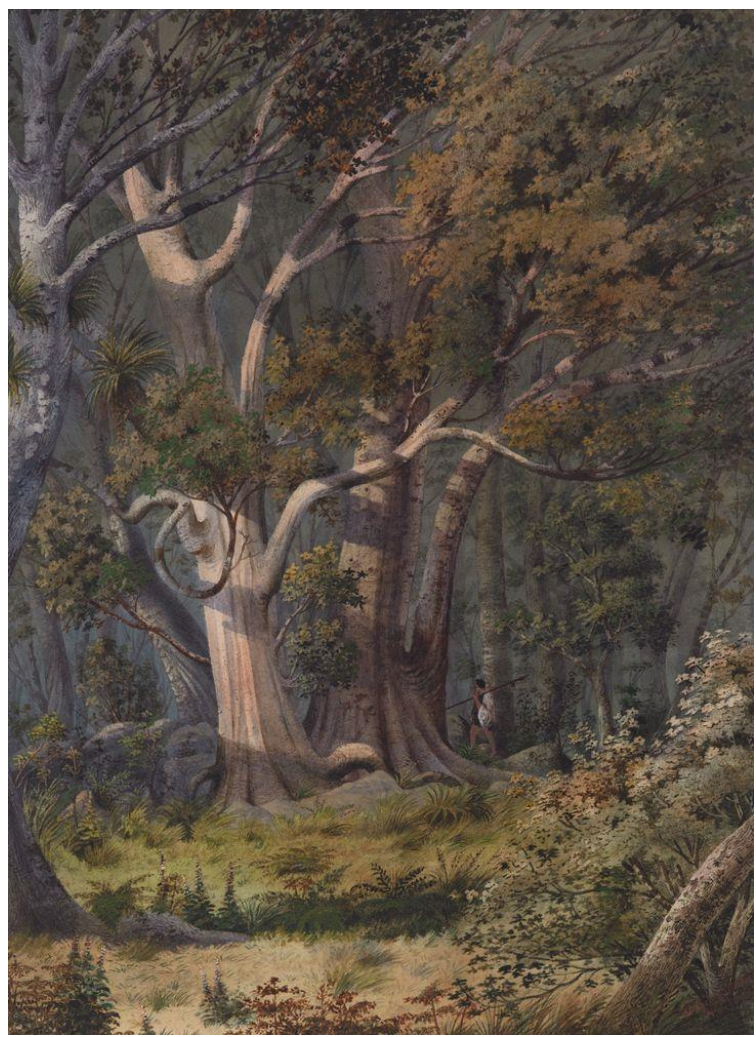

Fig. 83 Alfred Sharpe (1836-1908), Burial Place of Hone Heke, Bay of Islands, 1883, 454 x 750, Te Papa, 1977-0027-1. 


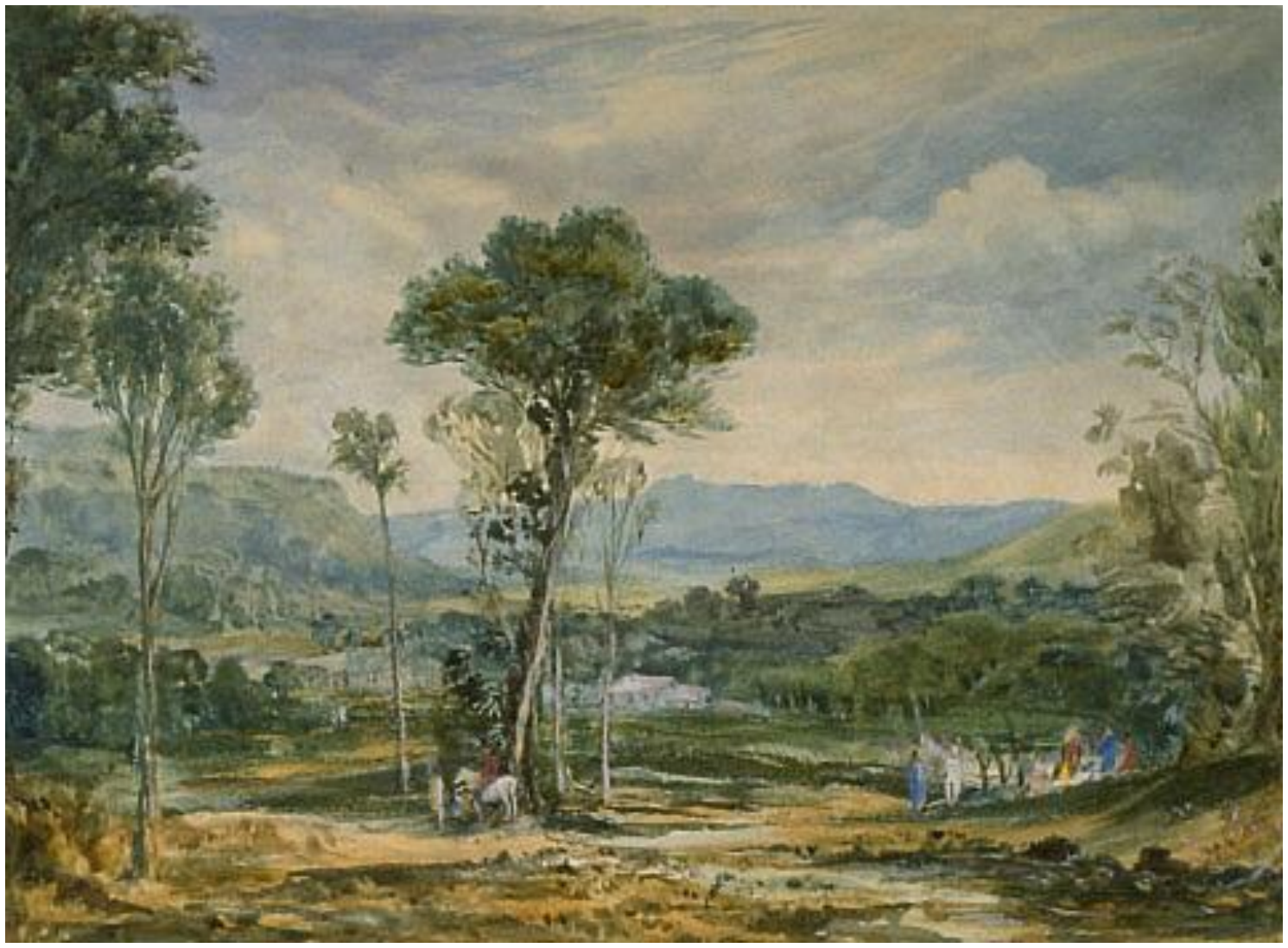

Fig. 84 Albin Martin (1813-1888), A New Zealand Landscape, watercolour and gouache, $270 \times 372$, AAG, M1885/1/170.

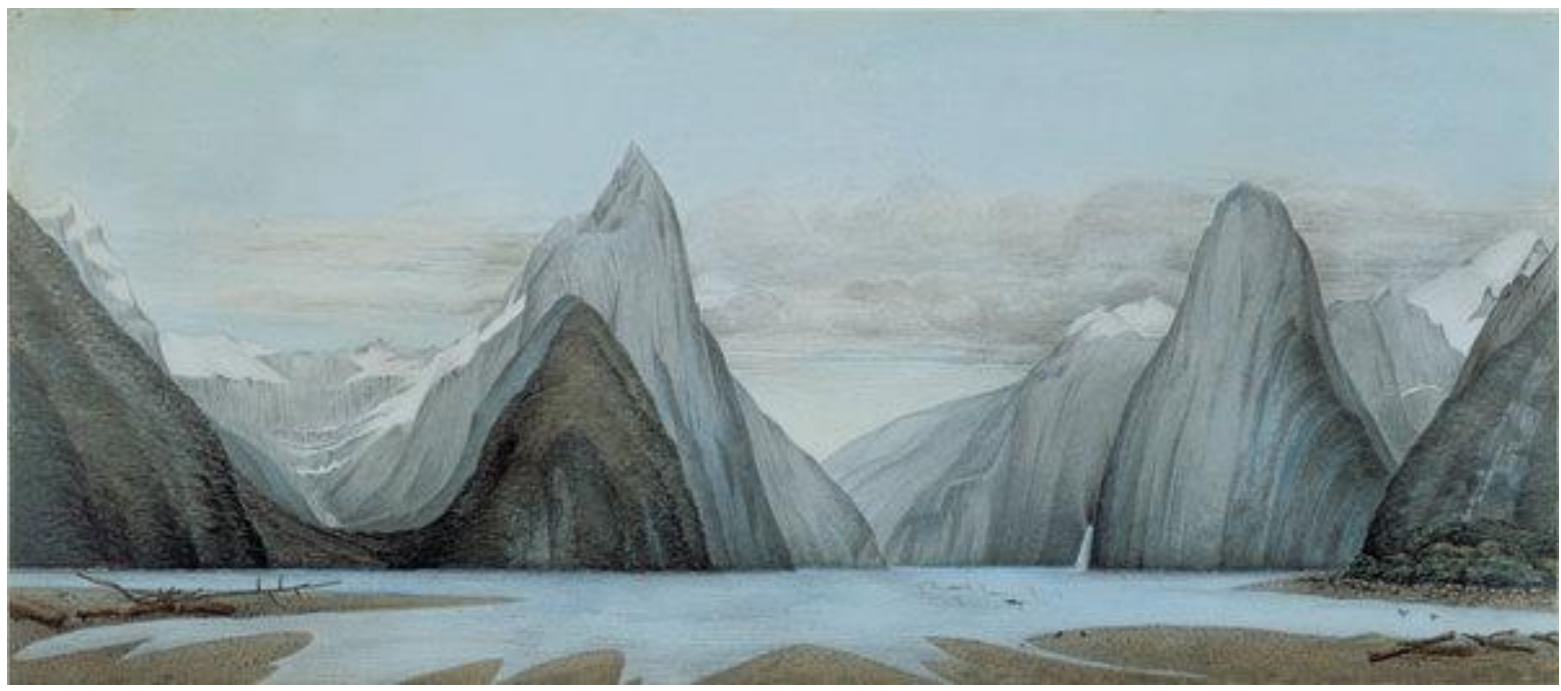

Fig. 85 John Buchanan (1819-1898), Milford Sound, 1863, 222 x 509, Hocken Collections, Uare Taoka o Hakena, University of Otago, a9892. 


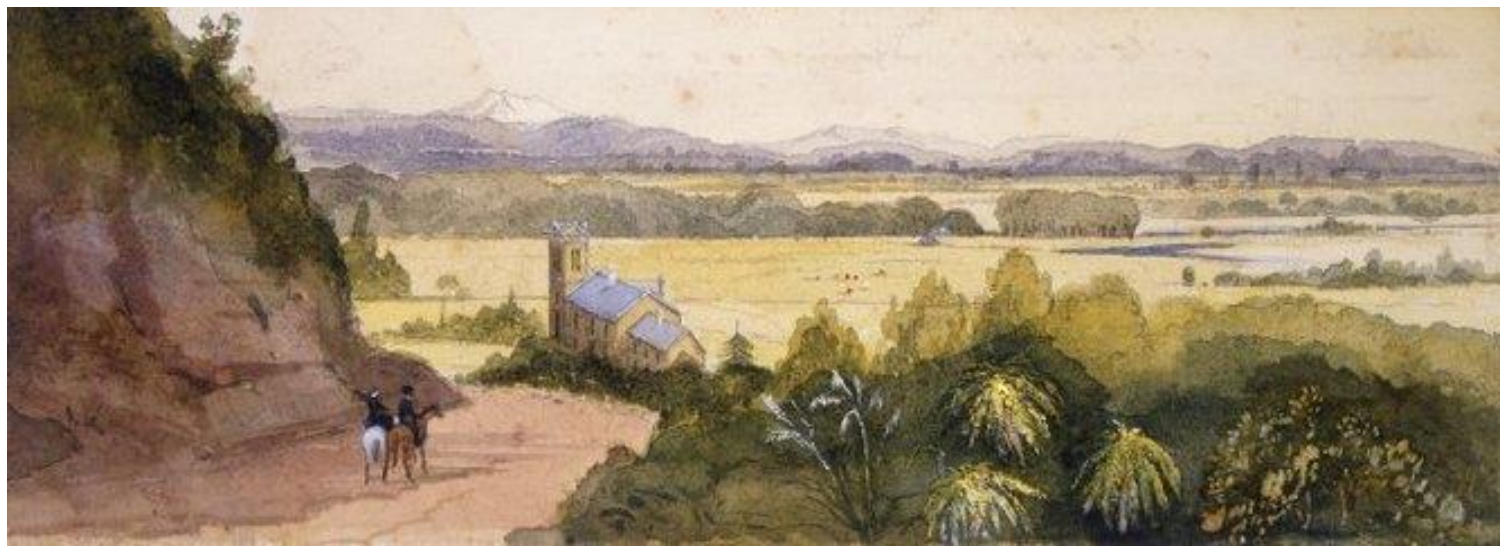

Fig. 86 William Fox (1812-1893), Westoe, c. 1872, 105 x 314, Alexander Turnbull Library, WC-048.

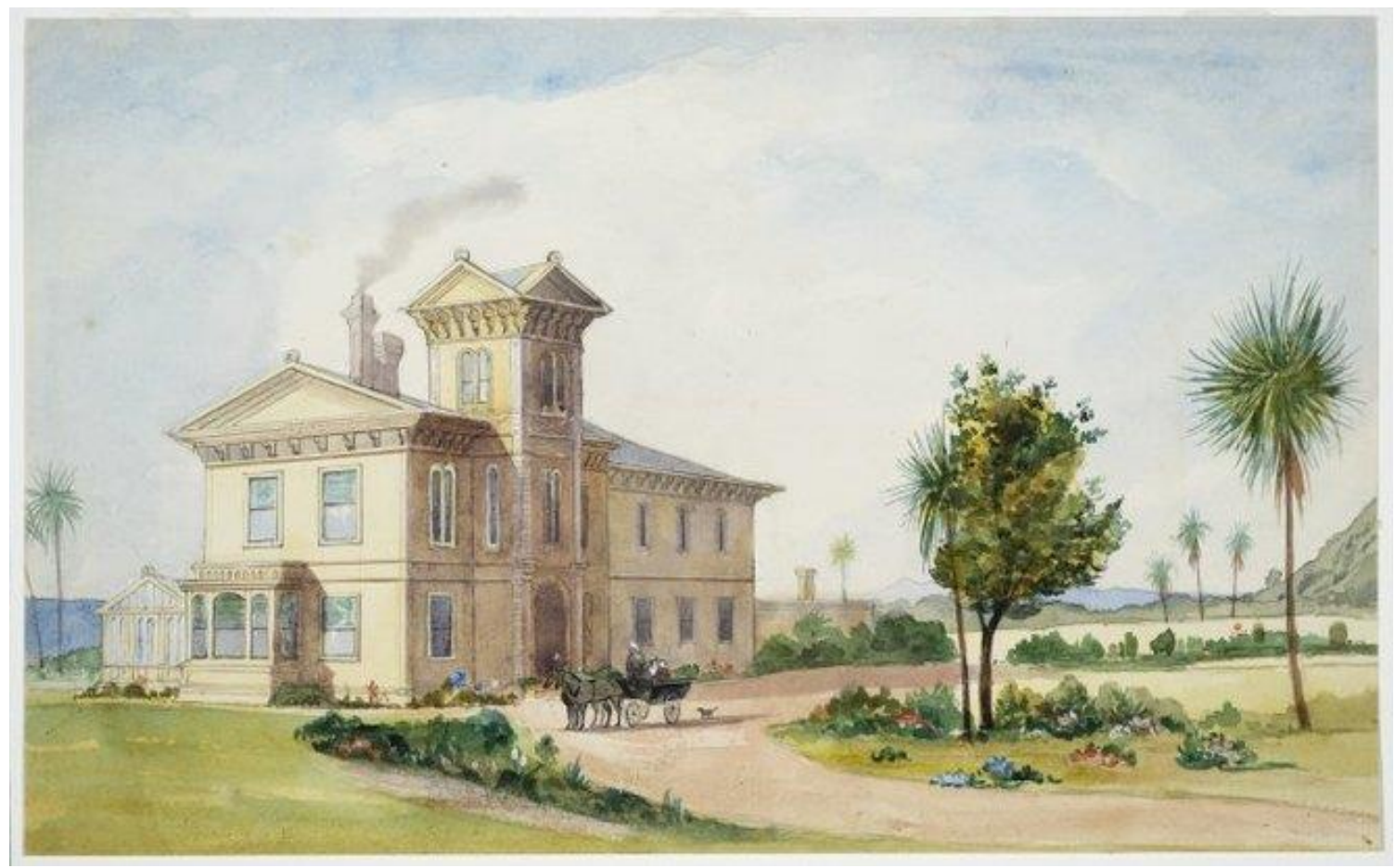

Fig. 87 William Fox, Westoe Rangitikei 1872, 255 x 413, Alexander Turnbull Library, WC050 . 


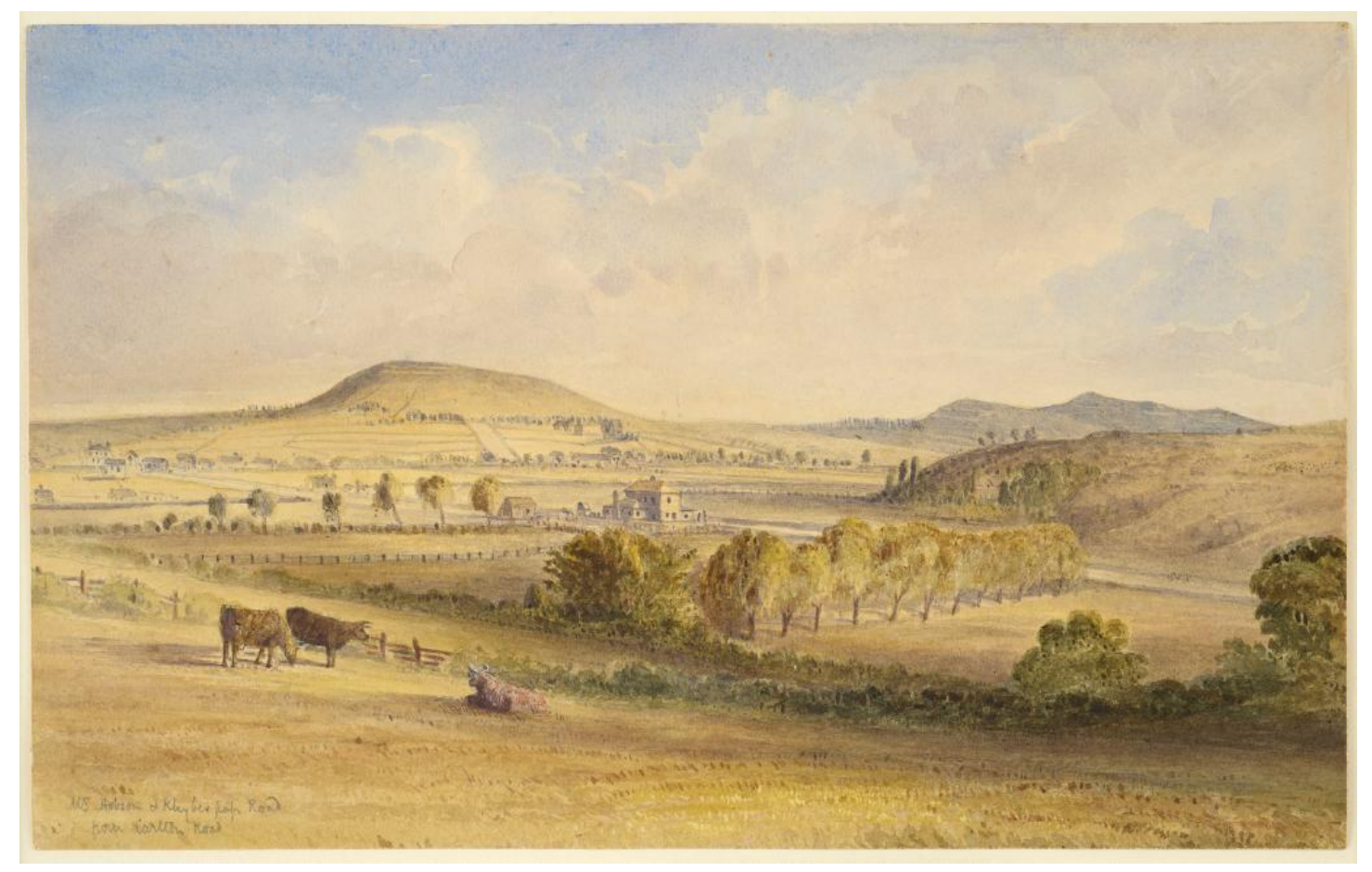

Fig. 88 John Kinder (1819-1903), Mt Hobson and Khyber Pass from Carlton Gore Road, 201 x 320, AAG, 1937/15/30. 
Appendix I: Sample Correspondence by Smythe

Fig. 1 Smythe to Pearse, 12 June 1953

Dunedin Public Art Gallery: Box 11, 15/22

Trum $12 \cdot 1953$

Elfinswaw

Naywars Neath

Dear mis Pearse

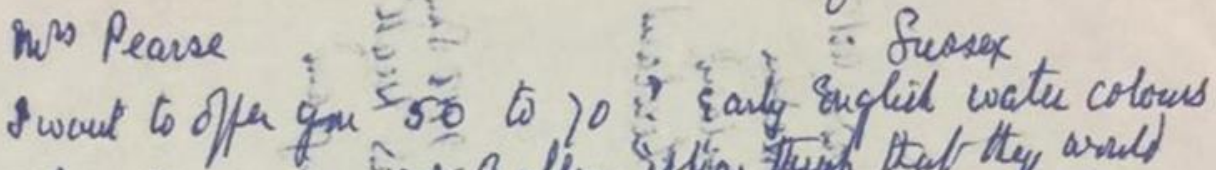

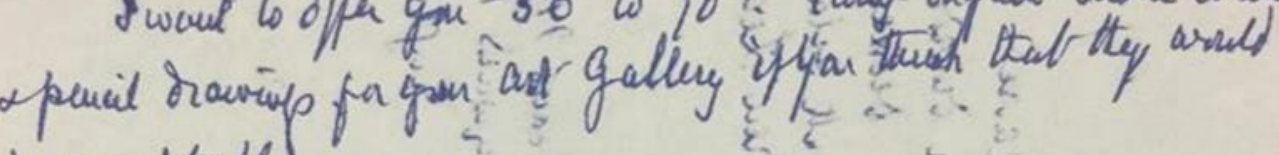
te acceptatle.

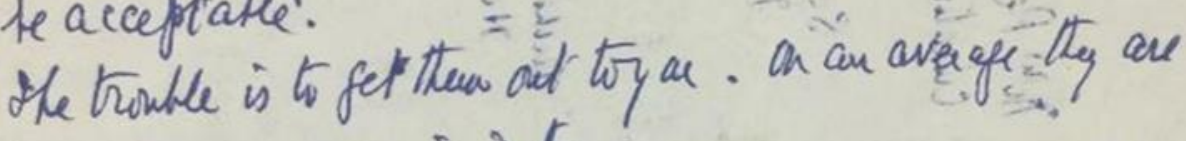
from $1800-1860$ in date.

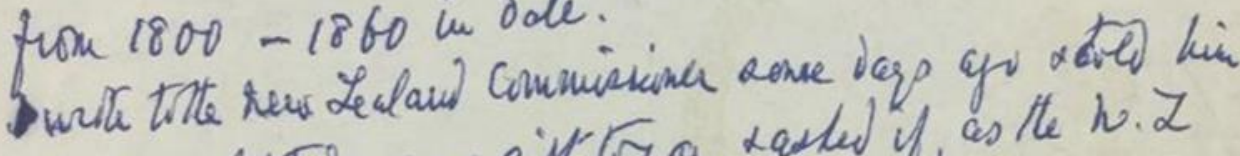
what I wauter tolo, as a gitt try a rasted y, as the h.Z

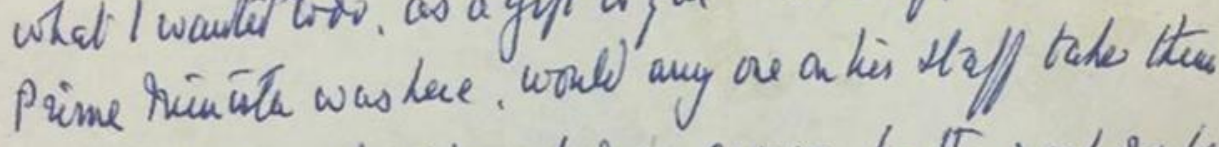
fach with him, hat / have has no answer, fa thes weeh so far: sante a weeh ago, hel if I have to rew then aut, it art the Ex peusive os bont kuw its comld afford it.

Boul fired wonld they he of auy use tortefalley aui wod

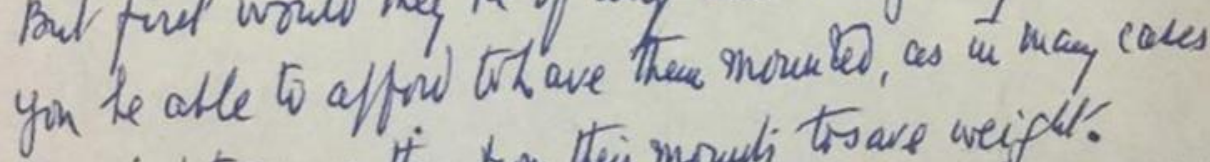

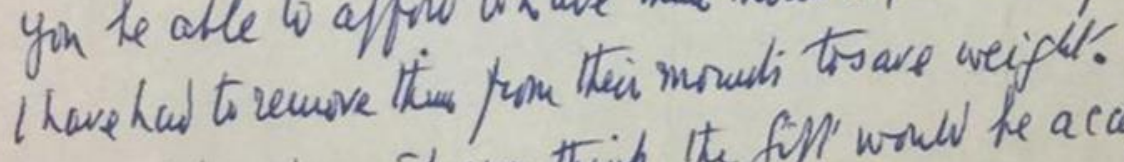

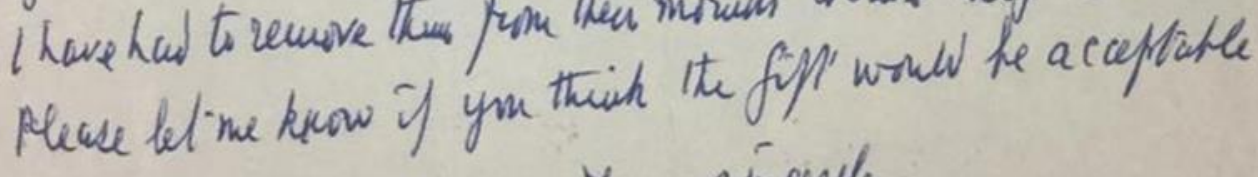

yours aincerlly

287 
Fig. 2 Smythe to National Art Gallery, 24 June 1956

Te Papa Archives: MU00008, box 3, item 6

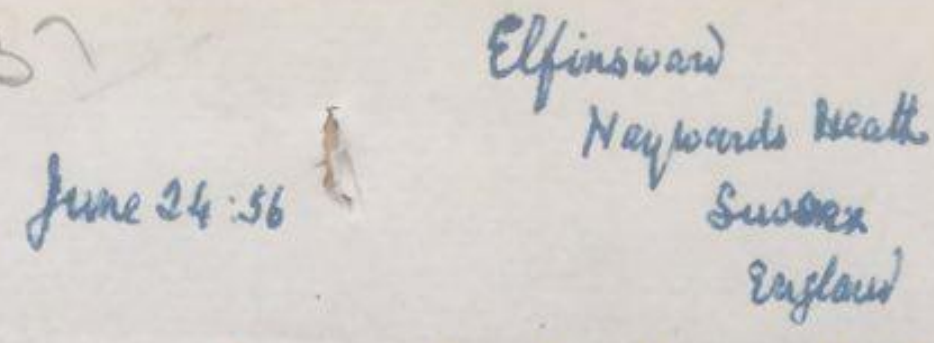

Geattemen

thave about 24 hraving in water colouss, wh: Ittein

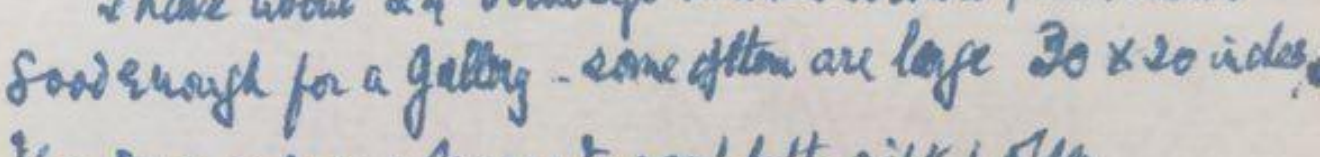
You may $n$ may nat cau to acoupt the gift i fore

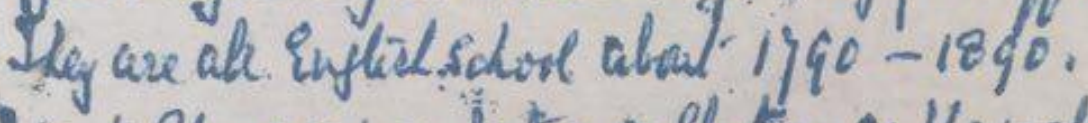

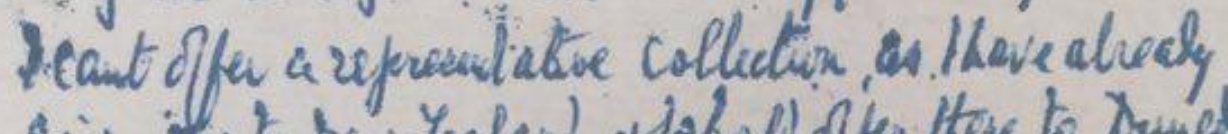

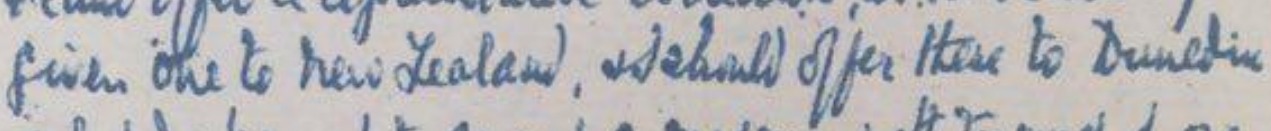

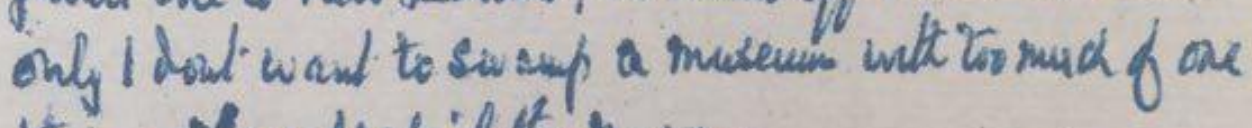
thing - I wouls efpill the hurecean Thas a pafer ento me wh: told muttil wellingta hel an ant

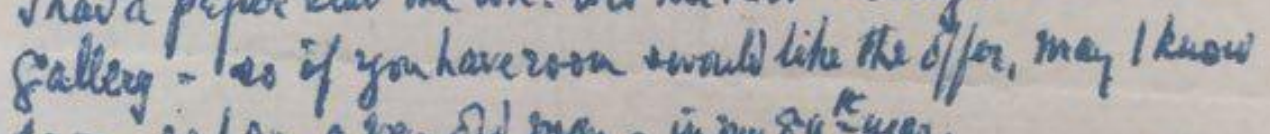

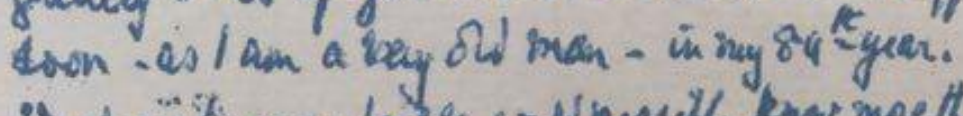

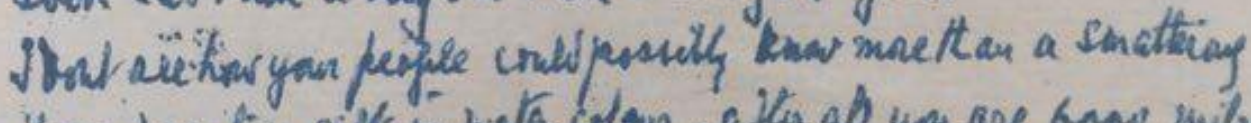

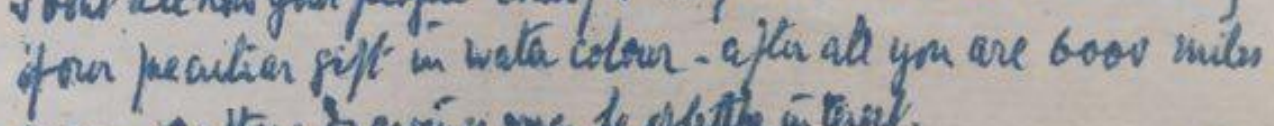

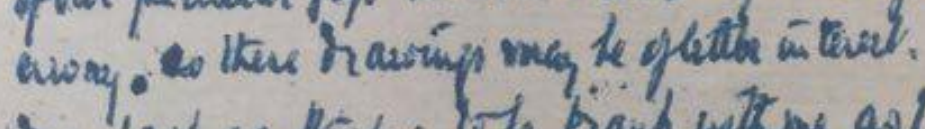

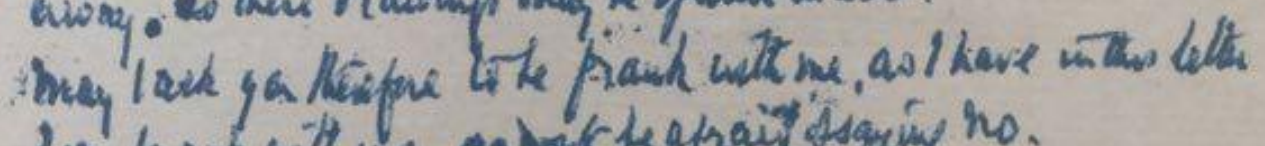

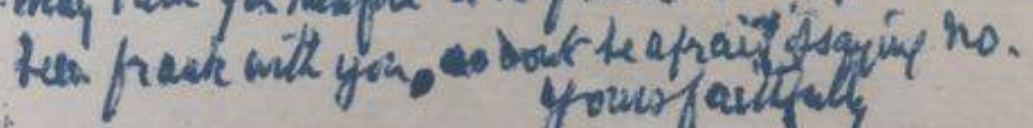
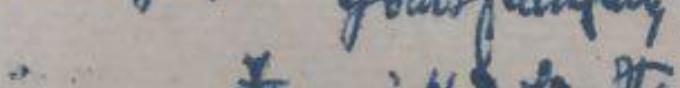


\section{Appendix II: New Zealand Gallery Directors 1950s-1980s}

\begin{tabular}{|c|c|c|c|c|}
\hline $\begin{array}{l}\text { Time in } \\
\text { Office }\end{array}$ & Dunedin & Wellington & Christchurch & Auckland \\
\hline 1945 & \multirow{20}{*}{$\begin{array}{c}\text { Annette } \\
\text { Pearse } \\
\text { (1893-1981) } \\
\text { [Curator } \\
\text { from } \\
\text { 1946-1958] }\end{array}$} & & & \\
\hline 1946 & & & & \\
\hline 1947 & & & & \\
\hline 1948 & & \multirow{21}{*}{$\begin{array}{c}\text { Stewart } \\
\text { Maclennan } \\
(1903-1973)\end{array}$} & & \\
\hline 1949 & & & & \\
\hline 1950 & & & & \\
\hline 1951 & & & & \\
\hline 1952 & & & & \\
\hline 1953 & & & & Eric \\
\hline 1954 & & & & Westbrook \\
\hline 1955 & & & William Sykes & $(1915-2005)$ \\
\hline 1956 & & & Baverstock & \\
\hline 1957 & & & $(1893-1975)$ & \\
\hline 1958 & & & [Honorary & \\
\hline 1959 & & & Curator from & Peter \\
\hline 1960 & & & 1949-1959] & Tomory \\
\hline 1961 & & & & $(1922-2008)$ \\
\hline 1962 & & & & \\
\hline 1963 & & & & \\
\hline 1964 & & & & \\
\hline 1965 & \multirow{7}{*}{$\begin{array}{c}\text { J.D. Charlton } \\
\text { Edgar } \\
(1903-1976)\end{array}$} & & & \\
\hline 1966 & & & & \\
\hline 1967 & & & & \\
\hline 1968 & & & & Gil Docking \\
\hline 1969 & & \multirow{10}{*}{$\begin{array}{l}\text { Melvin Day } \\
(1923-2016)\end{array}$} & & (1919-2015) \\
\hline 1970 & & & \multirow{10}{*}{$\begin{array}{c}\text { Brian Muir } \\
(1943-1989)\end{array}$} & \\
\hline 1971 & & & & \\
\hline 1972 & \multirow{9}{*}{ L.C. Lloyd } & & & \\
\hline 1973 & & & & \\
\hline 1974 & & & & \\
\hline 1975 & & & & \\
\hline 1976 & & & & \\
\hline \multicolumn{2}{|l|}{1977} & & & \\
\hline \multicolumn{2}{|l|}{1978} & & & \\
\hline \multicolumn{3}{|l|}{1979} & & \\
\hline \multicolumn{4}{|r|}{ Rodney Wilson } & \\
\hline \multicolumn{5}{|c|}{$(1945-2013)$} \\
\hline \multicolumn{5}{|l|}{1982} \\
\hline \multicolumn{5}{|c|}{ Luit Bieringa } \\
\hline \multicolumn{5}{|c|}{ (born 1943) } \\
\hline \multicolumn{5}{|l|}{1985} \\
\hline \multicolumn{5}{|l|}{1986} \\
\hline \multicolumn{5}{|l|}{1987} \\
\hline \multicolumn{5}{|l|}{1988} \\
\hline 1989 & & & & \\
\hline
\end{tabular}

